LADISLAO ROGER TICONA MELO

MONITORAÇÃO DE MODELOS FÍSICOS REDUZIDOS PARA INVESTIGAÇẪO DO COMPORTAMENTO DE ESTRUTURAS EM ESCALA REAL 


\title{
MONITORAÇÃO DE MODELOS FÍSICOS REDUZIDOS PARA INVESTIGAÇẪO DO COMPORTAMENTO DE ESTRUTURAS EM ESCALA REAL
}

\author{
Dissertação apresentada à Escola \\ Politécnica da Universidade de São Paulo \\ para obtenção do título de Mestre em \\ Engenharia
}




\title{
MONITORAÇÃO DE MODELOS FÍSICOS REDUZIDOS PARA INVESTIGAÇẪO DO COMPORTAMENTO DE ESTRUTURAS EM ESCALA REAL
}

\author{
Dissertação apresentada à Escola \\ Politécnica da Universidade de São Paulo \\ para obtenção do título de Mestre em \\ Engenharia \\ Área de Concentração: \\ Engenharia de Estruturas \\ Orientador: \\ Prof. Dr. Túlio Nogueira Bittencourt
}

São Paulo 
Este exemplar foi revisado e alterado em relação à versão original, sob responsabilidade única do autor e com a anuência de seu orientador.

São Paulo, 28 de setembro de 2011.

Assinatura do autor

Assinatura do orientador

FICHA CATALOGRÁFICA

Ticona Melo, Ladislao Roger

Monitoração de modelos físicos reduzidos para investigação do comportamento de estruturas em escala real / L.R. Ticona Melo. - ed.rev-- São Paulo, 2011.

242 p.

Dissertação (Mestrado) - Escola Politécnica da Universidade de São Paulo. Departamento de Engenharia de Estruturas e Geotécnica.

1.Modelos (Experimentação) 2.Estruturas (Monitoramento) 3.Mecânica da fratura (Experimentação) 4.Sensor I.Universidade de São Paulo. Escola Politécnica. Departamento de Engenharia de Estruturas e Geotécnica II.t. 
A meus pais Segundina e Gabriel por tudo que me deram na vida. Às minhas irmãs Geovanna e Rossi pelo apoio ao longo destes anos. À minha noiva Enma Diana pelo amor incentivo e carinho. 


\section{AGRADECIMENTOS}

A Deus, por todas as coisas maravilhosas que me deu na vida, na hora certa e no momento certo.

A meus queridos pais Segundina e Gabriel, minhas irmãs Geovanna e Rossi e minha noiva Enma Diana que mesmo a distancia nunca deixaram de me apoiar e incentivar nos momentos difíceis.

A meus avôs e tios Clodoaldo, Julio e à memória de minha tia Julia, os quais sempre me incentivaram e acreditaram em mim.

A meu orientador Prof. Túlio Nogueira Bittencourt pela confiança, orientação, paciência, compreensão e motivação na realização deste trabalho.

Ao Prof. Alfredo Pinto da Conceição Neto pela amizade, orientação, apoio e ensino da análise experimental de estruturas, os quais foram fundamentais na minha formação profissional.

Aos professores do Departamento de Engenharia de Estruturas e Geotécnica (PEF) que contribuíram na minha formação.

Aos amigos do Laboratório de Estruturas e Materiais (LEM) e do Laboratório de Mecânica Computacional (LMC-JAC), em especial a Leonardo, Fernando, Paulo, Jorge e Luis pela amizade e convivência ao longo destes anos.

Aos amigos especiais que fizeram com que minha estada no Brasil fosse agradável e me apoiaram durante o desenvolvimento desta pesquisa Marina, Edielce, Filino, Paulo, Melquiades, André e Ricardo.

Aos Professores da UNA-PUNO: Ing. Echegaray, Ing. Tupayachi e amigos peruanos Lucho, Raul, Guido, Genaro, Pedro e Ivan pelo incentivo, amizade e apoio.

À Diretoria e a todos os funcionários do Laboratório de Estruturas e Materiais - LEM, pelo apoio ao desenvolvimento do projeto, pela excelente mão-de-obra dedicada a este trabalho e pela utilização dos equipamentos.

À Diretoria e a todos os funcionários do Laboratório de Construção Civil - PCC, pelos equipamentos e apoio disponibilizados.

À Coordenação de Aperfeiçoamento de Pessoal de Nível Superior (CAPES), pelo suporte financeiro proporcionado à pesquisas. 


\section{RESUMO}

Esta pesquisa apresenta a monitoração de modelos reduzidos para a investigação do comportamento de estruturas. O estudo do comportamento estrutural consistiu basicamente na medição de grandezas físicas de forma experimental, para o qual os modelos físicos reduzidos foram submetidos a múltiplos ensaios em laboratório. Posteriormente, os dados experimentais foram tratados e analisados, para então serem comparados com os resultados dos modelos teóricos, avaliando assim, sua capacidade de simulação. No total foram monitorados três modelos reduzidos, cujas grandezas físicas foram medidas utilizando-se sensores elétricos, tais como: extensômetros, LVDT's e um servoatuador hidráulico, os quais estavam ligados ao sistema de aquisição da National Instrument, controlado por um computador de comando e pelos programas LabView e DynaTester.

Um dos modelos construído em alumínio foi utilizado a fim de se estudar o comportamento da ponte do rio Suaçui, assim como calibrar os modelos teóricos em função dos dados experimentais da estrutura real e do modelo reduzido e estabelecer uma relação entre eles. Os outros dois modelos construídos em microconcreto foram utilizados para estudar o comportamento de estruturas na fase não linear e em fratura, para o qual foram submetidos a carregamentos incrementais. A ponte de microconcreto foi ensaiada com o intuito de se verificar a variação da rigidez de sua seção transversal e a construção de uma relação experimental de momento-curvatura. As vigas levemente armadas foram ensaiadas a flexão em três pontos até a ruptura, com a finalidade de se verificar que seu comportamento depende de vários parâmetros tais como: taxa de armadura, tamanho da viga, forma da seção transversal e a aderência aço-concreto.

O estudo experimental foi complementado com ensaios de caracterização de materiais, estudos teóricos e o desenvolvimento de aplicativos como o programa PUENFLEX para o cálculo de relações de momento-curvatura de seções e o aplicativo desenvolvido em LabView para monitoração de estruturas que permite visualizar seu comportamento em tempo real.

Palavras-chave: Monitoração de estruturas, modelos físicos, sensores elétricos, momento curvatura, mecânica da fratura, microconcreto. 


\section{ABSTRACT}

This research presents the monitoring of scale reduced models for investigation the behavior of structures. The study of structural behavior consisted basically in the measurement of physical quantities on an experimental basis, to which the reduced physical models were subjected to multiple laboratory tests. Then the experimental data were processed and analyzed, so at the finally the results were compared with theoretical models and thereby to evaluate their ability to simulation. In total were monitored three reduced models, whose physical quantities were measured using electrical sensors such as strain gauges, LVDT's and a system hydraulics load, which in the same time were connected to the system of acquisition of the National Instrument, controlled by a computer command and DynaTester and LabView programs.

One of the models constructed of aluminum was used to study the behavior of Suaçuí river bridge, as well as calibrate the theoretical models on the basis of experimental data of the real structure and the reduced model and to establish a relationship between them. The other two models built in microconcrete were used to study the behavior of structures in the nonlinear phase and fracture, for which they were subjected to incremental loads. The bridge of microconcrete was tested in order to verify the variations the rigidity of their cross section and the construction of an experimental relationship for the moment-curvature. The beams with minimum flexural reinforcement were tested in three-point bending to failure, in order to verify that his behavior depends on various parameters such as reinforcement ratio, the beam size, shape of cross section and steel-concrete adherence.

The experimental study was completed with material characterization tests, theoretical studies and the development of applications such as PUENFLEX program for calculating the moment-curvature relationships for cross sections and the program developed in LabView for monitoring structures to visualize their behavior in real time.

Keywords: Monitoring of structures, physical models, electrical sensors, momentcurvature, fracture mechanics, microconcrete. 


\section{LISTA DE FIGURAS}

Figura 1.1 - Usina Hidrelétrica de Tucurui, localizada em Belém, no estado de Pará construída entre os anos 1976-1984 (Fonte: Wikipédia).

Figura 1.2 - Pilar do vertedouro da barragem - Ilha Solteira. (a) Pilar instrumentado para ensaio, (b) modelo físico reduzido - Laboratório de Engenharia de Estruturas - EESC - USP.

Figura 1.3 - (a) Aplicação do carregamento na viga de concreto armado em escala natural, (b) Aplicação do carregamento em vigas em escala reduzida.

Figura 1.4 - (a) Vista geral da obra Estação metroviária Alto do Ipiranga, (b) Representação esquemática dos sensores instalados na laje.

5

Figura 1.5 - (a) Ponte do rio Suaçui, (b) Modelo em escala reduzida da Ponte Suaçui, (c) Modelo reduzido da ponte de microconcreto, (d) Vigas levemente armadas de microconcreto. 9

Figura 1.6 - Esquema do pórtico para ensaios.

Figura 2.1 - Princípio e organização de um sistema de Monitoração de Estruturas (BALAGEAS, CLAUSPETER, GUEMaES, 2006).

Figura 2.2 - Esquema geral de um sistema de monitoração (FELIX, 2004). 16

Figura 2.3 - A ponte de Wheatstone. 25

Figura 2.4 - Diferentes tipos da ponte de Wheatstone. 26

Figura 2.5 - Principio de funcionamento de um LVDT. 27

$\begin{array}{ll}\text { Figura 2.6 - Esquema interno de um LVDT. } & 27\end{array}$

Figura 2.7 - Sinais de entrada e saída de um LVDT. 28

Figura 2.8 - Curva típica de resposta de um LVDT. 29

Figura 2.9 - Posicionamento correto de um LVDT. 29

Figura 2.10 - Esquema de um sistema de monitoração. 31

Figura 2.11 - Tipos de Processadores de Sinal: (a) Analógico e (b) Digital. 32

Figura 2.12 - Circuito conceptual da amostragem de um sinal. 33

Figura 2.13 - Diagrama de bloco Módulo SCXI-1600. 36

Figura 2.14 - Diagrama de circuito de quarto de ponte, usando extensômetros com dois e três fios. 38

Figura 2.15 - (a) Quarto de ponte, (b) Meia ponte. 39

Figura 2.16 - (a) Ponte completa tipo I; (b) ponte completa tipo II. 40

Figura 2.17 - (a) Painel frontal; (b) diagrama de blocos. 42

Figura 2.18 - Área de trabalho do programa DIAdem, onde mostra-se os dados obtidos da monitoração da ponte do rio Suaçui. $\quad 45$

Figura 3.1 - Sequência de Execução do modelo de teste (REINHORN, 2008). 49

Figura 3.2 - Semelhança Geométrica. $\quad 56$

Figura 3.3 - Semelhança Distorcida. $\quad 57$

Figura 3.4 - (a) Modelo Elástico da Estrutura TWA em escala 1:50. (b) Modelo em microconcreto em escala 1:10 para estudar a estrutura até a ruptura.

Figura 3.5 - Vista do modelo a escala 1:5 na mesa vibratória da Universidade de Berkeley. 62 
Figura 3.6 - Modelo do tabuleiro de concreto reforçado em escala 1:6,6.

Figura 4.1 - Vista geral da ponte real e seus elementos estruturais.

Figura 4.2 - (a) Detalhe do aparelho de apoio deslizante; (b) Aparelho de apoio fixo. 66

Figura 4.3 - Dimensões da Ponte Suaçui. $\quad 67$

Figura 4.4 - (a) Ponte do Rio Suaçui - Protótipo, (b) Modelo em escala reduzida.. 69

Figura 4.5 - Dimensões e seções transversais do modelo em escala reduzida. 71

Figura 4.6 - Vista do modelo reduzido montado sobre o pórtico de ensaios. 73

Figura 4.7 - Extensômetros instalados no modelo.

Figura 4.8 - Extensômetros instalados na treliça 1 e 2.

Figura 4.9 - Extensômetros instalados nas longarinas e transversinas. 76

Figura 4.10 - (a) Transdutores de medição instalados no modelo, (b) LDVT sendo suportado pela base magnética.

Figura 4.11 - Localização dos transdutores de deslocamento na treliça T1 e T2. 77

Figura 4.12 - (a) Sistema de aquisição da National Instruments da linha SCXI, (b) Instalação de fios no módulo SCXI 1317.

Figura 4.13 - Módulo para controle da aquisição de dados(medição de deformações e deslocamentos). 79

Figura 4.14 - Módulo para controle da aquisição de dados (Dados experimentais: força e deslocamentos).

Figura 4.15 - Principal código gráfico gerado no LabVIEW para o controle da aquisição de dados. 80

Figura 4.16 - Código gráfico do VI para calcular os deslocamentos usando o método das rigidezes. 80

Figura 4.17 - Código gráfico do VI para desenhar a geometria da deformada da estrutura. 81

Figura 4.18 - (a) Sistema de carregamento, (b) Aplicação da carga no modelo. 81

Figura 4.19 - Esquema para verificar o comportamento linear do modelo. 82

Figura 4.20 - Posicionamento da carga nas diferentes seções do modelo. 82

Figura 4.21 - Sequência dos posicionamentos de carga no modelo. 83

Figura 4.22 - Deformações nos extensômetros para o estudo do caso I. 84

Figura 4.23 - Deformações nos extensômetros para o estudo do caso II. 84

Figura 4.24 - Deformações nos extensômetros para o estudo do caso III. 85

Figura 4.25 - Deslocamento medidos nos LVDT's: (a) Estudo de caso I, (b) Estudo de caso II. 85

Figura 4.26 - Deslocamento medidos nos LVDT's para o estudo de caso III. 86

Figura 4.27 - Modelo numérico de barras: (a) em 2D, (b) em 3D. 87

Figura 4.28 - Curvas de carga-deslocamento do modelo para o estudo do caso I. 87

Figura 4.29 - Modelo numérico de barras e elementos finitos: (a) em 2D, (b) em 3D. 88

Figura 4.30 - Comparação dos deslocamentos teóricos e experimentais obtidos no meio do vão para o estudo do caso II.

Figura 4.31 - Comparação dos deslocamentos teóricos e experimentais obtidos no meio do vão para o estudo do caso III. 
Figura 4.32 - Comparação de deformações teóricos e experimentais obtidos no nas barras para o estudo do caso III posição $4 . \quad 91$

Figura 4.33 - Instalação de sensores na Ponte do Rio Suaçui. 92

Figura 4.34 - Extensômetros e LVDT's instalados na ponte. 93

Figura 4.35 - (a) Extensômetros bidirecionais instalados nos trilhos, (b) Esquema de instalação de extensômetros para medição de carga.

Figura 4.36 - (a) Dispositivo para calibrar o sistema de medição de cargas, (b) Medição de carga da roda do trem em tempo real.

Figura 4.37 - (a) Posicionamento da maquina Plasser na ponte (sentido Belo Horizonte BH - Vitoria V); (b) Trem com carregamento de operação normal na via. 95

Figura 4.38 - Passagem do trem viliato sobre a ponte do rio Suaçui. 96

Figura 4.39 - Medições durante passagem do Trem Viliato a 5 km/h: (a) Deformações nos elementos estruturais da ponte, (b) Deslocamento no meio do vão. 97

Figura 4.40 - Carga de roda durante passagem do Trem Viliato a 5 km/h. 98

Figura 4.41 - Peso por roda do Trem Viliato. 98

Figura 4.42 - Peso por roda do trem equivalente utilizado no estudo do modelo reduzido. 102

Figura 4.43 - Linha de influência teórica e experimental para o deslocamento no meio do vão do modelo.

Figura 4.44 - Posição da carga equivalente onde se produz o máximo deslocamento no meio do vão do modelo.

Figura 4.45 - (a) Deformações experimentais nas diagonais do modelo para o estudo do caso II, 105

Figura 4.46 - Posição da carga equivalente onde se produz a máxima solicitação na diagonal T1-D6. 106

Figura 4.47 - (a) Deformações experimentais nos banzos do modelo para o estudo do caso II, 107

Figura 4.48 - Posição da carga equivalente onde se produz a máxima solicitação no banzo T1-B4. 107

Figura 4.49 - (a) Deformações experimentais nas cordas do modelo para o estudo do caso II, (b) Linha de influência teórica e experimental da deformação da corda T1-C6. 108

Figura 4.50 - Posição da carga equivalente onde se produz a máxima solicitação na corda T1-C6. 108

Figura 4.51 - Medições durante passagem do trem Viliato: (a) Deformações nos elementos estruturais da ponte real, (b) Deslocamento no meio do vão.

Figura 4.52 - Grandezas físicas calculadas a partir do modelo numérico (a) Deformações, (b) Deslocamentos no meio do vão. 109

Figura 5.1 - Modelo em escala reduzida do pórtico armado (ponte). 114

Figura 5.2 - Diagrama tensão-deformação para o concreto comprimido. 116

Figura 5.3 - Diagrama tensão-deformação para a armadura passiva. 117

Figura 5.4 - Compatibilidade das deformações (OLIVEIRA, 2008). 118

Figura 5.5 - Seção discretizada em lamelas - aproximação trapezoidal. 120

Figura 5.6 - Fluxograma implementado no programa para cálculo de M-1/r (FUSCO, 1986). 121

Figura 5.7 - Seção transversal da viga do modelo reduzido (Unidade: mm). 121 
Figura 5.8 - Interface gráfica do aplicativo denominado Puenflex.

Figura 5.9 - (a) Relação Momento-curvatura da seção, (b) Relação Momento-deformação $\varepsilon_{o}$ no centro geométrico da seção.

Figura 5.10 - Disposição do modelo no pórtico de ensaios, dimensões em centímetros.

Figura 5.11 - Detalhe da geometria do modelo da ponte.

Figura 5.12 - Seção transversal da viga tabuleiro e o pilar.

Figura 5.13 - Disposição das armaduras longitudinais e transversais.

Figura 5.14 - Detalhe dos aparelhos de apoio e carga.

Figura 5.15 - Localização dos extensômetros na armadura da ponte.

Figura 5.16 - Localização dos extensômetros na superfície da ponte.

Figura 5.17 - Extensômetros colados no modelo reduzido.

Figura 5.18 - Sistema de monitoração instalado no modelo.

Figura 5.19 - Deformações medidas na seção 2 do modelo.

Figura 5.20 - Deformações medidas na armadura.

Figura 5.21 - Deformações medidas no microconcreto submetido a compressão.

Figura 5.22 - Deformações medidas no microconcreto submetido a tração.

Figura 5.23 - Deslocamento experimental no meio da viga tabuleiro.

Figura 5.24 - Curva carga vs. deslocamento.

Figura 5.25 - Diagrama experimental de distribuição de deformações.

Figura 5.26 - Seção discretizada em camadas e suas respectivas deformações.

Figura 5.27 - Relação momento-curvatura pseudo-experimental.

Figura 5.28 - Comparação da relação momento curvatura teórico e pseudo-experimental.

Figura 5.29 - (a) Modelo submetido a ensaio de flexão, (b) Formação das primeiras fissuras.

Figura 5.30 - Aparecimento de fissuras na medida em que incrementa a carga.

Figura 5.31 - Pórtico de ensaios para vigas levemente armadas.

Figura 5.32 - Zona de Processo de Fratura (SHAH, 1995).

Figura 5.33 - (a) Fissura coesiva (RUIZ, 1998), (b) Função de amolecimento (CARPINTERI et al, 2002). 157

Figura 5.34 - Curvas carga-deslocamento: (a) Ensaio de Hededal e Kroon (1991), (b) e (c) Ensaios de Gonzalo Ruiz (1998).

Figura 5.35 - Curvas carga-deslocamento de Jacinto Ruiz (2006): (a) Vigas T com comprimentos de mesa variável, (b) Vigas tipo T com taxa de armadura variável.

Figura 5.36 - (a) Curva carga-deslocamento de uma viga levemente armada, (b) Transição frágil-dúctil numa viga armada em função da taxa de armadura (RUIZ, 1998).

Figura 5.37 - Viga retangular armada: (a) Valores de abertura de fissura (mm), (b) Elementos danificados (com fissura ativa), (c) região de perda de aderência.

Figura 5.38 - Curva carga-deslocamento das vigas de seção retangular (a) e seção T (b) para diferentes taxas de armadura. 
Figura 5.39 - Curva carga-deslocamento das vigas de seção retangular e seção T com uma armadura (a) e $\begin{array}{ll}\text { duas armaduras (b). } & 163\end{array}$

Figura 5.40 - Proporções das vigas levemente armadas. 165

Figura 5.41 - Viga retangular (a) com uma barra de reforço R-1b, (b) com duas barras de reforço R-2b. 165

Figura 5.42 - Viga tipo T (a) com uma barra de reforço T-1b, (b) com duas barras de reforço T-2b. 165

Figura 5.43 - Vigas em massa para medir a energia de fratura. 166

Figura 5.44 - Corpo de prova para medir a tensão de aderência. 166

Figura 5.45 - Ensaio de flexão em três pontos (a) Viga retangular, (b) Viga tipo T. 168

Figura 5.46 - Curva carga-deslocamento das vigas de seção retangular: (a) $\rho=0,108 \%, \quad 170$

Figura 5.47 - Curva carga-deslocamento das vigas de seção T: (a) $\rho=0,065 \%$, (b) $\rho=0,13 \%$. 171

Figura 5.48 - Influencia da taxa de armadura no comportamento das vigas levemente armadas. 172

Figura 5.49 - Influencia da forma da seção no comportamento das vigas levemente armadas. 173

Figura 5.50 - Comparação teórico experimental das curvas de carga- deslocamento das vigas de seção

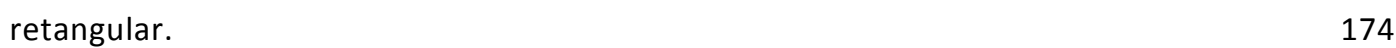

Figura 5.51 - Comparação teórico experimental das curvas de carga- deslocamento das vigas de seção T.

Figura 5.52 - Propagação de fissura em uma viga retangular levemente armada. 176

Figura 5.53 - Propagação de fissura em uma viga tipo T levemente armada. 176 


\section{LISTA DE TABELAS}

Tabela 3.1 - Classificação dos modelos fiscos reduzidos. Fonte: ACl-444 (1987).

Tabela 3.2 - Fatores de escala tipo.

Tabela 4.1 - Propriedades mecânicas das amostras ensaiadas.

Tabela 4.2 - Resumo das propriedades geométricas do protótipo.

Tabela 4.3 - Dimensões geométricas dos elementos do protótipo e do modelo.

Tabela 4.4 - Dimensões geométricas dos elementos do protótipo e do modelo.

Tabela 4.5 - Dimensões geométricas das seções do protótipo e do modelo adotadas. ..........................71

Tabela 4.6 - Resumo das propriedades geométricas e mecânicas do modelo....................................72

Tabela 4.7 - Especificações técnicas dos extensômetros elétricos.................................................74

Tabela 4.8 - Localização e nomenclatura dos extensômetros instalados no modelo................................75

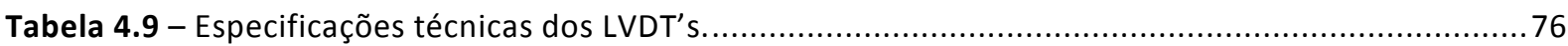

Tabela 4.10 - Deformações teóricos e experimentais nos elementos estruturais do modelo reduzido......90

Tabela 4.11 - Localização e nomenclatura dos extensômetros instalados na ponte...............................93

Tabela 4.12 - Envoltória de deformações e deslocamentos experimentais durante a ............................98

Tabela 4.13 - Grandezas físicas que descrevem o comportamento de uma estrutura...........................99

Tabela 5.1 - Resultados teóricos de Momento-curvatura....................................................... 124

Tabela 5.2 - Propriedades mecânicas do microconcreto. .................................................. 128

Tabela 5.3 - Propriedades mecânicas do aço CA-50 ...................................................... 128

Tabela 5.4 - Localização e nomenclatura dos extensômetros instalados no modelo............................131

Tabela 5.5 - Deslocamentos teóricos e experimentais na seção 2. .................................................138

Tabela 5.6 - Deformações teóricos e experimentais na zona 1 e 2 da seção......................................141

Tabela 5.7 - Deformações teóricos e experimentais na zona 3, 4 e 5 da seção. ................................142

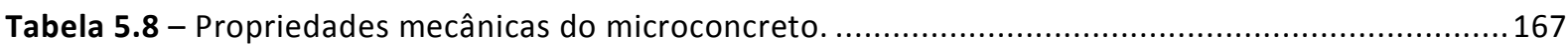

Tabela 5.9 - Propriedades mecânicas do arame recozido com nervura. .............................................. 167 


\section{SUMÁRIO}

\section{RESUMO}

\section{ABSTRACT}

\section{LISTA DE FIGURAS}

\section{LISTA DE TABELAS}

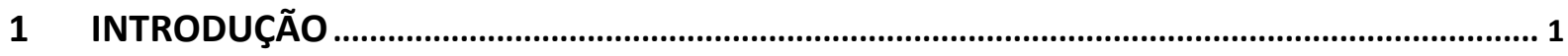

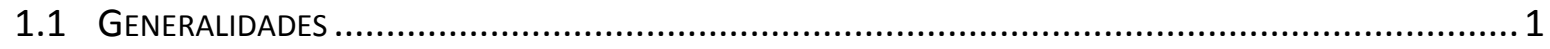

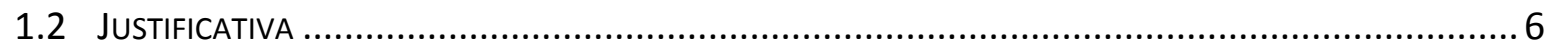

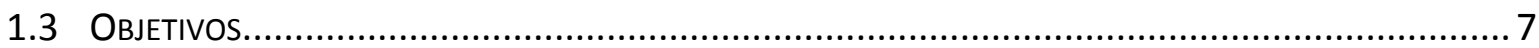

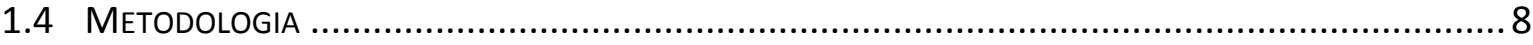

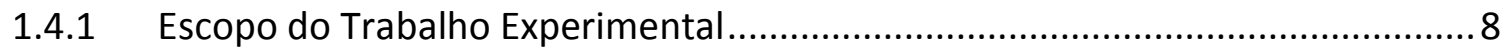

1.4.2 Modelos físicos a serem estudados ............................................................ 8

1.4.3 Instrumentação dos modelos ........................................................................ 10

1.4.4 Ambiente de desenvolvimento do trabalho laboratorial e de monitoração.....11

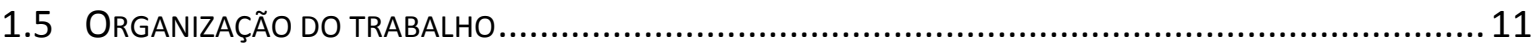

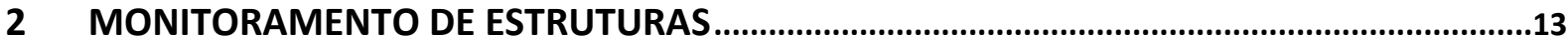

2.1 DeFINIÇÃO DE Monitoramento de ESTRUtURAS .............................................................. 13

2.2 MotIVAÇÃO PARA FAZER MONITORAÇÃO DE ESTRUTURAS........................................................ 14

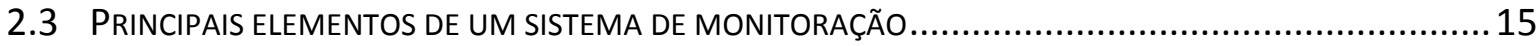

2.4 CLASSIFICAÇÃO DOS SISTEMAS DE MONITORAÇÃO DE ESTRUTURAS ............................................ 18

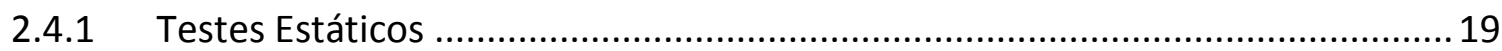

2.4.1.1 Testes de Comportamento ....................................................................... 19

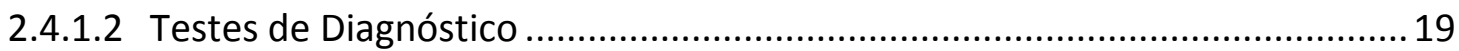

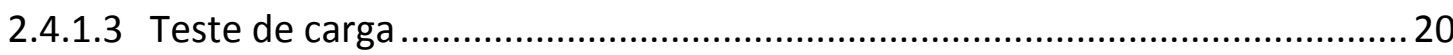

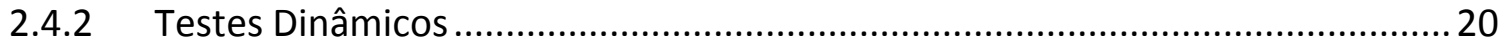

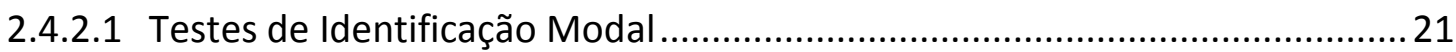

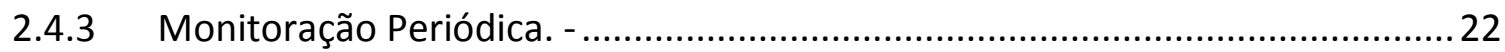

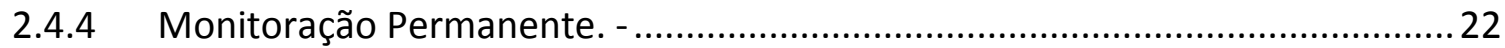

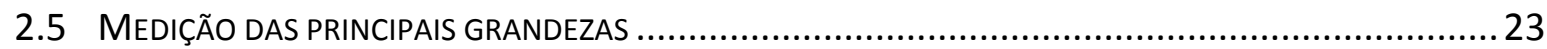

2.5.1 Métodos de Medição das Principais grandezas. - ..............................................22 
2.5.1.1 Medidores de deformação - Extensômetros elétricos ou straingages.

2.5.1.2 Transformador Linear de Diferença Variavel LVDTs (Linear Variable

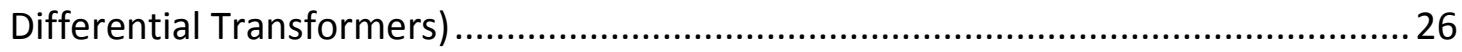

2.5.2 Instalação de um Sistema de Monitoração ........................................................ 30

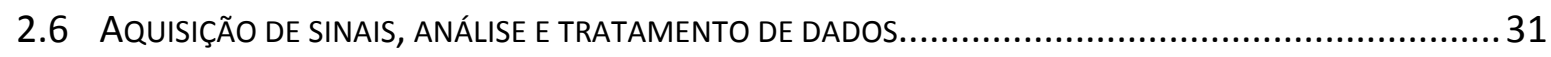

2.6.1 Arquitetura de um Sistema de Aquisição e Processamento de Sinais ...............31

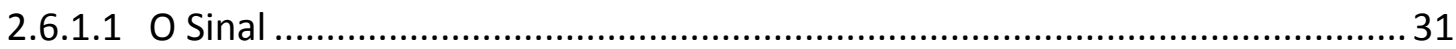

2.6.1.2 Tipos de Processadores de Sinais. - .............................................................. 32

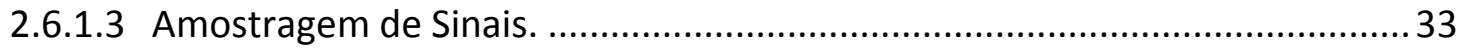

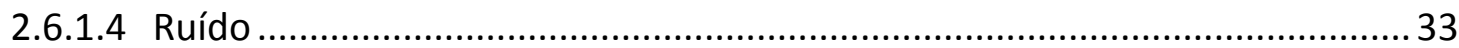

2.6.1.5 Manipulações matemáticas para sinais........................................................... 34

2.6.2 Diagrama de funcionamento do Sistema de Aquisição. .................................... 35

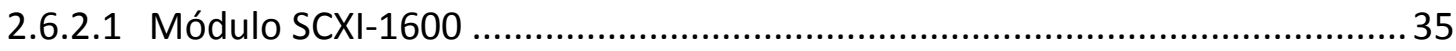

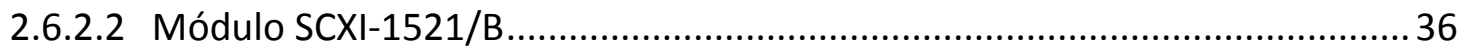

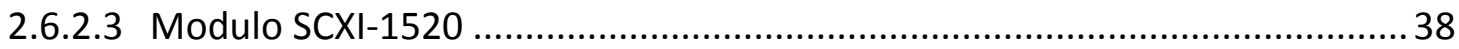

2.6.3 Programas para aquisição e processamento de dados.................................... 40

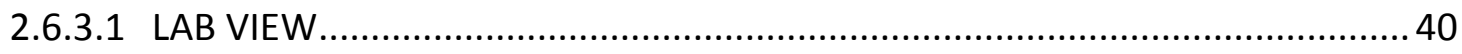

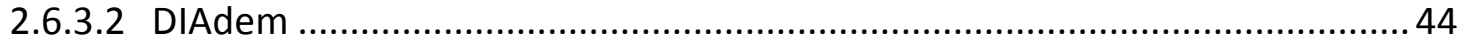

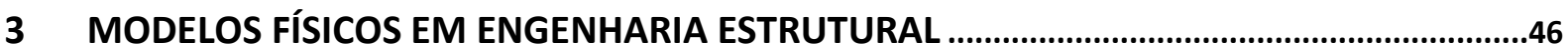

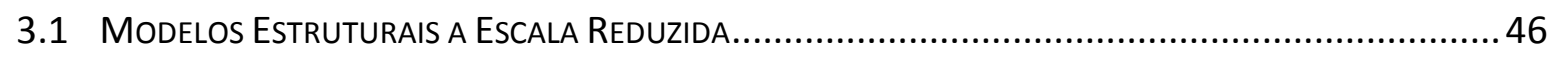

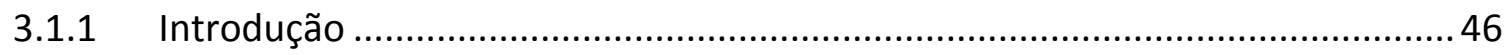

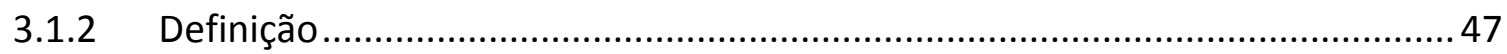

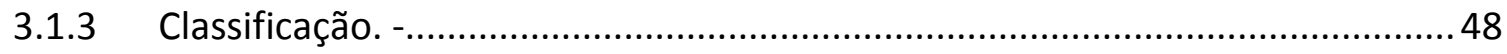

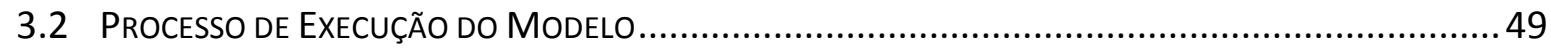

3.2.1 Fator de Escala de Modelos Experimentais. - ....................................................50

3.2.2 Fatores de Escala para Estruturas tipo ........................................................ 50

3.3 VANTAGEM E LIMITAÇÕES DOS MOdELOS FísICOS................................................................ 51

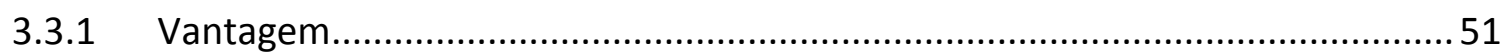

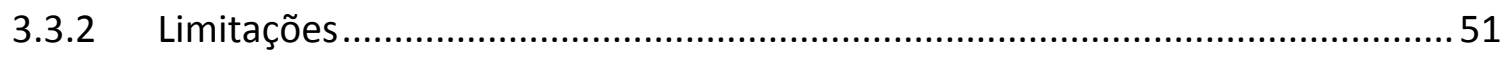

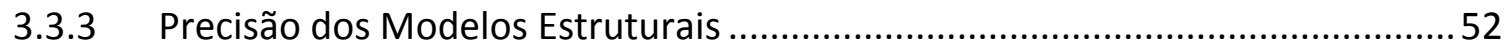

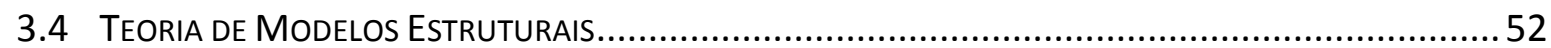




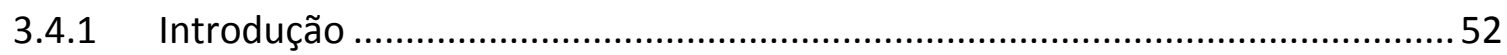

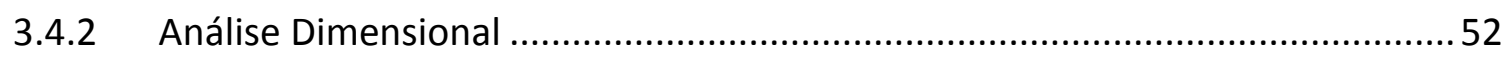

3.4.2.1 Forma de uma Equação Dimensional ............................................................53

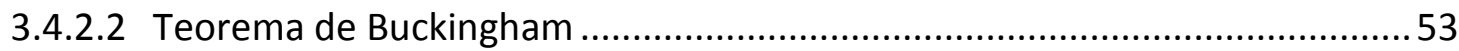

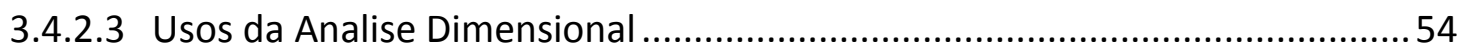

3.4.3 Semelhança de Modelos Estruturais .................................................................. 55

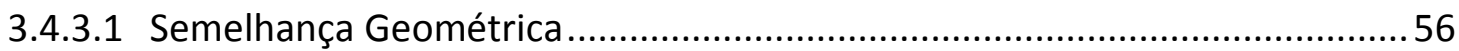

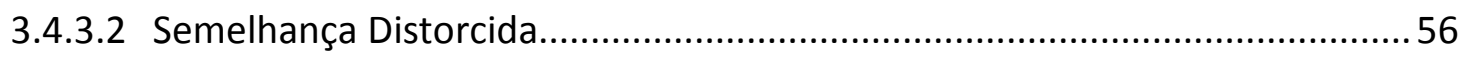

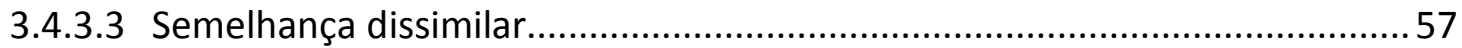

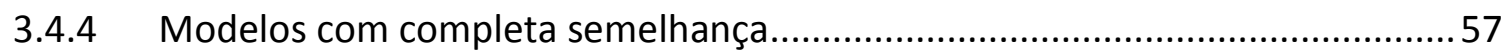

3.4.5 Dificuldades Tecnológicas Associadas com a Semelhança Completa .................60

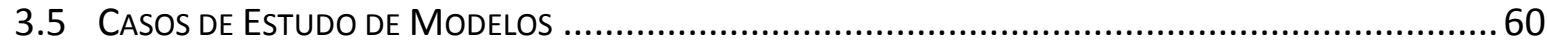

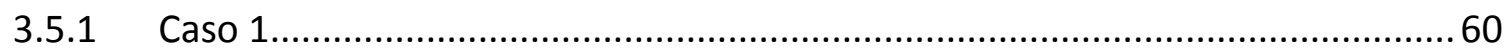

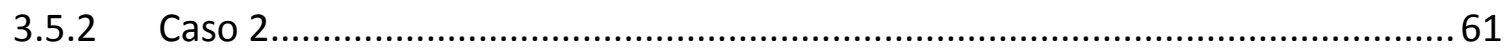

3.5.3 CASO 3: Tabuleiro de ponte de concreto reforçado ..........................................62

4 MONITORAÇÃO DA PONTE DO RIO SUAÇUI EM ESCALA REAL E REDUZIDA .....................64

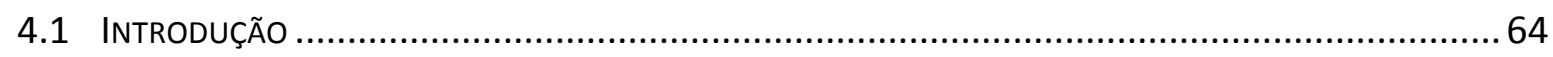

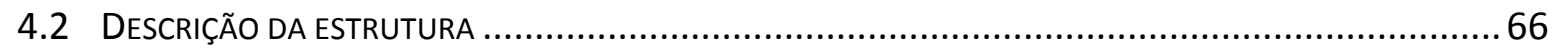

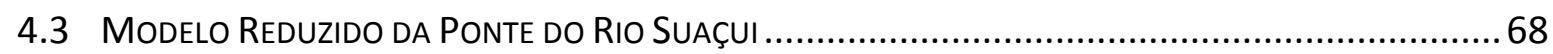

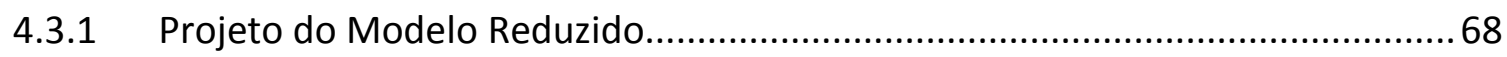

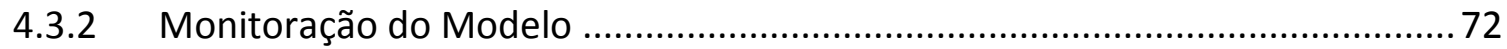

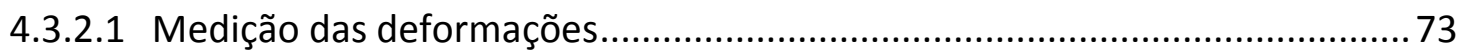

4.3.2.2 Medição de deslocamentos verticais ............................................................ 76

4.3.2.3 Sistema de aquisição................................................................................... 77

4.3.2.4 Ensaios de carga no modelo reduzido .......................................................... 81

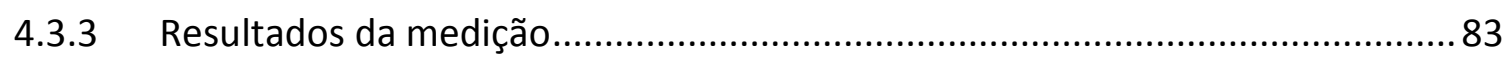

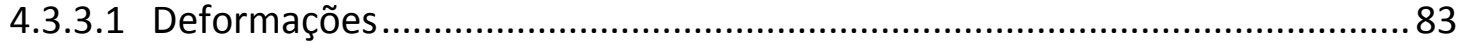

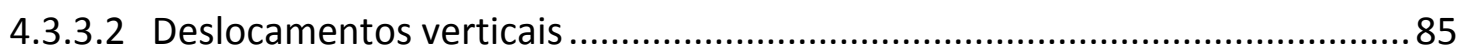

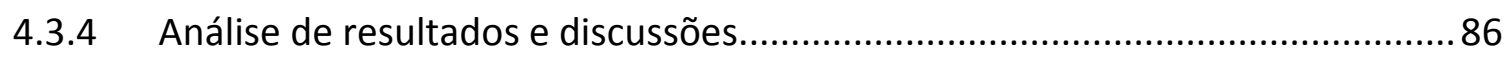

4.3.4.1 Comparação carga vs. deslocamento ............................................................. 86

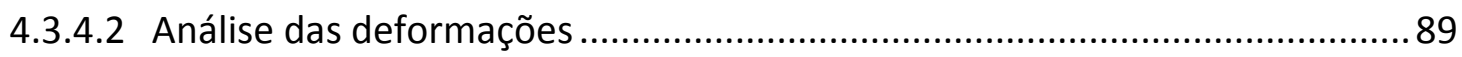




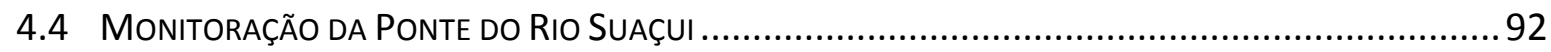

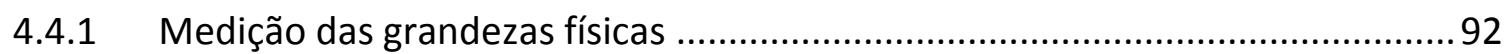

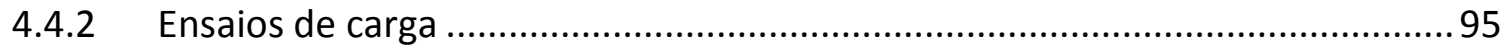

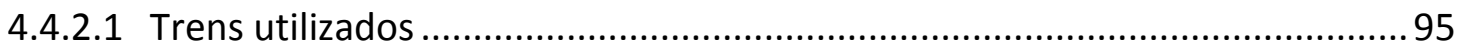

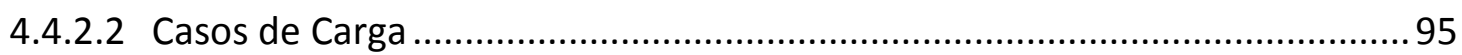

4.4.3 Realização dos ensaios com o trem viliato......................................................96

4.4.4 Resultados da medição durante a prova de carga ...........................................97

4.5 COMPORTAMENTO ESTRUTURAL DA PONTE EM ESCALA REAL E ESCALA REDUZIDA..........................99

4.5.1 Cálculo teórico das relações de semelhança e fatores de escala ......................99

4.5.2 Estudo comparativo de deformações e deslocamentos medidos na ponte real e no modelo reduzido. 101

4.5.2.1 Metodologia para determinar deformações e deslocamentos....................102

4.5.2.2 Comparação do deslocamento no meio do vão ...........................................103

4.5.2.3 Comparação de deformações nos elementos estruturais.............................104

4.5.2.4 Comparação de dados experimentais monitoradas na ponte real e os calculados no modelo numérico da ponte em escala reduzida ................................108

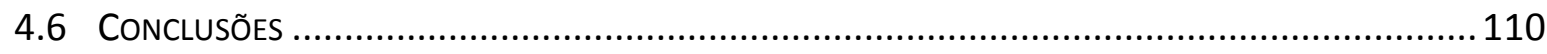

5 MODELOS REDUZIDOS DE MICROCONCRETO …................................................................112

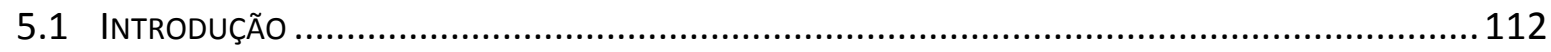

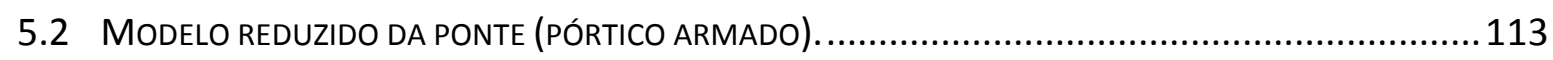

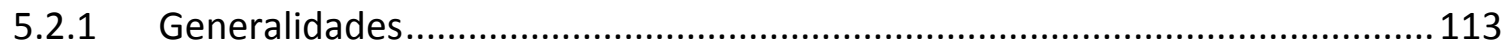

5.2.2 Conceitos básicos da relação momento-curvatura ..........................................114

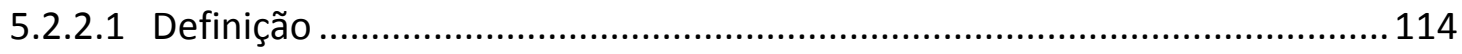

5.2.2.2 Diagramas de tensão deformação dos materiais .........................................116

5.2.2.3 Método de cálculo dos esforços resistentes ..............................................117

5.2.3 Aplicativo para o cálculo da relação momento - curvatura. ........................... 119

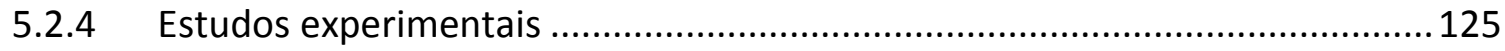

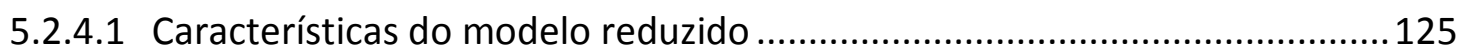

5.2.4.2 Caracterização e construção do modelo reduzido ......................................128

5.2.4.3 Execução do ensaio................................................................................. 129

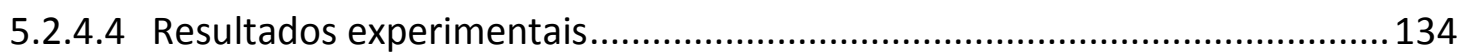


5.2.5 Apresentação de resultados e discussões...................................................137

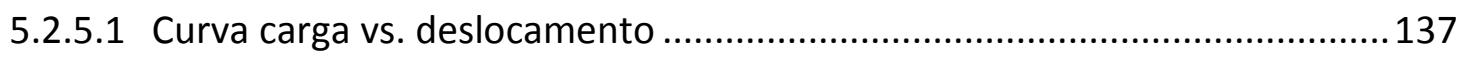

5.2.5.2 Diagrama de distribuição de deformações...................................................139

5.2.5.3 Relação Momento-Curvatura experimental............................................. 144

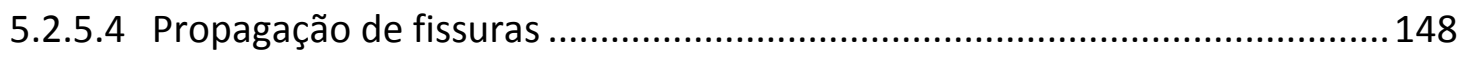

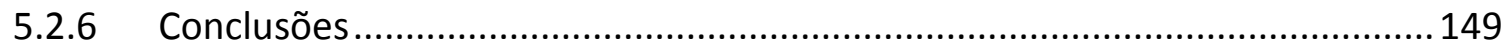

5.3 Modelo REDUZIDO DE VIGAS LEVEMENTE ARMADAS .......................................................... 150

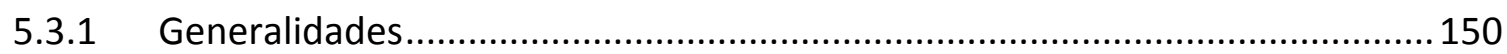

5.3.2 Conceitos básicos da mecânica da fratura aplicada ao concreto .....................152

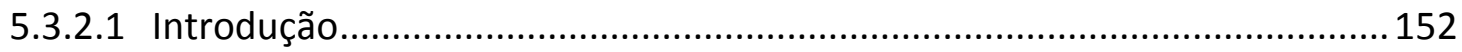

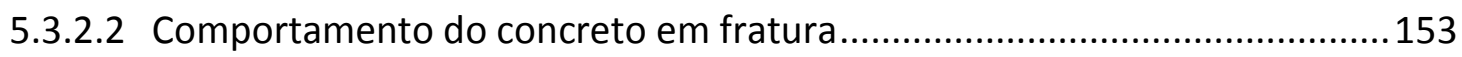

5.3.2.3 A viga levemente armada e armadura mínima em flexão ............................158

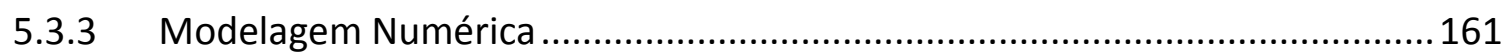

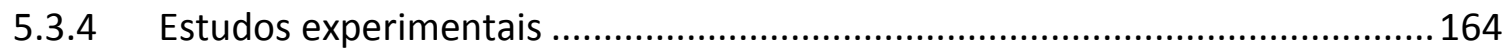

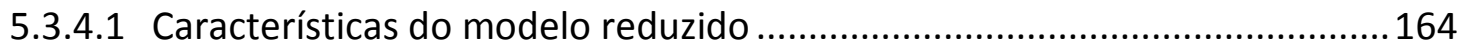

5.3.4.2 Caracterização e construção das vigas armadas .........................................166

5.3.4.3 Execução do ensaio.................................................................................. 167

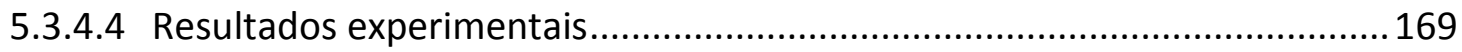

5.3.5 Apresentação de resultados e discussões..................................................... 171

5.3.5.1 Influência de parâmetros no comportamento das vigas.............................172

5.3.5.2 Comparação teórico-experimental das vigas levemente armadas ...............174

5.3.5.3 Propagação de fissuras ............................................................................ 175

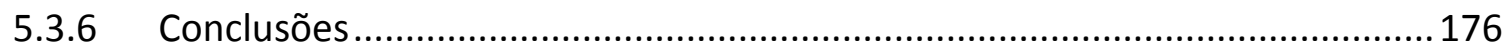

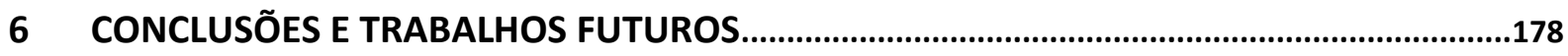

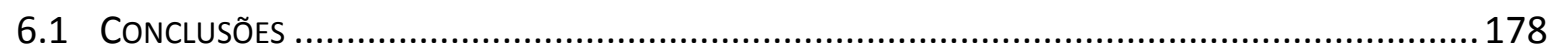

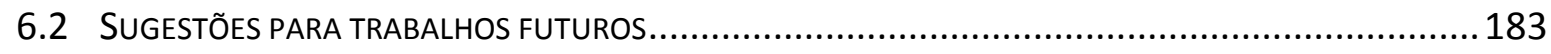

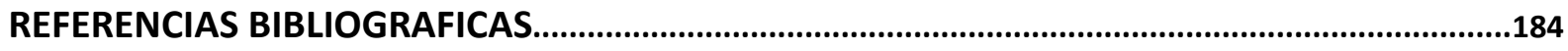

ANEXO A - FABRICAÇÃO DE MODELOS EM ESCALA REDUZIDA....................................190

ANEXO B - CARACTERIZAÇÃO DOS MATERIAIS....................................................212

ANEXO C - RESULTADOS EXPERIMENTAIS DOS MODELOS FÍSICOS............................... 231

ANEXO D - DIMENSIONAMENTO DA PONTE DE MICROCONCRETO ...............................239 


\section{Capítulo}

\section{INIRODUÇÃO}

\section{Introdução}

\subsection{Generalidades}

O comportamento de uma estrutura (real ou reduzida) pode ser quantificado através de grandezas físicas, entre os quais podemos mencionar: deslocamentos, deformações lineares, rotações, tensões, etc. Essas grandezas físicas podem ser obtidas teoricamente ou através de ensaios experimentais baseados no desenvolvimento de modelos.

Assim, o modelo pode ser definido como a representação ou interpretação simplificada da realidade, ou uma interpretação de um fragmento de um sistema, segundo uma estrutura de conceitos teóricos ou experimentais, e apresenta apenas uma visão ou cenário de um fragmento do todo. Também os modelos facilitam a compreensão e a visualização dos fenômenos intervenientes e servem de instrumento para estudar fenômenos físicos. Para representar um fenômeno físico complexo podem-se utilizar modelos físicos ou modelos matemáticos. 
Os modelos físicos ou modelos em escala são ferramentas usadas em diversos ramos da engenharia. Na área de engenharia estrutural, são usados para estudar o comportamento de estruturas, como por exemplo: usinas elétricas, pontes, barragens, eclusas e prédios sujeitos a forças externas, ventos ou a terremotos. Normalmente, a modelagem física é utilizada para complementar os cálculos dos modelos matemáticos durante um projeto muito grande e complexo. No modelo físico pode-se estudar também, em escala reduzida ou ampliada, diversos fenômenos físicos e utilizá-lo como referência para a calibração de modelos matemáticos. A construção de modelos físicos, em escalas reduzidas, embora estudada anteriormente por Arquimedes, Leonardo Da Vinci, entre outros, só foi possível após a descoberta da Teoria da Semelhança Mecânica por Isaac Newton e do Teorema de Buckingham.

Os modelos matemáticos representam os fenômenos naturais por meio de equações e símbolos abstratos que, em alguns casos são de difícil representação e solução. Além disso, necessitam constantemente do uso de coeficientes desconhecidos que deverão ser medidos na natureza ou em modelos físicos. Como a resolução das equações complexas nem sempre é possível, faz-se necessário desprezar certos termos e ainda formular hipóteses sobre a distribuição espacial de certas grandezas (modelos integrais) ou discretizar o espaço e o tempo (modelos numéricos). Esses modelos podem ser uni, bi e tridimensionais. A escolha das hipóteses simplificadoras e do tipo de modelo é fundamental para a validade dos resultados obtidos ${ }^{1}$.

Os modelos físicos têm a vantagem sobre os modelos matemáticos, de não apresentarem uma discretização do problema, pois esse é contínuo e pode ter uma representação geométrica tridimensional sem dificuldades.

Atualmente o comportamento de uma estrutura real ou em escala reduzida pode ser monitorado. Na monitoração, a medição das grandezas físicas relevantes é realizada com sistemas de elementos que são parte integrante da estrutura. Esses sistemas são constituídos por sensores, sistemas de aquisição, de processamento e

\footnotetext{
1 RIOS, J. L. P. Modelos matemáticos em hidráulica e no meio ambiente. Simpósio Luso Brasileiro sobre simulação e Modelação em Hidráulica. APRH - LNEC. Lisboa, 1986.
} 
de armazenamento de informação e sistemas de comunicação, com elevado grau de automatização, versatilidade e flexibilidade (BERGMEISTER E SANTA, 2001) ${ }^{2}$.

A monitoração em engenharia civil tem como objetivo avaliar a integridade estrutural, através da caracterização e a observação do comportamento físico e mecânico dos materiais e dos seus elementos estruturais quando submetidas a um determinado tipo de solicitação contínua ou temporária.

Geralmente as estruturas objeto deste tipo de monitoração são as obras de arte, tais como pontes, viadutos, barragens e túneis. Estruturas que pelo seu volume, dimensão e pela sua importância no domínio da mobilidade de pessoas no tecido urbano, requerem um acompanhamento atento quer durante a fase construtiva quer após a sua entrada em serviço (FIGUEIREDO, 2006).

A importância da monitoração de estruturas no âmbito da engenharia civil é uma realidade de aplicação no mundo. Em países como Canadá, Estados Unidos e Japão, por exemplo, o problema de degradação prematura de pontes rodoviárias vem sendo investigado com o auxilio de sistemas de monitoração. Os problemas de deterioração das estruturas decorrem do fato que boa parte delas já está envelhecida ou envelhecendo, sendo reconhecido que sua reconstrução demandará custos muito superiores ao de um programa criterioso de manutenção. Esse cenário implica na utilização da monitoração como agente capaz de fornecer o estado da estrutura observada com segurança.

O emprego da monitoração não se restringe somente a estruturas afetadas pela ação do tempo. Em estruturas novas, particularmente as que exigem elevados custos de construção, é recomendável a monitoração desde a fase construtiva, pois possibilita identificar os problemas ou danos estruturais nas etapas iniciais.

No Brasil, existem vários trabalhos relacionados sobre a monitoração de estruturas e modelos em escala reduzida. Como exemplo pode-se citar o estudo do projeto da Usina hidrelétrica de Tucuruí (Figura 1.1), em modelo de escala reduzida.

\footnotetext{
${ }^{2}$ BERGMEISTER, K.; SANTA, U. Global monitoring concepts for bridges. Structural Concrete, vol. 2, nro 1, p. 29-39. ISSN 1464-4177. 2001.
} 
Esse modelo foi construído e conduzido no Laboratório Saturnino de Brito, no Rio de Janeiro, durante um período de oito anos (Figura 1.1).

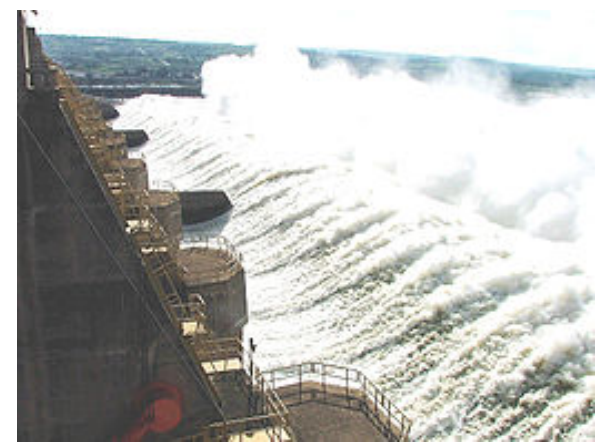

Figura 1.1 - Usina Hidrelétrica de Tucurui, localizada em Belém, no estado de Pará construída entre os anos 1976-1984 (Fonte: Wikipédia).

Outro trabalho experimental em modelos a escala reduzida foi desenvolvido na Escola de Engenharia de São Carlos da USP, onde estudou-se o comportamento de um pilar típico de vertedouro de Ilha Solteira, o qual foi construído em microconcreto a uma escala de 1:20, reproduzindo-se também os cabos de protensão e as respectivas ancoragens. As medições das tensões principais sob protensão foram feitas por meio de extensômetros elétricos (MARTINELLI, 2003) ( $^{3}$

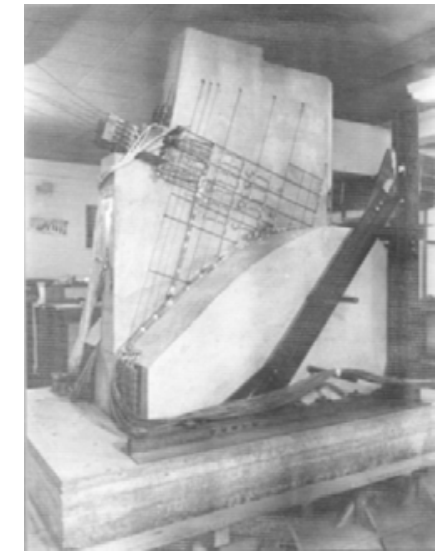

(a)

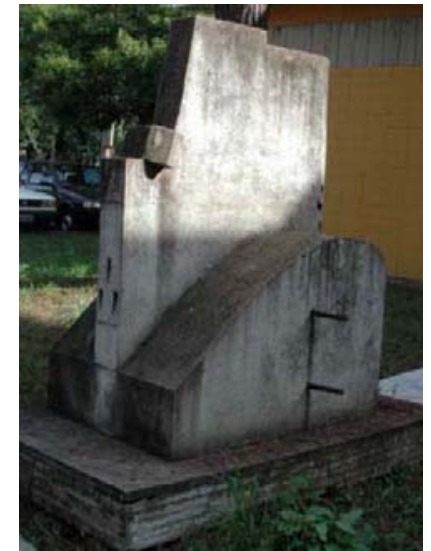

(b)

Figura 1.2 - Pilar do vertedouro da barragem - Ilha Solteira. (a) Pilar instrumentado para ensaio, (b) modelo físico reduzido - Laboratório de Engenharia de Estruturas - EESC - USP.

Na mesma escola de engenharia, Silva (2007) desenvolveu o estudo da ação da carbonatação em vigas de concreto armado em serviço, para o qual construiu vigas em escala natural e reduzida. Os resultados dessa pesquisa mostraram a

\footnotetext{
${ }^{3}$ MARTINELLE, D.A.O. Eu me recordo... Concreto colloquia 2003. EESC-USP. São Carlos - SP, 2003.
} 
eficácia dos modelos reduzidos em escala 1:5 para realizar estudos de carbonatação, com exceção de estudos na posição da fissura. Mas não se verificou se essa limitação também ocorre para escalas maiores (Figura 1.3).

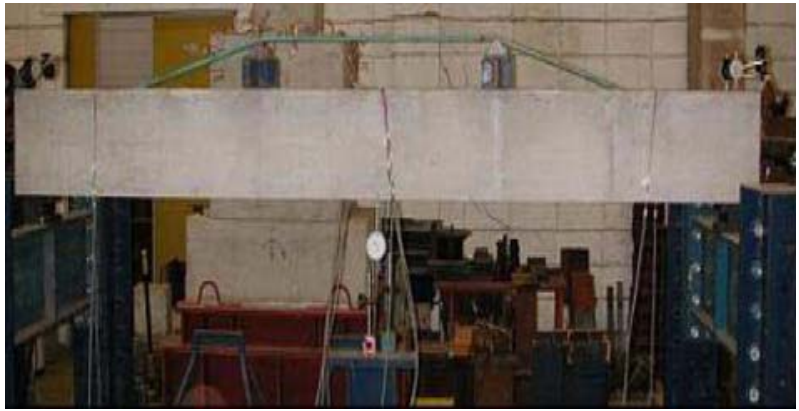

(a)

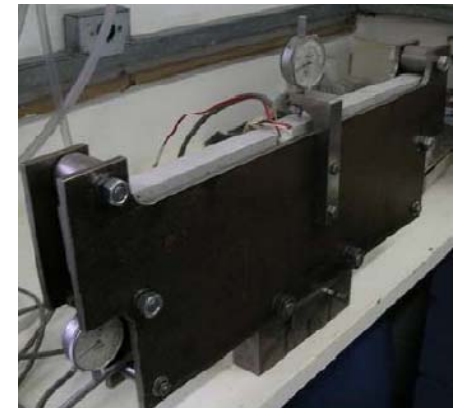

(b)

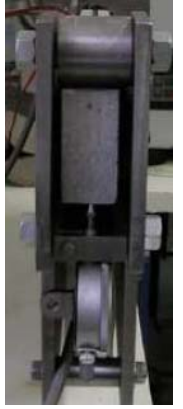

Figura 1.3 - (a) Aplicação do carregamento na viga de concreto armado em escala natural, (b) Aplicação do carregamento em vigas em escala reduzida.

Outra importante obra monitorada foi a laje de fundo da estação metroviária Alto do Ipiranga, instrumentada pela equipe do Laboratório de Estruturais e Materiais (LEM), da Escola Politécnica da Universidade de São Paulo, e pela equipe da Gavea Sensors. O objetivo desta monitoração era determinar as pressões na cota da face inferior da laje, as deformações no concreto e nas armaduras e a temperatura no concreto (ASSIS, 2007). Nessa monitoração, os resultados obtidos tinham um caráter mais qualitativo do que quantitativo, uma vez que os sensores utilizados não foram apropriadamente calibrados, mas tendo em vista as análises que puderam ser extraídas dos resultados dos sensores de deformação, tem-se uma mostra do que pode ser constatado em termos de comportamento estrutural mediante o emprego da monitoração (Figura 1.4).

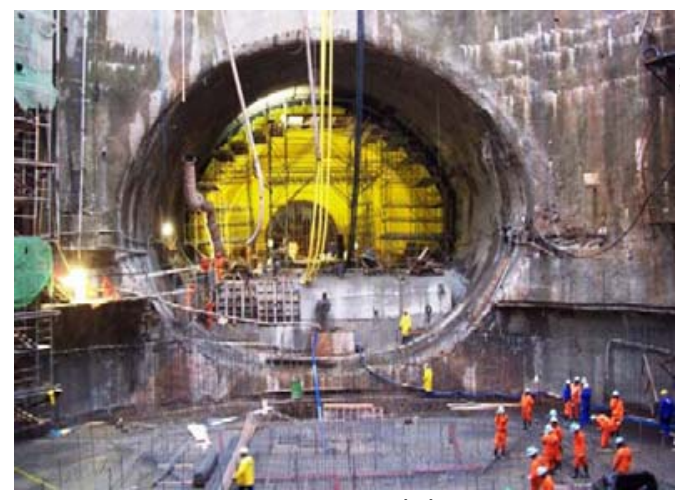

(a)

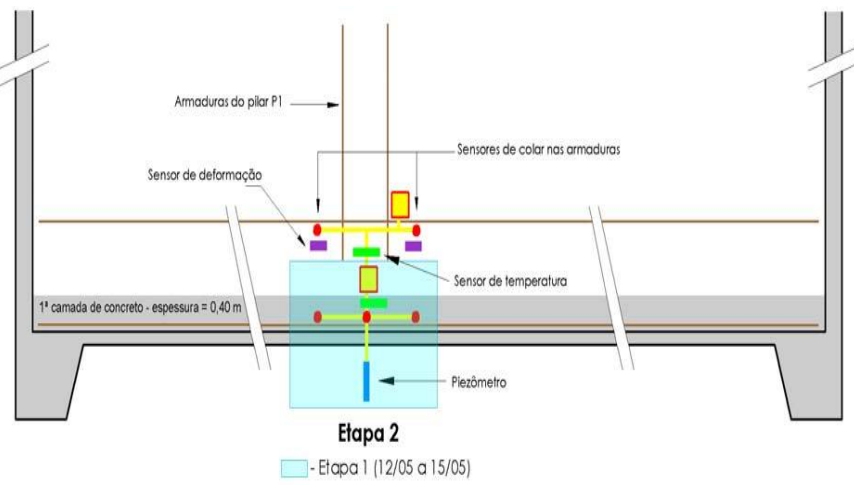

(b)

Figura 1.4 - (a) Vista geral da obra Estação metroviária Alto do Ipiranga, (b) Representação esquemática dos sensores instalados na laje. 


\subsection{Justificativa}

A principal motivação para a realização desta pesquisa foi a investigação do comportamento de estruturas em escala real através de modelos físicos em escala reduzida, utilizando recursos de monitoração, interpretação e análise numérica. Do mesmo modo, relacionar resultados experimentais obtidos dos modelos reduzidos e da estrutura real usando conceitos da Teoria de Modelos Estruturais e semelhança física.

Os modelos em escala reduzida são relativamente baratos e fáceis de construir e podem ser ensaiados até a ruptura sem grandes dificuldades ou prejuízos, permitindo assim um melhor conhecimento do comportamento das estruturas nesta fase.

$\mathrm{Na}$ área acadêmica, os modelos em escala reduzida conjuntamente como o sistema de monitoração podem servir como elementos de ensino e compreensão do comportamento de certo tipo de estruturas para alunos de graduação.

Com a construção e monitoração do modelo reduzido da ponte do rio Suaçui, estudou-se o comportamento na fase linear da estrutura e se obteve uma relação de semelhança com os dados experimentais obtidos da monitoração da ponte real. Além disso, este estudo foi complementado com a calibração do modelo numérico para o qual se usou o programa computacional SAP2000.

Com a construção e monitoração da ponte de microconcreto, estudou-se o comportamento da estrutura na fase linear e a não linearidade física, para o qual o modelo foi submetido a cargas incrementais para conhecer seu comportamento. Posteriormente, os dados experimentais foram comparados com resultados teóricos obtidos do aplicativo PUENFLEX desenvolvido para esta pesquisa, o qual calcula a relação momento-curvatura de uma seção.

Com a construção e monitoração das vigas levemente armadas, estudou-se o comportamento das vigas em fratura e foram ensaiadas até a ruptura com a finalidade de mostrar que seu comportamento depende de vários parâmetros como: o tamanho da viga, taxa de armadura, aderência aço-concreto e a forma da seção transversal. 


\subsection{Objetivos}

Esta pesquisa tem como objetivo geral estudar o comportamento estrutural dos modelos físicos construídos usando recursos de monitoração, quando submetidos a diferentes tipos de solicitações de carga.

Os objetivos específicos da presente pesquisa são:

- Monitoração e desenvolvimento de modelos físicos em escala reduzida de estruturas reais. Os modelos foram instrumentados por meio de sensores elétricos e ensaiados no laboratório para conhecer seu comportamento experimentalmente.

- Monitoração da Ponte do Rio Suaçui, onde se obteve dados experimentais do comportamento de uma estrutura real e serviu de base para realizar comparações com os dados experimentais obtidos do modelo reduzido.

- Estudo experimental das relações de momento-curvatura de uma seção transversal, para o qual foi desenvolvido um aplicativo em $\mathrm{C}++$ denominado PUENFLEX, o qual calcula teoricamente a relação momento-curvatura segundo a norma ABNT NBR 6118:2007.

- Estudo experimental de vigas levemente armadas cujo comportamento é sensível a vários parâmetros como: taxa de armadura, aderência aço-concreto, e forma da seção transversal.

- Modelagem numérica dos modelos físicos monitorados utilizando programas computacionais disponíveis baseados em Elementos Finitos e Elementos de Barra (SAP2000).

- Desenvolvimento de um programa computacional capaz de visualizar as deformações, deslocamentos e forças em tempo real de uma estrutura. $O$ programa LabVIEW será usado para a aquisição de dados e a criação da interface de monitoração.

- Domínio sobre as técnicas de monitoração, interpretação e análise numérica de estruturas, a partir das informações obtidas dos ensaios experimentais realizados, estabelecendo-se um ambiente integrado de modelagem numérica e experimental. 


\subsection{Metodologia}

\subsubsection{Escopo do Trabalho Experimental}

O trabalho experimental consistiu basicamente na construção de modelos reduzidos de acordo com o projeto de elaboração e o tipo de estudo que se pretende fazer com cada modelo. Na construção de modelos utilizou-se diferentes tipos de materiais, os quais foram apropriadamente caracterizados com a finalidade de se conhecer suas propriedades mecânicas e assim permitir uma completa interpretação dos resultados dos ensaios experimentais e teóricos.

Após construídos os modelos, esses foram submetidos a ensaios de carga com a finalidade de se conhecer seu comportamento. Todos os dados experimentais foram obtidos por um sistema de monitoração composto por sensores, equipamentos de aquisição e armazenamento de dados.

Finalmente fez-se o tratamento de dados, o que na monitoração de estruturas constitui uma das atividades fundamentais, da qual depende qualitativamente o esforço envolvido na interpretação do comportamento estrutural.

\subsubsection{Modelos físicos a serem estudados}

Nesta pesquisa, foram estudados três modelos, dos quais dois foram construídos em microconcreto e um em alumínio e são descritos a seguir:

a. Modelo reduzido da ponte do rio Suaçui. - Construído em alumínio e baseando-se nas dimensões da ponte real. Foi utilizado com a finalidade de se analisar deslocamentos e deformações experimentais quando submetidos a determinados carregamentos. Os dados experimentais desse modelo foram relacionados com os dados experimentais do modelo real utilizando conceitos de semelhança física. Os detalhes deste estudo são descritos no capitulo 4.

b. Modelo da ponte de microconcreto. - Construído com a finalidade de se analisar a variação de rigidez do modelo, considerando o estágio inicial e após submeter a estrutura a carregamentos crescentes. Na seção transversal no meio do vão do modelo, foram instalados extensômetros com a finalidade de medir deformações e assim construir a relação momento-curvatura 
experimental. Os detalhes deste estudo são descritos no capitulo 5, na primeira parte.

c. Modelo de vigas levemente armadas. - Essas vigas foram construídas em microconcreto com a finalidade de se conhecer seu comportamento em fratura. Para isso, foram ensaiadas várias vigas - com diferentes taxas de armaduras e dois tipos de seção transversal - até a ruptura. Os detalhes deste estudo são descritos no capitulo 5, na segunda parte.

Todos os materiais usados na construção dos modelos reduzidos foram caracterizados através de ensaios no laboratório com a finalidade de se determinar suas propriedades mecânicas. Assim, para o microconcreto foram determinados a energia de fratura, a resistência à compressão, a resistência à tração, o módulo de elasticidade e a tensão de aderência entre o aço e o microconcreto. Da mesma forma foram determinadas as propriedades do aço e do alumínio conforme detalhado no anexo B. Na figura 1.5 ilustra-se a ponte do Rio Suaçui e os três modelos em escala reduzida instaladas nos pórticos de ensaio do laboratório.

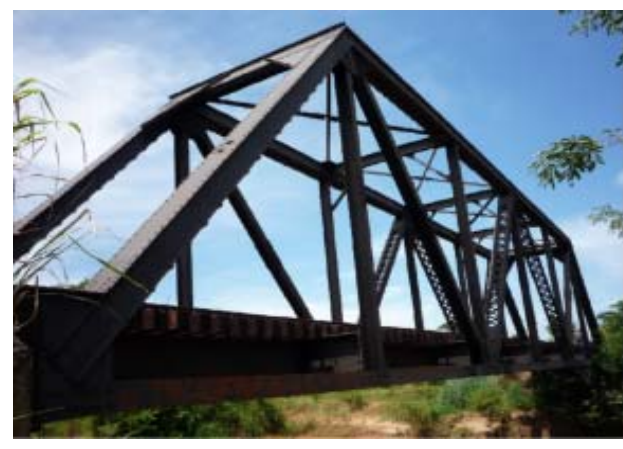

(a)

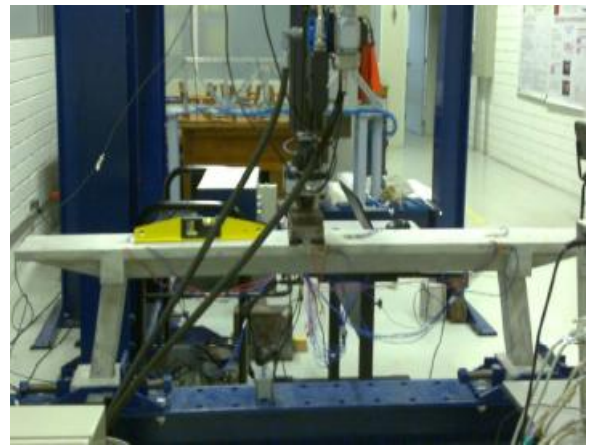

(c)

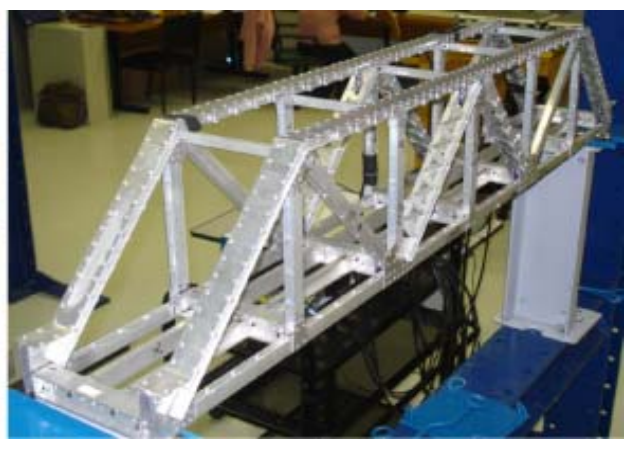

(b)

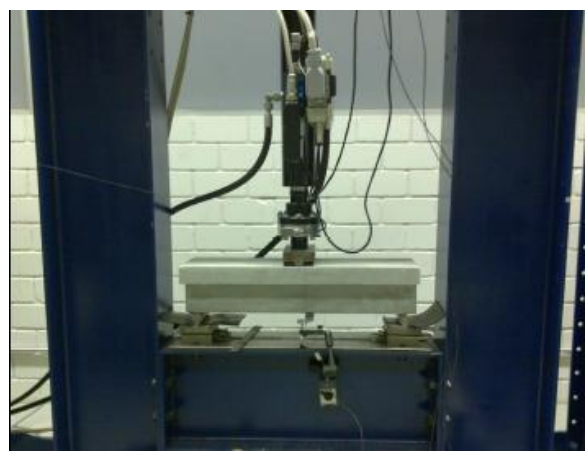

(d)

Figura 1.5 - (a) Ponte do rio Suaçui, (b) Modelo em escala reduzida da Ponte Suaçui, (c) Modelo reduzido da ponte de microconcreto, (d) Vigas levemente armadas de microconcreto. 
Para o suporte e ensaio dos modelos reduzidos foram confeccionados pórticos conforme o esquematizado na figura 1.6. Os quais foram fabricados com perfis de aço tipo "H" e adaptados para a instalação de equipamentos de carga (servoatuador) através de placas e parafusos.

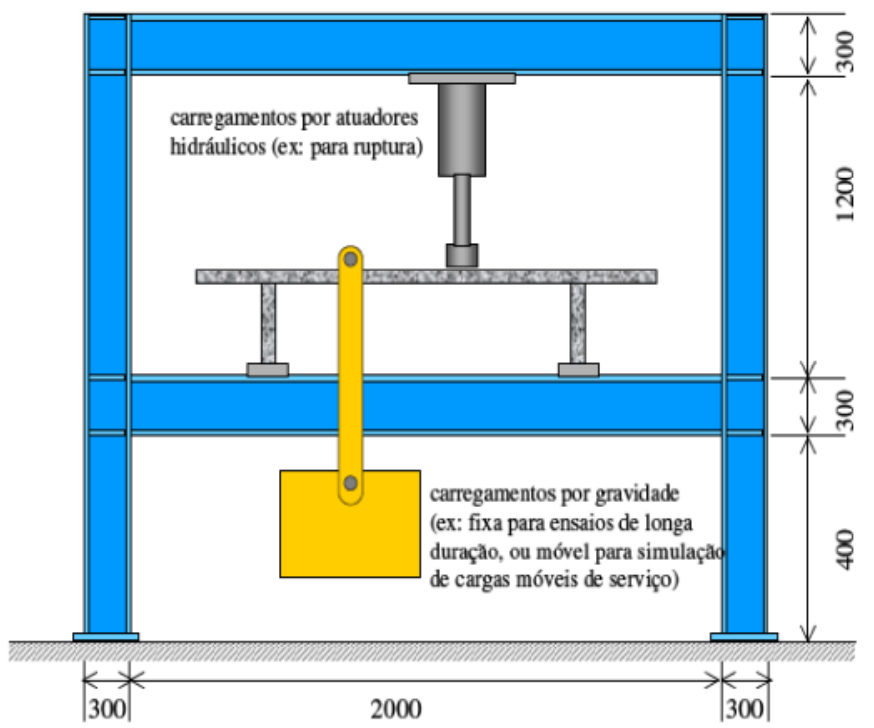

Figura 1.6 - Esquema do pórtico para ensaios.

\subsubsection{Instrumentação dos modelos}

A instrumentação dos modelos constitui-se basicamente na instalação de sensores com a finalidade de se monitorar grandezas físicas tais como: deformações, deslocamentos e cargas durante a execução dos ensaios.

A seguir são descritos os sensores utilizados para a medição de cada tipo grandeza física e as posições onde foram instalados no modelo:

- Para a medição das deformações foram utilizados extensômetros de resistência elétrica, cuja instalação foi executada nas seções mais solicitadas dos elementos estruturais do modelo físico e da estrutura real. A medição das deformações indicadas nesse item e nos demais parágrafos do texto referemse à quantificação das deformações lineares específicas.

- Para a medição dos deslocamentos foram utilizados transdutores de deslocamentos do tipo LVDT (linear variable differential transformer), cuja 
instalação foi realizada em posições onde teoricamente se obteria deslocamentos máximos.

- Para medição dos carregamentos, no caso do modelo em escala reduzida da ponte do rio Suaçui foram fabricados dispositivos especiais para aplicar cargas à estrutura. Enquanto nos modelos de microconcreto, a carga foi aplicada de forma incremental através do servoatuador hidráulico. No caso da monitoração da ponte do rio Suaçui, o peso dos eixos do trem foi medido de forma experimental, através de sistema de sensores elétricos instalados no trilho da via.

\subsubsection{Ambiente de desenvolvimento do trabalho laboratorial e de monitoração}

A confecção e monitoração dos modelos em escala reduzida foram realizadas no Departamento de Engenharia de Estruturas e Fundações da Escola Politécnica da USP (Laboratório de Estruturas e Materiais - LEM) com a ativa participação do autor e dos funcionários que com sua qualidade técnica ajudaram a reproduzir os modelos reduzidos apresentados nesta pesquisa.

\subsection{Organização do trabalho}

Este trabalho foi estruturado em seis capítulos e quatro anexos, de forma a sintetizar toda a pesquisa e esclarecer os principais aspectos trabalhados, como segue:

No capítulo 1 é feita uma introdução geral da pesquisa, procurando contextualizar e justificar o assunto abordado, assim como os objetivos gerais e específicos, a metodologia a seguir e a organização do trabalho.

No capítulo 2 apresenta-se uma breve descrição dos sistemas de monitoração de estruturas, seus principais componentes, métodos de medição de grandezas físicas, aquisição e análise de sinais e tratamento de dados.

No capítulo 3 são apresentados alguns conceitos básicos de modelos físicos em engenharia estrutural, suas vantagens e limitações, a teoria de Modelos Estruturais, a análise dimensional e alguns casos de estudo nessa área de pesquisa. 
No capítulo 4 é estudado o comportamento da ponte do rio Suaçui em escala real (protótipo) e escala reduzida (modelo). Os resultados experimentais obtidos nos ensaios foram utilizados para validar e calibrar os modelos teóricos, bem como estabelecer uma relação de semelhança entre o modelo e o protótipo.

No capítulo 5 é estudado o comportamento dos modelos físicos de microconcreto (ponte e vigas levemente armadas) quando submetidos a cargas incrementais. Além dos estudos experimentais, foram desenvolvidos também, modelos numéricos fundamentado em conceitos básicos de momento-curvatura e mecânica da fratura. Os resultados teóricos e experimentais foram comparados e discutidos finalmente.

No capítulo 6 são apresentadas as conclusões e contribuições da presente pesquisa de acordo com os estudos teóricos e experimentais executados.

Finalmente são apresentados: as referencias bibliográficas, o anexo A com a fabricação de modelos em escala reduzida, o anexo B com a caracterização dos materiais, o anexo $\mathrm{C}$ com os resultados experimentais dos modelos físicos e o anexo D com o dimensionamento da ponte de microconcreto. 


\section{Capítulo}

\section{MONTORAÇÃODEESTRUTURAS}

\section{Monitoração de Estruturas}

\subsection{Definição de Monitoração de estruturas}

A Monitoração de estruturas define-se como a leitura contínua e automática do comportamento de uma estrutura, com capacidade de fornecer informação confiável acerca da sua integridade. Esse conceito envolve a observação das estruturas ao longo do tempo e remotamente, através de medições estáticas e dinâmicas por intermédio de uma rede de sensores instalados nas estruturas, recorrendo frequentemente a algoritmos de análise que permitem identificar danos estruturais inerentes ao envelhecimento e degradação, em resultado da operacionalidade e exposição às condições ambientais.

Em geral tem como objetivo a avaliação da integridade estrutural, através da caracterização, por via da observação, do comportamento físico e mecânico dos materiais e seus elementos estruturais quando submetidos a um determinado tipo de solicitação contínua ou temporária (FIGUEIREDO, 2006). 
Segundo FARRAR e WORDEN (2006), o processo de implementação de uma estratégia de detecção de danos e a caracterização de estruturas é referido como monitoração de estruturas. Onde o dano é definido como alterações nos materiais e propriedades geométricas de um sistema estrutural, incluindo as alterações nas condições de contorno e conectividade do sistema, que afetam negativamente no desempenho da estrutura. Na figura 2.1, apresenta-se a organização de um sistema de monitoração

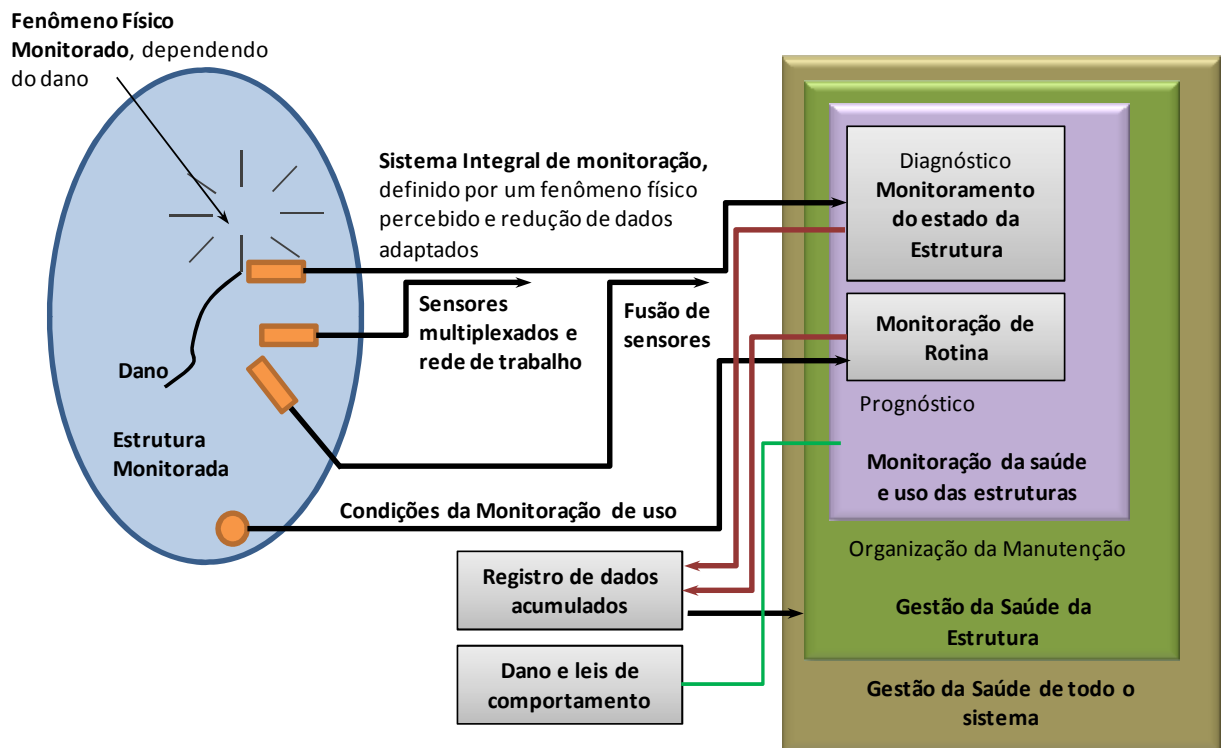

Figura 2.1 - Princípio e organização de um sistema de Monitoração de Estruturas (BALAGEAS, CLAUS-PETER, GUEMaES, 2006).

\subsection{Motivação para fazer monitoração de estruturas}

Conhecer a integridade das estruturas em tempo real e de maneira continua é de muito interesse para pesquisadores, construtores, usuários e equipes de manutenção de estruturas civis. Em efeito, a monitoração de estruturas permite: uma melhor utilização da estrutura e minimiza o tempo de inatividade, prevê falhas catastróficas e dá ao construtor uma melhoria em seus produtos (BALAGUEAS, 2006). Assim também, muda drasticamente a organização do trabalho dos serviços de manutenção:

- Substituindo inspeções programadas de manutenção de longo e curto prazo e reduzindo os trabalhos ao presente, em especial evitando a desmontagem de peças onde não há defeito oculto. 
- Minimizando drasticamente a participação humana, consequentemente diminui o trabalho e erros humanos, e assim melhora a segurança e confiabilidade. Essas mudanças drásticas na filosofia de manutenção foram descritas em vários trabalhos recentes, em especial para veículos aéreos militares, para aeronaves civis e para infra-estruturas civis.

A monitoração de estruturas apresenta também vantagens numa vertente estrutural e econômica, as quais são detalhadas a seguir:

- Monitoração e diagnóstico em tempo real.

- Redução do tempo de interrupções e otimização dos serviços de manutenção, reabilitação ou reforço.

- Estabelecimento de critérios de diagnóstico concretos para uma otimização dos custos relacionados com a manutenção, reabilitação e reforço da estruturas.

- Menor intervenção humana, redução das inspeções visuais e redução dos erros humanos na avaliação.

- Aumento da segurança para os utilizadores das obras de arte.

- Informação para calibração de modelos numéricos.

- Estimativa dos custos do ciclo de vida dos materiais.

\subsection{Principais elementos de um sistema de monitoração}

Um sistema automatizado de monitoração consiste numa rede de sensores ligados a um condicionador de sinal, e esse ao equipamento de aquisição de dados e armazenamento. A rede de sensores converte as grandezas físicas - deslocamento, deformação, etc. - em um análogo elétrico (sinal). O condicionador de sinal passa por amplificar, filtrar e equalizar o sinal para que esse ganhe níveis de tensão adequados, com boa relação sinal/ruído e distorção harmônica mínima. A aquisição do sinal analógico culmina na sua amostragem e posterior conversão A/D.

Segundo o FELIX (2004), os elementos que constituem os sistemas de monitoração podem ser agrupados nos seguintes subsistemas:

- Redes de sensores

- $\quad$ Sistema de aquisição de dados 
- Sistema de comunicação

- Controle da aquisição e tratamento de dados

- Modelo de avaliação e detecção de danos

- $\quad$ Sistema de gestão e de decisão.

A figura 2.2 ilustra a integração dos diferentes subsistemas num sistema de monitoração, com a rede de sensores e o sistema de aquisição instalados em obra e todo o sistema de pós-processamento de dados localizado em laboratório. Um módulo de comunicação remota estabelece a ligação da obra ao laboratório de análise.

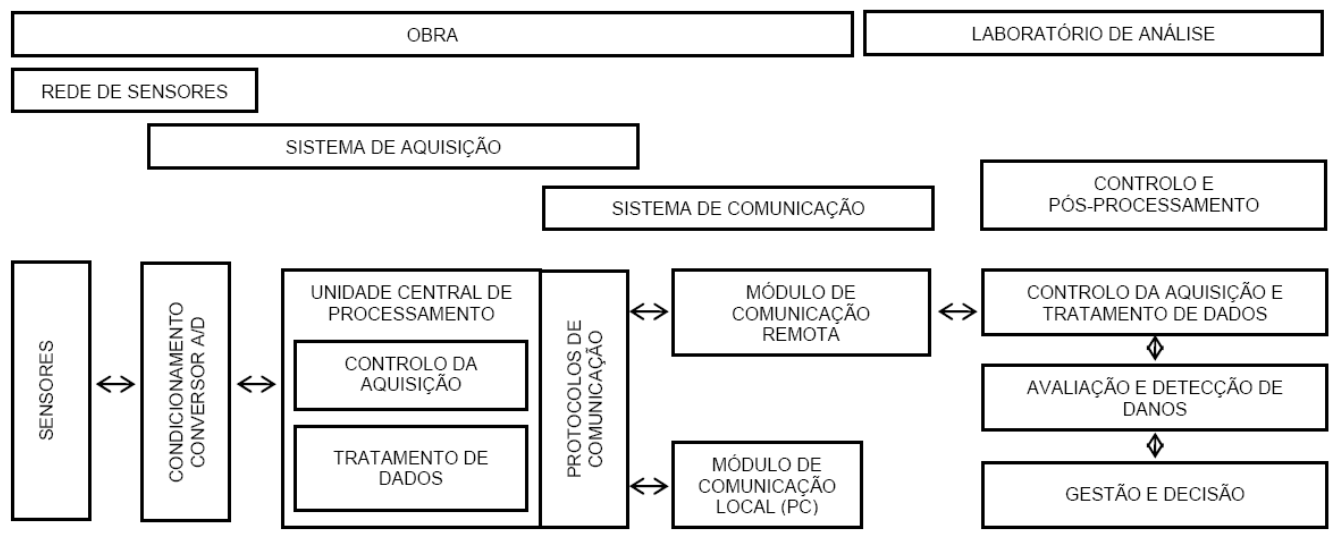

Figura 2.2 - Esquema geral de um sistema de monitoração (FELIX, 2004).

Felizmente, a gama de sensores disponíveis é vasto e abrange praticamente todos os parâmetros imagináveis. A maioria foi desenvolvida para atender às exigências de controle de processos industriais, enquanto outros foram desenvolvidos para fins médicos. As indústrias aeroespaciais e de eletrônica têm desenvolvido um grande número de avançadas tecnologias de detecção, algumas das quais oferecem precisão extremamente alta, embora a um preço muito elevado. Há, portanto, uma gama enorme de sensores disponíveis para o projetista de sistemas de monitoração de estruturas. No entanto, a monitoração de estruturas construídas exige alto desempenho e precisão, além de ser obtidos com segurança, contínua e usualmente por períodos prolongados (MOORE, 2003).

Atualmente, para aplicações de monitoração em Engenharia Civil, encontramse disponíveis sensores para medições de uma significativa lista de grandezas, 
destacando-se os sensores para medição de deformações, temperaturas, deslocamentos, rotações, acelerações e umidade relativa, sendo que, para as medições dessas grandezas, além dos sensores elétricos convencionais, já são bastante aplicados os sensores de fibra óptica.

Os processos de fabricação de sensores têm experimentado várias modificações nos últimos 20 anos, com impactos diretos na qualidade, na confiabilidade e no preço dos novos produtos. Após os avanços tecnológicos na eletrônica durante a década de 1980, que mediante o desenvolvimento dos circuitos integrados, viabilizou com sucesso a integração de componentes para a construção de sensores, melhorando seu desempenho, reduzindo custos e a década de 1990 testemunhou o franco desenvolvimento das técnicas de monitoração em estruturas e microestruturas.

Muitos sensores produzem sinais que não podem ser transferidos com segurança em qualquer distância, sem degradação. Alguns sensores necessitam de fontes de alimentação específica e de alta qualidade ou outras formas de excitação. Em outros casos, a saída de um dispositivo não é de uma forma que é facilmente interpretada pelo equipamento de monitoração: a faixa ou o estilo de saída do sensor pode ser incompatível com a entrada exigida pelos equipamentos de monitoração. Além disso, o sinal pode variar rapidamente para ser devidamente registrado. A obrigação de fazer a saída de um sensor compatível com os meios de transferência e a entrada para o equipamento de monitoração geralmente é atendida pelo condicionador do sinal.

Todo sistema de aquisição de dados tem como função o controle dos dados, os quais devem ser capturados, salvos e exibidos. Sinais analógicos podem ser tratados como analógicos ou convertidos para digital. Os sinais analógicos convertidos para digital depois de tratados, serão exibidos num formato gráfico quase analógico para facilitar o entendimento.

O tratamento de dados constitui outro elemento de suporte às atividades de interpretação, análise de comportamento da estrutura e tomadas de decisões. Idealmente, a componente de tratamento de dados deve ser de fácil utilização, e 
possuir ferramentas de visualização e manipulação estatística de resultados que possibilitem realizar o tratamento da informação bruta procedente do sistema de aquisição de dados e disponibilizados pelo sistema de comunicação. É esperado que os recursos disponíveis proporcionem ao utilizador uma visão preliminar, porém confiável, da resposta da estrutura monitorada, de modo a assegurar que a interpretação dos dados e a construção de modelos numéricos para fins de análises fundamentem-se em informações coerentes e adequadamente processadas (ASSIS, 2007).

As opções disponíveis para visualização de dados dependerá da qualidade do software que é fornecido. A apresentação gráfica de dados não pode oferecer boa resolução adequada a menos que a saída possa ser ampliada adequadamente por causa da resolução da tela. Como resultado, frequentemente é mais eficaz pensar em termos de separar os dados da aquisição e tarefas de apresentação para superar tais limitações.

\subsection{Classificação dos sistemas de monitoração de estruturas}

Para avaliar o comportamento estrutural para diferentes solicitações de carregamento, é necessário conhecer diversas formas de monitoração os quais serão divididos em quatro tipos. Cada forma de monitoração tem como objetivo último avaliar o comportamento estrutural e sua integridade.

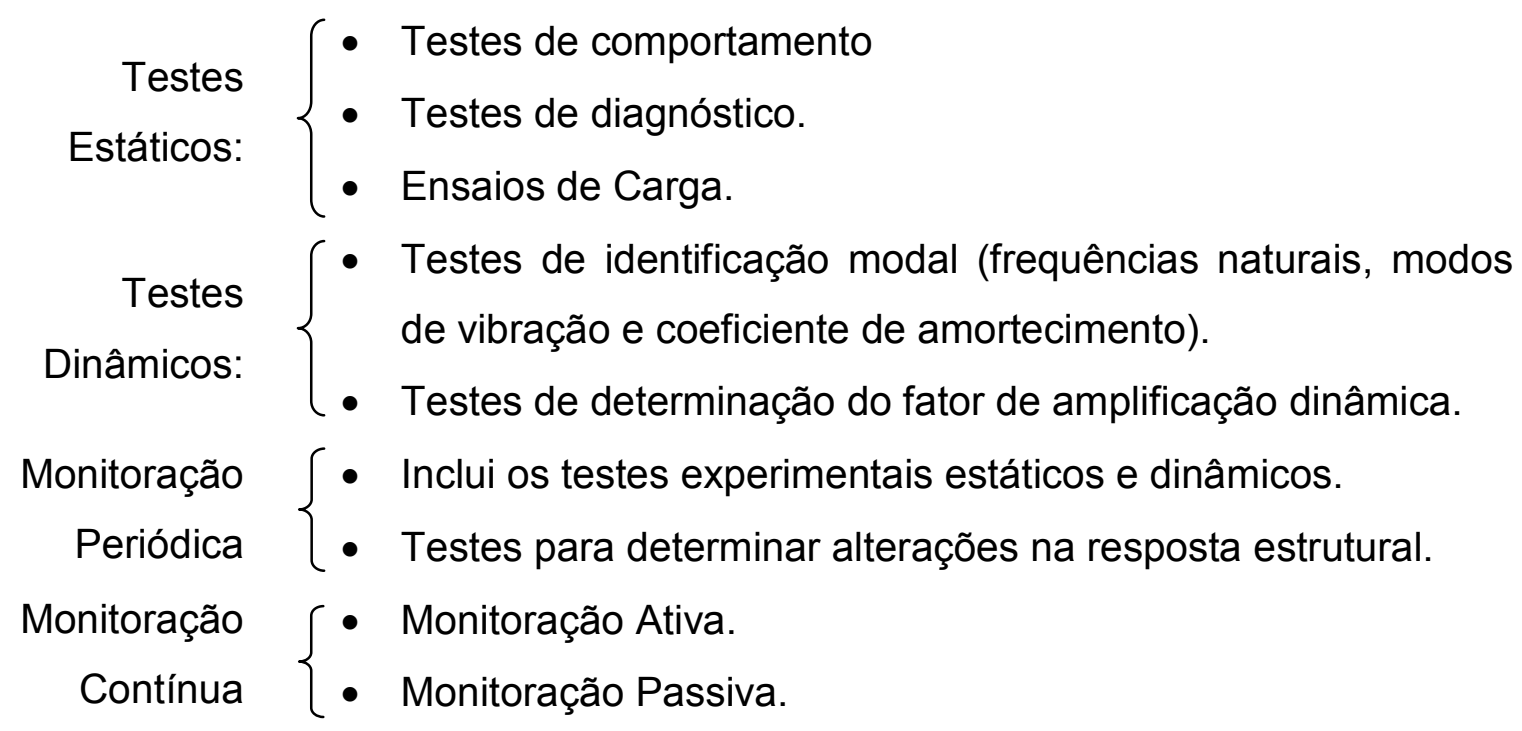




\subsubsection{Testes Estáticos}

Para propósitos de teste de pontes, as cargas estáticas são consideradas aquelas cargas que são inseridas na ponte lentamente, de modo a não provocar efeitos dinâmicos. No caso de teste com veículos, as cargas de veículos são consideradas estáticas quando os veículos são levados para a ponte a uma velocidade de rastreamento. Os testes estáticos podem ser subdivididos em testes de comportamento, testes de diagnóstico e ensaios de carga. Testes de carga dinâmica, como o nome indica, são realizados com a movimentação de cargas que excitam a resposta dinâmica da ponte (ISIS GUIDELINES SHM, 2001).

\subsubsection{Testes de Comportamento}

Testes de comportamento são realizados para estudar a mecânica do comportamento da ponte ou para verificar determinados métodos de análise. $\mathrm{O}$ objetivo, nesse último caso é verificar se os métodos analíticos podem ser usados com confiança para a concepção e avaliação de pontes semelhantes. As cargas aplicadas durante os ensaios, normalmente são mantidas iguais ou abaixo do nível de carga máxima de serviço, ou seja, carga máxima legalmente permitida. Um teste de comportamento fornece informações a respeito de como a carga é distribuída entre os vários elementos estruturais de uma ponte. O teste não fornece informação direta sobre a capacidade dos elementos estruturais para sustentar cargas.

\subsubsection{Testes de Diagnóstico}

Um teste de diagnóstico é o caminho mais seguro para determinar a origem dos defeitos, ou melhoramento, da capacidade de carga de um elemento estrutural. Além de ver os efeitos de interação entre os elementos estruturais.

A diferença entre os testes do comportamento e diagnóstico é que o teste de comportamento permite verificar certo tipo de análise, por exemplo, a análise de distribuição de cargas na seção transversal de uma ponte, enquanto o teste de diagnóstico pode estabelecer as condições de contorno no encontro entre um pilar e o tabuleiro. 


\subsubsection{Teste de carga}

Um teste de carga é realizado para estabelecer a capacidade segura de carga de uma ponte. Durante este ensaio, a estrutura é a submetida excepcionalmente a cargas estáticas elevadas que causam maiores respostas na ponte. Deve-se ressaltar que submeter uma ponte a um teste de carga suficientemente elevada nem sempre é uma confirmação da capacidade de carga da ponte. Apoiar a análise, baseada no raciocínio, é absolutamente essencial para determinar por que a ponte leva a carga aplicada nela.

Devido às cargas muito elevadas aplicadas à ponte, há sempre a possibilidade de que ela possa ser danificada. No entanto, pode-se afirmar que a possibilidade de sofrer um dano com o teste é extremamente pequeno, desde que o teste seja planejado e executado metodicamente e com muito cuidado.

Um teste de carga bem planejado pode ser realizado através do aumento gradual das cargas aplicadas, assegurando através da visualização na interface de um computador que as cargas aplicadas não submetam a estrutura a deformações para além do comportamento elástico (FIGUEIREDO, 2006).

\subsubsection{Testes Dinâmicos}

Como complemento aos testes de carga estática, os testes dinâmicos fornecem informações úteis sobre o comportamento atual da ponte sob o tráfego. Essa informação é geralmente difícil de obter analiticamente, devido à complexidade da estrutura real. Os testes dinâmicos são uma parte importante do processo de aceitação de novas pontes.

O objetivo do teste de carga dinâmica é determinar os parâmetros de controle do comportamento dinâmico das pontes. As principais características dinâmicas da estrutura são a freqüência de vibração fundamental e o fator de amplificação dinâmica. Essas propriedades geralmente não são analisadas em pormenor na fase de projeto em estruturas de pequena e mediana escala. Alguns parâmetros, tais como o fator de amplificação dinâmica, só podem ser estimados aproximadamente no momento do projeto. Contudo, essas quantidades são relativamente fáceis de 
obter, experimentalmente, e podem dar informações valiosas para a exploração e manutenção da ponte (AKIMOVS, PAEGLITIS, 2008).

\subsubsection{Testes de Identificação Modal}

Os testes de identificação modal são usados para determinar as propriedades modais da estrutura: frequências naturais, modos de vibração e coeficientes de amortecimento. O conhecimento das características dinâmicas tem importância geralmente para identificação de danos estruturais, para verificar a conformidade com o dimensionamento e para usar na calibração de modelos numéricos. As aproximações experimentais correntemente utilizadas para a identificação modal estão separadas em três tipos de testes:

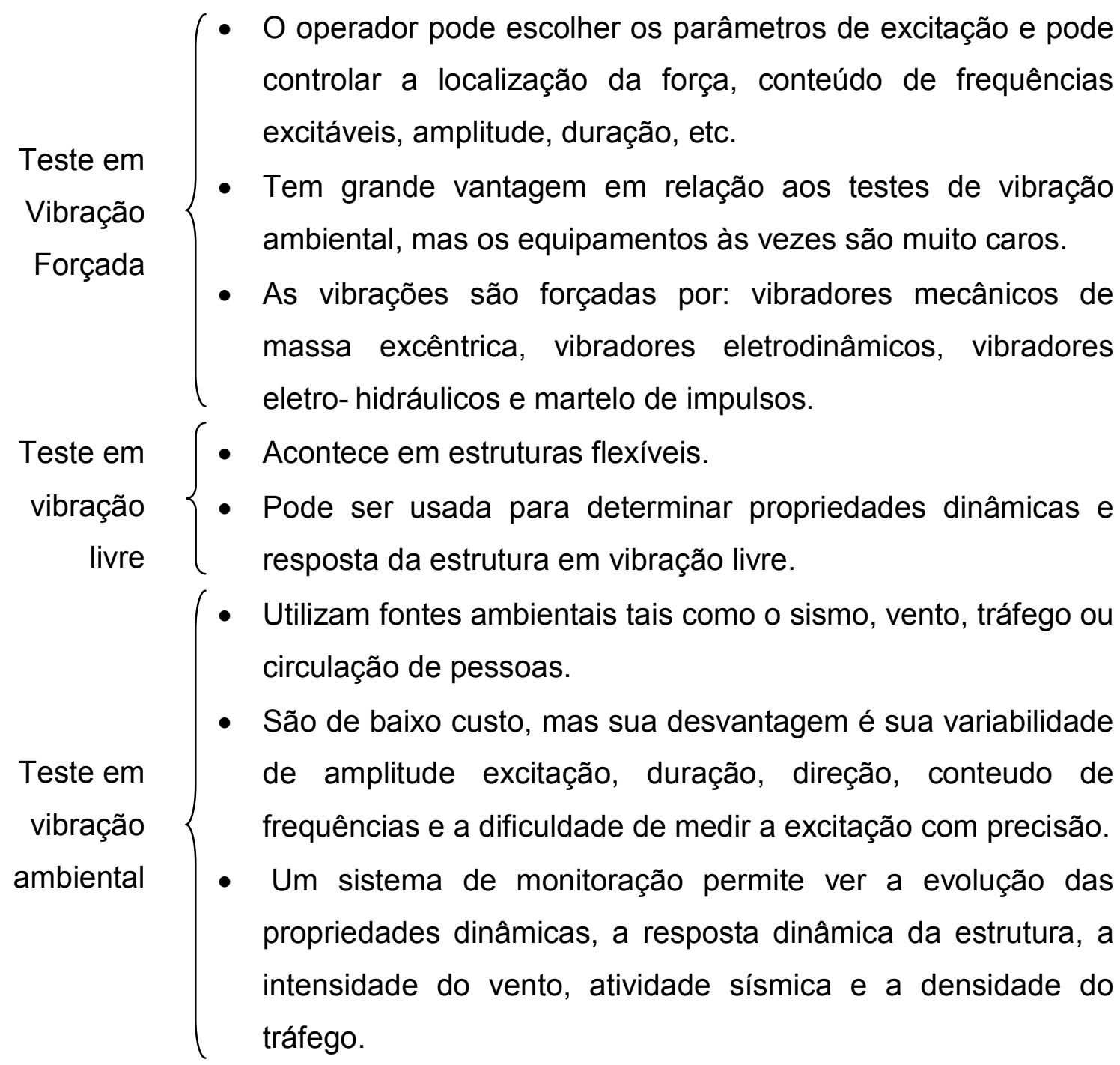




\subsubsection{Monitoração Periódica. -}

O objetivo da monitoração periódica de pontes é avaliar as mudanças do comportamento e o desempenho da ponte em longo prazo, por meio de medições intermitentes, separadas por meses ou anos.

Vantagens: A principal vantagem é o custo. Um sistema de monitoração temporário ou periódico pode ser mobilizado para a inspeção em qualquer momento. Sistemas de monitoração de longo prazo são caros e requerem manutenção para permanecer em ótima condição.

Outra vantagem é a flexibilidade. Novos parâmetros podem ser adicionados ou removidos do sistema, conforme necessário durante cada inspeção.

A terceira vantagem é o potencial de melhoria. Com o avanço da tecnologia permanentemente são desenvolvidos novos instrumentos e métodos, esses podem ser utilizados para uma melhor monitoração.

Limitações: A principal limitação para a monitoração periódica é a falta de disponibilidade. Normalmente, o sistema não está disponível durante situações críticas, como um terremoto ou vendaval. A monitoração periódica pode levar à inconsistência. Pode ser difícil de repetir as mesmas medidas usando os mesmos instrumentos

\subsubsection{Monitoração Permanente. -}

A finalidade de um sistema de monitoração permanente é acompanhar em longo prazo mudanças de comportamento e desempenho de uma estrutura por meio de medições contínuas. Aquisição de alta velocidade pode ser desencadeada para eventos importantes, tais como um terremoto ou ventos fortes e aquisição de baixa velocidade pode ser programado para medição diária, semanal ou mensal para estudos de longo prazo.

Vantagens: A disponibilidade do sistema é uma vantagem fundamental. O sistema está sempre disponível durante as solicitações críticas, como um terremoto ou vendaval. 
A consistência do sistema é uma segunda vantagem. Medidas registradas hoje podem ser diretamente comparadas com as medições obtidas há 10 anos.

Limitações: Uma limitação fundamental é o custo. Sistemas de monitoração de longo prazo são caros e exigem manutenção para permanecer na condição ideal. Como novos instrumentos e métodos são desenvolvidos, o sistema pode precisar ser atualizado para fornecer o máximo de utilidade (U. S. DPT TRANSP, 2009).

\subsection{Medição das principais grandezas}

Dentro das grandezas mais relevantes a serem medidas destacam-se as deformações, deslocamentos, acelerações, temperatura e umidade. A definição do tipo de grandeza física a ser monitorada depende do tipo de estudo que se pretende fazer numa estrutura. A seguir serão descritos os procedimentos para a medição das principais grandezas:

- Seleção da estratégia de monitoração

a. Identificação dos parâmetros a serem monitorados.

b. Avaliação e programação da monitoração.

C. Seleção de sistemas de monitoração.

d. Seleção da topologia de sensor e rede.

- Instalação e manutenção de sistema de monitoração.

\subsubsection{Métodos de Medição das Principais grandezas. -}

Existem diversos tipos de sensores usados na instrumentação e monitoração de estruturas, dentre os quais se destacam os que foram utilizadas na presente pesquisa:

\subsubsection{Medidores de deformação - Extensômetros elétricos ou straingages}

Podem ser resistivos ou a base de cristais (piezoelétricos). Seu princípio de funcionamento é baseado no fato de que deformações impostas a esse tipo de sensores implicam variações em sua resistência elétrica. Sendo assim, uma vez instalado à estrutura, pode-se medir deformações a partir de medidas elétricas obtidas do straingage (PORTELA, SILVA, 1996). 
Os extensômetros são usados em ensaios estáticos e dinâmicos sob condições de serviço, com boa precisão sem que a estrutura seja destruída. Assim, isso leva a uma análise quantitativa da distribuição de deformação sob condições reais de operação. As medições realizadas com extensômetros se caracterizam por:

- Alta precisão de medição.

- Pequeno tamanho e pouco peso.

- Excelentes respostas aos fenômenos dinâmicos.

- Fácil utilização desde que conhecida a boa técnica de utilização.

- Excelente linearidade.

- Medições possíveis dentro de uma ampla faixa de temperatura.

- Aplicáveis submersos em água ou em atmosfera de gás corrosivo desde que utilizado com tratamento apropriado.

- Usados como elementos transdutores para medidas de várias quantidades físicas (força, pressão, torque, aceleração, deslocamento).

- A saída (sinal analógico ou digital) pode ser aplicada à engenharia de controle (ANDOLFATO et al., 2004).

\section{Princípio de funcionamento: A ponte de Wheatstone.-}

Em 1843, o físico Sir Charles Wheatstone descobriu uma ponte para medição de resistências elétricas. Essa ponte, hoje conhecida como ponte de Wheatstone, é ideal para a medição de pequenas variações de resistência, como é o caso da variação de resistência de um extensômetro.

Como atrás foi dito, um extensômetro transforma uma deformação, numa variação proporcional da sua resistência elétrica. A relação entre a deformação aplicada $\left(\varepsilon=\Delta \mathrm{L} / \mathrm{L}_{\circ}\right)$ e a variação de resistência de um extensômetro é dada por:

$$
\frac{\Delta R}{R o}=k \varepsilon
$$

Onde Ro é a resistência inicial do extensômetro, $\Delta \mathrm{R}$ a variação dessa resistência por deformação e k usualmente conhecido como fator do extensômetro, é um valor característico dele, que é verificado e calculado experimentalmente. 
A ponte de Wheatstone está representada na seguinte figura:

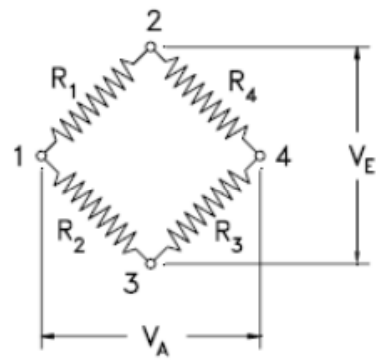

Figura 2.3 - A ponte de Wheatstone.

Os quatro braços da ponte contêm quatro resistências, $R_{1}$ a $R_{4}$. Se os nós 2 e 3 forem ligados a uma fonte de potência com tensão conhecida $V_{E}$, aparecerá outra diferença de potencial $V_{A}$, entre os nós 1 e 4 . $O$ valor de $V_{A}$ depende dos quocientes entre resistências $R_{1} / R_{2}$ e $R_{4} / R_{3}$. Tem-se então a seguinte equação:

$$
\frac{V_{A}}{V_{E}}=\frac{R_{1}}{R_{1}+R_{2}}-\frac{R_{4}}{R_{3}+R_{4}}=\frac{R_{1} R_{3}-R_{2} R_{4}}{\left(R_{1}+R_{2}\right)\left(R_{3}+R_{4}\right)}
$$

A ponte de Wheatstone diz-se equilibrada quando se tem:

$$
\frac{V_{A}}{V_{E}}=0
$$

Para a ponte ser equlibrada é necessário que se verifique:

$R_{1}=R_{2}=R_{3}=R_{4}$ ou então $R_{1} / R_{2}=R_{4} / R_{3}$

Partindo então do princípio que uma dada ponte de Wheatstone está equilibrada, qualquer variação de resistência em uma ou mais resistências da ponte, provocará uma diferença de potencial $\mathrm{V}_{\mathrm{A}}$ diferente de zero. Se se assumir, além disso, que a variação de resistência $\Delta R_{i}$ é muito inferior à própria resistência $\mathrm{R}_{\mathrm{i}}$, o que em geral é sempre válido, temos a seguinte relação:

$$
\frac{V_{A}}{V_{E}}=\frac{1}{4}\left(\frac{\Delta R_{1}}{R_{1}}-\frac{\Delta R_{2}}{R_{2}}+\frac{\Delta R_{3}}{R_{3}}-\frac{\Delta R_{4}}{R_{4}}\right)
$$

Ou em outra forma:

$$
\frac{V_{A}}{V_{E}}=\frac{k}{4}\left(\varepsilon_{1}-\varepsilon_{2}+\varepsilon_{3}-\varepsilon_{4}\right)
$$



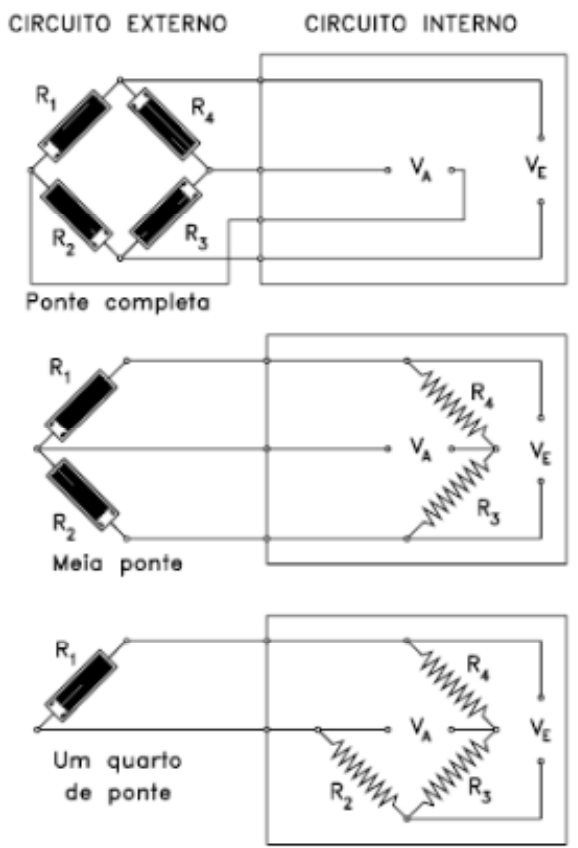

Figura 2.4 - Diferentes tipos da ponte de Wheatstone.

Podem ser usadas de três maneiras diferentes, a saber: ponte completa, meia ponte ou um quarto de ponte. Estas designações se prendem com o número de extensômetros usados na medição, sendo respectivamente, quatro, dois ou um extensômetro. De fato, a ponte de Wheatstone usada na medição é sempre uma ponte completa, ou seja, constituída por quatro resistências, sendo parcial ou completamente formada por extensômetros, como mostra a figura anterior.

No circuito externo encontram-se os extensômetros, que não são mais que resistências sujeitas a deformação. No circuito interno encontram-se as resistências que não sofrem deformação, necessárias para completar a ponte (PORTELA, SILVA, 1996).

\subsubsection{Transformador Linear de Diferença Variavel LVDTs (Linear Variable Differential Transformers)}

Os LVDTs são transdutores de deslocamento linear muito usados em aplicações industriais e na engenharia. Para a realização das medidas de deslocamento lineares, existem diversos tipos de sensores, das quais nesta pesquisa foram utilizados os LVDT's ou Transformador Linear Diferencial Variável. 


\section{Princípio de funcionamento}

Definimos deslocamento linear de um objeto as diferenças entre as posições iniciais medidas ao longo de um eixo único, conforme mostra a figura 2.5.

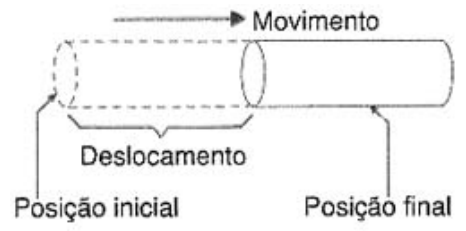

Figura 2.5 - Principio de funcionamento de um LVDT.

Na medida de um deslocamento deve-se ser levado em conta tanto a sua amplitude (distância percorrida) como o sentido e a direção em que isso ocorre ao longo de um eixo.

Existem diversas tecnologias possíveis para o uso de sensores na medida de deslocamentos. No entanto, uma das mais tradicionais é a que faz uso de um transformador diferencial, denominado LVDT.

Conforme mostra a figura 2.6, um LVDT consiste num transformador com um enrolamento secundário duplo e um enrolamento primário simples.

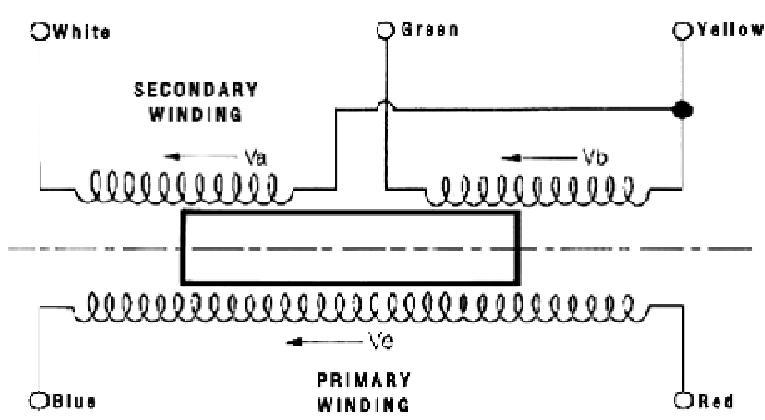

Figura 2.6 - Esquema interno de um LVDT.

O núcleo desse transformador é móvel, sendo acoplado ao mecanismo ou peça do qual se deseja monitorar o deslocamento. O enrolamento primário é então excitado por um sinal alternado cuja frequência depende da aplicação, sendo normalmente usada a própria tensão da rede de energia.

O sinal aplicado no primário induz nos secundários tensões que dependem basicamente de dois fatores: o tipo de material usado no núcleo e sua posição. Se o núcleo estiver centralizado, as tensões induzidas nas bobinas são tais que se 
cancelam e com isso a tensão medida nos terminais do secundário do transformador é nula. Quando o núcleo se desloca pela movimentação do objeto em que ele está acoplado, a indução dos sinais nas duas bobinas se altera e com isso a tensão medida na saída deixa de ser nula.

Tanto maior o deslocamento, maior é a tensão medida na saída, conforme mostra a figura 2.7 .

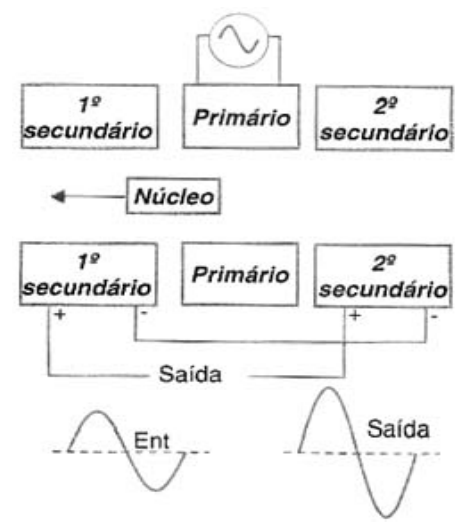

Figura 2.7 - Sinais de entrada e saída de um LVDT.

Esse tipo de configuração apresenta diversas vantagens interessantes que devem ser levadas em conta ao se fazer sua escolha para uma aplicação.

Uma delas está no fato de que o acoplamento entre as bobinas é feito através de um núcleo sem qualquer contato elétrico e de simplicidade muito grande. Isso garante uma robustez muito grande para esse sensor que praticamente não sofre desgaste.

\section{Precisão e Linearidade}

Quando se trata de sensores, a precisão e a linearidade são as características mais importantes que os projetistas observam. Os LVDT's são construídos de tal forma que dentro da faixa de deslocamentos para os quais são especificados sua linearidade é a maior possível.

Na figura 2.8 mostra-se a curva típica de resposta de um LVDT, onde se observa que, quando o núcleo começa a "escapar" da ação do campo criado por uma das bobinas, a linearidade é afetada. 


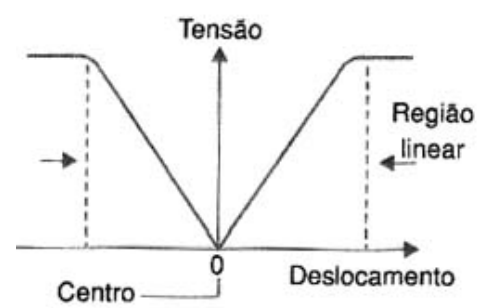

Figura 2.8 - Curva típica de resposta de um LVDT.

Isso vai ocorrer justamente nos extremos de sua trajetória, ou seja, quando os deslocamentos nos dois sentidos se aproximam e passam do máximo.

Para posicionar um LVDT corretamente é preciso aplicar o sinal na bobina primária e depois deslocando o sensor no sentido que se pretende ser positivo, verificar se a fase obtida na saída corresponde, conforme mostra a figura 2.9.

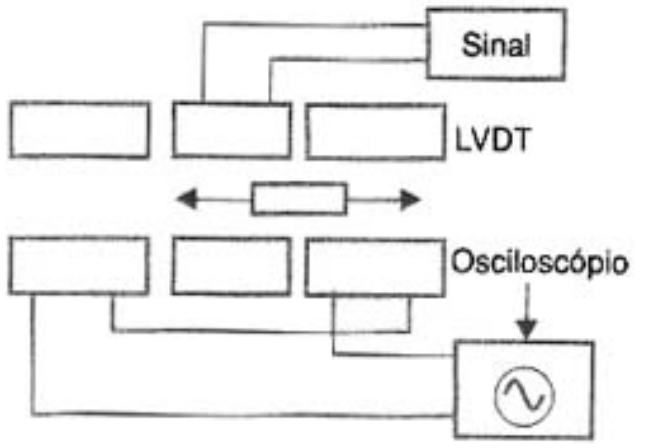

Figura 2.9 - Posicionamento correto de um LVDT.

É claro que, uma vez posicionado, se for constatada a inversão, basta inverter a polaridade da bobina primária.

A saída de um LVDT consiste num sinal senoidal na frequência de excitação. Para os tipos comuns essa frequência varia entre $50 \mathrm{~Hz}$ até $25 \mathrm{kHz}$.

A escolha da frequência depende da aplicação, normalmente sendo selecionada em função da possibilidade do deslocamento a ser medido numa peça que realize movimentos rápidos.

Nessas condições a frequência deve ser pelo menos 10 vezes maior que a frequência do deslocamento do núcleo do transformador. Nesse caso, o sinal da saída do circuito é convertido numa tensão contínua passando por um circuito condicionador (BRAGA, 2009). 


\subsubsection{Instalação de um Sistema de Monitoração}

A instalação do sistema de monitoração é uma fase delicada. Por isso, deve ser planejado em detalhes considerando seriamente as condições do local, organizando atividades de instrumentação, seqüências e horários.

Os componentes do sistema de monitoração podem ser embebidos no concreto fresco ou instalados na superfície da estrutura utilizando grampos, pinças ou colagem. Em ambos os casos a instalação do sistema de monitoração pode afetar a estrutura (por exemplo, incorporar sensores reduz a área da seção transversal, para definir as caixas de conexão ou cabos de extensão na superfície é necessário furar os buracos e instalar grampos, etc.). Portanto, é importante garantir que, do ponto de vista estrutural e estético seja possível instalar o sistema, e que a presença do sistema de monitoração, bem como os trabalhos de instalação não irá diminuir o desempenho da estrutura.

A instalação do sistema leva tempo, e se é para ser realizado durante a construção da estrutura, pode atrasar os trabalhos em obra. Componentes do sistema de monitoração que serão instalados por embebimento só podem ser instalados com segurança durante um curto período de tempo entre a conclusão de vergalhões e vazamento do concreto. Assim, o cronograma de instalação do sistema de monitoração tem que ser planejado com cuidado, tendo em conta o calendário dos trabalhos, o tempo necessário para a instalação do sistema, ao mesmo tempo tem que ser flexível para se adaptar às mudanças dos horários de trabalho que são frequentes em locais de construção.

Quando instalado, o sistema de monitoração tem que ser protegido, sobretudo se o acompanhamento é realizado durante a construção da estrutura. A proteção tem que evitar danos acidentais durante a construção, mas também para garantir a longevidade do sistema. Assim, todas as influências externas, periódicas ou permanentes, tais como vandalismo, roedores (ou outros animais), vento, chuva, sol, etc. têm que ser tidos em conta quando se esteja projetando a proteção para o sistema de monitoração (GLISIC, INAUDI, 2003). 
Na figura 2.10 apresenta-se o esquema de um sistema de monitoração

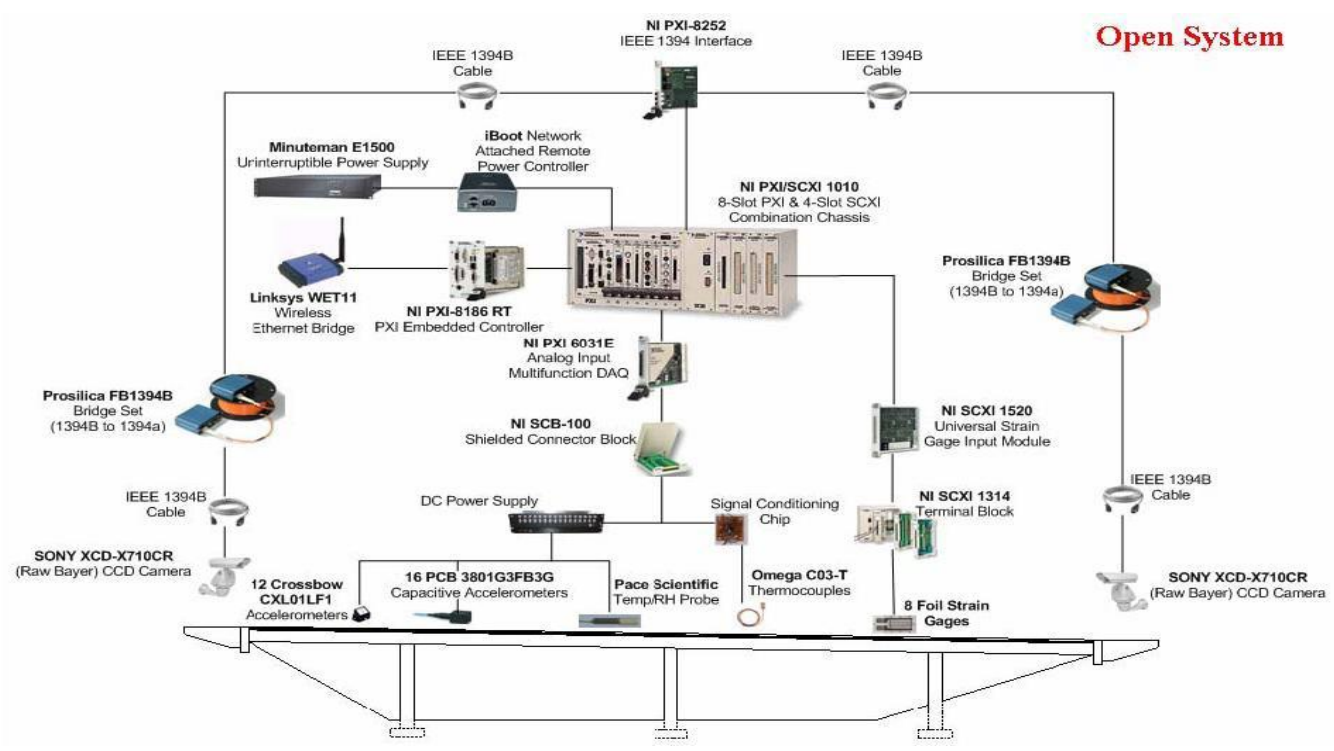

Figura 2.10 - Esquema de um sistema de monitoração.

\subsection{Aquisição de sinais, análise e tratamento de dados}

$\mathrm{Na}$ monitoração de estruturas usa-se um conjunto de sensores destinados a transformar as grandezas físicas em sinais elétricos. Após as diversas grandezas físicas estarem sob a forma de sinal elétrico (tensão ou corrente), essas precisam ser analisadas e processadas. A seguir são definidos alguns conceitos sobre tratamentos de dados e processamentos de sinais.

\subsubsection{Arquitetura de um Sistema de Aquisição e Processamento de Sinais}

O Sistema de aquisição e processamento de sinais tem como funções fundamentais, a aquisição das diversas grandezas físicas, efetuar o processamento, armazenamento e interação com o utilizador, e colocar as grandezas na saída do sistema para seu posterior interpretação.

\subsubsection{O Sinal}

O sinal é uma função que transmite informação sobre um fenômeno físico. Pode ser classificado em: sinal de tempo contínuo, sinal de tempo discreto, sinal par, sinal ímpar, sinal aleatório, determinístico, sinal de energia, sinal de potência, sinal periódico e sinal não periódico. Uma questão de fundamental importância no 
estudo de sinais e sistemas é o uso de sistemas para processar ou manipular sinais. Essa questão normalmente envolve uma combinação de algumas operações básicas: mudança de escala de amplitude, adição, multiplicação, diferenciação, integração, mudança de escala de tempo, reflexão e deslocamento.

No estudo dos sistemas é importante conhecer suas propriedades: Estável, com memória, sem memória, causal, não causal, invertível, invariante no tempo, variante no tempo, linear e não linear.

\subsubsection{Tipos de Processadores de Sinais.}

Para se realizar o processamento dos sinais tem de se obter amostras do sinal. Essa função da obtenção das amostras denomina-se de amostragem do sinal e é simulada pelos interruptores da figura 2.11.

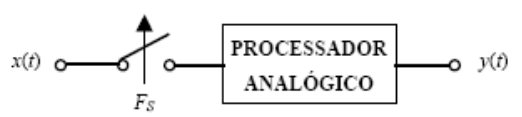

(a)

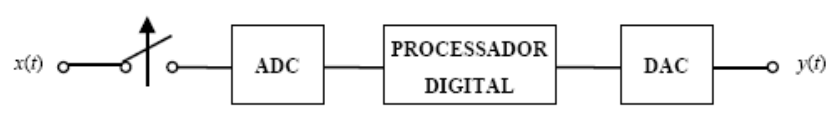

(b)

Figura 2.11 - Tipos de Processadores de Sinal: (a) Analógico e (b) Digital.

O processador analógico trata as amostras sob a forma de uma tensão (ou corrente) no interior do circuito e volta a colocar o resultado na saída sob a forma de tensão (ou corrente). Por outro lado, o processador digital, trata as amostras sob a forma de números digitais; esses processadores de sinal são denominados microprocessadores e microcontroladores. Dado os grandes avanços que têm existido nesse domínio, esses processadores são extremamente poderosos, rápidos e baratos. Os processadores digitais são assim os utilizados na quase totalidade dos sistemas de aquisição existentes. 


\subsubsection{Amostragem de Sinais.}

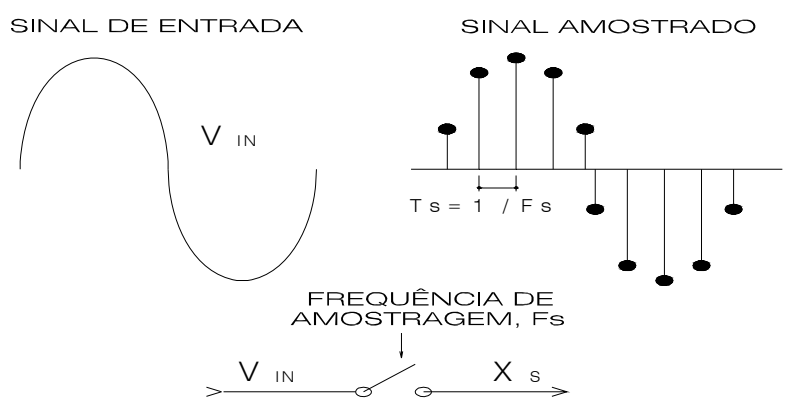

Figura 2.12 - Circuito conceptual da amostragem de um sinal.

$\mathrm{Na}$ figura 2.12 apresenta-se um diagrama conceptual da amostragem de um sinal. A amostragem pode ser "simulada" com a utilização de um interruptor que se fecha durante um instante de tempo e é atuada a um ritmo denominado de frequência de amostragem, Fs. A forma de onda do sinal amostrado pode ser vista também na figura 2.12. Essa onda tem a amplitude do sinal de entrada nos instantes de amostragem, e zero durante o restante intervalo de tempo.

Uma das questões fundamentais que se coloca é qual o valor da frequência de amostragem que deve ser escolhido para cada aplicação. Este tema foi investigado por Harry Nyquist. Segundo o denominado teorema de Nyquist, a

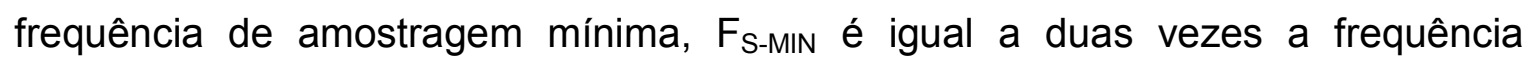
máxima do sinal de entrada, $\mathrm{F}_{\mathrm{IN}-\mathrm{MAX}}$, isto é:

$$
F_{S-M I N}=2 \cdot F_{I N-M A X}
$$

Desde que essa regra seja cumprida, toda a informação sobre o sinal é guardada, e, é assim possível, voltar a reconstituir integralmente o sinal amostrado (MARTINS, 2006).

\subsubsection{Ruído}

Chama-se ruído a todo sinal indesejado que interfere em uma medida, limitando sua exatidão. Têm-se os seguintes tipos de ruídos:

- Aleatório. - De origem térmica ou quântica, é gerado dentro do equipamento. 
- Interferência. - Captação, pelo transdutor, de sinais externos que podem ter, ou não, origem na mesma grandeza física que se deseja medir.

Em geral o que mais interessa não é o valor absoluto do ruído, mas sim seu valor percentual em relação ao sinal que se pretende medir. O valor de S/R (relação ruído sinal) pode aparecer em escala linear, mas é muitas vezes apresentado na forma logarítmica, ou seja, em decibéis (dB).

Para melhorar a relação $S / R$, existem técnicas implementáveis no nível do hardware (circuitos analógicos e digitais) e outras efetuadas por software (programas de tratamento do sinal digitalizado). Além de ter cuidados básicos como: Aterramento cuidadoso de todas as partes dos circuitos de medição, evitando a circulação de correntes de aterramento, especialmente próximo a resistores de valor alto, cabos curtos e blindagem metálica (REGAZZI, PEREIRA, SILVA, 2005)

\subsubsection{Manipulações matemáticas para sinais}

\section{Análise de Fourier}

A análise de Fourier consiste na representação de um sinal como uma superposição de senóides complexas, sendo que cada senóide dessa superposição terá uma informação única, uma vez que são ortogonais entre si. Isso fornece uma caracterização mais criteriosa dos sinais e sistemas, pois com essa análise podemos representar um sinal tanto no domínio do tempo quanto no domínio da frequência.

\section{Transformada de Laplace}

A Transformada de Laplace representa sinais de tempo contínuo como uma superposição ponderada de exponenciais complexas. Trata-se de um mapeamento do domínio do tempo em um plano complexo denominado plano $s$. A transformada de Fourier é obtida avaliando-se a transformada de Laplace no eixo $j \omega$ ou fazendo-se $s=j \omega$. Assim, a Transformada de Laplace pode representar uma classe mais geral de sinais do que a transformada de Fourier, incluindo sinais que não são absolutamente integráveis. 


\section{Transformada Z}

A transformada Z é a contraparte em termos discretos da transformada de Laplace. Logo, a transformada $Z$ representa sinais de tempo discreto como uma superposição ponderada de exponenciais complexas. Dessa forma, podemos usar a transformada Z para analisar sinais e sistemas que não são estáveis. Vale ressaltar que a Transformada $Z$ permite o estudo das características de sistemas e a derivação de estruturas computacionais para implementar sistemas de tempo discreto em computadores.

\section{Filtros Lineares}

Um filtro linear aplica uma operação matemática linear a um sinal de entrada. Os filtros lineares são muito comuns na eletrônica e no processamento digital de sinais. São comumente utilizados para eliminar as frequências não desejadas de um sinal de entrada ou para selecionar uma frequência de um sinal. Existe uma grande variedade e tecnologias de filtros.

Existem vários tipos de filtros lineares, entre eles: filtro passa-baixa, filtro passa-alta, filtro passa-faixa, filtro rejeita-faixa e filtro passa-tudo.

Os sinais a serem analisados necessitam de um número de cálculos matemáticos muito grandes para cada variável analisada no sinal de entrada para se ter sua saída correspondente. Uma das alternativas é usar microprocessadores, programando-os previamente para se manipular o sinal de entrada de acordo com o projeto.

\subsubsection{Diagrama de funcionamento do Sistema de Aquisição.}

Nesta seção vai mostrar-se uma breve descrição do sistema de aquisição de dados utilizado na presente pesquisa desenvolvido pela National Instrument.

\subsubsection{Módulo SCXI-1600}

O módulo SCXI-1600 é um encaixe de alto desempenho plug-and-play USB, dispositivo utilizado para conexão direta entre os computadores compatíveis com USB e sistemas SCXI. Recebe sinais analógicos de outros módulos SCXI e amplifica, digitaliza e envia dados por meio de um porto USB. Também pode 
controlar a entrada e saída digital, e os módulos de saída analógica SCXI. O SCXI1600 não tem interruptores DIP, jumpers, ou potenciômetros. São facilmente configurados e calibrados utilizando software. Na figura 2.13 ilustra-se o diagrama de funcionamento do bloco SCXI-1600.
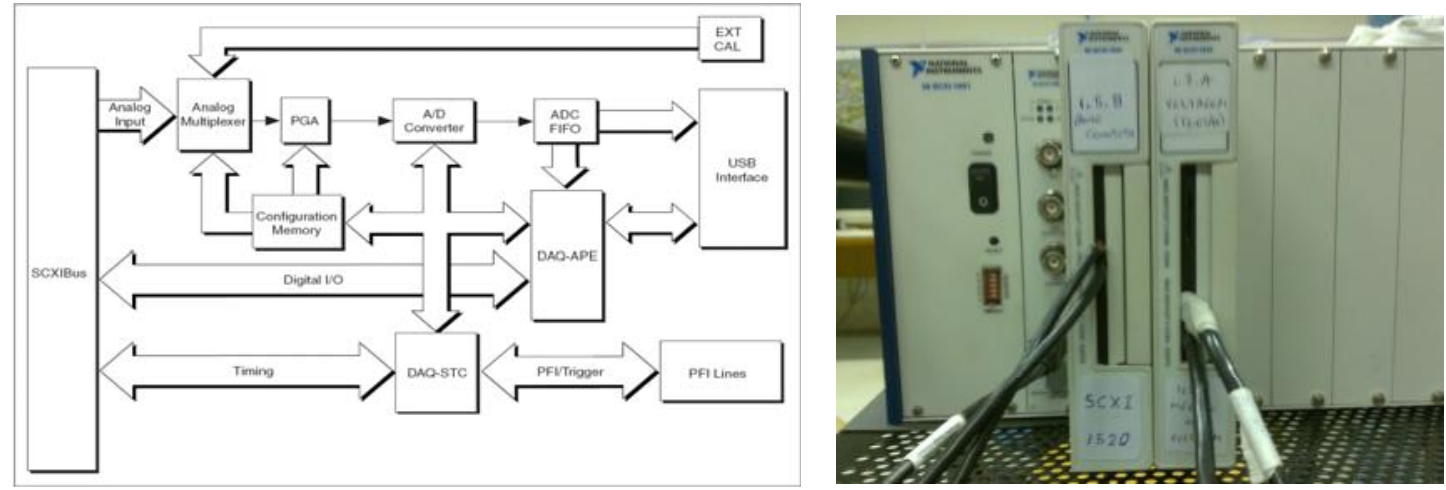

Figura 2.13 - Diagrama de bloco Módulo SCXI-1600.

Onde:

A/D.- Analógico - Digital

ADC.- Conversor Analógico - Digital - dispositivo eletrônico, que converte uma tensão de voltagem para um número digital.

FIFO (First-in-first-out). - Primeiro a entrar, primeiro a sair.

DAQ (Data Acquisition).- aquisição de dados - coleta e medição de sinais elétricos a partir de sensores, transdutores e sondas de teste ou equipamentos e processamento de dados de medição utilizando um computador.

PFI (Programmable function input).- Entrada de função Programáveis.

STC (System timing controller).- Sistema controlador de tempo.

\subsubsection{Módulo SCXI-1521/B}

O módulo SCXI-1521B tem 24 canais de módulo de interface para extensômetros de um quarto de ponte e são configurados através Measurement \& Automation Explorer (MAX). O SCXI-1521B tem resistores de $120 \Omega$.

Inclui as seguintes funcionalidades:

- Excitação em corrente contínua entre 0 e $5 \mathrm{~V}$, em 1023 passos.

- Circuito programável offset nulling. 
- $10 \mathrm{~Hz}$ filtro lowpass.

- Ganho da entrada analógica de 42 V / V.

- Software controlável de calibração shunt.

- Acessórios disponíveis para o SCXI-1521 / B:

\begin{tabular}{ll}
\hline \multicolumn{1}{c}{ Acessórios } & \multicolumn{1}{c}{ Descrição } \\
\hline SCXI-1317 & $\begin{array}{l}\text { Bloco de terminais montado com parafuso na frente do módulo SCXI- } \\
1521 / \text { B e proporciona fácil acesso ao terminal de conexões da fiação } \\
\text { do campo. }\end{array}$ \\
\hline SCXI-1310 & $\begin{array}{l}\text { Conector e casca de montagem, dispõe de } 96 \text { terminais tipo olhal para } \\
\text { fácil encaixe e solda do sinal de conexão e personalizada conectividade } \\
\text { de terminação. }\end{array}$ \\
\hline
\end{tabular}

\section{Modo de Operação do Módulo SCXI-1521/B}

Os terminais de entrada SCXI-1521/B consistem de três terminais por canal para ligação direta ao extensômetro com três fios. $E X+$ conecta-se a excitação de tensão, $Q T R$ conecta ao SCXI-1521/B resistor que completa o quarto de ponte, e $A l$ conecta ao SCXI-1521/B amplificador de entrada.

A etapa de amplificação de entrada é seguida pela etapa de amplificação adicional e filtro lowpass antes de chegar ao multiplexador de saída. O multiplexador é controlado pela interface digital e circuitos de controle.

O circuito de calibração shunt é composto de um resistor de valor fixo em série com um interruptor. Quando a chave é fechada, o resistor de calibração shunt é conectado em paralelo com o resistor que completa o quarto de ponte.

\section{Bloco de terminal SCXI 1317}

O bloco de terminal SCXI-1317 e o módulo SCXI-1521/B ligados permitem utilizar convenientemente extensômetros de quarto de ponte.

\section{Circuito de extensômetros de quarto de ponte com dois e três fios.}

Os diagramas de instalação de quarto de ponte da figura 2.14, mostra como fazer ligações de quarto de ponte usando dois e três fios. Se o transdutor é blindado, ligar a blindagem para a ligação GND no bloco de terminais SCXI-1317. 

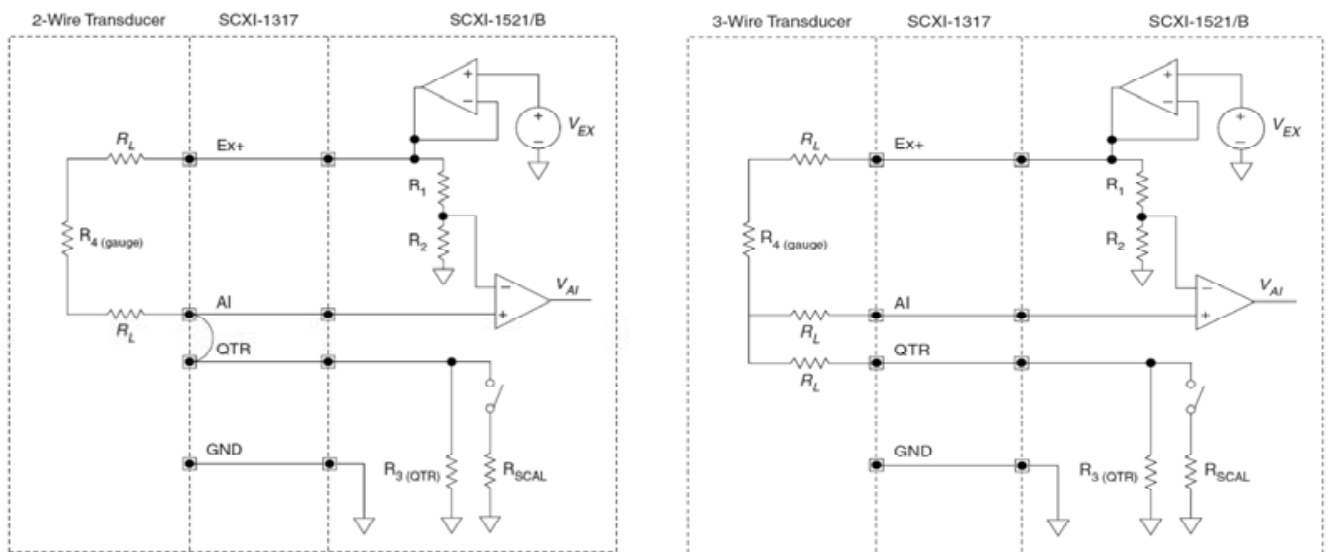

Figura 2.14 - Diagrama de circuito de quarto de ponte, usando extensômetros com dois e três fios.

Onde:

- $R_{1}$ e $R_{2}$ são resistores de meia ponte.

- $\mathrm{R}_{3}$ é o resistor de quarto de ponte (resistor fictício).

- $R_{4}$ é o elemento de medição ativa.

- $R_{\text {scal }}$ é o resistor shunt de calibração.

- $V_{E X}$ é a voltagem de excitação.

- $R_{L}$ é a resistência da ligação.

- $V_{A l}$ é a voltagem medida.

\subsubsection{Modulo SCXI-1520}

O módulo SCXI-1520 é um módulo de oito canais que usado com o bloco SCXI-1314, permite:

- Conectar sensores de todas as configurações de ponte, incluindo um quarto, meia e ponte completa.

- Estabelecer a excitação de DC entre 0 e 10V (incrementos dependente do software do driver).

- Estabelecer que a entrada analógica passe por uma freqüência de corte de 10 $\mathrm{Hz}, 100 \mathrm{~Hz}, 1 \mathrm{kHz}, 10 \mathrm{kHz}$ ou passar por cima.

- Programar o shunt de calibração utilizando dois circuitos independentes. 


\section{Bloco de terminal SCXI 1314}

O bloco de terminais SCXI-1314 é utilizado com o módulo SCXI-1520, permitindo ligar convenientemente extensômetros através de terminais. Há 88 terminais dispostos em oito grupos de 11. Cada grupo corresponde a um dos oito canais disponíveis no SCXI-1520.

\begin{tabular}{cl}
\hline Nome do sinal & \multicolumn{1}{c}{ Descrição } \\
\hline P+ & Sinal de excitação positiva. \\
P- & Sinal de excitação negativa. \\
S+ & Sinal de entrada positiva. \\
S- & Sinal de entrada negativa. \\
QTR & Conector do resistor de quarto de ponte. \\
RS+ & Sinal de sentido remoto positivo. \\
RS- & Sinal de sentido remoto negativo. \\
SCA (2 terminais) & Sinal de calibração shunt A. \\
SCB (2 terminais) & Sinal de calibração shunt B. \\
\hline
\end{tabular}

\section{Conectando sinais à Ponte de sensores}

Consiste em conectar os sinais de suporte para os diferentes tipos de configuração de extensômetro, assim como os sensores de ponte completa como carga, força, torque e sensores de pressão.

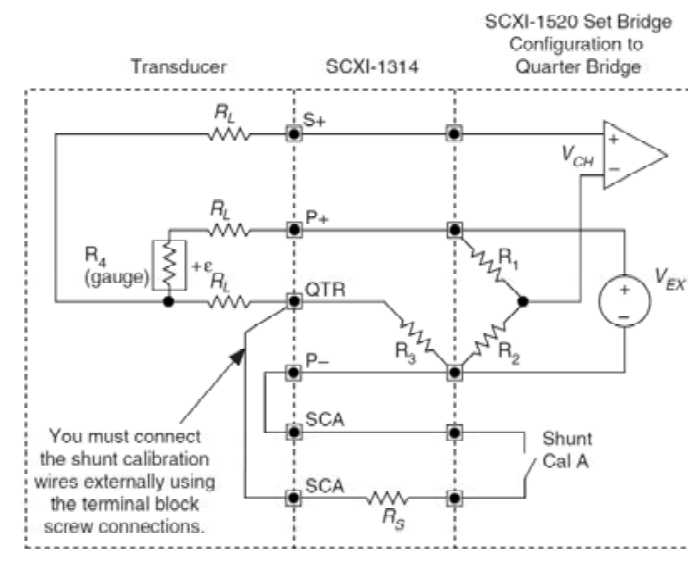

(a)

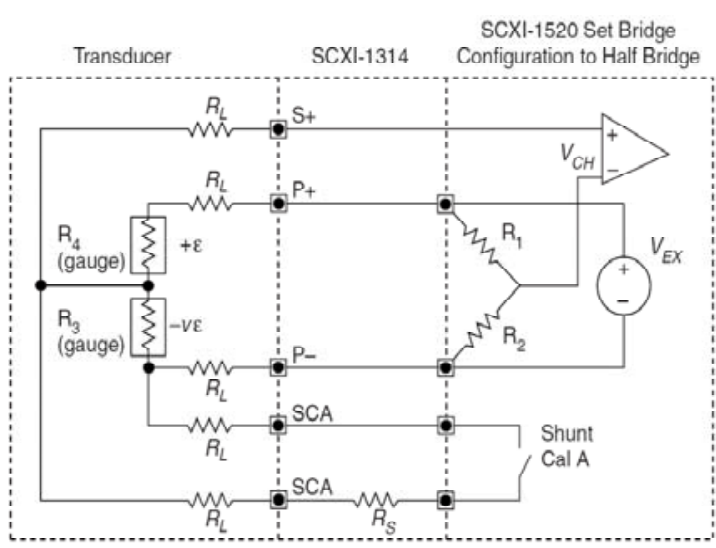

(b)

Figura 2.15 - (a) Quarto de ponte, (b) Meia ponte. 


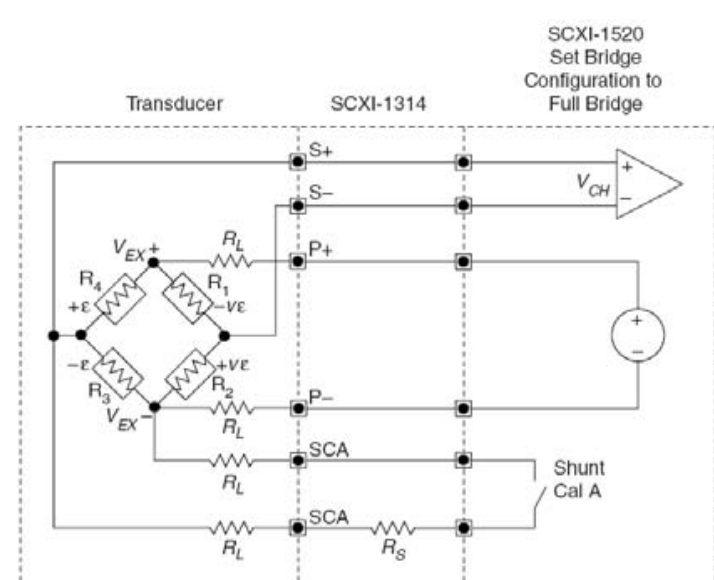

(a)

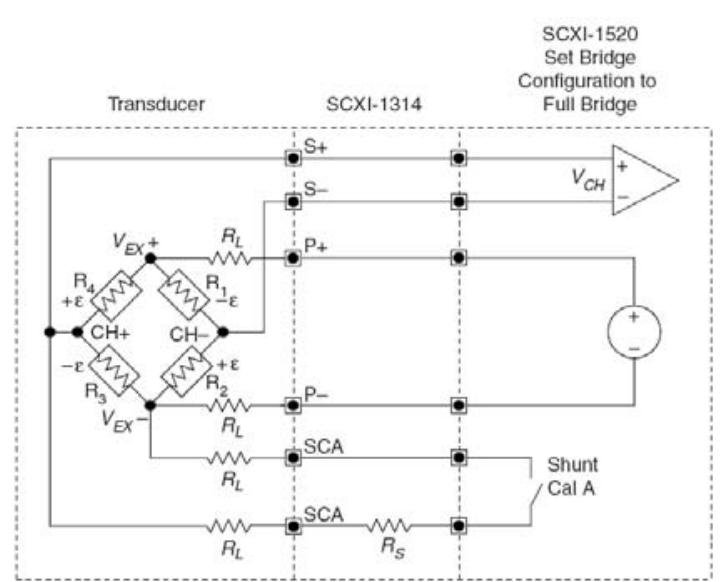

(b)

Figura 2.16 - (a) Ponte completa tipo I; (b) ponte completa tipo II.

Onde:

- $R_{1}$ e $R_{2}$ são resistores de meia ponte.

- $R_{3}$ é o resistor de quarto de ponte em figura 2.15(a).

- $R_{3}$ é o elemento de medição ativo de compressão devido ao efeito Poisson (-vع) figura 2.15(a)

- $R_{4}$ é o elemento de medição ativa de tensão de tração $(+\varepsilon)$.

- VEX é a voltagem de excitação.

- $R_{L}$ é a resistência da ligação.

- $\mathrm{V}_{\mathrm{CH}}$ é a voltagem medida.

\subsubsection{Programas para aquisição e processamento de dados}

\subsubsection{LAB VIEW}

O LabVIEW (acrônimo para Laboratory Virtual Instrument Engineering Workbench) é uma linguagem de programação Gráfica originária da National Instruments. A primeira versão surgiu em 1986 para o Macintosh e atualmente existem também ambientes de desenvolvimento integrados para os Sistemas Operacionais Windows, Linux e Solaris.

Os principais campos de aplicação do LabVIEW são a realização de medições e a automação. A programação é feita de acordo com o modelo de fluxo de dados, o que oferece a essa linguagem vantagens para a aquisição de dados e para a sua manipulação. 
Os programas em LabVIEW são chamados de instrumentos virtuais ou, simplesmente, VIs. São compostos pelo painel frontal, que contém a interface, e pelo diagrama de blocos, que contém o código gráfico do programa. O programa não é processado por um interpretador, mas sim compilado. Desse modo a sua performance é comparável à exibida pelas linguagens de programação de alto nível. A linguagem gráfica do LabVIEW é chamada "G".

\section{Metodologia de programação em LabVIEW}

Os blocos de funções são designados por instrumentos virtuais. Isso é assim porque, em princípio, cada programa (Sub-VI) pode ser usado como subprograma por qualquer outro ou pode, simplesmente, ser executado isoladamente.

O programador liga VIs com linhas (arames) de ligação e define, desse modo, o fluxo de dados. Cada VI pode possuir entradas ou saídas. A execução de um VI começa quando todas as entradas estão disponíveis; os resultados do processamento são então colocados nas saídas assim que a execução do subprograma tenha terminado. Dessa forma, a ordem pela qual as tarefas são executadas é definida em função dos dados. Uma ordem pré-definida (por exemplo, "da esquerda para a direita") não existe.

Os sub-VIs podem estar interligados com muita complexidade. Muitas das funções próprias do LabVIEW são, por sua vez, VIs normais, que podem ser modificados pelo programador (o que não é recomendado). Todos os Vls se baseiam numa série de funções básicas, chamadas "primitivas", que não podem ser modificadas pelo programador (ao invés dos VIs.)

O painel frontal do LabVIEW é um meio confortável para construir programas com uma boa interface gráfica. O programador não necessita escrever qualquer linha de código. A apresentação gráfica dos processos aumenta a facilidade de leitura e de utilização. Uma grande vantagem em relação às linguagens baseadas em texto é a facilidade com que se criam componentes que se executam paralelamente. Em projetos de grande dimensão é muito importante planejar a sua estrutura desde o início (como acontecem nas outras linguagens de programação). 
Cada VI tem duas partes distintas:

Painel Frontal: O painel frontal é a interface de usuário, usado para interagir com o usuário quando o programa está sendo executado. Os usuários podem assistir os dados do programa sendo atualizados em tempo real (como vão fluindo os dados, um exemplo seria uma calculadora, onde você coloca as suas entradas, e coloca-o o resultado na saída). Essa interface define os controles (que usamos como entrada podem ser botões, marcadores, etc.) e indicadores (usá-los como saídas, pode ser gráfico, etc.).

Diagrama de blocos: é o programa propriamente dito, onde se define a sua funcionalidade, os ícones são colocados aqui que executam uma função específica e interconexão (o código que controla o programa). Normalmente, existe uma terceira parte ícone/conector que são os meios utilizados para conectar um VI com outros VIs.

No painel frontal, encontram-se todos os tipos de controles ou indicadores, onde cada um desses elementos é atribuído no diagrama de blocos um terminal, ou seja, o usuário pode criar um projeto no painel frontal com controles e indicadores, onde esses elementos serão as entradas e saídas que interatuaram com o terminal do VI. Podemos observar no diagrama de blocos, todos os valores dos controles e indicadores, uma vez que o fluxo entre eles, quando um programa está sendo executado VI.

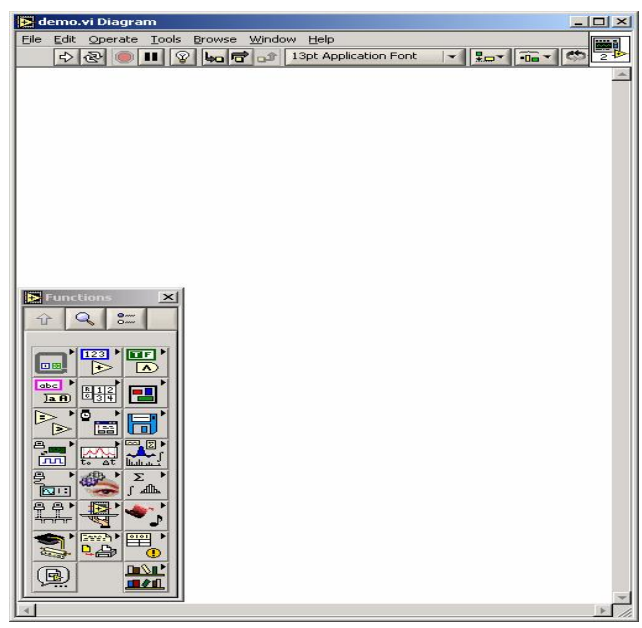

(a)

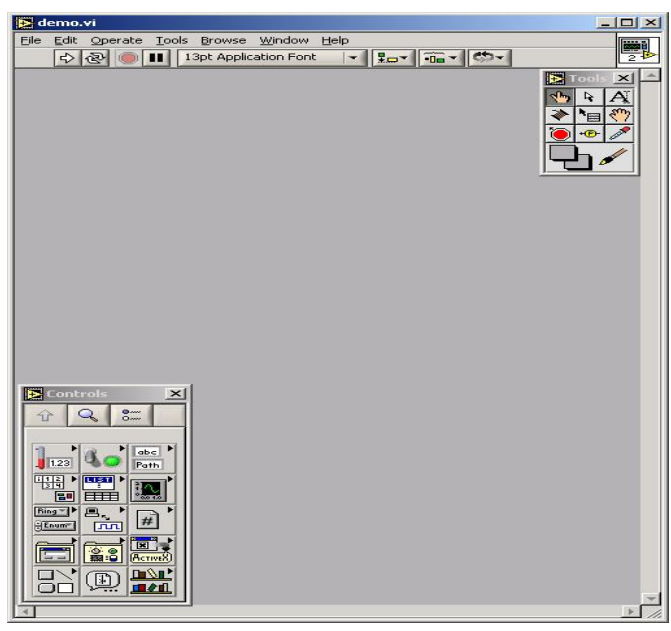

(b)

Figura 2.17 - (a) Painel frontal; (b) diagrama de blocos. 


\section{Desvantagem na programação com o LabVIEW}

As desvantagens da programação gráfica utilizada pelo LabVIEW comparada com a programação por código são, essencialmente:

- Pequenas mudanças podem obrigar a profundas reestruturações do programa, uma vez que sempre que se insere um novo bloco é necessário voltar a ligar os fios e os símbolos para restabelecer o funcionamento;

- Para evitar confusões de linhas é habitual introduzir mais variáveis do que aquelas que são estritamente necessárias, diminuindo-se assim a velocidade de programação e contrariando-se, de algum modo, o modelo de fluxo de dados.

- Programar graficamente não exige grandes conhecimentos do programador, no entanto é necessário um bom planejamento do algoritmo, para que o aplicativo fique otimizado.

\section{Principais usos:}

É utilizado principalmente por engenheiros e cientistas para tarefas como:

- Aquisição de dados e análise matemática.

- Comunicação e controle de instrumentos de qualquer fabricante.

- Automação industrial e programação dos PACs (Controlador de Automatização Programável).

- Projeto de controladores: simulação, prototipagem rápida e validação.

- Controle e acompanhamento do processo.

- Visão artificial e controle de movimento.

- Robótica e automação residencial e de redes de sensores sem fio.

- Em 2008, o programa foi usado para controlar o LHC, o maior acelerador de partículas construído até hoje.

\section{Ferramentas do LabVIEW.-}

LabVIEW pode fazer análise de sinais com funções matemáticas e processamento de sinais integrados, aliás inclui milhares de funções para aplicações de pesquisa de engenharia que podem ser usadas, sistemas 
operacionais embarcados de tempo real e FPGAs (field-programmable gate arrays).

Com essas poderosas ferramentas, pode fazer processamento de dados avançados, filtrar dados, fazer análises no domínio das frequências, análises de probabilidade e estatísticas, ajuste de curvas, interpolação de dados, processamento de dados digitais e muito mais. Para a visualização de dados, contém interfaces gráficas de usuário (GUIs) para interagir com suas aplicações e visualizar seus dados usando centenas de gráficos, indicadores e ferramentas de visualização em 2D e 3D.

\subsubsection{DIAdem}

O DIAdem, é uma nova versão do software interativo para gerenciar, analisar, visualizar e reportar dados obtidos de testes, que inclui novas funcionalidades e capacidades de filtragem para desenvolvimento avançado e análise automatizada. O DIAdem é projetado para ajudar engenheiros a tomar decisões baseadas em informações e atender a demanda dos ambientes de teste atuais, que requerem acesso rápido a grandes volumes de dados desorganizados, relatório consistente e visualização de dados. Com o DIAdem, engenheiros podem facilmente gerenciar, pesquisar, analisar e relatar os dados coletados durante a aquisição de dados ou gerados durante simulações e fornecer relatórios e visualização de dados consistentes para aplicações em indústrias como automotiva, aeroespacial, monitoração ambiental, teste estrutural e pesquisa.

Para análise avançada de dados, o DIAdem adiciona o novo Gerenciador de Cálculos e novas funcionalidades de filtragem, que são úteis para grandes grupos de desenvolvimento e análise automatizada. Para aplicações com uma elevada quantidade de canais como em indústrias automotivas e aeroespaciais, os engenheiros agora podem filtrar dentro do portal de dados no DIAdem para facilmente encontrar e acessar os diferentes canais na memória. Com o novo Gerenciador de Cálculo, os engenheiros podem criar algoritmos personalizados e compartilhá-los dentro de seus departamentos e grupos para aumentar a 
produtividade e reduzir erros. Na figura 2.18 apresenta-se a área de trabalho do programa DIAdem.

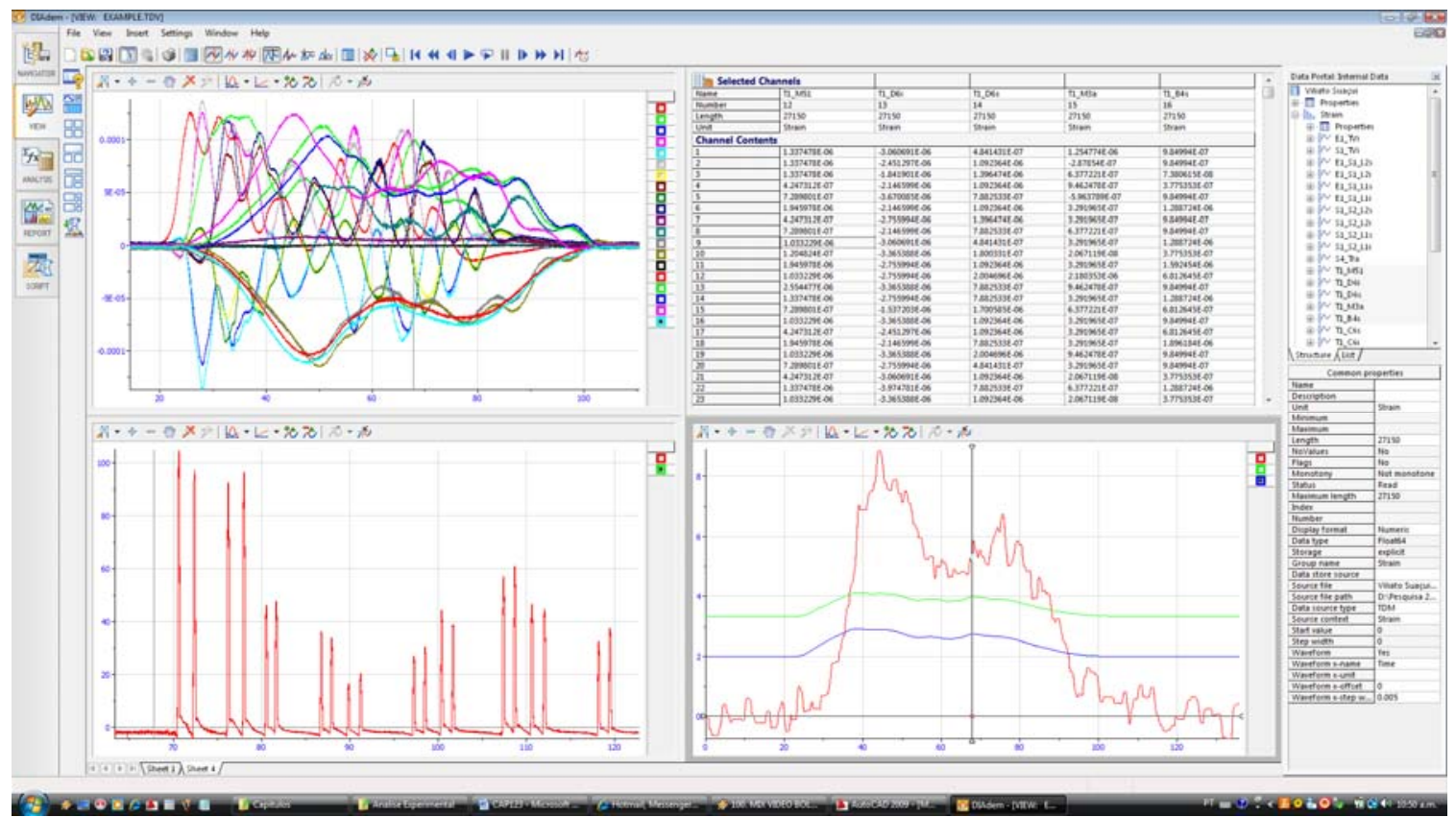

Figura 2.18 - Área de trabalho do programa DIAdem, onde mostra-se os dados obtidos da monitoração da ponte do rio Suaçui. 


\section{Capítulo}

\section{MODELOS ÁSICOS EMENGENHARIA ESTRUIURAL}

\section{Modelos Físicos em Engenharia Estrutural}

\subsection{Modelos Estruturais a Escala Reduzida}

\subsubsection{Introdução}

O uso de modelos em escala reduzida por engenheiros e construtores vem de tempos bem antigos, centenas ou milhares de anos atrás. No entanto, esses primeiros modelos eram principalmente de auxílio para o planejamento e construção de estruturas e não foram usados para predizer as deformações e as forças nos protótipos. Eles assemelhavam-se mais ao modelo arquitetônico moderno (maquetes).

Hossdorf (1972) refere que no século XV Leonardo da Vinci já sabia da existência de leis e formulações matemáticas referentes ao comportamento de estruturas geometricamente semelhantes. Ele estabeleceu teorias comparativas para uma série de formas construtivas simples. 
Para predizer o comportamento estrutural de um modelo precisam-se a medida das deformações, deslocamentos e forças. Assim, o desenvolvimento de modelos como uma ferramenta prática para entender o comportamento da estruturas protótipo foi fortemente influenciada pela análise de tensões experimentais. As técnicas mais utilizadas na análise de tensões experimentais foram desenvolvidas apenas há poucos anos, e atualmente são usadas também na monitoração de estruturas reais, tal como foi tratado no capitulo anterior.

Desde os anos 1920 têm sido usados medidores de deformação em modelos indiretos para o estudo de linhas de influência e para determinar as deflexões na estrutura. Beggs (1932) e Eney (1939) foram os primeiros a usar medidores especiais de deformação para obter linhas de influência em estruturas feitas de plástico e outros materiais.

O ano de 1940, com o desenvolvimento e a introdução dos Extensômetros Elétricos, pode ser considerado como o começo da análise moderna de tensões experimentais e modelo estrutural. Após a Segunda Guerra Mundial a análise experimental de estruturas por meio de modelos desenvolveu-se no mundo todo. $\mathrm{Na}$ década de 60 , tem-se também a introdução do microconcreto como material para a confecção de modelos que efetivamente representam o comportamento de elementos em concreto armado (MARTINS, 1990).

\subsubsection{Definição}

Um modelo pode ser definido como a redução de uma estrutura complicada ou complexa (edifício, ponte, etc.) conhecida como protótipo a uma estrutura muito simples, sem perder as características importantes do comportamento do protótipo (REINHORN, 2008).

Um modelo é definido também como qualquer representação física de uma estrutura ou parte da mesma. O ensaio de uma viga em laboratório pode ser considerado como um modelo, mesmo que tenha as mesmas dimensões da viga a ser utilizada na estrutura, pois está representando apenas parte da estrutura. Entretanto, o termo modelo é usualmente associado à escala reduzida e é aplicado a qualquer tipo de material (SILVA, 2007). 
Os modelos estruturais sempre desempenharam um papel significativo no ensino da engenharia estrutural, pesquisa e projeto com os quais se pode: obter dados experimentais para verificar a capacidade preditiva dos modelos numéricos, estudar o comportamento de sistemas estruturais complexos para o qual os modelos analíticos são demasiadamente complexos e estudar o comportamento de sistemas estruturais que combinam elementos com diferentes tipos de comportamento.

\subsubsection{Classificação. -}

A classificação dos modelos é de acordo com a resposta esperada durante sua utilização e o tipo de material usado, conforme apresentado na seguinte tabela:

Tabela 3.1 - Classificação dos modelos fiscos reduzidos. Fonte: ACl-444 (1987).

\begin{tabular}{|c|c|}
\hline Tipo de Modelo & Definição \\
\hline Modelo Elástico & $\begin{array}{l}\text { Tem uma geometria semelhante ao protótipo e é confeccionado com } \\
\text { materiais elásticos e homogêneos, o qual não precisa ser } \\
\text { necessariamente semelhante ao material do protótipo. Esse modelo } \\
\text { simula apenas o comportamento elástico do protótipo de concreto. }\end{array}$ \\
\hline Modelo Indireto & $\begin{array}{l}\text { O carregamento e os materiais não têm relação direta aos usados no } \\
\text { protótipo. Cargas e deformações são aplicadas para obter linhas ou } \\
\text { superfícies de influencia utilizando o principio de Muller-Breslau. } \\
\text { Tensões nos protótipos são deduzidas a partir dos diagramas de } \\
\text { influencia obtidos nos ensaios dos modelos, e consequentemente } \\
\text { somente o comportamento elástico linear pode ser determinado. }\end{array}$ \\
\hline Modelo Direto & $\begin{array}{l}\text { O modelo é carregado na mesma maneira que o protótipo, tal que as } \\
\text { tensões e as deformações sejam similares as do protótipo. }\end{array}$ \\
\hline $\begin{array}{l}\text { Modelo de } \\
\text { Resistência }\end{array}$ & $\begin{array}{l}\text { Modelo geometricamente semelhante ao protótipo, tanto nas } \\
\text { dimensões externas quanto nas internas. Os materiais do modelo } \\
\text { reproduzem fielmente as características dos materiais do protótipo. Tal } \\
\text { modelo pode prever o modo de comportamento do protótipo em todos } \\
\text { os níveis de carregamento, ate o ultimo. }\end{array}$ \\
\hline $\begin{array}{l}\text { Modelo do efeito } \\
\text { do Vento }\end{array}$ & $\begin{array}{l}\text { Há vários modos de classificar esse modelo. Pode-se utilizar modelo } \\
\text { de forma ou rigidez, nos quais a força total ou pressão do vento na } \\
\text { estrutura pode ser medida. Enquanto que no modelo aeroelástico, } \\
\text { ambas as propriedades, a forma e a rigidez do protótipo estrutural são } \\
\text { modeladas em métodos para medir o vento induzindo tensões e } \\
\text { deformações e a interação dinâmica da estrutura com o vento. }\end{array}$ \\
\hline Modelo dinâmico & $\begin{array}{l}\text { Esses modelos são usados para estudos de vibração e efeito de } \\
\text { carregamento dinâmico em estruturas. Pode ser testado em tabelas de } \\
\text { oscilação para estudar o efeito de terremoto ou em túnel de vento para } \\
\text { estudar o efeito aeroelástico. Modelos dinâmicos podem também ser } \\
\text { usados para estudar o efeito de explosão interna ou externa ou o efeito } \\
\text { de impacto nas estruturas. }\end{array}$ \\
\hline
\end{tabular}




\subsection{Processo de Execução do Modelo}

O sucesso de estudo de um modelo se caracteriza por um planejamento cuidadoso das diversas etapas do processo de execução do modelo. Um estudo experimental de uma estrutura de engenharia é em si um pequeno projeto de engenharia, e como em qualquer projeto de engenharia, precisa de uma seqüência lógica e criteriosa de eventos. O planejamento detalhado de um experimento é ainda mais essencial do que o planejamento de um cálculo analítico, porque o refinamento de um modelo estrutural a meio caminho através de um processo de execução é geralmente impossível (HARRIS, SABNIS, 1999).

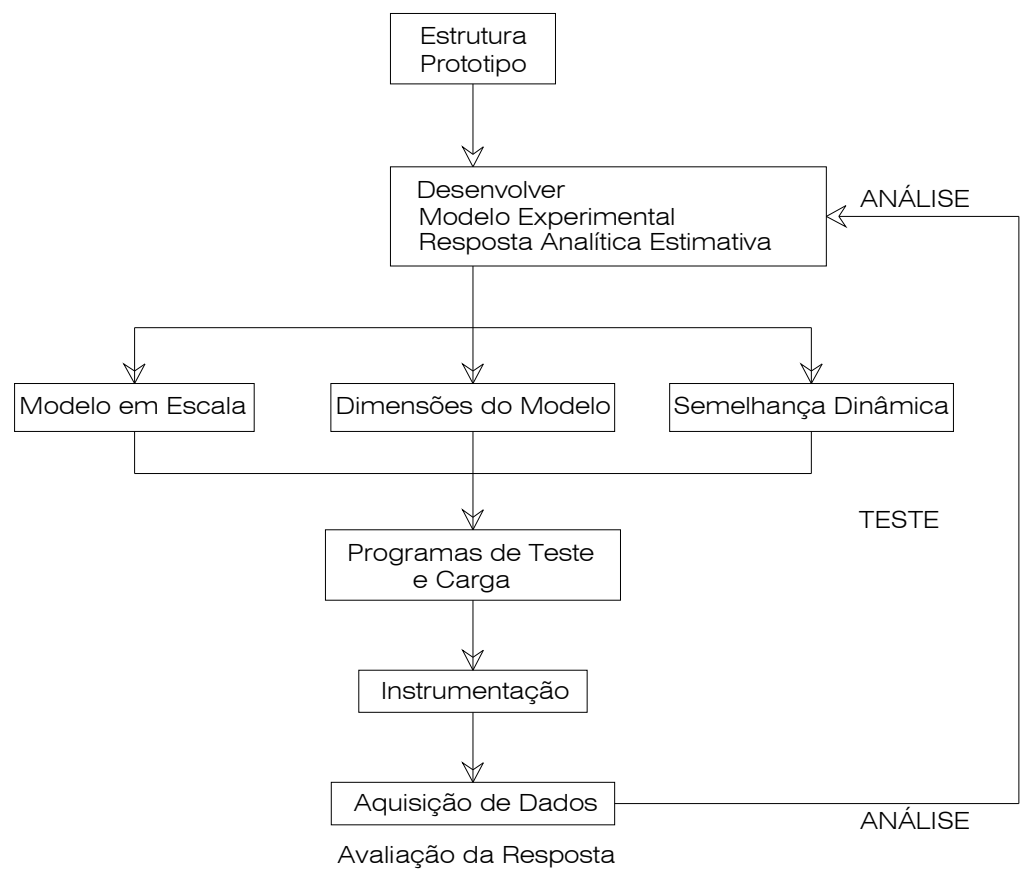

Figura 3.1 - Sequência de Execução do modelo de teste (REINHORN, 2008).

A seguir mostra-se a sequência de execução de um modelo físico:

1. Definir o objetivo dos testes experimentais (resposta desejada, mecanismo de falha, etc.).

2. Selecionar a escala, normalmente regida pelos recursos do laboratório (espaço, dispositivos de carregamento, etc.).

3. Seleção do tipo de material do modelo.

4. Condições de semelhança. Pode não obedecer a um modelo real. 
5. Projeto do modelo e plano de fabricação.

6. Instalação de sensores para medir a resposta da estrutura.

7. Salvar e armazenar dados experimentais (aquisição de dados).

8. Observar a resposta e análise de dados, e ter um diário de todas as atividades experimentais. Logo extrapolar dados e comparar com o protótipo.

\subsubsection{Fator de Escala de Modelos Experimentais. -}

Para a escolha de um ótimo fator de escala de um modelo que está sendo construído no laboratório deve-se ter em conta muitas considerações. Modelos muito pequenos requerem cargas leves, mas podem apresentar grande dificuldade na fabricação e instrumentação. Os modelos grandes são mais fáceis de construir, mas exigem equipamento de carga muito pesada.

O fator de escala $S_{(.)}$é definido pela relação de quantidades entre o protótipo e o modelo:

$$
S(.)=\frac{(.)_{p}}{(.)_{m}}
$$

Por exemplo:

Escala Geométrica: $S_{L}=$ Fator entre o comprimento do protótipo e do modelo.

Muitas vezes, quando se projeta um modelo, primeiro seleciona-se a escala geométrica e consequentemente determina-se o resto de fatores. Fatores tais como:

Escala de Força: $S_{F}=$ Relação da força aplicada ao protótipo e ao modelo.

Escala de Massa: $S_{M}=$ Relação da massa do protótipo e do modelo.

Escala de Área: $\mathrm{S}_{\mathrm{A}}=$ Relação da área do protótipo e do modelo.

\subsubsection{Fatores de Escala para Estruturas tipo}

Harris e Sabniss (1999) apresentam na tabela 3.2 fatores de escala para várias classes de estruturas, os mesmos que foram obtidos produto da experiência dos pesquisadores nessa área de trabalho, mas a escolha do fator de escala apropriado depende da disponibilidade de recursos no laboratório e outro fatores anteriormente mencionados. 
Tabela 3.2 - Fatores de escala tipo.

\begin{tabular}{lcc}
\hline Tipo de Estrutura & Modelo Elástico & Modelo de Resistência \\
\hline Cobertura em Casca & $1 / 200$ a $1 / 50$ & $1 / 30$ a $1 / 10$ \\
Ponte de rodovia & $1 / 25$ & $1 / 20$ a $1 / 4$ \\
Reator & $1 / 100$ a $1 / 50$ & $1 / 20$ a $1 / 4$ \\
Vigas e Lajes & $1 / 25$ & $1 / 10$ a $1 / 4$ \\
Represa & $1 / 400$ & $1 / 75$ \\
Efeito do vento & $1 / 300$ a $1 / 50$ & Não aplicável \\
\hline
\end{tabular}

\subsection{Vantagem e Limitações dos Modelos Físicos}

\subsubsection{Vantagem}

A principal vantagem de um modelo físico sobre um modelo analítico é que ela retrata o comportamento de uma estrutura completa, carregada até a fase de colapso. Embora progressos substanciais têm-se na análise de estruturas por computador, ainda não podemos prever analiticamente a capacidade de falha de sistemas estruturais tridimensionais, especialmente sob cargas complexas.

A outra motivação para realizar experimentos em estruturas a escala reduzida é reduzir custos. A redução de custos surge em duas áreas: redução no equipamento de carga e estruturas de retenção e redução no custo na fabricação da estrutura de teste, preparação e a eliminação após do teste.

\subsubsection{Limitações}

As principais limitações do uso de modelos estruturais em um ambiente de projeto são o tempo e custo. Na comparação entre modelos físicos e modelos analíticos, verifica-se que esses últimos são normalmente mais baratos e mais rápidos, e seria ilógico pensar que os modelos físicos suplantem ou substituam os modelos matemáticos, quando esses últimos conduzem a uma definição aceitável do comportamento da estrutura do protótipo. Assim os modelos físicos são quase sempre limitados para situações onde a análise matemática não é adequada ou inviável.

Outro fator limitante é que as mudanças no protótipo, resultantes de um estudo, poderão requerer um segundo modelo para verificar o projeto. Por tanto, 
considerações de ordem prática, muitas vezes sugerem que o modelo físico seja usado só para verificar um "quase finalizado" projeto (HARRIS, SABNIS, 1999).

\subsubsection{Precisão dos Modelos Estruturais}

O fator mais importante para o usuário do modelo analítico é talvez a confiabilidade dos resultados de um estudo de modelo físico. Assim, para obter dados confiáveis é necessário tratar estatisticamente os resultados, mas o custo de um teste simples é geralmente elevado. Portanto, a disponibilidade de dados é insuficiente e limitado para a aplicação de testes estatísticos.

Os fatores que afetam a precisão do modelo são: as propriedades do material, a precisão da fabricação, as técnicas de carregamento, métodos de medição e interpretação dos resultados.

\subsection{Teoria de Modelos Estruturais}

\subsubsection{Introdução}

Qualquer modelo estrutural deve ser projetado, carregado e interpretado de acordo com as condições de semelhança entre a estrutura do modelo e o protótipo. Essas condições de semelhança baseiam-se na teoria de modelo, que podem ser derivadas de uma análise dimensional dos fenômenos físicos envolvidos no comportamento da estrutura.

Geralmente um modelo matemático representa uma estrutura real que revela relações abstratas de determinadas grandezas, por exemplo, as forças com as deformações. enquanto um modelo físico representa a relação abstrata de grandezas exibidas por o modelo do mundo real. Nesse caso, desde que o modelo físico é reduzido de escala, a questão da seleção correta do fator de escala torna-se muito importante, e são determinadas através da análise de semelhança (LIANG, REINHORN, 2008).

\subsubsection{Análise Dimensional}

A análise dimensional oferece um benefício substancial em qualquer investigação do comportamento físico, porque permite ao experimentador combinar variáveis dentro de agrupamentos adimensionais ( $\pi$-termos), com uma consequente 
redução das quantidades desconhecidas. Em um sistema coerente de unidades de medida as unidades de um pequeno número de grandezas são independentes e adotadas como unidades fundamentais ou de base. As unidades das demais grandezas, chamadas unidades derivadas, são dependentes dessas unidades fundamentais, de acordo com leis físicas ou formulas de definição (SOUZA, 2004).

\subsubsection{Forma de uma Equação Dimensional}

Qualquer grandeza pode ser expressa em termos de grandezas básicas assim, por exemplo:

$$
A=F^{C_{1}} L^{C_{2}} T^{C_{3}}
$$

Onde:
A
= Variáveis dependentes.
$\mathrm{F}, \mathrm{L}, \mathrm{T}=$ Grandezas primárias (Unidades fundamentais).
$\mathrm{C}_{1}, \mathrm{C}_{2}, \mathrm{C}_{3} \quad=$ Constantes.

Da análise dimensional, tem-se:

$$
\alpha=C_{\alpha} a_{1}^{C 1} a_{2}{ }^{C 2} a_{3}{ }^{C 3} \ldots a_{n}{ }^{C n}
$$

Onde:

$$
\begin{array}{ll}
\alpha=\text { Grandeza secundária. } & \mathrm{a}_{\mathrm{i}}=\text { Grandeza primária. } \\
\mathrm{Ci}=\text { Constantes. } & \mathrm{C} \alpha=\text { Constante } .
\end{array}
$$

\subsubsection{Teorema de Buckingham}

O Teorema de Buckingham ocupa um lugar muito importante na teoria da análise dimensional. Este teorema diz que qualquer equação dimensionalmente homogênea que envolve certas grandezas físicas pode ser reduzida a uma equação equivalente envolvendo um conjunto completo de produtos adimensionais. O engenheiro de modelos estruturais pode entender esse teorema como a solução da equação para algumas grandezas físicas de interesse, ou seja:

$$
F\left(X_{1}, X_{2}, \ldots, X_{n}\right)=0
$$


Equivalentemente pode ser expressa na forma:

$$
G\left(\pi_{1}, \pi_{2}, \ldots, \pi_{n}\right)=0
$$

O número necessário de relações adimensionais ( $\pi$ - termos) é limitado pela seguinte condição:

$$
m=n-r
$$

Onde:

$$
\begin{aligned}
& \mathrm{X}_{\mathrm{i}}=\text { Grandezas físicas. } \\
& \pi_{\mathrm{i}}=\mathrm{Pi}-\text { Termo (Termos adimensionais). } \\
& \mathrm{m}=\text { Número de produtos adimensionais ( } \pi \text {-termos). } \\
& \mathrm{n}=\text { Número total de grandezas envolvidas. } \\
& \mathrm{r}=\text { Número de dimensões básicas ou fundamentais. }
\end{aligned}
$$

Assim ,por exemplo:

$$
\begin{aligned}
& \text { 1.- } F(q, l, \sigma)=0 \rightarrow G\left(\frac{l \sigma}{q}\right)=0 \\
& \text { 2.- } F(u, E, l, t, q, \rho)=0 \rightarrow G\left(\frac{u}{l}, \frac{q}{E l}, \frac{\rho l^{2}}{E t^{2}}\right)=0
\end{aligned}
$$

Nesses dois exemplos pode-se notar que as três variáveis físicas do primeiro e as seis variáveis físicas do segundo exemplo foram reduzidas para um e três produtos adimensionais, respectivamente. Geralmente, o número de produtos adimensionais $(m)$ é igual à diferença entre o número de variáveis físicas $(n)$ e o número de medidas fundamentais $(r)$. O primeiro exemplo foi um problema de mecânica estática, onde as dimensões fundamentais foram força e comprimento, ou seja, $m=n-r=3-2=1$. O segundo problema é um problema de mecânica dinâmica, as dimensões fundamentais foram força, comprimento e altura, ou seja, $m=6-3=3$.

\subsubsection{Usos da Analise Dimensional}

Uma das principais aplicações da analise dimensional é o estabelecimento das condições de semelhança física, que relacionam protótipos como modelos 
utilizados nos experimentos (SOUZA, 2004). A Análise dimensional pode ser usada pelo engenheiro de duas formas distintas:

Primeiro, ela pode ser útil em deduzir alguns resultados teóricos sobre o comportamento de um fenômeno físico a partir de observações experimentais. Tal situação pode ocorrer se eram conhecidas as variáveis físicas relevantes, que afetaram o estado de alguma outra variável física, mas não se conhecia a relação matemática que vinculava essas variáveis.

O segundo uso da Analise dimensional na área do projeto estrutural foi exposta sucintamente por Bridgman ${ }^{4}$ (1922): Na engenharia prática há uma grande quantidade de problemas tão complicados que a solução exata não é atingível. Sob essas condições a análise dimensional nos permite obter algumas informações sobre a forma do resultado que poderia ser obtido na prática, apenas por experimentos com uma ampla variação de argumentos da função desconhecida.

A fim de aplicar a análise dimensional, apenas tem-se que saber com que tipo de fenômeno físico se está tratando, e quais são as variáveis que entram na equação; não tem-se que escrever as equações de modo explícito, nem muito menos resolvê-las.

\subsubsection{Semelhança de Modelos Estruturais}

Para que um modelo possa representar o protótipo e que os resultados dos ensaios com modelos possam ser entendidos em relação aos protótipos, é preciso que haja semelhança, a começar pela semelhança geométrica. Em princípio, todos os adimensionais, fatores de forma e funções devem ter o mesmo valor no modelo quanto no protótipo. Em muitos casos introduzem-se distorções, devido a se adotar no modelo escalas diferentes para grandezas de um mesmo tipo: as consequências dessas distorções devem ser cuidadosamente analisadas, para evitar erros de interpretação dos resultados (SOUZA, 2004). A seguir serão descritos três tipos de modelos estruturais:

\footnotetext{
${ }^{4}$ BRIDGMAN, P.W. Dimensional Analysis, Yale University Press, New Haven, CT, 1922.
} 
- O modelo verdadeiro é aquele que mantém semelhança completa e satisfaz cada condição estabelecida pela análise dimensional.

- O modelo adequado mantém a semelhança de "primeira ordem". Para entender o comportamento de um protótipo nem sempre todas as grandezas são importantes, então é possível pensar que alguma das disposições estabelecidas pela análise dimensional é de importância de "segunda ordem".

- O modelo distorcido é o modelo que não satisfaz uma ou mais estipulações estabelecidos pela análise dimensional.

A seguir são descritos alguns tipos de Semelhança:

\subsubsection{Semelhança Geométrica}

Modelo e protótipo têm a mesma forma e comportamento geométrico, tal como se mostra na figura 3.2.
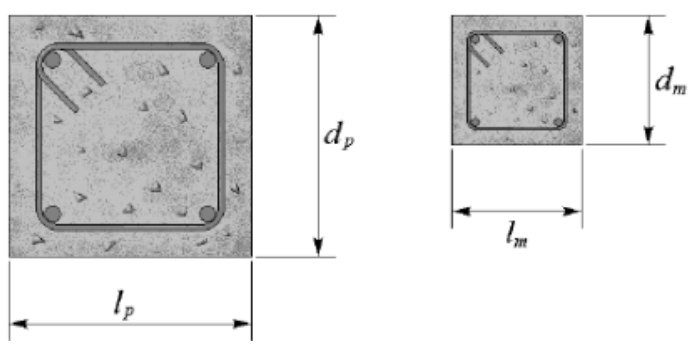

Figura 3.2 - Semelhança Geométrica.

$$
\frac{l_{p}}{d_{p}}=\frac{l_{m}}{d_{m}} \Rightarrow \frac{A_{p}}{A_{p}}=\left(\frac{d_{p}}{d_{m}}\right)^{2}=\left(\frac{l_{p}}{l_{m}}\right)^{2}
$$

Denota-se:

O fator de escala do comprimento: $S_{L}=\frac{l_{p}}{l_{m}}$

O fator de escala da área: $S_{A}=S_{L}^{2}$

\subsubsection{Semelhança Distorcida}

O modelo é uma reprodução do protótipo, mas são usados duas ou mais escalas diferentes. Por exemplo, uma escala é usada para a profundidade e a largura e outro para a altura (LIANG, REINHORN, 2008). 

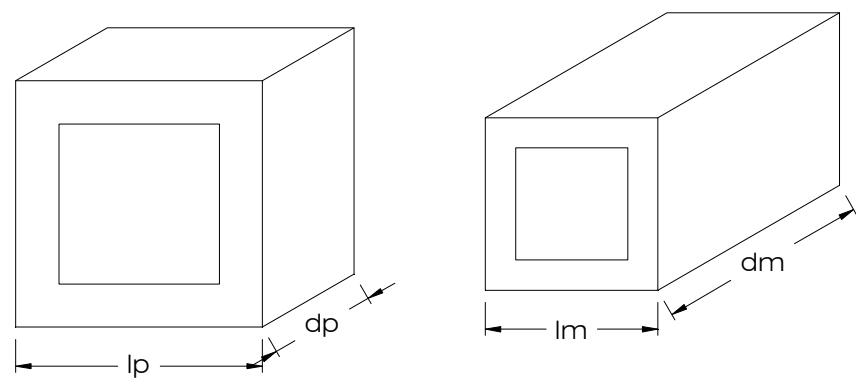

Figura 3.3 - Semelhança Distorcida.

Vê-se no caso de semelhança distorcida, $S_{l}=\frac{l_{p}}{l_{m}} \neq S_{d}=\frac{d_{p}}{d_{m}}$

\subsubsection{Semelhança dissimilar}

Nenhuma semelhança física entre o modelo e protótipo.

\subsubsection{Modelos com completa semelhança}

A partir do teorema de Buckingham qualquer fenômeno físico pode ser representado através de uma equação matemática que envolve um conjunto de produtos adimensionais (HARRIS, SABNIS, 1999), tal como se mostra na equação 3.7.

$$
\pi_{1}=\phi\left(\pi_{2}, \pi_{3}, \ldots, \pi_{n}\right)
$$

Com a equação 3.7 , pode se relacionar os adimensionais do protótipo e do modelo, tal como se mostra a seguir:

$$
\frac{\pi_{1 p}}{\pi_{1 m}}=\frac{\phi\left(\pi_{2 p}, \pi_{3 p}, \ldots, \pi_{n p}\right)}{\phi\left(\pi_{2 m}, \pi_{3 m}, \ldots, \pi_{n m}\right)}
$$

Onde $\pi_{1 \mathrm{~m}}$ refere-se $o \pi_{1}$ do modelo e $\pi_{1 \mathrm{p}}$ refere-se $0 \pi_{1}$ do protótipo.

Logo, a semelhança completa se dá quando todos os produtos adimensionais são iguais no modelo e no protótipo. Ou seja:

$$
\begin{aligned}
& \pi_{2 m}=\pi_{2 p} \\
& \pi_{3 m}=\pi_{3 p} \\
& \ldots \\
& \pi_{n m}=\pi_{n p}
\end{aligned}
$$


Assim, a equação 3.8 pode ser escrita assim:

$$
\begin{gathered}
\frac{\pi_{1 p}}{\pi_{1 m}}=\frac{\phi\left(\pi_{2 p}, \pi_{3 p}, \ldots, \pi_{n p}\right)}{\phi\left(\pi_{2 m}, \pi_{3 m}, \ldots, \pi_{n m}\right)}=1 \\
\pi_{1 p}=\pi_{1 m}
\end{gathered}
$$

Exemplo de aplicação: Formar um conjunto completo e independente de adimensionais a partir das quantidades listadas no quadro seguinte:

\begin{tabular}{cll}
\hline Símbolo & Quantidade & Unidade \\
\hline $\mathbf{L}$ & Comprimento & $\mathrm{L}$ \\
$\mathbf{Q}$ & Força & $\mathrm{F}$ \\
$\mathbf{M}$ & Massa & $\mathrm{FL}^{-1} \mathrm{~T}^{2}$ \\
$\sigma$ & Tensão & $\mathrm{FL}^{-2}$ \\
$\varepsilon$ & Deformação & --- \\
$\mathbf{a}$ & Aceleração & $\mathrm{LT}^{-2}$ \\
$\delta$ & Deslocamento & $\mathrm{L}$ \\
$\mathbf{U}$ & Coeficiente de Poisson & --- \\
$\mathbf{E}$ & Modulo de Elasticidade & $\mathrm{FL}^{-2}$ \\
\hline
\end{tabular}

As quantidades e suas dimensões são listadas em forma de matriz, na tabela seguinte:

\begin{tabular}{llllllllll}
\hline & $\mathbf{I}$ & $\mathbf{Q}$ & $\mathbf{M}$ & $\sigma$ & $\boldsymbol{\varepsilon}$ & $\mathbf{a}$ & $\delta$ & $\mathbf{U}$ & $\mathbf{E}$ \\
\hline $\mathbf{F}$ & 0 & 1 & 1 & 1 & 0 & 0 & 0 & 0 & 1 \\
$\mathbf{L}$ & 1 & 0 & -1 & -2 & 0 & 1 & 1 & 0 & -2 \\
$\mathbf{T}$ & 0 & 0 & 2 & 0 & 0 & -2 & 0 & 0 & 0 \\
\hline
\end{tabular}

A equação que governa o comportamento físico pode ser descrito pela equação 3.12 .

$$
f(l, Q, M, \sigma, \varepsilon, a, \delta, v, E)=0
$$

A equação 3.12 , pode ser expressa como produto contínuo das quantidades acima listadas:

$$
Q=k l^{a} M^{b} \sigma^{c} \varepsilon^{d} a^{e} \delta^{f} v^{g} E^{h}
$$

Para que a equação 3.13 seja dimensionalmente homogênea, tem-se cumprir a seguinte condição:

$$
\begin{aligned}
& F: b+c+h=1 \\
& L: a-b-2 c+e+f-2 h=0 \\
& T: 2 b-2 e=0
\end{aligned}
$$


A equação 3.14 tem sete incógnitas, e pode ser resolvida arbitrariamente para $a$, $e$ e $h$ em termos de $b, c$, e $f$, da seguinte forma:

$$
Q=k l^{2-2 b-f} M^{b} \sigma^{c} \varepsilon^{d} a^{b} \delta^{f} v^{g} E^{1-b-c}
$$

$\mathrm{Ou}$

$$
\left(\frac{Q}{E l^{2}}\right)=k\left[\left(\frac{M a}{E l^{2}}\right)^{b}\left(\frac{\sigma}{E}\right)^{c}(\varepsilon)^{d}\left(\frac{\delta}{l}\right)^{f}(v)^{g}\right]
$$

Para a conformação dos adimensionais, escolheram-se três grandezas independentes (comprimento $l$, o módulo $E$, e aceleração $a$ ) que serão exibidos pelo menos uma vez nos 9 - $3=6 \pi$-termos, é evidente que a massa $M$ ou aceleração $a$ também deve ser incluído, uma vez que estas são as duas únicas grandezas que possuem a dimensão tempo. Os seis $\pi$ - termos formados por inspeção são mostrados a seguir:

$$
\begin{array}{ll}
\pi_{1}=\frac{Q}{E l^{2}}, & \pi_{4}=\varepsilon, \\
\pi_{2}=\frac{M a}{E l^{2}}, & \pi_{5}=\frac{\delta}{l}, \\
\pi_{3}=\frac{\sigma}{E}, & \pi_{6}=v .
\end{array}
$$

As relações de semelhança e fatores de escala correspondentes ao exemplo anterior podem ser obtidas igualando adimensionais $\pi_{\mathrm{m}}=\pi_{\mathrm{p}}$. O fator de escala somente pode ser escolhido para quantidades dimensionalmente independentes que nesse caso são $S_{L}, S_{E}, S_{a}$ (geométrico, módulo e aceleração). O resto de fatores de escala ficaram em função dos fatores de escala arbitrários:

$$
\begin{array}{ll}
S_{Q}=S_{l}^{2} S_{E}, & S_{\varepsilon}=1, \\
S_{M}=\frac{S_{l}{ }^{2} S_{E}}{S_{a}}, & S_{\delta}=S_{l}, \\
S_{\delta}=S_{E}, &
\end{array}
$$

Deve-se notar que a deformação no modelo e no protótipo deve ser idêntico e a tensão somente será idêntica se $S_{E}=1$, este resulta quando se usa 0 mesmo material na construção do modelo e protótipo. 


\subsubsection{Dificuldades Tecnológicas Associadas com a Semelhança Completa}

Apresentam-se vários tipos de dificuldades ao tentar se conseguir semelhança completa nos modelos físicos, entre eles podemos enumerar algumas:

- Percepção errada de variáveis importantes.

- Deliberado requerimento de semelhança que é considerado não tão crítico, por exemplo, o uso do material no modelo com diferente coeficiente de Poisson, do que o protótipo.

- Irregularidades desde o modelo real, como o uso de um sistema de carga discreta para substituir uma carga contínua.

A falta de semelhança completa nas relações adimensionais no modelo e no protótipo, significa que a relação $\phi_{p} / \phi_{m}$ da equação 3.10 não seja mais a unidade. Embora, não seja possível na maioria dos casos fazer uma avaliação do valor real da relação, é essencial perceber que essa referência de semelhança afeta o resultado do modelo na medida em que a relação se afasta da unidade.

\subsection{Casos de Estudo de Modelos}

\subsubsection{Caso 1}

A estrutura do TWA (Trans World Airlines Maintenance) localizado na cidade de Kansas foi projetada com a ajuda de uma série de modelos estruturais tal como se mostra na figura 3.4. A estrutura é composta por quatro cascas, que têm vãos de até $96 \mathrm{~m}$ aproximadamente, e têm a forma de parabolóide hiperbólico cuja espessura varia de $75 \mathrm{~mm}$ a $150 \mathrm{~mm}$. Os quatro modelos separados foram usados para resolver uma série de questões do projeto. Assim, os modelos A1 e A2 foram construídos em escalas de 1:300 e 1:100 respectivamente e logo testados no túnel de vento para pesquisar a pressão e o fluxo do vento. Os resultados do modelo no túnel de vento foram usados na fase do projeto analítico para ajudar a gerar a proposta de projeto final. O terceiro modelo $A 3$ feito de plástico e escala de 1:50, foi construído para determinar o comportamento elástico sob diferentes condições de carregamento. Finalmente o modelo A4 foi o mais realista, construído em escala de 
1:10, e projetado para simular o verdadeiro comportamento da casca da estrutura de concreto reforçado até a falha.

O modelo de estudo foi desenvolvido pela firma Wiss, Janney, Elstner and Associates of Northbrook, II.

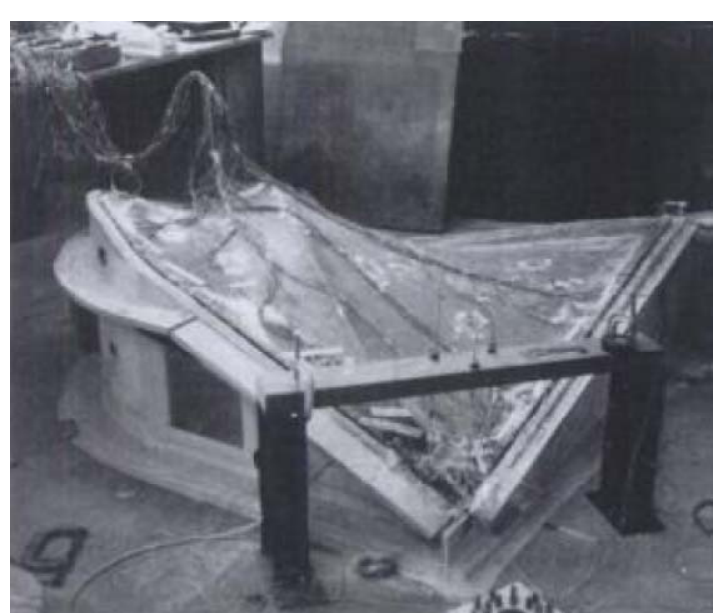

(a)

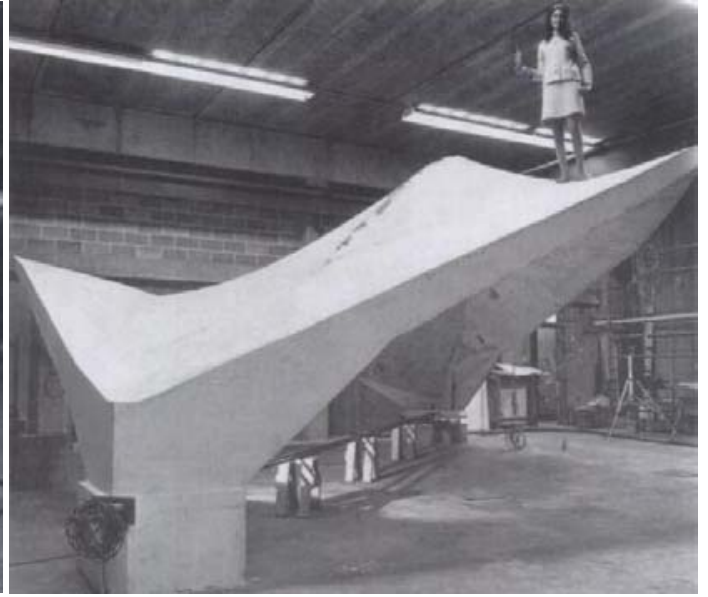

(b)

Figura 3.4 - (a) Modelo Elástico da Estrutura TWA em escala 1:50. (b) Modelo em microconcreto em escala 1:10 para estudar a estrutura até a ruptura.

\subsubsection{Caso 2}

Uma estrutura sismo-resistente de paredes de concreto armado foi projetada, construída e testada no laboratório de estruturas pelo Programa de cooperação U.S. - Instituto de pesquisas de Tsukuba, Japão. A estrutura consistia em pórticos com paredes e tinha sete andares (figura 3.5). O principal propósito das paredes de corte era providenciar resistência torsional à estrutura. Com este tipo de testes, se verificou-se que as propriedades da parede influenciaram no desempenho sísmico da estrutura.

Para escolher a estrutura de teste com as características indicadas teve-se em conta, as dimensões mais comuns das construções tanto no U.S. e Japão. A escala do modelo de 1:5 foi definida em função aos resultados obtidos na predição analítica da resposta da estrutura e as limitações do tamanho da mesa vibratória da Universidade de Califórnia, Berkeley. 
Um dos objetivos mais importantes desta pesquisa foi avaliar a confiabilidade da análise experimental em todos os estados limite da resposta sísmica do modelo em escala reduzida. O estudo do modelo foi desenvolvido por Bertero e Aktan ${ }^{5}$ (1984).

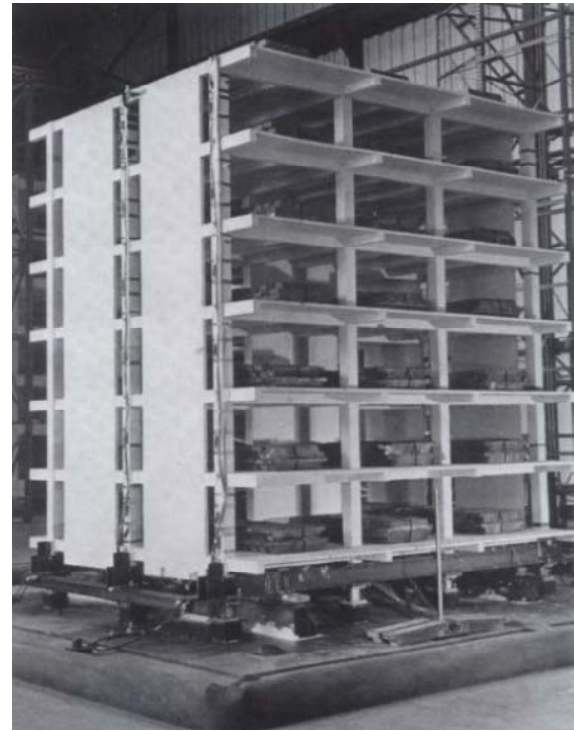

Figura 3.5 - Vista do modelo a escala 1:5 na mesa vibratória da Universidade de Berkeley.

\subsubsection{CASO 3: Tabuleiro de ponte de concreto reforçado}

A Case Western Reserve University, Perdikaris ${ }^{6}$ (1989) e seus associados desenvolveram uma pesquisa para estudar a resistência última e fadiga do tabuleiro de uma ponte típica de estrada de concreto armado sob cargas pulsantes e moveis. O tabuleiro da ponte tinha uma espessura de $216 \mathrm{~mm}$ sustentada por quatro vigas de aço W36x150 tal como se mostra na figura 3.6. Neste estudo foram testados um conjunto de 17 tabuleiros da ponte em escala 1:6,6 e seis painéis individuais em escala 1:3.

O objetivo desta pesquisa foi obter um melhor entendimento da resposta à fadiga do tabuleiro da ponte de concreto reforçado e apresentar uma descrição e

\footnotetext{
${ }^{5}$ BERTERO, V. V.; AKTAN, A. E.; CHARNEY, F. A.; and SAUSE, R. U.S. - Japan Cooperative Earthquake Research Program: Earthquake Simulation Tests and Associated Studies of a 1/5- Scale model of a 7-Story Reinforced Concrete Test Structure, Earthquake Engineering Research Center, Report No. UCB/EERC-84/05, University of California, Berkeley, 1984

${ }^{6}$ PERDIKARIS, P. C.; BEIM, S. R. and BOUSIAS, S. Slab continuity effect of ultimate and fatigue strength or R/C bridge deck models, ACI Struct. J. 86(4), 1989.
} 
explicação de vários mecanismos de transferência de carga presentes no tabuleiro durante sua expectativa de vida.

Vários parâmetros importantes foram estudados nesta pesquisa, entre eles temos os efeitos da relação de armadura à flexão, o espaçamento entre vigas de aço, restrição rotacional e lateral do tabuleiro, tipo e nível de carga aplicada sobre o padrão de fissuração, perda da rigidez, tempo de fadiga e modo de falha do tabuleiro da ponte.

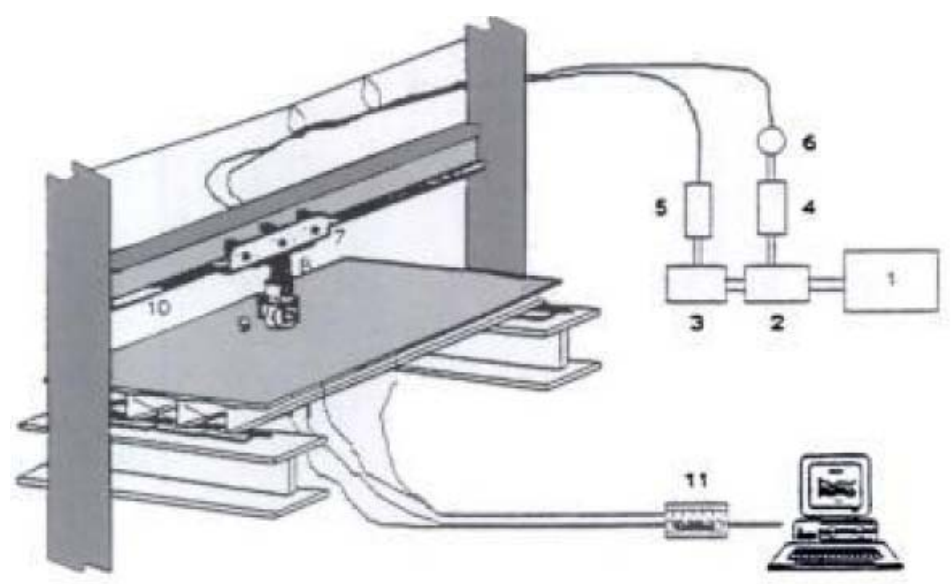

Figura 3.6 - Modelo do tabuleiro de concreto reforçado em escala 1:6,6. 


\section{Capítulo}

\section{MONTORAÇÃODAPONIE DO RJO SUAÇU EMESCALA REALEREDUZDA}

4 Monitoração da ponte do Rio Suaçui em escala real e reduzida

\subsection{Introdução}

O presente capítulo refere-se às atividades envolvidas no planejamento, instrumentação e monitoração do comportamento da Ponte do Rio Suaçui. O estudo do comportamento da estrutura é de vital importância frente à intensidade das ações provocadas pela passagem dos trens desde a sua construção e na determinação da real capacidade resistente.

A fim de entender melhor o comportamento da ponte, foi desenvolvido um modelo reduzido que serviu de base para fazer um estudo experimental preliminar da estrutura, e determinar quais são os elementos estruturais mais solicitados e, a partir disso, planejar adequadamente a monitoração da ponte real. Além disso, os dados experimentais obtidos da monitoração do modelo e do protótipo (ponte real), foram comparados entre si a fim de se obter alguma relação, pois o modelo reduzido inicialmente foi projetado de forma semelhante à estrutura real. 
A monitoração de estruturas em escala reduzida, executadas e testadas em laboratório em condições controladas e submetidas a ações conhecidas, permite testar e calibrar sensores de todo o sistema de monitoração e auxiliar na interpretação de dados medidos em estruturais reais.

O sistema de sensores utilizados na monitoração da ponte real e reduzida é composto por extensômetros elétricos de resistência (para medir as deformações nas diagonais, montantes, longarinas e transversinas) e LVDT's para medir deslocamentos.

A monitoração da Ponte Suaçui (figura 4.1) faz parte de um projeto de pesquisa em parceria entre a USP e a VALE DO RIO DOCE, que prevê o desenvolvimento na área de mineração, portos e ferrovias, estudos estruturais de pontes e vias permanentes da estrada de Vitória a Minas (EFVM) e avaliar sua capacidade máxima.

$\mathrm{Na}$ elaboração do projeto de monitoração e na concepção do modelo em escala reduzida foram analisadas também as seguintes documentações:

- Relatórios de inspeções realizadas por Engenheiros e Técnicos da VALE.

- Projetos estruturais originais.

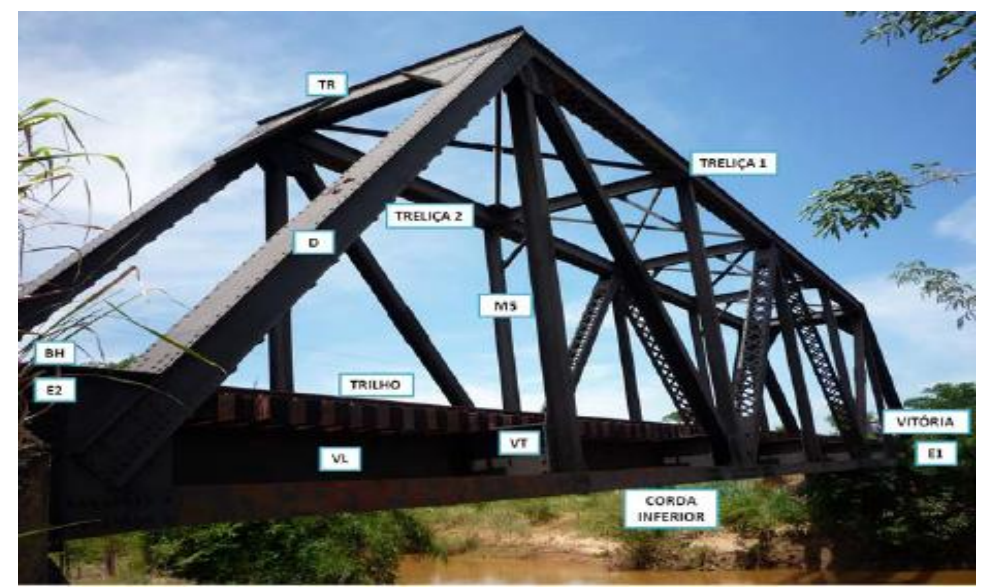

Figura 4.1 - Vista geral da ponte real e seus elementos estruturais.

O estudo experimental foi complementado com o desenvolvimento de modelos teóricos da ponte e do modelo reduzido, a fim de avaliar o desempenho estrutural e calibrá-los com os resultados experimentais obtidos a partir das monitorações produzidas quando da aplicação de cargas. 


\subsection{Descrição da estrutura}

A superestrutura da ponte sobre o Rio Suaçui é constituída por duas treliças Warren compostas com perfis de aço ASTM A 7.39, apoiada nas extremidades sobre aparelhos de apoio metálicos e possui $41 \mathrm{~m}$ de vão.

As treliças, com altura de $7,80 \mathrm{~m}$, são interligadas na sua região inferior por tabuleiro constituído por transversinas com aproximadamente $4 \mathrm{~m}$ de comprimento, conectadas à parte inferior dos montantes, e longarinas que, ligando-se às transversinas, se desenvolvem longitudinalmente em pares. Sobre as longarinas apóiam-se os dormentes de madeira e sobre esses os trilhos de perfis TR68 da ferrovia, cuja bitola é métrica, havendo também contratrilhos. Na parte superior as treliças são interligadas por vigas travessas e barras de contraventamento em $X$ unindo os seus montantes. As ligações nodais são constituídas de chapas de aço rebitadas, conforme pode ser observado na figura 4.1 .

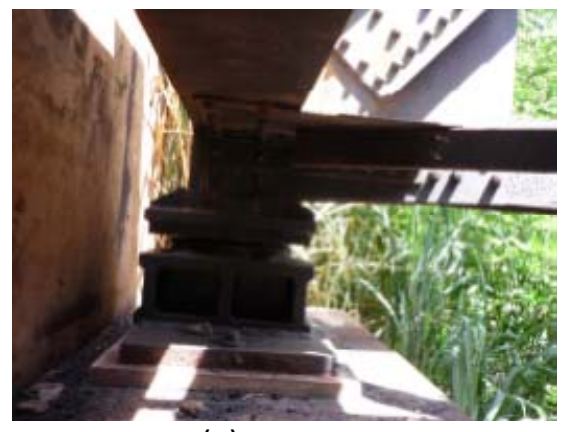

(a)

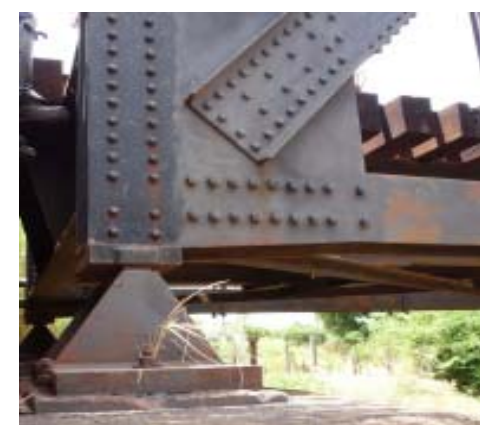

(b)

Figura 4.2 - (a) Detalhe do aparelho de apoio deslizante; (b) Aparelho de apoio fixo.

A superestrutura é apoiada em pilares, localizados junto aos encontros, através de dois pares de aparelhos de apoio metálicos, sendo que em uma das extremidades os apoios são fixos e na outra são deslizantes (figura 4.2).

Para conhecer o estado atual da ponte e antes de planejar o projeto de monitoração foi necessário fazer uma inspeção visual da obra para a obtenção e levantamento de dados. Os trabalhos de inspeção em obra tinham por objetivo, além de determinar a geometria real das seções transversais de toda a estrutura, 0 levantamento das anomalias existentes, notadamente os aspectos ligados à corrosão dos elementos metálicos, incluindo ligações, e o estado de conservação dos 
aparelhos de apoio. Esses dados vieram a ser essenciais no desenvolvimento do modelo numérico utilizado na interpretação dos resultados experimentais, que decorreram da monitoração do comportamento da ponte (tabela 4.2). Na figura 4.3 apresentam-se as dimensões reais da ponte obtidas no levantamento em campo.

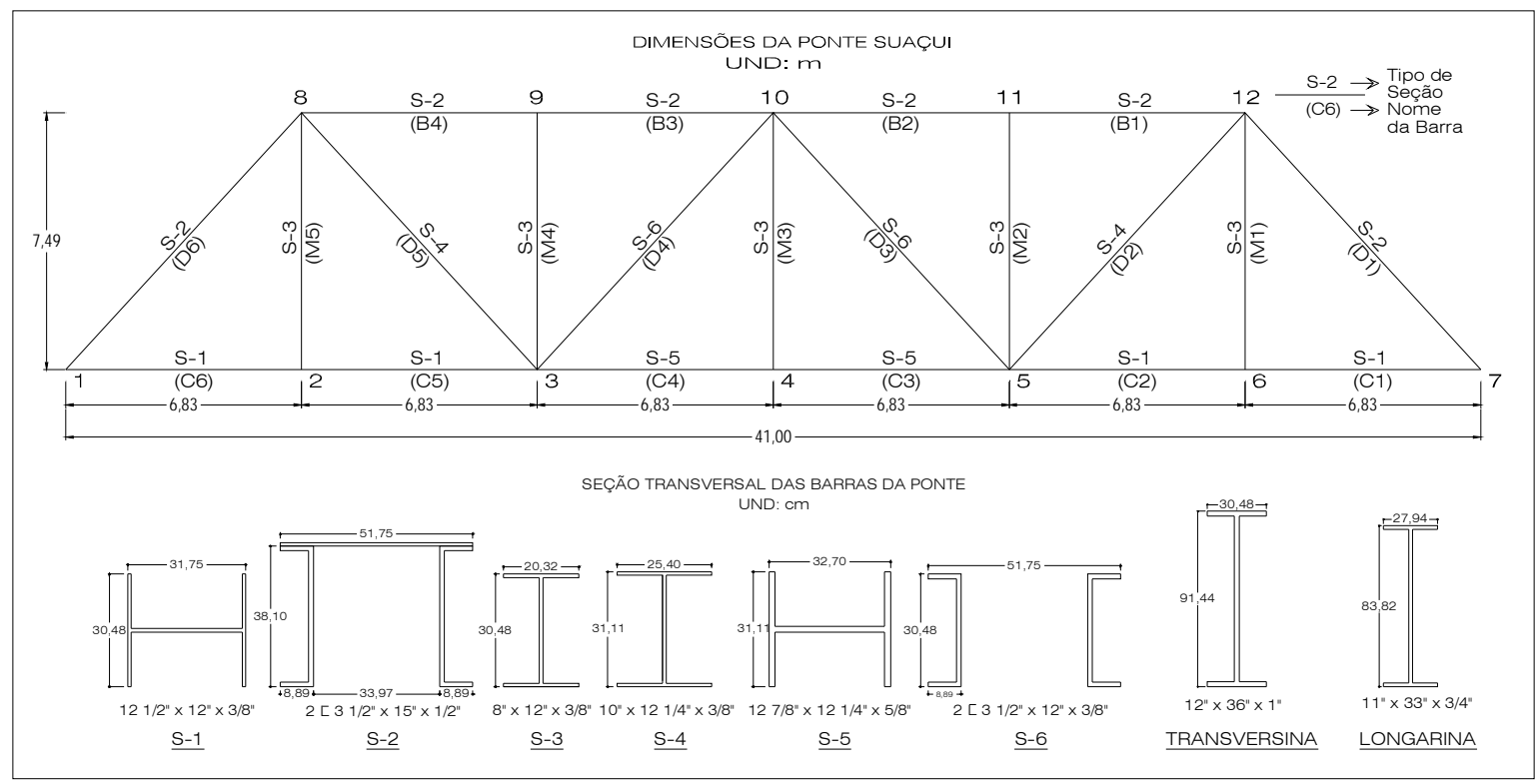

Figura 4.3 - Dimensões da Ponte Suaçui.

Os perfis de aço utilizados na construção da ponte foram caracterizados detalhadamente, através de ensaios mecânicos no Laboratório de Estruturas e Materiais. Os resultados desses ensaios (tabela 4.1) estão contempladas no relatório Caracterização mecânica dos perfis metálicos retirados da ponte sobre o Rio Suaçui LEM - VALE 06-09 FUSP 1982, (BITTENCOURT, 2010).

Tabela 4.1 - Propriedades mecânicas das amostras ensaiadas.

\begin{tabular}{lrrrrrr}
\hline \multirow{1}{*}{ Propriedades } & \multicolumn{3}{c}{ Amostra nova - perfil I } & \multicolumn{2}{c}{ Amostra velha - perfil I } \\
\cline { 2 - 7 } & \multicolumn{1}{c}{ Alma } & \multicolumn{1}{c}{ Mesa } & Média & Alma & Mesa & Média \\
\hline Módulo de elasticidade E (GPa) & 213,80 & 211,00 & $\mathbf{2 1 2 , 4 0}$ & 208,00 & 209,40 & $\mathbf{2 0 8 , 7 0}$ \\
Coeficiente de Poisson v & 0,28 & 0,28 & $\mathbf{0 , 2 8}$ & 0,28 & 0,28 & $\mathbf{0 , 2 8}$ \\
Resistência à ruptura $f_{\mathrm{U}}(\mathrm{MPa})$ & 476,30 & 450,30 & $\mathbf{4 6 3 , 3 0}$ & 431,60 & 400,20 & $\mathbf{4 1 5 , 9 0}$ \\
$\begin{array}{l}\text { Resistência ao escoamento } f_{\mathrm{y}} \\
\text { (MPa) }\end{array}$ & 310,00 & 277,90 & $\mathbf{2 9 4 , 0 0}$ & 279,30 & 248,40 & $\mathbf{2 6 3 , 9 0}$ \\
$\begin{array}{l}\text { Alongamento no limiar do } \\
\text { escoamento } \varepsilon_{\mathrm{y}}(\%)\end{array}$ & $\mathbf{1 , 5}$ & $\mathbf{1 , 5}$ & $\mathbf{1 , 5}$ & $\mathbf{0 , 5}$ & $\mathbf{0 , 9}$ & $\mathbf{0 , 7}$ \\
\hline
\end{tabular}


Tabela 4.2 - Resumo das propriedades geométricas do protótipo.

\begin{tabular}{|c|c|c|}
\hline \multirow{4}{*}{$\begin{array}{l}\text { Dimensões } \\
\text { Geométricas das } \\
\text { Barras }\end{array}$} & Nome do Elemento: & Dimensões: \\
\hline & $\begin{array}{l}\text { C1, C2, C3, C4, C5, C6, B1, } \\
\text { B2, B3, B4. }\end{array}$ & $\mathrm{L}=6,83 \mathrm{~m}$ \\
\hline & M1, M2, M3, M4, M5. & $\mathrm{L}=7,49 \mathrm{~m}$ \\
\hline & D1, D2, D3, D4, D5, D6. & $\mathrm{L}=10,14 \mathrm{~m}$ \\
\hline \multirow{9}{*}{$\begin{array}{l}\text { Dimensões } \\
\text { Geométricas e } \\
\text { Tipos de Seções } \\
\text { das Barras }\end{array}$} & Tipo de Seção: & Dimensões em cm: \\
\hline & S1 & $a=31,75 \quad b=30,48 \quad e=0,9525$ \\
\hline & S2 & $a=8,89(2) b=38,10 e=1,27$ \\
\hline & S3 & $a=20,32 \quad b=30,48 \quad e=0,9525$ \\
\hline & S4 & $a=25,40 \quad b=31,11 \quad e=0,9525$ \\
\hline & S5 & $a=32,70 \quad b=31,11 e=1,5875$ \\
\hline & S6 & $a=8,89(2) b=30,48 e=0,9525$ \\
\hline & TRANSVERSINA & $a=30,48 \quad b=91,44 e=2,54$ \\
\hline & LONGARINA & $a=27,94 \quad b=83,82 e=1,905$ \\
\hline
\end{tabular}

\subsection{Modelo Reduzido da Ponte do Rio Suaçui}

Com a construção do modelo reduzido da ponte do Rio Suaçui, pretende-se estudar o comportamento experimental da estrutura na fase linear e sua similaridade com o comportamento da estrutural real. A fim de que o modelo reduzido possa representar o protótipo e que os resultados experimentais possam ser estendidos ao protótipo, é preciso que exista semelhança entre eles.

Assim, o modelo reduzido foi projetado a partir das características e dimensões da ponte real, na qual se tentou manter no possível, as condições de semelhança geométrica. A semelhança em relação ao tipo de material não foi possível manter, pois, as dimensões da seção transversal das peças estruturais do modelo resultaram menores ao se aplicar o fator de escala. O único material comercialmente encontrado que oferece perfis estruturais de menor tamanho é o alumínio. Motivo pela qual, se escolheu esse material para sua fabricação.

\subsubsection{Projeto do Modelo Reduzido}

O modelo reduzido foi projetado a uma escala $\left(S_{L}\right)$ de 1:30. A dimensão dos elementos estruturais do modelo foi determinada multiplicando-se o fator de escala geométrica às dimensões reais da ponte (figura 4.4b). Na tabela 4.3 e 4.4, apresenta-se um resumo dos principais dimensões do protótipo e do modelo. 
Tabela 4.3 - Dimensões geométricas dos elementos do protótipo e do modelo.

\begin{tabular}{lcc}
\hline \multicolumn{1}{c}{ Nome do Elemento } & $\begin{array}{c}\text { Dimensões } \\
\text { no Protótipo }\end{array}$ & $\begin{array}{c}\text { Dimensões } \\
\text { no Modelo }\end{array}$ \\
\hline C1, C2, C3, C4, C5, C6, B1, B2, B3, B4. & $\mathrm{L}=6,83 \mathrm{~m}$ & $\mathrm{~L}=0,2278 \mathrm{~m}$ \\
M1, M2, M3, M4, M5. & $\mathrm{L}=7,49 \mathrm{~m}$ & $\mathrm{~L}=0,2498 \mathrm{~m}$ \\
D1, D2, D3, D4, D5, D6. & $\mathrm{L}=10,14 \mathrm{~m}$ & $\mathrm{~L}=0,3380 \mathrm{~m}$ \\
\hline
\end{tabular}

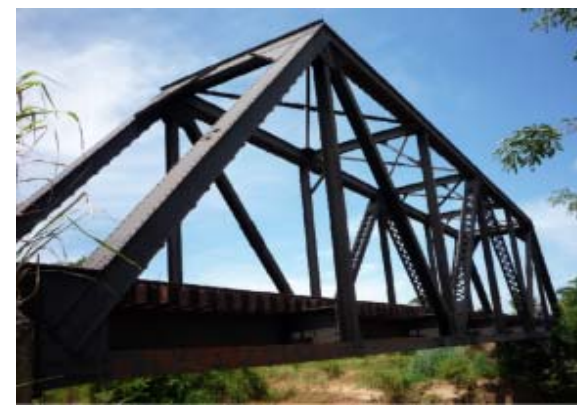

(a)

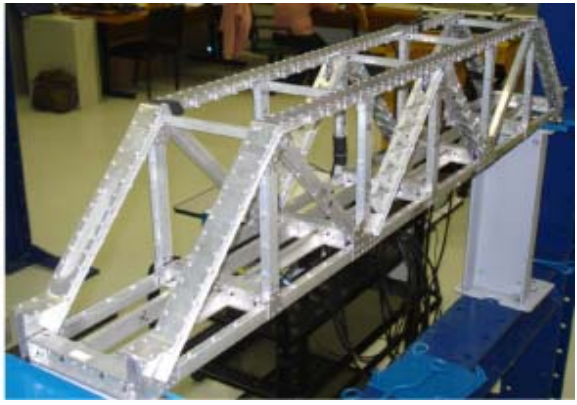

(b)

Figura 4.4 - (a) Ponte do Rio Suaçui - Protótipo, (b) Modelo em escala reduzida.

Da mesma forma foram determinadas as dimensões das seções do modelo:

Tabela 4.4 - Dimensões geométricas dos elementos do protótipo e do modelo.

\begin{tabular}{|c|c|c|}
\hline Tipo de Seção & $\begin{array}{l}\text { Dimensões no } \\
\text { Protótipo }\end{array}$ & Dimensões no Modelo \\
\hline \multirow{2}{*}{ S1 } & ${ }^{*} a=31,7{ }^{*} b=30,48$ & $a=1,058 b=1,016$ \\
\hline & ${ }^{*} \mathrm{e}=0,9525 \mathrm{~cm}$ & $e=0,0318 \mathrm{~cm}$ \\
\hline S2 & $\begin{array}{l}a=8,89(2) b=38,10 \\
e=1,27 \mathrm{~cm}\end{array}$ & $\begin{array}{l}a=0,296(2) b=1,270 \\
e=0,0423 \mathrm{~cm}\end{array}$ \\
\hline S3 & $\begin{array}{l}a=20,32 b=30,48 \\
e=0,9525 \mathrm{~cm}\end{array}$ & $\begin{array}{l}a=0,677 b=1,016 \\
e=0,0318 \mathrm{~cm}\end{array}$ \\
\hline S4 & $\begin{array}{l}a=25,40 \mathrm{~b}=31,11 \\
e=0,9525 \mathrm{~cm}\end{array}$ & $\begin{array}{l}a=0,847 \mathrm{~b}=1,037 \\
e=0,0318 \mathrm{~cm}\end{array}$ \\
\hline S5 & $\begin{array}{l}a=32,70 b=31,11 \\
e=1,5875 \mathrm{~cm}\end{array}$ & $\begin{array}{l}a=1,090 \mathrm{~b}=1,037 \\
e=0,0529 \mathrm{~cm}\end{array}$ \\
\hline S6 & $\begin{array}{l}a=8,89(2) b=30,48 \\
e=0,9525 \mathrm{~cm}\end{array}$ & $\begin{array}{l}a=0,296(2) b=1,016 \\
e=0,0318 \mathrm{~cm}\end{array}$ \\
\hline TRANSVERSINA & $\begin{array}{l}a=30,48 \mathrm{~b}=91,44 \\
e=2,54 \mathrm{~cm}\end{array}$ & $\begin{array}{l}a=1,016 b=3,048 \\
e=0,0847 \mathrm{~cm}\end{array}$ \\
\hline LONGARINA & $\begin{array}{l}a=27,94 b=83,82 \\
e=1,905 \mathrm{~cm}\end{array}$ & $\begin{array}{l}a=0,931 b=2,794 \\
e=0,0635 \mathrm{~cm}\end{array}$ \\
\hline
\end{tabular}

* Onde: $a$ = largura da seção, $b$ = altura da seção, e = espessura. 
Infelizmente, as dimensões das seções transversais dos elementos estruturais do modelo obtidas depois de multiplicado pelo fator de escala, resultaram em medidas não comerciais. A fabricação dessas seções demandaria um custo elevado, além de ser dificultoso e precisar maior tempo, o que não seria conveniente para o projeto.

Com as limitantes encontradas se tomou a decisão de construir um modelo, cujos comprimentos das barras ainda mantêm semelhança com o protótipo, mas as dimensões das seções transversais tiveram que ser modificadas e adaptadas, em função dos perfis de alumínio de menor tamanho encontrados. As referidas modificações afetarão os resultados esperados do modelo e não serão mais semelhantes ao protótipo. Então, o modelo construído passa a ser um modelo de menor aproximação, o que segundo a classificação ACl-444(1987) chama-se de Modelo Indireto.

No entanto, o modelo físico foi aproveitado para fazer um estudo detalhado do comportamento estrutural, em relação ao modelo matemático. Diferentes tipos de solicitações de carga foram aplicados ao modelo, obtendo-se dados experimentais que ajudaram a calibrar o modelo matemático e a compreender melhor seu comportamento.

Uma das dificuldades na construção do modelo foi reproduzir as seções tipo "H", pois em dimensões pequenas não existem perfis desse tipo, nem das dimensões desejadas, razão pela qual, se teve que compor seções a partir de seções tipo "C". Todos esses detalhes são mostrados nos desenhos de projeto e processo construtivo que estão no anexo A.

As dimensões dos perfis comerciais usados para projetar as seções definitivas e a disposição geométrica final do modelo ficaram de acordo com a figura 4.5. Na tabela 4.5 apresentam-se também a comparação entre as dimensões das seções do modelo semelhante e as seções adotadas finais. 
Tabela 4.5 - Dimensões geométricas das seções do protótipo e do modelo adotadas.

\begin{tabular}{|c|c|c|c|}
\hline $\begin{array}{l}\text { Tipo de Seção } \\
\text { Semelhante }\end{array}$ & $\begin{array}{c}\text { Dimensões no Modelo } \\
\text { Semelhante }\end{array}$ & $\begin{array}{c}\text { Tipo de Seção } \\
\text { não Semelhante }\end{array}$ & $\begin{array}{c}\text { Dimensões no Modelo } \\
\text { não Semelhante }\end{array}$ \\
\hline S1 & $\begin{array}{l}{ }^{*} a=1,058 * b=1,016 \\
{ }^{*} e=0,0318 \mathrm{~cm}\end{array}$ & S1 & $\begin{array}{l}a=1,905 b=1,270 \\
e=0,1587 \mathrm{~cm}\end{array}$ \\
\hline S2 & $\begin{array}{l}a=0,296(2) b=1,270 \\
e=0,0423 \mathrm{~cm}\end{array}$ & S2 & $\begin{array}{l}a=0,953(2) b=1,270 \\
e=0,1587 \mathrm{~cm}\end{array}$ \\
\hline S3 & $\begin{array}{l}a=0,677 b=1,016 \\
e=0,0318 \mathrm{~cm}\end{array}$ & S1 & $\begin{array}{l}a=1,905 \mathrm{~b}=1,270 \\
e=0,1587 \mathrm{~cm}\end{array}$ \\
\hline S4 & $\begin{array}{l}a=0,847 b=1,037 \\
e=0,0318 \mathrm{~cm}\end{array}$ & S1 & $\begin{array}{l}a=1,905 \mathrm{~b}=1,270 \\
e=0,1587 \mathrm{~cm}\end{array}$ \\
\hline S5 & $\begin{array}{l}a=1,090 \mathrm{~b}=1,037 \\
e=0,0529 \mathrm{~cm}\end{array}$ & S1 & $\begin{array}{l}a=1,905 b=1,270 \\
e=0,1587 \mathrm{~cm}\end{array}$ \\
\hline S6 & $\begin{array}{l}a=0,296(2) b=1,016 \\
e=0,0318 \mathrm{~cm}\end{array}$ & S3 & $\begin{array}{l}a=0,953(2) b=1,270 \\
e=0,1587 \mathrm{~cm}\end{array}$ \\
\hline TRANSVERSINA & $\begin{array}{l}a=1,016 b=3,048 \\
e=0,0847 \mathrm{~cm}\end{array}$ & TRANSVERSINA & $\begin{array}{l}a=2,540 \mathrm{~b}=3,240 \\
e=0,70 \mathrm{~cm}\end{array}$ \\
\hline LONGARINA & $\begin{array}{l}a=0,931 b=2,794 \\
e=0,0635 \mathrm{~cm}\end{array}$ & LONGARINA & $\begin{array}{l}a=0,953 \mathrm{~b}=2,54 \\
e=0,60 \mathrm{~cm}\end{array}$ \\
\hline
\end{tabular}

* Onde: $a$ = largura da seção, $b$ = altura da seção, e = espessura.

Por outro lado, os nós de encontro foram projetados conservando-se a forma do protótipo, mas não se conseguiu manter a semelhança da espessura na chapa de ligação de 3/8", pois o valor obtido ao aplicar o fator de escala resultou em uma espessura bem fina. Assim, a espessura adotada foi a menor existente no mercado caso de $1,00 \mathrm{~mm}$.

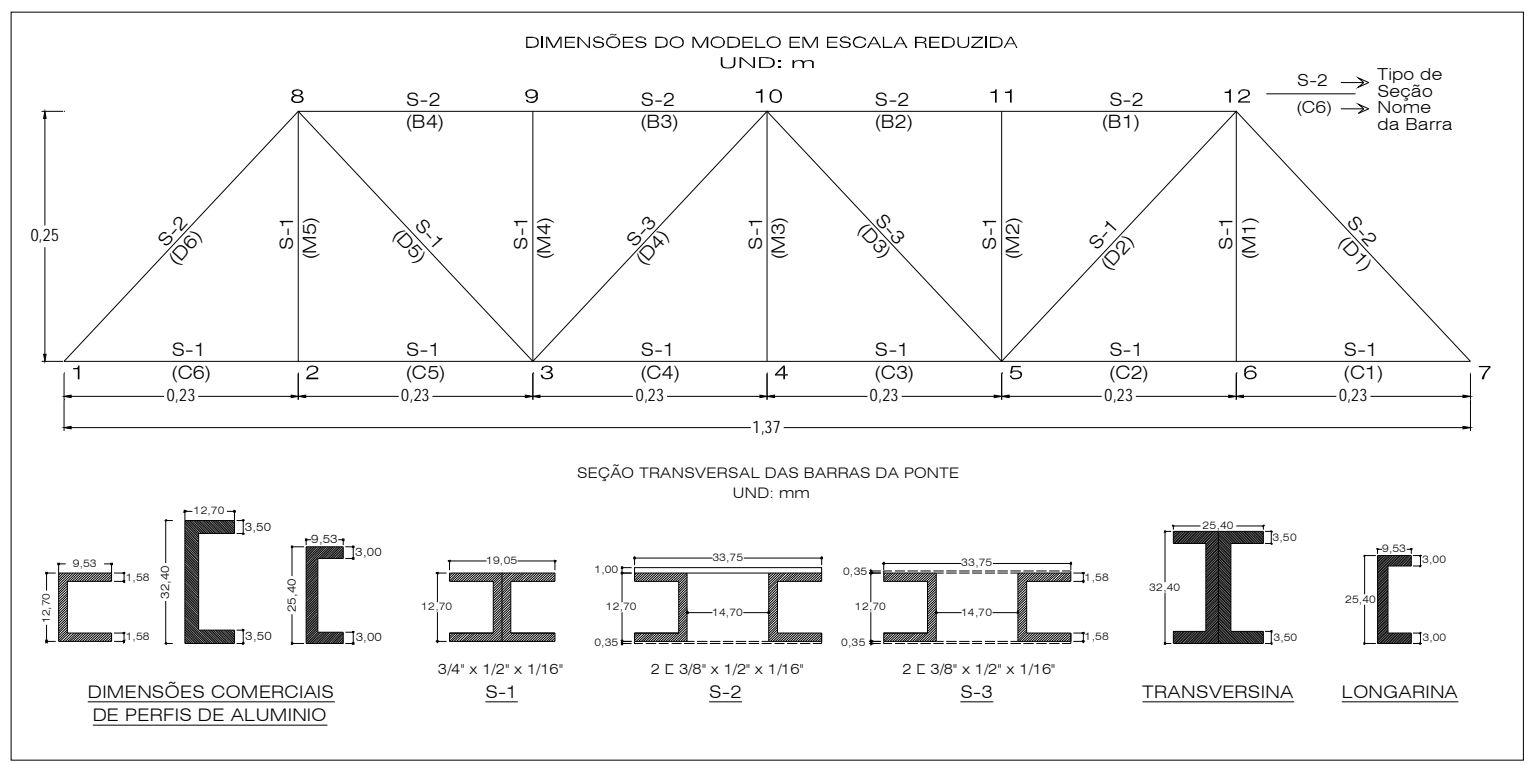

Figura 4.5 - Dimensões e seções transversais do modelo em escala reduzida. 
No caso dos rebites, também se teve dificuldades em manter a semelhança em dimensão e disposição, mas foi projetado tentando-se garantir a fixação dos nós e um comportamento estrutural similar ao de uma treliça.

Em conclusão o modelo em escala reduzida projetado tem semelhança com o protótipo, no que se refere a comprimentos de barras e as dimensões dos nós no cruzamento das barras. Mas nas seções transversais e na disposição dos rebites foi difícil manter essa semelhança, devido ao fato das dimensões calculadas não serem medidas comerciais, por isso se teve que dimensionar com perfis e rebites que se encontram facilmente no mercado.

$\mathrm{Na}$ tabela 4.6 apresenta-se um resumo das principais dimensões adotadas para os elementos estruturais do modelo, assim como a caracterização mecânica dos materiais usados na sua construção.

Tabela 4.6 - Resumo das propriedades geométricas e mecânicas do modelo.

\begin{tabular}{|c|c|c|}
\hline \multirow{4}{*}{$\begin{array}{l}\text { Dimensões } \\
\text { Geométricas das } \\
\text { Barras }\end{array}$} & Nome do Elemento: & Dimensões em m: \\
\hline & $\begin{array}{l}\text { C1, C2, C3, C4, C5, C6, B1, } \\
\text { B2, B3, B4 }\end{array}$ & $L=0,2278$. \\
\hline & M1, M2, M3, M4, M5 & $L=0,2498$ \\
\hline & D1, D2, D3, D4, D5, D6 & $\mathrm{L}=0,3380$. \\
\hline \multirow{6}{*}{$\begin{array}{l}\text { Dimensões } \\
\text { Geométricas e } \\
\text { Tipos de Seções } \\
\text { das Barras }\end{array}$} & Tipo de Seção: & Dimensões em cm: \\
\hline & S1 & $a=1,905 \quad b=1,27 \quad e=0,1587$ \\
\hline & S2 & $a=0,95(2) b=1,27 e=0,1587$ \\
\hline & S3 & $a=0,95(2) b=1,27 e=0,1587$ \\
\hline & TRANSVERSINA & $b=3,24$ e $=0,70$ \\
\hline & LONGARINA & $a=0,953 \quad b=2,54 \quad e=0,60$ \\
\hline \multirow{5}{*}{$\begin{array}{l}\text { Propriedades } \\
\text { Mecânicas do } \\
\text { Alumínio. }\end{array}$} & \multicolumn{2}{|c|}{$\begin{array}{l}\text { As propriedades mecânicas dos perfis do alumínio foram } \\
\text { caracterizadas por meio de ensaios, conforme se detalha no } \\
\text { anexo B. A seguir é apresentado um resumo das principais } \\
\text { propriedades obtidas: }\end{array}$} \\
\hline & \multicolumn{2}{|l|}{$\mathrm{E}=65,12 \mathrm{GPa}$} \\
\hline & \multicolumn{2}{|l|}{$v=0,33$} \\
\hline & \multicolumn{2}{|l|}{$f_{y}=210,24 \mathrm{MPa}$} \\
\hline & \multicolumn{2}{|l|}{$\mathrm{F}_{\mathrm{u}}=237,62 \mathrm{MPa}$} \\
\hline
\end{tabular}

\subsubsection{Monitoração do Modelo}

O modelo reduzido foi monitorado através de um sistema de sensores instalados ao longo da estrutura com finalidade de obter dados experimentais, que 
permitam estudar o comportamento da estrutura quando submetido a um tipo de carregamento. A monitoração consistiu basicamente na medição de dois tipos de grandezas físicas: as deformações nas barras do modelo e o deslocamento da estrutura no meio do vão.

Para isso, foi utilizado um sistema de aquisição e registro integrado que permitiu a medição automática e simultânea destas grandezas, com o mínimo de intervenção de operadores. Assim, toda a instrumentação foi testada e calibrada antes de iniciar os ensaios. Na figura 4.6 ilustra-se o modelo reduzido montado sobre o pórtico de ensaios e as nomenclaturas adotadas para identificação dos sensores na ponte.

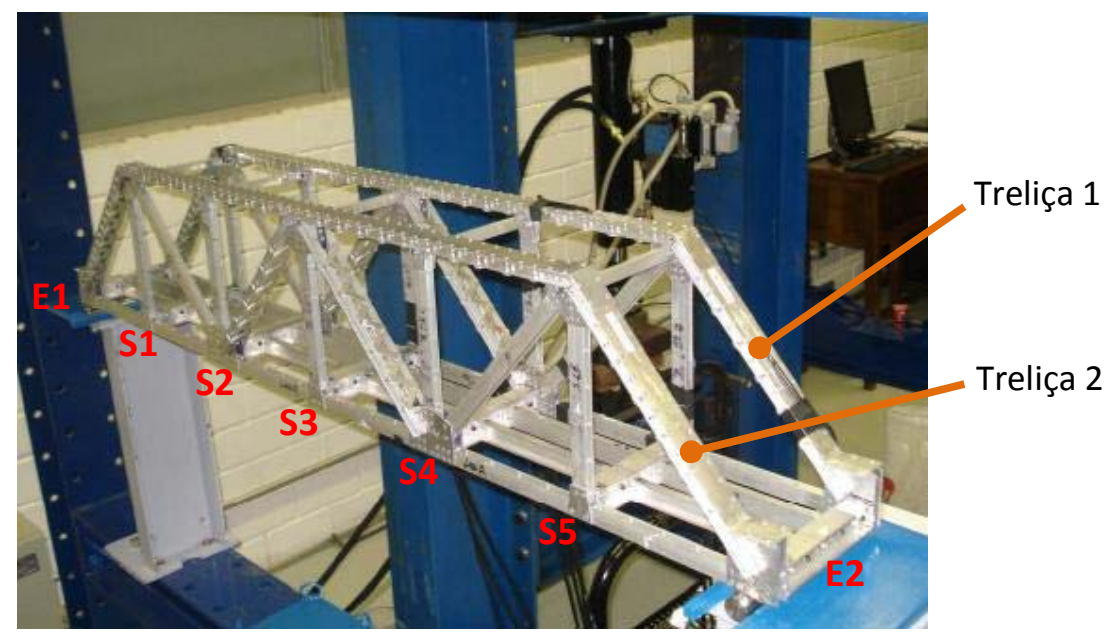

Figura 4.6 - Vista do modelo reduzido montado sobre o pórtico de ensaios.

\subsubsection{Medição das deformações}

A medição das deformações foi realizada utilizando extensômetros de resistência elétrica de $120 \Omega$, os quais foram colados à superfície do alumínio devidamente preparados e protegidos. Esses extensômetros quando colados num elemento de alumínio são auto-compensados para efeitos de temperatura, ou seja, dentro de certos limites de temperatura a sua variação não produzirá alteração significativa do valor da resistência do extensômetro. Pretendendo ser mais preciso na qualificação do efeito da temperatura sobre as medições efetuadas, o fabricante 
fornece a curva de comportamento desses extensômetros quando colados a uma superfície de referência. $\mathrm{Na}$ tabela 4.7 apresentam-se algumas características técnicas relevantes:

Tabela 4.7 - Especificações técnicas dos extensômetros elétricos.

\begin{tabular}{ll}
\hline Características & Especificação \\
\hline Serie Kyowa & KFG-5-120-C1-23 \\
Resistência elétrica & $120 \Omega$ \\
Fator de calibração (Gage fator) & 2,01 \\
Temperatura de funcionamento & $-10^{\circ} \mathrm{C}$ a $80^{\circ} \mathrm{C}$ \\
Comprimento de Grelha & $5 \mathrm{~mm}$ \\
\hline
\end{tabular}

A instalação dos extensômetros e a preparação da superfície para a colagem dos mesmos foi feita de acordo com os procedimentos recomendados na apostila de Extensometria de Conceição Neto (2006).

$\mathrm{Na}$ figura 4.7 ilustra-se o sistema de sensores instalados no modelo reduzido: extensômetros colados nas diagonais, montantes e cordas, as quais estão ligadas ao sistema de aquisição através de uma rede de fios conforme se mostra na figura.

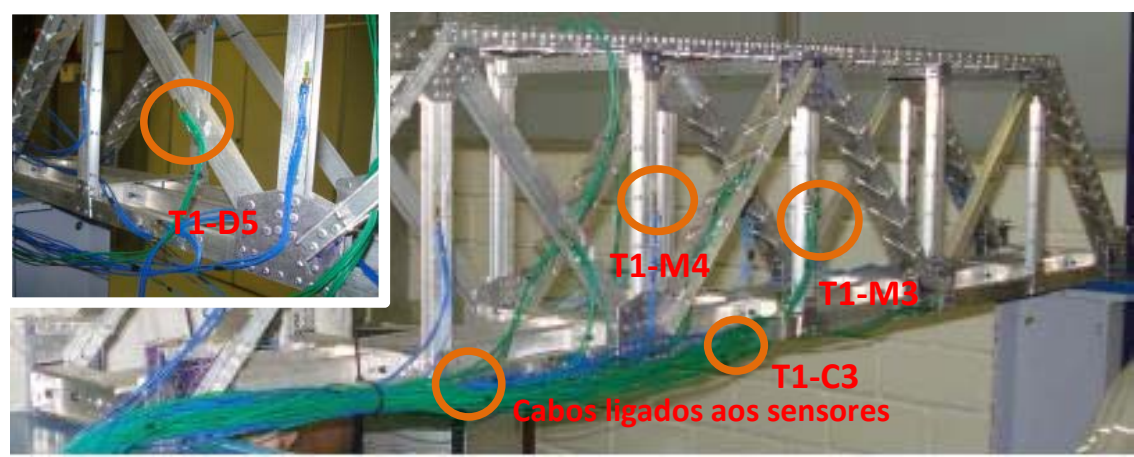

Figura 4.7 - Extensômetros instalados no modelo.

A tabela 4.8, apresenta a nomenclatura, localização e referência de cada um dos extensômetros instalados no modelo reduzido.

Na figura 4.8 e 4.9, apresenta-se o esquema completo da localização dos extensomêtros nas duas treliças do modelo. 
Tabela 4.8 - Localização e nomenclatura dos extensômetros instalados no modelo.

\begin{tabular}{|c|c|c|c|}
\hline Elemento & & Localização & Referencia \\
\hline $\begin{array}{l}\text { D6 } \\
\text { D5 } \\
\text { D4 } \\
\text { C5 } \\
\text { C5 } \\
\text { C4 } \\
\text { C4 } \\
\text { B4 } \\
\text { M5 } \\
\text { M4 } \\
\text { M3 } \\
\text { M3 }\end{array}$ & 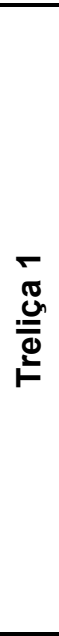 & 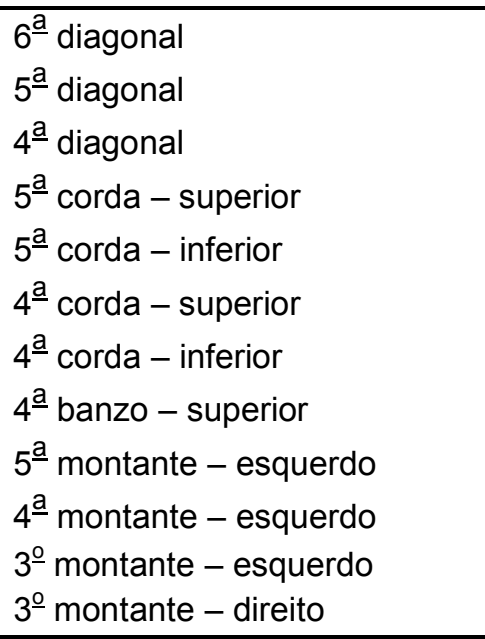 & $\begin{array}{l}\text { T1-D6s } \\
\text { T1-D5i } \\
\text { T1-D4s } \\
\text { T1-C5s } \\
\text { T1-C5i } \\
\text { T1-C4s } \\
\text { T1-C4i } \\
\text { T1-B4s } \\
\text { T1-M5e } \\
\text { T1-M4e } \\
\text { T1-M3e } \\
\text { T1-M3d }\end{array}$ \\
\hline $\begin{array}{l}\text { D1 } \\
\text { D1 } \\
\text { D2 } \\
\text { D3 } \\
\text { D3 } \\
\text { C2 } \\
\text { C3 } \\
\text { B2 } \\
\text { M1 } \\
\text { M2 } \\
\text { M3 }\end{array}$ & 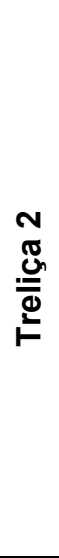 & $\begin{array}{l}1^{\underline{a}} \text { diagonal - inferior esquerdo } \\
1^{\underline{a}} \text { diagonal - inferior direito } \\
2^{\underline{\underline{a}}} \text { diagonal - superior } \\
3^{\underline{o}} \text { diagonal - superior } \\
3^{\underline{0}} \text { diagonal - inferior } \\
2^{\underline{a}} \text { corda - inferior } \\
3^{\underline{0}} \text { corda - inferior } \\
2^{\underline{a}} \text { banzo - superior } \\
1^{\underline{a}} \text { montante - esquerdo } \\
2^{\underline{a}} \text { montante - esquerdo } \\
3^{\underline{o}} \text { montante - esquerdo }\end{array}$ & $\begin{array}{l}\text { T2-D1e } \\
\text { T2-D1i } \\
\text { T2-D2s } \\
\text { T2-D3s } \\
\text { T2-D3i } \\
\text { T2-C2i } \\
\text { T2-C3i } \\
\text { T2-B2s } \\
\text { T2-M1e } \\
\text { T2-M2e } \\
\text { T2-M3e }\end{array}$ \\
\hline $\begin{array}{c}\text { S3 } \\
\text { S3 } \\
\text { S3-S2 } \\
\text { S3-S2 } \\
\text { S2-S1 } \\
\text { S2-S1 }\end{array}$ & 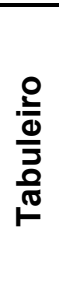 & $\begin{array}{l}3^{0} \text { transversina - superior } \\
3^{\circ} \text { transversina - inferior } \\
3^{\circ} \text { longarina - superior } \\
3^{\underline{0}} \text { longarina - inferior } \\
2^{\underline{a}} \text { longarina - superior } \\
2^{\underline{a}} \text { longarina - inferior }\end{array}$ & $\begin{array}{l}\text { S3-Tvs } \\
\text { S3-Tvi } \\
\text { L3s-S3-S2 } \\
\text { L3i-S3-S2 } \\
\text { L2s-S2-S1 } \\
\text { L2i-S2-S1 }\end{array}$ \\
\hline
\end{tabular}

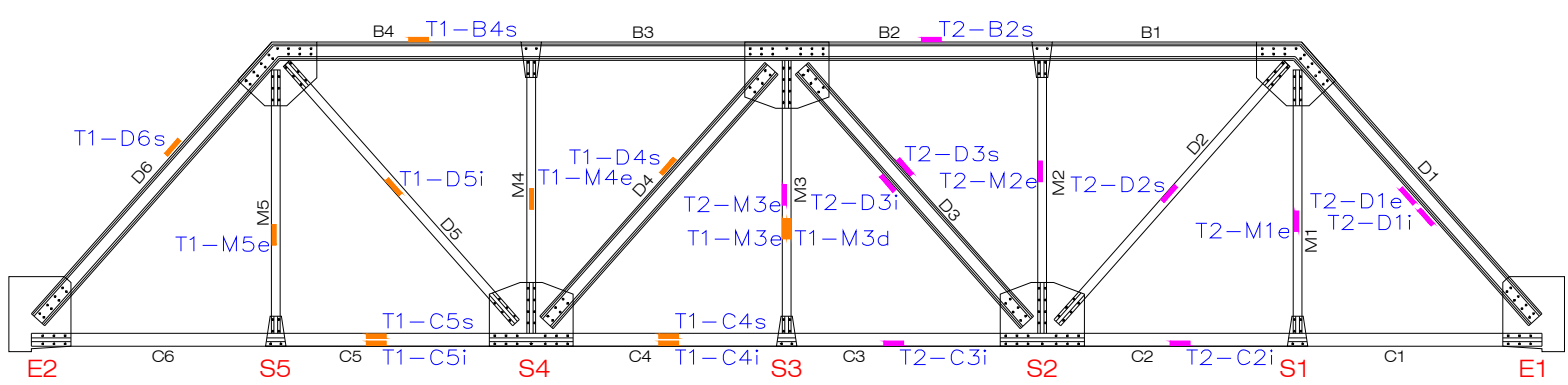

Figura 4.8 - Extensômetros instalados na treliça 1 e 2. 


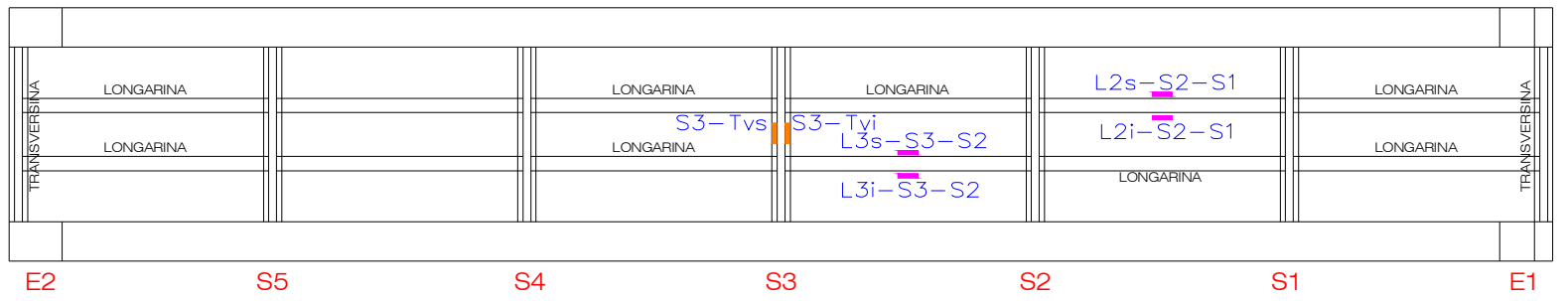

Figura 4.9 - Extensômetros instalados nas longarinas e transversinas.

\subsubsection{Medição de deslocamentos verticais}

A medição dos deslocamentos verticais foi realizada utilizando transdutores indutivos de deslocamentos (LVDT), os quais foram colocados no meio do vão do modelo apoiados sobre uma base de suporte magnética e esta, por sua vez, na viga baixa do pórtico de ensaios (figura 4.10a). Na tabela 4.9 são apresentadas as características técnicas dos transdutores utilizados.

Tabela 4.9 - Especificações técnicas dos LVDT's.

\begin{tabular}{ll}
\hline Características & Especificação \\
\hline Modelo & WI/10mm - T \\
Gama de Medição & $0-10 \mathrm{~mm}$ \\
Linearidade & $0,10 \% \mathrm{RO}$ \\
Sensibilidade & $100 \times 10-6 / \mathrm{mm}$ \\
Tensão de excitação recomendada & $5,0 \mathrm{~V}$ \\
Temperatura de funcionamento & $23^{\circ} \mathrm{C}$ \\
Coeficiente de Calibração & $1,03 \mathrm{~mm} / \mathrm{V}$ \\
\hline
\end{tabular}

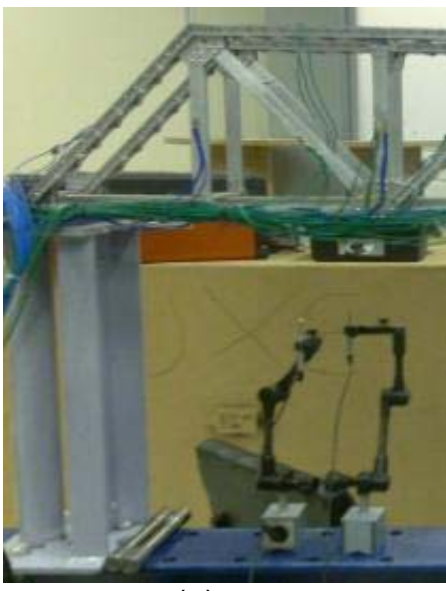

(a)

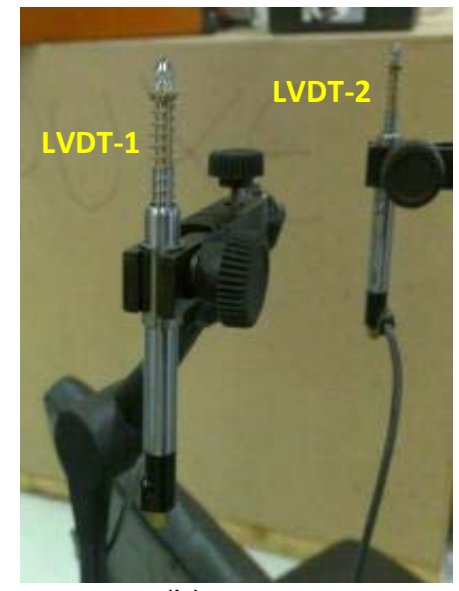

(b)

Figura 4.10 - (a) Transdutores de medição instalados no modelo, (b) LDVT sendo suportado pela base magnética. 
$\mathrm{Na}$ figura 4.11, apresenta-se o esquema da localização dos dois transdutores instalados no vão da ponte.

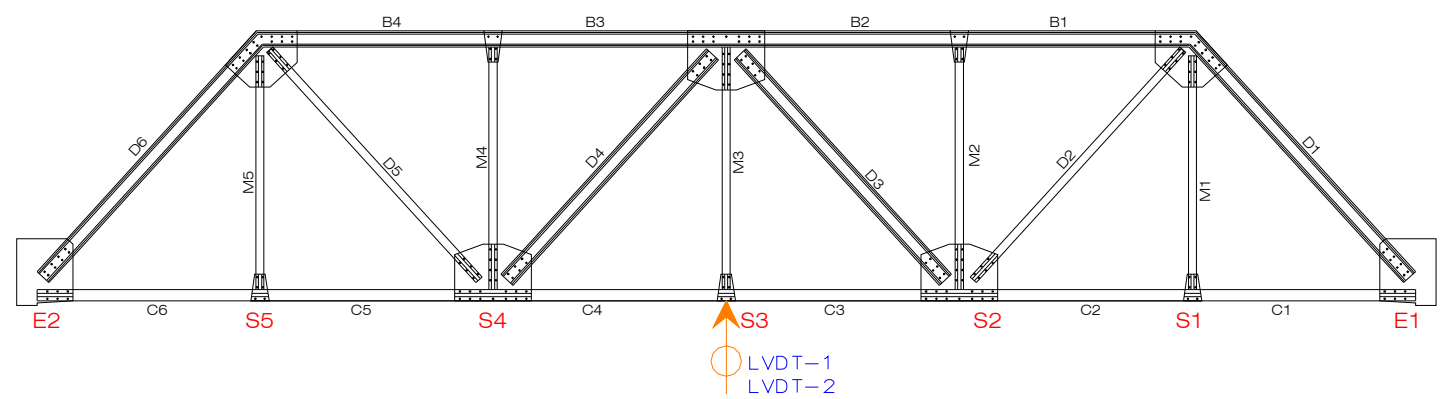

Figura 4.11 - Localização dos transdutores de deslocamento na treliça T1 e T2.

\subsubsection{Sistema de aquisição}

O sistema de aquisição que foi empregado na monitoração do modelo é o SCXI da National Instruments a qual se mostra na figura 4.12(a). Esse sistema realiza processamentos de dados em tempo real, bem como disponibiliza uma vasta gama de módulos I/O (analógicos e digitais) em um pacote extremamente robusto. É ideal para a obtenção de requisitos de controle em alta velocidade, usando protocolos digitais personalizados e sistemas de monitoração em ambientes agressivos. O hardware SCXI fornece opções ilimitadas de temporização, programação de eventos, sincronização e processamento de sinais dos sensores. A forma de funcionamento do sistema de aquisição foi descrito com maior detalhe no capitulo 2, item 2.6.2.

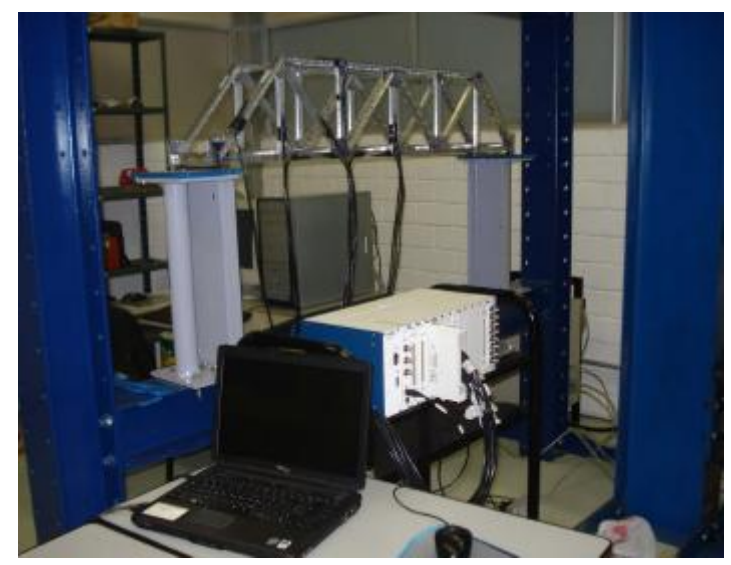

(a)

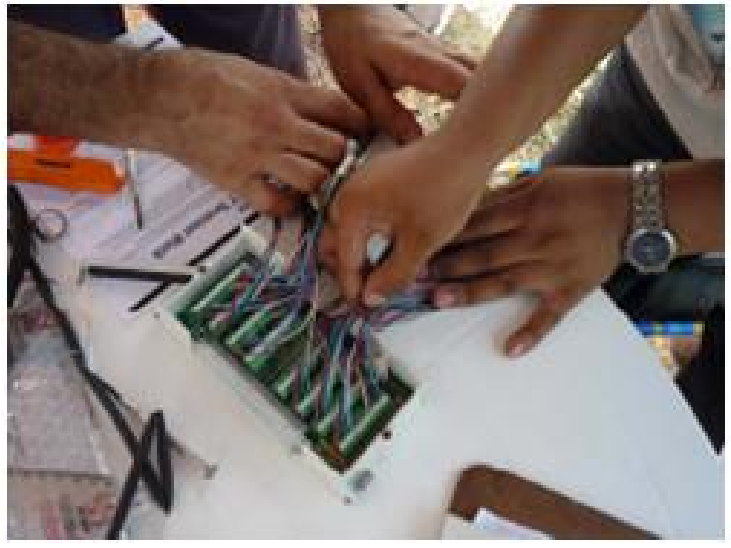

(b)

Figura 4.12 - (a) Sistema de aquisição da National Instruments da linha SCXI, (b) Instalação de fios no módulo SCXI 1317. 
O sistema SCXI que foi empregado na monitoração é composto pelos seguintes módulos: NI SCXI 1001 (chassis com 12 slots); NI SCXI 1125 e SCXI 1320 (placa para aquisição de sinal analógico programado por voltagem); NI SCXI 1520 e NI SCXI 1314 (placa para aquisição de extensômetros em ponte completa) e NI SCXI 1521B e SCXI 1317 (placa para aquisição de extensômetros em quarto de ponte).

A fim de ter o controle da aquisição e armazenamento de dados por meio dos equipamentos de monitoração, o autor desenvolveu um programa computacional no LabVIEW. O sistema integralmente desenvolvido é apresentado na figura 4.13 e é composto por quatro ambientes que são detalhados a seguir:

i. O primeiro ambiente apresenta a deformada da estrutura em tempo real. Os deslocamentos experimentais dos nós foram calculados usando conceitos de análise matricial de estrutura (método das rigidezes). Na figura 4.16 e 4.17 apresenta-se parte do código gráfico de programação gerado no LabVIEW que permite mostrar a deformada da estrutura.

ii. O segundo ambiente permite controlar parâmetros como: a taxa de amostragem, a frequência de aquisição e a escala de apresentação da deformada do modelo, já que a maioria das vezes os deslocamentos experimentais são tão pequenos que em escala real são difíceis de perceber.

iii. O terceiro ambiente permite controlar o armazenamento de dados no disco rígido do computador, estabelecendo claramente a localização das pastas e controla o funcionamento geral do programa. Na figura 4.15 apresenta-se o código principal do programa que trabalha juntamente com VIs desenvolvidos para o cálculo e desenho da deformada.

iv. O último ambiente consta de cinco abas. A primeira aba apresenta a leitura em tempo real das deformações e deslocamentos lidos no extensômetros e nos LVDTs. (figura 4.13). A segunda aba (figura 4.14) apresenta os dados experimentais calculados na estrutura tais como: força nas barras e deslocamento nos nós. As forças e os deslocamentos foram calculados a partir de dados experimentais lidos pelos extensômetros e as propriedades físicas e geometrias do material. A terceira aba apresenta os cálculos para 
determinar as frequências naturais do modelo a partir das leituras fornecidas pelos acelerômetros. A quarta e quinta aba permitem fazer leitura de arquivos *.txt, mostrá-los e manipula-os graficamente.

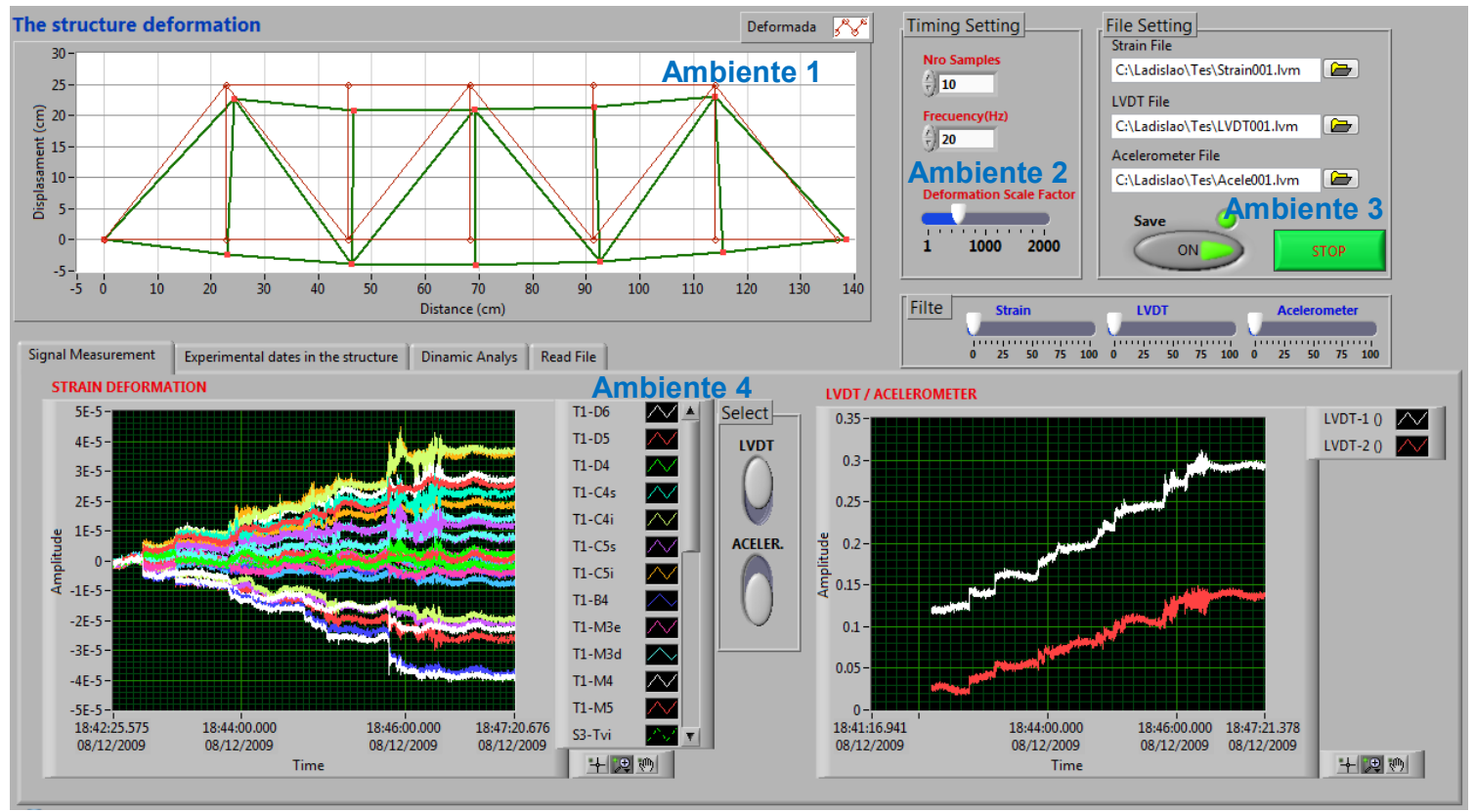

Figura 4.13 - Módulo para controle da aquisição de dados(medição de deformações e deslocamentos).

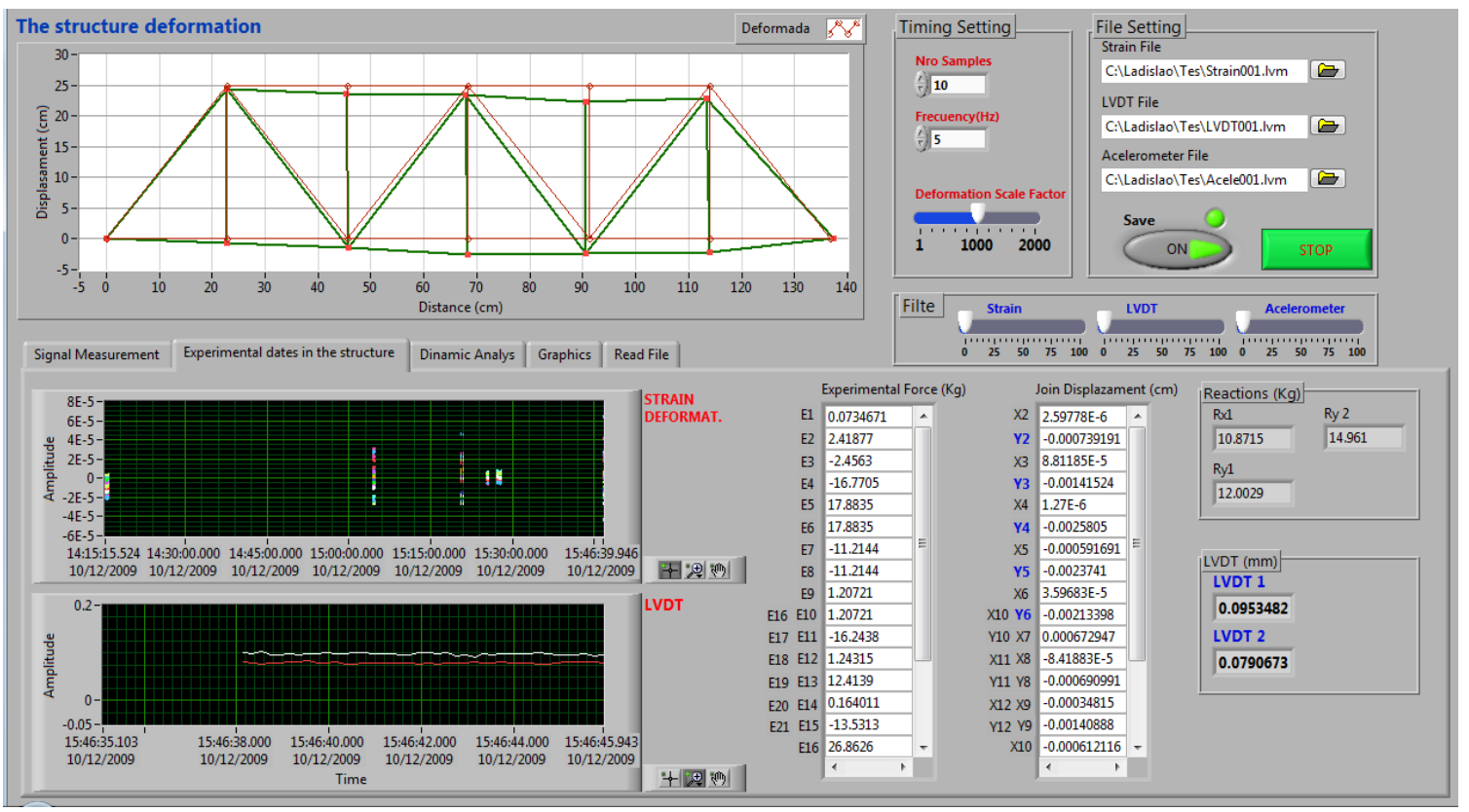

Figura 4.14 - Módulo para controle da aquisição de dados (Dados experimentais: força e deslocamentos). 


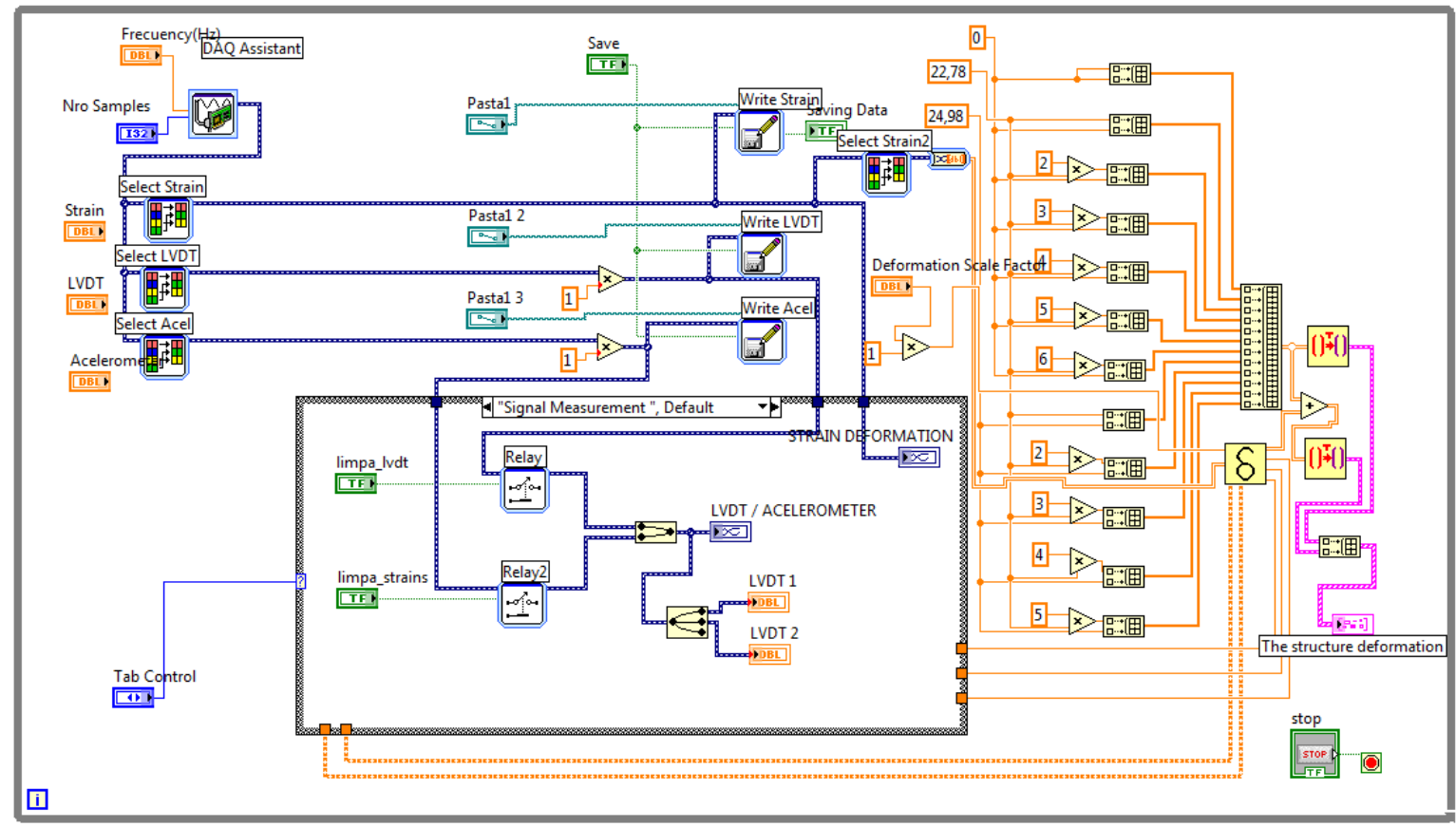

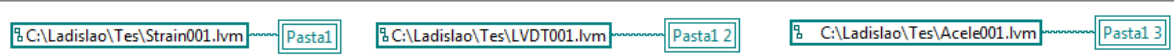

Figura 4.15 - Principal código gráfico gerado no LabVIEW para o controle da aquisição de dados.

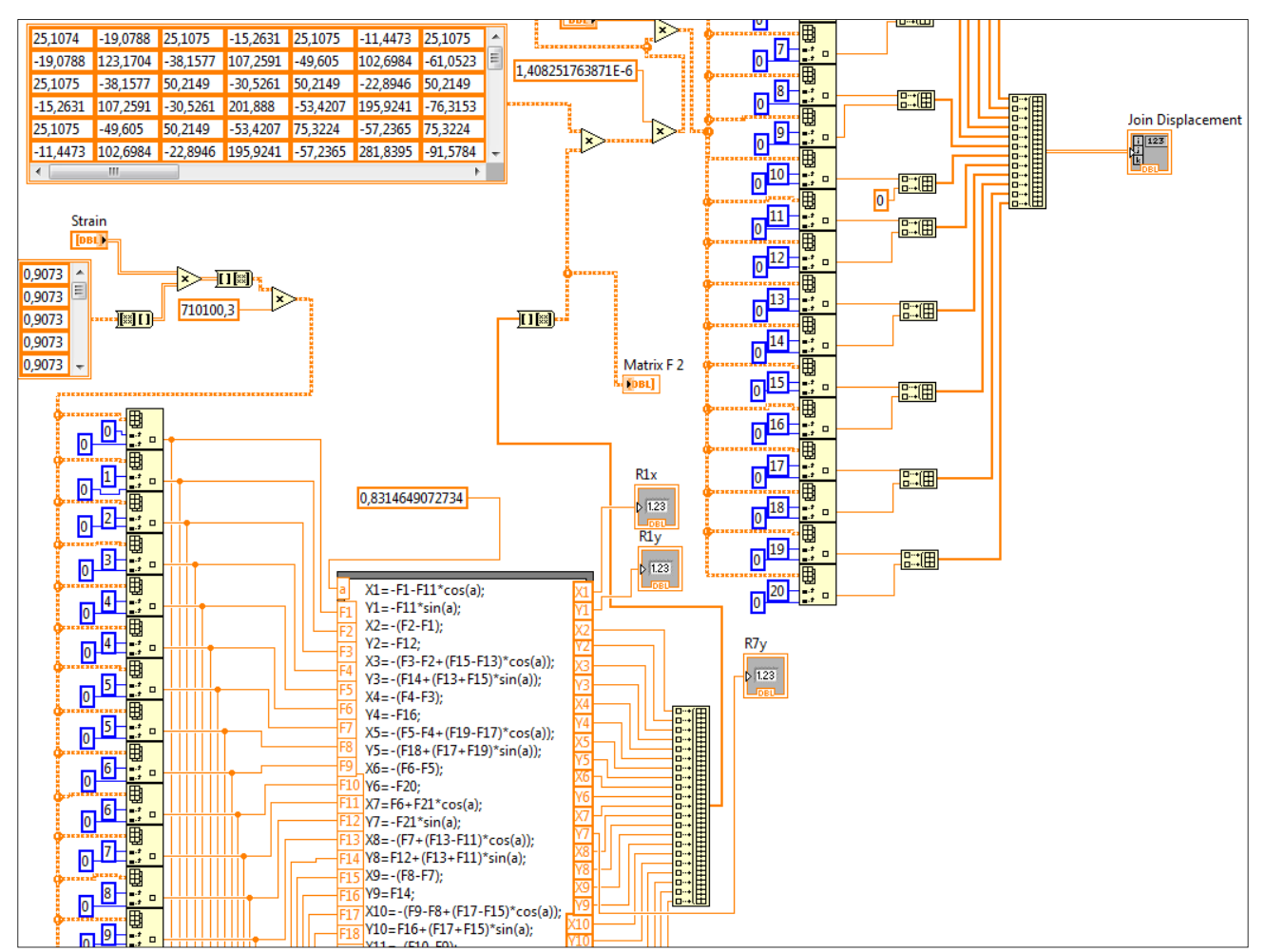

Figura 4.16 - Código gráfico do VI para calcular os deslocamentos usando o método das rigidezes. 


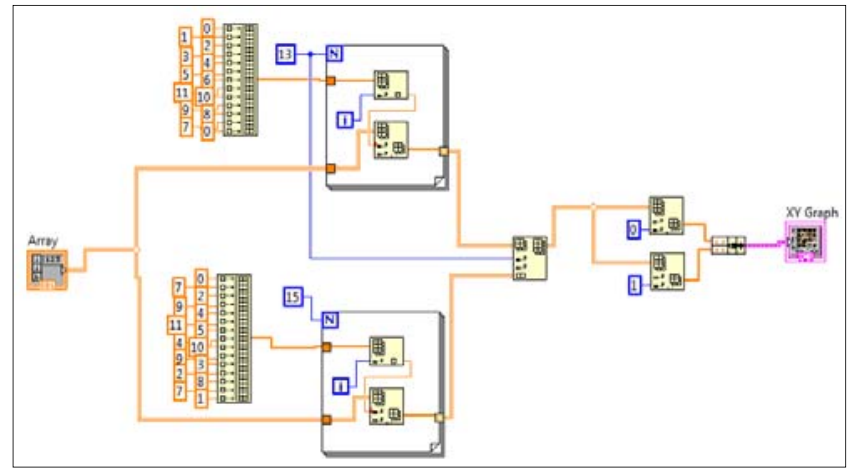

Figura 4.17 - Código gráfico do VI para desenhar a geometria da deformada da estrutura.

\subsubsection{Ensaios de carga no modelo reduzido}

O sistema de carregamento aplicado ao modelo reduzido foi confeccionado no laboratório e é composto por: uma base de suporte metálico suspenso em quatro cordas e pesos sobrepostos de forma circular de aproximadamente $27 \mathrm{~N}$, tal como se mostra na figura 4.18(a). O peso aplicado ao longo das seções do modelo foi arbitrário, pois o que se procurava era apenas uma resposta estrutural para poder monitorá-lo. Na figura 4.18(b) apresenta-se um exemplo de aplicação de carga.

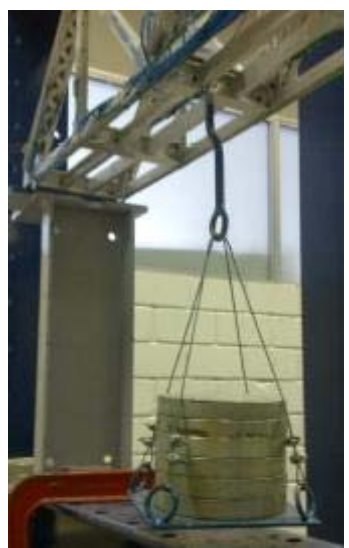

(a)

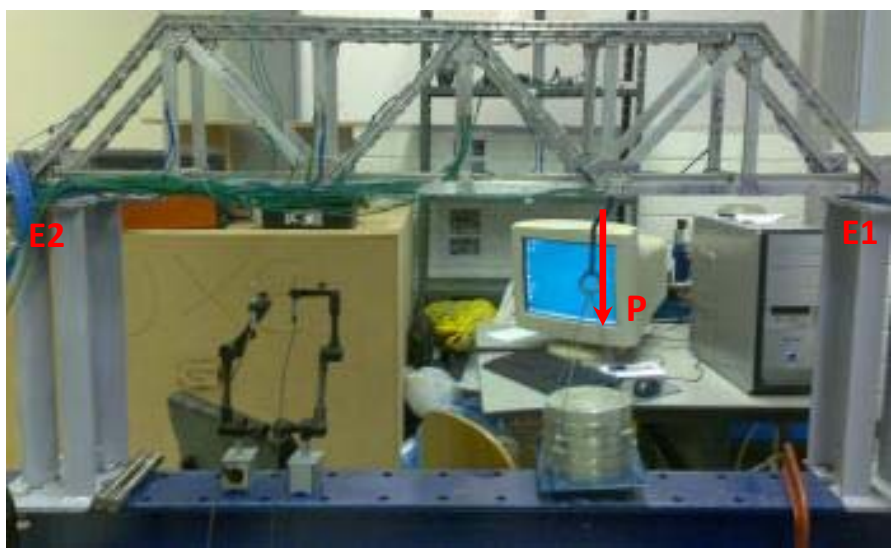

(b)

Figura 4.18 - (a) Sistema de carregamento, (b) Aplicação da carga no modelo.

Assim, a fim de estudar o comportamento da estrutura foram definidos três casos de carga, que são detalhados a seguir.

\section{CASO I: Carga incremental}

O estudo inicial realizado no modelo reduzido foi verificar o comportamento linear da estrutura. Para isso, o modelo foi submetido a cargas que foram 
incrementadas gradualmente com a finalidade de ter controle das deformações e deslocamentos e verificar o comportamento real da estrutura. Os deslocamentos foram medidos por dois LVDT's e as deformações por extensômetros. A carga foi incrementada cada $54 \mathrm{~N}(\Delta \mathrm{P})$ até atingir um peso final de 347,5 N. Essas cargas foram aplicadas nas seções S2 e S4 do modelo, tal como se ilustra na figura 4.19.

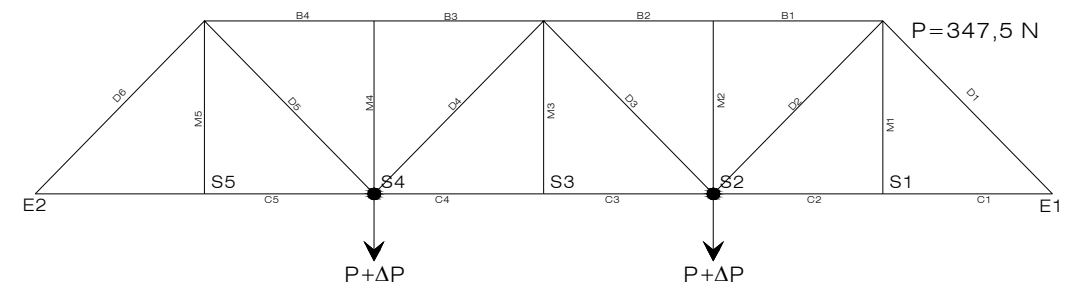

Figura 4.19 - Esquema para verificar o comportamento linear do modelo.

\section{CASO II: Carga móvel}

A carga aplicada durante este ensaio não foi precisamente móvel. $\mathrm{Na}$ realidade, a carga foi deslocada manualmente ao longo da estrutura tal como se ilustra na figura 4.20. Este estudo tem como finalidade visualizar o comportamento dos elementos estruturais para cada posição de carga. O peso considerado para este ensaio foi de $417,5 \mathrm{~N}$.
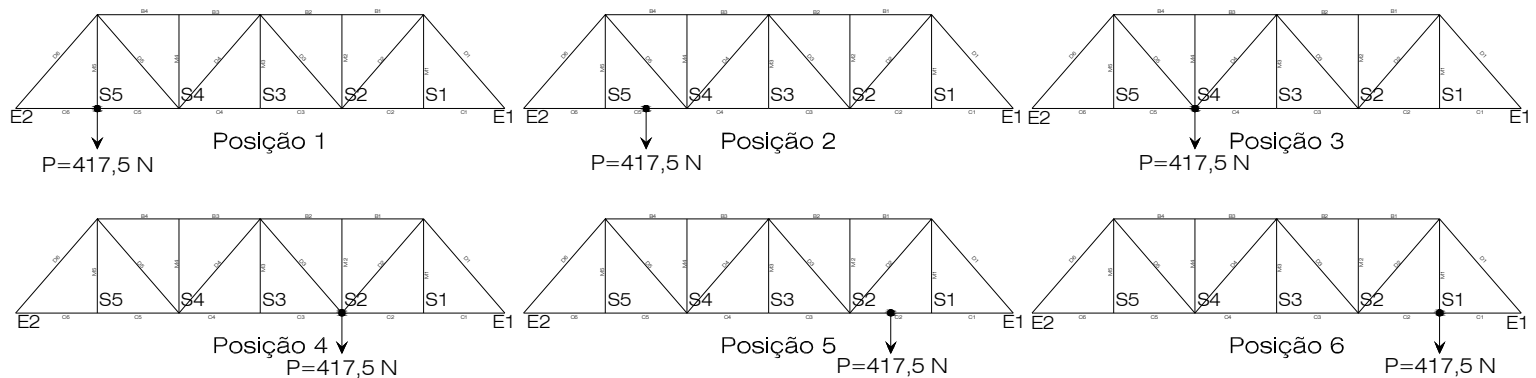

Figura 4.20 - Posicionamento da carga nas diferentes seções do modelo.

\section{CASO III: Carregamentos simétricos}

A finalidade deste estudo é verificar se o modelo físico tem comportamento simétrico, para cargas aplicadas em posições onde teoricamente a resposta da estrutura deveria ser simétrica conforme se mostra na figura 4.21. Primeiramente a carga $P=374,5 \mathrm{~N}$. foi aplicada na seção S1 e S5 e logo na seção S2 e S4. Para 
cada posição de carga procedeu-se com a leitura das deformações e deslocamentos para sua posterior análise.
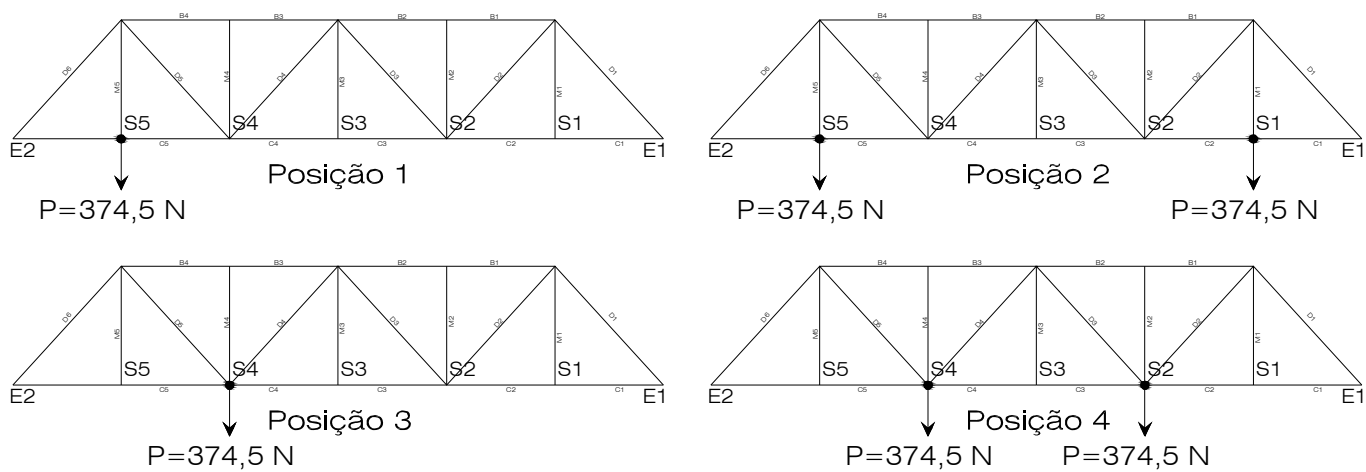

Figura 4.21 - Sequência dos posicionamentos de carga no modelo.

\subsubsection{Resultados da medição}

Nesta seção são apresentados os resultados mais significativos da medição efetuada no modelo durante os ensaios experimentais. As principais grandezas medidas foram as deformações e os deslocamentos.

A convenção de sinais adotada é a seguinte:

- Deformação negativa - encurtamento.

- Deformação positiva - alongamento.

- Deslocamento negativo - deslocamento vertical ascendente.

- Deslocamento positivo - deslocamento vertical descendente.

\subsubsection{Deformações}

As deformações foram medidas pelos extensômetros instalados nos diferentes elementos estruturais do modelo e o processamento de dados foi executado com ajuda do programa DIAdem, pois ele oferece muitas ferramentas de tratamento de dados experimentais.

A seguir apresentam-se os gráficos de tempo-deformação dos dados experimentais para cada estudo de caso.

Caso I: A medição das deformações para cada incremento de carga é apresentado pela figura 4.22, onde se observa que as deformações nos elementos estruturais aumentam na medida em que a carga cresce. 


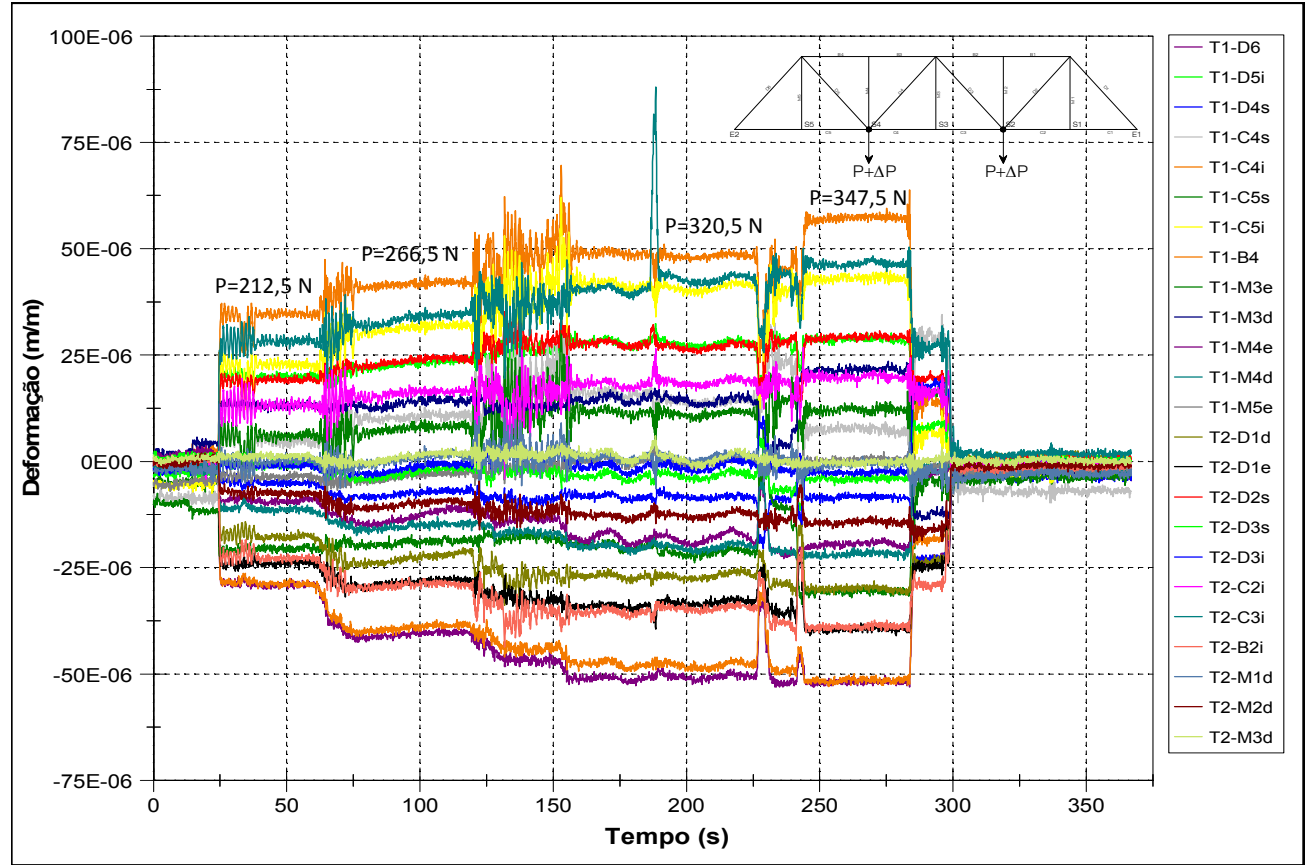

Figura 4.22 - Deformações nos extensômetros para o estudo do caso I.

Caso II: A figura 4.23 apresenta as deformações medidas durante as seis posições de carga. Em cada uma das posições de carga, percebe-se a variação das deformações dos elementos estruturais do modelo.

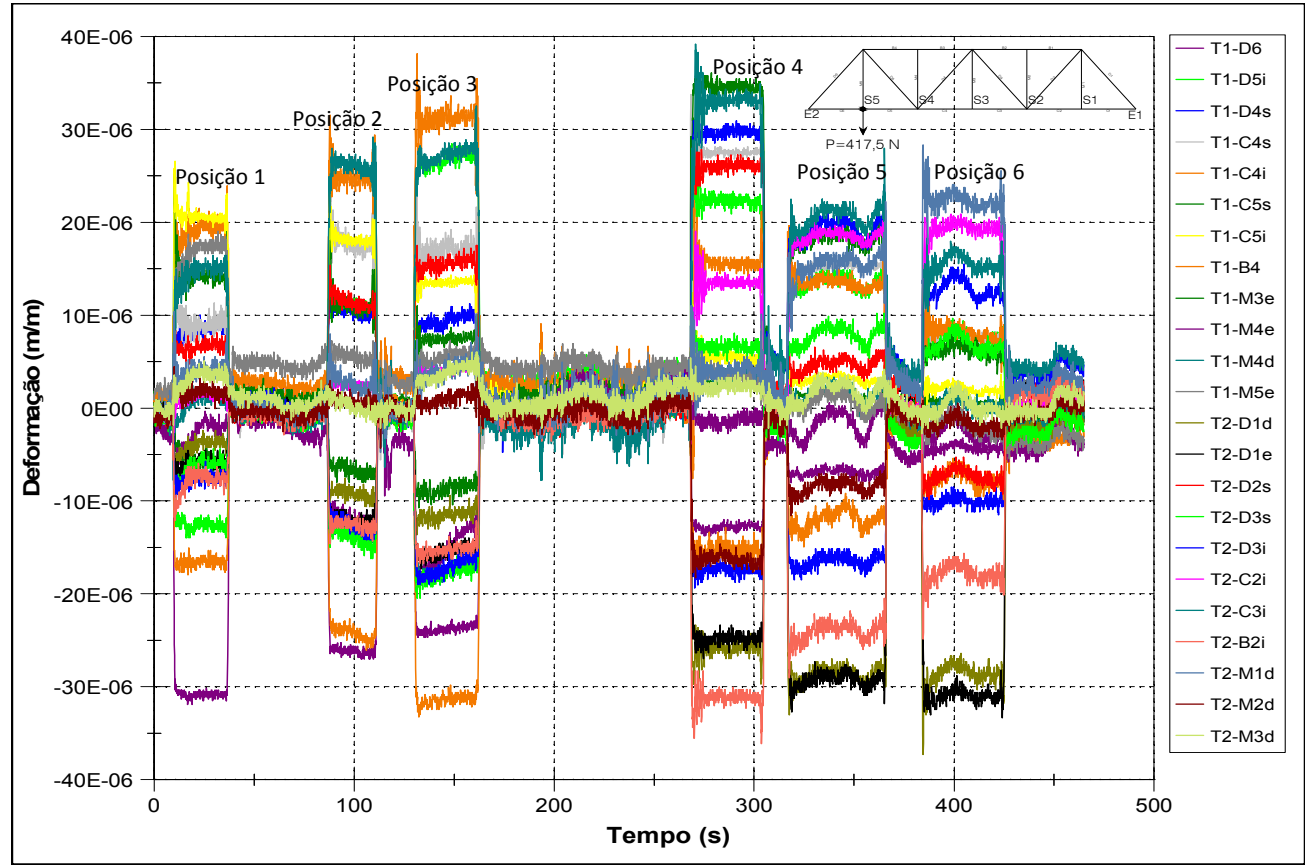

Figura 4.23 - Deformações nos extensômetros para o estudo do caso II. 
Caso III: O modelo foi carregado em quatro posições conforme se ilustra na figura 4.24, onde se percebe que a estrutura é mais solicitada quando o carregamento é locado na seção S2 e S4.

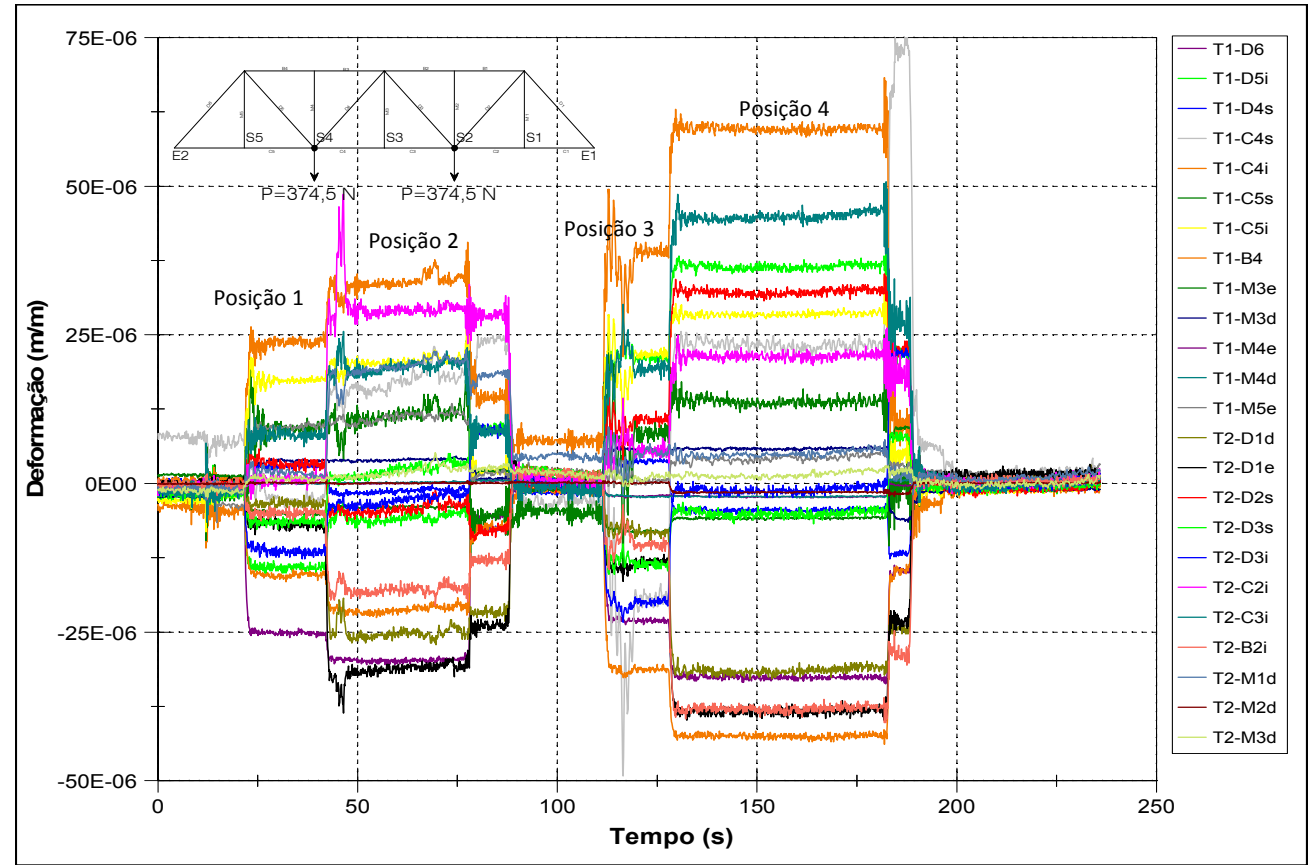

Figura 4.24 - Deformações nos extensômetros para o estudo do caso III.

\subsubsection{Deslocamentos verticais}

Os mais expressivos valores de deslocamento verticais ocorreram no meio do vão do modelo, para as diversas solicitações de carga. A seguir mostram-se a evolução dos deslocamentos em função do tempo de duração do ensaio e a carga.

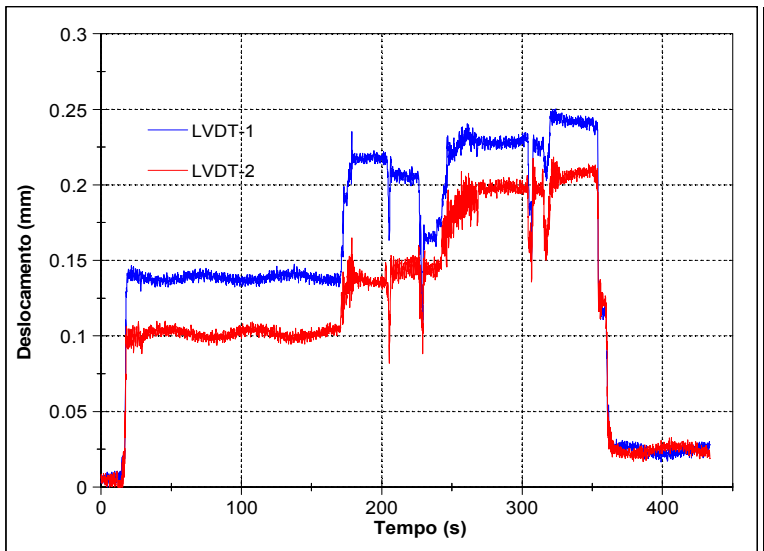

(a)

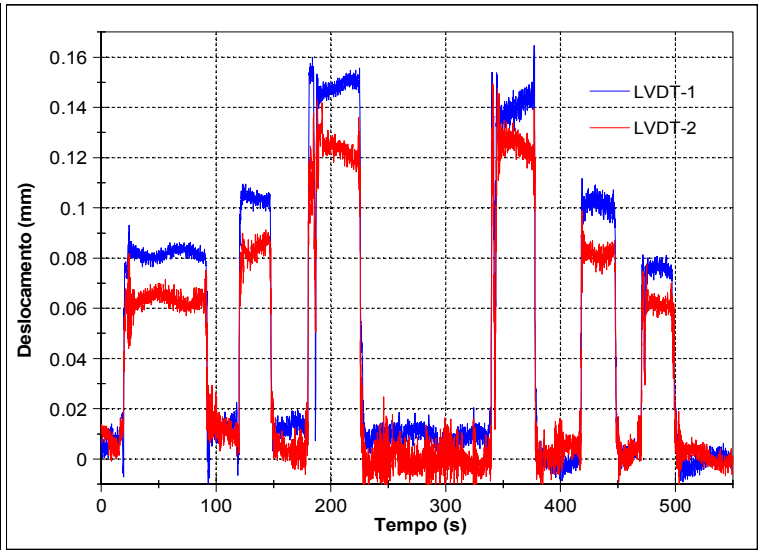

(b)

Figura 4.25 - Deslocamento medidos nos LVDT's: (a) Estudo de caso I, (b) Estudo de caso II. 


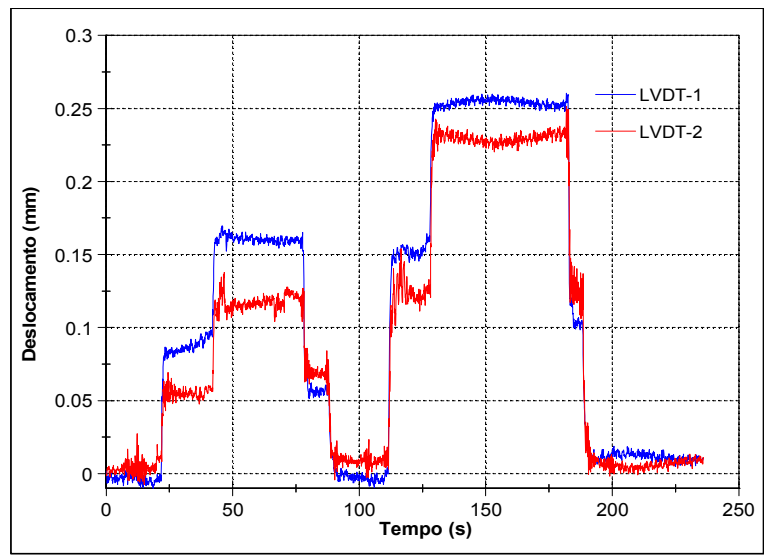

Figura 4.26 - Deslocamento medidos nos LVDT's para o estudo de caso III.

$\mathrm{Na}$ figura 4.25 e 4.26 apresentam-se os deslocamentos medidos pelos LVDT's instalados nas treliças do modelo reduzido durante o ensaio dos três estudos de caso.

\subsubsection{Análise de resultados e discussões}

As deformações e deslocamentos obtidos durante os ensaios experimentais foram para cargas locadas em posições especificas de forma manual. Portanto, a fim de fazer a análise e comparação com os modelos teóricos, estes também foram modelados de acordo com cada posição. Assim, os resultados experimentais serviram de base para comparar e calibrar o modelo teórico.

\subsubsection{Comparação carga vs. deslocamento}

A curva de carga-deslocamento experimental mostrada na figura 4.28 foi construída a partir das medições ilustradas na figura 4.25(a) para cada um das quatro solicitações de carga. Assim, por exemplo, para a carga máxima de 347,5 N se obteve uma deflexão no meio do vão de 0,2254 $\mathrm{mm}$. Esse valor experimental foi calculado como média das leituras efetuadas pelos dois LVDT's instalados nas treliças.

A modelagem numérica do modelo físico foi desenvolvida no programa SAP2000, cujas propriedades geométricas e do material foram adotadas dos ensaios de caracterização detalhados no anexo B. 
Inicialmente a modelagem da ponte em escala reduzida foi feita somente com elementos de barra em 2D e a ligação entre elas foi considerado como se fosse pórtico com comportamento elástico-linear do material, tal como se mostra na figura $4.27(a)$.
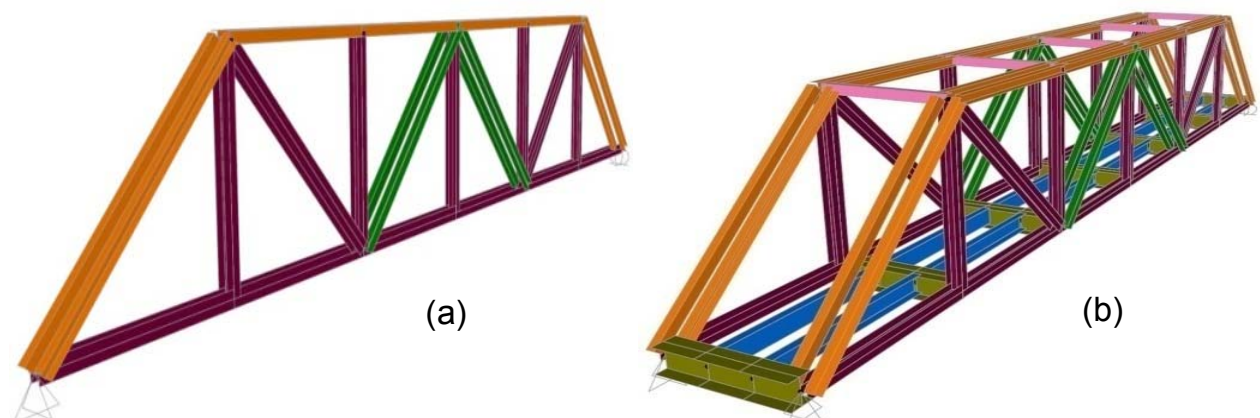

Figura 4.27 - Modelo numérico de barras: (a) em 2D, (b) em 3D.

Os resultados obtidos dessa modelagem mostram que o modelo numérico comporta-se muito rígido em relação ao modelo real, assim o deslocamento obtido para a carga máxima aplicada foi de $0,112 \mathrm{~mm}$, quase a metade do deslocamento experimental. Essa diferença considerável entre os resultados numéricos e experimentais motivou a calibração do modelo teórico, pois o modelo teórico não estava conseguindo representar adequadamente o comportamento do modelo real. Para isso, desenvolveram-se três modelos numéricos adicionais de onde se levou em conta a contribuição das transversinas e a ligação dos nós foi representada por elementos finitos, conforme se mostra na figura 4.29.

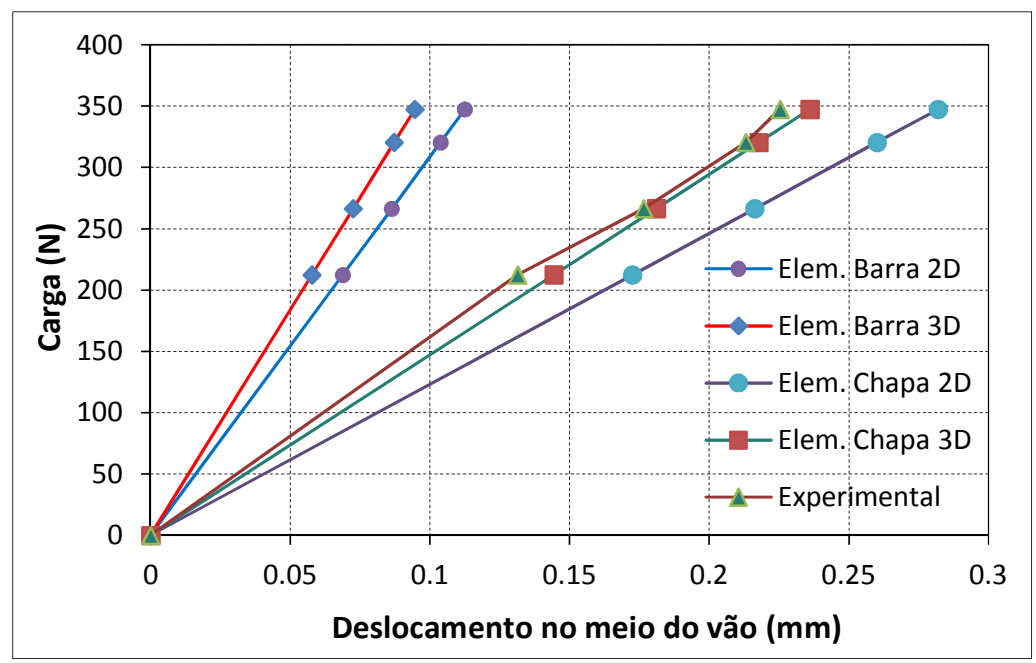

Figura 4.28 - Curvas de carga-deslocamento do modelo para o estudo do caso I. 
O segundo modelo foi desenvolvido espacialmente com as mesmas características que o modelo inicial e considerando todos os elementos da estrutura. O deslocamento obtido para a carga máxima foi de $0,095 \mathrm{~mm}$ muito menor que o modelo real e do modelo em 2D. Essa diminuição do deslocamento pode-se atribuir à contribuição das longarinas e transversinas ao acrescentar a rigidez da estrutura.

Assim, a elevada rigidez dos modelos teóricos iniciais pode ser devido às ligações das barras como pórticos e que não estão sendo apropriadamente representadas, pois o modelo real mostra-se muito menos rígido e os nós estão compostos por chapas. A fim de simular melhor as ligações entre barras, os nós foram representados por elementos finitos, os quais mostraram resultados muito mais próximos ao real.

Na figura 4.29 apresenta-se dois modelos numéricos composto por barras e elementos finitos para os nós de encontro em 2D e 3D. No cálculo do modelo em 2D se obteve um deslocamento de $0,282 \mathrm{~mm}$ para a carga máxima de solicitação, um pouco maior que o resultado experimental, enquanto que no modelo em $3 \mathrm{D}$ se obteve um deslocamento de $0,236 \mathrm{~mm}$ com desvio relativo de $4.75 \%$ em relação ao deslocamento experimental. Desses resultados pode-se concluir que os elementos finitos representaram melhor as ligações dos nós do modelo reduzido e conseguiu-se calibrar o modelo teórico para posteriores análises.
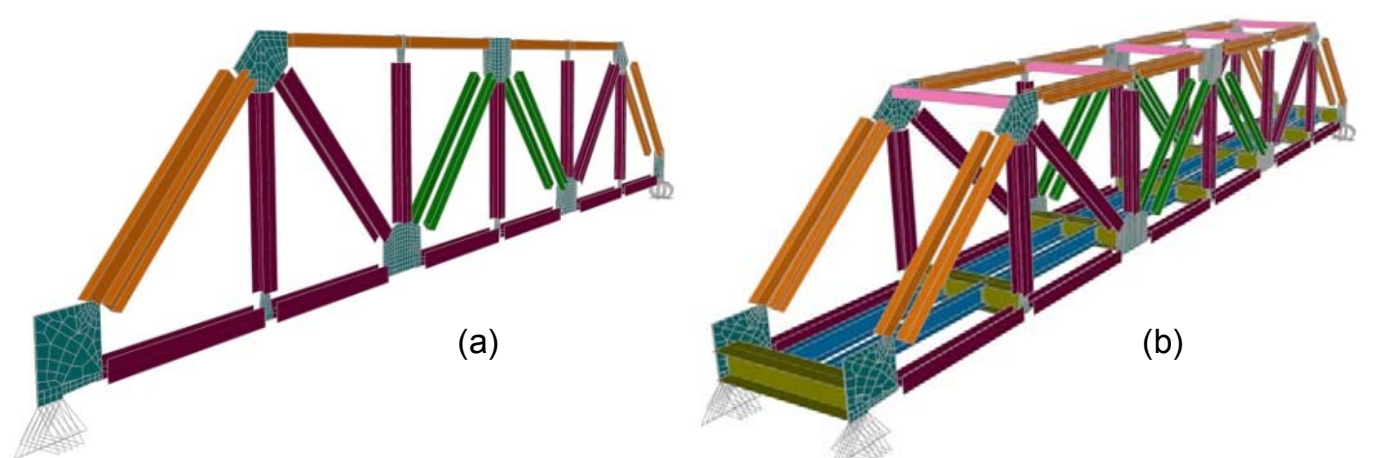

Figura 4.29 - Modelo numérico de barras e elementos finitos: (a) em 2D, (b) em 3D.

Na figura 4.28 apresenta-se a comparação da curva experimental com as diversas curvas teóricas, onde se percebe que o modelo numérico simulado com barras e elementos finitos em 3D teve melhor aproximação ao modelo real. 
Da mesma forma foram determinados os deslocamentos experimentais para os casos de estudo II e III a partir dos dados experimentais apresentados na figura 4.25 (b) e 4.26, onde se confirma que o modelo espacial desenvolvido com elementos de barra e elementos finitos tem melhor aproximação em relação aos dados experimentais, tal como se mostra no gráfico comparativo da figura 4.30 e 4.31 .

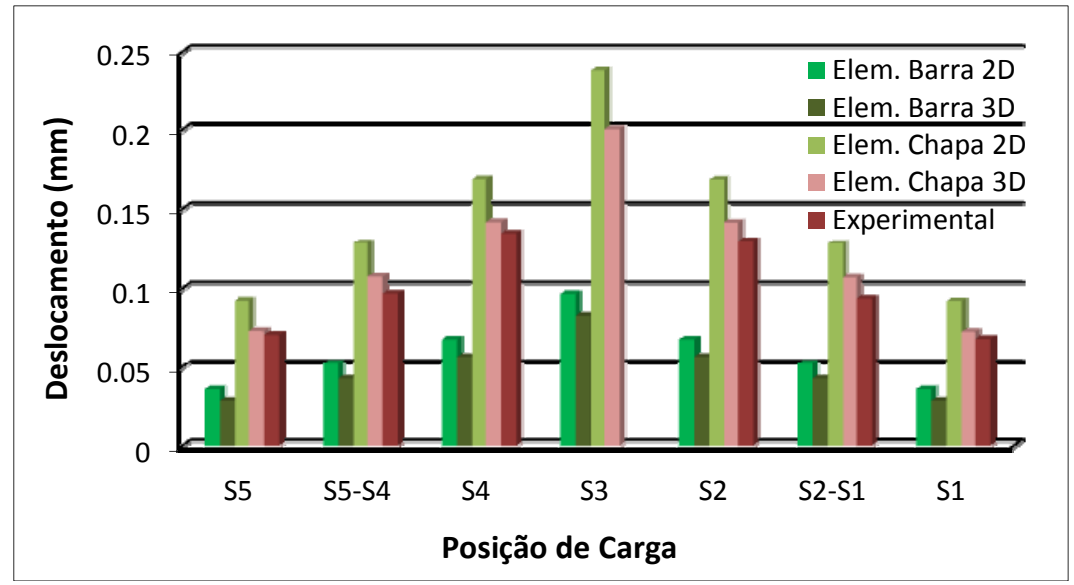

Figura 4.30 - Comparação dos deslocamentos teóricos e experimentais obtidos no meio do vão para o estudo do caso II.

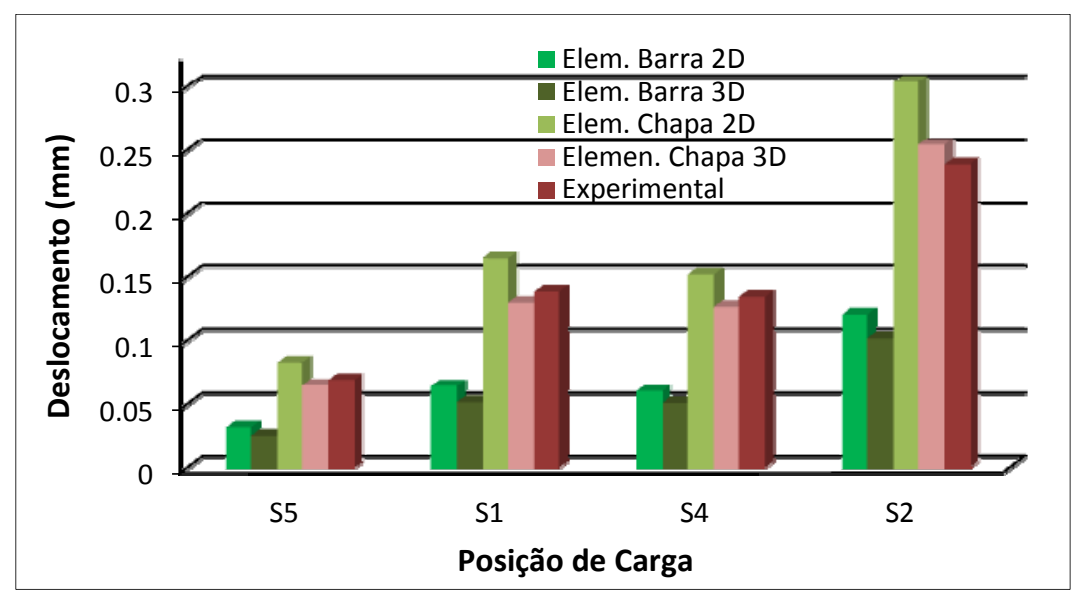

Figura 4.31 - Comparação dos deslocamentos teóricos e experimentais obtidos no meio do vão para o estudo do caso III.

\subsubsection{Análise das deformações}

Os dados experimentais apresentados nas figuras 4.22 a 4.24 permitiram obter as deformações de cada um dos elementos estruturais do modelo reduzido para as diferentes solicitações de carga. 
Devido à quantidade de informação obtida nos ensaios experimentais a análise das deformações foi feita para a condição de carga onde se apresentou a maior solicitação nos elementos estruturais. Essa maior solicitação apresentou-se no estudo do caso III, posição de carga 4.

As deformações experimentais selecionados foram comparadas com os resultados obtidos do modelo numérico - calibrado na etapa de análise dos deslocamentos - as quais são apresentados na tabela 4.10, onde a deformação teórica foi calculada a partir da força atuante $F$, a área da seção transversal $A$ e o módulo de elasticidade do material $E$ de cada barra, aplicando a seguinte equação $\varepsilon=F / E A$.

Tabela 4.10 - Deformações teóricos e experimentais nos elementos estruturais do modelo reduzido.

\begin{tabular}{crrrrrr}
\hline $\begin{array}{c}\text { Nome da } \\
\text { Barra }\end{array}$ & \multicolumn{1}{c}{$\begin{array}{c}\text { Força } \\
(\mathbf{N})\end{array}$} & $\begin{array}{c}\text { Área } \\
\left(\mathbf{m m}^{2}\right)\end{array}$ & $\begin{array}{c}\mathbf{E} \\
\left(\mathbf{N} / \mathbf{m m}^{2}\right)\end{array}$ & $\begin{array}{c}\text { Teórico } \\
(\mu \varepsilon)\end{array}$ & $\begin{array}{c}\text { Experim. } \\
(\mu \varepsilon)\end{array}$ & $\begin{array}{c}\text { Erro } \\
\%\end{array}$ \\
\hline T1-C6 & 61,30 & 90,73 & 65120 & 10,376 & & \\
T1-C5 & 58,90 & 90,73 & 65120 & 9,969 & 20,91 & 52,32 \\
T1-C4 & 219,30 & 90,73 & 65120 & 37,119 & 41,09 & 9,66 \\
T2-C3 & 219,40 & 90,73 & 65120 & 37,136 & 44,36 & 16,29 \\
T2-C2 & 58,90 & 90,73 & 65120 & 9,969 & 21,93 & 54,54 \\
T2-C1 & 61,40 & 90,73 & 65120 & 10,393 & & \\
T1-B4 & $-341,60$ & 113,44 & 65120 & $-46,242$ & $-42,31$ & $-9,29$ \\
T1-B3 & $-341,80$ & 113,44 & 65120 & $-46,269$ & & \\
T2-B2 & $-341,70$ & 113,44 & 65120 & $-46,256$ & $-38,43$ & $-20,36$ \\
T2-B1 & $-341,60$ & 113,44 & 65120 & $-46,242$ & & \\
T1-D6 & $-253,20$ & 113,44 & 65120 & $-34,275$ & $-32,50$ & $-5,46$ \\
T1-D5 & 253,60 & 90,73 & 65120 & 42,924 & 37,03 & $-15,92$ \\
T1-D4 & $-0,32$ & 99,83 & 65120 & $-0,049$ & $-4,40$ & 98,88 \\
T2-D3 & $-0,37$ & 99,83 & 65120 & $-0,058$ & $-1,05$ & 94,52 \\
T2-D2 & 253,70 & 90,73 & 65120 & 42,941 & 32,49 & $-32,17$ \\
T2-D1 & $-253,20$ & 113,44 & 65120 & $-34,275$ & $-34,87$ & 1,71 \\
T1-M5 & $-0,26$ & 90,73 & 65120 & $-0,043$ & 0,05 & 186,66 \\
T1-M4 & 0,17 & 90,73 & 65120 & 0,029 & $-2,25$ & 101,27 \\
T1-M3 & 0,25 & 90,73 & 65120 & 0,042 & 0,04 & $-5,36$ \\
T2-M2 & 0,17 & 90,73 & 65120 & 0,029 & $-1,48$ & 101,94 \\
T2-M1 & $-0,24$ & 90,73 & 65120 & $-0,040$ & 0,05 & 180,57 \\
\hline
\end{tabular}


O erro foi calculado da seguinte forma: $\operatorname{Erro}(\%)=\left(\frac{\varepsilon_{\exp }-\varepsilon_{\text {teor. }}}{\varepsilon_{\exp }}\right) \times 100$

As deformações experimentais nas cordas C2 a C5 mostraram-se relativamente maiores que o calculado teoricamente. Essa diferença pode ser atribuída ao fato que o modelo teórico não conseguiu representar apropriadamente as cordas, pois na realidade a seções dessas barras é composição de dois perfis ligados entre si através de rebites. Por outro lado as deformações experimentais das barras do banzo superior B4 e B2 e as diagonais D1 a D6 tiveram melhor aproximação com o modelo teórico, tendo um desvio relativo de 5,46\% a 32,17\%.

Da mesma forma, ao analisar as deformações das montantes M1 a M5, percebe-se que para esta condição de carga essas não absorveram esforços, pois isso foi observado nas leituras experimentais assim como nos resultados teóricos, o qual indica que o modelo teórico prevê bem o comportamento real da estrutura e tem boa capacidade preditiva. As deformações experimentais desta análise para cada um dos elementos estruturais é mostrado com maior detalhe no anexo C.

$\mathrm{Na}$ figura 4.32 apresenta-se a comparação gráfica das deformações experimentais e teóricas de cada um dos elementos estruturais apresentados na tabela 4.10.

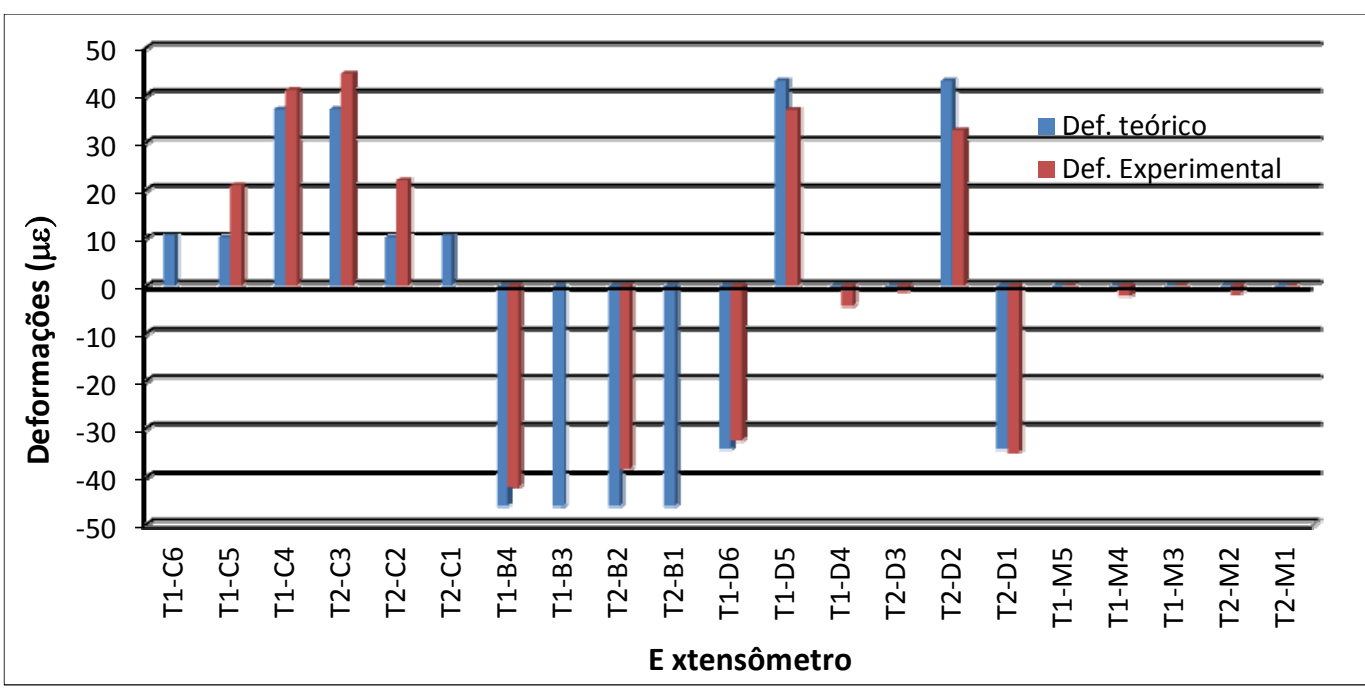

Figura 4.32 - Comparação de deformações teóricos e experimentais obtidos no nas barras para o estudo do caso III posição 4. 


\subsection{Monitoração da Ponte do Rio Suaçui}

Neste item apresenta-se um resumo das principais atividades envolvidas no planejamento, instrumentação e monitoração da Ponte do Rio Suaçui. Dando realce aos resultados experimentais obtidos nos ensaios de carga aos quais foi submetida a ponte, com a finalidade de usá-los mais a frente para a comparação com os resultados obtidos na monitoração do modelo reduzido.

A monitoração e instrumentação da estrutura real foi realizada pela equipe do Laboratório de Estruturas e Materiais (LEM), da Escola Politécnica da Universidade de São Paulo (EPUSP), com a participação do autor. A descrição detalhada da Monitoração da Ponte do Rio Suaçui consta no relatório final LEM - VALE 02-10 FUSP 1982, (BITTENCOURT, 2010).

\subsubsection{Medição das grandezas físicas}

$\mathrm{Na}$ observação do comportamento da Ponte durante a prova de carga procedeu-se à medição de três tipos de grandezas: deformações nos elementos estruturais, deslocamento vertical no meio do vão e acelerações em algumas seções da ponte.

A medição das deformações foi realizada utilizando extensômetros de resistência elétrica similares aos usados no modelo reduzido, os quais foram colados á superfície do aço devidamente preparados e protegidos. Na figura 4.33 apresentase o processo de instalação dos sensores na ponte pela equipe do LEM - USP.

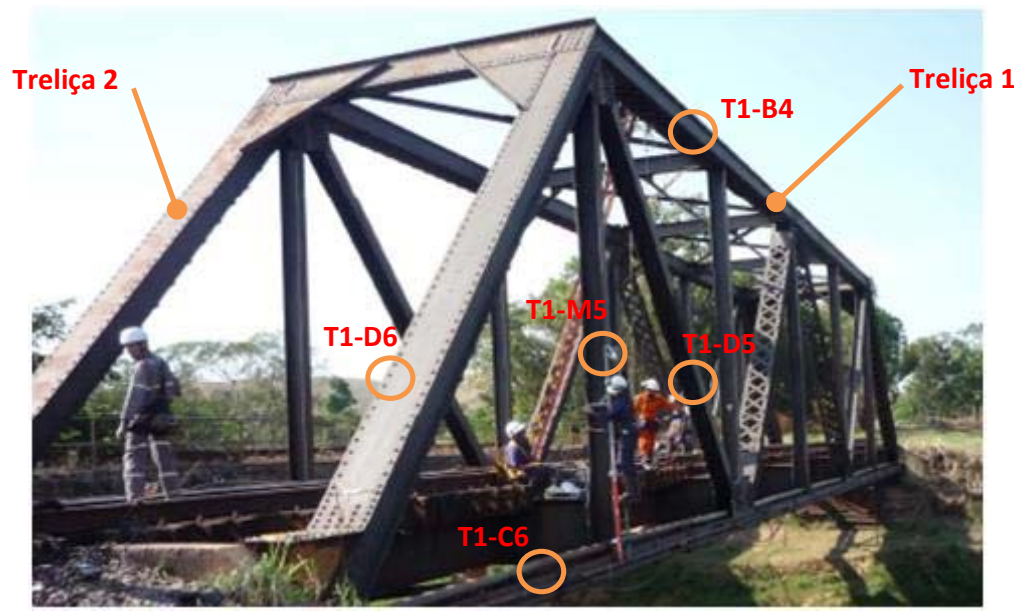

Figura 4.33 - Instalação de sensores na Ponte do Rio Suaçui. 
A tabela 4.11, apresenta a nomenclatura, localização e referencia de cada um dos extensômetros instalados na ponte.

\begin{tabular}{|c|c|c|c|}
\hline Elemento & & Localização & Referencia \\
\hline $\begin{array}{l}\text { D6 } \\
\text { D6 } \\
\text { D5 } \\
\text { C6 } \\
\text { C6 } \\
\text { B4 } \\
\text { B4 } \\
\text { M5 } \\
\text { M3 }\end{array}$ & 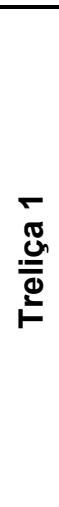 & 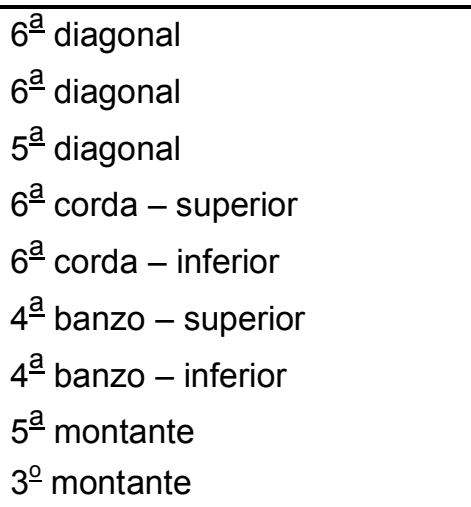 & $\begin{array}{l}\text { T1-D6s } \\
\text { T1-D6i } \\
\text { T1-D5a } \\
\text { T1-C6s } \\
\text { T1-C6i } \\
\text { T1-B4s } \\
\text { T1-B4i } \\
\text { T1-M51 } \\
\text { T1-M3a }\end{array}$ \\
\hline $\begin{array}{c}E 1 \\
\text { S1 } \\
\text { E1-S1 } \\
\text { E1-S1 } \\
\text { E1-S1 } \\
\text { E1-S1 } \\
\text { S1-S2 } \\
\text { S1-S2 } \\
\text { S1-S2 } \\
\text { S1-S2 }\end{array}$ & $\begin{array}{l}\frac{0}{\frac{0}{0}} \\
\frac{0}{5} \\
\frac{0}{\pi} \\
上\end{array}$ & $\begin{array}{l}\text { Enc. } 1^{\underline{a}} \text { transversina - inferior } \\
1^{\underline{a}} \text { transversina }- \text { inferior } \\
1^{\underline{a}} \text { longarina }- \text { superior } \\
1^{\underline{a}} \text { longarina - inferior } \\
2^{\underline{a}} \text { longarina - superior } \\
2^{\underline{a}} \text { longarina - inferior } \\
1^{\underline{a}} \text { longarina - superior } \\
1^{\underline{a}} \text { longarina - inferior } \\
2^{\underline{a}} \text { longarina - superior } \\
2^{\underline{a}} \text { longarina - inferior }\end{array}$ & $\begin{array}{l}\text { E1-Tvi } \\
\text { S1-Tvi } \\
\text { E1-S1-L1s } \\
\text { E1-S1-L1i } \\
\text { E1-S1-L2s } \\
\text { E1-S1-L2i } \\
\text { S1-S2-L1s } \\
\text { S1-S2-L1i } \\
\text { S1-S2-L2s } \\
\text { S1-S2-L2i }\end{array}$ \\
\hline
\end{tabular}

A medição dos deslocamentos verticais foi realizada utilizando transdutores indutivos de deslocamentos de $25 \mathrm{~mm}$, os quais foram colocados na seção S1 e S3 da ponte. Na figura 4.34, apresenta-se o esquema completo da localização dos extensomêtros e os LVDT's.

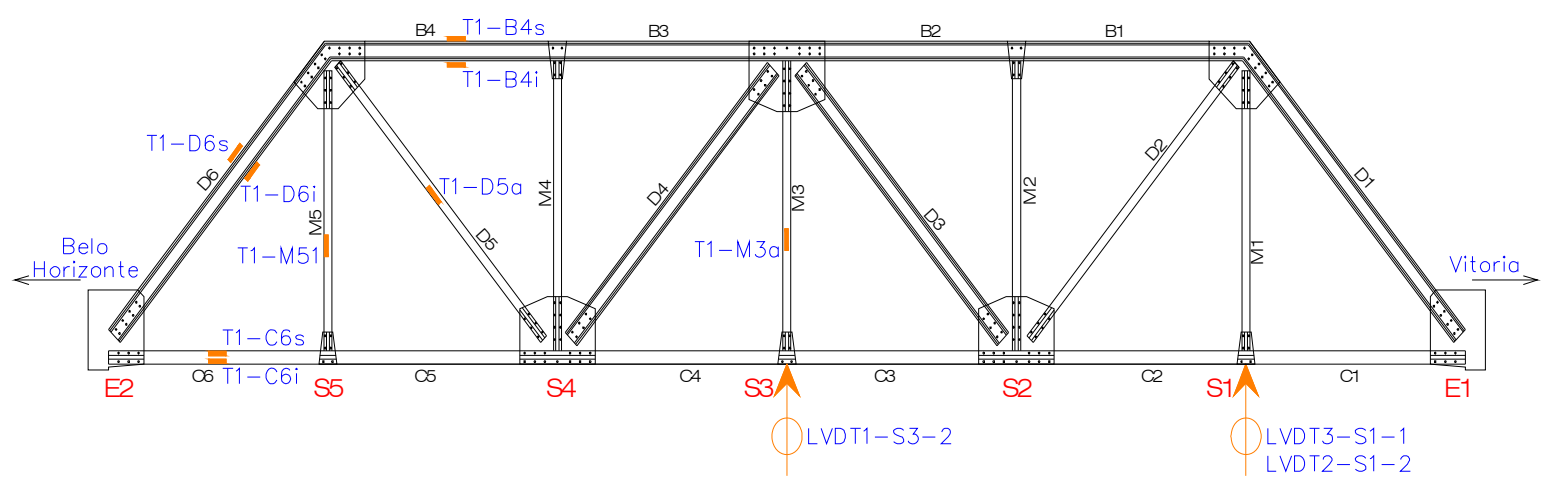

Figura 4.34 - Extensômetros e LVDT's instalados na ponte. 
A medição de carga e a detecção do instante de passagem da roda do trem sobre a estrutura, foi realizada por um sistema de extensômetros elétricos bidirecionais ligados em ponte completa, instalados na alma do trilho e posicionados a $45^{\circ}$ nas linhas neutras de duas seções transversais, localizadas entre dormentes consecutivos e distantes entre si $30 \mathrm{~cm}$ (figura 4.35a). Esse sistema permite medir deformações que são proporcionais à diferença entre as forças cortantes, associadas à flexão do trilho no plano longitudinal perpendicular à superfície inferior do patim, nas duas seções consideradas (CONCEIÇÃO NETO, 2009).

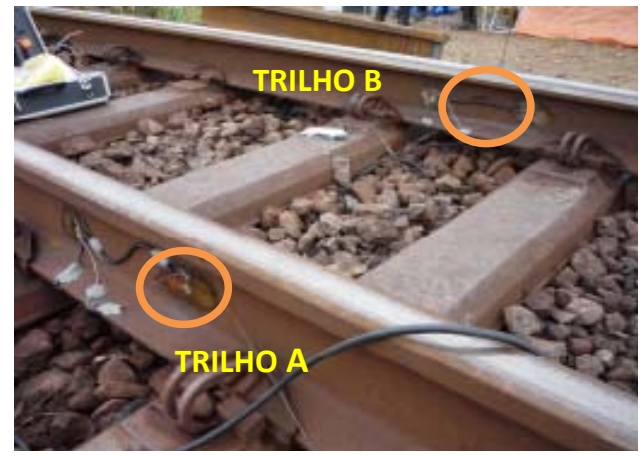

(a)

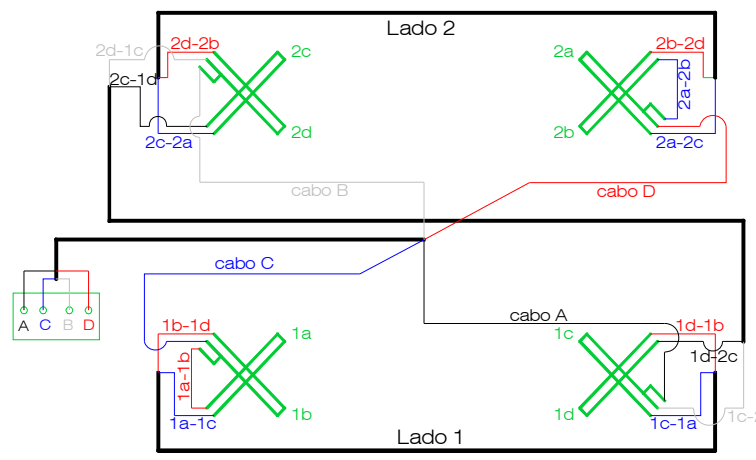

(b)

Figura 4.35 - (a) Extensômetros bidirecionais instalados nos trilhos, (b) Esquema de instalação de extensômetros para medição de carga.

O sistema de medição de carga foi calibrado utilizando um dispositivo de aplicação de esforços auto-equilibrado, apoiado no trilho fora da região de influência do transdutor, um cilindro hidráulico e uma célula de carga acompanhada de condicionador de sinais com medidor digital, tal como se mostra na figura 4.36a.

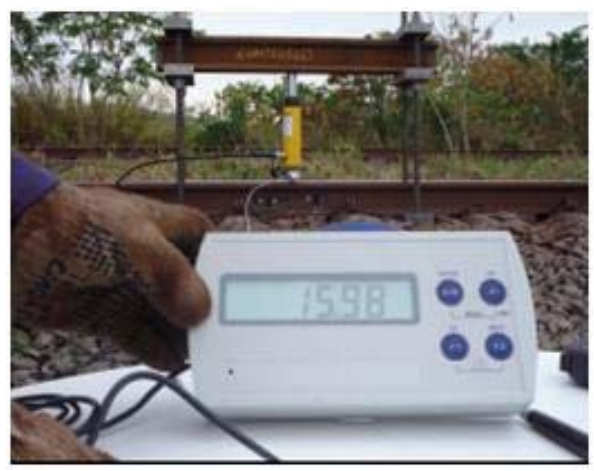

(a)

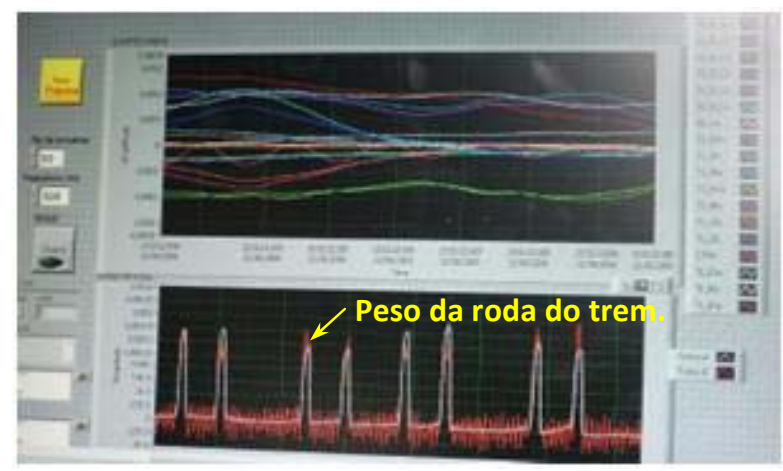

(b)

Figura 4.36 - (a) Dispositivo para calibrar o sistema de medição de cargas, (b) Medição de carga da roda do trem em tempo real. 
Com o sistema de medição de carga instalado e uma vez conhecida a distância entre rodeiros de um truque e a distância entre truques dos vagões, os sinais adquiridos permitiram calcular a velocidade média de passagem das rodas do trem e estimar suas posições na estrutura num instante de tempo de duração do ensaio. Na figura 4.36b apresenta-se a medição de cargas da passagem do trem em tempo real, onde cada pico representa o peso de cada uma das rodas do trem.

Em relação ao sistema de aquisição empregado na monitoração da ponte é o mesmo equipamento da National Instrument que foi usado na monitoração do modelo reduzido.

\subsubsection{Ensaios de carga}

Nesta seção são descritas as principais características dos trens utilizados na realização dos ensaios e os casos de carga aos quais a ponte foi submetida.

\subsubsection{Trens utilizados}

Nos ensaios foram considerados três tipos de trens denominados: trem Plasser cujo peso aproximado é $300 \mathrm{kN}$ e a distância entre eixos é $8 \mathrm{~m}$, trem Viliato composto por uma locomotiva e quatro vagões e trem com carregamento de minério de operação normal. O peso de cada eixo dos trens foi determinado através do sistema de medição de carga instalado na via.

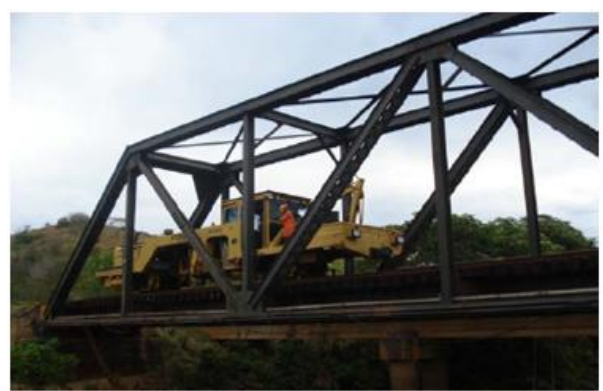

(a)

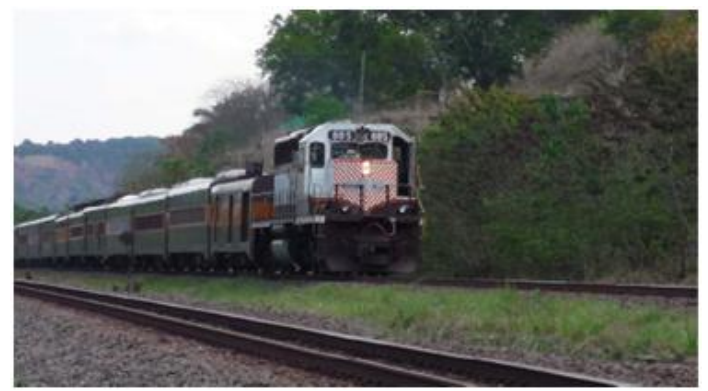

(b)

Figura 4.37 - (a) Posicionamento da maquina Plasser na ponte (sentido Belo Horizonte BH - Vitoria V); (b) Trem com carregamento de operação normal na via.

\subsubsection{Casos de Carga}

Os casos de carga foram propostos para cada tipo de trem empregado durante a monitoração da ponte, com o objetivo de induzir valores elevados nas grandezas físicas. A seguir, detalham-se os casos de carga adotados: 


\section{Caso 1: Maquina Socadeira Plasser}

$\mathrm{O}$ trem trafegou em ambos os sentidos $\mathrm{BH} \rightarrow \mathrm{V}$ e $\mathrm{V} \rightarrow \mathrm{BH}$ em diferentes velocidades nominais de $5 \mathrm{~km} / \mathrm{h}$ a $60 \mathrm{~km} / \mathrm{h}$ tal como se mostra na figura $4.37(\mathrm{a})$.

\section{Caso 2: Trem Viliato}

O trem viliato trafegou ao longo da estrutura da ponte a velocidades nominais de $5 \mathrm{~km} / \mathrm{h}, 14 \mathrm{~km} / \mathrm{h}, 25 \mathrm{~km} / \mathrm{h}$ e $35 \mathrm{~km} / \mathrm{h}$. As medições na velocidade de 5 $\mathrm{km} / \mathrm{h}$ referem-se a uma solicitação quase estática da estrutura da ponte e foram utilizadas para fazer comparações como o modelo numérico e com os resultados do modelo reduzido. Na figura 4.38 apresenta-se o posicionamento do trem viliato sobre a ponte.

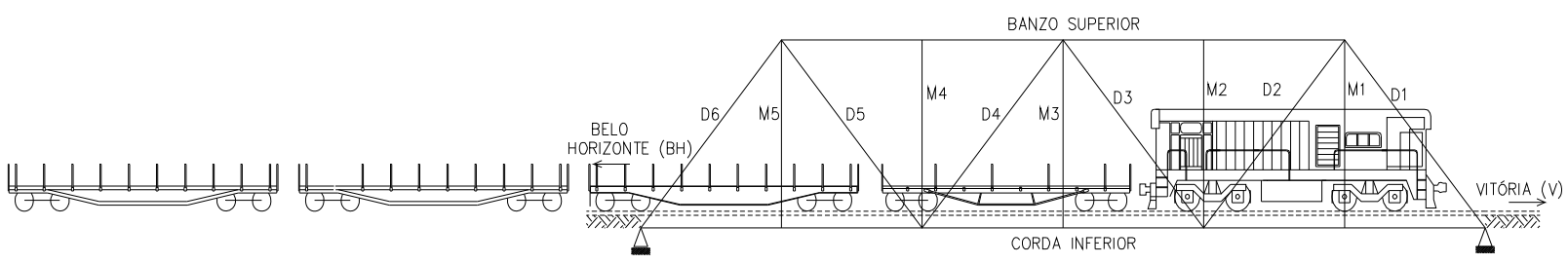

Figura 4.38 - Passagem do trem viliato sobre a ponte do rio Suaçui.

\section{Caso 3: Trem com carregamento de minério}

Neste caso a passagem dos trens sobre a ponte foi similar às condições de operação normal da via.

Desses casos de carga, apenas o caso 2 é descrito a detalhe nesta pesquisa com a finalidade de fazer a comparação com os resultados do modelo reduzido. Os demais casos de carga foram descritos no relatório final LEM - VALE 02-10 FUSP 1982, (BITTENCOURT, 2010).

\subsubsection{Realização dos ensaios com o trem viliato}

Antes de iniciar as medições, as cargas de roda do trem viliato foram determinadas através de pesagem, utilizando-se os transdutores do trilho "A". As cargas de eixo foram estimadas tomando-se duas vezes o valor da carga de roda medida para cada eixo do veículo. A pesagem de eixos foi realizada na velocidade de $5 \mathrm{~km} / \mathrm{h}$ e nas demais velocidades o transdutor de carga de roda do trilho " $A$ " foi 
utilizado apenas para a detecção dos eixos do trem permitindo, uma vez conhecidas as distâncias entre eixos da locomotiva, estimar as velocidades médias efetivas durante as passagens da composição.

As deformações dos extensômetros foram medidas antes do veículo atingir a ponte (leituras iniciais de referência ou "offset's") e cada vez que o mesmo parou nas posições indicadas (leituras para a estrutura deformada). Nota-se que esse procedimento, referente à tomada de leituras iniciais, foi adotado como padrão para todas as medições realizadas com os sensores e transdutores utilizados. Os valores considerados como corretos e definitivos foram sempre calculados tomando-se a diferença entre o valor medido durante um determinado evento de passagem de veículo sobre a ponte e o valor "de offset" correspondente à leitura inicial.

\subsubsection{Resultados da medição durante a prova de carga}

A seguir apresentam-se as deformações de todos os elementos estruturais monitorados durante a passagem do trem viliato e a medição do deslocamento no meio do vão. A convenção de sinais adotada para entender os dados experimentais é a mesma utilizada na monitoração do modelo reduzido.

Na figura 4.39(a) apresentam-se as deformações medidas nas diagonais, montantes, cordas e banzos da ponte e variam em função ao tempo de duração da prova de carga, enquanto que na figura 4.39(b) apresenta-se os deslocamentos medidos no meio do vão.

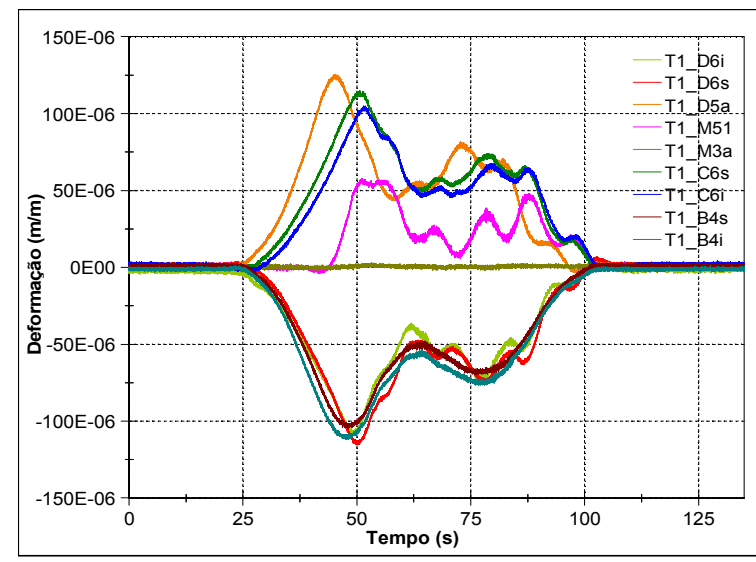

(a)

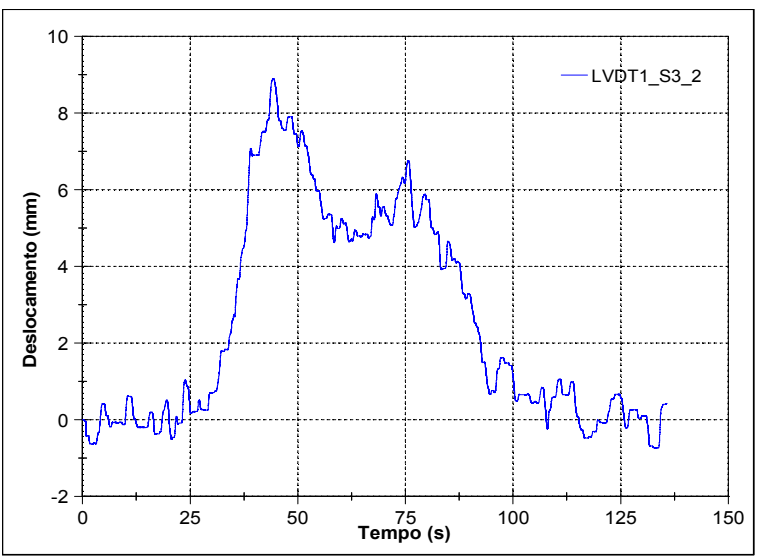

(b)

Figura 4.39 - Medições durante passagem do Trem Viliato a $5 \mathrm{~km} / \mathrm{h}$ : (a) Deformações nos elementos estruturais da ponte, (b) Deslocamento no meio do vão. 
A envoltória de deformações e deslocamentos apresentada na tabela 4.12 foi obtida a partir dos dados experimentais apresentados na figura 4.39 e servirá para fazer a comparação com os resultados obtidos na monitoração do modelo reduzido.

Tabela 4.12 - Envoltória de deformações e deslocamentos experimentais durante a passagem do trem viliato

\begin{tabular}{|c|c|c|c|}
\hline Extensômetros & $\begin{array}{l}\text { Deformação Máx. } \\
(\mu \mathrm{m})\end{array}$ & LVDT & $\begin{array}{c}\text { Deslocamento Máx. } \\
(\mathrm{mm})\end{array}$ \\
\hline T1_M51 & 56 & LVDT1-S3 & 8,80 \\
\hline T1_M3a & -1 & & \\
\hline T1_D6i & -106 & & \\
\hline T1_D6s & -114 & & \\
\hline T1_D5a & 123 & & \\
\hline T1_B4s & -104 & & \\
\hline T1_B4i & -110 & & \\
\hline T1_C6s & 111 & & \\
\hline T1_C6i & 99 & & \\
\hline
\end{tabular}

O peso das rodas do trem foram medidas pelo sistema de medição de carga instalado no trilho "A", cujos valores nominais são apresentados na figura $4.40 \mathrm{e}$ 4.41.

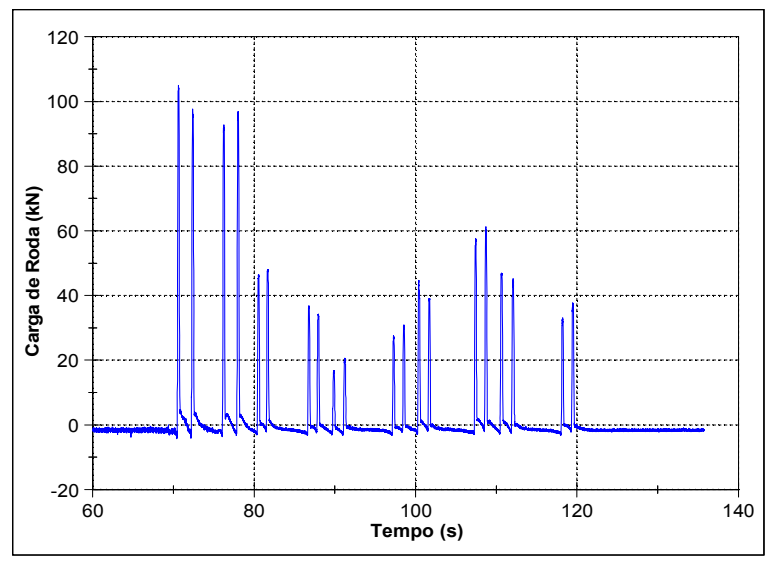

Figura 4.40 - Carga de roda durante passagem do Trem Viliato a $5 \mathrm{~km} / \mathrm{h}$.

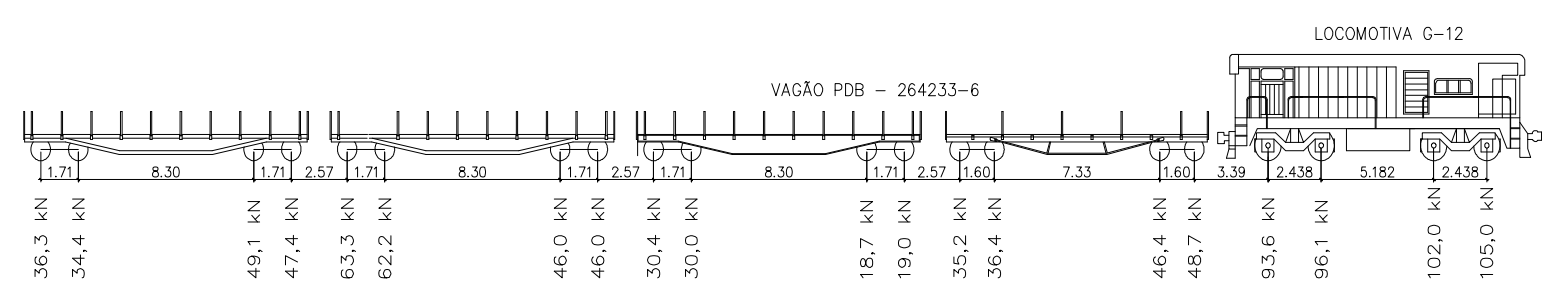

Figura 4.41 - Peso por roda do Trem Viliato. 


\subsection{Comportamento estrutural da ponte em escala real e escala reduzida}

A relação do comportamento da ponte em escala real (protótipo) e em escala reduzida (modelo) foi estudada através da teoria de modelos estruturais, o qual permitiu avaliar as deformações e deslocamentos experimentais tanto do modelo quanto do protótipo e a relação de semelhança existente entre eles.

Antes de se fazer o estudo comparativo experimental das grandezas físicas do modelo e do protótipo, foi necessário deduzir teoricamente as relações de semelhança existente entre eles, os quais são detalhados a seguir.

\subsubsection{Cálculo teórico das relações de semelhança e fatores de escala}

A partir da análise dimensional e o teorema de Buckingham pode-se fazer uma formulação matemática, que descreva o comportamento físico de uma estrutura através de um conjunto de adimensionais ( $\pi$-termos) que relacionam grandezas físicas. Essas grandezas e suas dimensões estão descritas na tabela 4.13.

Tabela 4.13 - Grandezas físicas que descrevem o comportamento de uma estrutura.

\begin{tabular}{cll}
\hline Símbolo & Quantidade & Dimensões \\
\hline $\mathbf{F}$ & Força & $\mathrm{F}$ \\
$\mathbf{M}$ & Momento & $\mathrm{FL}$ \\
$\mathbf{P}$ & Carga pontual & $\mathrm{F}$ \\
$\mathbf{q}$ & Carga distribuída & $\mathrm{FL}^{-1}$ \\
$\mathbf{E}$ & Módulo de elasticidade & $\mathrm{FL}^{-2}$ \\
$\mathbf{A}$ & Área & $\mathrm{L}^{2}$ \\
I & Inércia & $\mathrm{L}^{4}$ \\
I & Comprimento & $\mathrm{L}$ \\
$\delta$ & Deslocamento & $\mathrm{L}$ \\
$\theta$ & Rotação & --- \\
\hline
\end{tabular}

A equação que governa o comportamento físico do modelo pode ser descrito principalmente pela relação das seguintes grandezas: força $F$, carga pontual $P$, carga distribuída $q$, módulo de elasticidade $E$, área $A$, comprimento $l$ e descolamento $\delta$, tal como se mostra na equação 4.1 .

$$
f(F, P, q, E, A, l, \delta)=0
$$


A força pode ser escrita também como função de outras variáveis:

$$
F=f^{\prime}(P, q, E, A, l, \delta)
$$

A equação 4.2, pode ser expressa como produto contínuo:

$$
F=K P^{a} q^{b} E^{c} A^{d} l^{e} \delta^{f}
$$

A equação dimensional para a expressão anterior também pode ser escrita assim:

$$
(F)=(F)^{a}\left(\frac{F}{L}\right)^{b}\left(\frac{F}{L^{2}}\right)^{c}\left(L^{2}\right)^{d}(L)^{e}(L)^{f}
$$

Para que a equação 4.4 seja dimensionalmente homogênea, tem-se cumprir a seguinte condição:

$$
\begin{aligned}
& F: a+b+c=1 \\
& L:-b-2 c+2 d+e+f=0
\end{aligned}
$$

As duas equações anteriores têm seis incógnitas, e pode ser resolvida arbitrariamente para $a$ e $e$ em termos de $b, c, d$ e $f$, da seguinte forma:

$$
\begin{aligned}
& a=1-b-c \\
& e=b+2 c-2 d-f
\end{aligned}
$$

Logo, substituindo a equação 4.6 em 4.3 temos:

$$
F=K\left(P^{1-b-c} q^{b} E^{c} A^{d} l^{b+2 c-2 d-f} \delta^{f}\right)
$$

$\mathrm{Ou}$

$$
\left(\frac{F}{P}\right)=K\left[\left(\frac{q l}{P}\right)^{b}\left(\frac{E l^{2}}{P}\right)^{c}\left(\frac{A}{l^{2}}\right)^{d}\left(\frac{\delta}{l}\right)^{f}\right]
$$

Para a conformação dos termos adimensionais escolheram-se três grandezas independentes (comprimento $l$, o módulo $E$, e carga distribuída $q$ ) que serão exibidos pelo menos uma vez nos 6 - $2=4 \pi$-termos, os quais são mostrados a seguir:

$$
\begin{array}{ll}
\pi_{1}=\frac{q l}{P} & \pi_{3}=\frac{A}{l^{2}} \\
\pi_{2}=\frac{E l^{2}}{P} & \pi_{4}=\frac{\delta}{l}
\end{array}
$$


Para que um modelo possa ser considerado semelhante ao protótipo, os termos adimensionais ( $\pi$-termos) devem ser iguais tanto no modelo quanto no protótipo, assim: $\pi_{\mathrm{m}}=\pi_{\mathrm{p}}$. Dessa igualdade são obtidos os fatores de escala que relacionam as grandezas físicas do modelo e do protótipo, entre elas temos o fator de escala geométrica $S_{L}$, o fator de escala do tipo de material $S_{E}$ e fator de escala da carga distribuída $S_{Q}$, cujas relações são mostradas na equação 4.10.

$$
\frac{l_{p}}{l_{m}}=S_{L} \quad \frac{q_{p}}{q_{m}}=S_{Q} \quad \frac{E_{p}}{E_{m}}=S_{E}
$$

O resto de relações para a carga $P$, o deslocamento $\delta$ e a área $A$ é determinado em função aos fatores estabelecidos na equação 4.10.

$$
\begin{aligned}
& \pi_{1}: \quad \frac{q_{p} l_{p}}{P_{p}}=\frac{q_{m} l_{m}}{P_{m}} \Rightarrow P_{p}=S_{Q} S_{L} P_{m} \\
& \pi_{2}: \quad \frac{E_{p} l_{p}^{2}}{P_{p}}=\frac{E_{m} l_{m}{ }^{2}}{P_{m}} \Rightarrow P_{p}=S_{E} S_{L}{ }^{2} P_{m} \\
& \pi_{3}: \frac{A_{p}}{l_{p}{ }^{2}}=\frac{A_{m}}{l_{m}{ }^{2}} \Rightarrow A_{p}=S_{L}{ }^{2} A_{m} \\
& \pi_{4}: \frac{\delta_{p}}{l_{p}}=\frac{\delta_{m}}{l_{m}} \Rightarrow \delta_{p}=S_{L} \delta_{m}=\frac{S_{Q}}{S_{E}} \delta_{m}
\end{aligned}
$$

As equações 4.10 a 4.14 são de especial importância porque permite estabelecer uma relação direta do comportamento estrutural entre o protótipo e o modelo reduzido. Isso quer dizer que os resultados obtidos nos ensaios com modelos podem ser estendidos aos protótipos, através de estes fatores.

\subsubsection{Estudo comparativo de deformações e deslocamentos medidos na ponte real e no modelo reduzido.}

$\mathrm{Na}$ monitoração da ponte do rio Suaçui (protótipo) nem todos os elementos estruturais foram monitorados, portanto a comparação foi efetuada apenas em alguns elementos estruturais, tais como: na diagonal T1-D6, o banzo T1-B4, a corda T1-C6 e o deslocamento no meio do vão S3. 


\subsubsection{Metodologia para determinar deformações e deslocamentos}

$\mathrm{Na}$ estrutura em escala real, as deformações dos elementos estruturais foram calculadas como a média das medições efetuadas pelos dois extensômetros instalados em cada barra, durante a passagem do trem viliato, tal como se indica na tabela 4.12. Assim, para a diagonal T1-D6 se calculou uma deformação de $110 \mu \varepsilon$, para o banzo T1-B4 uma deformação de $-107 \mu \varepsilon$ e para a corda T1-C6 uma deformação de $105 \mu \varepsilon$.

$\mathrm{Na}$ estrutura em escala reduzida, para determinar deformações e deslocamentos que sejam semelhantes aos calculados no protótipo, é necessário que o modelo físico tenha uma semelhança geométrica, nas cargas aplicadas e nas propriedades do material. Assim, o modelo reduzido da ponte do rio Suaçui foi projetado levando-se em conta essas condições de semelhança e construído em alumínio a uma escala geométrica de 1:30.

A seguir calculam-se os fatores de escala através da equação 4.10 que serão usados mais a frente para fazer as comparações entre o modelo e o protótipo.

$\mathrm{S}_{\mathrm{L}}=l_{\mathrm{p}} / l_{\mathrm{m}}=30 ; \mathrm{S}_{\mathrm{E}}=E_{\mathrm{p}} / E_{\mathrm{m}}=3,205 ;$ onde:

$l_{\mathrm{p}}=41 \mathrm{~m}$ (comprimento do vão da ponte real).

$l_{\mathrm{m}}=1,367 \mathrm{~m}$ (comprimento do vão do modelo).

$E_{\mathrm{p}}=208,7 \mathrm{GPa}$ (Módulo de elasticidade do aço da ponte real).

$E_{\mathrm{m}}=65,12 \mathrm{GPa}$ (Módulo de elasticidade do alumínio do modelo reduzido).

A carga equivalente do trem viliato utilizada no estudo do modelo foi calculado através da equação 4.12 assim, por exemplo, a carga de roda mais pesada é determinado da seguinte forma: $P_{\mathrm{m}}=P_{\mathrm{p}} / \mathrm{S}_{\mathrm{E}} \mathrm{S}_{\mathrm{L}}{ }^{2}=36,40 \mathrm{~N}$, onde: $P_{\mathrm{p}}=105$ $k N, S_{L}=30$ e $S_{E}=3,205$.

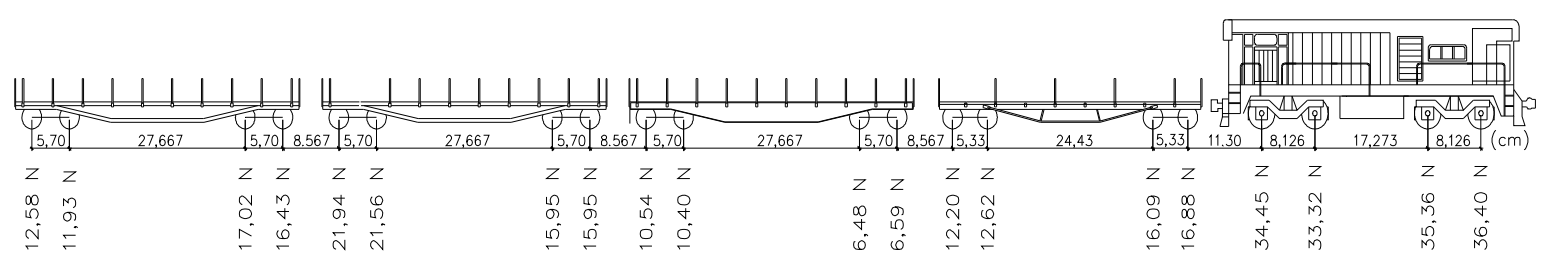

Figura 4.42 - Peso por roda do trem equivalente utilizado no estudo do modelo reduzido. 
A figura 4.42 apresenta o peso de todas as rodas do trem equivalente, cujos valores foram calculados da mesma forma como foi calculado o peso da roda mais pesada, a partir dos pesos das rodas do trem viliato mostrado na figura 4.41.

Nos ensaios efetuados no modelo reduzido, as cargas do trem equivalente não foram aplicadas diretamente ao modelo, pois sua fabricação de acordo com os pesos e dimensões estabelecidas foi complicada, por isso, para o cálculo de deformações e deslocamentos foram determinadas linhas de influência experimentais para cada elemento estrutural do modelo. Essas linhas de influência foram construídas a partir dos dados experimentais do estudo do caso II, onde foi possível monitorar o comportamento de cada barra e o deslocamento no meio do vão para diferentes posições de carga.

Assim, as deformações e deslocamentos devido ao sistema de cargas equivalentes ao trem viliato foi obtido através do produto da intensidade da carga pela ordenada da linha de influência no ponto de aplicação da carga.

\subsubsection{Comparação do deslocamento no meio do vão}

O deslocamento máximo medido durante a passagem do trem viliato na estrutural real foi $\delta_{p}=8,8 \mathrm{~mm}$.

O deslocamento teórico esperado num modelo perfeitamente semelhante aplicando a equação 4.14 seria: $\delta_{\mathrm{m}}=\delta_{\mathrm{p}} / \mathrm{S}_{\mathrm{L}}=0,293 \mathrm{~mm}$, onde $\delta_{\mathrm{p}}=8,8 \mathrm{~mm}$ e $\mathrm{S}_{\mathrm{L}}=$ 30 .

Para o cálculo do deslocamento no meio do vão do modelo reduzido, primeiramente foi determinada a linha de influência experimental a partir das medições do estudo do caso II, cujos dados foram apresentados na figura 4.25 e 4.30. A linha de influência experimental mostrada na figura 4.43 foi calculada, dividindo os deslocamentos medidos nos ensaios do caso II entre a metade carga aplicada $(P=208,75 N)$, pois essa carga foi suportada por duas treliças.

Logo, o deslocamento máximo para a carga do trem equivalente aconteceu na posição em que a terceira roda do trem coincidiu com a seção S3 do modelo, tal como se mostra na figura 4.44 , e foi obtido multiplicando a intensidade das cargas 
pelas ordenadas da linha de influência nos pontos de aplicação das cargas. O valor máximo calculado foi $\delta_{\mathrm{m}}^{\prime}=0,1393 \mathrm{~mm}$.

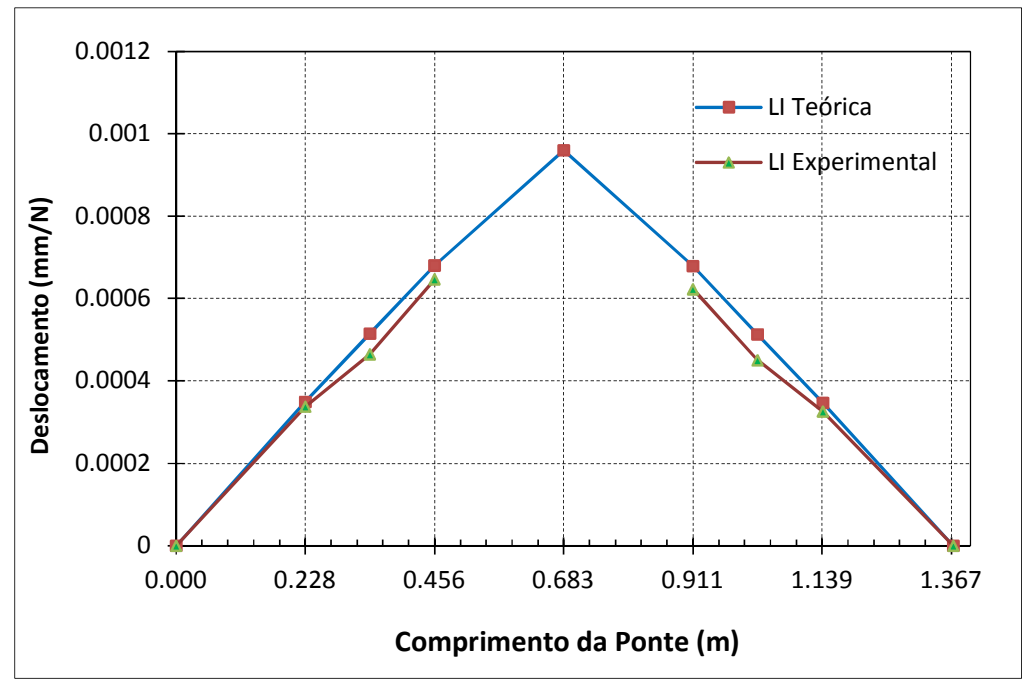

Figura 4.43 - Linha de influência teórica e experimental para o deslocamento no meio do vão do modelo.

O deslocamento obtido para um modelo perfeitamente semelhante: $\delta_{\mathrm{m}}=$ $0,293 \mathrm{~mm}$, é maior que o calculado em nosso modelo $\delta_{\mathrm{m}}^{\prime}=0,1393 \mathrm{~mm}$. Essa diferença deve-se ao fato que o modelo se comportou muito mais rígido que o esperado. Essa rigidez pode ser atribuída ao tamanho das seções do modelo que são muito maiores que as seções do modelo perfeitamente semelhante. Essa diferença foi advertida na etapa de projeto e fabricação do modelo.

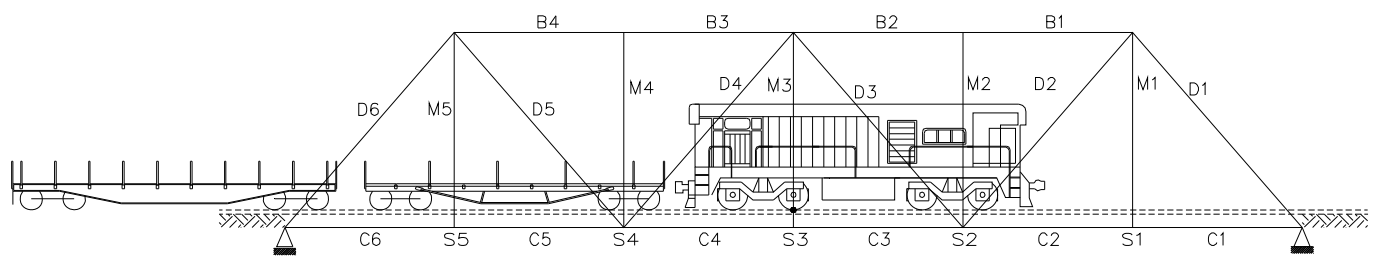

Figura 4.44 - Posição da carga equivalente onde se produz o máximo deslocamento no meio do vão do modelo.

\subsubsection{Comparação de deformações nos elementos estruturais}

Para entender melhor a influência das deformações no modelo e no protótipo, essas serão analisadas do ponto de vista de forças as quais foram calculadas a partir das fórmulas de resistência de materiais: $F=E$.A.E, onde $F$ é a força, $E$ o módulo de elasticidade do material, $A$ área da seção transversal e $\varepsilon$ deformação. 


\section{Diagonal T1-D6}

A deformação máxima medida durante a passagem do trem viliato na estrutural real foi de $\varepsilon_{p}=-110 \mu \varepsilon$, cuja força equivalente é igual $F_{p}=-312,22 \mathrm{kN}$ para uma seção transversal de $136 \mathrm{~cm}^{2}$ e um módulo de elasticidade de 208,7 GPa.

A força teórica esperada num modelo perfeitamente semelhante aplicandose a equação 4.12 seria: $F_{m}=F_{p} / S_{E} S_{L}{ }^{2}=-108,24 N$ onde $S_{L}=30$ e $S_{E}=3,205$.

Para o cálculo da deformação da diagonal T1-D6 do modelo reduzido, primeiramente foi determinada a linha de influência experimental a partir das medições do estudo do caso II, cujo resumo de dados é apresentado na figura 4.45(a). A linha de influência experimental mostrada na figura 4.45(b) foi calculada, da mesma forma como foi calculada a linha de influência do deslocamento.

Logo, a deformação máxima para a carga do trem equivalente aconteceu na posição em que a quinta roda do trem coincidiu com a seção S5 do modelo, tal como se mostra na figura 4.46, e foi obtido multiplicando-se a intensidade das cargas pela ordenada da linha de influência no ponto de aplicação das cargas. $O$ valor máximo calculado foi $\varepsilon_{p}=-20,17 \mu \varepsilon$, cuja força equivalente é igual $F_{m}^{\prime}=-149,0 \mathrm{~N}$ para uma seção transversal de $1,134 \mathrm{~cm}^{2}$ e um módulo de elasticidade de 65,12 GPa.

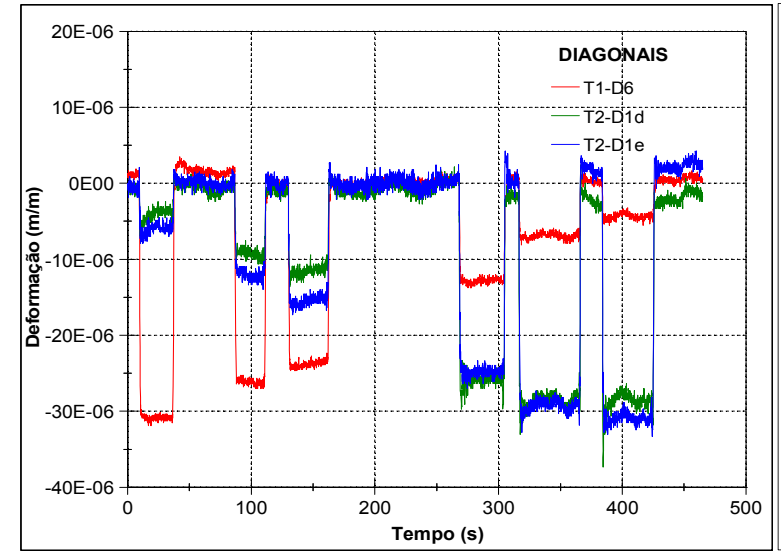

(a)

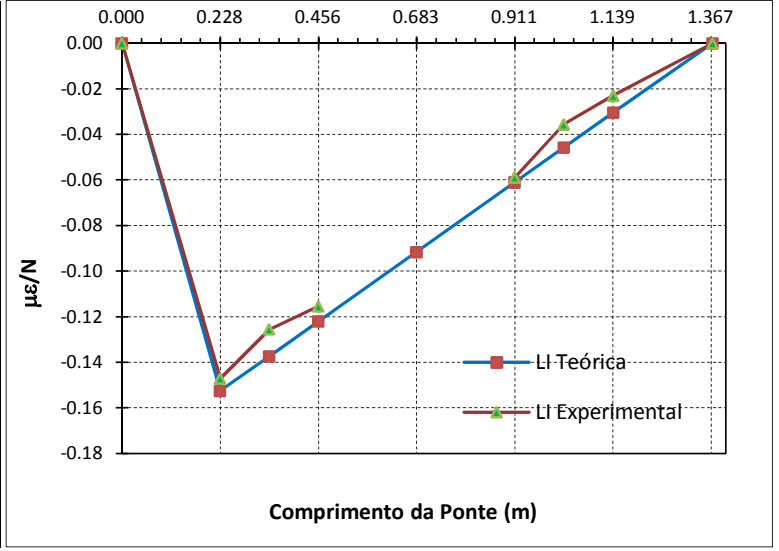

(b)

Figura 4.45 - (a) Deformações experimentais nas diagonais do modelo para o estudo do caso II, (b) Linha de influência teórica e experimental da deformação da diagonal T1-D6. 
A força obtida para o modelo perfeitamente semelhante: $F_{m}=-108,24 \mathrm{~N}$, é menor que o calculado em nosso modelo $\mathrm{F}_{\mathrm{m}}=-149,0 \mathrm{~N}$, essa diferença confirma que o modelo se comportou de forma mais rígida devido às seções adotas. Portanto se pode afirmar que o incremento de seção nas barras do modelo diminuiu os deslocamentos no meio do vão e aumentou as forças axiais nas barras para uma mesma carga.

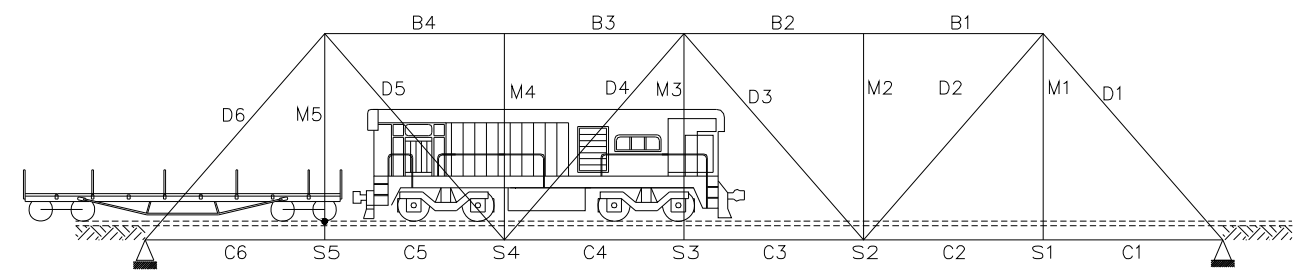

Figura 4.46 - Posição da carga equivalente onde se produz a máxima solicitação na diagonal T1-D6.

\section{Banzo T1-B4}

A deformação máxima medida durante a passagem do trem viliato na estrutural real foi de $\varepsilon_{p}=-107 \mu \varepsilon$, cuja força equivalente é igual $F_{p}=-303,7 k N$ para uma seção transversal de $136 \mathrm{~cm}^{2}$ e um módulo de elasticidade de 208,7 GPa.

A força teórica esperada num modelo perfeitamente semelhante aplicando a equação 4.12 seria: $F_{m}=F_{p} / S_{E} S_{L}^{2}=-105,29 N$ onde $S_{L}=30$ e $S_{E}=3,205$.

Para o cálculo da deformação no banzo T1-B4 do modelo reduzido, primeiramente foi determinada a linha de influência experimental a partir das medições do estudo do caso II, cujo resumo de dados é apresentado na figura 4.47(a). A linha de influência experimental mostrada na figura 4.47(b) foi calculada, da mesma forma como foi calculada a linha de influência do deslocamento.

A deformação máxima para a carga do trem equivalente aconteceu na posição em que a quarta roda do trem coincidiu com a seção $\$ 4$ do modelo, tal como se mostra na figura 4.48 , e foi obtido multiplicando-se a intensidade das cargas pela ordenada da linha de influência no ponto de aplicação das cargas. $O$ valor máximo calculado foi $\varepsilon_{\mathrm{p}}=-22,34 \mu \varepsilon$, cuja força equivalente é igual $F_{m}^{\prime}=-165,0$ $\mathrm{N}$ para uma seção transversal de $1,134 \mathrm{~cm}^{2}$ e um módulo de elasticidade de 65,12 GPa. 


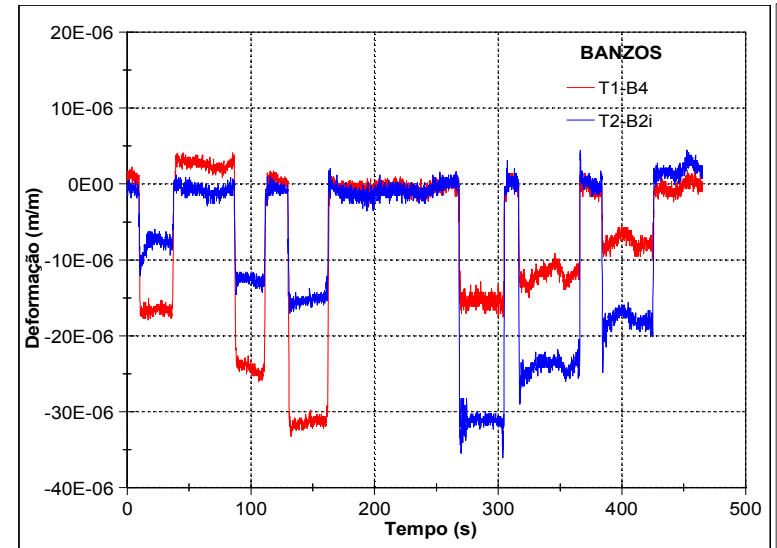

(a)

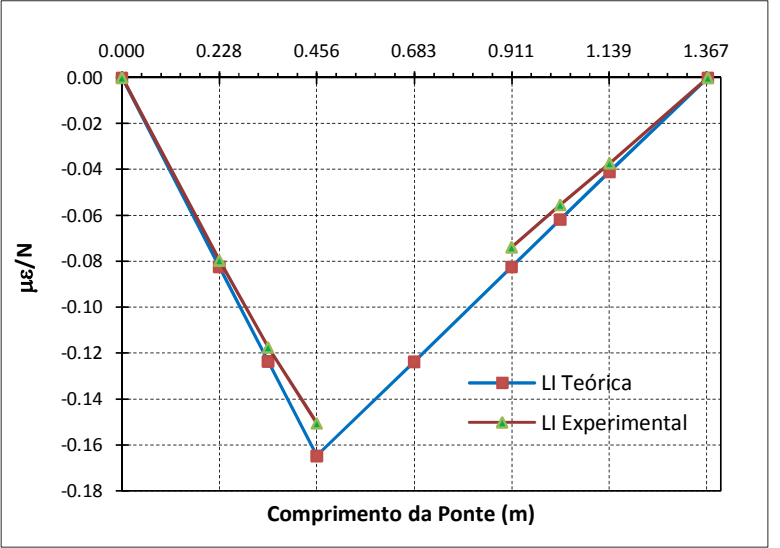

(b)

Figura 4.47 - (a) Deformações experimentais nos banzos do modelo para o estudo do caso II,

(b) Linha de influência teórica e experimental da deformação do banzo T1-B4.

A força obtida para o modelo perfeitamente semelhante: $F_{m}=-105,29 \mathrm{~N}$, é menor que o calculado no modelo $F_{m}^{\prime}=-165,0 \mathrm{~N}$, essa diferença confirma novamente que o modelo se comportou mais rígido que o esperado.

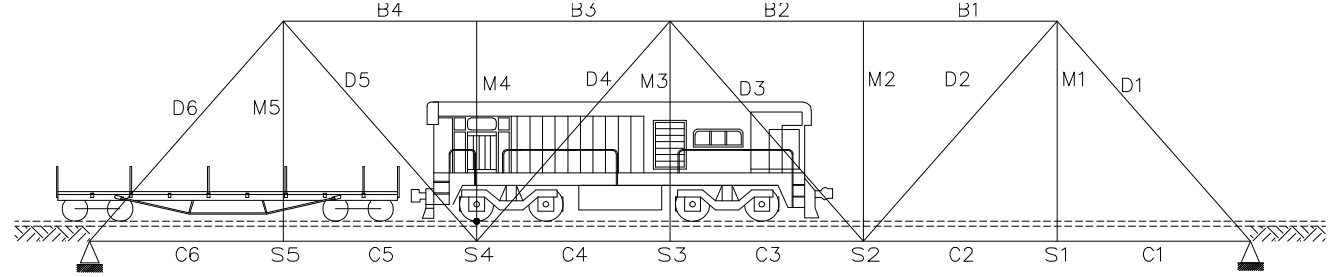

Figura 4.48 - Posição da carga equivalente onde se produz a máxima solicitação no banzo T1-B4.

\section{Corda T1-C6}

A deformação máxima medida durante a passagem do trem viliato na estrutural real foi de $\varepsilon_{p}=105 \mu \varepsilon$, cuja força equivalente é igual $F_{p}=192,05 \mathrm{kN}$ para uma seção transversal de $86 \mathrm{~cm}^{2}$ e um módulo de elasticidade de 208,7 GPa.

A força teórica esperada num modelo perfeitamente semelhante aplicando a equação 4.12 seria: $F_{m}=F_{p} / S_{E} S_{L}^{2}=66,58 N$ onde $S_{L}=30$ e $S_{E}=3,205$.

Para o cálculo da deformação na corda T1-C6 do modelo reduzido, primeiramente foi determinada a linha de influência experimental a partir das medições do estudo do caso II, cujo resumo de dados é apresentado na figura 4.49(a). A linha de influência experimental mostrada na figura 4.49(b) foi calculada, da mesma forma como foi calculada a linha de influência do deslocamento. 
A deformação máxima para a carga do trem equivalente aconteceu na posição em que a quarta roda do trem coincidiu com a seção S5 do modelo, tal como se mostra na figura 4.50, e foi obtido multiplicando-se a intensidade das cargas pela ordenada da linha de influência no ponto de aplicação das cargas. $O$ valor máximo calculado foi $\varepsilon_{p}=9,23 \mu \varepsilon$, cuja força equivalente é igual $F_{m}^{\prime}=54,53 \mathrm{~N}$ para uma seção transversal de $0,907 \mathrm{~cm}^{2}$ e um módulo de elasticidade de 65,12 GPa.

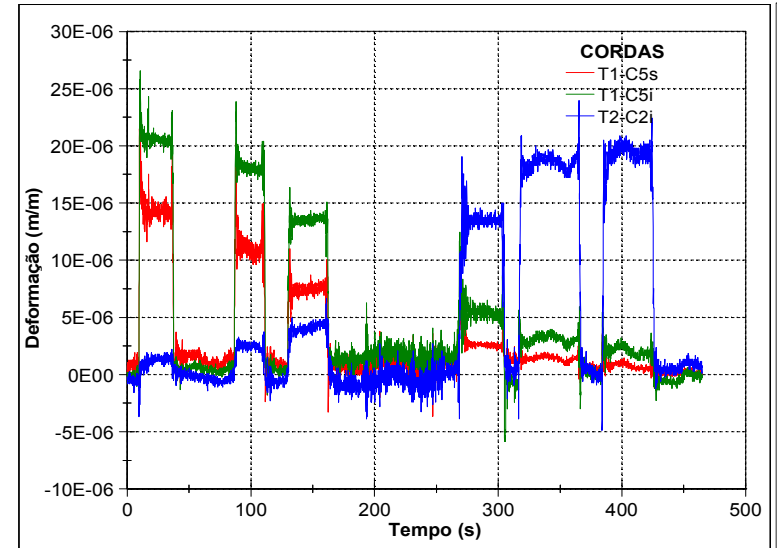

(a)

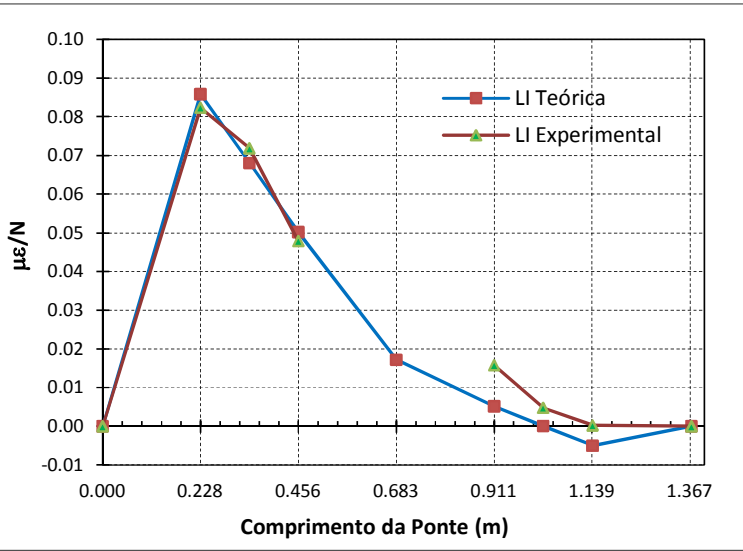

(b)

Figura 4.49 - (a) Deformações experimentais nas cordas do modelo para o estudo do caso II, (b) Linha de influência teórica e experimental da deformação da corda T1-C6.

A força obtida para o modelo perfeitamente semelhante: $F_{m}=66,58 \mathrm{~N}$, é relativamente maior que o calculado no modelo $\mathrm{F}_{m}^{\prime}{ }_{m}=54,53 \mathrm{~N}$, neste caso não se deu a lógica estabelecida nas outras duas análises anteriores.

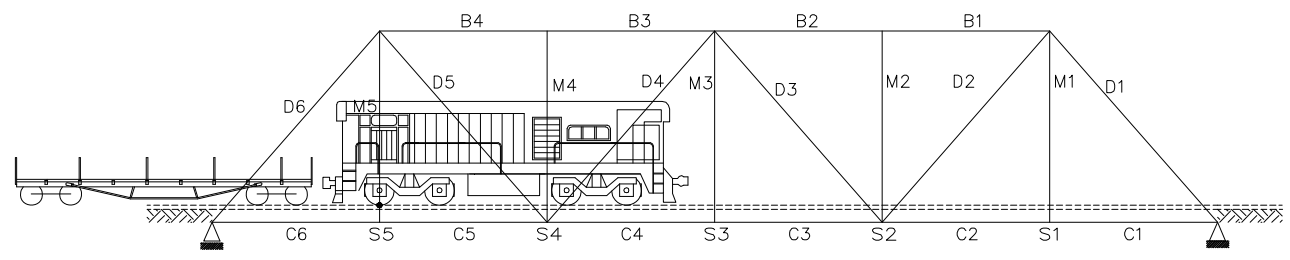

Figura 4.50 - Posição da carga equivalente onde se produz a máxima solicitação na corda T1-C6.

\subsubsection{Comparação de dados experimentais monitoradas na ponte real e os calculados no modelo numérico da ponte em escala reduzida}

A monitoração da ponte em escala real caracterizou-se pela medição de grandezas físicas em função do tempo, onde a passagem dos trens de carga a 
determinadas velocidades permitiu conhecer o comportamento de cada um dos elementos instrumentados para diferentes posições de carga. Essas grandezas monitoradas na escala real são apresentadas na figura 4.51 .

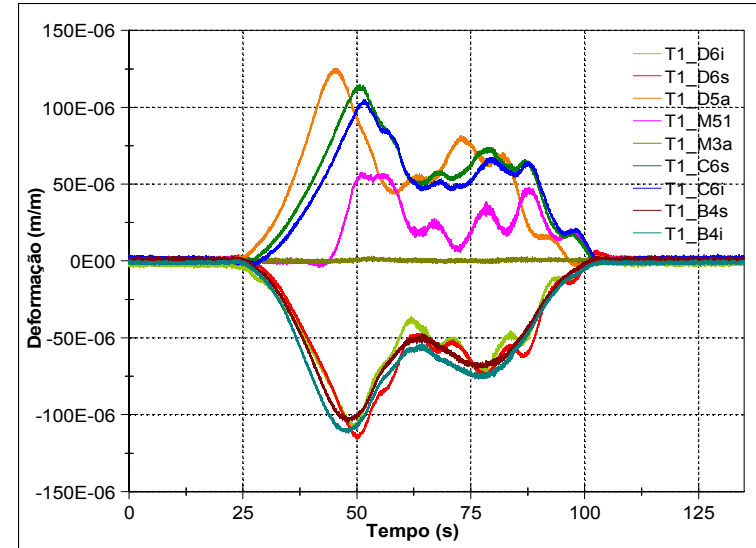

(a)

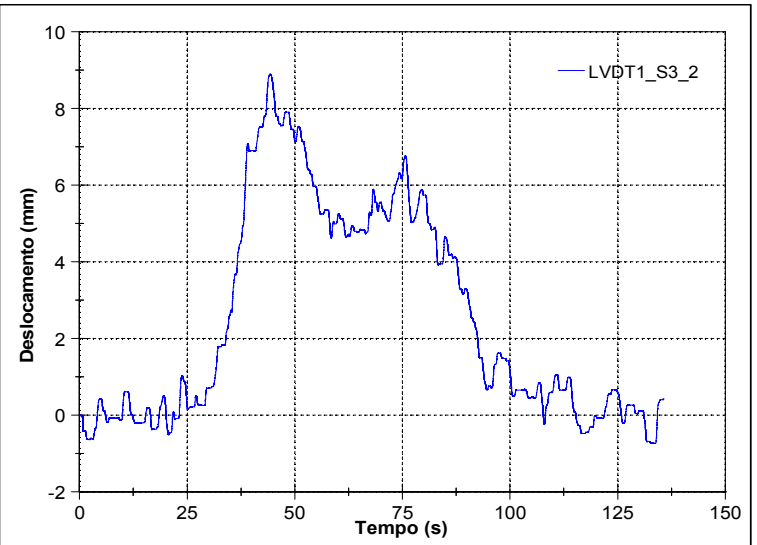

(b)

Figura 4.51 - Medições durante passagem do trem Viliato: (a) Deformações nos elementos estruturais da ponte real, (b) Deslocamento no meio do vão.

No modelo reduzido não se conseguiu simular no laboratório o ensaio efetuado na ponte real, mas se conseguiu simular no modelo numérico calibrado da ponte em escala reduzida. A simulação numérica foi efetuada no programa SAP2000 aproveitando o módulo de "Linear Direct Integration - History" onde foi possível simular a passagem do trem sobre a ponte durante um período de tempo e conhecer o comportamento de cada um dos elementos estruturais do modelo reduzido. Esses resultados numéricos são apresentados na figura 4.52.

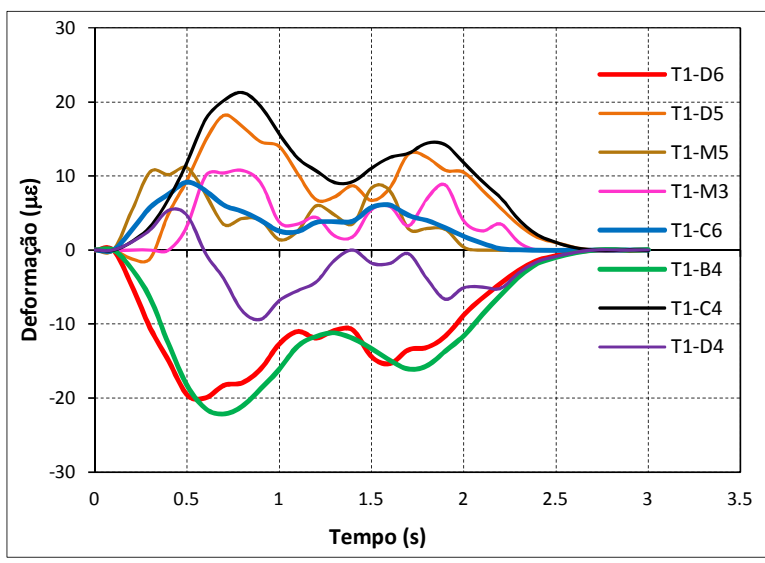

(a)

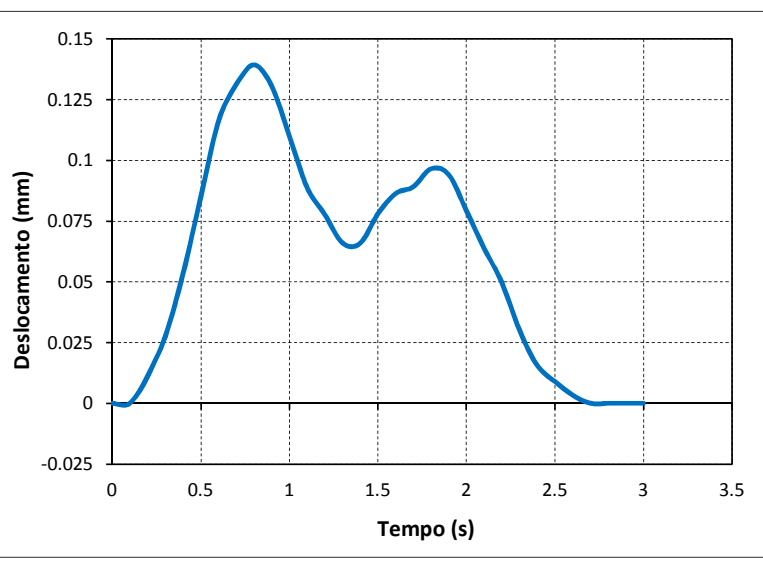

(b)

Figura 4.52 - Grandezas físicas calculadas a partir do modelo numérico (a) Deformações, (b) Deslocamentos no meio do vão. 
Nas figuras 4.51 e 4.52 observa-se que as deformações e os deslocamentos teóricos e experimentais de cada um dos elementos estruturais do modelo reduzido e da ponte real apresentam relativa semelhança para cada posição da carga móvel. Essa semelhança fica definida pela relação de escalas, tal como foi mostrado na análise do deslocamento máximo no meio do vão e as deformações máximas nas barras T1-D6, T1-B4 e T1-C6 (itens 4.5.2.2 e 4.5.2.3).

\subsection{Conclusões}

Do estudo experimental e teórico da ponte em escala real e em escala reduzida podemos chegar às seguintes conclusões:

- A construção do modelo reduzido ajudou no planejamento da monitoração da ponte real e permitiu entender melhor seu comportamento estrutural. Também foi utilizado para testar e calibrar os equipamentos de monitoração, assim como treinar o pessoal do laboratório na instalação de sensores.

- Para ter controle dos ensaios no modelo, foi desenvolvido um programa no LabView que permitiu monitorar, analisar e armazenar dados, assim como visualizar o comportamento da estrutura em tempo real para cada solicitação de carga.

- Os dados experimentais obtidos dos ensaios efetuados no modelo reduzido foram uteis para calibrar o modelo teórico. Assim, os modelos numéricos desenvolvidos com elementos finitos e elementos de barra em 3D deram resultados muito mais próximos aos experimentais.

- Na modelagem numérica, embora a estrutura tenha sido modelada como pórtico, analisando os esforços resultantes nos elementos, percebe-se que os esforços axiais, são significativos. Já os momentos fletores são praticamente nulos. Pode-se afirmar então, que os elementos trabalham como barras de treliça e não como barras de pórtico.

- A monitoração da ponte do rio Suaçui permitiu conhecer o comportamento real da ponte frente à intensidade de ações provocada de passagem dos 
trens e forneceu dados experimentais para fazer estudos de semelhança com o modelo reduzido.

- O modelo reduzido ao ser comparado com o modelo em escala real mostrou certa semelhança em seu comportamento, pois os resultados dos deslocamentos e as deformações apresentam uma relação definida pelos fatores de escala.

- As deformações e deslocamentos medidos na monitoração da ponte real puderam ser reproduzidos numericamente com a ajuda do programa SAP2000 e seu módulo: Linear Direct Integration - History. 


\section{Capítulo}

\section{MODELOS REDUZDOS DE MCROCONCRETO}

\section{Modelos reduzidos de microconcreto}

\subsection{Introdução}

Neste capítulo apresenta-se o estudo teórico-experimental do comportamento estrutural de dois modelos físicos construídos em microconcreto.

Entre os modelos físicos a serem estudados tem se: uma ponte (pórtico de concreto armado) a fim de se verificar o comportamento devido às solicitações de carga incremental no meio do vão e vigas levemente armadas com o objetivo de se conhecer o comportamento em fratura.

No estudo do comportamento de estruturas através de modelos reduzidos, o microconcreto se apresenta como um material adequado para a execução de microestruturas. Assim, observando-se as exigências prescritas pela análise dimensional em relação ao uso do microconcreto como um material semelhante ao concreto comum, algumas de suas propriedades mecânicas foram verificadas na 
etapa de dosagem no laboratório para se obter essa semelhança. Tais propriedades são apresentadas no Anexo B.

Os materiais usados na construção dos modelos foram caracterizados segundo as especificações da Associação Brasileira de Normas Técnicas e ensaiadas no Laboratório de Estruturas e Materiais LEM-USP. A caracterização das principais propriedades foi feita através da moldagem de corpos de prova, os quais foram fabricados e curados ao mesmo tempo que os modelos. Por meio dos ensaios realizados com os corpos de prova determinaram-se o módulo de elasticidade, resistência a compressão, resistência a tração, tensão de aderência e energia de fratura.

Outro fator importante, no estudo dos modelos, são as medições das grandezas físicas tais como deformações, deslocamentos e carga. Para tal fim, foi montado um sistema de monitoração compostos por sensores (straingages, LVDT's e células de carga) e um sistema de aquisição modelo SCXI da National Instruments cujo funcionamento está detalhado no item 2.6.2 da presente pesquisa.

\subsection{Modelo reduzido da ponte (pórtico armado).}

\subsubsection{Generalidades}

Com a construção do modelo em escala reduzida pretende-se estudar o comportamento experimental da estrutura de microconcreto na fase linear e a não linearidade física do material. A não linearidade física dos materiais que compõem uma seção transversal pode ser estudada através de suas relações de tensãodeformação. Neste trabalho, as deformações foram obtidas de forma experimental por meio de leituras fornecidas pelos extensômetros instalados, durante a execução do ensaio.

Esses dados experimentais foram utilizados para se construir o diagrama da relação momento-curvatura experimental e a distribuição de tensões, da seção em estudo, para cada incremento de carga.

As principais grandezas físicas foram monitoradas por um sistema de sensores instalados especificamente no meio do vão da viga e a seção transversal 
dessa região foi instrumentada ao longo de sua altura com extensômetros colados no aço e no microconcreto. Na figura 5.1 ilustra-se o modelo reduzido montado sobre o pórtico de ensaios.

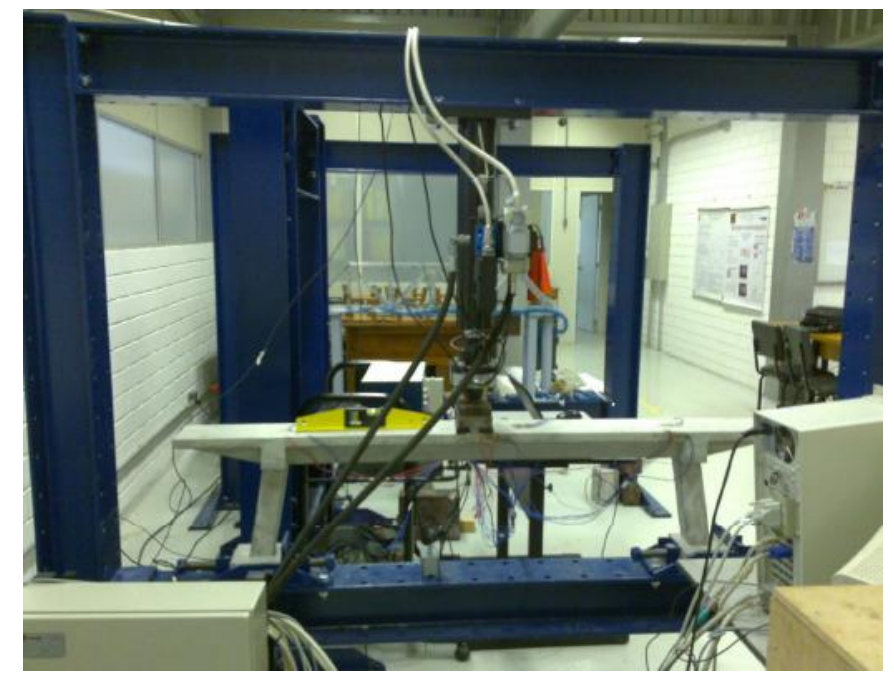

Figura 5.1 - Modelo em escala reduzida do pórtico armado (ponte).

Todo o estudo experimental foi complementado com um estudo analítico. Para isso, utilizaram-se algumas ferramentas de análise estrutural comercias como o SAP2000 e também foi desenvolvido um programa que permitiu calcular o momentocurvatura usando o modelo constitutivo do aço e do concreto segundo a Norma ABNT NBR 6118:2007. Assim, os resultados experimentais permitiram validar o modelo teórico.

Com a finalidade de se ter um melhor entendimento deste estudo experimental, nos itens seguintes serão apresentados alguns conceitos básicos de momento-curvatura, os mesmos que foram usados como base teórica para montar o aplicativo que gera a relação momento-curvatura em forma automática.

\subsubsection{Conceitos básicos da relação momento-curvatura}

\subsubsection{Definição}

A relação momento curvatura de uma seção de concreto armado é obtida em função dos modelos constitutivos do concreto e do aço. Além disso, depende da geometria e das armaduras longitudinais e transversais. Esse diagrama é a base para definir um modelo não linear. 
A hipótese usual da teoria de Elasticidade linear, que consiste em atribuir a cada barra seu modulo de elasticidade $E$ e seu momento de inércia $I$, corresponde a uma lei momento-curvatura linear, sem limite da curvatura na análise. A inclinação da reta que representa essa lei é dada pelo produto EI. Essa hipótese está longe de refletir a verdadeira resposta do material concreto armado. Assim, ao invés de atribuir a cada barra seu modulo de elasticidade e seu momento de inércia, usa-se a relação de momento-curvatura. Possibilita-se com isso a análise não linear, que pode então atender além das condições de equilíbrio, também as de compatibilidade e as leis constitutivas dos materiais (BUCHAIM, 2001).

As hipóteses básicas consideradas para a construção do diagrama momento-curvatura são apresentadas a seguir:

- As seções transversais ao eixo da peça, inicialmente planas, permanecem planas e normais ao eixo deformado. Com essa hipótese, as deformações normais são proporcionais à distância da linha neutra.

- Na compressão e na tração antes da fissuração há aderência perfeita (sem deslizamento) entre a armadura e o concreto circundante. O mesmo já não se pode afirmar na tração após a fissuração, pois há deslizamento entre os materiais. Entretanto, pode-se afirmar que ainda há igualdade dos alongamentos médios do aço e do concreto.

- $\quad$ O efeito da fluência do concreto não é considerado.

- A colaboração do concreto à tração é desprezada.

- Para a relação tensão-deformação do aço adotou-se a recomendação da ABNT NBR 6118:2007.

- Para a relação tensão-deformação do concreto comprimido foi adotado o diagrama parábola-retângulo da ABNT NBR 6118:2007.

- As considerações adotadas para a construção das relações momentocurvatura $(\mathrm{M}-1 / \mathrm{r})$ são válidas somente para concretos normais, com resistência característica à compressão entre 20 a $50 \mathrm{MPa}$. 


\subsubsection{Diagramas de tensão- deformação dos materiais}

\section{Concreto}

O concreto é considerado um material elastoplástico, mas sob ação de cargas de compressão da ordem de até $50 \%$ de sua resistência, apresenta um comportamento aproximadamente elástico-linear tal como estabelece a ABNT NBR 6118:2007. A distribuição de tensões no concreto é complexa e de difícil representação.

Para dimensionamento das peças de concreto, a norma brasileira recomenda que a distribuição de tensões na seção pode ser representada pelo diagrama parábola-retângulo considerando para este uma altura de área comprimida igual a 0,8 da linha neutra.

Na figura 5.2 mostra-se a distribuição de tensão para o trecho parabólico do diagrama parábola-retângulo e está descrita pela equação (5.1).

$$
\sigma_{c}=\left\{\begin{array}{cl}
0,85 f_{c d}\left[1-\left(1-\frac{\varepsilon_{c}}{0,002}\right)^{2}\right] & ; 0 \leq \varepsilon_{c} \leq 0,002 \\
0,85 f_{c d} & ; 0,002 \leq \varepsilon_{c} \leq 0,0035
\end{array}\right.
$$

Onde $\sigma_{c}$ é a tensão no concreto, $\varepsilon_{c}$ a deformação no concreto e $f_{c d} a$ resistência de cálculo à compressão do concreto.

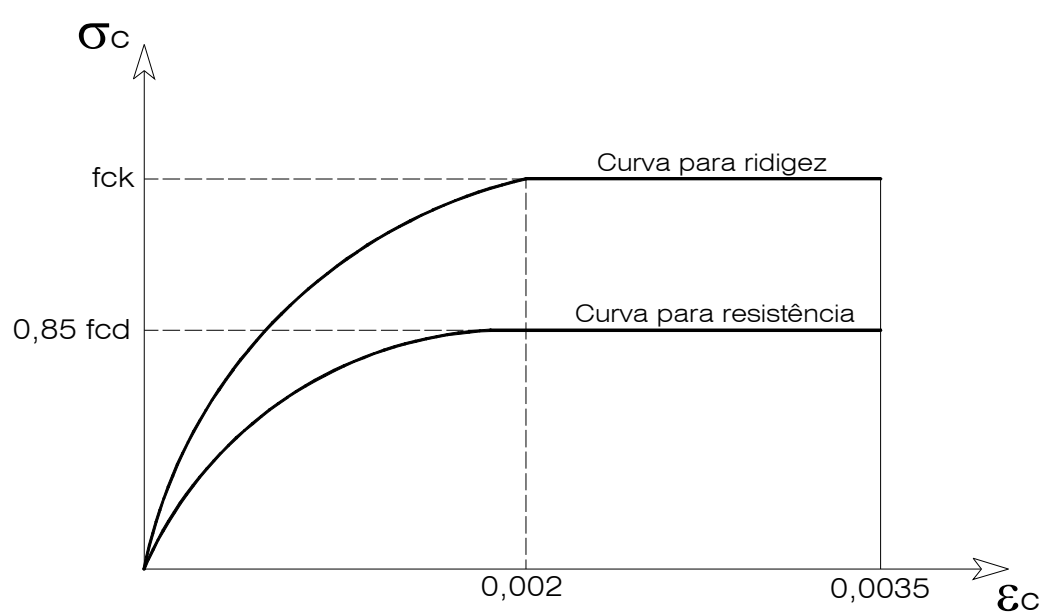

Figura 5.2 - Diagrama tensão-deformação para o concreto comprimido. 


\section{Aço de armadura passiva}

A norma ABNT NBR 6118:2007 apresenta uma relação simplificada de tensão-deformação para o aço passivo, mostrada na figura 5.3 e descrita pela equação (5.2).

$$
\sigma_{s}= \begin{cases}-f_{y d} & ;-0,010 \leq \varepsilon_{s} \leq-\varepsilon_{s y} \\ E_{s} \varepsilon_{s} & ;-\varepsilon_{s y} \leq \varepsilon_{s} \leq \varepsilon_{s y} \\ f_{y d} & ; \varepsilon_{s y} \leq \varepsilon_{s} \leq 0,010\end{cases}
$$

Onde $\sigma_{\mathrm{s}}$ é a tensão no aço passivo, $\varepsilon_{\mathrm{s}}$ a deformação no aço, $\mathrm{E}_{\mathrm{s}}$ o modulo de elasticidade e $f_{y d}$ a resistência de cálculo ao escoamento do aço.

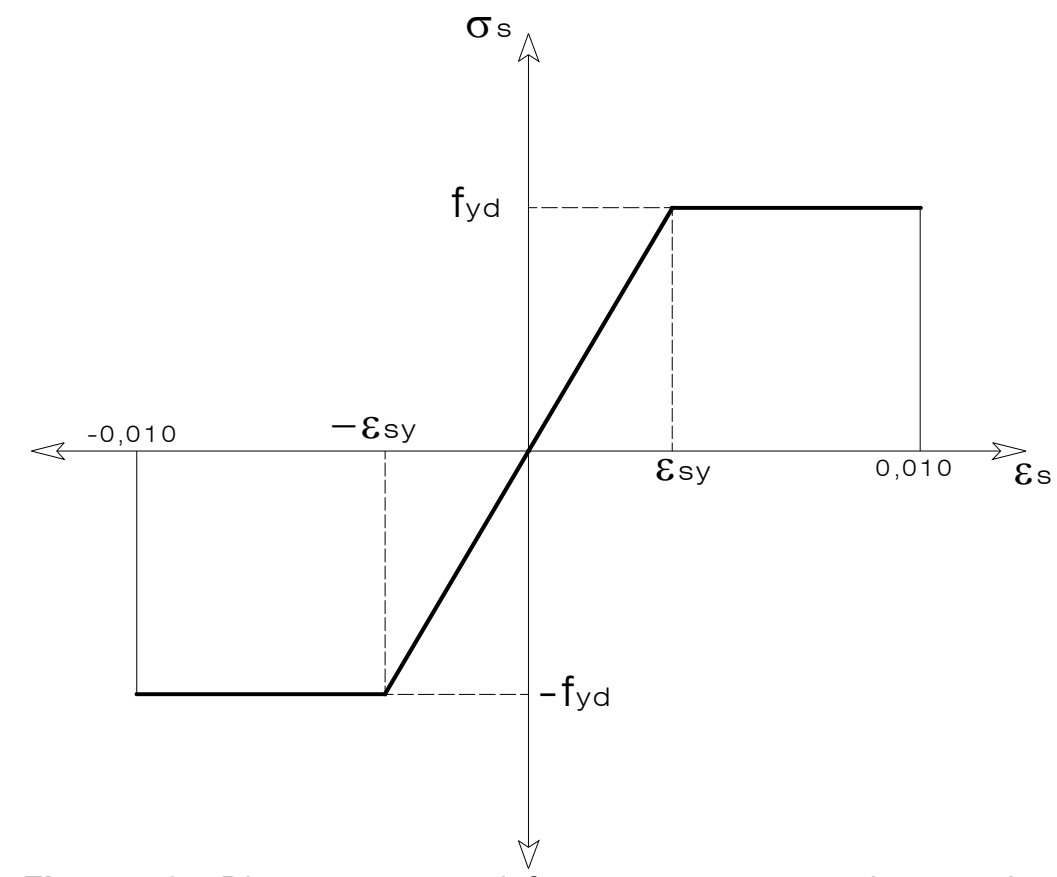

Figura 5.3 - Diagrama tensão-deformação para a armadura passiva.

\subsubsection{Método de cálculo dos esforços resistentes}

A análise do comportamento momento-curvatura, para uma carga axial constante realiza-se de forma incremental. Em cada passo impõe-se um incremento de curvatura, determina-se por iteração a posição do eixo neutro de maneira a equilibrar o esforço normal interno com o externo, assim finalmente avalia-se o momento associado. 
Como condição de compatibilidade utiliza-se a hipótese de seções planas, isto implica que a distribuição das deformações é linear ao longo da seção transversal, tal como se apresenta na figura 5.4.

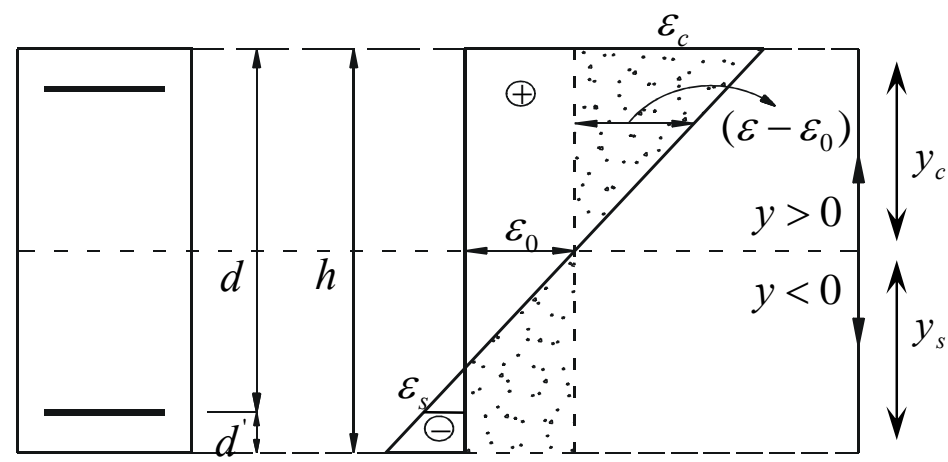

Figura 5.4 - Compatibilidade das deformações (OLIVEIRA, 2008).

A curvatura de uma seção é definida pela equação (5.3) e é obtida a partir da figura anterior.

$$
\frac{1}{r}=\frac{\varepsilon_{s}-\varepsilon_{c}}{d} \quad \frac{h}{r}=h \cdot\left(\frac{\varepsilon_{s}-\varepsilon_{c}}{d}\right)
$$

Onde $\varepsilon_{\mathrm{c}}$ é a deformação extrema no concreto comprimido, $\varepsilon_{\mathrm{s}}$ a deformação na armadura de tração, $h$ a altura da seção e $d$ a distância entre a face superior da seção e a armadura.

Conforme se mostra na figura 5.4 a curvatura da barra não depende da deformação total $\varepsilon$ de suas fibras, mas tão somente da diferença $\varepsilon-\varepsilon_{0}$ entre a deformação total e a deformação da fibra situada ao nível do centro geométrico da seção. Desse modo resultam as seguintes condições de compatibilidade de deformações em função da curvatura (FUSCO, 1986):

No concreto

$\mathrm{Na}$ armadura

$$
\frac{1}{r}=\frac{\varepsilon_{c}-\varepsilon_{o}}{y_{c}} \Rightarrow \varepsilon_{c}=\varepsilon_{o}+\frac{y_{c}}{r}
$$

$$
\frac{1}{r}=\frac{\varepsilon_{s}-\varepsilon_{o}}{y_{s}} \Rightarrow \varepsilon_{s}=\varepsilon_{o}+\frac{y_{s}}{r}
$$

Com os diagramas de tensão-deformação conhecidos tanto do aço quanto do concreto, ficam determinadas as tensões: 


$$
\begin{aligned}
& \sigma_{c}=f \varphi_{1}\left(\varepsilon_{o}, \frac{y_{c}}{r}\right) \\
& \sigma_{s}=f \varphi_{2}\left(\varepsilon_{o}, \frac{y_{s}}{r}\right)
\end{aligned}
$$

Por outro lado, quando uma seção de concreto é solicitada a forças externas surgem deformações e tensões internas. A fim de garantir o equilíbrio na seção, devem-se cumprir algumas condições de equilíbrio:

$$
\begin{gathered}
N=\int \sigma_{c} d A_{c}+\sum \sigma_{s} A_{s} \Rightarrow N=\int \varphi_{1}\left(\varepsilon_{o}, \frac{y_{c}}{r}\right) d A_{c}+\sum \varphi_{2}\left(\varepsilon_{o}, \frac{y_{s}}{r}\right) \cdot A_{s} \\
M=\int \sigma_{c} \cdot d A_{c} \cdot y_{c}+\sum \sigma_{s} A_{s} \cdot y_{s} \Rightarrow M=\int \varphi_{1}\left(\varepsilon_{o}, \frac{y_{c}}{r}\right) d A_{c} \cdot y_{c}+\sum \varphi_{2}\left(\varepsilon_{o}, \frac{y_{s}}{r}\right) \cdot A_{s} \cdot y_{s}
\end{gathered}
$$

Com as expressões (5.8) e (5.9) podem ser determinados os diagramas (M-N-1/r), para uma seção transversal conhecida.

\subsubsection{Aplicativo para o cálculo da relação momento - curvatura.}

O aplicativo desenvolvido para a presente pesquisa teve a finalidade de calcular teoricamente as relações momento-curvatura de uma seção, com as características similares à seção que foi objeto de estudo experimental. Para gerar as relações de momento-curvatura, o aplicativo leva em consideração as hipóteses estabelecidas no item 5.2.2.1.

Os esforços resistentes da seção foram calculados com o método das lamelas, o qual consiste na discretização do elemento em faixas ao longo da altura, possibilitando a integração da seção através do somatório das camadas. As camadas podem ter diferentes espessuras e serem constituídas por diferentes materiais, possibilitando, por exemplo, a simulação de barras longitudinais de aço imersas no concreto. É importante notar que o método das lamelas é aproximado, dependendo do grau de discretização adotado, para o caso de concreto armado, 8 a 12 camadas são suficientes para a obtenção de bons resultados (figura 5.5). O uso de camadas com espessuras diferentes podem melhorar os resultados, situando as mais delgadas próximas aos extremos da seção, (OLIVEIRA, 2008). 
A distribuição de tensões e deformações é calculada por diferentes métodos de aproximação. A maioria dos pesquisadores recomenda o uso do método da aproximação trapezoidal, pois oferece melhores resultados em relação aos outros.

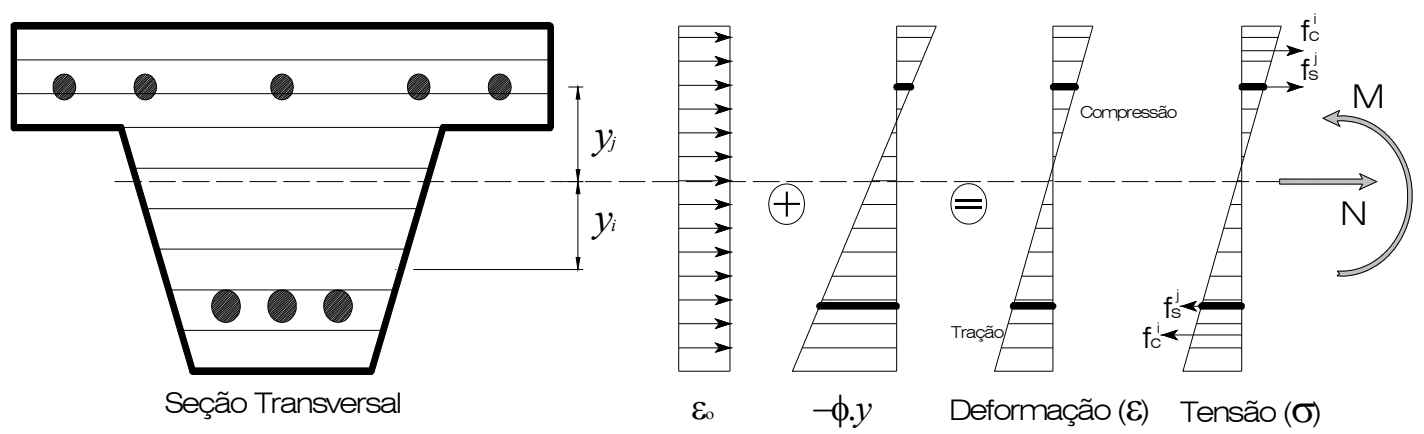

Figura 5.5 - Seção discretizada em lamelas - aproximação trapezoidal.

Usando a aproximação trapezoidal, as equações (5.8) e (5.9) podem ser escritas da seguinte forma:

Esforço normal:

$$
N=\sum_{i=1}^{n c} \frac{\left(\sigma_{x}^{i, b}+\sigma_{x}^{i, t}\right)}{2} \cdot b_{i} \cdot h_{i}+\sum_{j=1}^{n b} \sigma_{s}^{j} \cdot A_{s}^{j}
$$

Momento fletor:

$$
M=\sum_{i=1}^{n c} y_{i} \cdot \frac{\left(\sigma_{x}^{i, b}+\sigma_{x}^{i, t}\right)}{2} \cdot b_{i} \cdot h_{i}+\sum_{j=1}^{n b} y_{j} \cdot \sigma_{s}^{j} \cdot A_{s}^{j}
$$

Onde $A$ é a área da seção, $A_{s}^{j}$ área da barra de aço, $n b$ número de barras de aço, $n c$ número de camadas, $\sigma_{s}^{j}$ tensão na barra $j, \sigma_{x}^{i, b}$ tensão no concreto na base da camada $i, \sigma_{x}^{i, t}$ tensão no concreto no topo da camada $i, b_{i}$ largura da camada $i, h_{i}$ espessura da camada $i, y_{i}$ distância do centro geométrico do trapézio $i$ ao centro geométrico da seção, $y_{j}$ distância do eixo da barra de aço $j$ ao centro geométrico da seção.

A sequência de cálculo da relação momento-curvatura, usado no aplicativo, pode ser resumida no fluxograma da figura 5.6, onde o parâmetro $\varepsilon_{0}$ é determinado a partir das condições limites estabelecidas na equação 5.12.

$$
\begin{aligned}
& \varepsilon_{c, \text { max }}=\varepsilon_{o, \text { max }}+\frac{y_{c i}}{r} \leq \varepsilon_{c d, \lim }=\left(3,5 \% 00 \varepsilon_{c d} \leq 2 \%\right) \\
& \varepsilon_{s i, \text { max }}=\varepsilon_{o, \text { max }}+\frac{y_{s i}}{r} \leq \varepsilon_{s d, \lim }=10 \% 0
\end{aligned}
$$




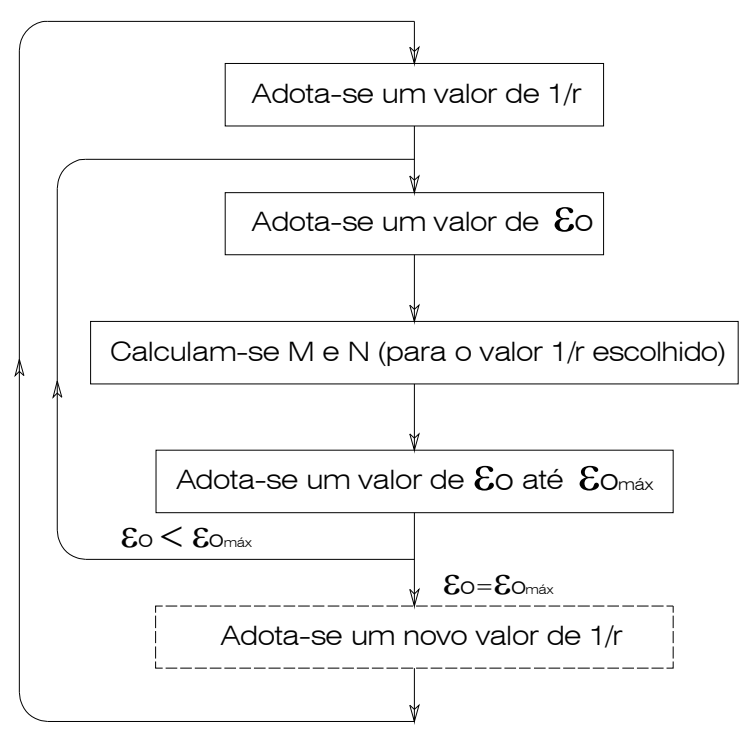

Figura 5.6 - Fluxograma implementado no programa para cálculo de M-1/r (FUSCO, 1986).

Os resultados calculados no aplicativo foram validados com o programa SAP2000. Essa comparação é apresentada no cálculo feito para a seção transversal do modelo reduzido.

\section{Momento-curvatura teórico para o modelo reduzido}

A relação momento-curvatura foi calculada para a seção transversal da viga do modelo reduzido, cujas características geométricas são ilustradas na figura 5.7.

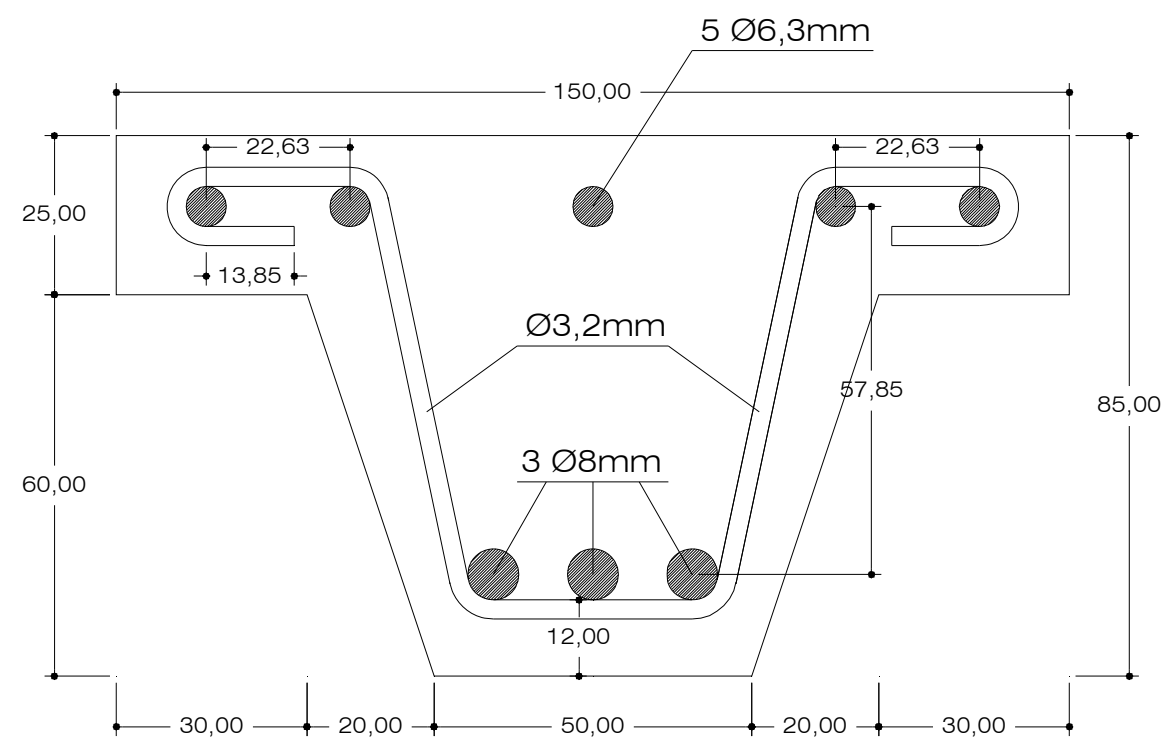

Figura 5.7 - Seção transversal da viga do modelo reduzido (Unidade: mm). 
Antes de iniciar o processo de cálculo, o programa foi alimentado com informações relacionadas às propriedades dos materiais, as características geométricas da seção e os parâmetros de aproximação.

As propriedades dos materiais foram obtidas a partir dos ensaios de caracterização, os mesmos apresentados com maior detalhe no anexo B. Para fins de cálculo, utilizaram-se nessa parte, apenas algumas das propriedades, as quais são listadas nos itens a seguir.

De modo a facilitar o ingresso de dados, o aplicativo apresenta uma interface gráfica tal como se ilustra na figura 5.8 a qual permite editar os valores de forma rápida e simples.

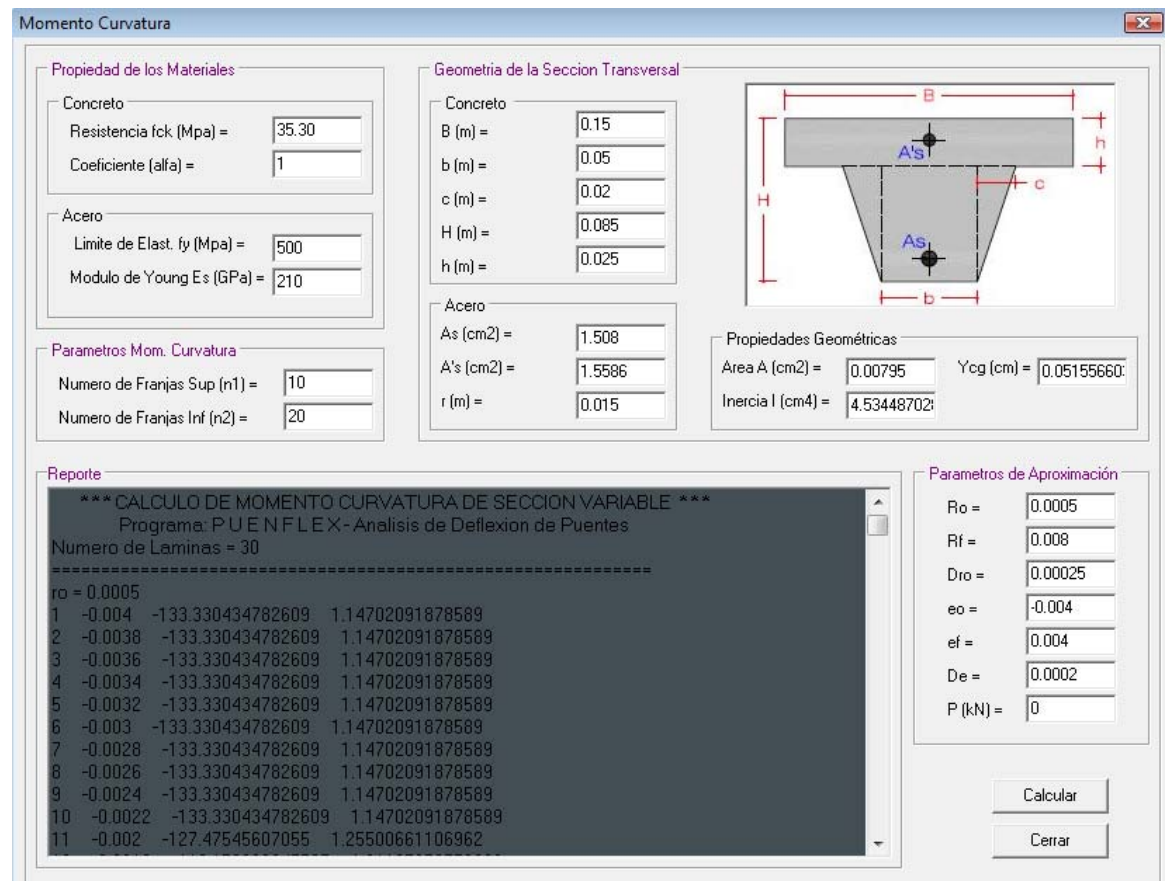

Figura 5.8 - Interface gráfica do aplicativo denominado Puenflex.

Os valores adotados para gerar o momento-curvatura teórico da seção do modelo são apresentados a seguir:

Propriedades dos Materiais

Microconcreto

$\mathrm{f}_{\mathrm{ck}}=35,30 \mathrm{MPa}$. (Resistência à compressão)

$\alpha=1$ (Fator de redução) 
Aço CA-50

$\mathrm{f}_{\mathrm{yk}}=500 \mathrm{MPa}$ (Resistência característica ao escoamento do aço)

$\mathrm{E}_{\mathrm{s}} \quad=210 \mathrm{GPa}$ (Modulo de elasticidade do aço)

As $\quad=1,508 \mathrm{~cm}^{2}$ (Aço na parte inferior da seção: $3 \phi 8 \mathrm{~mm}$ )

A's $\quad=1,5586 \mathrm{~cm}^{2}$ (Aço na parte superior da seção: $5 \phi 6,3 \mathrm{~mm}$ )

Parâmetros de Aproximação:

Número de lamelas na mesa: 10

Número de lamelas na alma: 20

Os intervalos de variação considerados para a curvatura $(h / r)$ e a deformação $(\varepsilon)$, com o fim de calcular a força normal $N$ e o momento resistente $M$, são:

$$
\begin{array}{ll}
\text { Curvatura } & 0,0005 \leq \frac{h}{r} \leq 0,008 \rightarrow \Delta \frac{h}{r}=0,00025 \\
\text { Deformação } & -0,004 \leq \varepsilon \leq 0,004 \rightarrow \Delta \varepsilon=0,0002
\end{array}
$$

Os resultados da relação momento-curvatura e momento-deformação no centro geométrico obtidos por meio do aplicativo são apresentados na figura 5.9 e na tabela 5.1 , os quais para serem considerados como válidos, foram comparados com os resultados obtidos no programa SAP2000. O modelo constitutivo (Mander Unconfined) providenciados pelo modulo de SAP2000 foi adaptado em função às propriedades do material, para assim fazer a comparação respectiva.

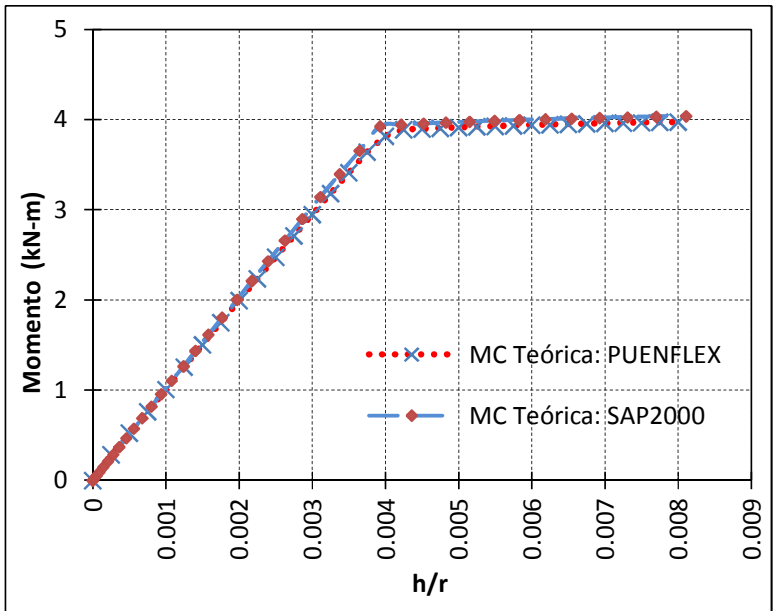

(a)

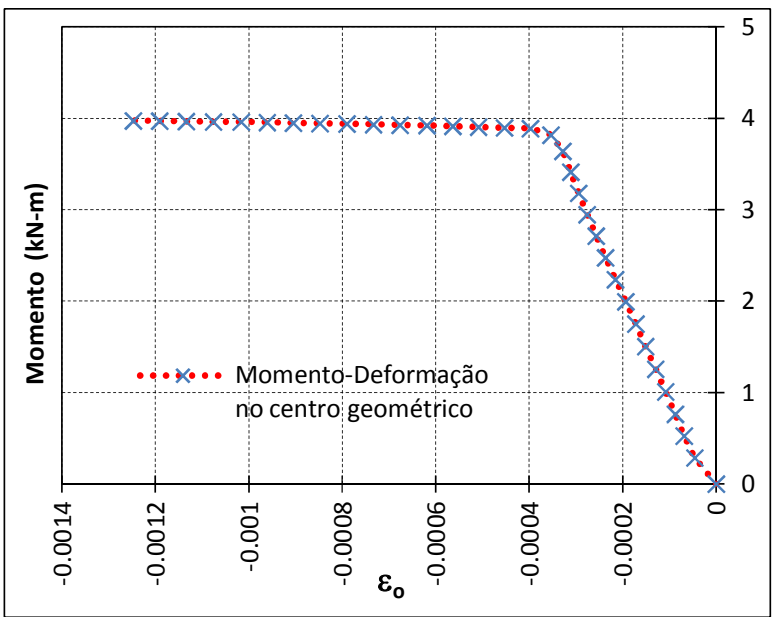

(b)

Figura 5.9 - (a) Relação Momento-curvatura da seção, (b) Relação Momento-deformação $\varepsilon_{0}$ no centro geométrico da seção. 
Tabela 5.1 - Resultados teóricos de Momento-curvatura.

\begin{tabular}{|c|c|c|}
\hline \multirow{2}{*}{$h / r$} & \multicolumn{2}{|c|}{ Momento (kN-m) } \\
\hline & Puenflex & SAP2000 \\
\hline 0 & 0,000 & 0,000 \\
\hline 0,00025 & 0,287 & \\
\hline 0,0005 & 0,526 & 0,511 \\
\hline 0,00075 & 0,764 & \\
\hline 0,001 & 1,010 & 1,025 \\
\hline 0,00125 & 1,258 & \\
\hline 0,0015 & 1,505 & 1,536 \\
\hline 0,00175 & 1,751 & \\
\hline 0,002 & 1,996 & 2,034 \\
\hline 0,00225 & 2,238 & \\
\hline 0,0025 & 2,477 & 2,536 \\
\hline 0,00275 & 2,714 & \\
\hline 0,003 & 2,949 & 3,035 \\
\hline 0,00325 & 3,182 & \\
\hline 0,0035 & 3,413 & 3,518 \\
\hline 0,00375 & 3,643 & \\
\hline 0,004 & 3,819 & 3,932 \\
\hline 0,00425 & 3,891 & \\
\hline 0,0045 & 3,898 & 3,957 \\
\hline 0,00475 & 3,906 & \\
\hline 0,005 & 3,916 & 3,974 \\
\hline 0,00525 & 3,924 & \\
\hline 0,0055 & 3,928 & 3,988 \\
\hline 0,00575 & 3,934 & \\
\hline 0,006 & 3,942 & 4,001 \\
\hline 0,00625 & 3,946 & \\
\hline 0,0065 & 3,950 & 4,012 \\
\hline 0,00675 & 3,956 & \\
\hline 0,007 & 3,962 & 4,022 \\
\hline 0,00725 & 3,964 & \\
\hline 0,0075 & 3,967 & 4,031 \\
\hline 0,00775 & 3,972 & \\
\hline
\end{tabular}

Da tabela 5.1 e a figura 5.9 (a), pode-se observar que os momentos obtidos no aplicativo são muito próximos aos calculados pelo SAP2000. As diferenças de aproximação podem ser atribuídas ao fato de usar modelos constitutivos diferentes.

Em função à comparação feita, os valores calculados no aplicativo podem ser considerados como confiáveis. 


\subsubsection{Estudos experimentais}

Os estudos experimentais consistem na descrição detalhada dos procedimentos de construção, montagem e monitoração do modelo reduzido, assim como os ensaios efetuados sobre ele, com o objetivo de se obter parâmetros que permitam entender melhor o comportamento não linear da estrutura, do ponto de vista do material (microconcreto).

\subsubsection{Características do modelo reduzido}

A idéia de construir um modelo com as características já fabricadas veio do concurso DARTE, que é realizado no encontro de Betão Estrutural na Faculdade de Engenharia da Universidade do Porto no Portugal. Esse concurso consiste no ensaio de modelos reduzidos executados pelos concorrentes (grupos de estudantes das diversas escolas de Engenharia Civil de Portugal), para avaliar sua máxima resistência (MAIA, 2004).

As dimensões do modelo em estudo foram adaptadas, levando-se em consideração as sugestões do regulamento do concurso DARTE. Na figura 5.10, apresentam-se algumas dimensões adotadas e a disposição do modelo no pórtico de ensaios.

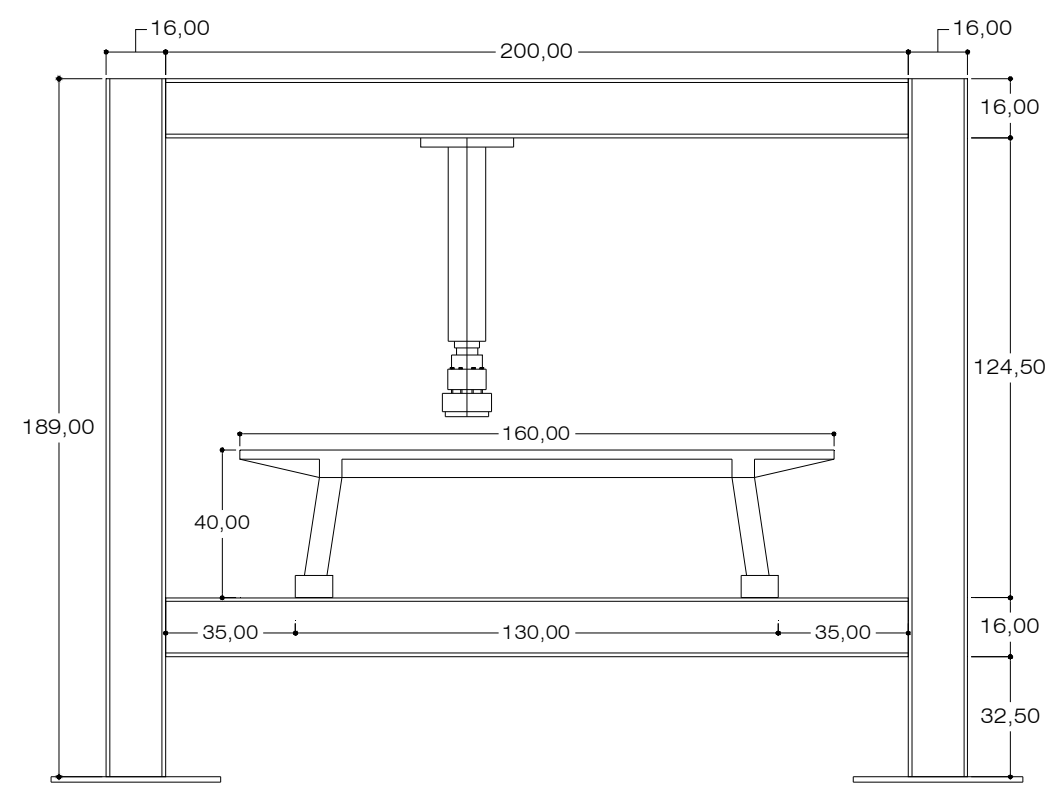

Figura 5.10 - Disposição do modelo no pórtico de ensaios, dimensões em centímetros. 
Uma vez definida a geometria, as seções transversais e o comprimento do modelo, procedeu-se ao dimensionamento do tabuleiro, pilares e sapatas. $O$ cálculo e as verificações correspondentes foram feitas de acordo a norma ABNT NBR 6118:2007.

A figura 5.11, ilustra a geometria do modelo em planta e elevação.
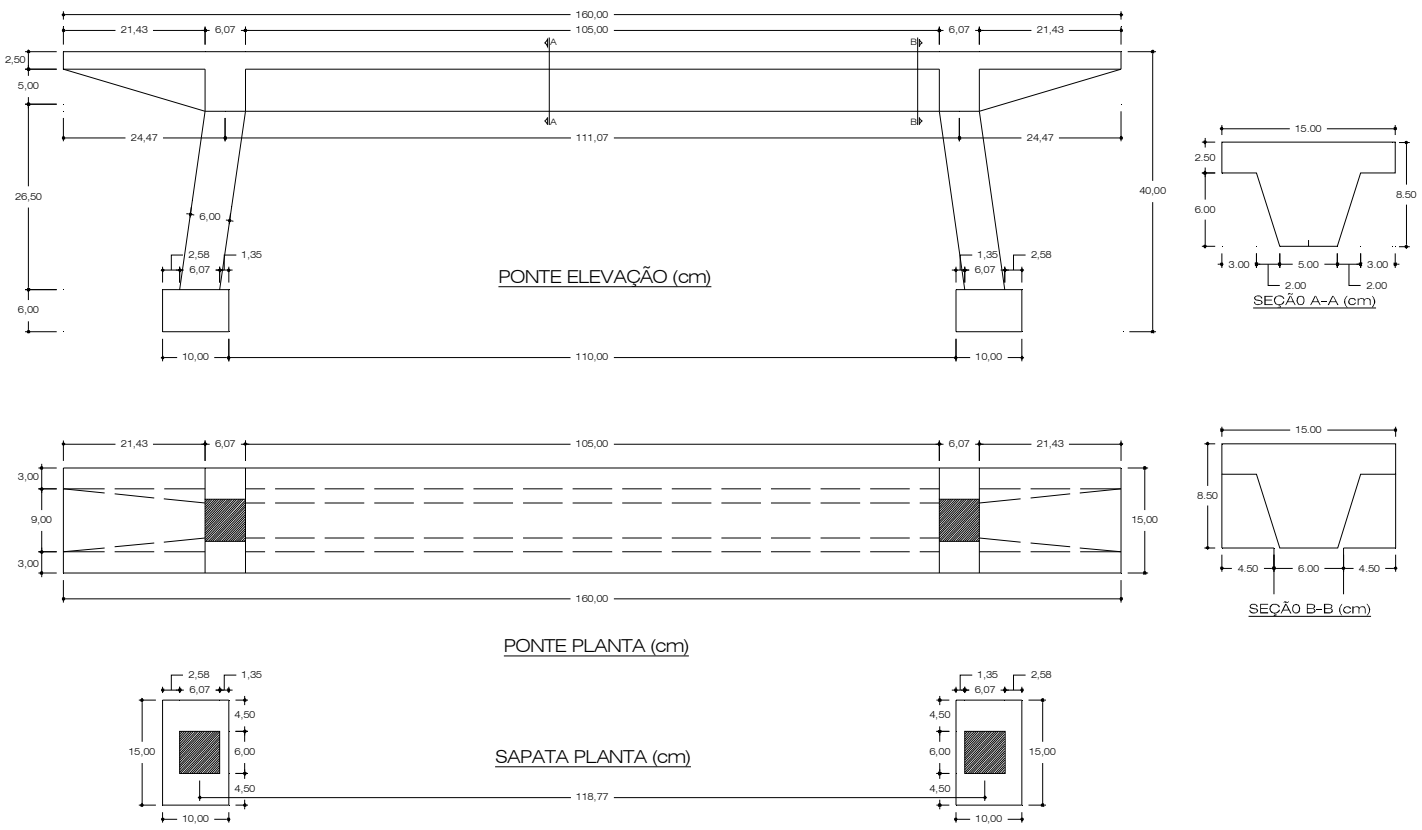

Figura 5.11 - Detalhe da geometria do modelo da ponte.

Viga tabuleiro: O dimensionamento da viga-tabuleiro foi realizado para uma carga arbitrária de $\mathrm{P}=22,50 \mathrm{kN}$, em seguida determinou-se o momento solicitante que, como não podia deixar de ser, ocorreu no meio do vão da vigatabuleiro. Para tal fizeram-se as seguintes considerações:

- Desprezou-se a parcela do momento devido ao peso próprio da estrutura, visto que esta representa apenas o $1 \%$ da carga de $22,50 \mathrm{kN}$.

- Considerou-se que a carga aplicada era concentrada no meio do vão, quando na realidade é distribuída por uma pequena área.

Feitas tais considerações, calculou-se o valor do momento, através de um modelo matemático simples, resultando um valor de $\mathrm{M}=4,05 \mathrm{kN}-\mathrm{m}$. 
Conforme o cálculo detalhado no anexo D, a seção será armada com $3 \phi 8$ $\mathrm{mm}$, o suficiente para suportar o momento solicitado.

Em relação ao esforço cortante, a seção transversal foi armada com dois tipos de estribos, espaçados a cada $2,50 \mathrm{~cm}$ ao longo de toda a viga, conforme o dimensionamento efetuado. Na figura 5.12 ilustram-se as formas dos estribos da viga-tabuleiro e do pilar.
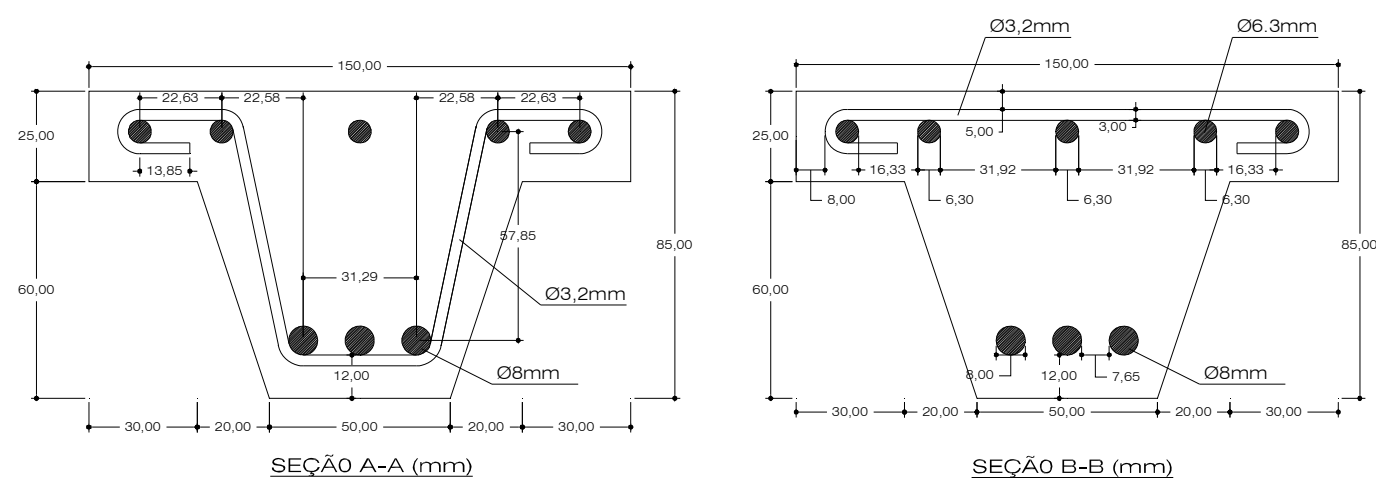

$\underline{\text { SEÇÃO B-B (mm) }}$

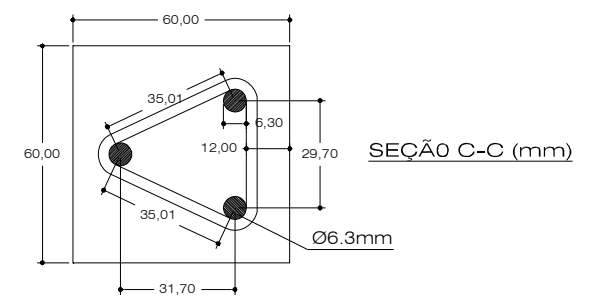

Figura 5.12 - Seção transversal da viga tabuleiro e o pilar.

Pilares : Os pilares, segundo o modelo de cálculo adotado, deveriam estar sujeitos à flexo - compressão. De acordo com tal consideração, e feitos os cálculos, verificou-se que os pilares não precisavam de armadura para resistir o esforço máximo que lhes foi imposto (12 kN em cada pilar e momentos bem baixos). Contudo, por uma questão de estabilidade achou-se que seria vantajoso colocar alguma armadura vertical e alguns estribos para se precaver sobre algum erro que pudesse existir na execução do modelo. Assim, considerou-se razoável colocar $3 \phi$ $6,3 \mathrm{~mm}$ em cada pilar com estribos que deveriam ficar espaçados a cada $5 \mathrm{~cm}$ (figura 5.13).

Sapatas: Também, as sapatas estavam claramente superdimensionadas, pelo que não foi necessário armá-la, de forma que se optou apenas por dobrar os 
ferros dos pilares para o interior de cada sapata de acordo com a facilidade na execução. Na figura 5.13 é apresentado o detalhamento e a disposição da armadura no modelo. Nelas mostram-se a locação das barras longitudinais, a distribuição dos estribos e a forma das ancoragens.

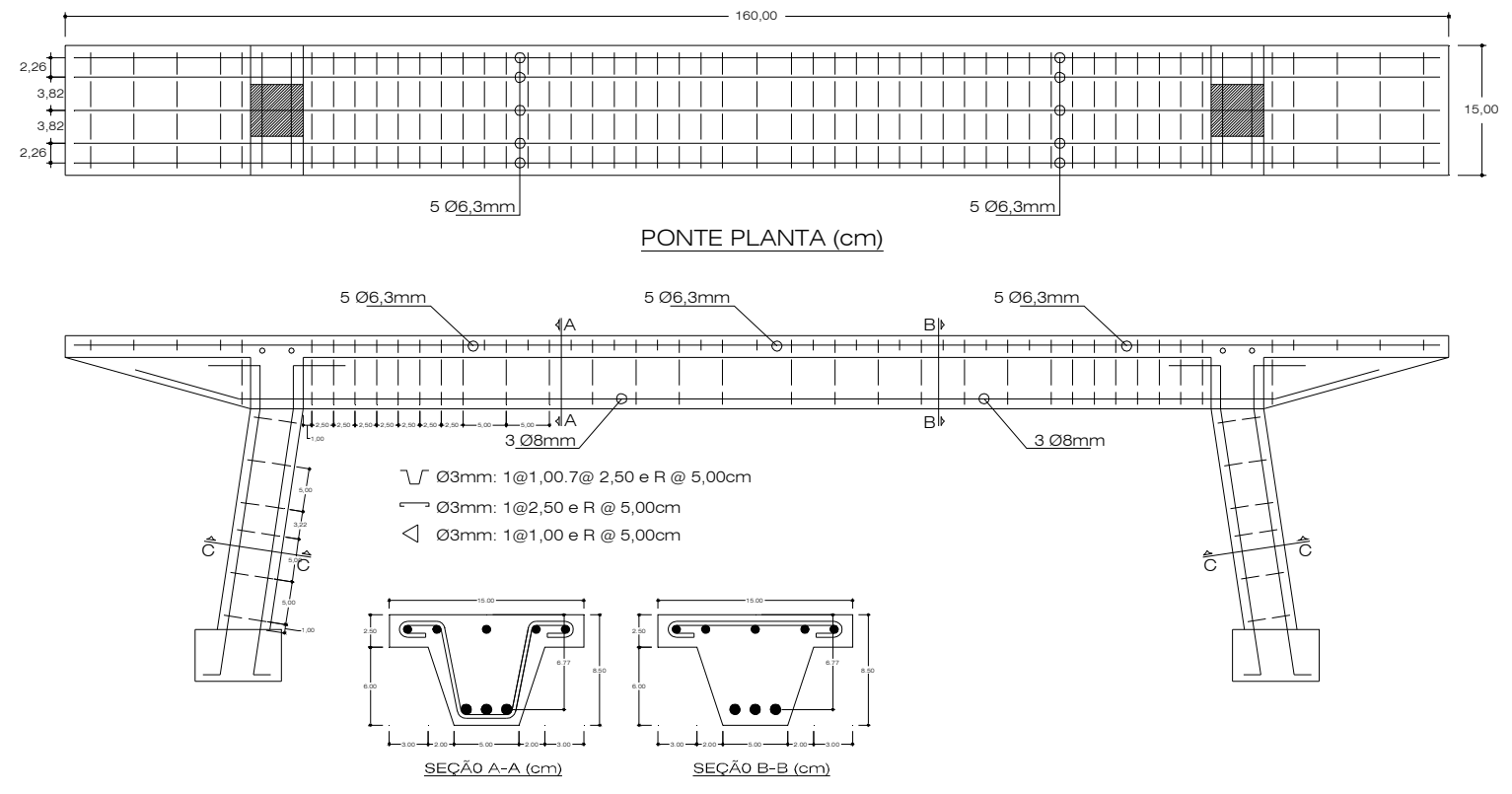

Figura 5.13 - Disposição das armaduras longitudinais e transversais.

\subsubsection{Caracterização e construção do modelo reduzido}

A seguir apresenta-se um resumo das principais propriedades mecânicas obtidas dos ensaios de caracterização dos materiais:

Tabela 5.2 - Propriedades mecânicas do microconcreto.

\begin{tabular}{ccc}
\hline $\begin{array}{c}\text { Resistência à } \\
\text { Compressão } \\
\text { (MPa) }\end{array}$ & $\begin{array}{c}\text { Resistência à } \\
\text { Tração } \\
\text { (MPa) }\end{array}$ & $\begin{array}{c}\text { Módulo de } \\
\text { Elasticidade } \\
\text { (GPa) }\end{array}$ \\
\hline $35,30 \pm 0,28$ & $4,37 \pm 0,19$ & $26,78 \pm 0,66$ \\
\hline
\end{tabular}

Tabela 5.3 - Propriedades mecânicas do aço CA-50.

\begin{tabular}{ccc}
\hline $\begin{array}{c}\text { Módulo de } \\
\text { Elasticidade } \\
(\mathrm{GPa})\end{array}$ & $\begin{array}{c}\text { Resistência à } \\
\text { Ruptura } \mathbf{f}_{\mathrm{u}} \\
(\mathrm{MPa})\end{array}$ & $\begin{array}{c}\text { Resistência ao } \\
\text { Escoamento } \mathbf{f}_{\mathrm{y}} \\
(\mathbf{M P a})\end{array}$ \\
\hline 210,00 & 550,00 & 500,00 \\
\hline
\end{tabular}


O processo construtivo e a caracterização dos materiais do modelo reduzido estão descritos com maior detalhe nos anexos $A$ e $B$, respectivamente.

\subsubsection{Execução do ensaio}

O ensaio de carga consistiu, basicamente, em aplicar uma carga incremental ao modelo e acompanhar as respectivas deformações, deslocamentos e formação de fissuras durante a carga. Para isso, o modelo foi montado e fixado no pórtico de ensaios, através de um dispositivo de apoio. Esse apoio foi fabricado especificamente para as dimensões da sapata do modelo, e sua fixação foi feita através de quatro parafusos verticais e dois parafusos horizontais.

A carga aplicada na viga foi através de um aparelho de aço (tipo rotula), cuja função era transmitir e concentrar a carga vertical ao longo da largura da viga tabuleiro e anular os momentos no ponto de aplicação. Na figura 5.14, ilustram-se os detalhes dos aparelhos tanto de apoio quanto da carga.
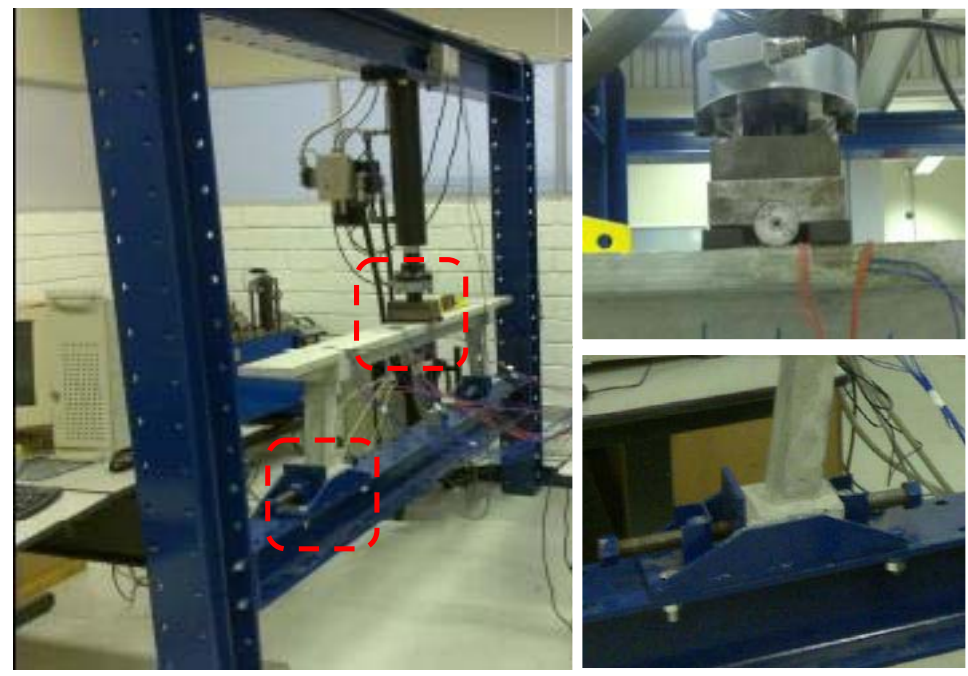

Figura 5.14 - Detalhe dos aparelhos de apoio e carga.

A seguir detalham-se os tipos de sensores usados, na monitoração do modelo durante o ensaio de carga:

\section{Medição das deformações e deslocamentos}

A medição das deformações foi realizada utilizando extensômetros de resistência elétrica de $120 \Omega$, cujas características já foram apresentadas na tabela 
4.7 do capitulo anterior. Esses extensômetros foram colados na superfície do microconcreto e nas barras do aço, tendo o cuidado suficiente para se obter uma adequada aderência entre eles.

Nas figuras 5.15 a 5.17 ilustra-se o esquema completo da localização dos extensômetros tanto na armadura quanto na superfície do microconcreto.

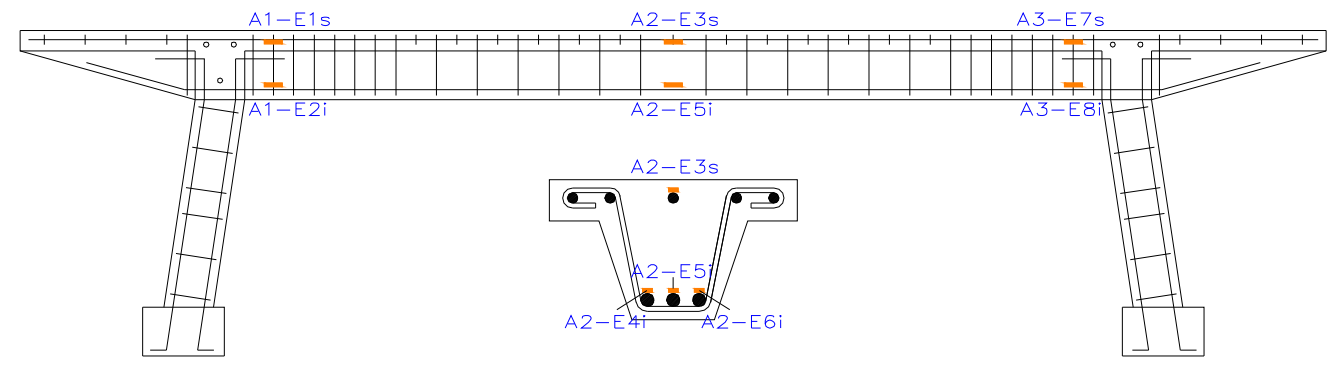

Figura 5.15 - Localização dos extensômetros na armadura da ponte.

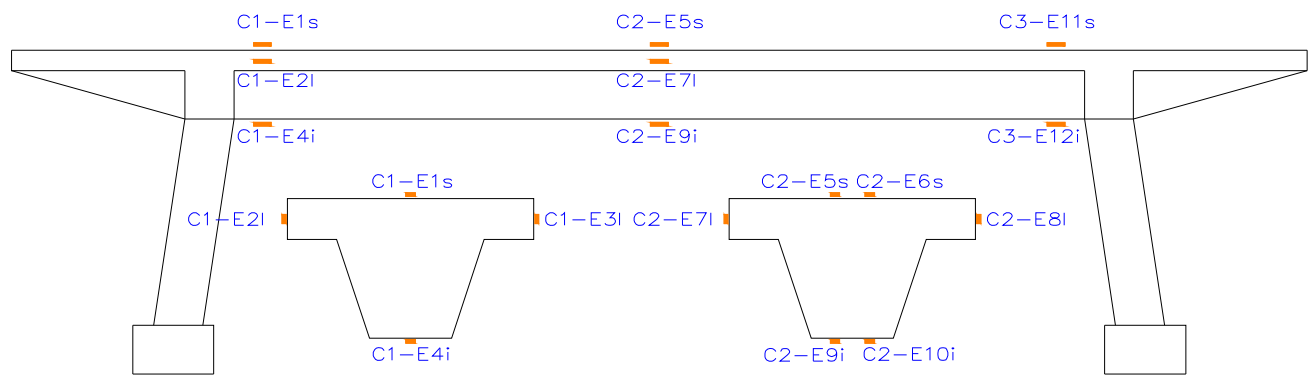

Figura 5.16 - Localização dos extensômetros na superfície da ponte.
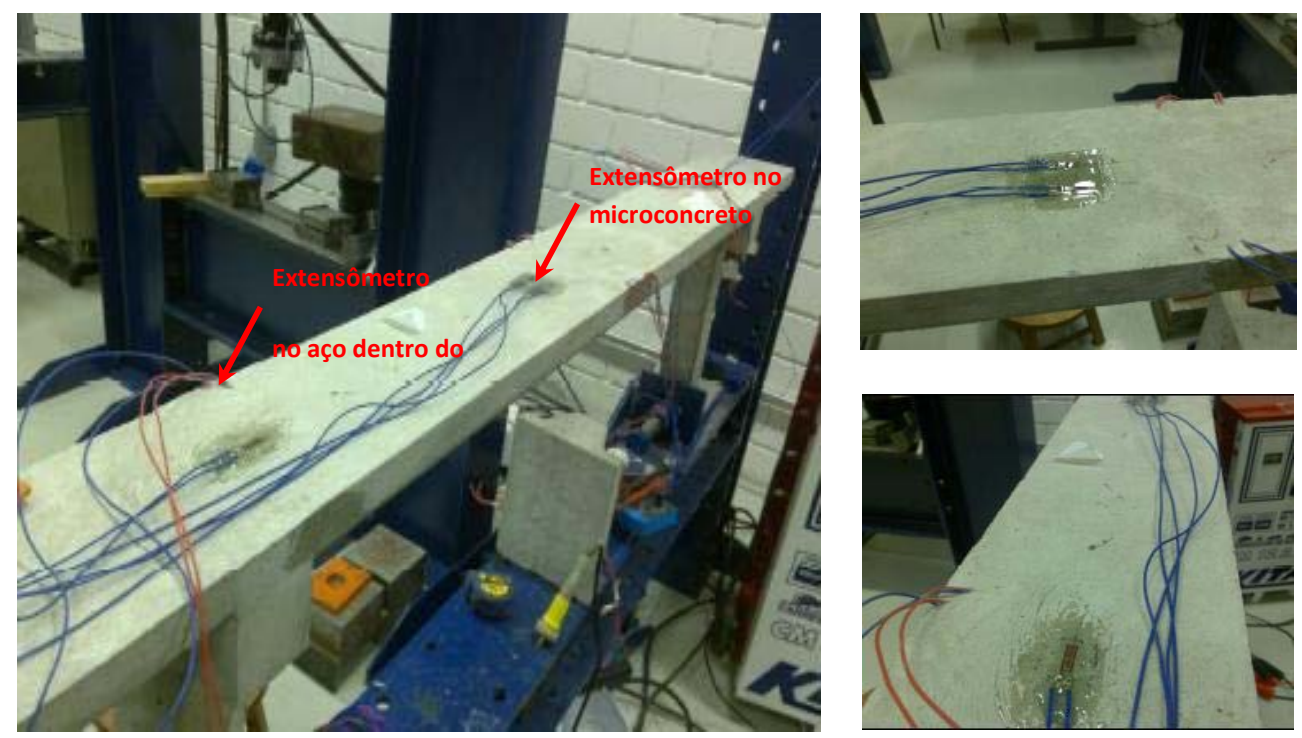

Figura 5.17 - Extensômetros colados no modelo reduzido. 
$\mathrm{Na}$ tabela 5.4 apresentam-se a disposição e a nomenclatura dos extensômetros usados no modelo.

Tabela 5.4 - Localização e nomenclatura dos extensômetros instalados no modelo.

\begin{tabular}{|c|c|c|c|}
\hline Seção & $\begin{array}{l}\text { Região de } \\
\text { Instrum. }\end{array}$ & Localização & Referência \\
\hline \multirow[b]{2}{*}{1} & Aço & $\begin{array}{l}\text { Seção 1: superior } \\
\text { Seção 1: inferior }\end{array}$ & $\begin{array}{l}\text { A1-E1s } \\
\text { A1-E2i }\end{array}$ \\
\hline & Microconcreto & $\begin{array}{l}\text { Seção 1: superior } \\
\text { Seção 1: lateral } \\
\text { Seção 1: lateral } \\
\text { Seção 1: inferior }\end{array}$ & $\begin{array}{l}\text { C1-E1s } \\
\text { C1-E2I } \\
\text { C1-E3I } \\
\text { C1-E4i }\end{array}$ \\
\hline \multirow[b]{2}{*}{2} & Aço & $\begin{array}{l}\text { Seção 2: superior } \\
\text { Seção 2: inferior } \\
\text { Seção 2: inferior } \\
\text { Seção 2: inferior }\end{array}$ & $\begin{array}{l}A 2-E 3 s \\
A 2-E 4 i \\
A 2-E 5 i \\
A 2-E 6 i\end{array}$ \\
\hline & Microconcreto & $\begin{array}{l}\text { Seção 2: superior } \\
\text { Seção 2: superior } \\
\text { Seção 2: lateral } \\
\text { Seção 2: lateral } \\
\text { Seção 2: inferior } \\
\text { Seção 2: inferior }\end{array}$ & $\begin{array}{l}\text { C2-E5s } \\
\text { C2-E6s } \\
\text { C2-E7I } \\
\text { C2-E8I } \\
\text { C2-E9i } \\
\text { C2-E10i }\end{array}$ \\
\hline \multirow[t]{2}{*}{3} & Aço & $\begin{array}{l}\text { Seção 3: superior } \\
\text { Seção 3: inferior }\end{array}$ & $\begin{array}{l}\text { A3-E7s } \\
\text { A3-E8i }\end{array}$ \\
\hline & Microconcreto & $\begin{array}{l}\text { Seção 3: superior } \\
\text { Seção 3: inferior }\end{array}$ & $\begin{array}{l}\text { C3-E11s } \\
\text { C3-E12i }\end{array}$ \\
\hline
\end{tabular}

A tomada de medidas dos deslocamentos foi realizada utilizando transdutores indutivos de deslocamento (LVDT), os quais foram dispostos no meio do vão da viga tabuleiro.

\section{Carregamento do modelo e o sistema de aquisição}

O modelo reduzido foi ensaiado através de um dispositivo composto por um servoatuador, uma central hidráulica, um quadro elétrico de interface e um computador de comando. Esse sistema permitiu o ensaio em força e em 
deslocamento, baseado nos transdutores internos do servoatuador ou em outros aplicados externamente (LVDT's). A velocidade de carga foi de $0,005 \mathrm{~mm} / \mathrm{min}$.

Na figura 5.14 ilustra-se o sistema de monitoração instalado para o ensaio do modelo reduzido.

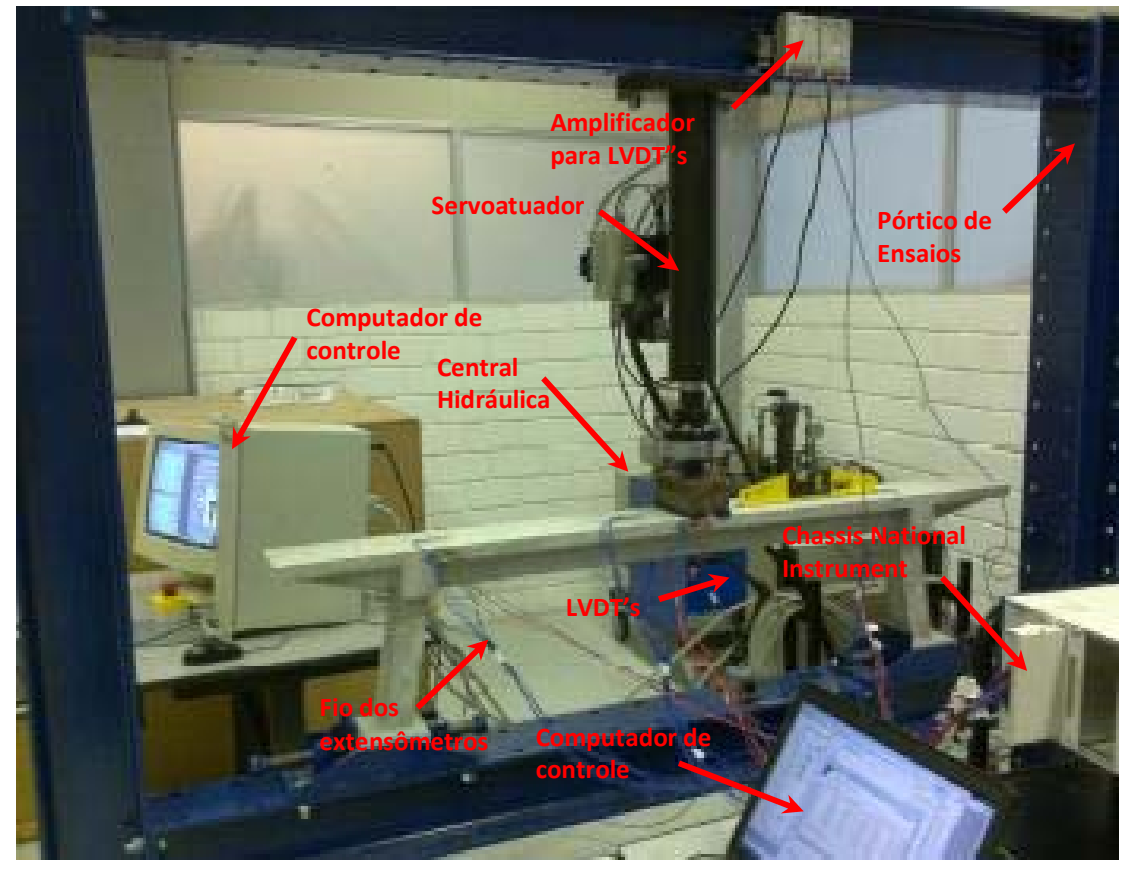

Figura 5.18 - Sistema de monitoração instalado no modelo.

O servoatuador tinha uma capacidade de carga máxima estática em compressão de $100 \mathrm{kN}$ e de $50 \mathrm{kN}$ em tração. Além disso, estava equipado com transdutor de deslocamento magnetostrictivos Gefran (serie IK1A) montado no seu interior e com célula de carga tração/compressão de 100 kN. As informações obtidas do ensaio foram processadas por um computador de controle Pentium IV, com placa gráfica, adequada para suportar DirectX e com 2 cartas $\mathrm{PCl}$ de controle e aquisição de dados. O aplicativo de controle do sistema era o software DynaTester, que opera exclusivamente em Windows98 e estava configurado para as especificações do sistema em termos de hardware.

A tomada de medidas das deformações foi realizada com outro sistema de monitoração complementar ao anterior, devido a seu melhor desempenho para a medição deste tipo de grandezas físicas. No sistema da National Instrument, todos 
os extensômetros foram ligados através de fios à placa NI SCXI 1521B, SCXI 1317 e SCXI 1001. No total foram instrumentados extensômetros em três seções da estrutura. O aplicativo de controle do sistema foi o software LabView, o mesmo que permitiu monitorar e salvar todos os dados experimentais com uma frequência de amostragem de $1000 \mathrm{~Hz}$.

\section{Realização do ensaio}

Para a obtenção de resultados estáveis, o sistema de carga foi ligado 30 min antes de se iniciar o ensaio, a fim de se estabilizar a temperatura de todos os componentes eletrônicos e do óleo e circuito hidráulico, e assim obter menores flutuações indesejadas na leitura de dados. Nesse sistema também foi adicionado LVDT's, com a finalidade de se obter medidas de deslocamentos, para cada incremento de carga. A calibração dos LVDT's foi feita externamente e os ganhos de calibração foram inseridos no DynaTester, a fim de se fazer automaticamente a conversão no momento do ensaio.

No caso dos extensômetros, esses foram ligados ao chassis da National Instrument, para logo serem calibrados por meio do seu aplicativo de controle. A calibração dos extensômetros consistiu em aplicar "offset" às leituras iniciais antes de começar o ensaio.

Após todas as configurações feitas no hardware foi necessário configurar a sessão de ensaio e os respectivos procedimentos. Nesse processo indicaram-se os transdutores que irão controlar o ensaio e os que irão ser monitorados e registrados no arquivo de resultados.

Uma vez iniciada a sessão e os procedimentos verificados, passou-se à fase de pré-carga. Essa fase consistiu na movimentação manual do servoatuador até ficar em contato com a viga tabuleiro, de modo a assegurar que exista continuidade de ação, quando carregamos no botão de iniciar ensaio. A pré-carga foi feita por deslocamento e o servoatuador foi levado a uma velocidade lenta e de modo suave, até a posição onde a estrutura comece a ser solicitada, com o objetivo de diminuir os efeitos de acomodamento nos apoios e no ponto de aplicação de carga, devido ao esmagamento do microconcreto. 
Logo depois de aplicada a pré-carga de $3,89 \mathrm{kN}$, os dois sistemas de monitoração foram ligados ao mesmo tempo para começar o ensaio. O tempo de duração de todo o ensaio foi aproximadamente 1 hora e 27 minutos.

\subsubsection{Resultados experimentais}

A seguir apresentam-se os resultados da medição efetuada no modelo durante a execução do ensaio especificamente da seção 2 , pois é a seção que será analisada na presente pesquisa. Os resultados traduzem a variação de cada grandeza para cada incremento de carga. A convenção de sinais adotada é a seguinte: deformação negativa (encurtamento), deformação positiva (alongamento) e deslocamento positivo (descendente).

\section{Deformações}

As deformações foram medidas pelos seis extensômetros colados nas faces da seção transversal e quatro extensômetros na armadura. As medições foram variando em função do incremento de carga e do tempo de duração do ensaio, tal como se ilustra na figura 5.19.

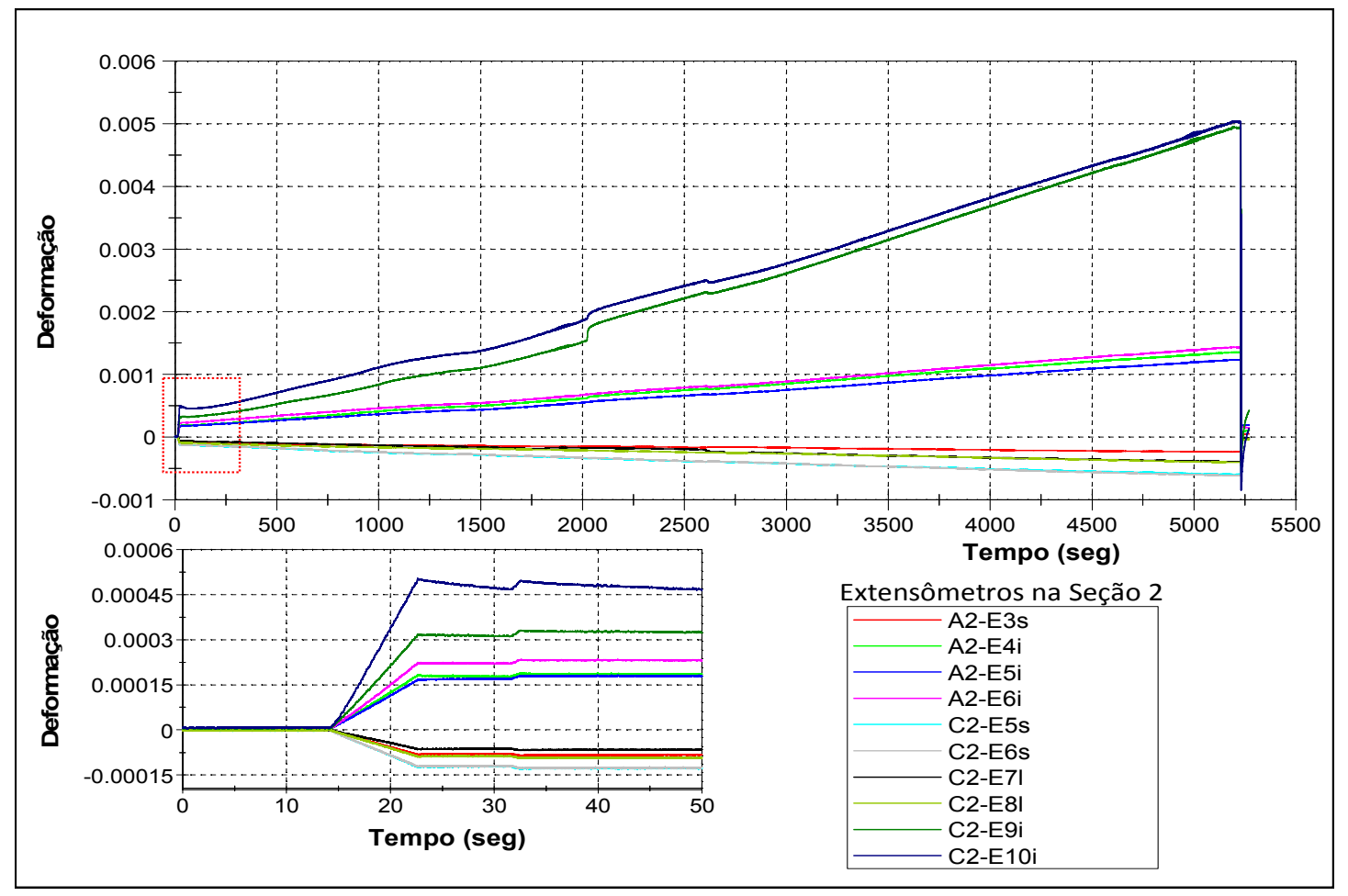

Figura 5.19 - Deformações medidas na seção 2 do modelo. 
Nas figuras 5.20 a 5.22 , ilustram-se com maior detalhe as deformações medidas tanto na armadura quanto no microconcreto.

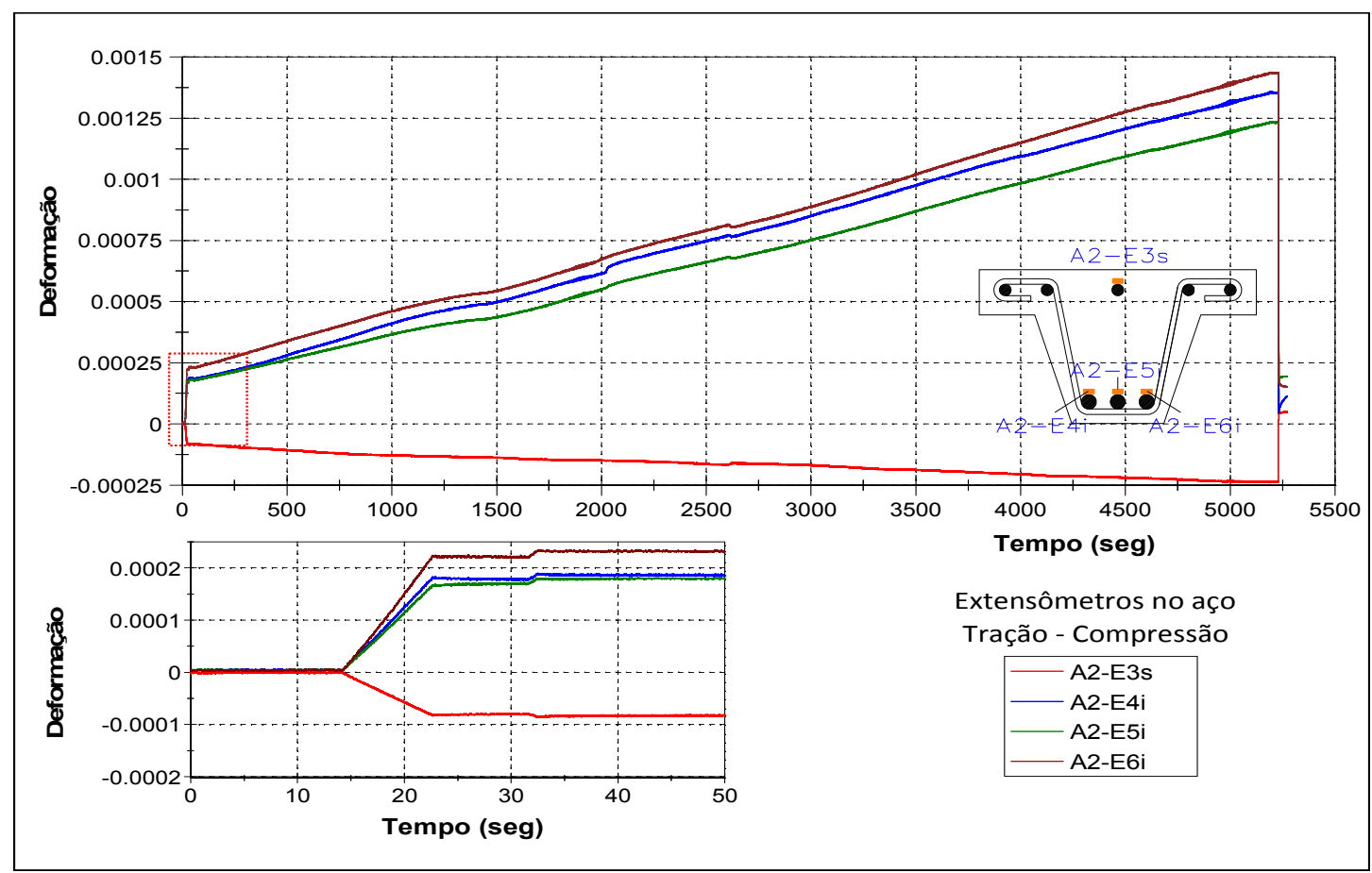

Figura 5.20 - Deformações medidas na armadura.

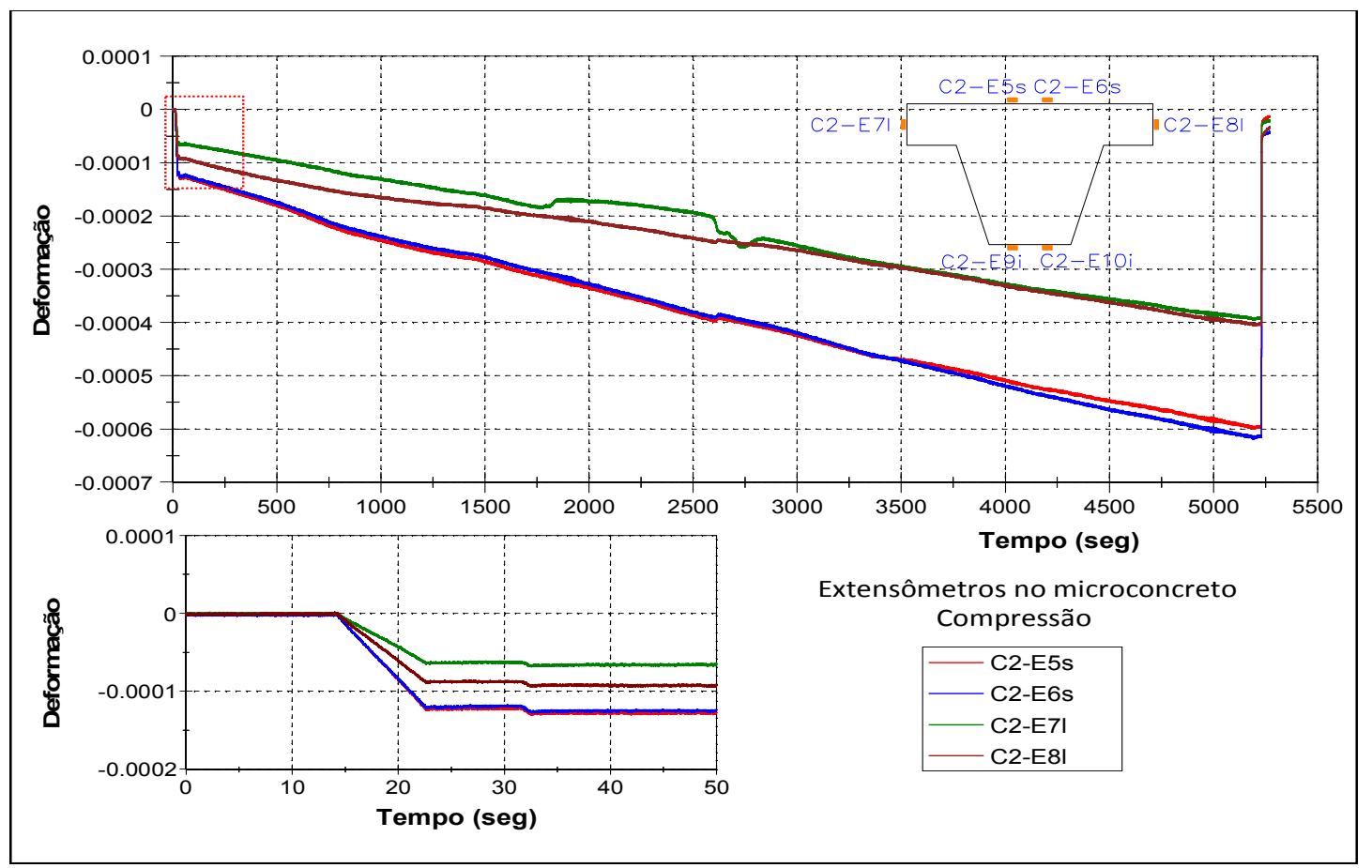

Figura 5.21 - Deformações medidas no microconcreto submetido a compressão. 


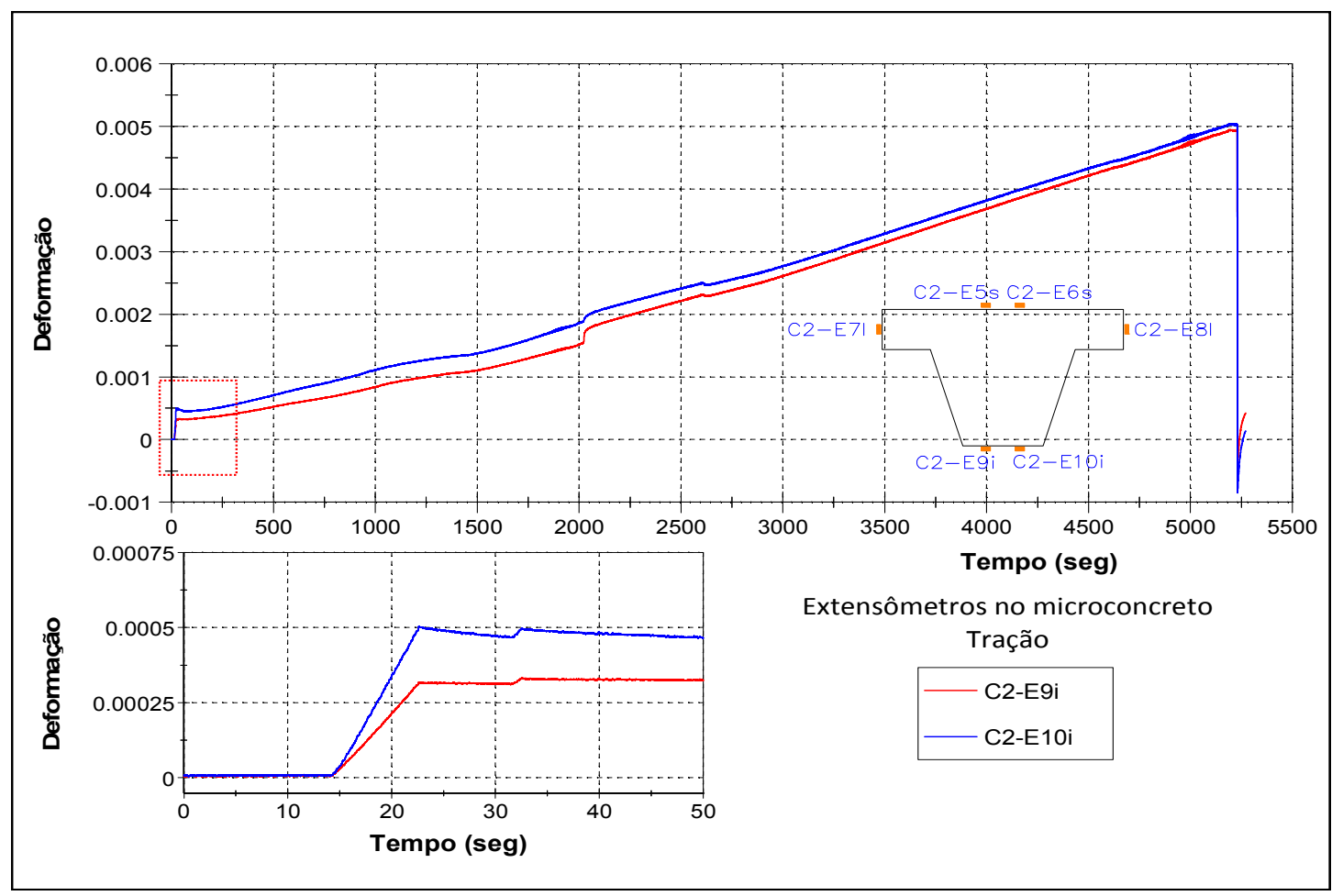

Figura 5.22 - Deformações medidas no microconcreto submetido a tração.

\section{Deslocamento vertical}

O deslocamento foi medido pelo LVDT instalado embaixo da seção mais solicitada. Os valores da medição mudaram em função do incremento de carga e do tempo de duração do ensaio, tal como se ilustra na figura 5.23.

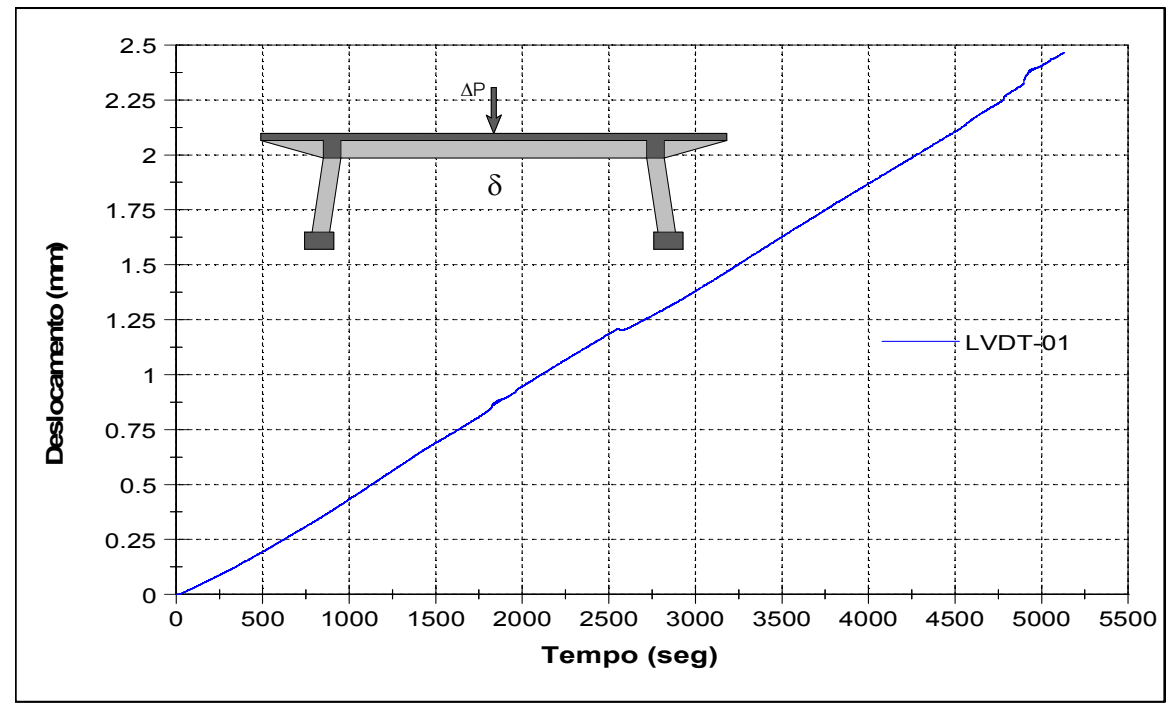

Figura 5.23 - Deslocamento experimental no meio da viga tabuleiro. 


\subsubsection{Apresentação de resultados e discussões}

Os dados experimentais da deformação (figura 5.19 a 5.22), o deslocamento (figura 5.23) e a força, são fornecidos pelos controladores de sistema DynaTester e LabView e estão em função do tempo de duração do ensaio. A construção das curvas que relacionem essas grandezas foram montadas em função da simultaneidade em que acontecem os fenômenos. A seguir descrevem-se os resultados obtidos do ensaio de flexão no modelo reduzido, a comparação entre os dados teóricos e experimentais e suas respectivas discussões.

\subsubsection{Curva carga vs. deslocamento}

$\mathrm{Na}$ figura 5.24, apresenta-se a curva experimental de carga vs. deslocamento, na qual se pode perceber, ao começo do ensaio, que a relação carga-deslocamento apresenta um comportamento não linear até uma carga de 5,5 $\mathrm{kN}$, devido provavelmente ao acomodamento nos apoios. Na realidade, qualquer pequena irregularidade no contato do apoio com a superfície do concreto, ou falta de alinhamento que faça com que o contato não seja uniforme, afeta a flexibilidade elástica da estrutura. Assim, muitos trabalhos experimentais concordam em que o deslocamento na parte elástica é dependente das condições do apoio da estrutura (Planas, Guinea, Elises, 1992).

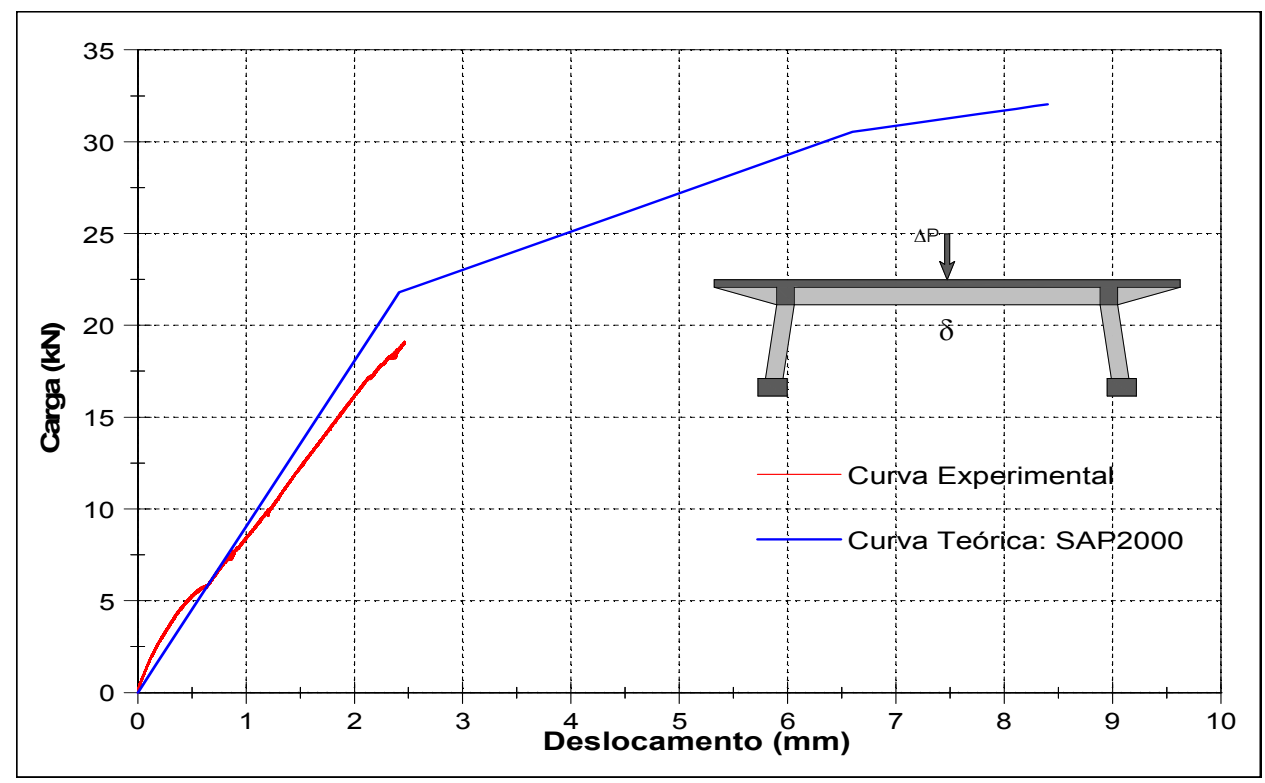

Figura 5.24 - Curva carga vs. deslocamento. 
Uma vez superado o acomodamento, a estrutura começa a comportar-se linearmente, tal como esperado, até uma carga de 17,25 kN. A partir dessa carga a viga tabuleiro começa a perder rigidez e incrementar aos poucos o deslocamento chegando a atingir 2,46 mm para uma carga de $19,16 \mathrm{kN}$. A perda de rigidez podese atribuir ao fato de aparecerem as primeiras fissuras na seção mais solicitada (figura 5.30a).

O cálculo de curva teórica foi feita no programa SAP2000, onde as propriedades geométricas e do material foram adotadas a partir das dimensões do modelo e a caracterização dos materiais, respectivamente.

A tabela 5.5 apresenta uma comparação entre os deslocamentos teóricos e experimentais, no meio do vão da viga tabuleiro.

Tabela 5.5 - Deslocamentos teóricos e experimentais na seção 2.

\begin{tabular}{cccr}
\hline $\mathbf{P}(\mathbf{k N})$ & $\begin{array}{c}\text { Teórico } \\
\delta(\mathbf{m m})\end{array}$ & $\begin{array}{c}\text { Experimental } \\
\delta(\mathbf{m m})\end{array}$ & $\begin{array}{c}\text { Erro } \\
\%\end{array}$ \\
\hline 0 & 0 & 0 & 0,00 \\
1,50 & 0,166 & 0,094 & $-76,76$ \\
3,89 & 0,431 & 0,310 & $-39,03$ \\
4,59 & 0,509 & 0,406 & $-25,31$ \\
5,48 & 0,606 & 0,562 & $-8,01$ \\
6,49 & 0,719 & 0,727 & 1,05 \\
7,59 & 0,841 & 0,868 & 3,14 \\
8,37 & 0,928 & 0,990 & 6,29 \\
9,90 & 1,097 & 1,190 & 7,82 \\
10,61 & 1,175 & 1,302 & 9,78 \\
11,85 & 1,313 & 1,447 & 9,26 \\
12,78 & 1,416 & 1,563 & 9,41 \\
13,56 & 1,502 & 1,676 & 10,37 \\
14,06 & 1,558 & 1,725 & 9,70 \\
15,14 & 1,677 & 1,863 & 9,95 \\
16,61 & 1,840 & 2,056 & 10,50 \\
17,25 & 1,911 & 2,168 & 11,86 \\
17,62 & 1,952 & 2,231 & 12,51 \\
18,39 & 2,037 & 2,358 & 13,63 \\
18,70 & 2,072 & 2,426 & 14,59 \\
19,16 & 2,122 & 2,463 & 13,85 \\
\hline & & &
\end{tabular}


Onde o erro foi calculado da seguinte forma:

$$
\operatorname{Erro}(\%)=\left(\frac{\delta_{\text {exp }}-\delta_{\text {teor. }}}{\delta_{\exp }}\right) \times 100
$$

Pode-se observar pelos valores acima demonstrados e a figura 5.24, que os deslocamentos experimentais obtiveram uma variação de $1 \%$ a $15 \%$ em relação às teóricas e a estrutura teve um comportamento linear até o nível de carga aplicado, com exceção dos valores no começo do ensaio, pois essa flutuação se atribui ao acomodamento da estrutura.

Os deslocamentos obtidos experimentalmente na maioria dos casos foram superiores aos teóricos. Da comparação efetuada, foi possível constatar que o modelo teórico mostrou-se mais rígido que o modelo físico, isto devido provavelmente ao fato de que esse foi analisado utilizando-se elementos de barra nas quais não foram considerados parâmetros influentes na rigidez da estrutura como a aderência aço-concreto e a fissuração

O modelo reduzido não foi ensaiado até a ruptura, pois o objetivo do estudo era verificar o comportamento não linear da estrutura em suas primeiras fases e determinar a relação momento-curva de forma experimental.

\subsubsection{Diagrama de distribuição de deformações}

As deformações tanto na armadura quanto no microconcreto foram apresentadas nas figuras 5.19 a 5.22 , nas quais, pode-se perceber que a pré-carga inicial aplicada à estrutura foi rapidamente identificada pelos sensores de deformação. Por outro lado se confirma que houve uma etapa de acomodamento da estrutura nos primeiros instantes da aplicação de carga, devido ao fato da curva de deformações não se mostrar linear desde o começo do ensaio.

A fim de ilustrar o diagrama de distribuição de deformações, os valores atribuídos de deformação para uma determinada zona da seção, foram calculados como media dos valores medidos pelos extensômetros instalados nessa região. De acordo à instrumentação feita, a seção pode ser dividida em cinco zonas de medição, as quais são detalhadas a seguir: 
Zona 1: corresponde à média das deformações medidas pelos extensômetros C2-E9i e C2-E10i, na face inferior da seção transversal

Zona 2: corresponde à média das deformações medidas pelos extensômetros A2-E4i, A2-E5i e A2-E6i, na armadura inferior da seção.

Zona 3: corresponde à deformação medida pelo extensômetro $A 2-E 3 s$, na armadura superior da seção transversal.

Zona 4: corresponde à média das deformações medidas pelos extensômetros C2-E7I e C2-E8I, nas faces laterais da seção transversal.

Zona 5: corresponde à média das deformações medidas pelos extensômetros C2-E5s e C2-E6s, na face superior da seção transversal.

Na figura 5.25, apresenta-se o diagrama de distribuição de deformações ao longo da altura da seção para cada incremento de carga, obtidas a partir dos dados experimentais mostrados na figura 5.19.

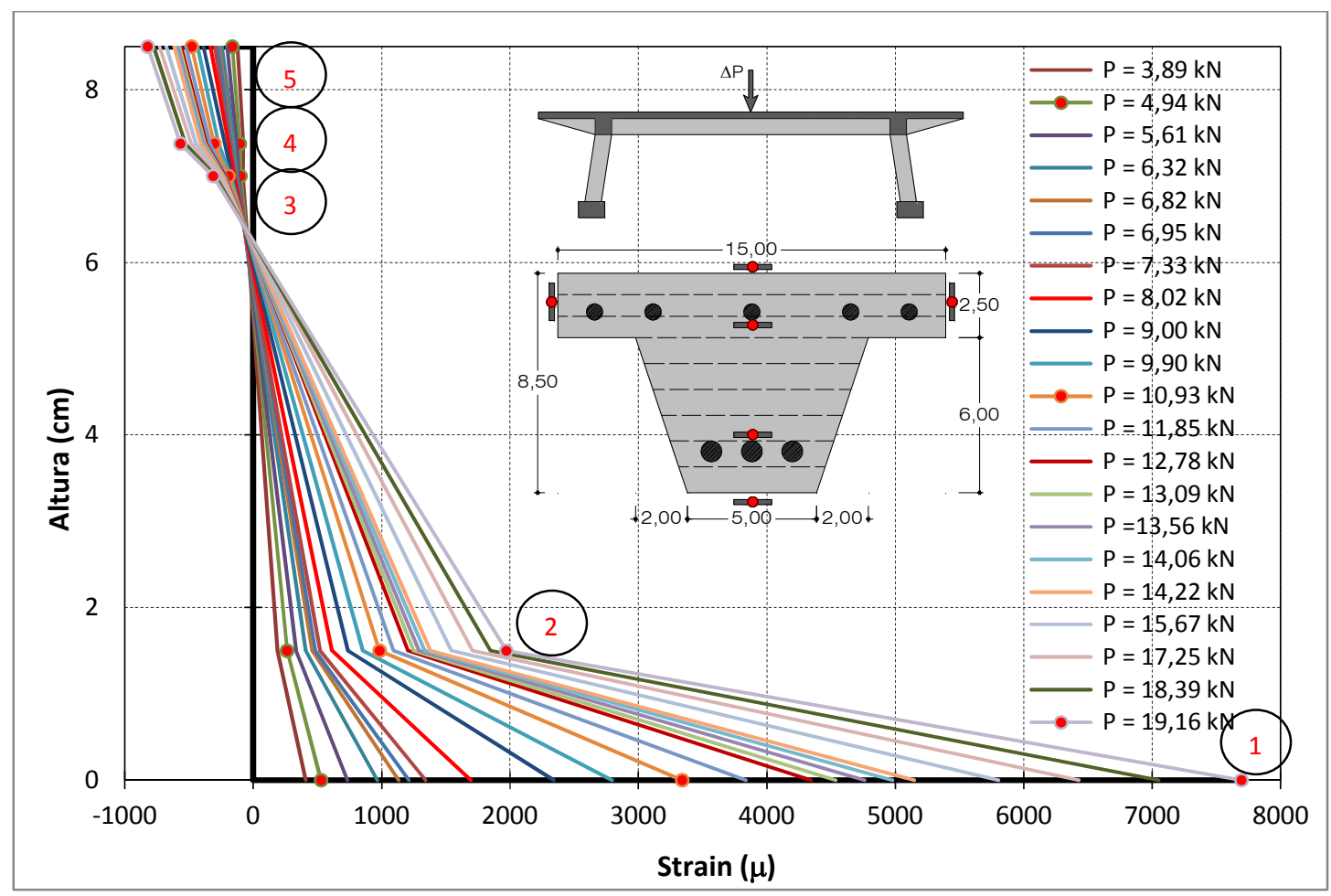

Figura 5.25 - Diagrama experimental de distribuição de deformações. 
No diagrama experimental de deformações, pode-se perceber a existência de compatibilidade de deformação entre as deformações medidas na zona 2-3-4-5, isto é, que a distribuição das deformações ao longo da zona 2-3-4-5 é aproximadamente linear. Por outro lado, a deformação da zona 1 apresenta certa compatibilidade de deformação, em relação a outras zonas, para cargas relativamente pequenas, e uma descontinuidade maior à medida que se incrementa a carga. Este fenômeno pode-se atribuir ao fato de que o concreto nessa zona apresentou fissuração devido ao esforço de tração a que foi submetido durante o ensaio.

$\mathrm{Na}$ tabela 5.6 apresentam-se as deformações teóricas e experimentais da zona 1 e 2, os quais correspondem à região tracionada da seção.

Tabela 5.6 - Deformações teóricos e experimentais na zona 1 e 2 da seção.

\begin{tabular}{|c|c|c|c|c|c|c|}
\hline \multirow{2}{*}{$\begin{array}{c}P \\
(k N)\end{array}$} & \multicolumn{3}{|c|}{1} & \multicolumn{3}{|c|}{2} \\
\hline & $\begin{array}{c}\varepsilon \text { teórico. } \\
(\mu)\end{array}$ & $\begin{array}{c}\varepsilon \text { exper. } \\
(\mu)\end{array}$ & $\begin{array}{c}\text { Erro } \\
(\%)\end{array}$ & $\begin{array}{c}\varepsilon \text { teórico. } \\
(\mu)\end{array}$ & $\begin{array}{c}\varepsilon \text { exper. } \\
(\mu)\end{array}$ & $\begin{array}{c}\text { Erro } \\
(\%)\end{array}$ \\
\hline 0 & 0,00 & 0,00 & 0,00 & 0,00 & 0,00 & 0,00 \\
\hline 3,89 & 479,43 & 408,50 & $-17,36$ & 369,81 & 190,00 & $-94,64$ \\
\hline 4,94 & 607,56 & 529,00 & $-14,85$ & 468,06 & 264,00 & $-77,29$ \\
\hline 5,61 & 688,65 & 734,00 & 6,18 & 530,32 & 335,00 & $-58,31$ \\
\hline 6,32 & 778,03 & 965,50 & 19,42 & 599,16 & 410,67 & $-45,90$ \\
\hline 6,82 & 839,60 & 1135,00 & 26,03 & 646,49 & 459,67 & $-40,64$ \\
\hline 6,95 & 856,28 & 1211,00 & 29,29 & 659,31 & 483,67 & $-36,32$ \\
\hline 7,33 & 902,98 & 1342,00 & 32,71 & 695,18 & 521,33 & $-33,35$ \\
\hline 8,02 & 989,15 & 1695,00 & 41,64 & 761,29 & 614,33 & $-23,92$ \\
\hline 9,00 & 1110,92 & 2339,50 & 52,51 & 854,61 & 739,33 & $-15,59$ \\
\hline 9,90 & 1223,02 & 2793,00 & 56,21 & 940,37 & 854,67 & $-10,03$ \\
\hline 10,93 & 1351,61 & 3340,50 & 59,54 & 1038,81 & 984,33 & $-5,53$ \\
\hline 11,85 & 1466,77 & 3837,00 & 61,77 & 1126,91 & 1093,00 & $-3,10$ \\
\hline 12,78 & 1583,76 & 4343,50 & 63,54 & 1216,34 & 1207,00 & $-0,77$ \\
\hline 13,09 & 1622,20 & 4533,50 & 64,22 & 1245,70 & 1248,33 & 0,21 \\
\hline 13,56 & 1682,25 & 4761,50 & 64,67 & 1291,53 & 1293,67 & 0,17 \\
\hline 14,06 & 1745,63 & 4977,50 & 64,93 & 1339,90 & 1337,67 & $-0,17$ \\
\hline 14,22 & 1765,98 & 5145,50 & 65,68 & 1355,42 & 1379,67 & 1,76 \\
\hline 15,67 & 1949,85 & 5801,50 & 66,39 & 1495,63 & 1543,67 & 3,11 \\
\hline 17,25 & 2150,15 & 6428,50 & 66,55 & 1648,06 & 1708,67 & 3,55 \\
\hline 18,39 & 2295,51 & 7050,50 & 67,44 & 1758,47 & 1846,67 & 4,78 \\
\hline 19,16 & 2394,66 & 7694,50 & 68,88 & 1833,68 & 1970,67 & 6,95 \\
\hline
\end{tabular}


As deformações teóricas ao longo da seção foram calculadas utilizando-se o método das lamelas implementado no aplicativo PUENFLEX. O procedimento de cálculo consistiu basicamente em determinar para carga $P$ um momento fletor atuante $M$ na seção de estudo. Com o momento $M$ e a relação momento-curvatura e relação momento-deformação apresentada na figura 5.9, determinou-se a curvatura $h / r$ e a deformação no centro geométrico $\varepsilon_{0}$. Finalmente, para determinar as deformações de cada lamela foram utilizadas as equações 5.4 e 5.5 onde $\varepsilon_{c}$ é a deformação no concreto, $\varepsilon_{\mathrm{s}}$ é a deformação na armadura, $y_{s}$ e $y_{c}$ é a distância desde o centro de gravidade da seção até a lamela.

Na tabela 5.7 apresentam-se as deformações teóricas e experimentais da zona 3, 4 e 5, os quais correspondem à região comprimida da seção.

Tabela 5.7 - Deformações teóricos e experimentais na zona 3, 4 e 5 da seção.

\begin{tabular}{|c|c|c|c|c|c|c|c|c|c|}
\hline \multirow{2}{*}{$\underset{(k N)}{P}$} & \multicolumn{3}{|c|}{3} & \multicolumn{3}{|c|}{4} & \multicolumn{3}{|c|}{5} \\
\hline & $\begin{array}{c}\varepsilon \text { teórico. } \\
(\mu)\end{array}$ & $\begin{array}{c}\varepsilon \text { exper. } \\
(\mu)\end{array}$ & $\begin{array}{c}\text { Erro } \\
(\%)\end{array}$ & $\begin{array}{c}\varepsilon \text { teórico. } \\
(\mu)\end{array}$ & $\begin{array}{c}\varepsilon \text { exper. } \\
(\mu)\end{array}$ & $\begin{array}{c}\text { Erro } \\
(\%)\end{array}$ & $\begin{array}{c}\varepsilon \text { teórico. } \\
(\mu)\end{array}$ & $\begin{array}{c}\varepsilon \text { exper. } \\
(\mu)\end{array}$ & $\begin{array}{c}\text { Erro } \\
(\%)\end{array}$ \\
\hline 0 & 0,00 & 0,00 & 0,00 & 0,00 & 0,00 & 0,00 & 0,00 & 0,00 & 0,00 \\
\hline 3,89 & $-77,11$ & $-81,73$ & 5,65 & $-87,27$ & $-75,98$ & $-14,86$ & $-188,84$ & $-122,50$ & $-54,16$ \\
\hline 4,94 & $-100,70$ & $-98,98$ & $-1,74$ & $-113,63$ & $-104,38$ & $-8,86$ & $-242,89$ & $-162,50$ & $-49,47$ \\
\hline 5,61 & $-115,18$ & $-116,00$ & 0,71 & $-129,85$ & $-126,50$ & $-2,65$ & $-276,55$ & $-202,50$ & $-36,57$ \\
\hline 6,32 & $-130,08$ & $-128,00$ & $-1,62$ & $-146,65$ & $-148,00$ & 0,91 & $-312,39$ & $-242,00$ & $-29,09$ \\
\hline 6,82 & $-140,82$ & $-132,00$ & $-6,68$ & $-158,71$ & $-162,00$ & 2,03 & $-337,64$ & $-264,50$ & $-27,65$ \\
\hline 6,95 & $-143,74$ & $-135,00$ & $-6,47$ & $-161,99$ & $-169,50$ & 4,43 & $-344,50$ & $-275,50$ & $-25,05$ \\
\hline 7,33 & $-152,02$ & $-143,00$ & $-6,30$ & $-171,27$ & $-185,00$ & 7,42 & $-363,82$ & $-297,00$ & $-22,50$ \\
\hline 8,02 & $-167,71$ & $-149,00$ & $-12,56$ & $-188,83$ & $-191,50$ & 1,40 & $-399,96$ & $-332,50$ & $-20,29$ \\
\hline 9,00 & $-190,38$ & $-165,00$ & $-15,38$ & $-214,13$ & $-219,50$ & 2,45 & $-451,63$ & $-387,00$ & $-16,70$ \\
\hline 9,90 & $-211,97$ & $-173,00$ & $-22,53$ & $-238,16$ & $-268,50$ & 11,30 & $-500,06$ & $-434,00$ & $-15,22$ \\
\hline 10,93 & $-236,52$ & $-192,00$ & $-23,19$ & $-207,53$ & $-302,50$ & 31,39 & $-555,35$ & $-479,00$ & $-15,94$ \\
\hline 11,85 & $-258,74$ & $-210,00$ & $-23,21$ & $-290,24$ & $-334,50$ & 13,23 & $-605,16$ & $-522,00$ & $-15,93$ \\
\hline 12,78 & $-281,61$ & $-221,00$ & $-27,43$ & $-315,65$ & $-363,00$ & 13,04 & $-656,10$ & $-560,00$ & $-17,16$ \\
\hline 13,09 & $-289,30$ & $-228,00$ & $-26,89$ & $-324,19$ & $-376,50$ & 13,89 & $-673,05$ & $-574,00$ & $-17,26$ \\
\hline 13,56 & $-301,43$ & $-233,00$ & $-29,37$ & $-337,63$ & $-387,50$ & 12,87 & $-699,67$ & $-590,50$ & $-18,49$ \\
\hline 14,06 & $-314,25$ & $-236,00$ & $-33,16$ & $-351,85$ & $-397,00$ & 11,37 & $-727,79$ & $-604,50$ & $-20,40$ \\
\hline 14,22 & $-318,44$ & $-240,00$ & $-32,68$ & $-356,48$ & $-406,00$ & 12,20 & $-736,91$ & $-616,50$ & $-19,53$ \\
\hline 15,67 & $-356,26$ & $-257,00$ & $-38,62$ & $-398,35$ & $-446,00$ & 10,68 & $-819,23$ & $-675,50$ & $-21,28$ \\
\hline 17,25 & $-398,96$ & $-274,00$ & $-45,61$ & $-445,48$ & $-483,00$ & 7,77 & $-910,71$ & $-727,50$ & $-25,18$ \\
\hline 18,39 & $-431,06$ & $-295,00$ & $-46,12$ & $-480,82$ & $-526,00$ & 8,59 & $-978,44$ & $-773,50$ & $-26,50$ \\
\hline 19,16 & $-453,47$ & $-311,00$ & $-45,81$ & $-505,45$ & $-566,00$ & 10,70 & $-1025,26$ & $-821,50$ & $-24,80$ \\
\hline
\end{tabular}


O erro foi calculado da seguinte forma: $\operatorname{Erro}(\%)=\left(\frac{\varepsilon_{\exp }-\varepsilon_{\text {teor. }}}{\varepsilon_{\text {exp }}}\right) \times 100$

$\mathrm{Na}$ zona 1 (tabela 5.6), pode-se observar que as deformações experimentais são muito maiores em relação às teóricas. Para cargas relativamente pequenas se obtiveram variações menores que 19,42\%. Na medida em que a carga aumenta, existe um maior distanciamento entre os resultados experimentais e teóricos, chegando a uma variação de 68,88\%. Essa diferença pode-se atribuir a muitos fatores, entre eles, que o microconcreto fissurou-se nessa região e o extensômetro continuou medindo deformações no concreto fissurado. Para fins de cálculo da relação momento-curvatura, não serão consideradas as deformações medidas dessa zona.

As deformações experimentais na zona 2 (tabela 5.6) correspondentes à armadura inferior obtiveram uma variação de $10,03 \%$ a $94,64 \%$ em relação às teóricas para cargas iniciais. Essa diferencia pode-se atribuir ao fato de que no modelo teórico considera-se que a tensão de tração é somente absorvida pela armadura e despreza-se a contribuição do concreto. Para cargas maiores a 10,93 kN observa-se uma melhor aproximação entre o modelo teórico e experimental.

Na zona 3-4-5 (tabela 5.7), as deformações obtidas experimentalmente na maioria dos casos foram menores que as teóricas. Esse fenômeno responde certamente ao que foi estabelecido na etapa de dimensionamento da viga tabuleiro, na qual à medida que ocorre o aumento progressivo do valor do momento que atua na seção, a linha neutra muda de posição, diminuindo sua profundidade e, consequentemente, a altura da região comprimida de concreto, o que implica no aumento da deformação que ocorre no aço tracionado.

No digrama de distribuição de deformações apresentada na figura 5.25, pode-se perceber que a profundidade da zona comprimida efetivamente diminui com o incremento de carga e a tendência de acordo com os dados experimentais é que a linha neutra da seção suba até a mesa, fazendo que a viga se comporte como se fosse uma viga retangular maior. A viga foi dimensionada para um momento de 4,05 kN-m, no Estádio III e uma altura de zona comprimida de $2,37 \mathrm{~cm}$. 


\subsubsection{Relação Momento-Curvatura experimental}

Para o cálculo experimental da relação momento-curvatura foram consideradas algumas hipóteses, apresentadas a seguir:

- Considera-se que a deformação compreendida entre duas deformações experimentais varia linear e proporcionalmente a distancia entre elas.

- A colaboração do concreto à tração é desprezada.

- Os modelos constitutivos para o aço e o concreto foram adotados da norma ABNT NBR 6118:2007 e são válidos para o microconcreto também.

\section{Cálculo do momento}

Os esforços resistentes da seção foram calculados usando o método das lamelas, com a diferença que ao invés de usar as deformações calculadas teoricamente, foram usados as deformações experimentais.

Assim, a seção foi divida em nove camadas, três camadas na mesa superior e seis camadas na alma. A deformação para cada camada foi calculada a partir das deformações experimentais apresentadas na figura 5.25, por exemplo, as deformações $\varepsilon_{c} 3, \varepsilon_{c} 4, \quad \varepsilon_{c} 5, \quad \varepsilon_{c} 6$ e $\varepsilon_{c} 7$ foram calculadas interpolando-se as deformações experimentais $\varepsilon_{s}^{\prime} 2$ e $\varepsilon_{s}^{\prime} 3$. Uma vez calculada a deformação pseudoexperimental para cada camada, procedeu-se a calcular os esforços internos. Para isso, as deformações pseudo-experimentais foram introduzidas dentro dos modelos constitutivos do aço e do concreto.

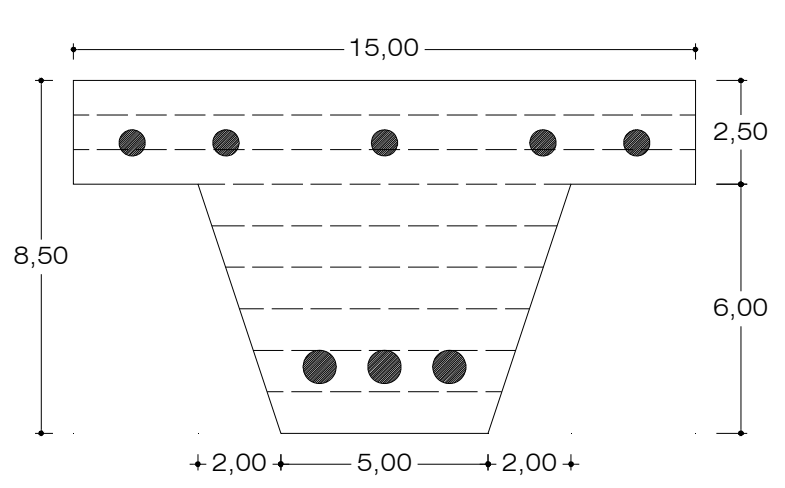

Distribuição de deformações experimentais
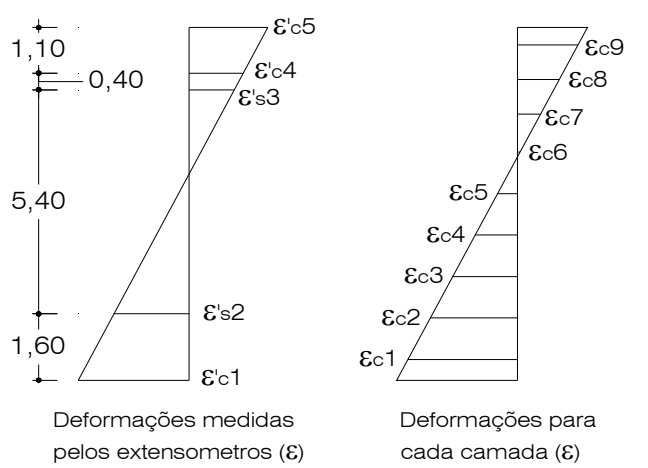

Figura 5.26 - Seção discretizada em camadas e suas respectivas deformações. 
Finalmente, o momento experimental foi calculado ao aplicar as condições de equilibro na seção, para o qual foram usadas as equações (5.9) e (5.11).

\section{Cálculo da curvatura}

Por conceito teórico, a curvatura de uma seção pode ser definida como a diferença entre duas de suas deformações, dividida pela distância entre elas.

O cálculo da curvatura experimental da seção foi realizada usando os conceitos teóricos (equação 5.3), com a diferença que ao invés de usar as deformações teóricas, foram usados as deformações experimentais.

Assim, as cinco deformações experimentais medidas na seção permitiram determinar quatro curvaturas para cada caso de carga. Os valores calculados das curvaturas eram próximos entre si, a exceção da curvatura calculada entre a zona 1 e 2, razão pela qual, teve que ser desconsiderada na estimativa da curvatura. Portanto, a curvatura da seção foi determinada como média das três curvaturas experimentais restantes.

$\mathrm{Na}$ figura 5.27, apresenta-se a relação momento-curvatura, gerada a partir dos dados experimentais e as hipóteses de cálculo adotadas.

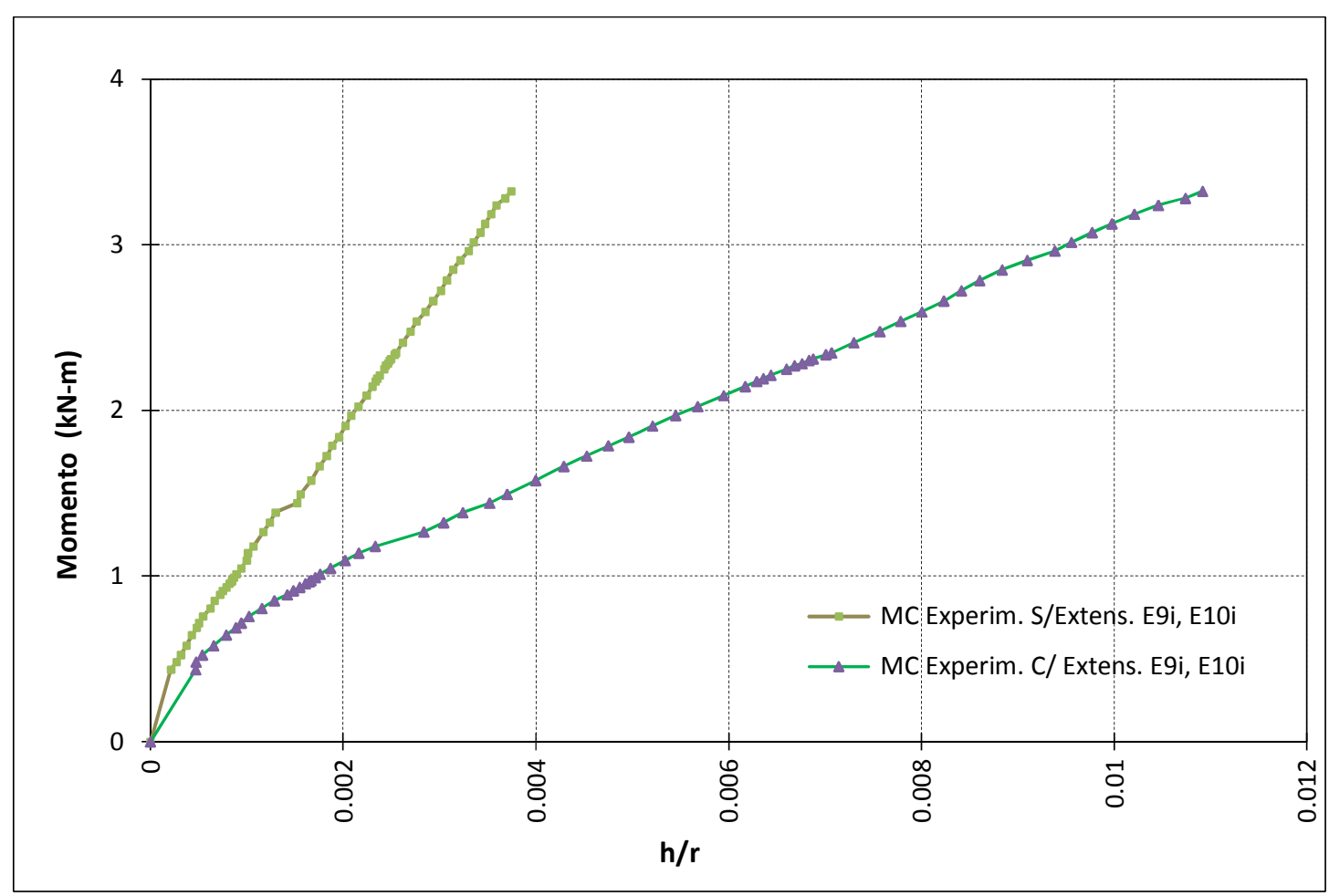

Figura 5.27 - Relação momento-curvatura pseudo-experimental. 
$\mathrm{Na}$ figura anterior ilustram-se duas curvas, uma mostrando a relação momento-curvatura sem considerar as deformações medidas na zona 1 (Extensômetro E9i e E10i), e a outra curva considerando-as, das quais pode-se concluir, que as medidas de deformação da zona 1 influenciam bastante na forma da relação momento-curvatura.

Assim, a relação de momento-curvatura gerada considerando as deformações da zona 1 mostra uma inclinação baixa, o que leva a entender, que a seção da estrutura é muito flexível, situação que não é real, e divergem das curvaturas calculadas nas outras partes da seção.

$\mathrm{Na}$ geração da outra curva não foram consideradas as deformações da zona 1, e esta representou melhor o comportamento da seção, pois as curvaturas calculadas nos outros pontos da seção eram próximas entre si.

\section{Comparação teórico-experimental da relação momento-curvatura}

Durante o ensaio o modelo reduzido foi submetido a uma carga incremental, que começou com uma pré-carga de $3,89 \mathrm{kN}$ e foi incrementando até uma carga de 19,16 kN. Para cada incremento de carga foi calculado o momento e a curvatura experimental, de acordo com os procedimentos explicados nos itens anteriores e são mostrados na figura 5.27. Assim, o momento calculado para a carga de $19,16 \mathrm{kN}$ foi de $3,32 \mathrm{kN}-\mathrm{m}$ e uma curvatura de 0,003746. Para essa mesma carga, o momento calculado teoricamente foi de $3,45 \mathrm{kN}-\mathrm{m}$ e uma curvatura de 0,003540 (figura 5.28). Fazendo-se a comparação entre os valores teóricos e experimentais, pode-se dizer que os momentos experimentais obtiveram uma variação de $3,90 \%$ em relação aos teóricos e as curvaturas experimentais obtiveram uma variação de 5,50\% em relação às teóricas.

Da comparação efetuada, foi possível constatar e confirmar, que o modelo físico comportou-se menos rígido que os modelos adotados teoricamente, e as relações de momento-curvatura teóricas e experimentais apresentaram-se relativamente coerentes entres si.

Por outro lado observa-se que a relação momento-curvatura experimental, ao começo do ensaio mostrou um comportamento não linear, isto devido ao acomodamento da estrutura, como indicado nas análises anteriores. À medida em 
que o momento atuante na seção aumenta, a estrutura começa a comportar-se linearmente.

Na figura 5.28, ilustram-se a comparação da relação de momento curvatura teórico e pseudo-experimental.

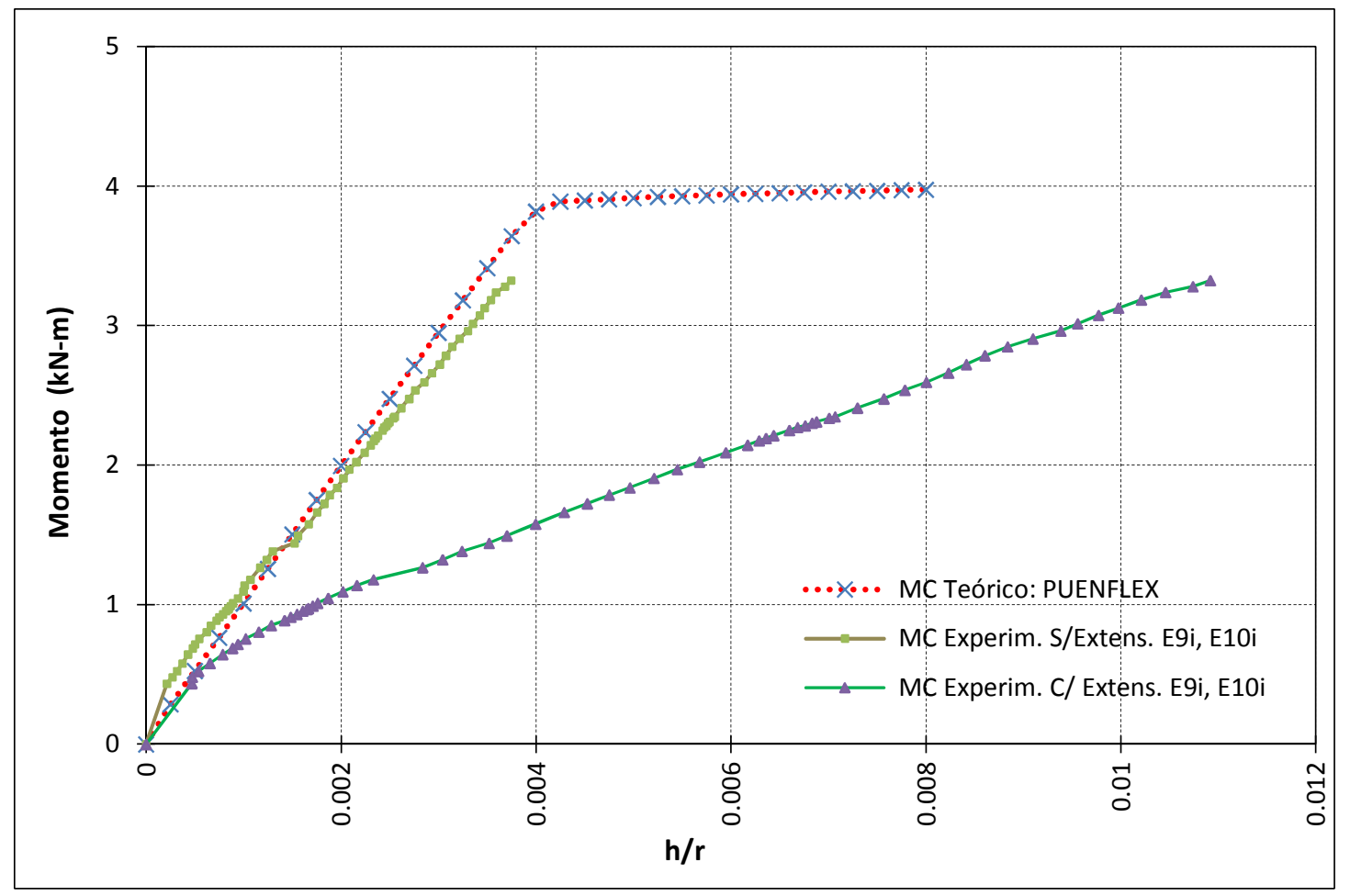

Figura 5.28 - Comparação da relação momento curvatura teórico e pseudo-experimental.

De todas as comparações feitas entre os resultados experimentais e teóricos pode-se observar que sempre existe uma diferença e dificilmente vão coincidir os valores. Essas diferenças podem ser justificadas pelas simplificações adotadas no modelo numérico. Assim, na pesquisa de modelo físico não se consideraram muitos parâmetros determinantes no comportamento real da estrutura, entre eles pode-se mencionar: a aderência existente entre o aço e o concreto, a resistência à tração do concreto, as condições de contorno reais e modelos constitutivos muito mais realistas tanto do concreto quanto do aço. 


\subsubsection{Propagação de fissuras}

As peças de concreto armado fissuram quando são submetidas a pequenas intensidades de tensões de tração. Essas tensões surgem nas peças de concreto devido aos esforços solicitantes, provocados pelas cargas atuantes e por esforços internos. No estudo experimental de nosso modelo mostra-se apenas o comportamento das fissuras provenientes da flexão.

O modelo ao ser submetido a uma força $\mathrm{P}$ (figura 5.29 a), para pequenos valores de $P$, enquanto a tensão de tração foi inferior à resistência do microconcreto à tração na flexão, a viga não apresentou fissuras, ou seja, as suas seções permaneceram no Estádio I. Nessa fase, originou-se um sistema de tensões principais de tração e de compressão.

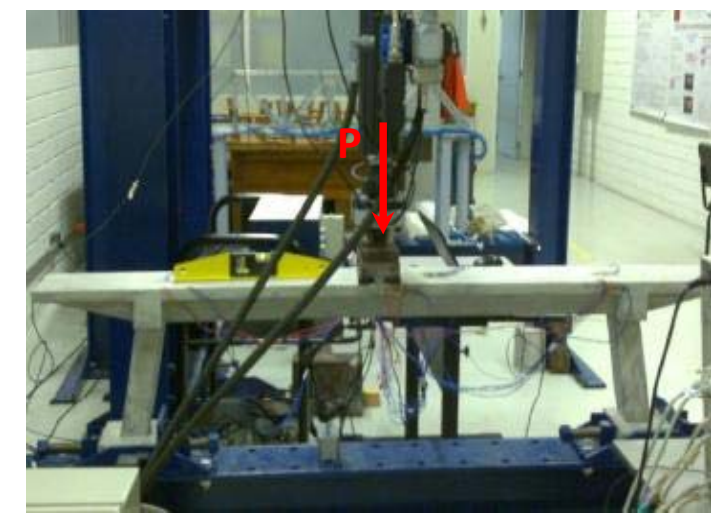

(a)

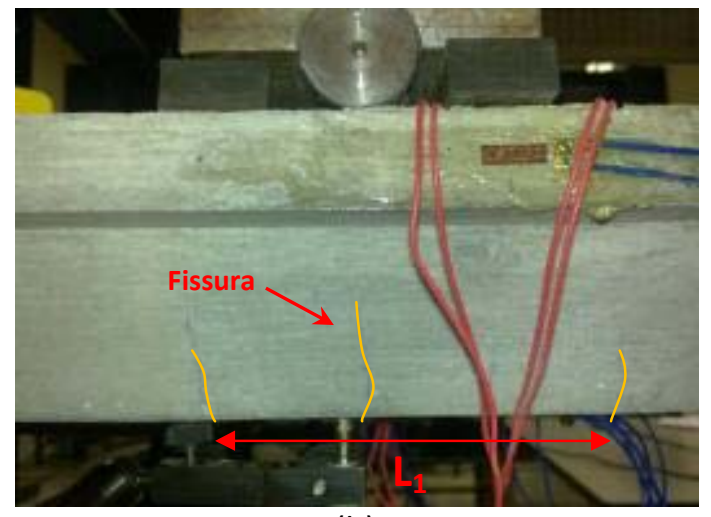

(b)

Figura 5.29 - (a) Modelo submetido a ensaio de flexão, (b) Formação das primeiras fissuras.

Com o aumento do carregamento, no trecho de momento máximo $\left(L_{1}\right)$, a resistência do concreto à tração é ultrapassada e surgem as primeiras fissuras de flexão (verticais) tal como se ilustra na figura 5.29 (b). Nas seções fissuradas, a viga encontra-se no Estádio II e a resultante de tração é resistida exclusivamente pelas barras longitudinais. No início da fissuração da região central, os trechos junto aos apoios, sem fissuras, ainda se encontram no Estádio I.

Continuando o aumento do carregamento, surgiram novas fissuras num trecho maior $\left(L_{3}>L_{2}>L_{1}\right)$, as quais já começaram a se inclinar, por causa da inclinação das tensões principais de tração, tal como se mostra na figura 5.30 (b). 


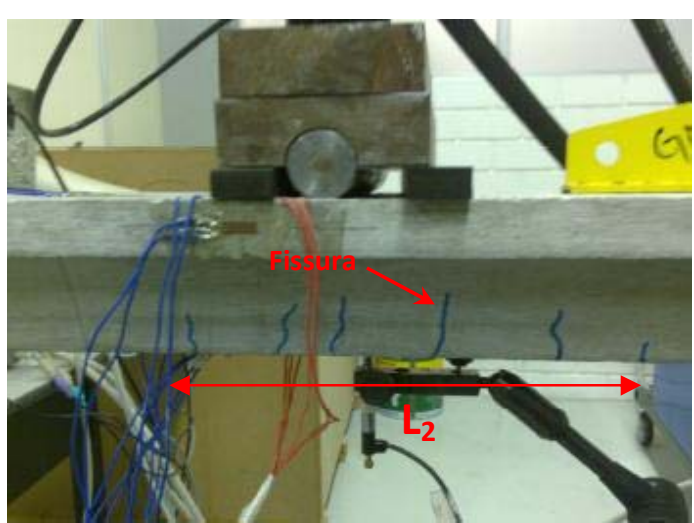

(a)

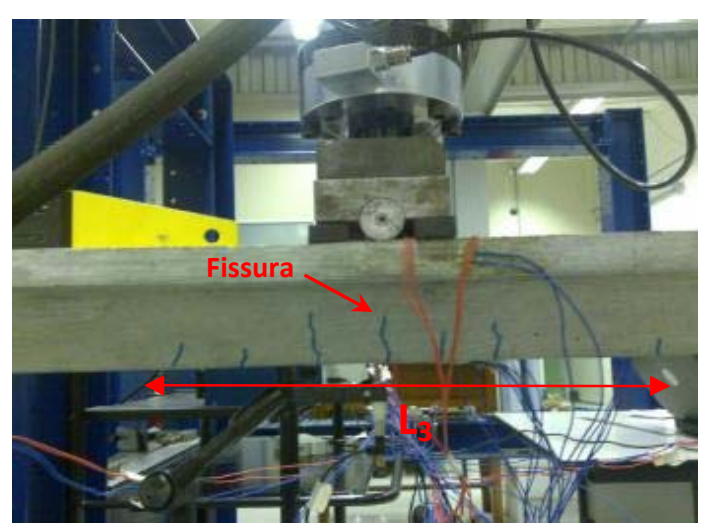

(b)

Figura 5.30 - Aparecimento de fissuras na medida em que incrementa a carga.

\subsubsection{Conclusões}

Do estudo experimental e teórico da ponte de microconcreto podemos chegar às seguintes conclusões:

- As condições de apoio influenciam diretamente na flexibilidade da estrutura, pois a curva carga-deslocamento experimental ao começo apresenta um comportamento não linear.

- A perda de rigidez da viga tabuleiro foi corroborada experimentalmente, pois com o aumento da carga, a seção começou a apresentar fissuras e o deslocamento aumentou relativamente. Esse fenômeno foi presenciado na última parte do ensaio, na transição da parte linear a não linear.

- $\quad \mathrm{Na}$ comparação das curvas de carga-deslocamento, o modelo teórico se mostra um pouco rígido, mas se ajusta razoavelmente aos resultados experimentais.

- As deformações medidas experimentalmente permitiram construir o diagrama de distribuição de tensões ao longo da seção, observando-se a mudança de posição da linha neutra e verificando-se que esta se comporta de acordo as hipóteses teóricas de dimensionamento.

- Existe uma considerável diferença entre as deformações teóricas calculadas pela Resistência de Materiais e as experimentais, o que evidencia que a teoria linear simples não considera o efeito de forma. 
- O diagrama momento-curvatura teórico se ajusta razoavelmente aos resultados experimentais, de forma semelhante à curva de cargadeslocamento, o que demonstra o cuidado na realização da caracterização dos materiais e a execução do ensaio.

- Para se obter uma melhor capacidade de prever o comportamento do modelo teórico, o programa desenvolvido deve ser implementado com parâmetros que atualmente não estão sendo consideradas como a aderência aço-concreto, a resistência à tração do concreto e modelos constitutivos mais realistas.

\subsection{Modelo reduzido de vigas levemente armadas}

\subsubsection{Generalidades}

Com a construção de vigas levemente armadas, pretende-se estudar seu comportamento em fratura e mostrar que o comportamento das vigas é sensível a vários parâmetros, tais como: o tamanho da viga, taxa de armadura, tensão de escoamento da armadura, aderência aço-concreto e a forma da seção transversal.

Para isso, empreendeu-se um programa experimental que, além de ensaiar vigas levemente armadas de várias formas de seção transversal, com distintas taxas de armadura e considerando a aderência, se obtenha todos os parâmetros característicos do concreto, do aço, e da superfície de contato aço-concreto. Esses ensaios servirão para comprovar a capacidade de prever o comportamento do modelo teórico.

Foram ensaiados no total 12 vigas armadas com duas formas de seção transversal (retangular e tipo $\mathrm{T}$ ) e duas taxas de armadura. Todas as vigas foram fabricadas a partir dos mesmos materiais: microconcreto e barras de aço. A composição do microconcreto e o processo de fabricação influenciam em suas propriedades e, portanto, no processo de fratura. Por isso procurou-se obter uma boa homogeneidade do microconcreto usando sempre os mesmos materiais de 
partida, com o mesmo traço, e seguindo-se o mesmo processo de fabricação e cura em todas as betonadas.

A medição das grandezas físicas para o estudo das vigas levemente armadas, como a flecha no meio do vão, a abertura de fissuras e a carga aplicada, foram monitoradas a partir de um sistema de ensaio flexível composto por um pórtico de ensaios, um servoatuador, uma central hidráulica, um quadro elétrico de interface, dois LVDT's e um computador de comando. Na figura 5.31 ilustra-se o pórtico de ensaios para vigas levemente armadas.

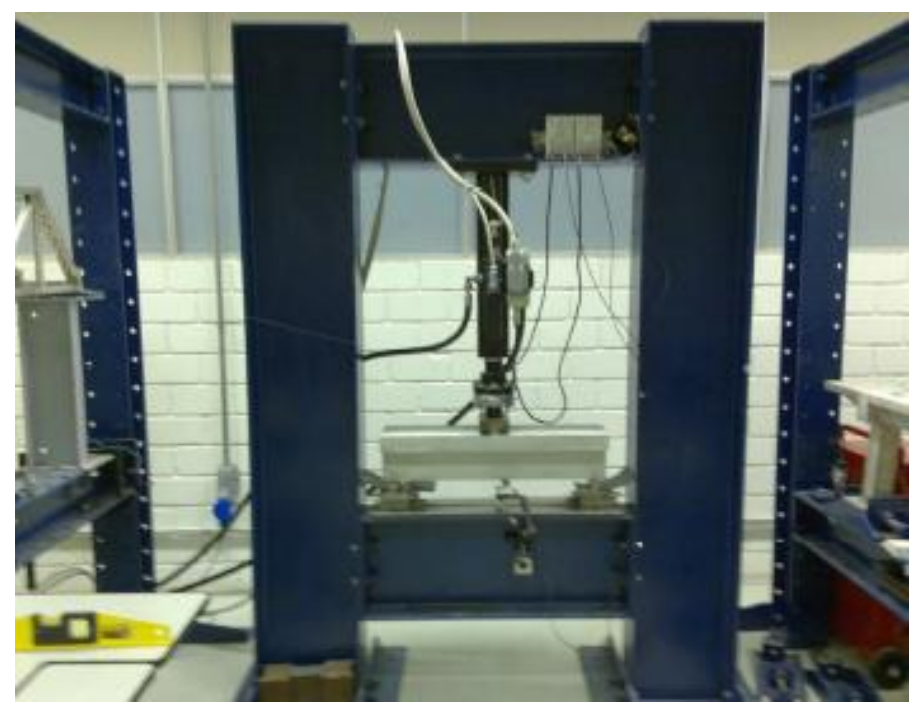

Figura 5.31 - Pórtico de ensaios para vigas levemente armadas.

A fim de se comparar os resultados teóricos e experimentais, o estudo experimental foi complementado com a modelagem numérica das vigas levemente armadas. A modelagem numérica foi desenvolvida, especificamente pela equipe de pesquisadores numéricos do projeto CNPq - Estudo Experimental de Parâmetros de Fratura Coesiva para Modelagem Física e Numérica de Estruturas de Concreto em Escala Reduzida, em função dos dados experimentais fornecidos pelo autor da presente dissertação.

Com a finalidade de se obter um melhor entendimento deste estudo experimental, nos itens seguintes serão apresentados alguns conceitos básicos de mecânica de fratura. 


\subsubsection{Conceitos básicos da mecânica da fratura aplicada ao concreto}

\subsubsection{Introdução}

A aplicação dos conceitos da Mecânica de Fratura a materiais como o concreto, visa uma melhor caracterização da ruptura desse tipo de material, com o intuito de integrar no futuro esses conceitos nas normas de projeto e detalhamento de estruturas de concreto armado. A introdução de uma teoria baseada num critério de colapso energético e que contempla a propagação progressiva do fraturamento ao longo da estrutura poderia explicar, de acordo com sólidos princípios físicos, varias regras antigas de projeto de natureza puramente empírica, assim como auxiliar no embasamento do projeto de estruturas inovadoras (BORGES, 2002).

A aplicação da Mecânica da Fratura para análise de estruturas de concreto é relativamente recente, pois essa só foi possível com o desenvolvimento da Mecânica da Fratura Não Linear, tendo em vista as tentativas mal sucedidas de aplicação da Mecânica da Fratura Elástica linear às estruturas de concreto. Isto é, devido à existência de mecanismos complexos à frente da trinca que consomem parte da energia aplicada ao corpo sólido, fazendo com que ocorra uma propagação estável das trincas (GUETTI, 2006).

Do ponto de vista do projeto e controle de estruturas, o fenômeno de fratura manifesta-se essencialmente pelo denominado efeito escala, que não tem lugar na teoria clássica de estruturas. Na teoria clássica, a resistência de duas estruturas geometricamente semelhantes fabricada com os mesmos materiais é a mesma quando se expressa em tensão, força por unidade de área. Isso implica que a resistência de uma pequena viga de laboratório de alguns centímetros de altura deve ser a mesma que a de uma viga proporcional a dez vezes sua altura. Segundo estudos experimentais a realidade não é tão simples. A resistência da viga maior pode reduzir-se até um terço da pequena, dependendo do material e do tipo de ruptura

Infelizmente, o efeito escala não admite uma generalização simples e existem formas de ruptura pouco sensíveis a os fenômenos de fratura, como a ruptura por flexão em vigas com taxa de armadura elevada e outros ainda mais 
sensíveis, como a ruptura do concreto em massa, a ruptura de vigas levemente armadas, ou a ruptura por cortante em quase todas suas versões (RUIZ, 1998).

À medida que a Mecânica da Fratura avança em seus estudos, a sua aplicação em materiais parcialmente frágeis, proporciona uma nova visão de como proceder na realização de projetos mais seguros, confiáveis e até mesmo econômicos, pois novos fatores de segurança para os projetos são propostos, com valores mais baixos do que os adotados atualmente pelas normas, além de propor uma redução das armaduras quando a estrutura é analisada considerando a lei do efeito escala (BAZANT, 2002).

\subsubsection{Comportamento do concreto em fratura}

O concreto é um material composto por cimento, areia, agregados, água e às vezes, alguns aditivos misturados para formar um material sólido. A ocorrência de fissuras é um fenômeno intrínseco das estruturas de concreto. Normalmente a interface é considerada a região mais fraca, que os demais constituintes desse compósito.

Devido à sua composição o concreto desenvolve microfissuras a partir de certo nível de solicitação tensional. Logo, na medida em que estas microfissuras crescem e se unem umas com outras, geram fissuras macroscópicas causando a ocorrência do fenômeno de localização de deformações e o amolecimento do concreto. $\mathrm{O}$ fato de que os concretos rompem sempre por fissuração levou aos pesquisadores a deixar as teorias clássicas, procurando aplicar ao concreto, conceitos de mecânica da fratura.

A resposta de amolecimento do concreto irá depender grandemente de seus constituintes, como, por exemplo, o tamanho do agregado e a relação águacimento, que tem efeito direto na porosidade da matriz do material e da interface entre agregado e matriz. Observa-se um aumento da resistência à tração para uma redução da porosidade, logo, a energia de fratura deve mudar com o decréscimo da relação a/c. Desta forma, se a porosidade decresce, um aumento de energia de fratura é esperado (GUETTI, 2006). 
O processo de fratura no concreto é influenciado pela Zona de Processo de Fratura, que contribui para o comportamento inelástico desse material, sendo esse um dos principais motivos para a impossibilidade da aplicação direta da MFEL para se caracterizar o crescimento de trincas neste material.

A ZPF consome grande parte da energia oriunda do carregamento aplicado na estrutura, contribuindo, portanto, para uma propagação estável das trincas, e é governada por mecanismos complexos (figura 5.32). Dentre os mecanismos da Zona de Processo de Fratura podem ser destacados os seguintes: a) Microtrincas; b) Deflexão da direção de propagação da trinca; c) Ligação das faces da trinca pela presença do agregado (costura); d) Rugosidade das superfícies da trinca; e) Ocorrência de vazios rombudos na ponta da trinca; f) Ramificação da trinca.

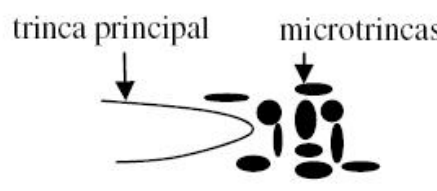

a) Microtrincas

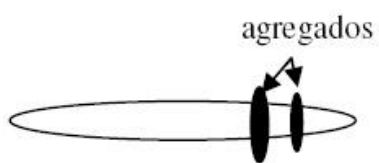

c) Costura

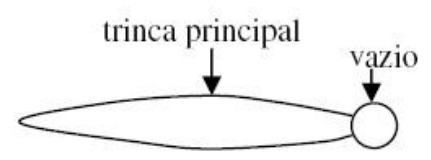

e) Ocorrência de vazios rombudos na ponta da trinca

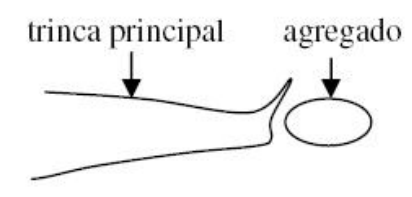

b) Deflexão da direção de propagação da atrito nas faces da trinca

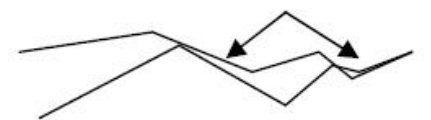

d) Rugosidade das superfícies da trinca trincas secundárias

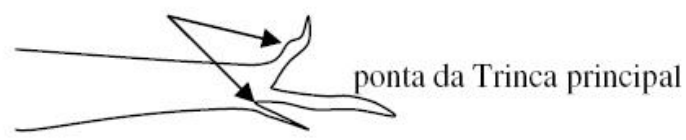

f) Ramificação da trinca

Figura 5.32 - Zona de Processo de Fratura (SHAH, 1995).

Existem vários modelos desenvolvidos de fratura aplicável ao concreto, as quais podem ser classificadas basicamente em modelos de fratura linear e modelos de fratura não linear. 


\section{Modelos de fratura linear}

A mecânica da fratura elástica e linear é aplicável a muitos materiais, em especial materiais metálicos; além disso, a linearidade permite aplicar o princípio de superposição, o qual torna possível estudar situações complexas de carga através de soluções para casos fáceis. Ao começo se tentou estudar o concreto utilizando esta teoria, fazendo-se muitas pesquisas para verificar se o concreto respondia em fratura como um material elástico-linear. Essas pesquisas têm mostrado que a teoria da fratura elástica linear só descreve bem o comportamento do concreto no caso de grandes fissuras em estruturas grandes, como em uma represa (RUIZ, 1998).

\section{Modelos de fratura não linear}

Os modelos de fratura não linear podem ser separados em dois grandes grupos. O primeiro é formado pelos modelos que se apoiam nos conceitos da mecânica da fratura elástica linear e que se diferenciam desses apenas nas condições de crescimento e instabilidade das fissuras, mantendo a idéia de que uma fissura não transmite tensões entre suas fases, com um extremo bem definido que avança num meio elástico. Também são conhecidos como modelos de mecânica de fratura elástica linear modificada (ELICES E PLANAS, 1988).

O segundo é denominado modelos de fratura progressiva. A diferença das teorias clássicas da fratura, na qual inclui-se a mecânica da fratura elástica linear e a mecânica elástica linear modificada. Nesses modelos o comportamento do material é estudado desde seu estado inicial, sem fissurar, até a ruptura completa. O estudo baseia-se numa relação tensão-deformação com amolecimento: a partir de certo valor de deformação o material exibe rigidez negativa. Essa formulação com amolecimento deve ir acompanhada de um critério de localização de dano, pois de outro modo pode acontecer que a fratura se concentre numa zona de volume nulo, não produzindo dissipação de energia (BAZANT, 1986).

Os modelos de fratura progressiva podem ser classificados em três grupos os quais são os de modelos de fissura coesiva, de fissuração em banda e não locais (ELISES, PLANAS, GUINEA, 1993). 
Modelos de fissuração em banda.- Supõem que a localização acontece numa banda de espessura determinada por várias vezes o tamanho máximo do agregado. A relação de amolecimento se estabelece entre a tensão e a deformação na banda. Atualmente esses modelos não são muito usados, uma vez que não foi demonstrada experimentalmente a existência de uma banda de fissuração, não preservam a condição de compatibilidade e equilíbrio em todos os pontos da banda. Esse método foi proposto por Bazant, Oh (1983), Borst e outros pesquisadores.

Modelos não locais. - A formulação desses modelos introduz uma elevada complexidade nos cálculos, o que motivou que seu uso não seja tão comum. 0 modelo baseia-se em que a evolução das tensões e deslocamentos num ponto depende do escorregamento em pontos situados a distância finita (não local). Este método foi proposto por Bazant, Belytscho (1984), Oh, Borst, Lin, Whu e outros pesquisadores.

Modelos de fissura coesiva.- Este modelo considera que 0 desenvolvimento da fissura acontece numa zona de espessura nula, e estabelecese uma relação com amolecimento entre a tensão e os deslocamentos nos dois lados da fissura (HILLERBORG et al, 1976). A seguir uma breve revisão das hipóteses sobre as quais se baseia os modelos de fissura coesiva:

- Os modelos de fissura coesiva supõem que existe transmissão de tensões entre as fases internas da fissura.

- Fora da zona de processo de fratura o comportamento do material é elástico-linear. (Simplificação feita para centrar o estudo só a zona de fratura).

- A fissura coesiva inicia-se ao alcançar em algum ponto a resistência à tração do material, $\mathrm{f}_{\mathrm{t}}$. A deformação local é idealizada como uma abertura de fissura, $w$, enquanto que as tensões coesivas simulam o amolecimento do material (figura 5.33a) e assume que é função de $w$ :

$$
\sigma=\mathrm{f}(w), \text { sendo } \mathrm{f}(0)=\mathrm{f}_{\mathrm{t}} \text { e } \mathrm{f}(w)>0 ;
$$

Onde $\mathrm{f}(w)$ é a função de amolecimento (característica do material). 
- Quando a fissura avança no decorrer da área, as tensões e deslocamentos em cada ponto dessa área recorrerão completamente à curva de amolecimento, o que requer um fornecimento energético por unidade de área que se denomina energia especifica de fratura, $\mathrm{G}_{\mathrm{F}}$, dada por:

$$
G_{F}=\int_{0}^{\infty} \sigma \cdot d w=\int_{0}^{w c} f(w) \cdot d w
$$

A expressão anterior $G_{F}$ pode-se interpretar como a área embaixo da curva de amolecimento da figura 5.33(b).

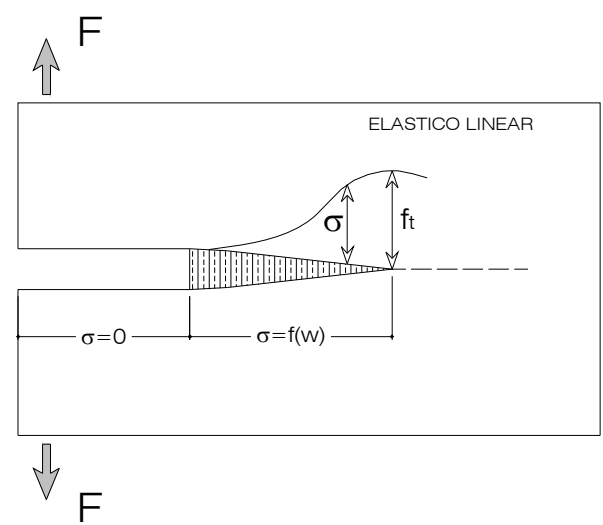

(a)

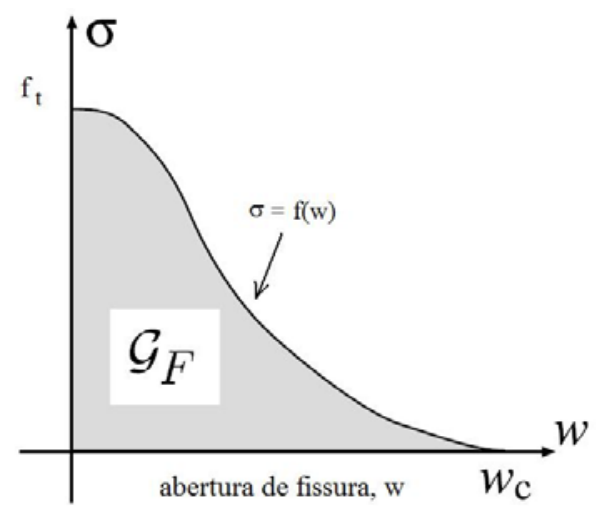

(b)

Figura 5.33 - (a) Fissura coesiva (RUIZ, 1998), (b) Função de amolecimento (CARPINTERI et al, 2002).

Assim, a energia de fratura é um parâmetro característico do material, pois a curva de amolecimento é uma propriedade do material.

A partir dos parâmetros característicos do material $\left(\mathrm{E}, \mathrm{f}_{\mathrm{t}}, \mathrm{G}_{\mathrm{F}}\right)$ obtiveram-se outros dois parâmetros, com dimensões de comprimento, Hillerborg (1976) definiu como comprimento característico, $I_{c h}$, a seguinte expressão:

$$
l_{c h}=\frac{E \cdot G_{F}}{f_{t}^{2}}
$$

O segundo parâmetro denominou-se abertura de fissura característica, e define-se como:

$$
w_{c h}=\frac{G_{F}}{f_{t}}
$$

Essas relações características representam um índice de fragilidade ou ductilidade do elemento estrutural. 


\subsubsection{A viga levemente armada e armadura mínima em flexão}

As vigas levemente armadas quando submetidas a uma carga até o colapso, apresentam uma ruptura frágil que se caracteriza pelo desenvolvimento de uma única fissura na zona de máximo momento fletor e não por meio de uma fissuração múltipla como no caso de vigas armadas ordinariamente. Por isso, se faz simples a abordagem desse tipo de vigas por meio da mecânica de fratura.

Adiante apresenta-se um estudo dos ensaios realizados sobre vigas com baixa taxa de armadura, onde foram selecionados vários casos característicos com o objetivo de se descrever o comportamento típico desse elemento estrutural.

Nas figuras 5.34 a-c, ilustram-se curvas de carga-deslocamento, obtidas a partir de ensaios de flexão em três pontos sobre vigas com diversas taxas de armadura e considerando o tipo de superfície de contato do aço (nervurado ou liso). A fig. 5.34(a) mostra resultados dos ensaios efetuados por Hededal e Kroon (1991) em vigas fabricadas com concreto de alta resistência e armadas com aço nervurado. Essas vigas caracterizam-se pelo aparecimento de um pico de carga mais agudo, isso devido a um pequeno entalhe feito na fibra inferior.

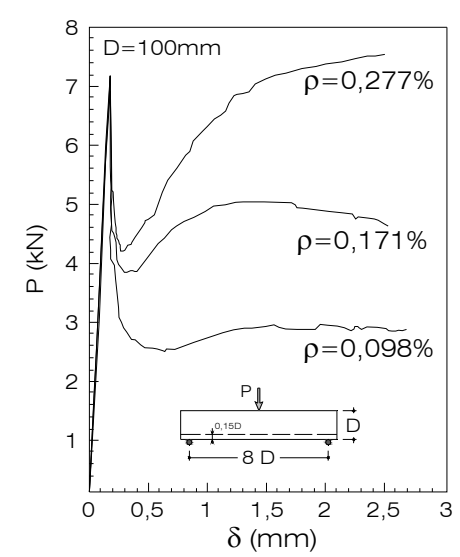

(a)

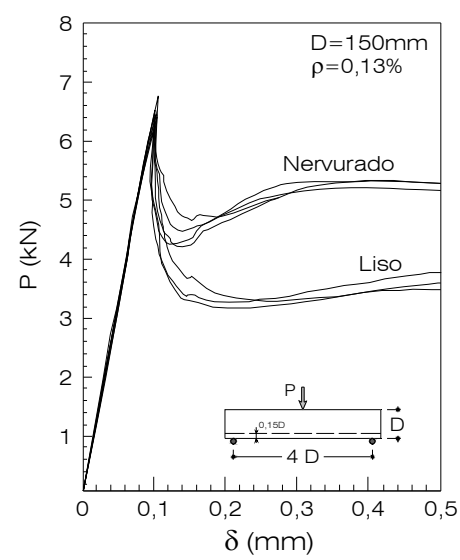

(b)

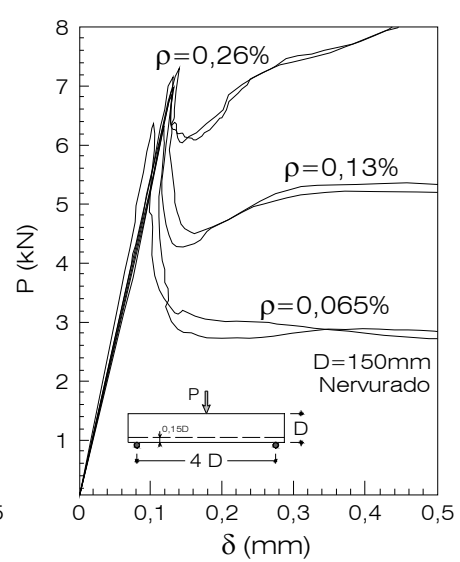

(c)

Figura 5.34 - Curvas carga-deslocamento: (a) Ensaio de Hededal e Kroon (1991), (b) e (c) Ensaios de Gonzalo Ruiz (1998).

$\mathrm{Na}$ figuras $5.34 \mathrm{~b}-\mathrm{c}$, apresentam-se resultados dos ensaios efetuados por Ruiz (1998) em vigas de microconcreto armadas algumas com aço liso e outras com aço nervurado. 
A influência da taxa da armadura na resposta global da estrutura da viga fica claramente mostrada nas figuras 5.34 a-c, assim como na figura 5.34.b mostrase que aderência influência substancialmente.

Outro fator que influência consideravelmente no comportamento das vigas levemente armadas é a forma da seção transversal. Na figura 5.35(a), mostram-se os resultados dos ensaios efetuados por Jacinto Ruiz (2006) em vigas T, cujas mesas variavam: da largura da seção retangular até uma largura de mesa igual à altura da viga. Nelas pode-se perceber um efeito de forma, uma vez que o pico de carga aumenta menos do que previsto pelo calculo teórico da estrutura à medida que se torna mais larga a mesa da viga.

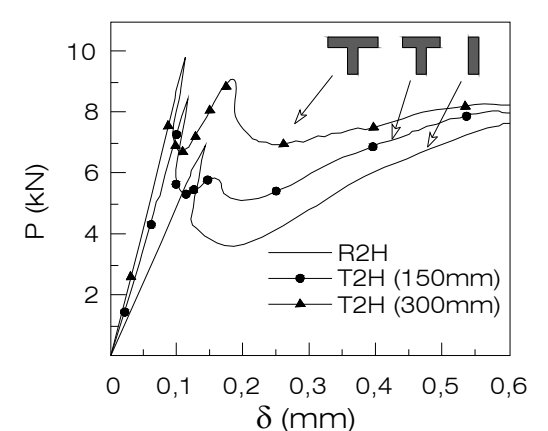

(a)

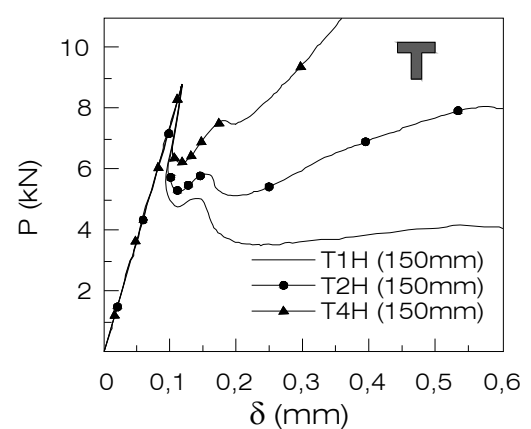

(b)

Figura 5.35 - Curvas carga-deslocamento de Jacinto Ruiz (2006): (a) Vigas T com comprimentos de mesa variável, (b) Vigas tipo T com taxa de armadura variável.

A pesar das diferenças existentes entre os materiais e os dispositivos de ensaio, as figuras têm muita semelhança entre si.

\section{Curva carga-deslocamento de uma viga levemente armada}

A curva carga-deslocamento de uma viga levemente armada pode-se esquematizar conforme ilustrado na figura 5.36 (a).

No tramo OA tem-se um comportamento linear, logo segue-lhe uma resposta não linear até a carga máxima de fissuração, ponto $B$. Desde o máximo de fissuração, $B$, até o momento em que o aço se plastifica (ponto D) a resposta da viga segue a curva $B C D$, em forma de U. Em D a curva desce lentamente até um tramo horizontal, E, que continuaria indefinidamente se o aço fosse perfeitamente plástico, mas na prática acaba ao produzir-se o escoamento e subsequente ruptura 
do aço. Se o aço tem uma transição entre sua resposta elástica - linear e seu comportamento perfeitamente plástico, o pico D suaviza-se e a curva apresenta uma curvatura suave representada pela linha de traços CD'E.

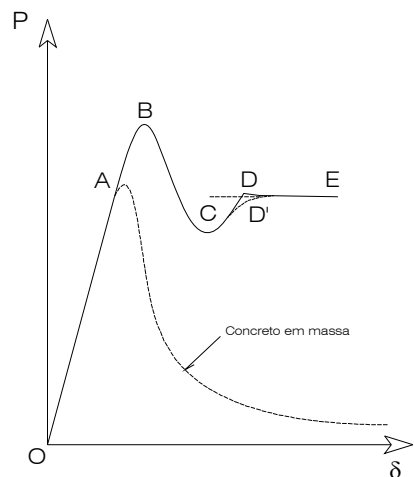

(a)

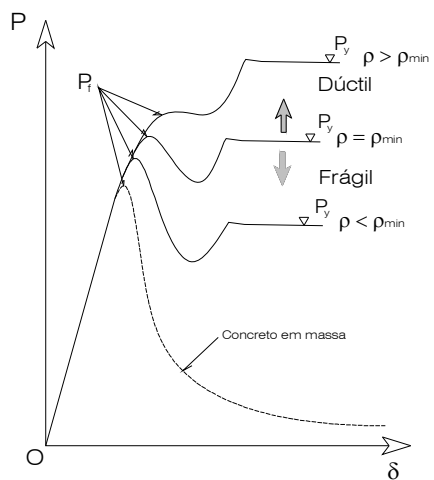

(b)

Figura 5.36 - (a) Curva carga-deslocamento de uma viga levemente armada, (b) Transição frágil-dúctil numa viga armada em função da taxa de armadura (RUIZ, 1998).

O comportamento elástico depende basicamente da resistência à tração do concreto, $f_{t}$, limitada pela posição do ponto A na figura anterior. Após esse limite gera-se uma zona de fratura que começa a crescer em direção à armadura através do cobrimento.

Quando a zona de fratura alcança a armadura, produzem-se simultaneamente dois fenômenos: a zona de fratura fica costurada pela armadura, que ainda está em regime elástico e se opõe ao avanço da fissura, no mesmo tempo que ao aumentar a solicitação no aço chega-se ao limite da resistência de contato aço-concreto na zona próxima à fratura, de modo que o aço desliza. Portanto, o máximo B e os ramos adjacentes da curva carga-deslocamento estão controlados pela taxa de armadura, as propriedades da interação aço-concreto aderência entre ambos os materiais- e pelo cobrimento (RUIZ, 1998).

\section{Armadura mínima em flexão}

A quantidade de armadura necessária para uma viga depende das solicitações de carga externa. Mas essas armaduras são dimensionadas geralmente com o objetivo de se evitar a ruptura frágil da viga, já que existem muitos critérios construtivos que conduzem a seções de concreto que resistiriam às cargas de projeto sem armadura. Nesse caso é necessário definir qual é a 
quantidade mínima de aço a ser colocada na viga para que em nenhum caso rompa de modo frágil. Essa quantidade de aço costuma ser expressa como a razão entre a área de aço que se coloca na zona tracionada, As, e a área da seção do concreto, Ac. Essa razão denomina-se taxa de armadura e, normalmente, é representada pela letra $\rho$. Então, chamam-se vigas levemente armadas, às vigas que tem uma quantidade de aço próxima a esse mínimo.

A figura 5.36(b) esquematiza graficamente a transição que se produz numa viga levemente armada solicitada à flexão em três pontos ao aumentar-se a taxa da armadura. Assim, o comportamento frágil ou dúctil da viga é definido pela taxa de armadura, portanto, a viga tem taxa mínima se a carga máxima que pode suportar (máximo de fissuração: $P_{f}$ ) coincide com o nível de carga exterior quando o aço está plastificado, trabalhando à sua resistência de escoamento, e a fissuração está completamente desenvolvida $\left(P_{y}\right)$ :

$\begin{array}{ll}\text { Comportamento frágil } & : \mathrm{P}_{\mathrm{f}}>\mathrm{P}_{\mathrm{y}} \\ \text { Taxa mínima } \rho_{\text {min. }} & : \mathrm{P}_{\mathrm{f}}=\mathrm{P}_{\mathrm{y}} \\ \text { Comportamento dúctil } & : \mathrm{P}_{\mathrm{f}}<\mathrm{P}_{\mathrm{y}}\end{array}$

Devido ao fato de que o valor da $P_{f}$ está essencialmente controlado pelo processo de fratura, as vigas levemente armadas mostram o efeito escala, portanto a taxa mínima de armadura deve também depender do tamanho.

\subsubsection{Modelagem Numérica}

A criação do modelo computacional e visualização dos resultados, o pré e pós-processamento foram realizados pelo programa GID (GID HOMEPAGE), com o qual, na fase de pré-processamento definiram-se a geometria, a malha de elementos finitos, os materiais utilizados e as cargas. As propriedades adotadas para o material foram obtidas nos ensaios de caracterização do microconcreto e do aço que estão apresentados na tabela 5.8 e 5.9 .

O concreto é representado com elementos finitos triangulares de três nós com descontinuidade incorporada, dentro do contexto da Aproximação Contínua de Descontinuidades Fortes (OLIVER, 1996), enquanto que as barras da armadura são representadas com elementos lineares de dois nós. 
Para representar o comportamento não linear do concreto utilizou-se o modelo constitutivo baseado na mecânica do dano contínuo, modelo de dano somente à tração para representar o comportamento na região de localização de deformação (banda de localização para o caso bidimensional).

Para considerar a possível perda de aderência e deslizamento entre a barra de aço e o concreto, foram usados elementos especiais de interface, posicionados entre os elementos de concreto e das barras. Esses elementos compartilham nós com os elementos finitos sólidos de concreto e os unifilares das barras, e apresentam um comportamento de deslizamento relativo rígido-perfeitamente plástico. A tensão de aderência foi ajustada de acordo com os resultados dos ensaios de arrancamento.

Aplicou-se a simulação numérica de propagação de fissuras, desenvolvida por MANZOLI \& SHING (2006). A análise pelo método de elementos finitos foi realizada através do programa OMEGA, com recursos de análise de descontinuidades implementadas em linguagem FORTRAN que foram inseridas no referido programa computacional de análise não linear pelo Método dos Elementos Finitos OMEGA. A visualização dos resultados foi feita pelo módulo de pósprocessamento do programa GID.

$\mathrm{Na}$ figura 5.37 apresenta-se um exemplo de modelagem de uma das vigas levemente armadas.

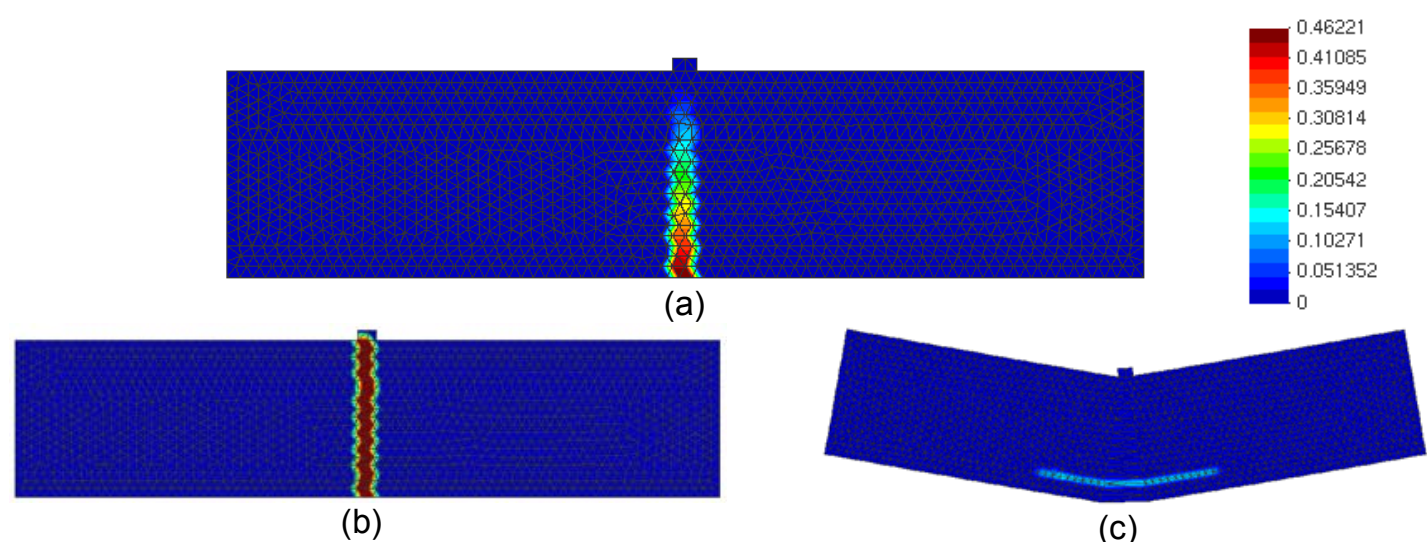

Figura 5.37 - Viga retangular armada: (a) Valores de abertura de fissura ( $\mathrm{mm}$ ), (b) Elementos danificados (com fissura ativa), (c) região de perda de aderência. 
A seguir são apresentadas as curvas de carga-deslocamento das vigas levemente armadas (figura 5.38 e 5.39), calculadas teoricamente com a ajuda do programa OMEGA. O desenvolvimento numérico foi feito pela equipe de pesquisadores do projeto $\mathrm{CNPq}$ - Estudo Experimental de Parâmetros de Fratura Coesiva para Modelagem Física e Numérica de Estruturas de Concreto em Escala Reduzida, em função aos dados experimentais. Nesta pesquisa só se apresentam os resultados finais, para fins de comparação.

Na figura 5.38 ilustra-se a curva de carga-deslocamento para diferentes taxas de armadura de uma mesma seção. Na figura 5.39 mostra-se a curva de cargadeslocamento de seções diferentes para uma mesma quantidade de armadura.

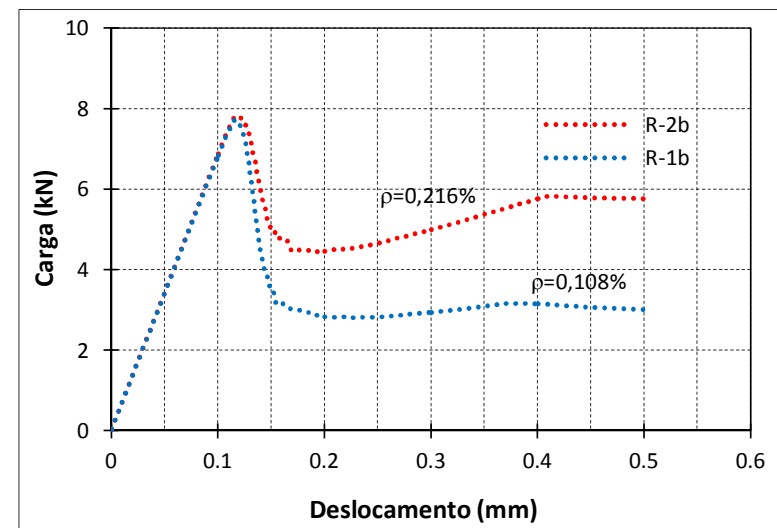

(a)

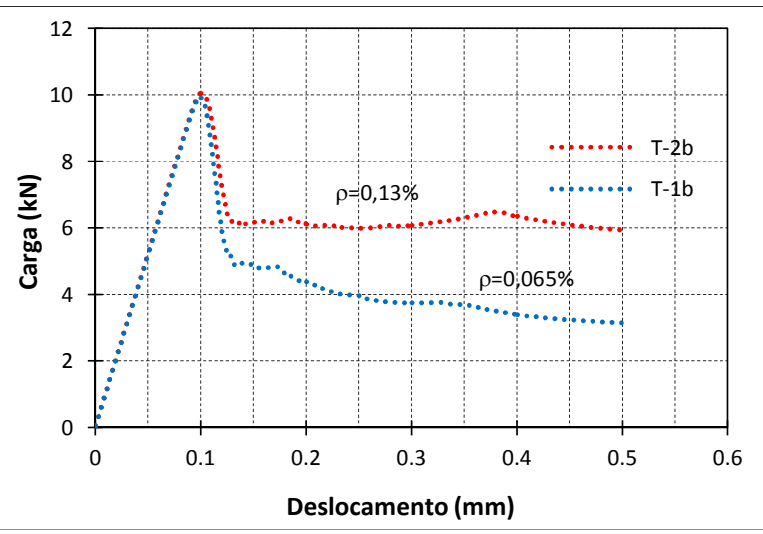

(b)

Figura 5.38 - Curva carga-deslocamento das vigas de seção retangular (a) e seção T (b) para diferentes taxas de armadura.

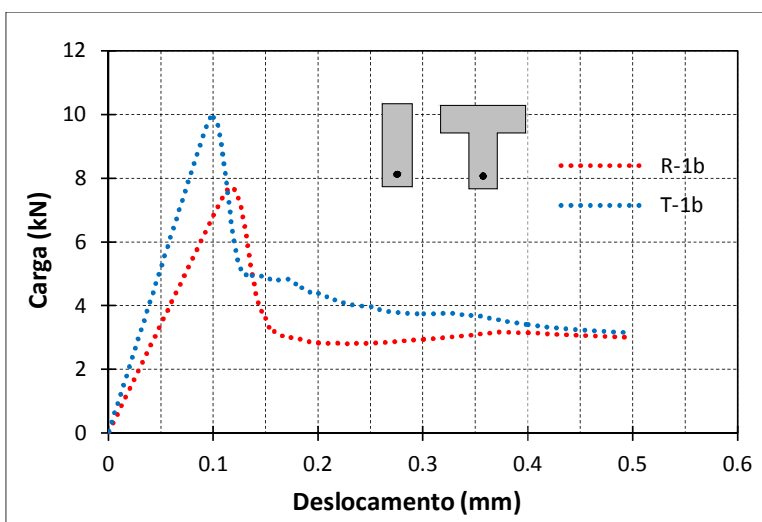

(a)

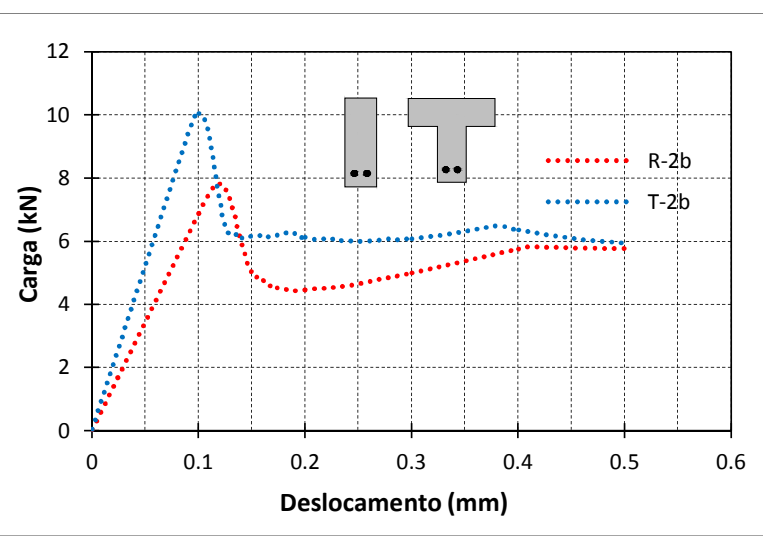

(b)

Figura 5.39 - Curva carga-deslocamento das vigas de seção retangular e seção T com uma armadura (a) e duas armaduras (b). 


\subsubsection{Estudos experimentais}

Neste item apresenta-se uma descrição do programa experimental desenvolvido com o objetivo de se conhecer o comportamento em fratura das vigas levemente armadas. O que se pretende mostrar é que o comportamento das vigas é sensível à forma da seção transversal e à taxa de armadura, sobre a evolução do processo de fratura, à medida que são carregadas.

Foram escolhidos dois tipos de seções, uma retangular e outro tipo $\mathrm{T}$ com duas taxas de armadura diferentes, executadas com um microconcreto com tamanho máximo de agregado de $4,8 \mathrm{~mm}$. As armaduras escolhidas possuíam seções suficientemente pequenas para que as vigas armadas se situem na zona de transição dúctil-frágil. O diâmetro nominal da armadura foi de 3,215 mm.

Além disso, ensaios padronizados de caracterização e controle foram realizados para determinar a resistência à compressão, a resistência à tração, o módulo de elasticidade e a energia de fratura do microconcreto. Do mesmo modo, os parâmetros mecânicos do aço e as propriedades de aderência entre aço e concreto também foram determinadas em ensaios de laboratório.

\subsubsection{Características do modelo reduzido}

As dimensões das vigas baseiam-se na dimensão máxima do agregado de acordo como as recomendações do RILEM. Também, optou-se pelo tamanho dos corpos de prova, conforme observado em alguns trabalhos experimentais encontrados na bibliografia.

A figura 5.40 mostra as proporções dos corpos de prova, considerando a dimensão máxima do agregado de 4,8 $\mathrm{mm}$. Assim, as dimensões foram adotadas em função da altura da seção: o comprimento total da viga era 4,5 vezes a altura, o vão de apoio tinha um comprimento de quatro vezes a altura e a largura da seção foi assumida como constante para todos os corpos de prova $(B=5 \mathrm{~cm})$. 


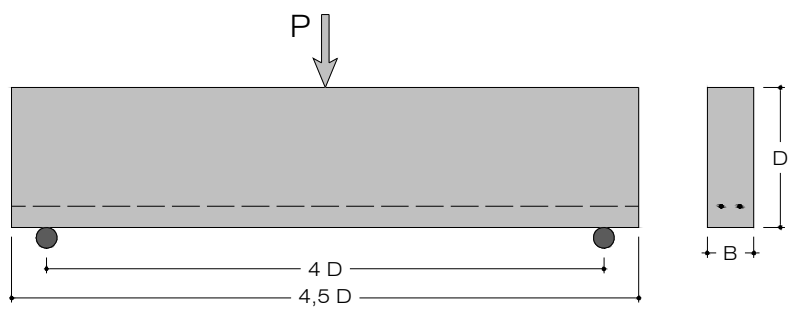

Figura 5.40 - Proporções das vigas levemente armadas.

Foram projetadas e fabricadas vigas armadas para realizar ensaios e comparar com os modelos teóricos. Os parâmetros variados nos ensaios das vigas levemente armadas são: a seção transversal e a taxa de armadura.

Nas figuras 5.41 e 5.42 são ilustradas: a geometria, as dimensões da seção transversal e a taxa de armadura, adotadas para a fabricação das vigas.
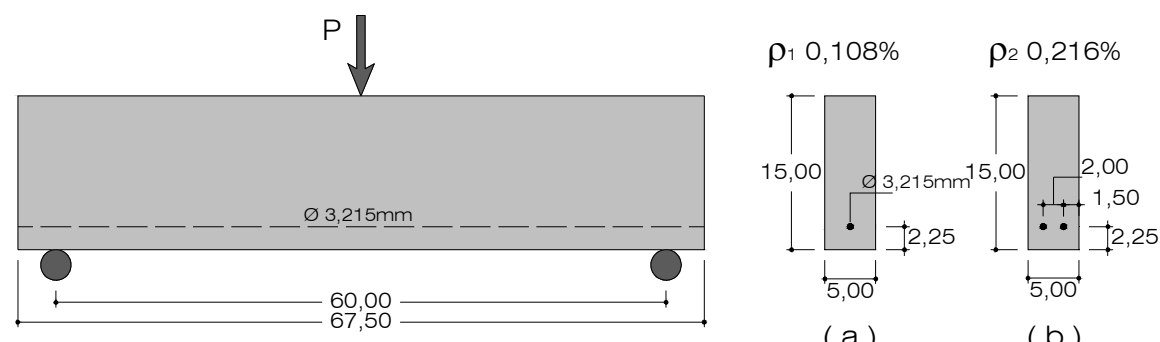

( a )

( b )

Figura 5.41 - Viga retangular (a) com uma barra de reforço R-1b, (b) com duas barras de reforço R-2b.
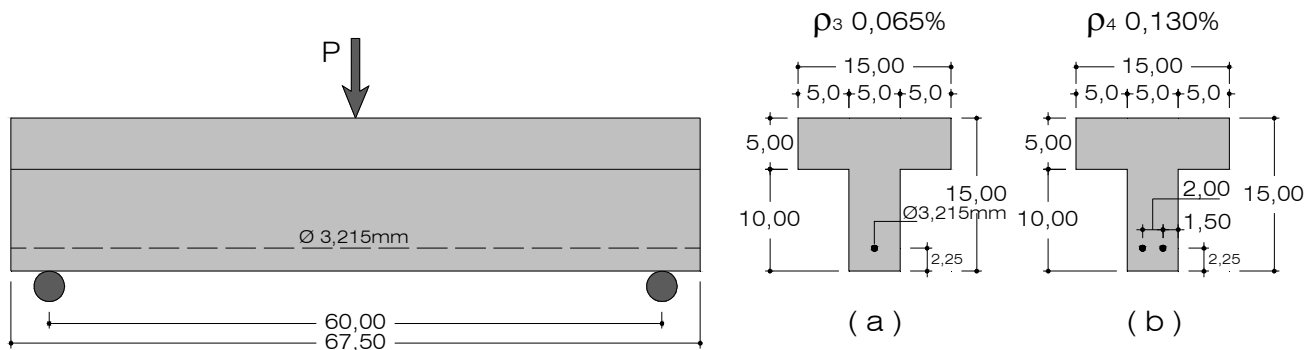

( a )

( b )

Figura 5.42 - Viga tipo T (a) com uma barra de reforço $T-1 b$, (b) com duas barras de reforço $T-2 b$.

No total foram concretados 12 corpos de prova armados com arame recozido (3 para cada tipo de seção e taxa de armadura). O cobrimento do arame em todos os casos foi de $15 \%$ da altura da viga e seu posicionamento foi feito através de espaçadores. Teve-se especial cuidado para que os arames estivessem completamente cobertos pela massa de concreto. 


\subsubsection{Caracterização e construção das vigas armadas}

Os ensaios de caracterização dos materiais usados na fabricação das vigas levemente armadas foram realizados para determinar: a resistência à compressão, a resistência à tração, o módulo de elasticidade e a energia de fratura do microconcreto. Do mesmo modo, a resistência ao escoamento e o módulo de elasticidade do aço e as propriedades de aderência aço-concreto.

Para os ensaios de compressão e módulo de elasticidade fabricaram-se corpos de prova de $5 \mathrm{~cm}$ de diâmetro e $10 \mathrm{~cm}$ de altura (12 corpos de prova), e para ensaios de tração diametral (6 corpos de prova).

Também se fabricaram vigas em massa para a caracterização das propriedades do microconcreto em fratura. Todas elas tinham $5 \mathrm{~cm}$ de largura e seu comprimento era 4,5 vezes sua altura (6 corpos de prova), conforme são ilustradas na figura 5.43. Um entalhe foi cortado na seção central até a metade da altura um dia antes de se ensaiar a viga. O corte foi efetuado por via úmida.
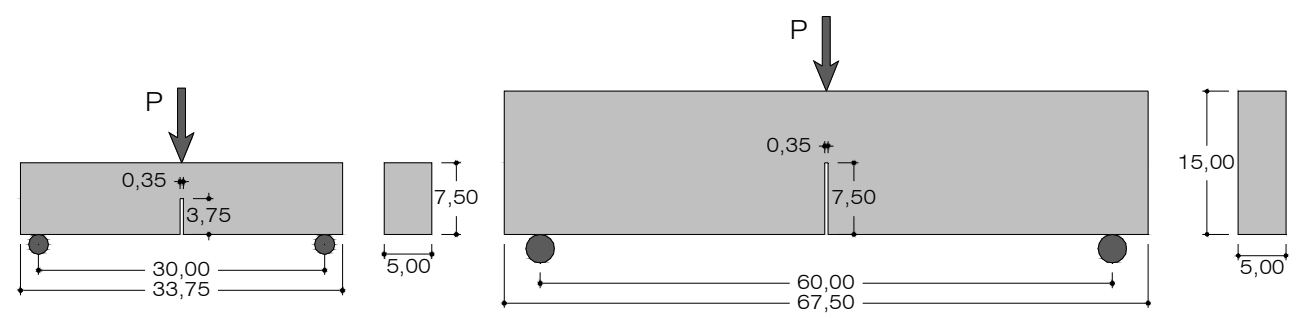

Figura 5.43 - Vigas em massa para medir a energia de fratura.

Para realizar os ensaios de aderência foram concretadas 3 corpos de prova de $7,5 \times 7,5 \times 15 \mathrm{~cm}$ com um arame situado no meio da seção, tal como se mostra na figura 5.44 .

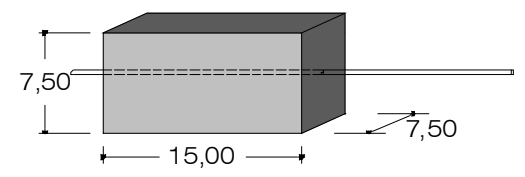

Figura 5.44 - Corpo de prova para medir a tensão de aderência.

$\mathrm{Na}$ tabela 5.8 e 5.9 apresenta-se um resumo das principais propriedades mecânicas obtidas dos ensaios de caracterização: 
Tabela 5.8 - Propriedades mecânicas do microconcreto.

\begin{tabular}{cccccc}
\hline $\begin{array}{c}\text { Resistência à } \\
\text { Compressão } \\
(\mathbf{M P a})\end{array}$ & $\begin{array}{c}\text { Resistência à } \\
\text { Tração } \\
(\mathbf{M P a})\end{array}$ & $\begin{array}{c}\text { Módulo de } \\
\text { Elasticidade } \\
(\mathbf{G P a})\end{array}$ & $\begin{array}{c}\mathbf{G}_{\mathbf{F}} \\
\mathbf{( N / m})\end{array}$ & $\begin{array}{c}\mathbf{L}_{\mathrm{ch}} \\
(\mathbf{m m})\end{array}$ & $\begin{array}{c}\mathbf{w}_{\mathrm{ch}} \\
(\boldsymbol{\mu m})\end{array}$ \\
\hline $35,47 \pm 0,46$ & $4,40 \pm 0,17$ & $26,95 \pm 0,56$ & $72,43 \pm 1,12$ & 100 & 16,5 \\
\hline
\end{tabular}

Tabela 5.9 - Propriedades mecânicas do arame recozido com nervura.

\begin{tabular}{|c|c|c|}
\hline $\begin{array}{c}\text { Módulo de } \\
\text { Elasticidade } \\
\text { (GPa) }\end{array}$ & $\begin{array}{c}\text { Resistência à } \\
\text { Ruptura } f_{u} \\
(\mathrm{MPa})\end{array}$ & $\begin{array}{c}\text { Resistência ao } \\
\text { Escoamento } \mathrm{f}_{\mathrm{y}} \\
(\mathrm{MPa})\end{array}$ \\
\hline $114,77 \pm 3,85$ & $401,11 \pm 13,11$ & $346,39 \pm 6,25$ \\
\hline
\end{tabular}

Todo o processo construtivo e a caracterização dos materiais das vigas levemente armadas estão descritos com maior detalhe no anexo A e B da presente pesquisa.

\subsubsection{Execução do ensaio}

As vigas armadas foram ensaiadas à flexão em três pontos, conforme se ilustra na figura 5.45(a). O ensaio consistiu basicamente, em aplicar uma carga incremental às vigas e acompanhar os deslocamentos e abertura das fissuras durante a aplicação da carga.

Da figura $5.45(b)$, pode-se perceber que o corpo de prova apoia-se em cada extremo sobre um pequeno cilindro e uma placa de aço, que por sua vez, repousa sobre uma articulação anti-torção formada por uma placa que pode girar sobre outro cilindro polido, cujo eixo é paralelo ao eixo da viga, o conjunto repousa sobre uma linha de rótulas que permitem o deslocamento, com atrito virtual nulo, sobre os planos de apoio. Assim, os apoios são dispositivos que permitem o giro em todas as direções e deslocamento horizontal.

Todo o equipamento de ensaio foi montado sobre um pórtico metálico com uma rigidez muito mais elevada que a rigidez da viga, pois como os deslocamentos nos materiais frágeis são muito reduzidos, a componente de deformação do próprio pórtico pode afetar o controle do ensaio. 


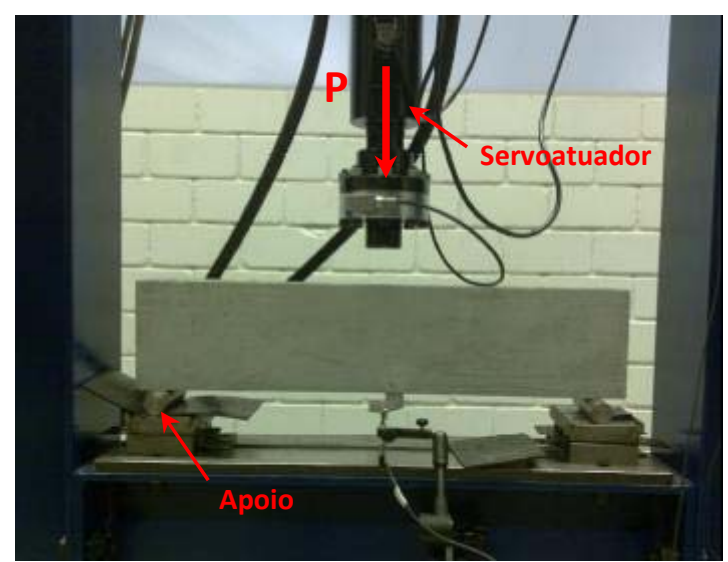

(a)

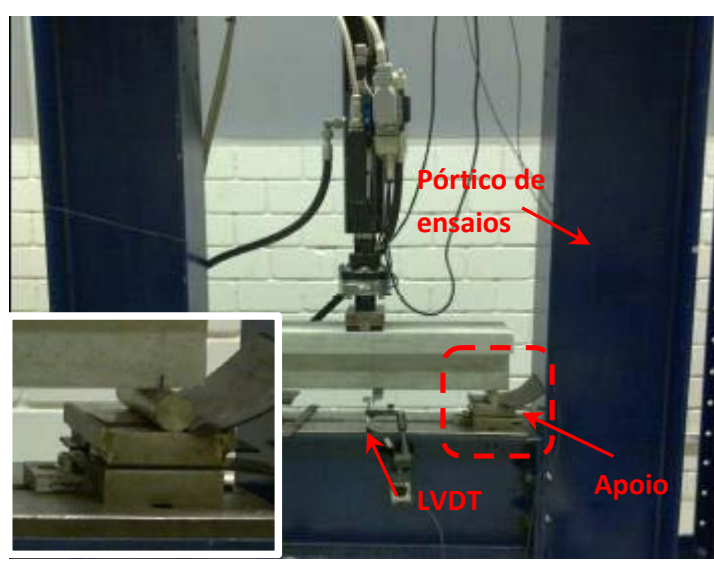

(b)

Figura 5.45 - Ensaio de flexão em três pontos (a) Viga retangular, (b) Viga tipo T.

\section{Sistema de monitoração}

As vigas levemente armadas foram submetidas a carregamento através de um sistema flexível de ensaios composto por um pórtico de ensaios, um servoatuador, uma central hidráulica, um quadro elétrico de interface e um computador de comando. As características e o funcionamento desse equipamento foram detalhados na descrição dos ensaios realizados na ponte de microconcreto (item 5.2.4.3)

As deflexões das vigas foram medidas através de um LVDT instalado embaixo delas, cuja base magnética foi apoiada na viga metálica do pórtico de ensaios. Também se colou um perfil metálico rígido na parte inferior da viga para servir de referência na medição.

O registro de dados foi armazenado automaticamente pelo computador de comando, a frequência de amostragem era de $100 \mathrm{~Hz}$ (100 pontos por segundo), onde cada registro inclui a leitura de cada um dos três sensores: posição do servoatuador, carga e a flecha.

\section{Realização do ensaio}

Um ensaio que envolve fratura frágil (como é típico dos elementos estruturais baseados em concreto) exige certos cuidados que assegurem o seu sucesso. O que acontece é que em materiais rígidos e frágeis um pequeno incremento de deslocamento significa um grande aumento de força e quando se dá 
a fratura, dá-se uma queda abrupta da força resistente para um incremento minúsculo do deslocamento.

Esse fato torna o controle desses ensaios bastante complicado e, como tal, exige que as condições de realização do ensaio estejam otimizadas.

Para conseguirem-se bons resultados nesse tipo de ensaio, deve-se garantir que o pórtico metálico envolvente tenha uma rigidez bem mais elevada que a estrutura a ensaiar (rigidez do pórtico no mínimo 10 vezes superior à da viga). servoatuador hidráulico deve estar o mais recuado possível a fim de minimizar a energia acumulada (o óleo hidráulico pressurizado no interior atua como uma mola) que é liberada no momento da fratura.

A carga aplicada às vigas foi controlada em deslocamento, para assegurar o controle e registro dos efeitos pós-fratura.

O procedimento de ensaio efetuado para cada corpo de prova foi o mesmo seguido no ensaio da ponte de microconcreto (item 5.2.4.3).

\subsubsection{Resultados experimentais}

As curvas de carga-deslocamento foram obtidas através dos ensaios de flexão em três pontos sobre as vigas levemente armadas. No total foram ensaiados doze corpos de prova, três exemplares por cada tipo de viga mostrado na figura 5.41 e 5.42 .

Uma das dificuldades encontradas na execução dos ensaios foi que o computador de comando do sistema flexível, em algumas ocasiões, perdia controle do servoatuador. Como é sabido, o servoatuador é o equipamento destinado a aplicar a carga aos corpos de prova e, ao ficar fora de controle, o incremento de carga se produzia rapidamente, ocasionando a ruptura quase imediata das vigas e sem ter a possibilidade de salvar as leituras do processo de ensaio. Esse fenômeno aconteceu devido a muitas razões, entre elas: as vigas não foram posicionadas adequadamente no pórtico de ensaios, originando instabilidade no ensaio e também o equipamento era novo, pois apresentava alguns defeitos de 
configuração. Por esse motivo perderam-se quatro corpos de prova ( $R-1 b-1, R-1 b-$ 2, R-2b-3 e T-2b-3).

Todos os dados registrados depois de cada ensaio foram submetidos a um processo de tratamento, o qual consistiu basicamente em: correção da zona não linear da curva carga-deslocamento $(P-\delta)$ no começo do ensaio e a correção do zero em deslocamento. Essa sequência de tratamento de dados foi adotada de acordo com as recomendações estabelecidas por Gonzalo Ruiz (1998).

A correção correspondente à não linearidade da curva $\mathrm{P}-\delta$ foi realizada adotando como parte inicial do ensaio, a prolongação da zona em que começa a existir a linearidade em $\mathrm{P}-\delta$. Essa correção é devida ao fato de que a estrutura nos primeiros instantes do ensaio sofre um acomodamento na parte dos apoios como produto da carga aplicada. Após linearizar-se a parte inicial dos dados $\mathrm{P}-\delta$, procedeu-se a realizar a correção zero em deslocamento, restando a todo o registro o valor de $\delta$ que corresponde à carga inicial nula.

$\mathrm{Na}$ figura 5.46 ilustram-se as curvas de $\mathrm{P}-\delta$ experimentais das vigas de seção retangular $(5 \times 15 \times 67,5 \mathrm{~cm})$ com duas diferentes taxas de armadura. Durantes o ensaio dessas vigas foram perdidos três corpos de prova devido aos motivos explicados anteriormente.

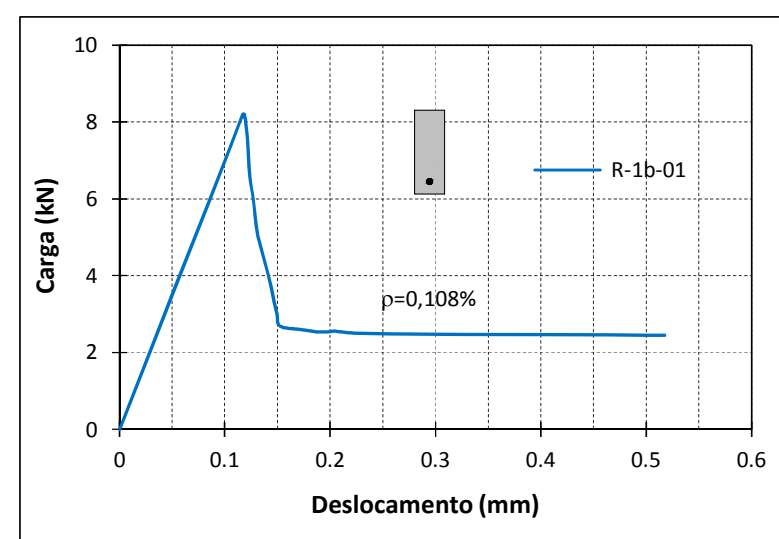

(a)

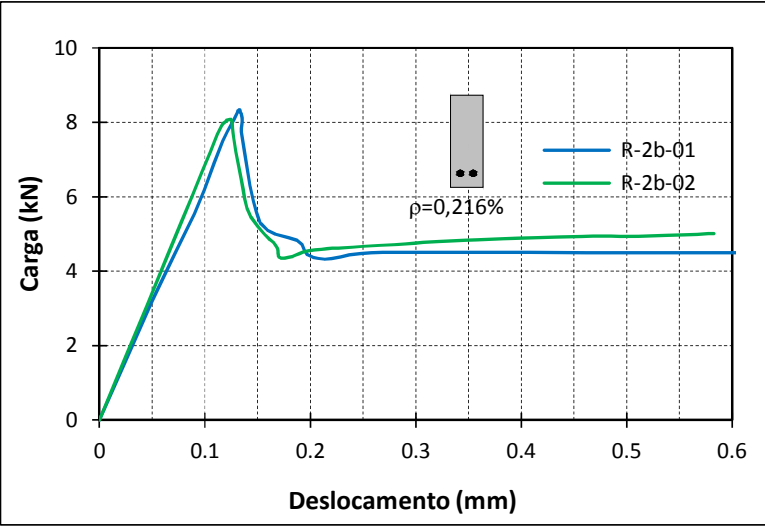

(b)

Figura 5.46 - Curva carga-deslocamento das vigas de seção retangular: (a) $\rho=0,108 \%$, (b) $\rho=0,216 \%$. 
$\mathrm{Na}$ figura 5.47 ilustram-se as curvas de $\mathrm{P}-\delta$ experimentais das vigas de seção T com duas diferentes taxas de armadura. Felizmente, perdeu-se apenas um corpo de prova durante os ensaios dessas vigas.

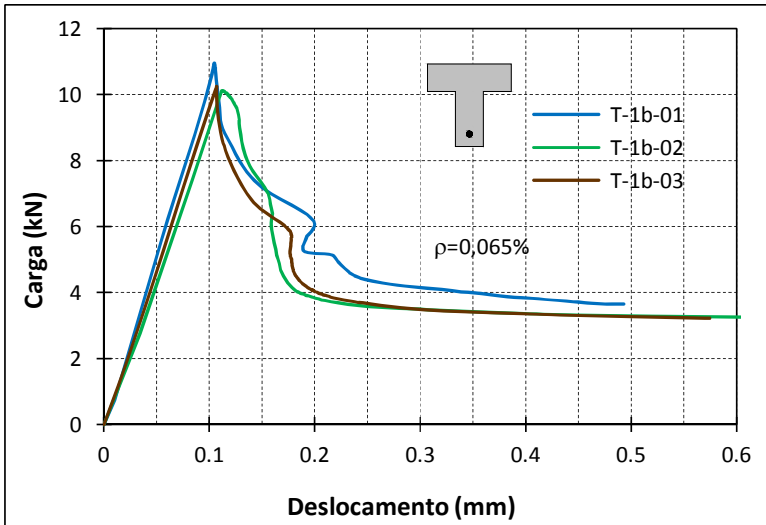

(a)

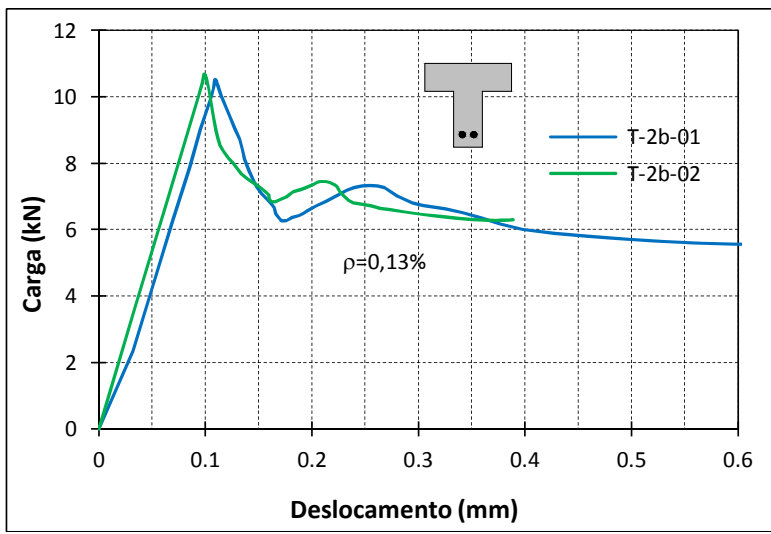

(b)

Figura 5.47 - Curva carga-deslocamento das vigas de seção T: (a) $\rho=0,065 \%$, (b) $\rho=0,13 \%$.

Das curvas de carga-deslocamento apresentadas na figura 5.46 e 5.47, pode-se perceber que as vigas com a mesma seção e mesma taxa de armadura, não tem a mesma inclinação inicial. Segundo a literatura encontrada ao respeito indica-se que esse fenômeno é conhecido nesse tipo de ensaios e se deve à impossibilidade de conseguir as mesmas condições de apoio em todos os ensaios aparamente iguais. Qualquer pequena irregularidade no contato de apoio com a superfície do concreto, qualquer falta de alinhamento que faça que o contato não seja uniforme, etc, são causas suficiente para produzir inclinações iniciais diferentes em ensaios que deveriam ser idênticos.

As curvas de carga-deslocamento de cada viga são apresentadas com maior detalhe no Anexo C.

\subsubsection{Apresentação de resultados e discussões}

A partir dos resultados experimentais de carga-deslocamento foram feitos um conjunto de estudos para verificar a influência dos parâmetros (aderência, taxa de armadura e forma da seção) no comportamento real das vigas levemente armadas. Do mesmo modo, foram comparadas as curvas $\mathrm{P}-\delta$ teóricas calculadas no item 5.3.3 com os resultados experimentais, com a finalidade de validar o modelo teórico. 
A seguir descrevem-se todos esses estudos realizados, a comparação entre dados teóricos e experimentais e suas respectivas discussões.

\subsubsection{Influência de parâmetros no comportamento das vigas}

Nas figuras 5.48 e 5.49, apresentam-se as curvas de carga-deslocamento experimentais das vigas levemente armadas, as quais foram combinadas com a finalidade de observar a influência dos parâmetros.

Assim, para mostrar a influência da taxa de armadura foram comparadas as curvas $P-\delta$ das vigas de seção similar (retangular e T, figura 5.48), armadas com aço nervurado e diferente taxa de armadura. Resulta evidente a influência da taxa no comportamento posterior à carga máxima das vigas, e ainda pode-se distinguir uma leve influência da taxa no mesmo valor da carga máxima. Também se observou durante os ensaios, que as vigas não tinham um comportamento dúctil, pois quando se alcançou a carga máxima, a ruptura foi brusca. Isso devido à baixa taxa de armadura nas vigas $(0,065 \%-0,216 \%)$.

Outro fator importante que se pode perceber das curvas experimentais, é que o comportamento posterior ao máximo também depende da aderência entre os materiais aço e microconcreto. Esta afirmação pode ser feita em função dos ensaios realizados por Gonzalo Ruiz (figura 5.34b-c) - os corpos de prova desse estudo são relativamente similares aos ensaios realizados nesta pesquisa - cujos resultados experimentais guardam relativa semelhança.

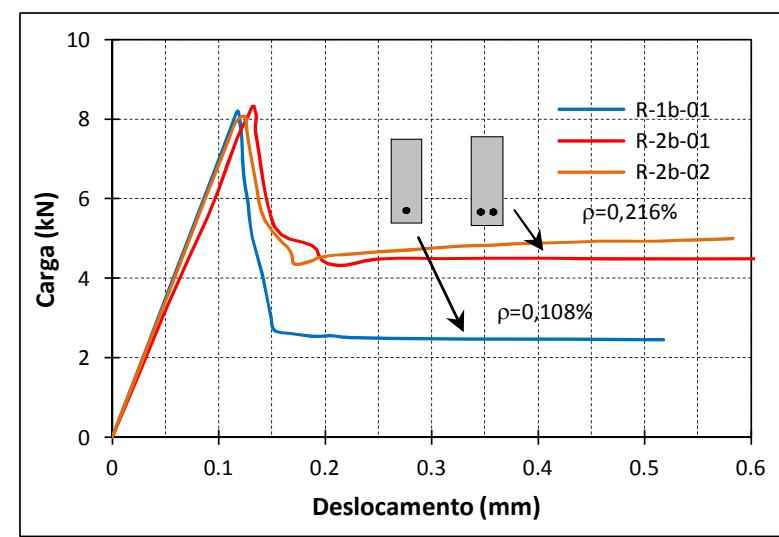

(a)

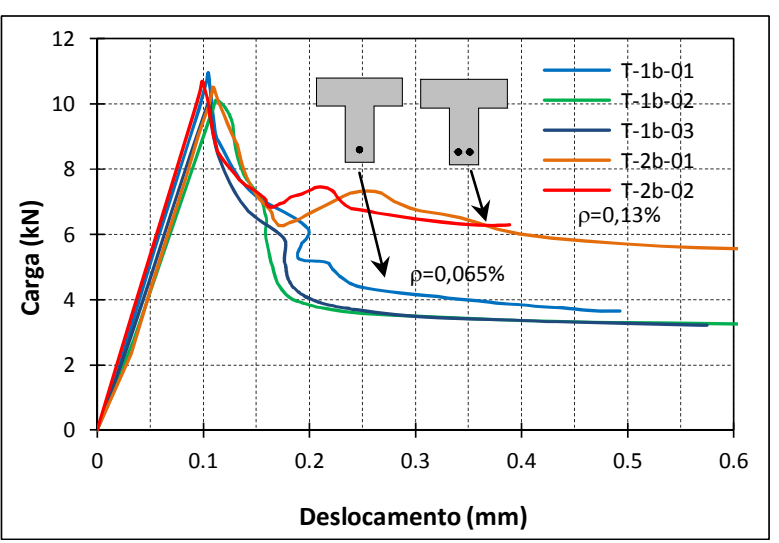

(b)

Figura 5.48 - Influencia da taxa de armadura no comportamento das vigas levemente armadas. 
O efeito de forma da seção transversal pode ser estudado a partir das curvas apresentadas na figura 5.49. Nota-se que o modelo físico reproduz claramente a resposta real da viga quando a seção muda. Das curvas experimentais pode-se perceber que a viga $\mathrm{T}$ tem maior rigidez inicial e a carga máxima é um pouco maior que uma viga retangular. No entanto, observa-se que o aumento não segue aqueles calculados usando a teoria linear simples. Essa observação pode ser facilmente explicada: a presença da mesa da viga $T$ faz com que o eixo neutro suba e a zona de processo de fratura se desenvolva como se a viga $T$ fosse uma viga retangular maior. Esse fenômeno foi visto no ensaio efetuado no modelo anterior (ponte de microconcreto), onde foram instalados sensores ao longo da seção a fim de se observar a mudança do eixo neutro à medida que se incrementava a carga (item 5.2.5.2). Portanto, existe uma espécie de efeito de forma o qual é apropriadamente reproduzido por esse modelo e que se assemelha ao efeito de tamanho conhecido.

Além disso, as vigas T mostram uma ressalto na parte inferior do trecho em forma de "U" da curva P- $\delta$ que corresponde ao momento em que a fissura atinge a mesa da viga $\mathrm{T}$. No momento em que ocorre esse segundo pico a armadura está longe da ponta da trinca e o pico é fortemente influenciado pela taxa de armadura.

Similares resultados experimentais foram obtidos nos ensaios efetuados por Jacinto Ruiz (2006) e foram mostradas na figura 5.35.

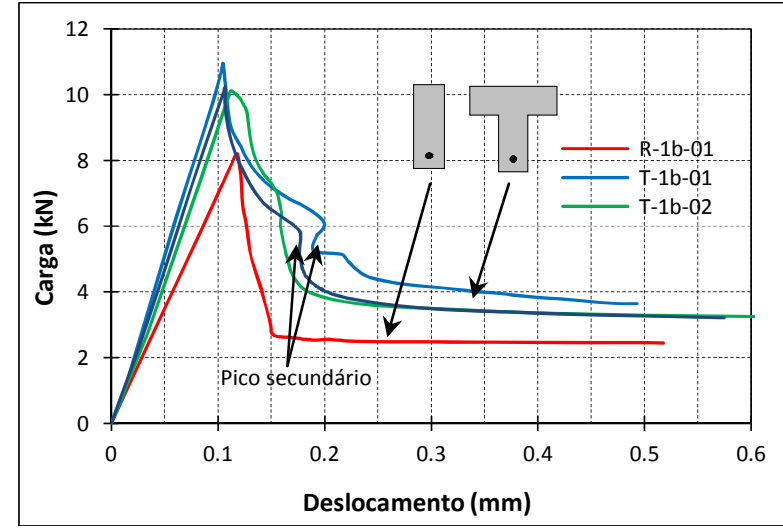

(a)

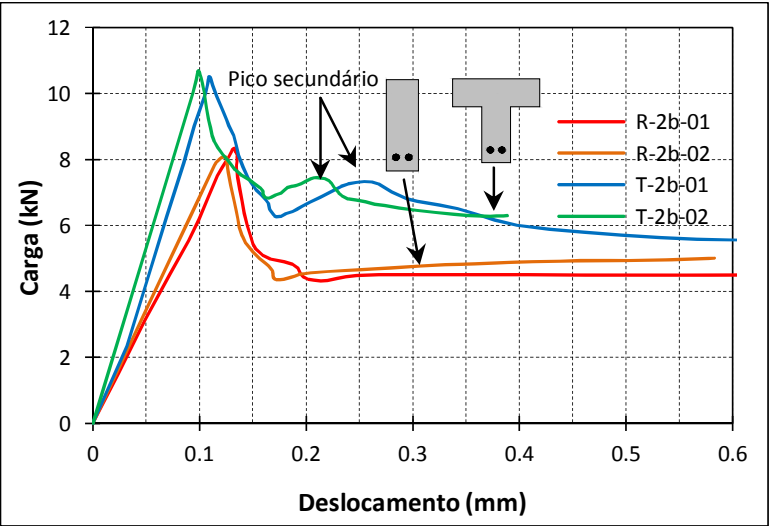

(b)

Figura 5.49 - Influencia da forma da seção no comportamento das vigas levemente armadas. 


\subsubsection{Comparação teórico-experimental das vigas levemente armadas}

A flexibilidade das vigas reais foi corrigida em relação à teórica do modelo antes de se fazer a comparação de curvas, pois no ensaio de flexão em três pontos a representação da parte elástica da curva $\mathrm{P}-\delta$, depende muito das condições de apoio, da superfície de contato apoio-concreto e do acomodamento da estrutura. A correção consiste simplesmente em adicionar ao deslocamento experimental de cada ponto do registro a flecha que, com essa carga exterior, teria uma viga elástica; a flexibilidade dessa viga calcula-se para que a tramo inicial $P-\delta$ do resultado coincida com 0 tramo inicial $\mathrm{P}-\delta$ teórico do modelo. Um exemplo de correção da curva carga - deslocamento viga R-2b-02 (figura C.13), é apresentado no anexo $\mathrm{C}$.

Nas curvas da figura 5.50 e 5.51 percebe-se que o modelo teórico prediz a carga máxima com bastante exatidão. O comportamento posterior à carga máxima de fissuração das curvas analíticas também se ajustam razoavelmente às bandas dos resultados experimentais.

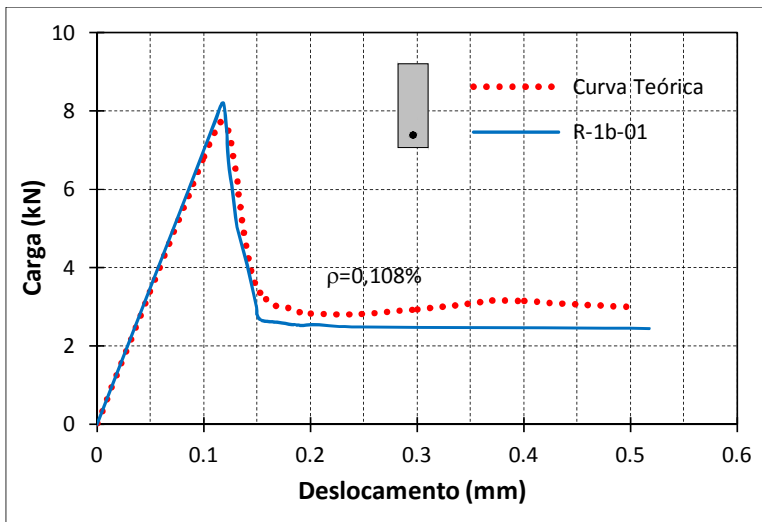

(a)

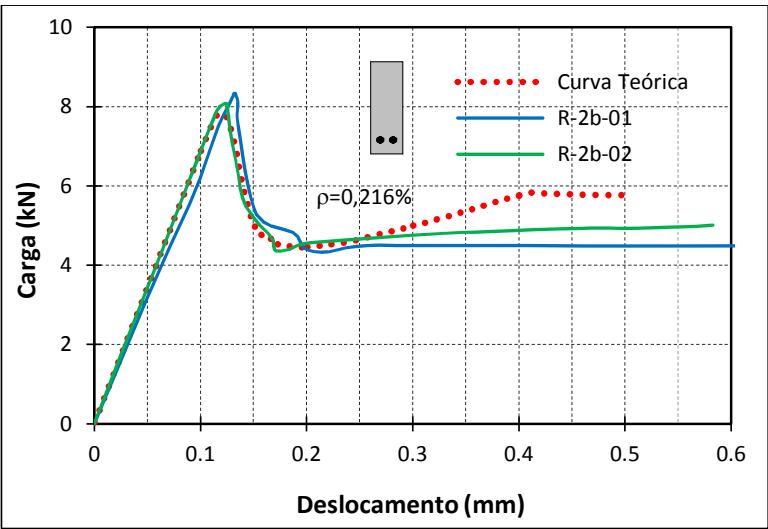

(b)

Figura 5.50 - Comparação teórico experimental das curvas de carga- deslocamento das vigas de seção retangular.

Na figura 5.50 a curva teórica após a carga máxima mostra-se ligeiramente mais rígida que a experimental. Esse fenômeno pode ser atribuído a que não se conseguiu representar apropriadamente a aderência real existente entre o aço e o microconcreto. 
Assim, a aderência é determinante no comportamento da viga depois da carga máxima: tanto o modelo teórico como os ensaios reais confirmam que uma maior aderência proporciona rigidez entre a carga máxima e a plastificação do aço.

Outro parâmetro que influência no comportamento das vigas é a taxa de armadura. A mesma que é corroborada pelas curvas experimentais e teóricas desenvolvidas nesta pesquisa. Na zona posterior à carga máxima de fissuração, as vigas são mais resistentes quando tem mais armadura, e a posição do nível de carga constante depois da plastificação é dependente também da taxa de armadura. Assim, as curvas teóricas mostram claramente que a carga máxima não depende da taxa de armadura, no entanto, nas curvas experimentais a variação da carga máxima impede observar claramente esse fenômeno.

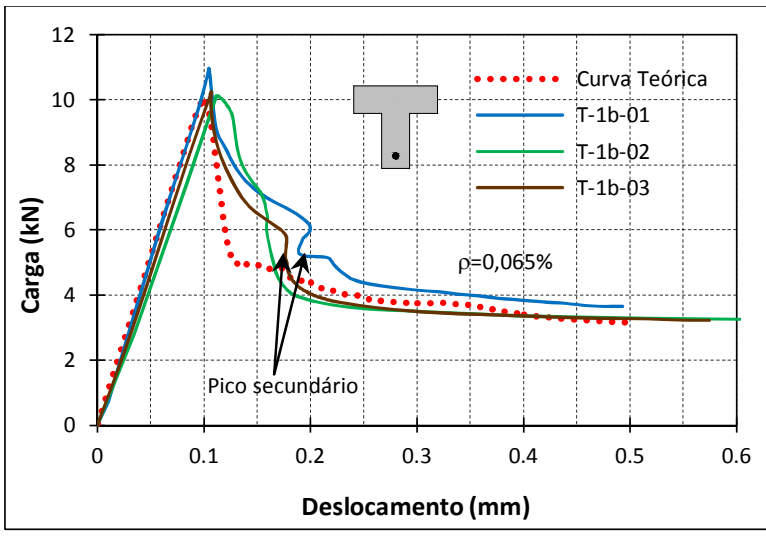

(a)

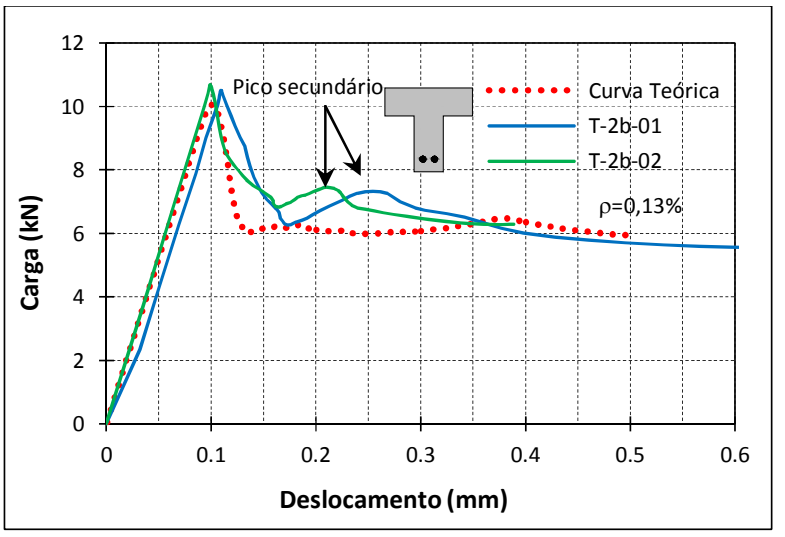

(b)

Figura 5.51 - Comparação teórico experimental das curvas de carga- deslocamento das vigas de seção $T$.

$\mathrm{Na}$ figura 5.51 pode-se observar que a curva teórica não conseguiu capturar o segundo pico que corresponde ao inicio da propagação da fissura através da mesa da viga $T$. Esse fenômeno pode ser devido a que a análise numérica tenha sido efetuada por meio de modelo em $2 \mathrm{D}$, podendo trazer alguma distorção nos resultados.

\subsubsection{Propagação de fissuras}

Como foi definido ao começo do estudo, as vigas levemente armadas se caracterizam por desenvolver uma única fissura na zona de máximo momento fletor. Esse fenômeno foi presenciado durante a execução dos ensaios tanto nas 
vigas retangulares quanto nas vigas de seção $T$, conforme se ilustra na figura 5.52 e 5.53 .

A fissura começa a se propagar uma vez que a resistência à tração do microconcreto é ultrapassada. Assim, a fissura começa a crescer em direção à armadura através do cobrimento. Quando a fissura alcança a armadura, durante uns instantes fica costurada, pois a armadura impede o avanço. Com o incremento de carga a solicitação no aço aumenta e ultrapassa a resistência de aderência existente entre a armadura e o concreto, de modo que o aço se desliza, dando continuidade ao avanço da fissura até chegar ao ponto em que a viga colapsa.
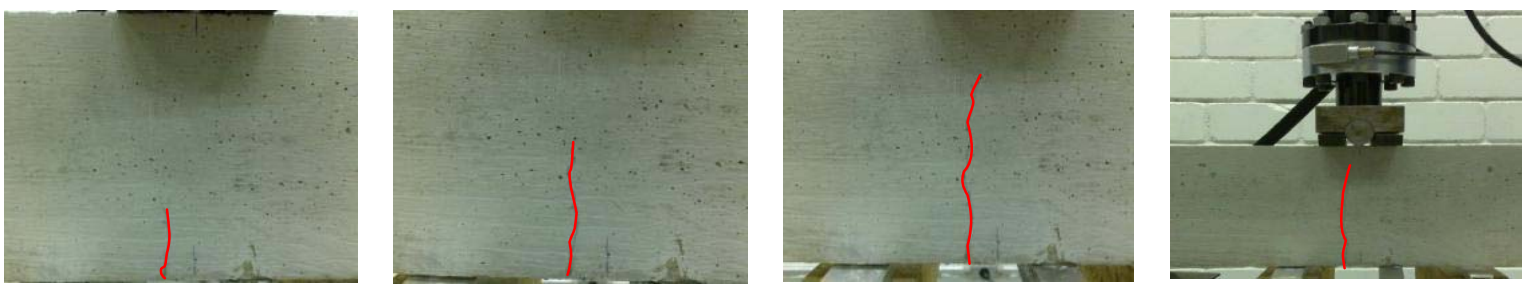

Figura 5.52 - Propagação de fissura em uma viga retangular levemente armada.
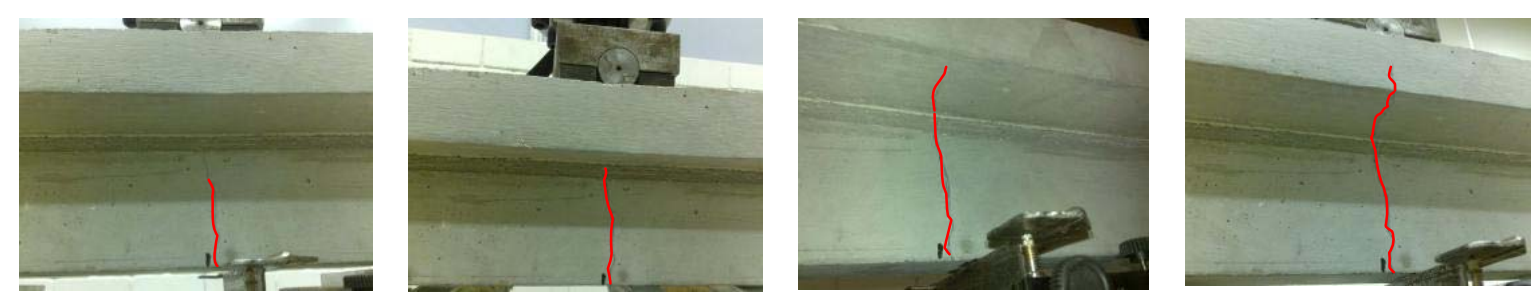

Figura 5.53 - Propagação de fissura em uma viga tipo T levemente armada.

\subsubsection{Conclusões}

Do estudo experimental e teórico das vigas levemente armadas podemos chegar às seguintes conclusões:

- As condições de apoio no ensaio têm influência no comportamento inicial da estrutura, pois para vigas com características semelhantes, a curva carga-deslocamento apresenta uma inclinação inicial diferente e se deve ao fato de que é difícil conseguir as mesmas condições de apoio em todos os ensaios aparamente iguais. 
- Os parâmetros de aderência, taxa de armadura e forma da seção influem no comportamento das vigas levemente armadas. Essa afirmação foi corroborada tanto teórica como experimentalmente.

- De acordo com as curvas teóricas pode-se afirmar que a carga máxima nas vigas levemente armadas não depende da taxa de armadura, no entanto, a variação da carga máxima nas curvas experimentais impede a observação clara desse fenômeno.

- O comportamento posterior à carga máxima é influenciado pela taxa de armadura e a aderência entre $o$ aço e o concreto.

- As vigas de seção T apresentam maior rigidez inicial e maior carga máxima do que as vigas retangulares, e esses valores são menores do que os esperados de acordo com a teoria linear simples. Esse estudo experimental evidencia a existência de um efeito de forma.

- Com os resultados dos ensaios de caracterização dos materiais obteve-se uma boa aproximação entre os resultados numéricos e experimentais, o que demonstra o elevado nível de controle realizado durante os ensaios.

- O modelo teórico mostra as mesmas tendências que as vigas reais com relação à variação das respostas com os parâmetros estudados.

- O modelo teórico prediz bem a carga máxima e o comportamento posterior à carga máxima, que se ajustam razoavelmente às bandas dos resultados experimentais. 


\section{Capítulo}

\section{CONCLUSÕESE TRABALHOS FUTUROS}

\section{CONCLUSÕES E TRABALHOS FUTUROS}

\subsection{Conclusões}

\section{Monitoração de estruturas}

No planejamento da monitoração de estruturais reais, é recomendável, sempre que possível, uma visita previa ao local para uma inspeção visual e recolhimento de dados das condições reais da estrutura. Assim como a verificação das condições de trabalho para a instalação de sensores, que geralmente são árduas e podem exigir cuidados especiais de segurança.

É necessário ressaltar que, embora a utilização de bons sistemas de monitoração propicie diversos benefícios à estrutura estudada, por questões de custo, praticidade e limitações técnicas, a rede de sensores não é instalada em toda a estrutura. Por isso, na etapa de preparação do projeto de monitoração, é importante fazer uma simulação da estrutura real através de modelos reduzidos ou modelos 
matemáticos, a fim de se conhecer os elementos estruturais mais solicitados e a ordem de grandeza das medições.

Os modelos reduzidos constituíram ferramentas importantes no laboratório para calibrar, testar e avaliar sensores antes de serem utilizados na estrutura real, assim como treinar o pessoal envolvido na monitoração para a adequada instalação de sensores.

Os equipamentos da National Instrument, usados na monitoração da estrutura real e nos modelos, se mostraram eficientes. Os dados adquiridos foram de boa qualidade e limpos de ruídos, devido aos filtros de ruído analógico e digital e todo o sistema de tratamento de dados existentes no equipamento. Além disso, esses equipamentos dispunham de uma série de módulos e blocos de terminal com os quais era possível quantificar qualquer tipo de grandeza física.

Para manipular, armazenar, tratar e ter controle da aquisição de dados do modelo reduzido da ponte do rio Suaçui, foi desenvolvido um programa de monitoração no LabView. Esse aplicativo trabalha juntamente com o sistema de monitoração da National Instrument e permite visualizar a configuração deformada da estrutura em tempo real, o deslocamento dos nós, assim como as deformações e forças atuantes em cada elemento estrutural, aproveitando as medições experimentais feitas pelos sensores.

\section{Modelos físicos reduzidos}

$\mathrm{Na}$ presente pesquisa foram desenvolvidos três modelos físicos reduzidos. Um deles foi projetado em função das características da ponte do rio Suaçui, a fim de se estudar seu comportamento em escala real e reduzida, e as outras duas foram projetadas em função de investigações similares efetuadas por outros pesquisadores, a fim de corroborar e estudar comportamentos não lineares e em fratura.

A etapa de planejamento, projeto e construção de um modelo reduzido é importante, pois disso depende a qualidade dos resultados que se espera para entender o comportamento de uma determinada estrutura. Assim, um modelo físico, como qualquer projeto de engenharia, precisa de uma sequência lógica e criteriosa de 
eventos para sua fabricação, e é considerado semelhante se ele representa bem o comportamento de uma estrutura real.

Os modelos físicos em escala reduzida são ferramentas muito importantes para fazer estudos em laboratório a custos relativamente baixos em relação ao estudo no protótipo. Mas conseguir reproduzir um modelo físico com características semelhantes ao protótipo nem sempre é fácil. Múltiplos fatores influenciam tais como: o fator de escala, o tipo de material a ser usado na construção e a mão-de-obra.

A escolha dos fatores de escala deve ser feita levando-se em conta muitas considerações. Modelos muito pequenos requerem cargas leves, mas são difíceis de fabricar, enquanto modelos maiores são mais fáceis de fabricar, mas exigem equipamentos de carga muito mais pesados. Portanto, a seleção dos fatores de escala depende da disponibilidade de recursos no laboratório (espaço, dispositivos de carregamento, etc.).

$\mathrm{Na}$ construção do modelo reduzido da ponte do rio Suaçui, não foi possível conseguir uma semelhança perfeita com o protótipo, pois as dimensões das seções transversais do modelo, obtidas depois de multiplicadas pelo fator de escala, resultaram medidas não comerciais. Portanto, tal modelo projetado tem semelhança com o protótipo, no que se refere a comprimentos de barras e as dimensões dos nós de encontro. Nas seções transversais e na disposição dos rebites foi difícil manter essa semelhança, já que foram usados perfis e rebites que se encontram facilmente no mercado.

Finalmente, os modelos reduzidos, além de poderem ser utilizados para estudo de estruturas, podem ser usados também como ferramentas de ensino a alunos de graduação, especificamente na área de Resistência de Materiais e Análise Estrutural, e mostrando o comportamento de estruturas experimentalmente.

\section{Estudo do comportamento de modelos físicos reduzidos}

Os dados experimentais obtidos dos ensaios efetuados nos modelos reduzidos foram uteis para comparar e calibrar modelos teóricos. 
Para o estudo do modelo reduzido da ponte do rio Suaçui desenvolveram-se vários modelos numéricos, dos quais o modelo numérico feito como elementos finitos e elementos de barra em 3D deu resultados muito próximos aos experimentais. Para a execução da modelagem foi usado o programa SAP2000.

A monitoração da ponte do rio Suaçui (estrutura real) forneceu dados experimentais, que serviram de base para fazer estudos de efeito escala com o modelo reduzido usando conceitos de teorias estruturais. Desse estudo se conclui que o modelo reduzido se comportou um pouco rígido em relação a um modelo perfeitamente semelhante devido ao tamanho das seções transversais, mas que no comportamento global se mostrou coerente e semelhante com o modelo real.

No modelo reduzido não se conseguiu simular no laboratório os ensaios da passagem dos trens na ponte real, mas se conseguiu simular no seu modelo numérico calibrado. A simulação numérica foi efetuada no programa SAP2000 aproveitando o módulo de "Linear Direct Integration - History". Os resultados dessa simulação confirmam que o modelo reduzido apresenta um comportamento semelhante à estrutura real.

Na modelagem numérica, a estrutura do modelo e do protótipo foi representada como um pórtico, mas analisando os esforços resultantes, percebe-se que os esforços axiais são muito mais significativos que o os momentos fletores. Podendo-se afirmar então que os elementos trabalham como barras de treliça e não como pórtico. Essa situação foi confirmada pelas medições efetuadas nos ensaios experimentais.

No caso do modelo da ponte de microconcreto, seu comportamento linear dependeu basicamente das condições de apoio, pois a curva de carga-deslocamento experimental ao começo apresentou um comportamento não linear.

Durante a execução dos ensaios, se percebeu a perda de rigidez da viga tabuleiro com o incremento da carga, pois o microconcreto começou apresentar fissuras e o deslocamento aumentou relativamente.

A instalação de sensores na seção transversal mais solicitada permitiu construir o diagrama de distribuição de tensões e observar a variação da posição da linha neutra, permitindo verificar que, à medida que a carga aumenta, a linha neutra 
sobe até a mesa da seção, fazendo com que a viga se comporte como uma viga retangular maior.

Para determinar a relação teórica da relação momento-curvatura de uma seção, foi desenvolvido um aplicativo usando os modelos constitutivos estabelecidos pela norma ABNT NBR 6118:2007, a qual, antes de ser utilizado para fazer comparações com os resultados experimentais foi validada como o programa SAP2000.

Os dados experimentais permitiram construir um diagrama de momentocurvatura usando conceitos teóricos (método das lamelas) para logo ser comparado com o diagrama teórico gerado no aplicativo. Dessa comparação foi possível constatar que o modelo físico se comportou menos rígido que o teórico.

No que se refere ao comportamento das vigas levemente armadas, essas dependeram basicamente dos parâmetros de aderência aço-concreto, taxa de armadura, forma da seção transversal e tamanho da viga. Essa conclusão pode ser feita em função dos resultados teóricos e experimentais obtidos durante o estudo desse tipo de vigas.

Nos ensaios dessas vigas, também se teve a influencia das condições do apoio no comportamento inicial, pois para vigas com características semelhantes, a curva carga-deslocamento apresentou inclinações diferentes.

Os resultados teóricos calculados como a ajuda do programa OMEGA, predisseram bem a carga máxima e o comportamento posterior à carga máxima, que se ajustaram razoavelmente às bandas dos resultados experimentais.

\section{Caracterização das propriedades mecânicas dos materiais}

Os modelos reduzidos, ao terem dimensões reduzidas requerem que os componentes mantenham as suas proporções. Assim, por exemplo, para estudar os modelos de concreto em escala reduzida os componentes do microconcreto e as barras de aço devem ter dimensões menores. O que normalmente não se dispõe para comprar e devem ser adaptados. Assim, para a construção desses modelos, se conseguiu dosar um microconcreto com propriedades similares a um concreto 
convencional com boa resistência e trabalhabilidade, para que possam ser usadas em regiões onde exista alta concentração de armaduras e espaços pequenos.

Em relação às armaduras, elas foram adaptadas a partir de aços lisos, na qual foram impressas nervuras para simular uma armadura normalmente usada numa estrutural real e garantir a aderência aço-concreto, que é uma propriedade mecânica muito importante no comportamento de estruturas.

Todos os materiais utilizados na construção dos modelos reduzidos, como o microconcreto, o aço e o alumínio, foram caracterizados para interpretar e analisar adequadamente o comportamento dos modelos reduzidos.

\subsection{Sugestões para trabalhos futuros}

Este trabalho apenas abordou alguns aspectos referentes ao comportamento de estruturas em escala real e reduzida, comportamento de estruturas na fase nãolinear e em fratura, colaborando com novos dados, esclarecendo alguns aspectos e suscitando novas duvidas. Dessa forma, sugere-se que outros estudos na área abordem questões como:

- Fazer uma Monitoração de uma estrutura em escala real e reduzida de uma estrutura de concreto. Esse estudo permitiria avaliar e aferir os parâmetros de efeito escala e efeito forma.

- Estudar experimentalmente o comportamento dinâmico de uma estrutura através de modelos reduzidos. Para isso seria necessário usar outro tipo de sensores, como os acelerômetros, e determinar os valores das frequências naturais, cujas variações podem ser utilizadas para determinar a presença de algum dano.

- Realizar um volume maior de ensaios de vigas levemente armadas, para o qual seria necessário variar parâmetros como: a taxa de armadura, modificar a posição dos apoios e o ponto de aplicação da carga, incrementar a largura da mesa, e assim ter melhor conhecimento do comportamento em fratura deste tipo de vigas.

- Fazer estudo experimental de pilares onde seja possível estudar efeitos da não linearidade geométrica e da não linearidade física. 


\section{REFERENCIAS BIBLIOGRAFICAS}

ABNT - Associação Brasileira de Normas Técnicas. NBR 6118:2003: Projeto de estruturas de concreto - procedimento.

.NBR 7222:1994: Argamassa e concreto - Determinação da resistência à tração por compressão diametral de corpos-de-prova cilíndricos - Método de ensaio, Rio de Janeiro, 1994.

.NBR 5739:1994: Ensaios de compressão de corpos-de-prova cilíndricos de concreto - Método de ensaio, Rio de Janeiro, 1994.

.NBR 6207:1982: Arame de aço - ensaios de tração - Método de ensaio, Rio de Janeiro, 1980.

.NBR 7223:1992: Concreto - Determinação da consistência pelo abatimento do tronco de cone, Rio de Janeiro.

.NBR 8522:2003: Concreto - Determinação dos módulos estáticos de elasticidade e de deformação e da curva tensão-deformação.

.NBR 6152:2002: Materiais metálicos - Ensaio de tração à temperatura de ambiente, Rio de Janeiro, 2002.

AKIMOVS, E.; PAEGLITIS, A. Load Testing of New Bridges in Latvia, Latvia 2008.

ANDOLFATO, R.P.; CAMACHO, J. S.; BRITO, G. A. Extensometria Básica. Apostila do Núcleo de Ensino e Pesquisa da Alvenaria Estrutural da Universidade Estadual Paulista "Julio de Mesquita Filho", Ilha Solteira, 2004.

ASSAHI, P. N. Sistema de forma para estruturas de concreto. ASSAHI Engenharia Ltda., São Paulo, 2006.

ASSIS, W. S. Sistemas computacionais de apoio à monitoração de Estruturas de Engenharia Civil. Tese de Doutorado. Escola Politécnica da Universidade de São Paulo, 2007.

BAZANT, Z. P. Mechanic of distributed cracking. Applied Mechanics Review, 39,No 5, 675-705, 1986. 
BAZANT, Z. P. Concrete fracture models: testing and practice. Engineering Fracture Mechanics, V.69,165-205, 2002.

BALAGEAS, D.; CLAUS-PETER F.; GUEMES A. Structural Health Monitoring. Editorial John Wiley \& Sons Inc, 2006.

BEGGS, G. E. An accurate mechanical solution of statically indeterminate structures by use of paper models and special gages, Proc. Am. Cronc. Inst., 18, 58-82, 1932.

BITTENCOURT, T. N. Monitoração da Ponte do Rio Suaçui, Relatório Técnico Final LEM - VALE 02-10 FUSP 1982, São Paulo, 2010.

BORGES, A. J. Análise do comportamento de vigas de concreto de alto desempenho por meio da mecânica da fratura. Tese de Doutorado. Escola Politécnica da Universidade de São Paulo, 2002.

BUCHAIM, R. A influência da não-linearidade física do concreto armado na rigidez à flexão e na capacidade de rotação plástica. Dissertação de mestrado. Escola Politécnica da Universidade de São Paulo, 2001.

BUTRON, V. L. Comportamento estrutural de pontes estaiadas efeitos de segundo ordem. Dissertação de mestrado. Escola Politécnica da Universidade de São Paulo, 2007.

CAMPILHO, A. Instrumentação Eletrônica. Métodos e técnicas de medição. Faculdade de Engenharia da Universidade do Porto, Porto, 2000.

CARPINTERI, A. CHIAIA, B. CORNETTI, P. A scale-invariant cohesive crack model for quase-brittle materials. Engineering Fracture Mechanics, 69, 207-217, 2002.

CIFUENTES H., MEDINA F. Comparación del valor de la energía de fractura real del hormigón obtenido por distintos métodos. Anales de Mecánica de la Fractura 26, Vol. 1, pag. 51-56, 2009.

CONCEIÇÃO NETO, A. P. Extensômetria. Apostila do Instituto de Pesquisas Tecnológicas IPT, São Paulo, 2006. 
CONCEIÇÃO NETO, A. P. e Outros. Medição de carga estática por eixos dos trens da Linha 3 - Vermelha do Metro de São Paulo, $49^{\circ}$ Congresso Brasileiro do Concreto, CBC 2007, IBRACON, Bento Gonçalves, RS, 2007.

ELICES, M. AND PLANAS, J. Materials models, in State of Art Report in Fracture of Concrete, Chapter 3, (Ed. Elfgren, L), RILEM TC90, 1988.

ELICES, M., PLANAS, J. and GUINEA, G. V. Modelling cracking in rocks and cementitious materials. In Fracture and Damage of Concrete and Rock-2, (Ed. Rossmanith, H. P.), E \& FN Spon, London, 3-33, 1993.

ENEY, W.J. New deformeter apparatus. Eng. News-Record, 122 (7), 16, 221, 1939.

FARRAR, C. R.; WORDEN, K. An Introduction to structural health monitoring. Philosophical Transactions of the Royal Society A (2007) 365, 303-315, 2006.

FELIX, C. M. Monitoração e Análise do Comportamento de Obras de Arte. Tese de Doutorado. Faculdade de Engenharia da Universidade do Porto, Porto, 2004.

FIGUEIREDO, E. J. F. Monitoração e Avaliação do Comportamento de Obras de Arte. Dissertação de mestrado. Faculdade de Engenharia da Universidade do Porto, Porto, 2006.

FIGUEIREDO, L. J.; GAFANIZ, A. R.; LOPES G. S.; PEREIRA, R. Aplicações de Acelerômetros. Monografia Instrumentação e Aquisição de Sinais. Lisboa, Portugal, 2007.

FRANÇA, V. H. Aderência Aço-Concreto - Uma análise do comportamento do concreto fabricado com resíduos de borracha. Dissertação de mestrado. Universidade Estadual Paulista UNESP, 2004.

FUSCO, P. B. Estruturas de Concreto: Solicitações Normais, ed. Guanabara Dois, Rio de Janeiro, 1986.

GID HOMEPAGE. Centre Internacional de Mètodes Numèrics en la Enginyeria (CIMNE) Barcelona (Spain). Disponível em: http://gid.cimne.upc.es.

GLISIC, B.; INAUDI, D. Structural Monitoring of Concrete Bridges during Whole Lifespan, 82nd Annual Meeting of the Transportation Research Board (TRB), January 12-16, 2003, Washington DC, USA, (2003), On CD, paper number 03-3012. 
GUETTI, P. C. Métodos experimentais para determinação de propriedades do concreto baseados na mecânica da fratura. Dissertação de mestrado. Escola de Engenharia da Universidade Federal de Minas Gerais, 2006.

GUINEA, G. V. Medida de la energía de fractura del hormigón. Tese de Doutorado. Departamento de Ciencias de Materiales, E. T. S. de Ingenieros de Caminos, Canales y Puertos. Universidad Politécnica de Madrid, 1990.

HEDEDAL, O. and KROON, I. B. Lightly reinforced high-strength on concrete, M SC Thesis, University of Aalborg Denmark, 1991.

HARRIS, H. G.; SABNIS G. M. Structural modeling and experimental techniques, 2nd edition, CRC PRESS, Boca Raton, 1999.

HILlERBORG, A. MODEER, M. and PETERSSON, P. E. Analysis of crack formation and crack growth in concrete by means of fracture mechanics and finite elements. Cement and Concrete Research, 6, 773-782, 1976.

HU, X. Y WITTMANN, F. Size effect on toughness induced by crack close to free surface. Engineering Fracture Mechanics, V. 65, pag. 209-221, 2000.

ISIS CANADA. Guidelines for Structural Health Monitoring. Design Manual No. 2, Canada, 2001.

JANNEY, J.R.; BREEN, J.E. and GEYMAYER, H. Use of models in structural engineering, in Models for Concrete Structures, ACI SP-24, American Concrete Institute, Detroit, MI, pp 1-18. 1970.

KARIHALOO, B.L., ABDALLA, H.M. Y IMJAI, T. A simple method for determining the true specific fracture energy of concrete. Magazine of Concrete Research, $V$. 55, pag. 471-481, 2003.

KLEIN, D. L. Microconcreto - Método de dosagem. Apostila do curso de posgraduação em engenharia civil, Universidade Federal do Rio Grande do Sul, Porto Alegre, 1985.

LIANG, Z.; REINHORN, A. M. Modeling and similitude. Lecture notes of Departamento of Civil, Structural and Environmental Engineering of University at Buffalo, Buffalo - New York, 2008. 
MAIA L.M. Dimensionar, construir e ensaiar um modelo de uma passagem superior em betão estrutural no contexto do concurso DARTE-BE2004. Seminário de estruturas. Faculdade de Engenharia da Universidade do Porto, 2004.

MANZOLI, O. L.; SHING, P B. A general technique to embed non-uniform discontinuities into standard solid finite elements. Computers \& Structures, v. 84, n.10-11, p. 742-757, 2006.

MARTINS, A. R. Técnica experimental para aplicação de modelos de microconcreto. Tese de Doutorado. Universidade de São Paulo, 1990.

MARTINS, J. M. Introdução aos Sistemas de Aquisição e Processamento de Sinais. Escola Superior de Tecnologia de Setubal, Portugal, 2006.

MOORE J. F. A. Monitoring Building Structures, Editora Black and Son Ltd, London, 2003.

MOREIRA, E. M. S. Análise experimental em escala reduzida de ligações entre paredes de alvenaria estrutural de blocos cerâmicos submetidas a ações verticais. Dissertação de mestrado. Escola de Engenharia de São Carlos Universidade de São Paulo, 2007.

OLIVER, J. Modeling strong discontinuities in solid mechanics via strain softening constitutive equations. part 1: Fundamentals. part 2: Numerical Simulation. Int. J. Num. Meth. Eng., 39(21):3575-3600, 1996.

OLIVEIRA R. Relação momento-normal-curvatura com a consideração do coeficiente de fluência equivalente. Anais do $50^{\circ}$ Congresso Brasileiro do Concreto, IBRACON 2008,

OLSHAUSEN, B. Aliasing. PSC129-Sensory processes, University of California, Berkeley, 2000.

PAPOULIS, A. Signal Analysis, Editor McGraw-Hill, United State of America, 1977.

PLANAS, J., ELICES, M. , GUINEA, G.V. Measurement of the Fracture Energy using Three Point Bend Tests 2 Influence of bulk energy dissipation. Material and Structures, 25, 305-312, 1992.

PORTELA, A.; SILVA A. Mecânica dos Materiais, Editora Platano, Lisboa, 1996. 
RABINER, L. R.; GOLD, B. Theory and application of digital signal processing. Editor Prentice-Hall, New Yersey, 1975.

REGAZZI, R. D.; A.; PEREIRA, P. S.; SILVA, M. F. Soluções Práticas de Instrumentação e Automação, Editora 3R.KWG, Rio de Janeiro, 2005.

REINHORN, A. M. Experimental methods in structural engineering. Lecture notes of Departamento of Civil, Structural and Environmental Engineering of University at Buffalo, Buffalo - New York, 2008.

RILEM 50-FMC Determination of the fracture energy of mortar and concrete by means of three-point load tests on notched beams. RILEM Draft Recommendation, v. 18, n. 106, pp. 285-290, 1985.

RUIZ, J. C. Study of cracking processes in reinforced concrete elements. Tese de Doutorado. Universidad de Castilla La Mancha, Escuela Técnica Superior de Ingenieros de Caminos, Canales y Puertos, Espanha, 2006.

RUIZ, L. G. Influencia del tamaño y de la adherencia en la armadura mínima de vigas en flexión. Tese de Doutorado. Departamento de Ciencias de Materiales, E. T. S. de Ingenieros de Caminos, Canales y Puertos. Universidad Politécnica de Madrid, 1998.

SCHWETZ, P. F. Analise teórico-experimental de uma laje nervurada em modelo reduzido sujeita a um carregamento linear. Dissertação de mestrado. Programa de pós-graduação em Engenharia Civil - Universidade Federal do Rio Grande do Sul, Porto Alegre, 2005.

SHAH, P. S.; SWARTZ, S. E.; OUYANG, C. Fracture mechanics of concrete, livro, John Wiley \&Sons, Inc. 1995.

SILVA, V. M. Ação da carbonatação em vigas de concreto armado em serviço, construídas em escala natural e reduzida. Tese de Doutorado. Escola de Engenharia de São Carlos - Universidade de São Paulo, 2007. 
Anexo

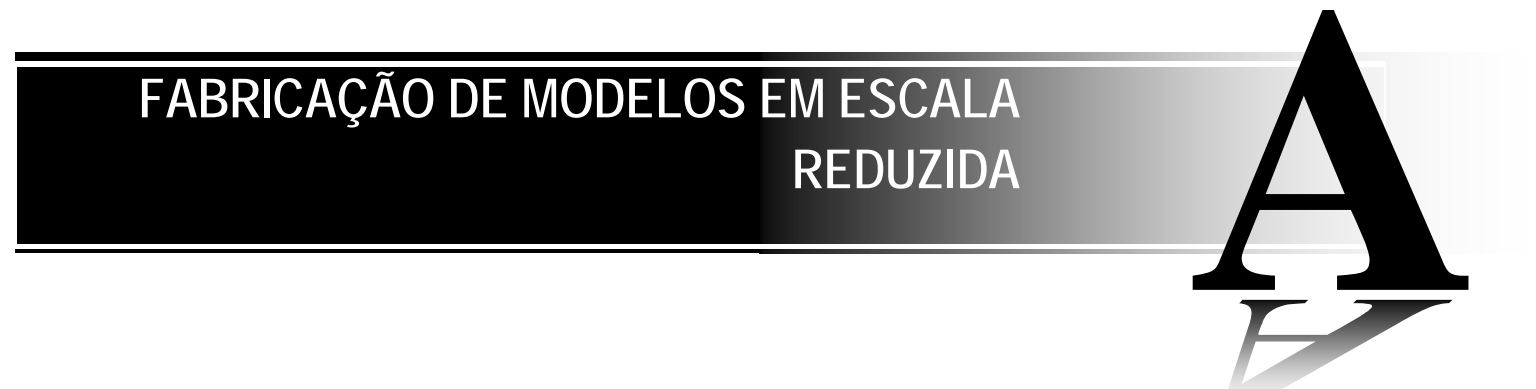

\section{A.1 Modelo Reduzido da Ponte do Rio Suaçui}

O material usado para a construção do modelo foi o alumínio, onde as dimensões e a geometria foram definidas de acordo com o dimensionamento apresentado no Capítulo 4.

Para a construção do modelo foi necessário fazer um detalhamento de todos os elementos que fazem parte da estrutura, tais como: nós de encontro, seção transversal das barras, disposição de rebites e geometria da estrutura em geral.

\section{A.1.1 Projeto do modelo reduzido}

A seguir são apresentados todos os desenhos utilizados para a fabricação do modelo e uma pequena descrição: Nas figuras A.1 e A.2 são apresentadas as vistas em elevação e em planta do modelo, onde podem ser visualizados o comprimento e a disposição das barras: banzo superior, banzo inferior, diagonais, montantes, longarinas e transversinas, ligadas através dos nós de encontro.Nas figuras A.3 e A.4 são apresentados os detalhamentos das seções transversais dos elementos da 
estrutura, tipos de nós de encontro, a disposição dos rebites e o espaçamento entre eles.

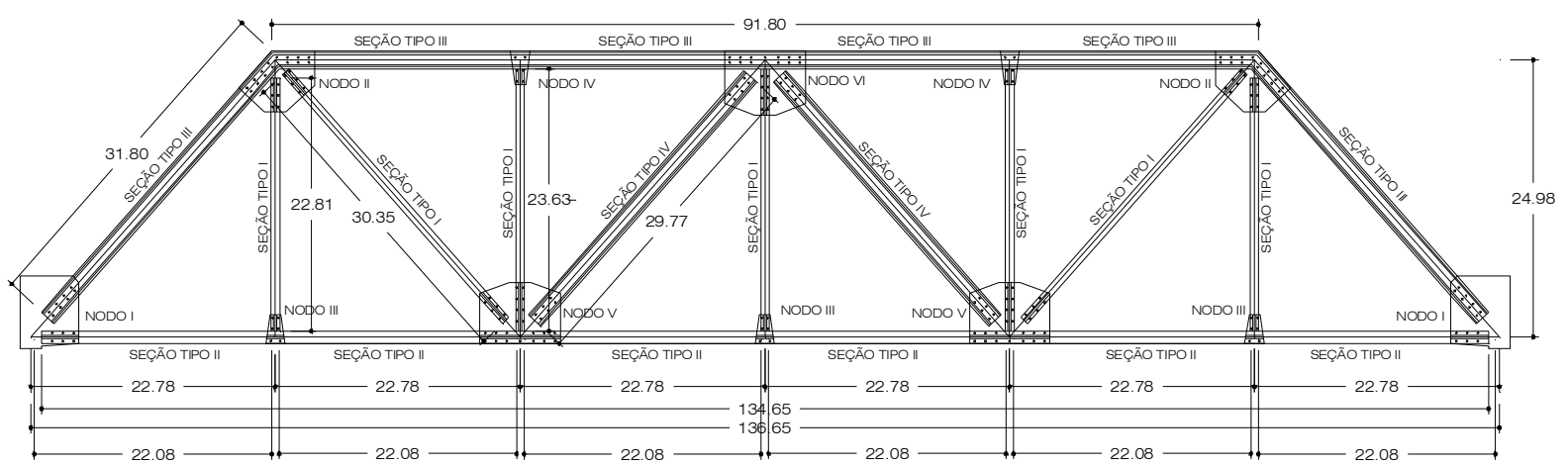

Figura A.1 - Elevação do modelo (Unidade: $\mathrm{cm}$ ).

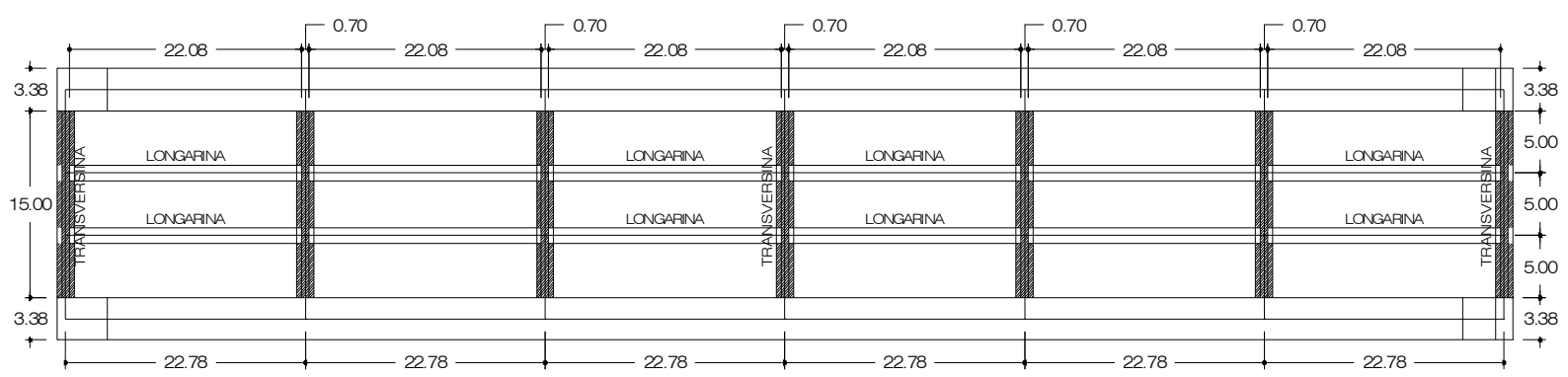

Figura A.2 - Vista em planta do modelo (Unidade: $\mathrm{cm}$ ).

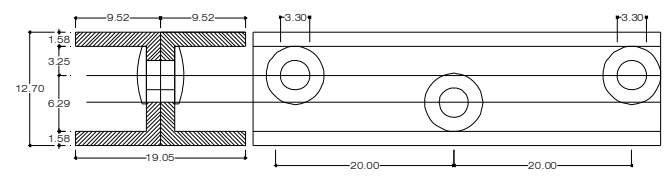

SEÇÃO TIPOI ( $(\mathrm{mm})$
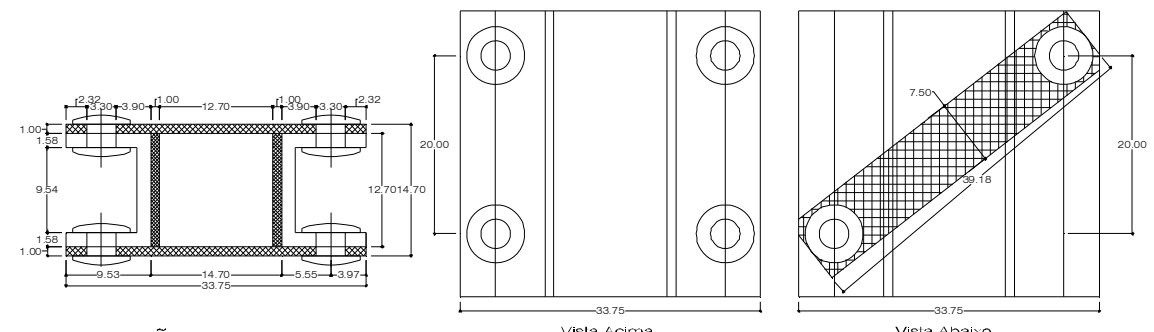

SEÇÃO TIPO II (mm)
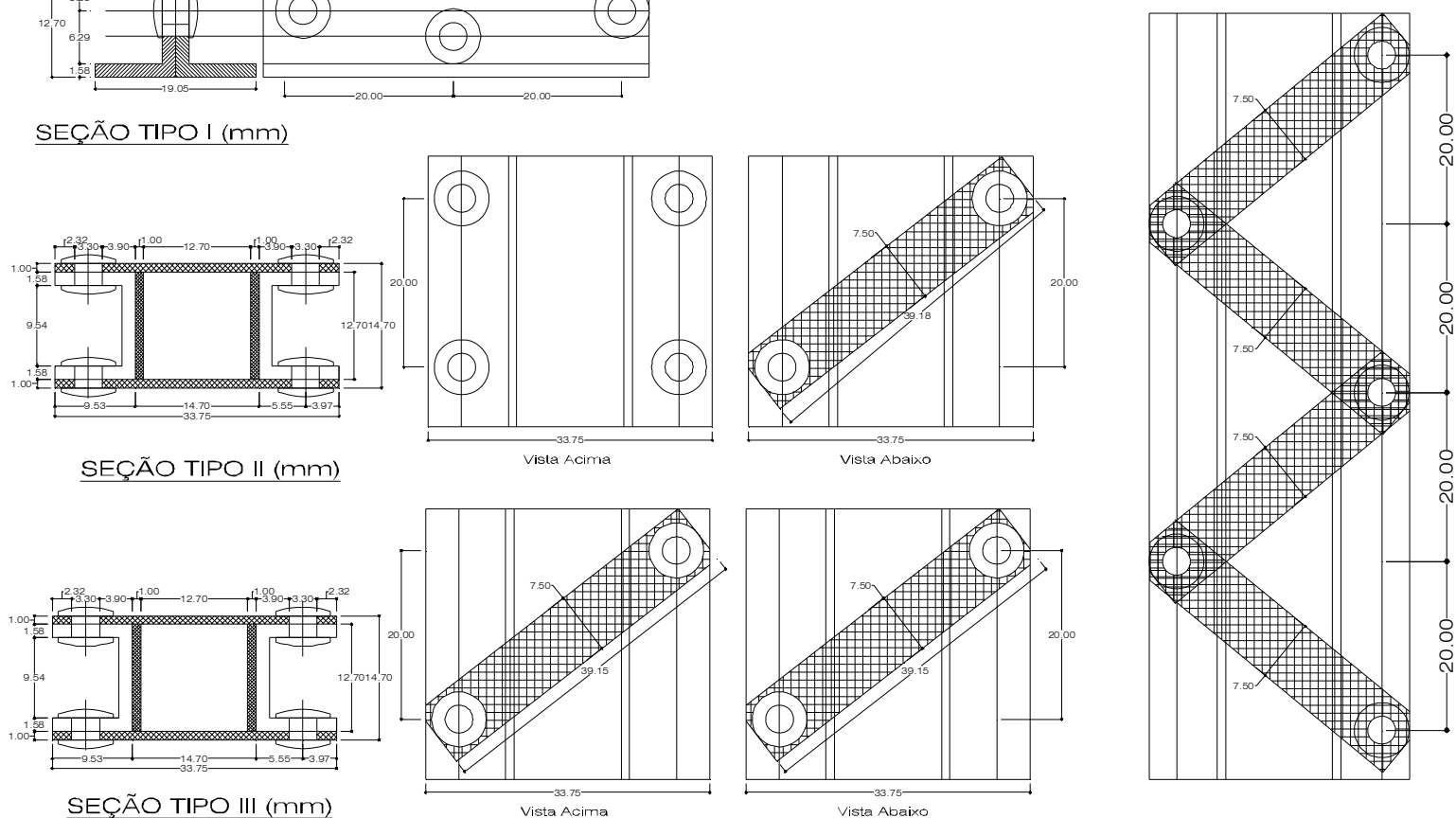

SEÇÃO TIPO III (mm)

Figura A.3 - Detalhamento das seções transversais das barros do modelo (Unidade: $\mathrm{cm}$ ). 


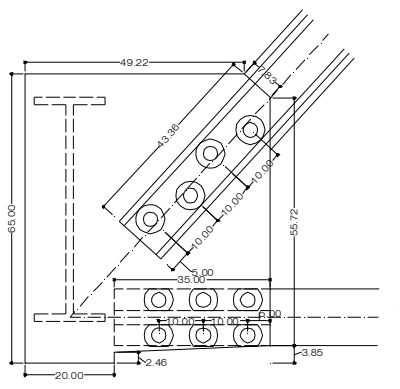

NÓ TIPO I (mm)

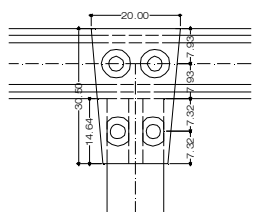

NÓ TIPO IV (mm)

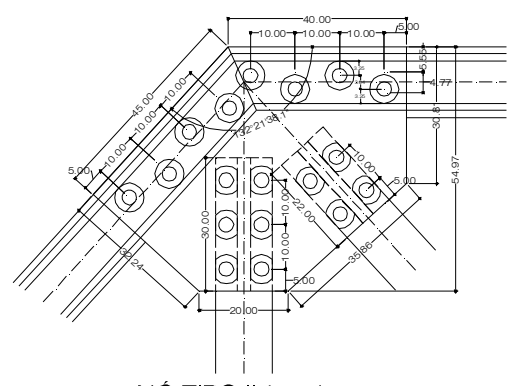

NÓ TIPO II (mm)

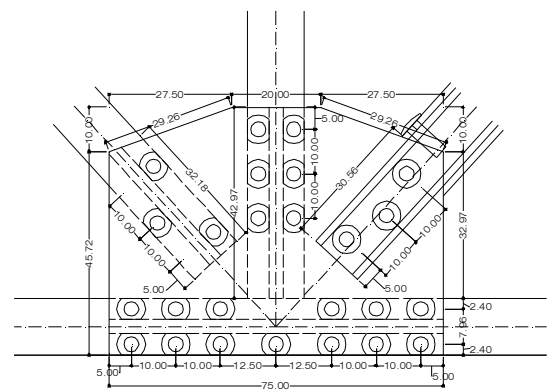

$\underline{N O ́}$ TIPO $\vee(\mathrm{mm})$

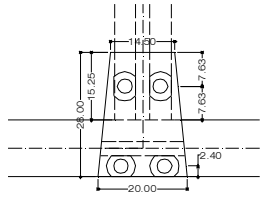

NÓ TIPO III (mm)

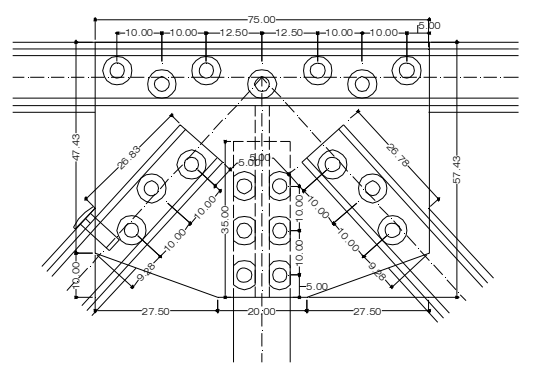

NÓ TIPO VI (mm)

Figura A.4 - Detalhamento dos nós de encontro do modelo.

\section{A.1.2 Fabricação do Modelo}

O processo construtivo pode se pode descrito em três etapas:

1.- Fabricação de peças de cada uma das treliças;

2.- Montagem de nós e das treliças;

3.- Montagem da ponte em conjunto;

A fabricação de todas as peças da treliça foi realizada de acordo com as dimensões estabelecidas no projeto com alta precisão, uma vez que um pequeno erro dificultaria a montagem geral da treliça.

Com o intuito de se melhorar a precisão e a qualidade do trabalho algumas ferramentas de trabalho foram adaptadas e gabaritos de referencia foram usados. Os gabaritos foram fabricados para peças com processos construtivos repetitivos, pois esses ajudariam a acelerar o processo construtivo com precisão e rapidez.

A construção do modelo iniciou-se com a fabricação das barras da treliça. A fim de se obter as seções de acordo com o projeto procedeu-se à união dois perfis tipo "U", utilizando-se rebites espaçados, conforme ilustrado na figura A.3 (SEÇÃO 
TIPO I). Os rebites foram colocados ao longo do comprimento da barra de maneira que trabalhem monoliticamente.

Uma vez terminada a fabricação das barras da treliça, iniciou-se o corte das chapas de alumínio, as quais posteriormente uniram as barras para formar os nós de encontro. Cada um dos nós possui sua própria geometria, suas dimensões e disposição de rebites (figura A.4). Antes do processo de furação e colocação dos rebites, as chapas e as barras foram pré-montadas, a fim de verificar se as peças da estrutura estavam com as dimensões corretas. A figura A.4 ilustra o processo de fabricação das peças.
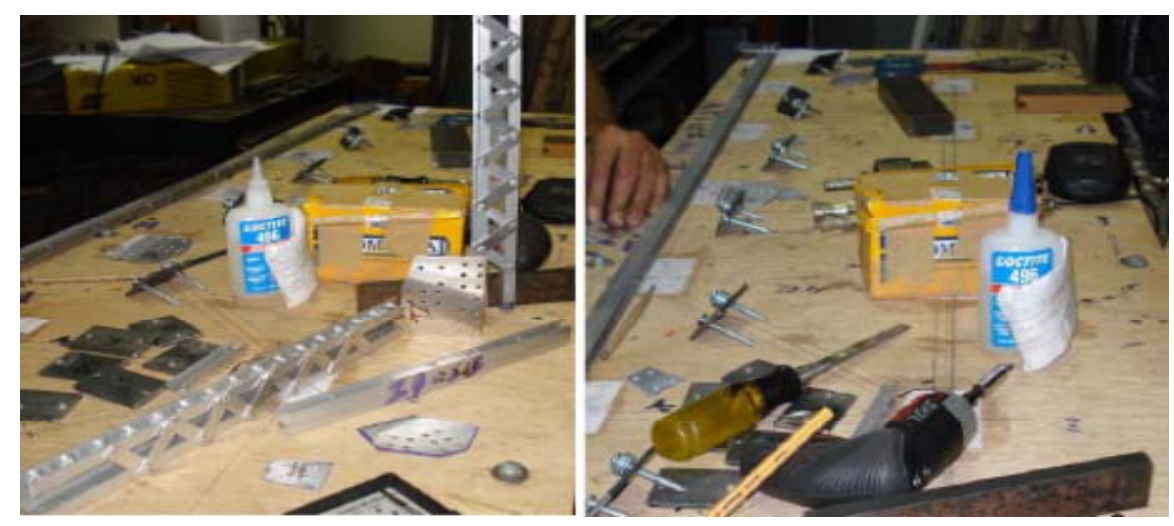

Figura A.4 - Esquerda: Barras e chapas do modelo. Direita: Fixação das barras para montagem.

Com as chapas furadas e as barras prontas, montou-se a treliça numa superfície horizontal, adaptando-se uma mesa de madeira tipo "compensado naval". Antes do inicio da montagem do modelo, foi feito um desenho da treliça sobre a mesa, definindo os eixos das barras e os nós de encontro. A finalidade de fazer o desenho foi a de ajudar na montagem das peças da estrutura.

Todas as barras da treliça foram fixadas, de acordo com o desenho feito na mesa. Em seguida procedeu-se a colagem das chapas nas barras para fixá-las eventualmente e assim facilitar seu rebitamento. Esse procedimento se repetiu em todos os nós. 

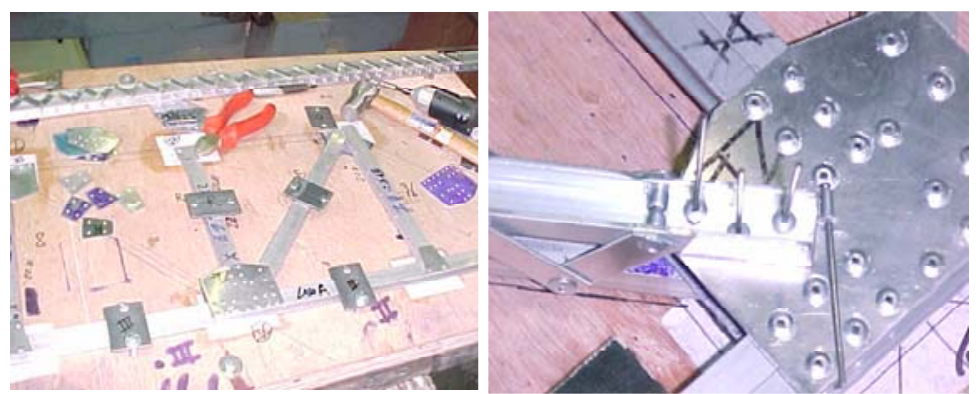

Figura A.5 - Esquerda: Fixação de barras e nós na mesa de madeira. Direita: Rebite de um nó.

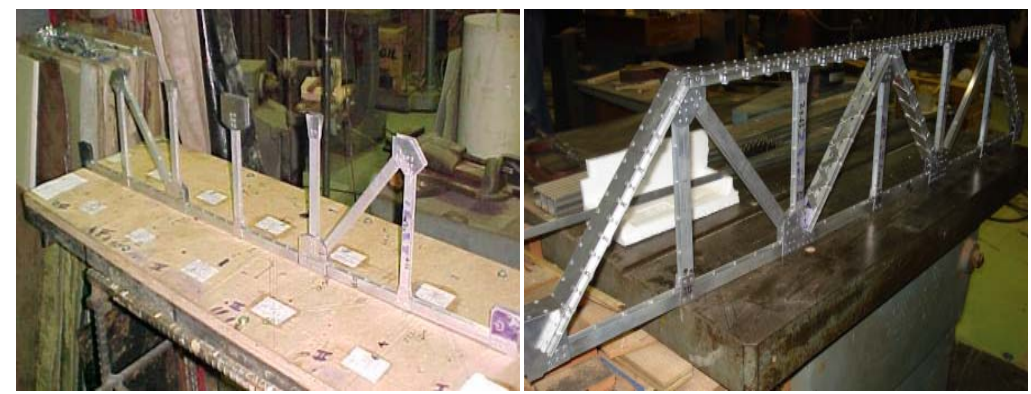

Figura A.6 - Parte da montagem da primeira treliça.

Os detalhes dos diferentes tipos de nós são mostrados a seguir:
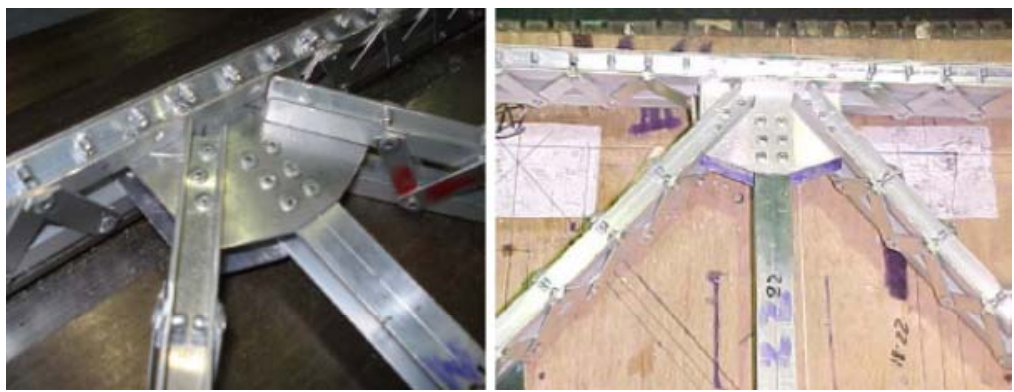

Figura A.7 - Detalhes do nó VI.
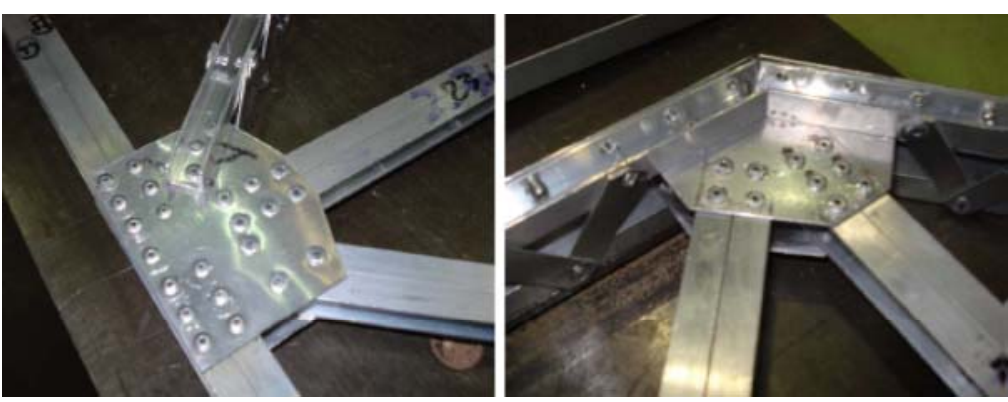

Figura A.8 - Esquerda: Nodo V. Direita: Nodo II 
Os procedimentos construtivos para a segunda treliça foram os mesmos seguidos para a primeira treliça. Com as duas treliças prontas, iniciou-se a montagem da estrutura completa do modelo. Os elementos estruturais encarregados de unir as duas treliças foram as transversinas e longarinas. A função principal das transversinas e longarinas de receber e transmitir os carregamentos aplicados nelas às treliças e daí aos apoios.
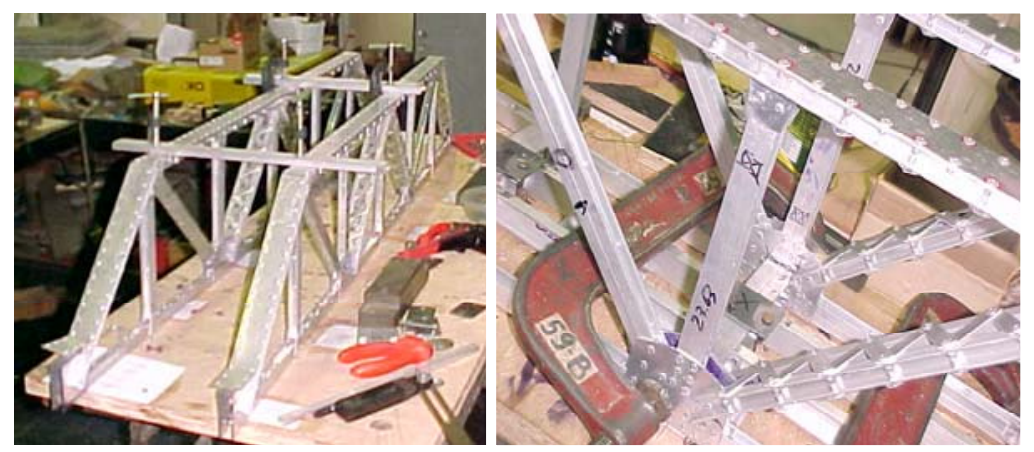

Figura A.9 - Esquerda: Montagem das duas treliças. Direita: Rebite de transversinas.

Para a ligação das transversinas com as treliças, foram utilizadas pequenas cantoneiras feitas de chapas de alumínio de uma $1 \mathrm{~mm}$ de espessura. Estas peças foram fixadas em cada elemento usando rebites e parafusos pequenos. Para definir a posição exata da localização das transversinas foi necessária a execução de uma pré-montagem. A necessidade de se fazer a montagem foi devido ao pequeno espaço para rebitar as cantoneiras com as transversinas e os nós da treliça, devido à quantidade de rebites colocados. Na figura $\mathrm{A} .10$ é apresentada a montagem final do modelo.

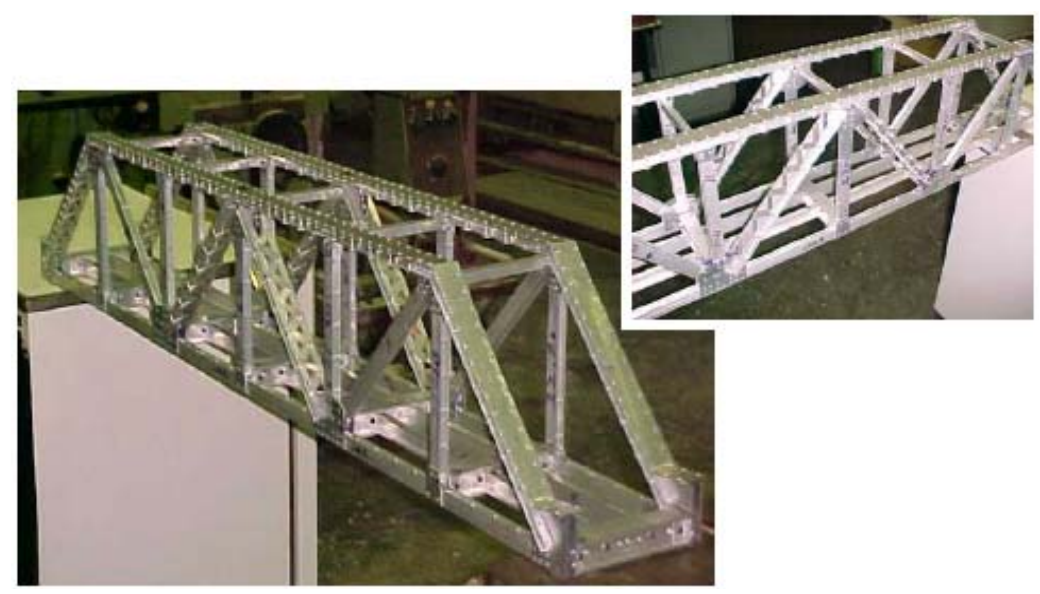

Figura A.10 - Montagem final do modelo da ponte. 


\section{A.2 Modelo reduzido de Ponte e Vigas de microconcreto}

Os materiais usados para a construção da ponte e as vigas foram o aço e microconcreto. Foi necessária a elaboração de um traço especial para o microconcreto, por ser um concreto especial para modelos em escala reduzida. Neste item são apresentados os desenhos de detalhamento do projeto executivo, o método de dosagem adotado para se obter um microconcreto com características similares a um concreto convencional e o processo construtivo dos modelos. A etapa de dimensionamento é apresentada no Capítulo 5 e no Anexo D.

\section{A.2.1 Projeto do modelo reduzido da ponte de microconcreto.}

Na figura A.11 é apresentada a geometria da ponte de microconcreto, as quais permitiram definir o sistema de formas para a etapa de concretagem.
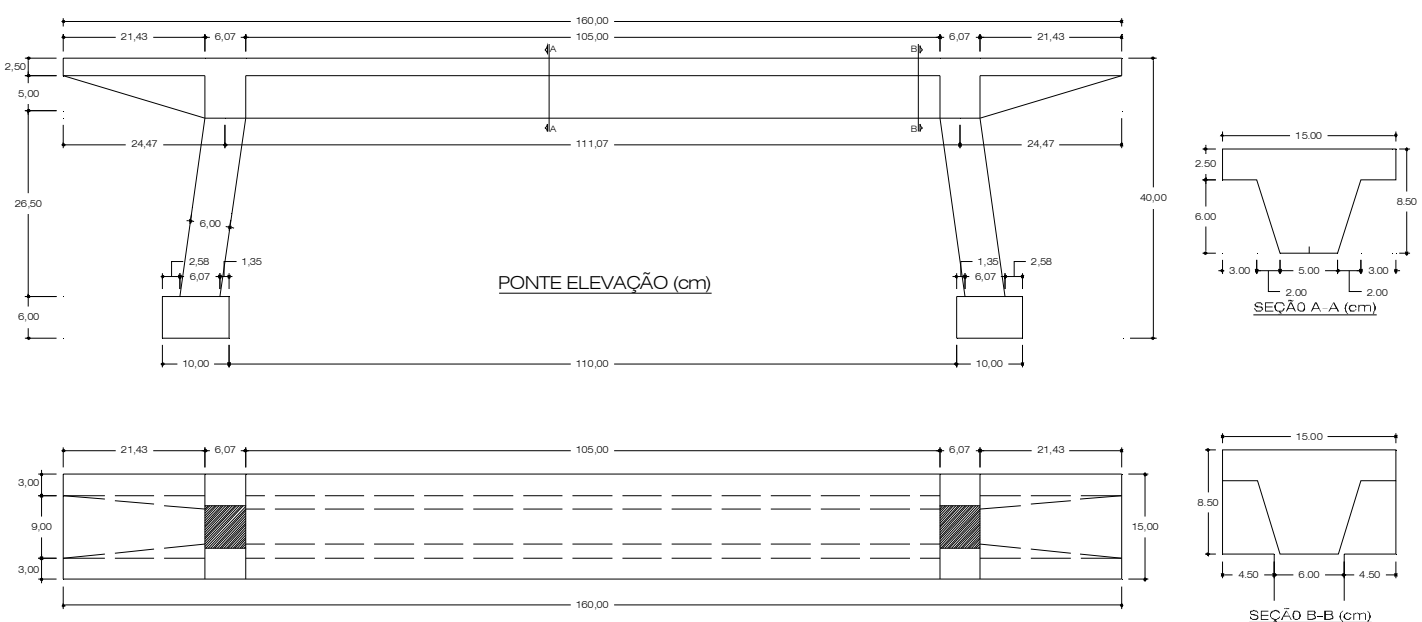

PONTE PLANTA (cm)

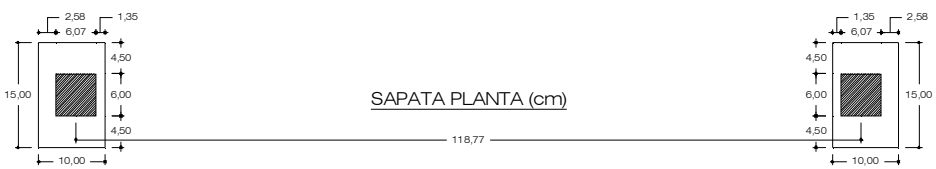

Figura A.11 - Detalhe da geometria do modelo da ponte. 

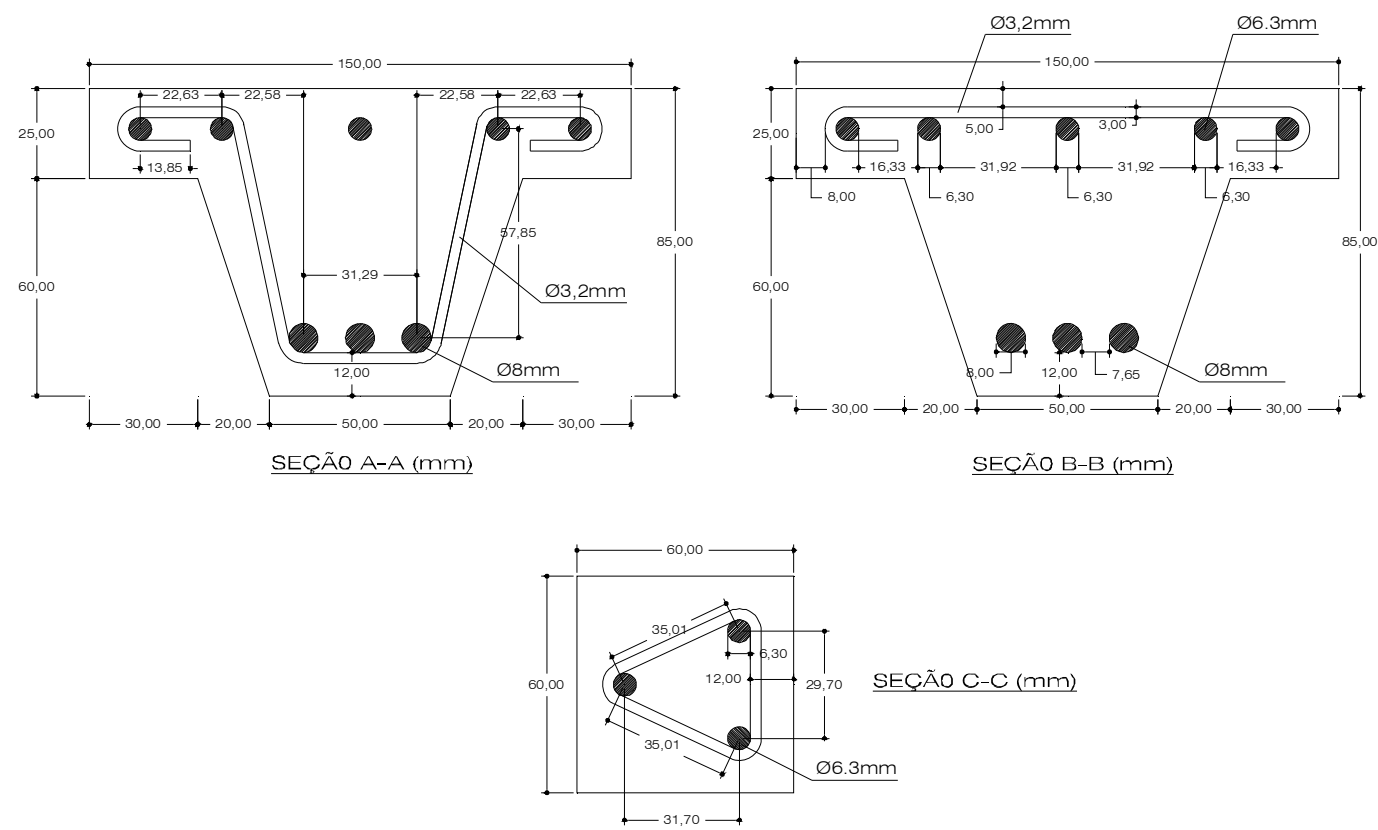

Figura A.12 - Disposição das armaduras de aço na viga tabuleiro e nos pilares.

Na figura A.12 e A.13 são apresentados os detalhamentos das disposições das armaduras do modelo, bem como, a locação das barras longitudinais, a distribuição dos estribos e a forma das ancoragens.

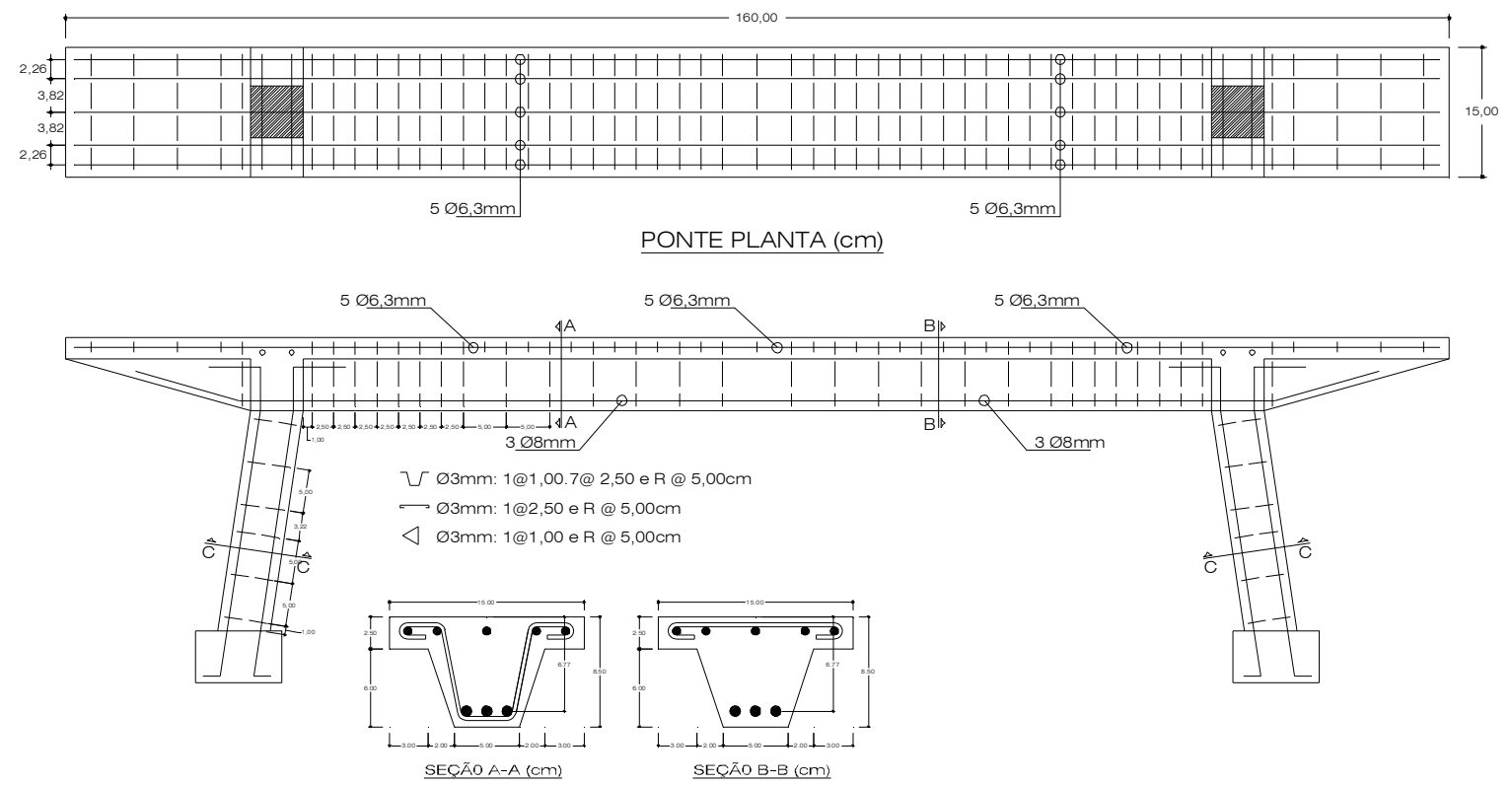

Figura A.13 - Disposição das armaduras longitudinais e estribos. 


\section{A.2.2 Projeto do modelo reduzido das vigas de microconcreto.}

A forma e as dimensões dos modelos de viga foram definidas no capitulo 5 . Para fins de estudo, foram projetas seis tipos de vigas, as quais se detalham nas figuras A.14, figura A.15 e figura A.16.
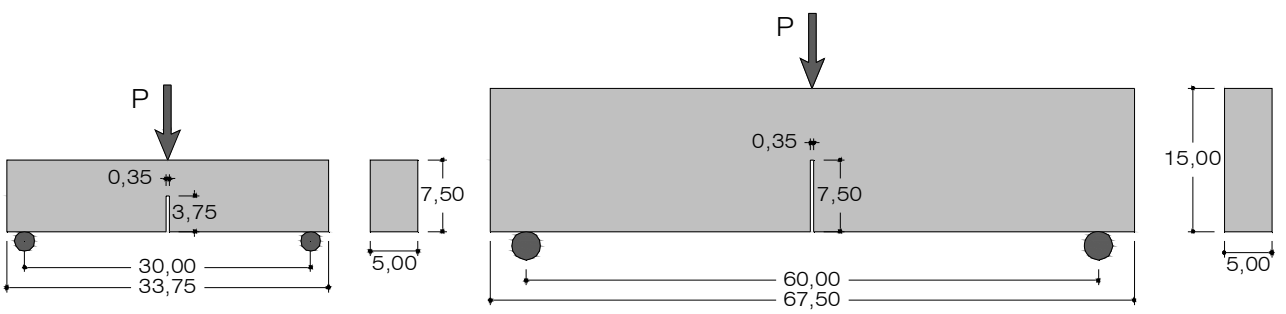

Figura A.14 - Viga sem armadura de altura variável para medir a energia de fratura.
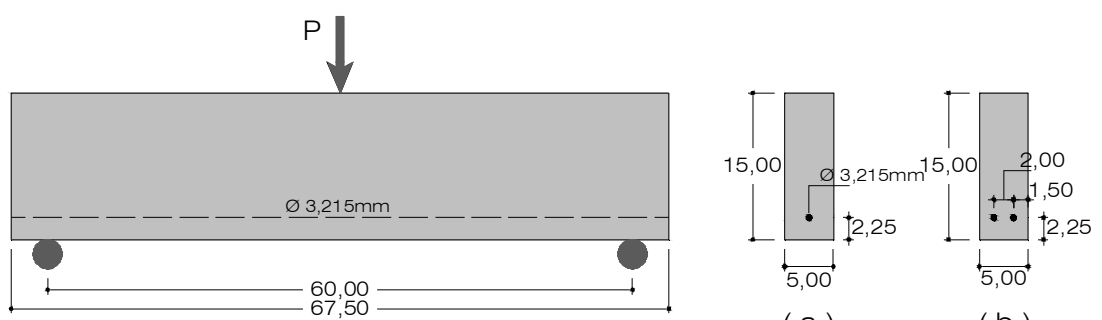

(a)

(b)

Figura A.15 - Viga retangular (a) com uma barra de reforço R-1b, (b) com duas barras de reforço R$2 b$.
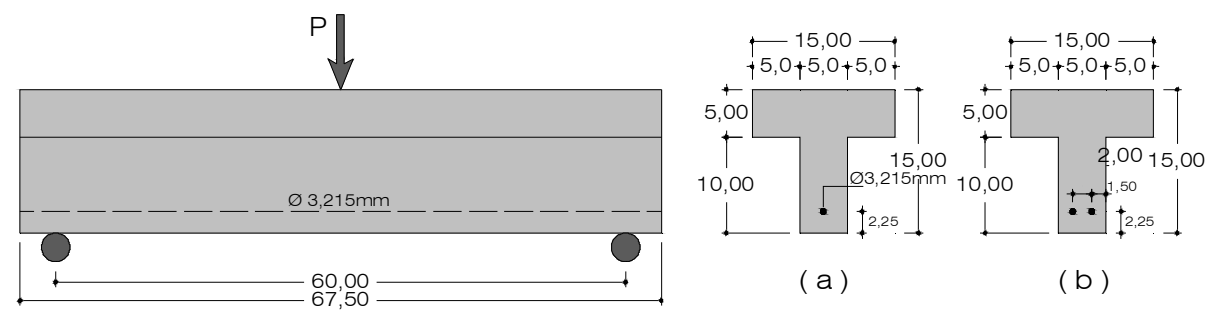

(a)

(b)

Figura A.16 - Viga tipo T (a) com uma barra de reforço $T-1 b$, (b) com duas barras de reforço T-2b.

\section{A.2.3 Fabricação dos Modelos}

O processo construtivo dos modelos pode ser descrito em quatro etapas:

1.- Dosagem do microconcreto;

2.- Definição do sistema de formas;

3.- Preparação das armaduras;

4.- Concretagem do modelo e cura; 


\section{A.2.3.1 Dosagem do microconcreto}

No estudo do comportamento de estruturas através de modelos reduzidos o microconcreto se apresenta como um material adequado para a execução de microestruturas (KLEIN, 1985). Assim, observando as exigências prescritas pela Análise Dimensional, com respeito ao uso de microconcreto como um material semelhante ao concreto, verifica-se que as seguintes condições devem ser atendidas:

- Possuir um módulo de deformação longitudinal com valor próximo ao do concreto comum (módulos de deformação muito baixos influem negativamente na resistência da aderência armadura - microconcreto);

- Tensões de compressão, tração (por compressão diametral), relações entre as tensões de compressão e tração, semelhantes às do concreto;

- Boa trabalhabilidade para possibilitar a confecção de modelos.

Sendo o microconcreto uma argamassa criteriosamente dosada com o intuito de alcançar as exigências acima estabelecidas é importante que se conheça as propriedades dos materiais componentes, bem como o estudo de diversas composições.

Para determinar o traço apropriado para a construção dos modelos deste trabalho, o microconcreto dosado deve cumprir algumas exigências mínimas definidas no projeto:

- Resistência a compressão: fck = 30 Mpa.

- Boa trabalhabilidade pela alta concentração de armadura em espaços pequenos (espaçamento mínimo 7,6 mm).

A seguir apresentam-se a seqüência de procedimentos seguidos para a dosagem do microconcreto:

\section{Escolha do tipo de microconcreto}

A escolha do tipo de microconcreto a ser empregado na concretagem do modelo reduzido depende de vários fatores tais como tamanho das peças, diâmetro e disposição da armadura. De acordo como esses critérios, o tipo de 
microconcreto escolhido foi aquele cujo tamanho máximo de agregado é igual a $4,8 \mathrm{~mm}$ e que utiliza frações de areia passantes na peneira $4,8 \mathrm{~mm}$ e retidas nas peneiras 2,4 mm, 1,2 mm, 0,6 mm, 0,3 mm e 0,15 mm. A relação entre a separação de armaduras mínimas e o tamanho do agregado máximo é 1,58, o qual se pode considerar razoável para um adequado acomodamento dos agregados entre as armaduras.

\section{Determinação da tensão $\mathbf{f}_{c j}$}

A seguir, devem ser relacionadas às resistências fcj e fck pela expressão preconizada pela NBR-6118.

$$
f_{c j}=f_{c k}+1,65 S_{d}
$$

Onde:

fcj = Resistência média do microconcreto à compressão, prevista para a idade de j dias.

fck = Resistência característica do microconcreto à compressão (projeto).

$\mathrm{Sd}=$ Desvio padrão de dosagem, igual a $4 \mathrm{MPa}$, de acordo com a norma NBR-6118.

Deste modo, especificada a resistência $\mathrm{f}_{\mathrm{ck}}=30 \mathrm{Mpa}$ para o projeto em questão, encontrou-se um $\mathrm{f}_{\mathrm{c} 28}=36,6 \mathrm{Mpa}$ aos 28 dias.

\section{Obtenção do fator água/cimento pela curva de Abrams}

Com o $\mathrm{f}_{\mathrm{c} 28}$ calculado, entrou-se na curva de correlação resistência - fator (a/c) de Abrams traçada para o tipo de microconcreto em questão, e determinou-se o fator água/cimento (a/c) de 0,45.

\section{Determinação das massas específicas do cimento e agregado}

A caraterização do cimento e do agregado não foram feitas nesta pesquisa e foram adotadas da caracterição padrão que se tem no Laboratorio de Estruturas e Materiais da USP para estes materiais:

- Cimento: Portland CP II E 32, densidade $\gamma \chi=3150$ kg/m3;

- Agregado: Areia do rio, peneirada e lavada de densidade $\gamma \alpha=2620 \mathrm{~kg} / \mathrm{m} 3$.

- Cálculo do traço - p 
Em correspondência com o tipo de microconcreto retira-se da tabela A.1 o valor do fator água/materiais secos $(\mathrm{H})$. Substituindo na equação A.2 os valores de $\mathrm{H}$ e $(\mathrm{a} / \mathrm{c})$ obtêm-se o traço em peso $\mathrm{p}$ :

$$
p=\frac{100 \cdot(a / c)}{H}-1
$$

Onde:

a/c = Fator água/cimento, Kg de água por kg de cimento .

$\mathrm{p}=$ Traço em peso de agregado na mistura, $\mathrm{kg}$ de agregado por $\mathrm{kg}$ de cimento.

$\mathrm{H}=$ Quantidade de água, em relação aos materiais secos (cimento + agregado) em \%.

Tabela A.1 - Valores do fator água/materiais secos em função do diâmetro máximo do microconcreto.

\begin{tabular}{cc}
\hline$\varnothing(\mathbf{m m})$ & $\mathbf{H} \%$ \\
\hline 4,8 & 10,00 \\
2,4 & 10,90 \\
1,2 & 13,00 \\
\hline
\end{tabular}

Em porcentagem ter-se-á:

$$
\begin{array}{ll}
\text { Para o cimento: } & \frac{1}{1+a} \cdot 100(\%) \\
\text { Para o agregado: } & \frac{a}{1+a} \cdot 100(\%)
\end{array}
$$

Cálculo do consumo de cimento

Utilizando-se a equação A.5 e os valores de $p, \gamma_{c}, \gamma_{a}$ e (a/c), calcula-se o consumo de cimento $\mathrm{C}$ em $\mathrm{kg} / \mathrm{m3}$, ou seja:

Onde:

$$
C=\frac{1000}{(a / c)+\frac{1}{\gamma_{c}}+\frac{p}{\gamma_{a}}}
$$

$\mathrm{C}=$ Quantidade de cimento por metro cúbico de mistura $(\mathrm{Kg} / \mathrm{m} 3)$.

a/c = Fator água/cimento, Kg de água por kg de cimento.

$\mathrm{p}=$ Traço em peso de agregado na mistura, $\mathrm{kg}$ de agregado por $\mathrm{kg}$ de cimento. 
$\gamma_{\mathrm{c}}=$ Massa específica do cimento $(\mathrm{kg} / \mathrm{dm} 3)$.

$\gamma_{\mathrm{a}}=$ Massa específica do agregado $(\mathrm{kg} / \mathrm{dm} 3)$.

\section{Desdobramento do traço}

Existem diversos métodos de composição dos agregados e em todos eles se observa a preocupação de compor o agregado de modo a tornar os vazios da mistura o mínimo possível. Deste modo é obtida a máxima compacidade da massa e a melhor resistência, pois se sabe que a resistência cresce com a compacidade.

Segundo Klein (1985), o método que melhor se ajusta ao microconcreto é o método de Gorisse, e consiste na determinação de um ponto $A$, originando uma curva granulométrica bi-linear. Esta curva ao interceptar as demais colunas dá origem aos porcentuais de agregados, por fração granulométrica, componentes do microconcreto.

As coordenadas do ponto A são:

$$
\begin{gathered}
X=\frac{D}{2} \\
Y=50-\sqrt{D}+k
\end{gathered}
$$

Onde:

$\mathrm{X}=$ Abscissa .

$\mathrm{D}=$ Diâmetro do agregado máximo ( $\mathrm{D}=4,8 \mathrm{~mm} ; \mathrm{D}=2,4 \mathrm{~mm}$ e $\mathrm{D}=1,2 \mathrm{~mm})$.

$\mathrm{Y}=$ Ordenada.

K = Parâmetro de correção função do tipo grão do agregado (arredondado) e consumo de cimento fornecido pela tabela A.2.

Tabela A.2 - Parâmetro de correção.

\begin{tabular}{cc}
\hline $\begin{array}{c}\text { Consumo de } \\
\text { cimento em kg/m3 }\end{array}$ & $\mathrm{K}$ \\
\hline $\mathbf{6 0 0}$ & -10 \\
$\mathbf{5 5 0}$ & -8 \\
$\mathbf{5 0 0}$ & -6 \\
$\mathbf{4 5 0}$ & -4 \\
$\mathbf{4 0 0}$ & -2 \\
$\mathbf{3 5 0}$ & 0 \\
$\mathbf{3 0 0}$ & +2 \\
\hline
\end{tabular}


Para obter um traço apropriado para que o microconcreto tenha boa resistência e trabalhabilidade, foi necessário estabelecer uma correlação entre as variáveis: resistência à compressão $\left(\mathrm{f}_{\mathrm{c} j}\right)$, quantidade de água $(\mathrm{H})$ e a relação $(\mathrm{a} / \mathrm{c})$. Nos testes, a relação a/c se manteve constante $(a / c=0,45)$, e a quantidade de água $\mathrm{H}$ foi variando com a finalidade de obter um microconcreto resistente $\mathrm{e}$ trabalhável.

Os resultados de alguns dos testes se apresentam na tabela A.3 e A.4.

Tabela A.3 - Definição dos parâmetros da curva granulométrica segundo o método de Gorisse.

\begin{tabular}{ccccccc}
\hline Teste & $\mathbf{H ( \% )}$ & $\mathbf{C ~ ( K g / m 3 )}$ & Traço & $\mathbf{X}$ & $\mathbf{K}$ & $\mathbf{Y}$ \\
\hline $\mathbf{1}$ & 10 & 475 & $1: 3,5$ & 2,40 & $-5,02$ & 42,49 \\
$\mathbf{2}$ & 13 & 586 & $1: 2,5$ & 2,40 & $-9,43$ & 38,38 \\
$\mathbf{3}$ & 15 & 653 & $1: 2$ & 2,40 & $-12,13$ & 35,68 \\
\hline
\end{tabular}

A avaliação dos traços foi feita em função dos resultados obtidos nos ensaios de resistência a compressão simples e trabalhabilidade.

Os ensaios de resistência à compressão axial seguiram as recomendações das NBR 5739:2007. Os corpos de prova moldados tinham $50 \mathrm{~mm}$ de diâmetro e $100 \mathrm{~mm}$ de altura mostrada na figura A.17(a) e foram ensaiadas aos 7, 14 e 28 dias. Os resultados desses testes aos 28 dias se apresentam na tabela A. 4.

O ensaio de trabalhabilidade que determina o índice de consistência da massa foi executado de acordo com o método de ensaio da NBR 7215:1996b. O índice de consistência é a média aritmética do diâmetro do material espalhado (medido em três alinhamentos ortogonais) a partir de um cone de microconcreto padronizado colocado sobre uma mesa giratória que é submetida a 30 golpes durante 30 segundos, tal como se pode observar na figura A.17 (b).

Tabela A.4 - Resultados dos ensaios de compressão simples e espalhamento.

\begin{tabular}{cccc}
\hline Traço & $\begin{array}{c}\mathbf{H} \\
\mathbf{( \% )}\end{array}$ & $\begin{array}{c}\mathbf{f}_{\mathrm{cj}} \text { (28 dias) } \\
\text { (Mpa) }\end{array}$ & $\begin{array}{c}\text { Ensaio de } \\
\text { espalhamento (cm) }\end{array}$ \\
\hline $1: 3,5$ & 10 & 37,25 & 25,00 \\
$1: 2,5$ & 13 & 36,80 & 27,00 \\
$1: 2$ & 15 & 35,80 & 32,00 \\
\hline
\end{tabular}




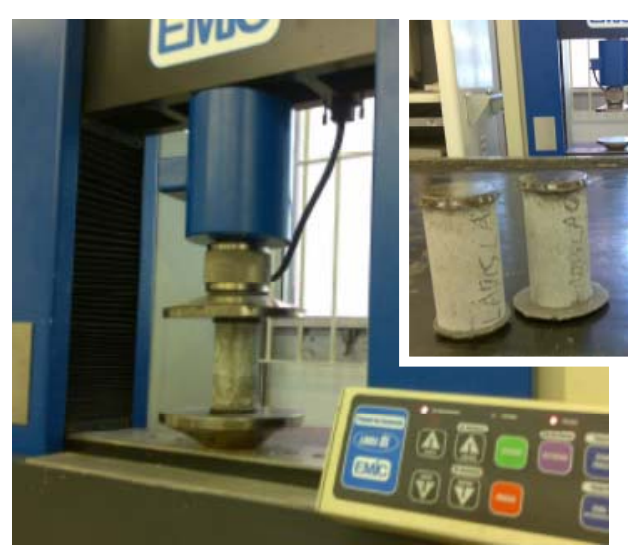

(a)

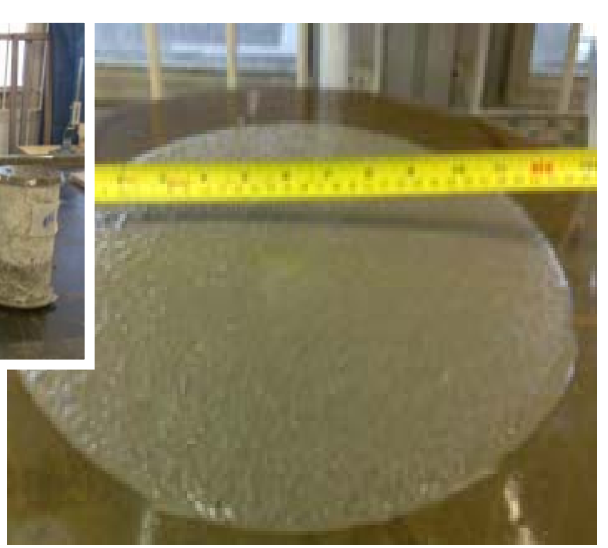

(b)

Figura A.17 - (a) Ensaio de resistência à compressão; (b) Ensaio de espalhamento "Flow Test".

Da tabela A.4, pode-se perceber que a dosagem que melhor satisfaz nossas exigências de resistência e trabalhabilidade é o traço 1:2 com $H=15 \%$ (quantidade de água). Finalmente, o traço selecionado foi usado para a preparação do microconcreto cujo desdobramento é apresentado na tabela A.5. Este desdobramento foi determinado pelo método das curvas de referencia de Gorisse.

Tabela A.5 - Desdobramento do traço.

\begin{tabular}{|c|c|c|c|c|}
\hline \multirow[t]{2}{*}{ Material } & \multirow[b]{2}{*}{$\%$} & \multicolumn{2}{|c|}{ Traço } & \multirow{2}{*}{$\begin{array}{c}\text { Consumo } \\
\mathrm{Kg} / \mathrm{m} 3\end{array}$} \\
\hline & & Peso & $\%$ & \\
\hline Cimento & & 1 & 33.33 & 653 \\
\hline \multicolumn{5}{|l|}{ Agregado } \\
\hline $2.4 \mathrm{~mm}$ & 64.32 & 1.286 & 42.880 & 840.34 \\
\hline $1.2 \mathrm{~mm}$ & 8.92 & 0.178 & 5.947 & 116.53 \\
\hline $0.6 \mathrm{~mm}$ & 8.92 & 0.178 & 5.947 & 116.53 \\
\hline $0.3 \mathrm{~mm}$ & 8.92 & 0.178 & 5.947 & 116.53 \\
\hline $0.15 \mathrm{~mm}$ & 8.92 & 0.178 & 5.947 & 116.53 \\
\hline Agua & & 0.45 & 15.000 & 294 \\
\hline
\end{tabular}

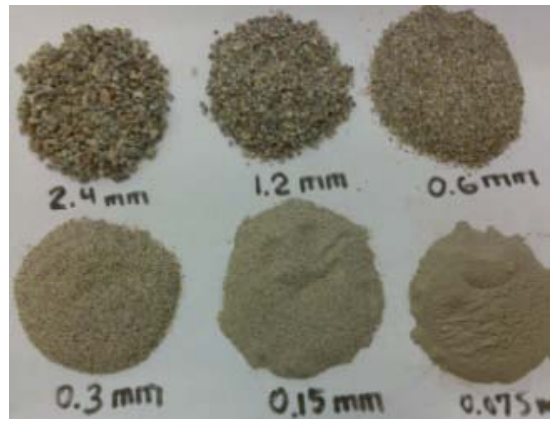

Figura A.18 - Tamanho dos agregados usados para o microconcreto.

\section{A.2.3.2 Definição do sistema de formas da ponte e as vigas}

As formas para moldagem da ponte em escala reduzida e das vigas foram montadas com a utilização de placas de compensado naval de $12 \mathrm{~mm}$ e $6 \mathrm{~mm}$ de espessura, fixadas sobre uma mesa a fim de se trabalhar adequadamente. 
Devido à complexidade da geometria do modelo da ponte, para a composição das formas (tabuleiro, pilares e sapata), a madeira foi cortada em múltiplas peças de acordo com os desenhos apresentados nas figuras A.19 e A.20, para então serem unidas através de pregos e parafusos.

Entretanto, a montagem das formas das vigas foram relativamente mais simples (figuras A.14, A.15 e A.16), pois sua geometria não apresenta irregularidades tanto quanto ao modelo da ponte.

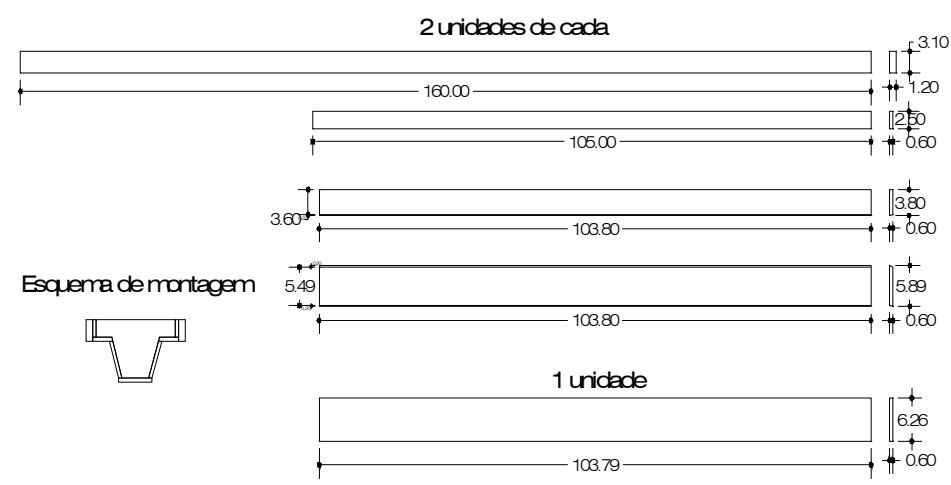

Figura A.19 - Desenho das formas para compor a viga tabuleiro.

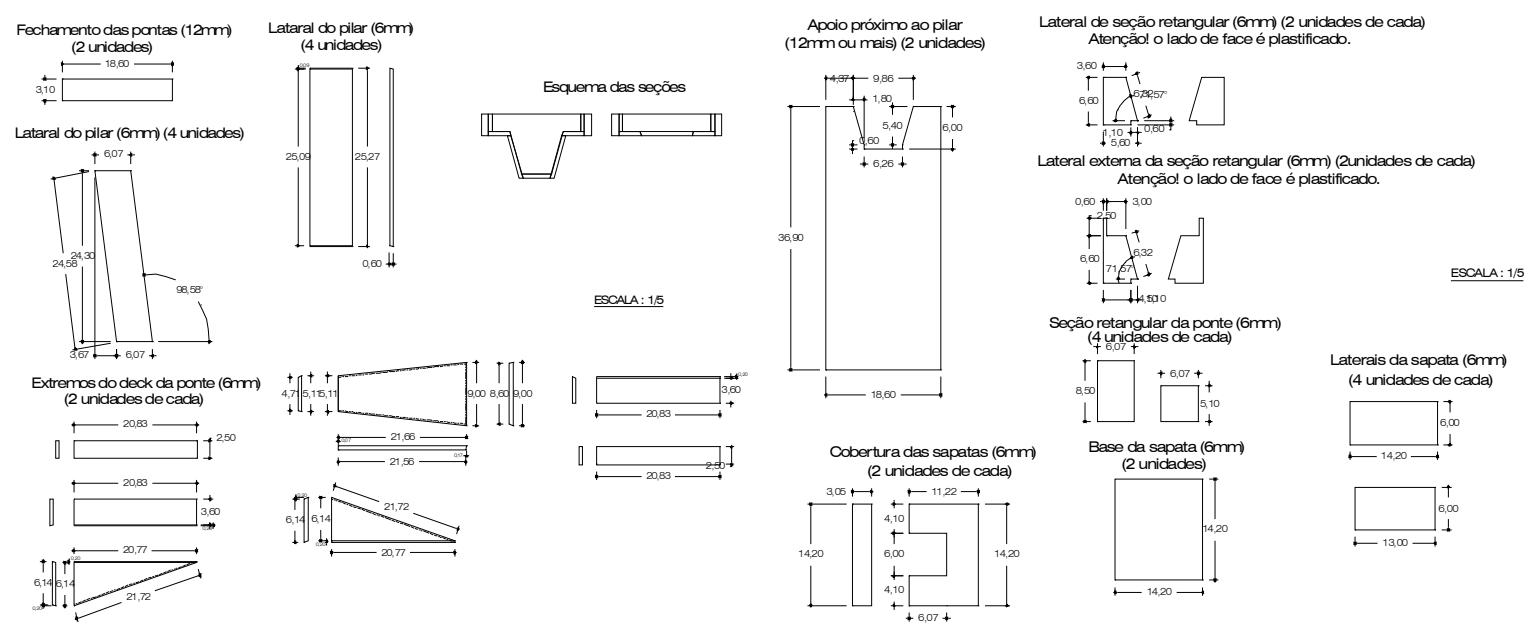

Figura A.20 - Desenho das formas da viga tabuleiro, os pilares e as sapatas.

Antes de iniciar com a montagem, todas as peças foram cobertas com um impermeabilizante, a fim de proteger a madeira da umidade e assim aproveitá-la posteriormente para outros modelos a serem executados. 
Cada uma das peças de madeira cortadas foi codificada para facilitar a montagem da forma, tal como se mostra na figura A.21.
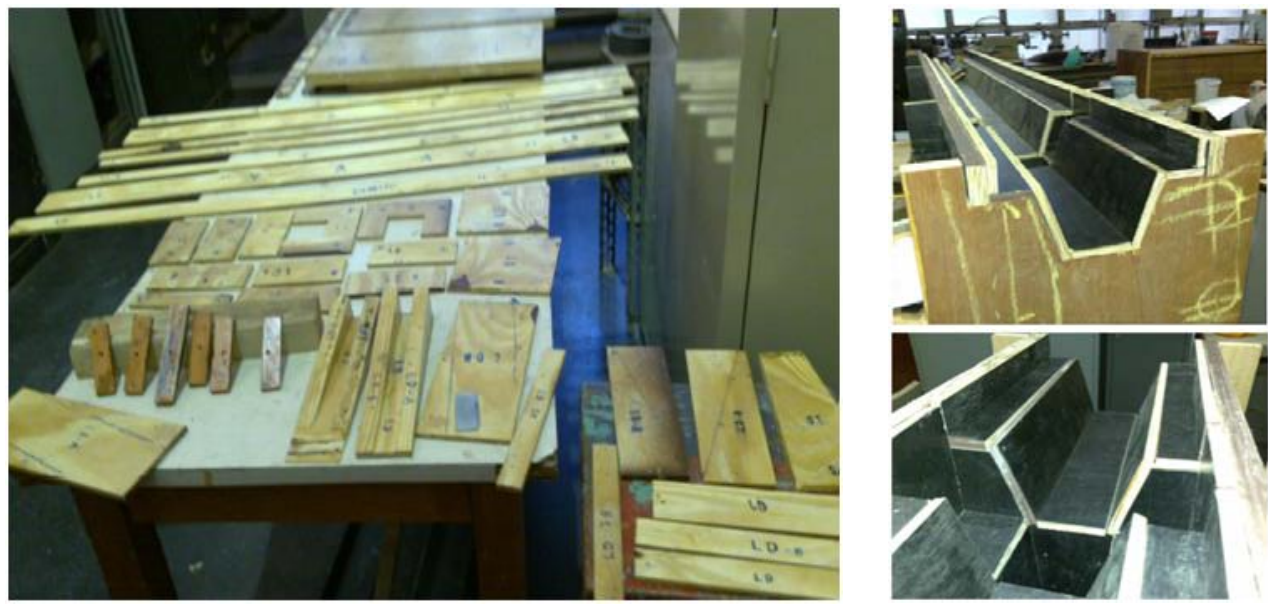

Figura A.21 - Peças da forma do modelo codificadas e montadas.

Na figura A.22 apresenta-se a montagem final da forma da ponte, na qual se pode perceber que a geometria é complexa pelo que os trabalhos de execução da forma necessitaram boa precisão no corte das peças e mão de obra qualificada.
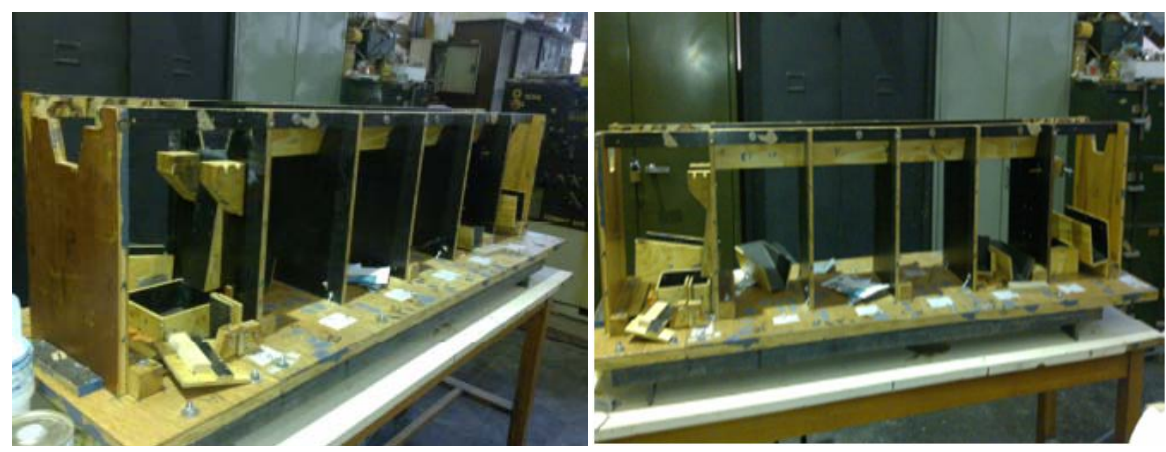

Figura A.22 - Forma montada do modelo de ponte de microconcreto.

Para o caso das vigas de microconcreto as formas foram fabricadas de acordo a geometria estabelecida no projeto, a seguir apresentam-se as dimensões dos corpos de prova para os quais foram construídas as formas:

Corpos de prova sem reforço: Flexão em três pontos
Largura: $\mathrm{B}=5,00 \mathrm{~cm}$
$\mathrm{D} 1: \mathrm{D}=7,50 \mathrm{~cm}$
D2: $D=15,00 \mathrm{~cm}$

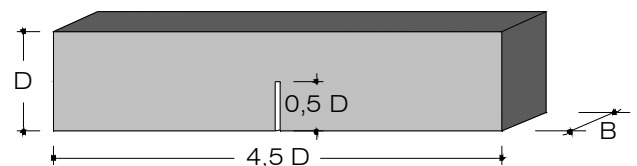


Corpos de prova: Ensaio de aderência:

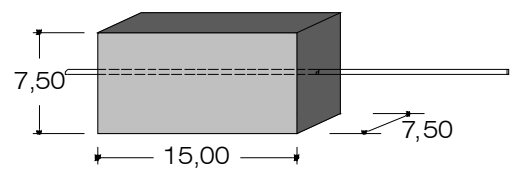

Corpos de prova com reforço: Flexão em três pontos (figura A.15 e A.16)

- 02 Formas de dimensão (Retangular)

: $5,0 \mathrm{~cm} \times 7,5 \mathrm{~cm} \times 33,75 \mathrm{~cm}$.

- 02 Formas de dimensão (Retangular)

: $5,0 \mathrm{~cm} \times 15,0 \mathrm{~cm} \times 67,5 \mathrm{~cm}$.

- 02 Formas de dimensão (Seção tipo T)

: $5,0 \mathrm{~cm} \times 15,0 \mathrm{~cm} \times 67,5 \mathrm{~cm}$.

- 02 Formas de dimensão (Retangular com furo) $\quad: 7,5 \mathrm{~cm} \times 7,5 \mathrm{~cm} \times 15,0 \mathrm{~cm}$.

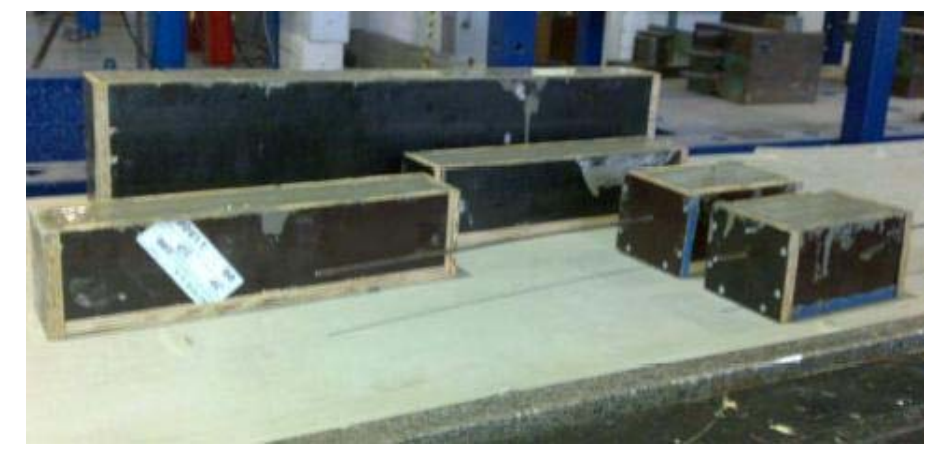

Figura A.23 - Concretagem e forma das vigas de microconcreto.

\section{A.2.3.3 Preparação das armaduras}

No modelo reduzido da ponte, as armaduras longitudinais do tabuleiro e do pilar foram confeccionadas de aço comum CA-50 de $8 \mathrm{~mm}$ e $6,3 \mathrm{~mm}$ e os estribos de arame recozido de $3,215 \mathrm{~mm}$. O processo da preparação das armaduras começou com o corte dos aços longitudinais e dos estribos nos comprimentos e quantidades estabelecidos no projeto.

Os modelos de viga foram reforçados da maneira mais simples, para estudar o comportamento em fratura. A quantidade de aço colocada em cada viga varia em função do tipo de estudo a ser feito no corpo de prova. $\mathrm{Na}$ armação utilizou-se arame recozido de $3,215 \mathrm{~mm}$.

A fim de se obter uma boa aderência entre o aço - microconcreto, o aço originalmente liso foi modificado em relação a sua rugosidade, imprimindo-se nervuras por meio de um processo mecânico feito com um torno. O diâmetro do 
arame na parte mais profunda ficou um 6.5\% menor que o diâmetro original, enquanto a outra parte ficou um $8,25 \%$ mais grossa.

$\mathrm{Na}$ figura A.24 são mostrados os gabaritos usados para a dobragem dos estribos do tabuleiro e do pilar.
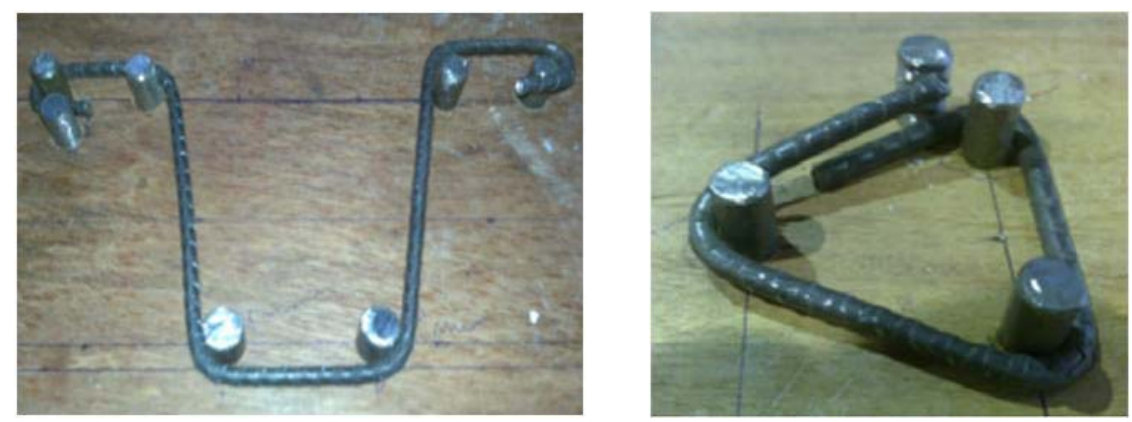

Figura A.24 - Dobragem dos estribos do tabuleiro e do pilar da ponte em escala reduzida.

O processo da armação foi difícil devido às reduzidas dimensões dos elementos, sendo difícil materializar o previsto no projeto. Em seguida apresentamse algumas figuras que permitem perceber como decorreu o processo de montagem das armaduras e o grau de perfeição / erro que essas continham. $\mathrm{Na}$ figura A.25, apresenta-se a amarração do aço longitudinal nos estribos do tabuleiro.
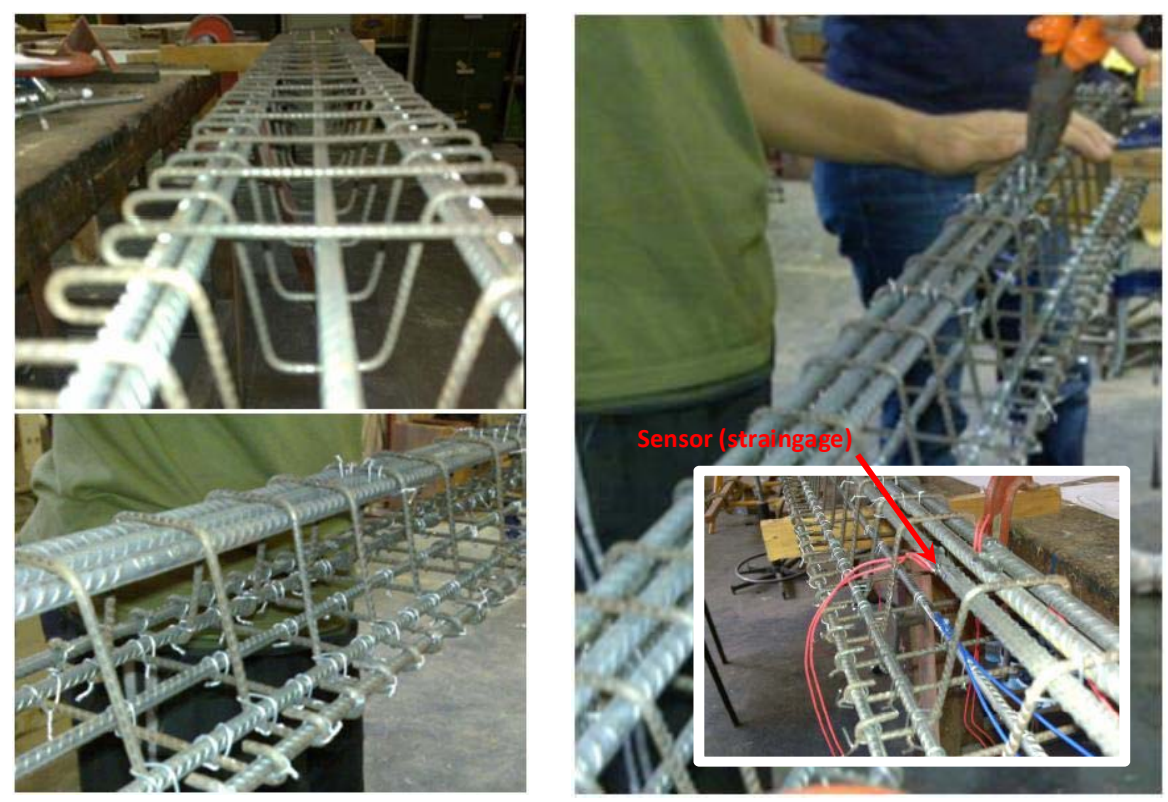

Figura A.25 - Armação do tabuleiro (Aço longitudinal e estribos) e instalação de straingages. 


\section{A.2.3.4 Concretagem dos modelos}

Para a preparação do microconcreto os materiais foram dosados por peso de acordo com o traço estabelecido na tabela A.5. As frações de areia foram obtidas a partir de peneiramento e a mistura dos materiais constituintes do microconcreto foi feita em uma betoneira adaptada de eixo vertical de $20 \mathrm{Kg}$. de capacidade.

A concretagem da ponte foi realizada em quatro etapas, pois o volume de microconcreto necessário para sua confecção foi de 0.030 m3 (aprox. 75 kg.) e a betoneira não possuía esta capacidade. Durante a mistura tomou-se todas as precauções possíveis a fim de se obter alta semelhança entre os amassamentos de microconcreto, bem como um controle muito intenso de todo o processo de fabricação. O adensamento foi feito com a ajuda de uma mesa vibratória. A seguir são apresentadas algumas fotos nas quais pode-se observar o processo de concretagem da ponte.

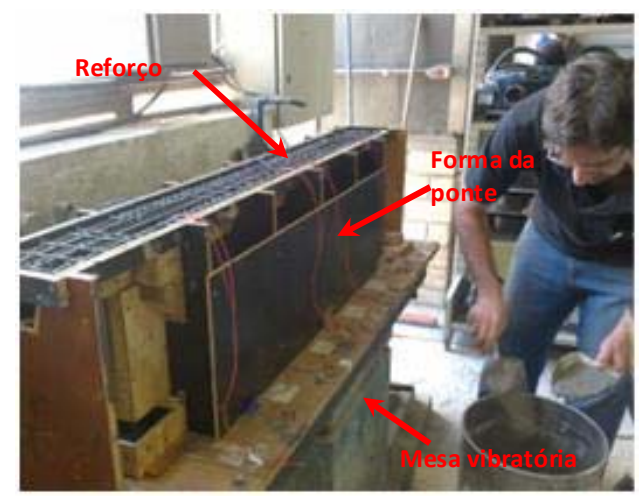

(a)

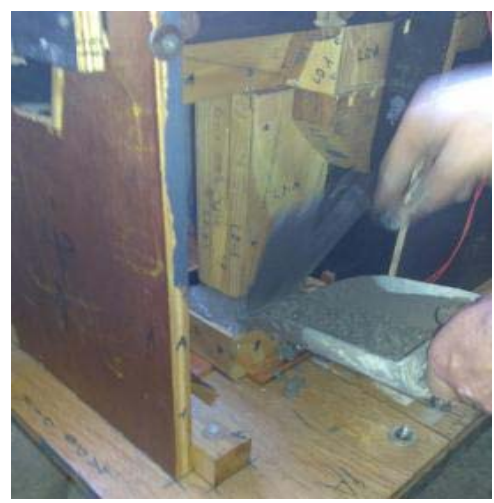

(b)

Figura A.26 - (a) Forma instalada acima da mesa vibratória, (b) Concretagem da sapata.

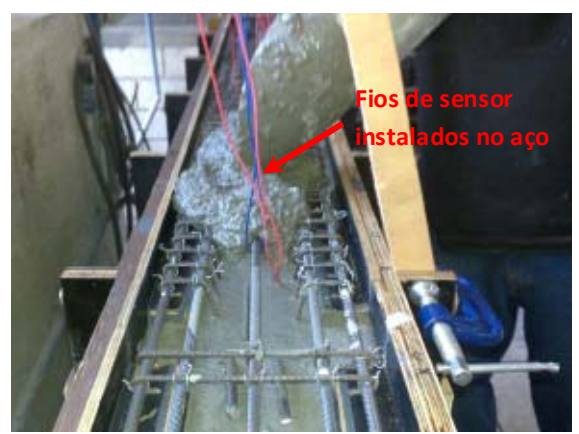

(a)

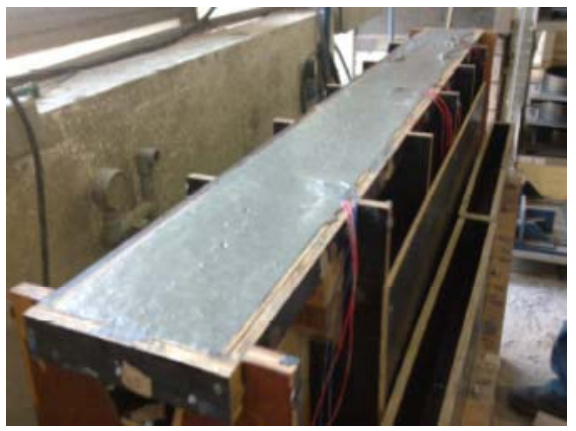

(b)

Figura A.27 - (a) Concretagem do tabuleiro, (b) Final da concretagem. 
A concretagem das vigas foi relativamente mais simples e foram feitas em datas diferentes devido a reduzida quantidade de formas disponíveis. Foram retirados corpos de prova para cada betonada com a finalidade de caracterizá-los apropriadamente. O volumem de microconcreto necessário para as vigas e os corpos de prova foram de $0,10 \mathrm{~m} 3$.

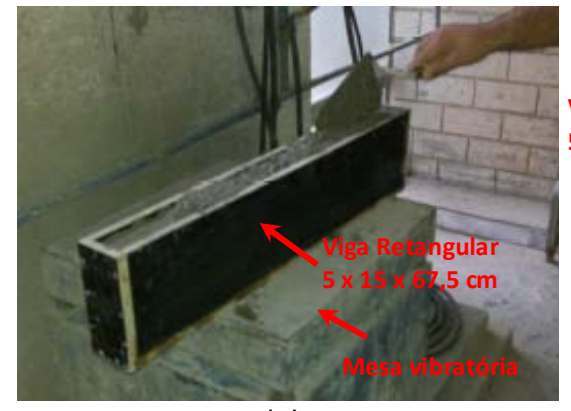

(a)

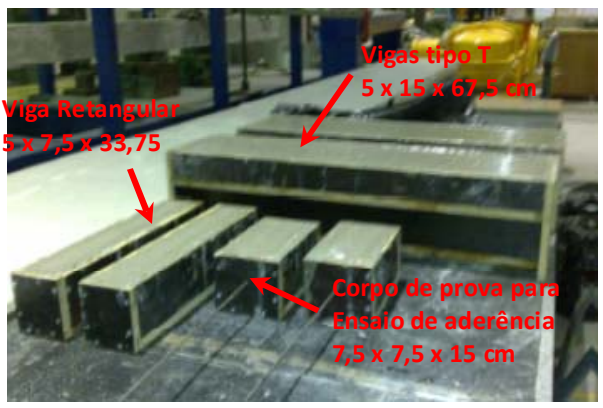

(b)

Figura A.28 - Concretagem das vigas: (a) Seção retangular, (b) Seção tipo T e retangulares.

\section{A.2.3.5 Desforma e cura dos modelos}

As formas para o caso da ponte foram retiradas em duas etapas. $\mathrm{Na}$ primeira etapa foram retiradas as formas do tabuleiro 24 horas após da concretagem, para facilitar o processo de cura do modelo conforme se mostra na figura A.29 (a). O resto de peças da forma foram retiradas após 7 dias da concretagem com a ajuda da ponte rolante do laboratório LEM, que permitiu suspender o modelo por meio de cordas para facilitar a desforma e assim não danificá-la, pois a forma pode ser aproveitada para fabricar outros modelos, este processo é apresentado na figura A.29 (b). Para o caso das vigas, as formas foram retiradas 24 horas após a concretagem e posteriormente reutilizadas para a concretagem de novas vigas.

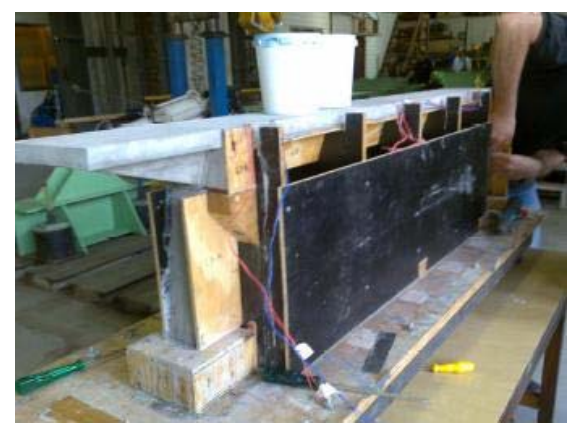

(a)

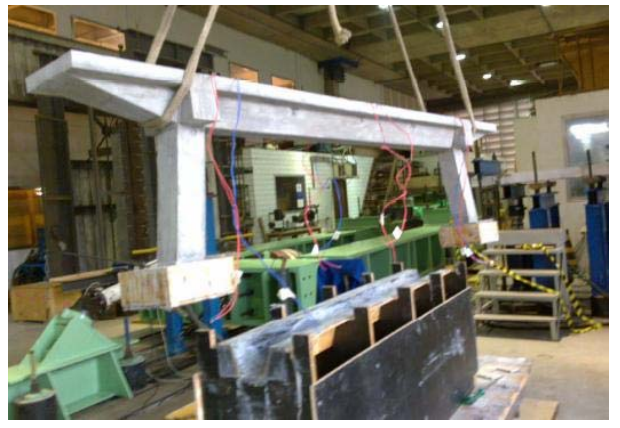

(b)

Figura A.29 - (a) Desforma do tabuleiro e pilares, (b) Estrutura suspensa fora da forma. 
O tipo de cura adotado para cada modelo foi diferente. No caso da ponte foi coberta com panos molhados e uma plástica longa (figura A.30), para envolver a estrutura de corpo inteiro e assim não deixar escapar a umidade que foi diariamente aplicada durante um período de 28 dias.

As vigas de microconcreto foram submersas dentro da água durante 28 dias. Em relação aos corpos de prova estes foram desmoldados após 24 horas da concretagem e submetidos ao mesmo processo de cura.

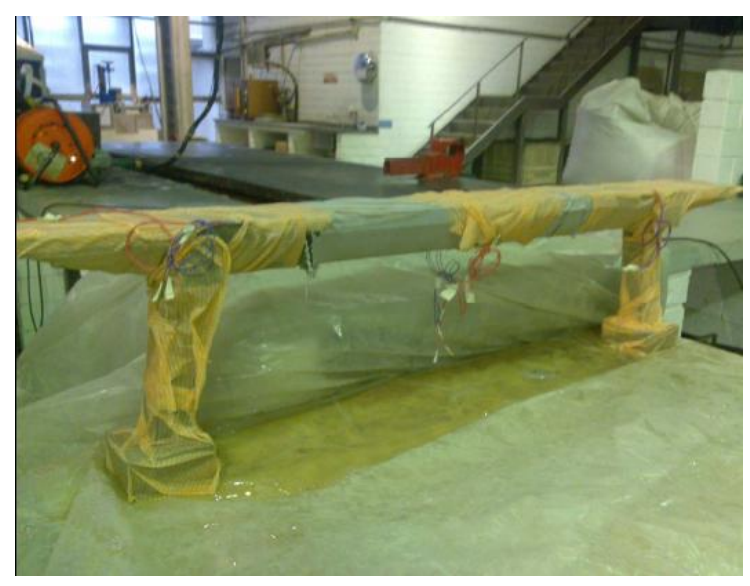

Figura A.30 - Ponte coberto com pano molhado e uma capa de plástico. 
Anexo

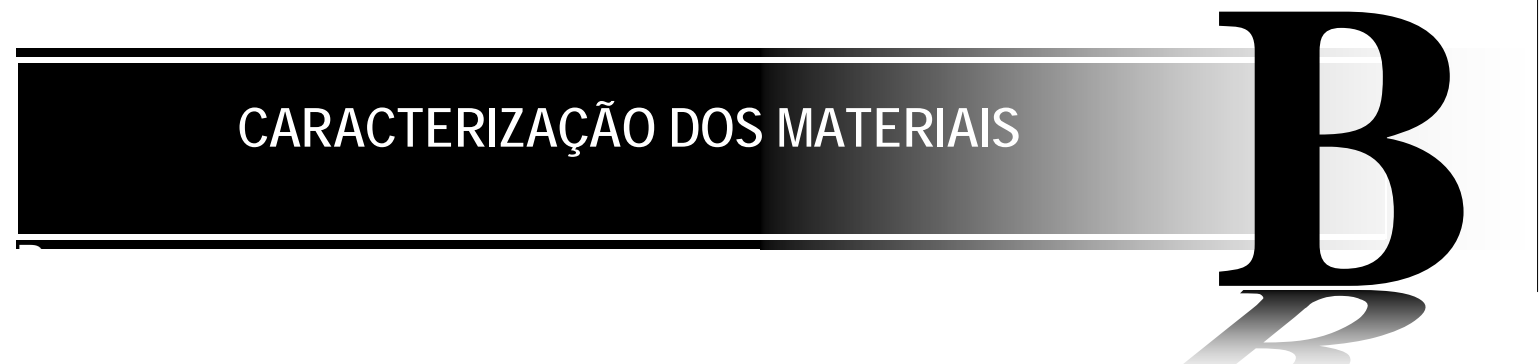

\section{B.1 Introdução}

Todos os materiais usados nesta pesquisa foram caracterizados de acordo com as especificações da Associação Brasileira de Normas Técnicas - ABNT.

A caracterização é dividida em duas partes, a saber, os materiais utilizados na fabricação do modelo de alumínio e os materiais utilizados na fabricação dos modelos de microconcreto. Todos os ensaios foram realizados no Laboratório do LEM USP (Laboratório de Estruturas e Materiais).

A caracterização dos materiais é importante porque permite conhecer as propriedades físicas e mecânicas dos materiais a serem utilizados na análise e interpretação do comportamento de modelos físicos. 


\section{B.2 Caracterização do alumínio utilizado no modelo da ponte.}

Para a caracterização do alumínio foram realizados os ensaios de tração em corpos de prova usinados à temperatura ambiente de modo a não afetar as propriedades do metal, conforme a NBR 6152:2002.

As amostras foram preparadas das mesmas peças usadas na construção do modelo. O ensaio realizado nas amostras consistiu em solicitar o corpo de prova à tração, até a ruptura, com o propósito de se determinar as propriedades mecânicas do material em estudo.

A geometria dos corpos de prova está ilustrada na figura B.1.

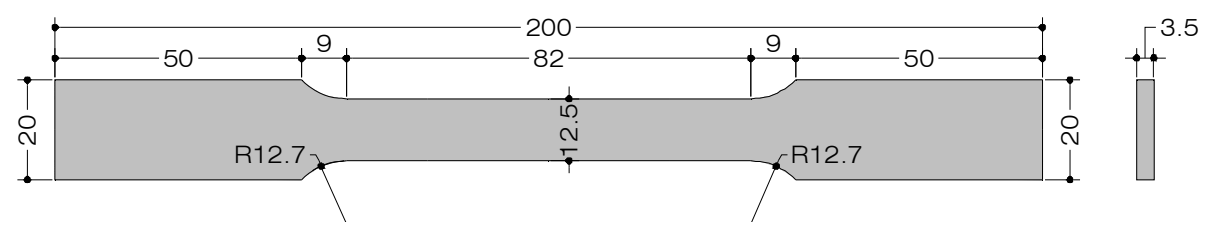

Figura B.1 - Forma do corpo-de-prova usinado em mm.

Os ensaios de tração foram realizados à temperatura ambiente na prensa universal de marca EMIC com célula de carga de $5 \mathrm{kN}$ apresentado na figura B.2(a). Os dados do ensaio foram transferidos ao computador acoplado à prensa de onde se podem retirar os valores de carga e deslocamento. Cada corpo de prova foi instrumentado com extensômetros elétricos tipo roseta, posicionados na região central os quais permitiram medir as deformações longitudinais e transversais. $\mathrm{Na}$ figura B.2 (b) apresenta-se o corpo de prova depois do ensaio de tração.

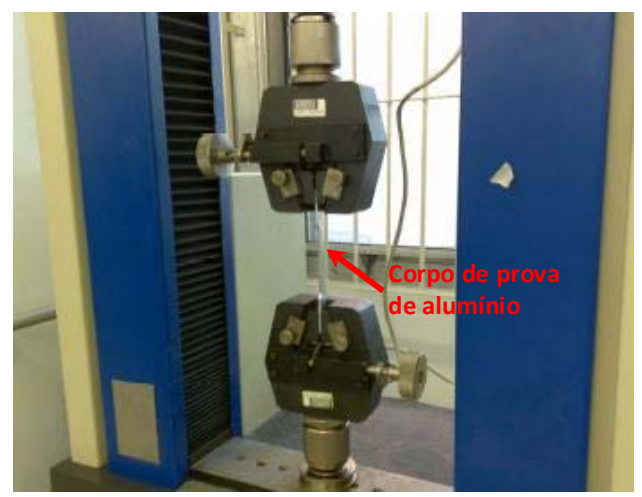

(a)

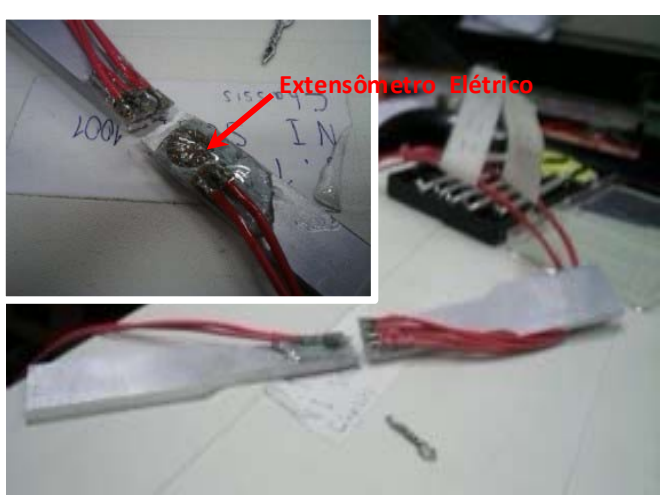

(b)

Figura B.2 - (a) Ensaio na prensa universal EMIC, (b) Corpo de prova depois do ensaio. 
Os resultados dos ensaios experimentais são apresentados na tabela B.1, onde estão citados o módulo de elasticidade, o coeficiente de Poisson, a tensão máxima de resistência e escoamento.

Tabela B.1 - Propriedades mecânicas do alumínio.

\begin{tabular}{ccccc}
\hline $\begin{array}{c}\text { Corpo de } \\
\text { Prova }\end{array}$ & $\begin{array}{c}\text { Módulo de } \\
\text { Elasticidade E } \\
\text { (Gpa) }\end{array}$ & $\begin{array}{c}\text { Coeficiente } \\
\text { de Poisson } \\
v\end{array}$ & $\begin{array}{c}\text { Tensão máx. de } \\
\text { Resistência fu } \\
\text { (MPa) }\end{array}$ & $\begin{array}{c}\text { Tensão máx. de } \\
\text { Escoamento fy } \\
\text { (MPa) }\end{array}$ \\
\hline CP1 & 65,63 & 0,33 & 244,32 & 212,87 \\
CP2 & 65,48 & 0,34 & 235,58 & 209,08 \\
CP3 & 64,26 & 0,33 & 232,96 & 208,78 \\
\hline Média & $\mathbf{6 5 , 1 2}$ & $\mathbf{0 , 3 3}$ & $\mathbf{2 3 7 , 6 2}$ & $\mathbf{2 1 0 , 2 4}$ \\
D. Padrão & 0,75 & 0,01 & 5,95 & 2,28 \\
\hline
\end{tabular}

Os cálculos das propriedades mecânicas foram feitas a partir dos dados do ensaio, assim, para se determinar o coeficiente de Poisson relacionou-se as deformações transversais e longitudinais $\left(u=\varepsilon_{t} / \varepsilon_{\mathrm{L}}\right)$ e para o caso do módulo de elasticidade determinou-se a inclinação da curva carga - deformação longitudinal.

A figura B.3 ilustra o gráfico tensão - deformação do corpo de prova ensaiado, na qual se percebe que ao começo existe um leve acomodamento, devido ao fato de que o corpo de prova não é prendido adequadamente pela prensa universal EMIC.

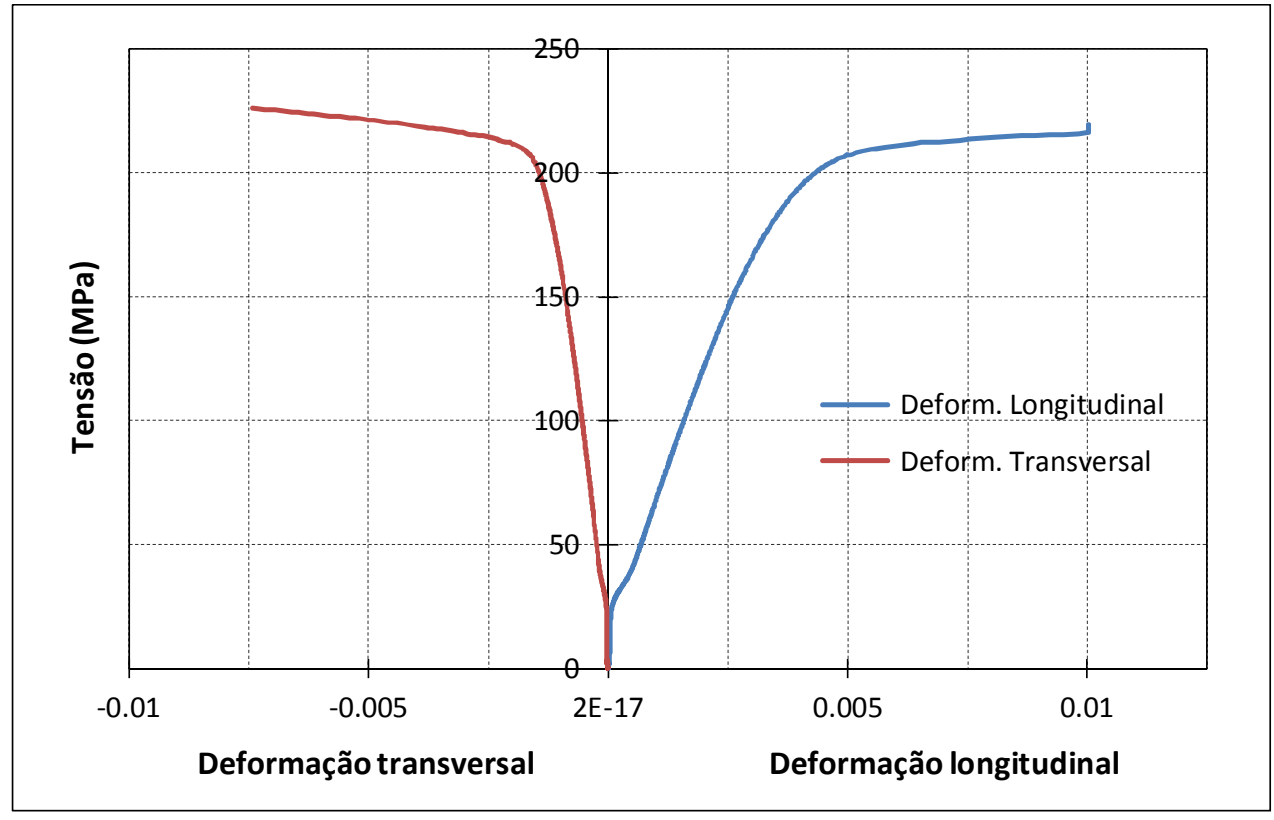

Figura B.3 - Gráfico tensão-deformação nas duas direções: transversal e longitudinal. 


\section{B.3 Propriedades mecânicas do microconcreto}

\section{B.3.1 Resistência à compressão simples}

Os corpos de prova foram moldados e preparados segundo a NBR 5738:1994 e ensaiados de acordo com a NBR 5739:1994. A caracterização do microconcreto utilizado nas vigas e na ponte foi realizada utilizando-se corpos de prova com 50mm de diâmetro e 100mm de altura e são ilustrados na figura B.4 (a).

A moldagem dos corpos de prova foi feita em formas metálicas, apoiadas sobre uma mesa vibratória. O microconcreto foi colocado em duas camadas de alturas aproximadamente iguais. O processo de vibração foi após de cada camada, com a finalidade de permitir o adensamento conveniente nos moldes. No total, 9 corpos de prova referente às vigas e 9 corpos de prova referente à ponte, foram ensaiados nas idades de 7, 14 e 28 dias.

O cálculo da resistência à compressão de cada corpo de prova foi determinada dividindo-se a carga máxima entre a seção transversal. Na tabela B.2 e B.3 apresentam-se a idade do ensaio, a carga máxima de ruptura, a resistência à compressão de cada um dos corpos de prova. Também se apresenta a resistência à compressão média, com seu desvio padrão, obtida considerando todos os ensaios.

Tabela B.2 - Valores de resistência a compressão dos corpos de prova das vigas.

\begin{tabular}{ccccccc}
\hline $\begin{array}{c}\text { Tipo de } \\
\text { Concreto }\end{array}$ & $\begin{array}{c}\text { Corpo de } \\
\text { Prova }\end{array}$ & $\begin{array}{c}\text { Idade } \\
\text { (dias) }\end{array}$ & $\begin{array}{c}\text { Carga de } \\
\text { Ruptura } \\
\text { (kN) }\end{array}$ & $\begin{array}{c}\text { Resistência } \\
\text { Individual } \\
\text { (MPa) }\end{array}$ & $\begin{array}{c}\text { Resistência } \\
\text { Média } \\
\text { (Mpa) }\end{array}$ & $\begin{array}{c}\text { Desvio } \\
\text { Padrão } \\
\text { (Mpa) }\end{array}$ \\
\hline \multirow{4}{*}{ CP1 } & 7 & 53,92 & 27,46 & & \\
& CP2 & 7 & 54,23 & 27,62 & 27,61 & 0,15 \\
& CP3 & 7 & 54,49 & 27,75 & & \\
\cline { 2 - 6 } A & CP4 & 14 & 63,11 & 32,14 & & \\
& CP5 & 14 & 61,38 & 31,26 & 31,70 & \\
& CP6 & 14 & 56,57 & 28,81 & & \\
& CP7 & 28 & 68,62 & 34,95 & & \\
& CP8 & 28 & 70,35 & 35,83 & 35,47 & 0,46 \\
& CP9 & 28 & 69,94 & 35,62 & & \\
\hline
\end{tabular}

Nota: $\left(^{\star}\right)$ Deficiência do ensaio pelo fato de que o corpo de prova não apresentava nenhum dano. 
Tabela B.3 - Valores de resistência a compressão dos corpos de prova da ponte.

\begin{tabular}{ccccccc}
\hline $\begin{array}{c}\text { Tipo de } \\
\text { Concreto }\end{array}$ & $\begin{array}{c}\text { Corpo de } \\
\text { Prova }\end{array}$ & $\begin{array}{c}\text { Idade } \\
\text { (dias) }\end{array}$ & $\begin{array}{c}\text { Carga de } \\
\text { Ruptura } \\
\text { (kN) }\end{array}$ & $\begin{array}{c}\text { Resistência } \\
\text { Individual } \\
\text { (MPa) }\end{array}$ & $\begin{array}{c}\text { Resistência } \\
\text { Média } \\
\text { (Mpa) }\end{array}$ & $\begin{array}{c}\text { Desvio } \\
\text { Padrão } \\
\text { (Mpa) }\end{array}$ \\
\hline \multirow{5}{*}{ CP1 } & 7 & 55,76 & 28,40 & & \\
& CP2 & 7 & 53,51 & 27,25 & 27,83 & 0,81 \\
& CP3 & 7 & 48,11 & $24,50 * *$ & & \\
\cline { 2 - 7 } B & CP4 & 14 & 57,43 & $29,25 * *$ & & \\
& CP5 & 14 & 59,89 & 30,50 & 31,02 & 0,73 \\
& CP6 & 14 & 61,91 & 31,53 & & \\
& CP7 & 28 & 43,10 & $21,95 *$ & & \\
& CP8 & 28 & 69,68 & 35,49 & 35,30 & 0,28 \\
& CP9 & 28 & 68,92 & 35,10 & & \\
\hline
\end{tabular}

Nota: $\left(^{\star}\right)$ Deficiência do ensaio pelo fato de que o corpo de prova não apresentava nenhum dano.

(**) Deficiência no processo de concretagem do corpo de prova (segregação).

Nesse ensaio a carga foi aplicada a uma velocidade de 0,30 MPa/seg, sendo um valor dentre os intervalos recomendados pela norma.

A resistência à compressão aos 28 dias, em quase todos os corpos de prova, apresentou resultados maiores do que da resistência da dosagem, tendo em vista o desvio padrão utilizado no cálculo dos traços. Assim, no cálculo da resistência média foram descartados os resultados dos corpos de prova que apresentaram algum tipo de defeito decorrente do processo de moldagem ou alguma deficiência no processo de execução do ensaio.

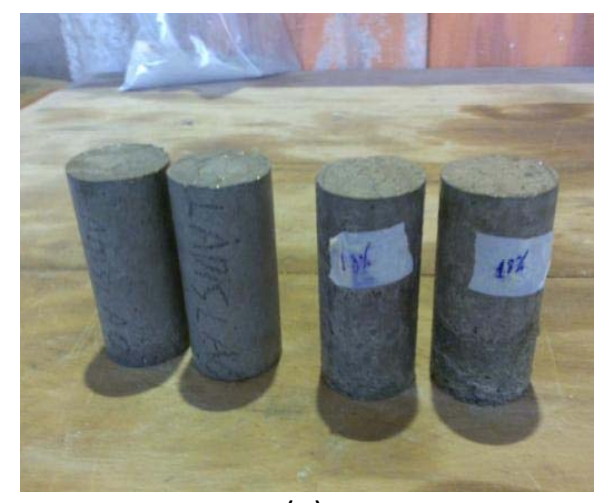

(a)

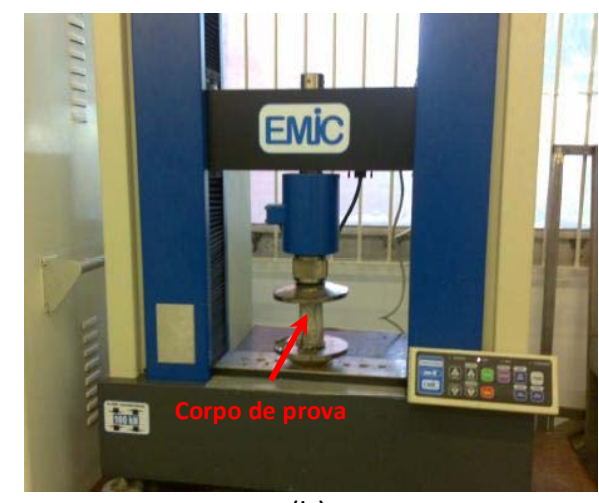

(b)

Figura B.4 - (a) Corpos de prova de 50 x 100mm, (b) Ensaio de compressão simples. 


\section{B.3.2 Resistência à tração por compressão diametral}

Os valores de resistência a tração por compressão diametral foram determinados segundo as recomendações da NBR 7222:1994.

Neste ensaio, os corpos de prova do tipo usado no ensaio de compressão, foram colocados com o seu eixo em posição horizontal entre os pratos da prensa, tal como se mostra na figura B.5(a), e aplicou-se uma carga progressivamente a uma velocidade de 0,05 $\mathrm{MPa} / \mathrm{seg}$ até a ruptura do corpo de prova por fendimento no plano vertical. Na figura B.5(b), ilustra-se os corpos de prova depois do ensaio.

No total, 3 corpos de prova referente às vigas e 3 corpos de prova referente à ponte, foram ensaiados na idade de 32 dias após da concretagem.

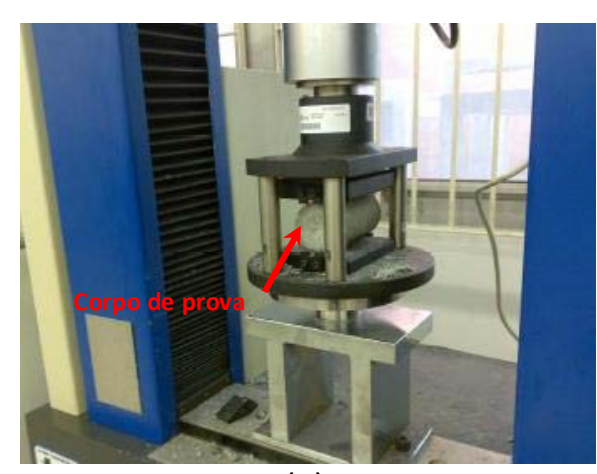

(a)

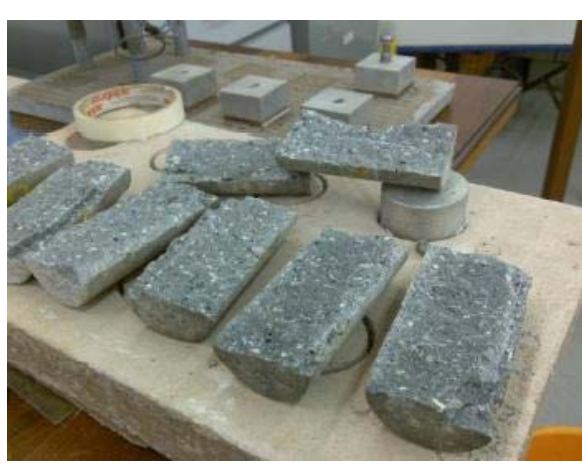

(b)

Figura B.5 - (a) Ensaio na prensa universal EMIC, (b) Corpo de prova depois do ensaio.

O cálculo da resistência à tração de cada corpo de prova foi realizado com a seguinte expressão:

$$
f_{t, D}=\frac{2 F}{\pi \cdot d \cdot L}
$$

Onde $F$ é a carga máxima de ruptura obtida no ensaio, $d$ é diâmetro do corpo de prova e $L$ é a altura do corpo de prova. Na tabela B.4 e B.5 apresentam-se a idade do ensaio, a carga máxima de ruptura, a resistência à tração de cada um dos corpos de prova. Também apresenta-se a resistência à tração media, com seu desvio padrão, obtida considerando-se todos os ensaios. 
Tabela B.4 - Valores de resistência à tração dos corpos de prova das vigas.

\begin{tabular}{ccccccc}
\hline $\begin{array}{c}\text { Tipo de } \\
\text { Concreto }\end{array}$ & $\begin{array}{c}\text { Corpo de } \\
\text { Prova }\end{array}$ & $\begin{array}{c}\text { Idade } \\
\text { (dias) }\end{array}$ & $\begin{array}{c}\text { Carga de } \\
\text { Ruptura } \\
\text { (kN) }\end{array}$ & $\begin{array}{c}\text { Resistência } \\
\text { Individual } \\
\text { (MPa) }\end{array}$ & $\begin{array}{c}\text { Resistência } \\
\text { Media } \\
\text { (Mpa) }\end{array}$ & $\begin{array}{c}\text { Desvio } \\
\text { Padrão } \\
\text { (Mpa) }\end{array}$ \\
\hline \multirow{4}{*}{ A } & CP1 & 32 & 33560 & 4,27 & & \\
& CP2 & 32 & 34104 & 4,34 & 4,40 & 0,17 \\
& CP3 & 32 & 36115 & 4,60 & & \\
\hline
\end{tabular}

Tabela B.5 - Valores de resistência à tração dos corpos de prova da ponte.

\begin{tabular}{ccccccc}
\hline $\begin{array}{c}\text { Tipo de } \\
\text { Concreto }\end{array}$ & $\begin{array}{c}\text { Corpo de } \\
\text { Prova }\end{array}$ & $\begin{array}{c}\text { Idade } \\
\text { (dias) }\end{array}$ & $\begin{array}{c}\text { Carga de } \\
\text { Ruptura } \\
\text { (kN) }\end{array}$ & $\begin{array}{c}\text { Resistência } \\
\text { Individual } \\
\text { (MPa) }\end{array}$ & $\begin{array}{c}\text { Resistência } \\
\text { Media } \\
\text { (Mpa) }\end{array}$ & $\begin{array}{c}\text { Desvio } \\
\text { Padrão } \\
\text { (Mpa) }\end{array}$ \\
\hline \multirow{3}{*}{ B } & CP1 & 32 & 33300 & 4,24 & & \\
& CP2 & 32 & 35395 & 4,51 & 4,37 & 0,19 \\
& CP3 & 32 & 29833 & $3,80 *$ & & \\
\hline
\end{tabular}

Nota: $\left(^{*}\right)$ Deficiência do ensaio pelo fato de que o corpo de prova não apresentava nenhum dano.

\section{B.3.3 Módulo de elasticidade}

Com a finalidade de se determinar o módulo de elasticidade do microconcreto, foram ensaiadas três corpos de prova de cada um dos modelos físicos em estudo (tabela B.6 e B.7). Os valores do módulo de elasticidade foram determinados segundo as recomendações da NBR 8522:2003.

Segundo a norma, o módulo de elasticidade no concreto é dado pela declividade da curva tensão-deformação sobre uma carga uniaxial. O carregamento foi aplicado progressivamente a uma velocidade de 0,25 MPa/seg até que seja alcançada uma tenção de aproximadamente $30 \%$ da resistência à compressão do microconcreto.

Na tabela B.6 e B.7 são apresentados os resultados dos ensaios executados. Vale ressaltar que os corpos de prova tiveram suas superfícies retificadas para garantir uma uniforme distribuição do carregamento. 
Tabela B.6 - Valores do módulo de elasticidade dos corpos de prova das vigas.

\begin{tabular}{|c|c|c|c|c|c|}
\hline $\begin{array}{l}\text { Tipo de } \\
\text { Concreto }\end{array}$ & $\begin{array}{c}\text { Corpo de } \\
\text { Prova }\end{array}$ & $\begin{array}{l}\text { Idade } \\
\text { (dias) }\end{array}$ & $\begin{array}{c}\text { Módulo de } \\
\text { Elasticidade } \\
\text { (GPa) }\end{array}$ & $\begin{array}{l}\text { M. elasticidade } \\
\text { Média } \\
\text { (GPa) }\end{array}$ & $\begin{array}{c}\text { Desvio } \\
\text { Padrão } \\
\text { (GPa) }\end{array}$ \\
\hline \multirow{3}{*}{ A } & CP1 & 28 & 26,53 & \multirow{3}{*}{26,95} & \multirow{3}{*}{0,56} \\
\hline & $\mathrm{CP} 2$ & 28 & 27,58 & & \\
\hline & $\mathrm{CP} 3$ & 28 & 26,73 & & \\
\hline \multicolumn{6}{|c|}{ Tabela B.7 - Valores do módulo de elasticidade dos corpos de prova da ponte. } \\
\hline $\begin{array}{l}\text { Tipo de } \\
\text { Concreto }\end{array}$ & $\begin{array}{c}\text { Corpo de } \\
\text { Prova }\end{array}$ & $\begin{array}{l}\text { Idade } \\
\text { (dias) }\end{array}$ & $\begin{array}{c}\text { Módulo de } \\
\text { Elasticidade } \\
\text { (GPa) }\end{array}$ & $\begin{array}{l}\text { M. elasticidade } \\
\text { Média } \\
(\mathrm{GPa})\end{array}$ & $\begin{array}{c}\text { Desvio } \\
\text { Padrão } \\
\text { (GPa) } \\
\end{array}$ \\
\hline \multirow{3}{*}{ B } & CP1 & 28 & 26,64 & \multirow{3}{*}{26,78} & \multirow{3}{*}{0,66} \\
\hline & $\mathrm{CP} 2$ & 28 & 26,20 & & \\
\hline & CP3 & 28 & 27,50 & & \\
\hline
\end{tabular}

\section{B.3.4 Tensão de aderência}

\section{B.3.4.1 Definição}

Este ensaio consiste em extrair uma barra de aço posicionado no centro de um corpo de prova de concreto, colocado sob placas de apoio de uma máquina de ensaio. As duas extremidades da barra são projetadas para fora corpo de prova, medindo-se a força de tração aplicada a um dos extremos e os escorregamentos. Este ensaio de arrancamento é normalizado pelo RILEM 1973 e ASTM C234: 1991 (FRANÇA, 2004).

O ensaio de aderência é um ensaio sobre o material composto concreto armado e está destinado a avaliar a resistência da ligação

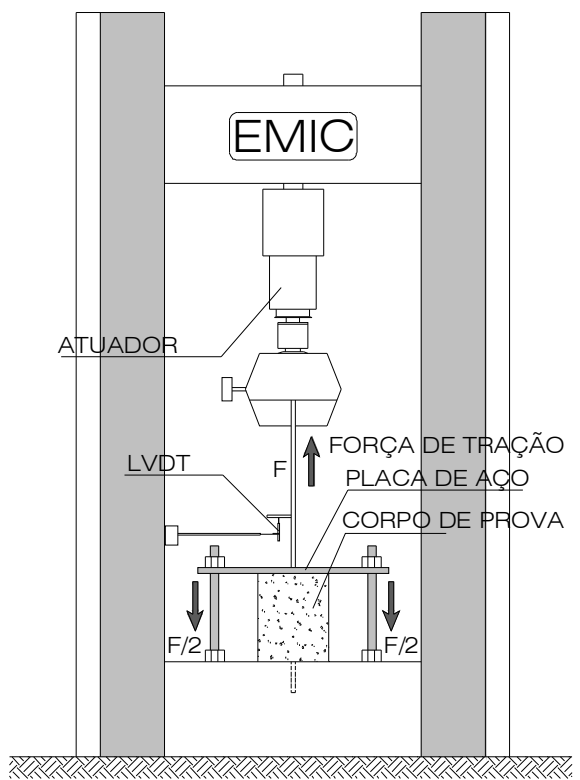

Figura B.6 - Disposição geral do ensaio de arrancamento. entre o concreto e a armadura. Uma vez rompida a ligação aço-concreto, a barra sofre um deslizamento dentro do bloco de microconcreto. O valor lido da resistência máxima permite calcular a tensão de cisalhamento da ligação, denominada tensão de aderência. 


\section{B.3.4.2 Metodologia de ensaio}

Os ensaios de tensão de aderência foram realizados na prensa universal de marca EMIC com célula de carga de $5 \mathrm{kN}$ apresentado na figura B.7(a). Antes de se iniciarem os ensaios foi necessário fabricar um dispositivo que consiste numa placa de aço muito rígida, unida por duas barras grossas à base do pórtico, essas barras foram parafusadas com a finalidade de prender o corpo de prova durante a execução do ensaio. A placa também foi perfurada para permitir o passo do arame.

O ensaio de arracamento inicia-se no momento em que o atuador se desloca para acima e começa a exercer força no arame, pois ele está prendido por uma mordaça do equipamento e embutido na massa do microconcreto. Os dados de carga e deslocamento são salvos de maneira automática pelo computador que está ligado ao equipamento. Sem embargo, as leituras de deslocamento são relativas, porem não muito confiáveis. Por isso, foi necessário a instalação de um LVDT adicional com intuito de obter os valores reais de deslizamento da armadura no microconcreto, conforme mostrado na figura B.6.

No total 3 corpos de prova foram preparados e ensaiados com armadura incorporada de $3,215 \mathrm{~mm}$. A armadura foi posicionada na vertical e parte central da seção transversal, tal como se ilustra na figura B.7(b). Os ensaios de arrancamento foram executados aos 32 dias após moldados os corpos de prova.

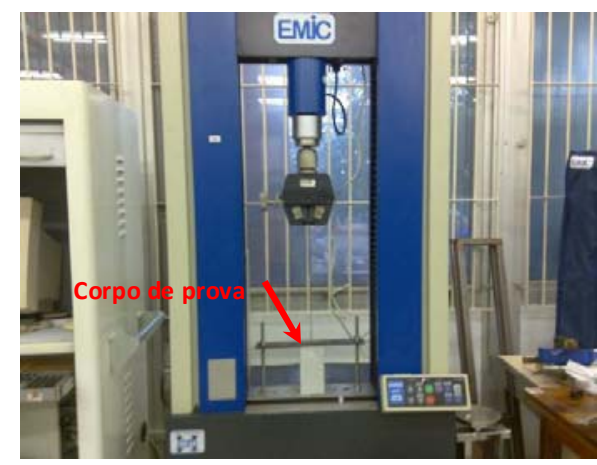

(a)

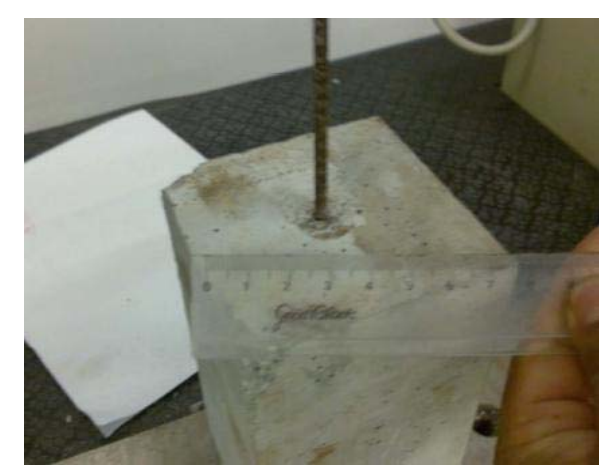

(b)

Figura B.7 - (a) Ensaio de arrancamento aço - microconcreto, (b) Corpo de prova depois do ensaio. 


\section{B.3.4.3 Resultados}

Todos os corpos de prova ensaiados pelo teste de arrancamento apresentaram ruptura do arame antes de alcançar a ruptura por aderência - ou seja o aço não apresentou deslizamento total - resultados similares são apresentados no trabalho de tese de doutorado de Gonzalo Ruiz López (1998).

A metodologia para processar os dados dos ensaios de arrancamento foi adotada segundo a tese acima mencionada, na qual se apresenta 0 desenvolvimento teórico e experimental para calcular a tensão de aderência. De acordo com os testes de aderência com arames, as tensões de aderência açomicroconcreto resistiram até o limite da capacidade mecânica dos arames, assim esses se romperam sem deslizar no extremo.

Neste caso, para o cálculo de $\tau_{c}$ supondo que a tensão de aderência deslizamento num ponto da barra é rígido-plástica, à tensão rígido-plástica lhe corresponde uma função F-u de tipo parabólico expressado pela seguinte equação:

$$
F=\sqrt{2 \cdot A_{s} \cdot E_{s} \cdot \tau_{c} \cdot p \cdot u}
$$

Onde $p$ é o perímetro do arame, As é área da seção transversal do arame, Es o módulo de elasticidade, $u$ o deslizamento do arame em relação ao microconcreto e $F$ é a força atuante no arame.

Por conseguinte, se ajustarmos aos dados experimentais uma curva parabólica, pode-se calcular o valor da tensão de aderência máxima, $\tau_{c}$, que é o único valor não conhecido.

Nos ensaios efetuados existe uma região inicial de acomodamento entre as faces de contato aço-microconcreto, o que faz necessário dar início o ajuste quando a curva experimental F-u começa a mostrar comportamento parabólico.

\section{Ajuste da curva Força - deslocamento e obtenção de $\tau_{c}$.}

O processo de ajuste para a obtenção do $\tau_{c}$ pode ser resumido nos seguintes passos:

- Obtenção da curva Força - deslizamento F-u. 
- Estabelecer o ponto onde a curva começa a seguir uma função parabólica. O valor da força correspondente será denominado $\mathrm{F}_{\mathrm{o}}$.

- Estabelecer o ponto onde a curva começa a sair da função parabólica. O valor da força correspondente será denominado $F_{f}$. Em alguns casos pode ser recomendável retirar o $\mathrm{F}_{\mathrm{f}}$ um pouco antes do último ponto experimental, se por acaso existisse alguma irregularidade no final do ensaio.

- A seguir se determinaram os coeficientes que melhor ajustam a seguinte parábola no intervalo de valores de F, que vão desde Fo até Ff:

$$
u=a+b \cdot F^{2}
$$

A existência do termo independente $a$ da expressão B.3, deve-se a uma zona inicial de acomodação entre as faces de contato aço-microconcreto.

O cálculo de $\tau_{c}$ é determinado usando a seguinte expressão:

$$
\tau_{c}=\frac{1}{2 \cdot \text { As.Es.p.b }}
$$

Onde o $b$ é o valor do coeficiente que melhor ajusta a parábola e o resto de parâmetros já foram esclarecidos acima.

Os parâmetros conhecidos para calcular a tensão de aderência são: As = 8,118mm2, $E s=114770 \mathrm{~N} / \mathrm{mm} 2$ e $p=10,10 \mathrm{~mm}$. Na tabela B.8 apresenta-se os valores da tensão de aderência máxima calculadas para cada corpo de prova.

Tabela B.8 - Valores da tensão de aderência.

\begin{tabular}{ccccccccc}
\hline & $\begin{array}{c}\mathbf{F}_{\mathbf{o}} \\
\mathbf{( N )}\end{array}$ & $\begin{array}{c}\mathbf{u}_{\mathbf{o}} \\
(\mathbf{m m})\end{array}$ & $\begin{array}{c}\mathbf{F}_{\mathbf{f}} \\
\mathbf{( N )}\end{array}$ & $\begin{array}{c}\mathbf{u}_{\mathbf{f}} \\
(\mathbf{m m})\end{array}$ & $\begin{array}{c}\mathbf{a} \\
(\mathbf{m m})\end{array}$ & $\begin{array}{c}\mathbf{b} \\
(\mathbf{m m} / \mathbf{N})\end{array}$ & $\begin{array}{c}\tau_{\mathbf{c}} \\
(\mathbf{M P a})\end{array}$ & $\begin{array}{c}\mathbf{F} \text { máx. } \\
\mathbf{( N )}\end{array}$ \\
\hline EA-CP1 & 1695,62 & 0,0544 & 2715,86 & 0,1262 & 0,008534 & $1,60 \mathrm{E}-08$ & 3,33 & 3174,80 \\
EA-CP2 & 1364,40 & 0,0348 & 2833,80 & 0,1371 & 0,003864 & $1,66 \mathrm{E}-08$ & 3,20 & 3272,00 \\
EA-CP3 & 1447,55 & 0,0466 & 2740,14 & 0,1425 & 0,009476 & $1,77 \mathrm{E}-08$ & 3,00 & 3250,00 \\
\hline & & & & & & Media & $\mathbf{3 , 1 8}$ & $\mathrm{MPa}$ \\
& & & & & & D. Padrão & $\mathbf{0 , 1 7}$ & $\mathrm{MPa}$ \\
\hline
\end{tabular}

As figuras B.8, B.9 e B.10 ilustram gráficos da curva experimental da carga versus deslizamento e a curva de ajuste baseado na função de tensão de aderência-deslizamento rígido plástica para cada corpo de prova. 


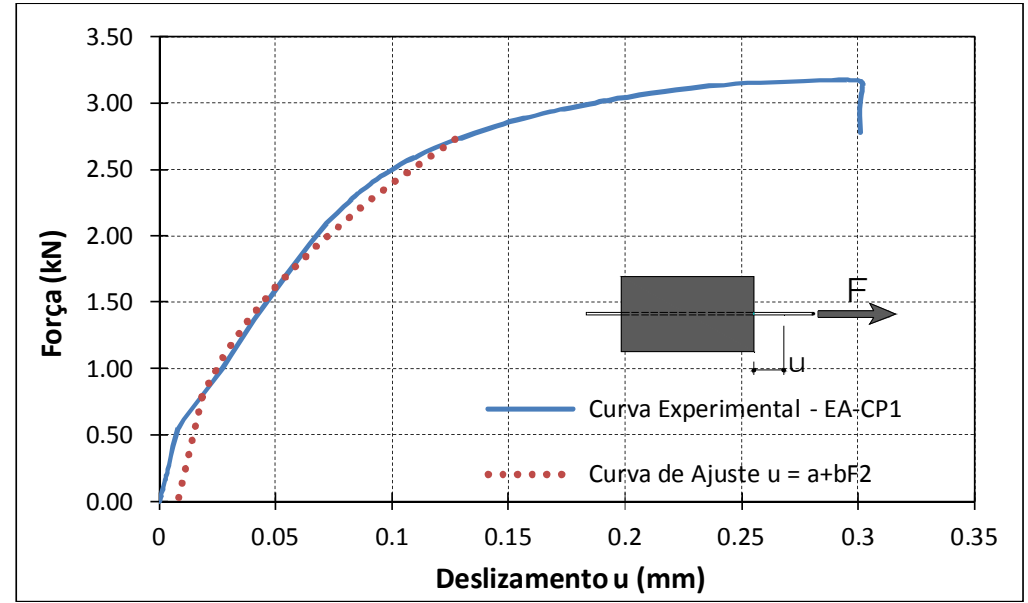

Figura B.8 - Curva força-deslizamento F-u, do ensaio experimental e curva de ajuste baseado na lei tensão de aderência-deslizamento rígido-plástica do EA-CP1.

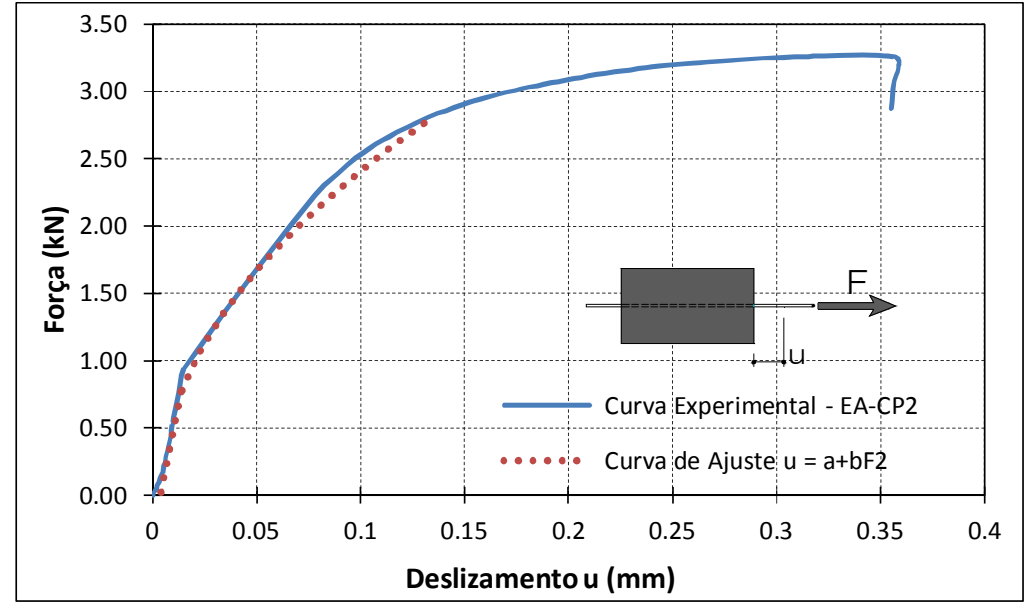

Figura B.9 - Curva força-deslizamento F-u, do ensaio experimental e curva de ajuste baseado na lei tensão de aderência-deslizamento rígido-plástica do EA-CP2.

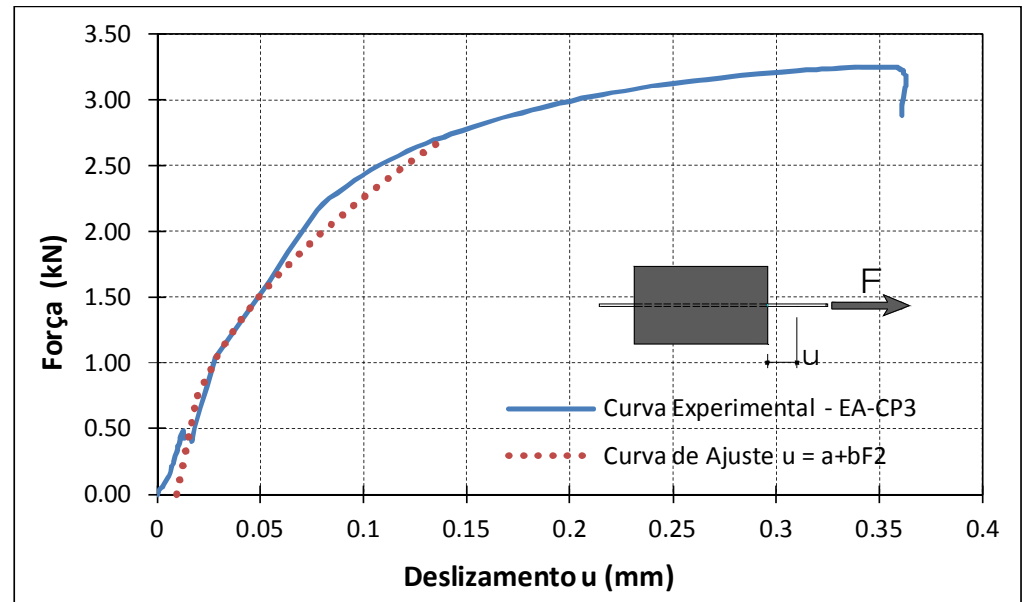

Figura B.10 - Curva força-deslizamento F-u, do ensaio experimental e curva de ajuste baseado na lei tensão de aderência-deslizamento rígido-plástica do EA-CP3. 


\section{B.3.5 Energia de fratura}

\section{B.3.5.1 Definição}

A energia de fratura é um parâmetro do concreto que se define como a energia necessária para criar uma unidade de área "completamente fissurada" (GUINEA, 1990). A consideração da energia de fratura como propriedade do material exige sua independência em relação a qualquer parâmetro geométrico ou procedimento de obtenção, pois numerosos pesquisadores constataram que a energia da fratura obtida segundo as recomendações do RILEM mostra um efeito escala (CIFUENTES, 2009).

Quando a fissura avança no decorrer da área, as tensões e deslocamentos em cada ponto desta área recorrerão completamente à curva de amolecimento, o que requer um fornecimento energético por unidade de área que se denomina energia específica de fratura, $G_{F}$, dada por:

$$
G_{F}=\int_{0}^{\infty} \sigma \cdot d w=\int_{0}^{w c} f(w) \cdot d w
$$

A expressão anterior $\mathrm{G}_{\mathrm{F}}$ pode-se interpretar como a área embaixo da curva de amolecimento.

\section{B.3.5.2 Metodologia de ensaio}

Nesta pesquisa a energia de fratura foi determinada pelo método do trabalho de fratura (work-of-fracture method - WFM), proposto pelo comitê técnico RILEM 50-FMC (1985) e esta baseada no cálculo da área sob a curva força deslocamento vertical obtida do ensaio à flexão em três pontos. A energia de fratura foi determinada pela seguinte expressão:

$$
G_{f}=\frac{A_{l}+M g \delta_{o}}{b\left(d-a_{o}\right)}
$$

Onde $A_{l}$ é a área sob o gráfico delimitado pela reta horizontal que corta com o eixo vertical em 0,10 da força máxima, $\delta_{0}$ é a deflexão correspondente de ruptura, $M$ é a massa total da viga entre os apoios, e $g$ a aceleração da gravidade.

No entanto, a energia calculada segundo as recomendações do RILEM não representa a energia de fratura real do concreto, pois tem certa dependência de 
parâmetros. Motivo pela qual, a energia de fratura real do concreto foi calculada usando o método simplificado proposto por Karihaloo et al (2003), o qual se baseia no modelo de fratura local desenvolvido por Hu et al (2000) e consiste na obtenção da energia de fratura RILEM $\left(G_{f}\right)$ para profundidades relativas de entalhe diferente. Com os valores de $\mathrm{G}_{f}$ obtidos para cada profundidade de entalhe e com a aplicação da equação B.7 se obtém o valor da energia de fratura real $\mathrm{G}_{\mathrm{F}}$ independente do tamanho da zona do ligamento.

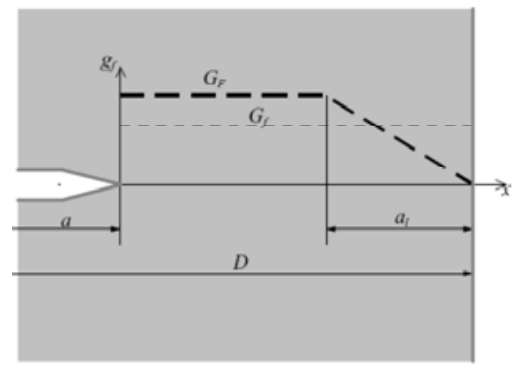

$$
\begin{gathered}
g_{f}(x)= \begin{cases}G_{F} & x<D-a-a_{l} \\
G_{F}\left[1-\frac{x-\left(D-a-a_{l}\right)}{a_{l}}\right] & x>D-a-a_{l}\end{cases} \\
G_{f}(a / D)=\frac{\int_{0}^{D-a} g_{f}(x) d x}{D-a}
\end{gathered}
$$

Onde $g_{f}$ é o valor da energia de fratura local, D é a altura da viga, $a$ é a profundidade inicial do entalhe e $a_{l}$ a zona de transição.

No total foram ensaiados seis corpos de prova de dois tamanhos diferentes, entalhadas na seção central até a metade da altura. O vão de apoio tinha um comprimento de quatro vezes da altura tal como se ilustra na figura B.11. Durante os ensaios não se conseguiu obter os dados experimentais de dois corpos de prova, devido à perdida de controle do servoatuador encarregado de aplicar a carga.
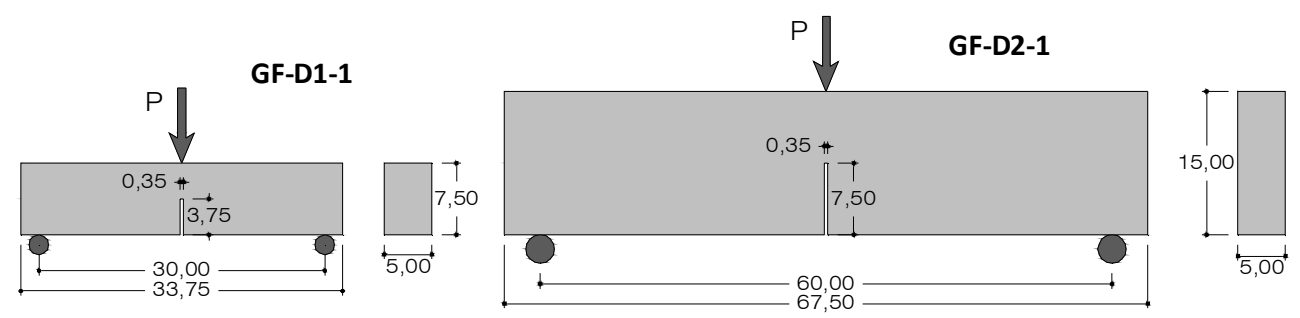

Figura B.11 - Vigas em massa para medir a energia de fratura.

A figura B.12 ilustra o dispositivo experimental usado na execução dos ensaios, onde o deslocamento e a abertura da fissura foram medidas pelos dois 
LVDT'S instalados. O procedimento de execução dos ensaios foram os mesmos seguidos nos ensaios das vigas levemente armadas.

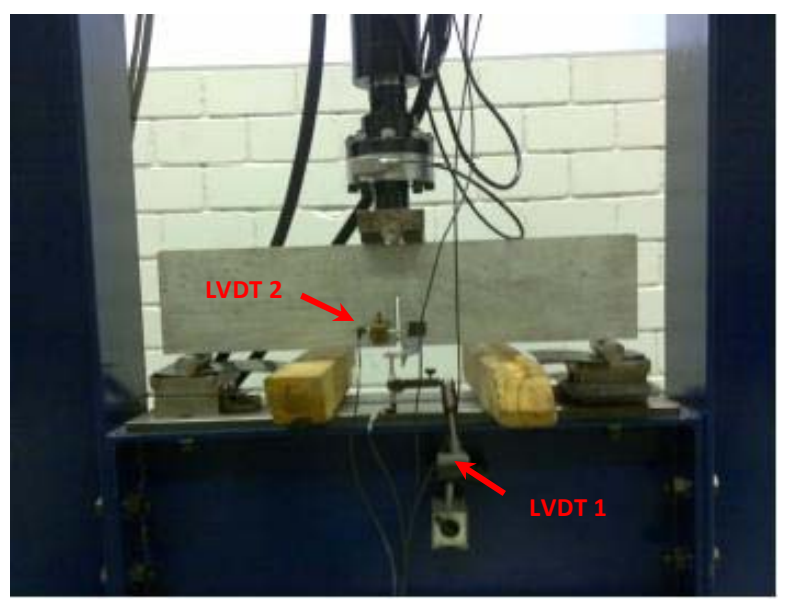

Figura B.12 - Ensaio de flexão em três pontos em vigas entalhadas para determinar a energia de fratura, o LVDT 1 permitiu medir o deslocamento da viga e o LVTD 2 a abertura da fissura.

Geralmente as curvas de carga-deslocamento, ao começo do ensaio se apresentam não lineares, este devido ao acomodamento ou incrustação dos apoios e do ponto de aplicação de carga no concreto e implica um consumo de energia por micro-fissuração local que não foi considerado no cálculo do valor de $\mathrm{G}_{\mathrm{f}}$.

Esta zona inicial se caracteriza por ser uma curva com inclinação crescente que se estabiliza numa linha reta ao crescer a carga até o momento da ruptura. Este tipo de ensaios se caracteriza por apresentar ruptura frágil. Na figura B.13 apresenta-se a evolução da fissura durante a o ensaio de flexão em três pontos.
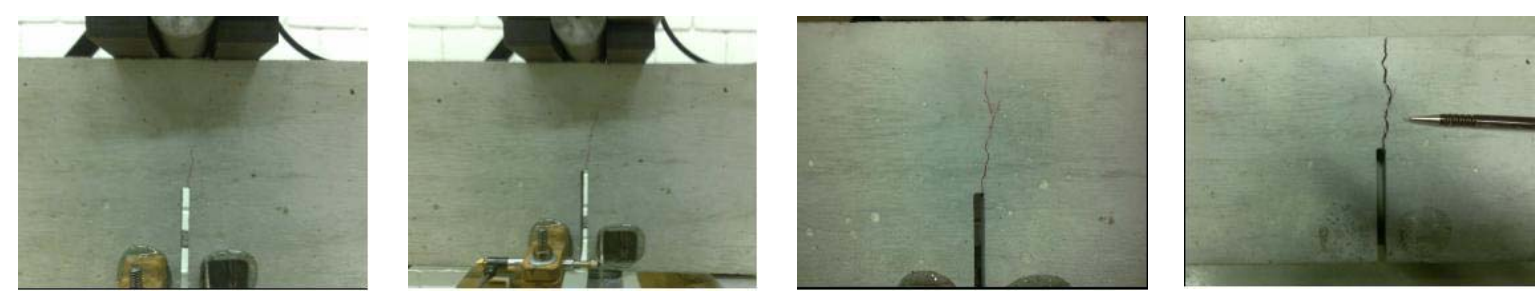

Figura B.13 - Propagação de fissura acima do entalhe antes durante o ensaio.

\section{B.3.5.3 Resultados}

A energia de fratura RILEM foi calculada usando a equação B.6 com os dados experimentais apresentados na figura B.14 e B.15. Na tabela B.9 apresentase um resumo dos valores de energia de fratura RILEM calculados para cada corpo 
de prova, onde se observa que os resultados obtidos mostram uma dependência do tamanho da zona do ligamento.

Tabela B.9 - Valores da energia de fratura RILEM.

\begin{tabular}{cccccccc}
\hline $\begin{array}{c}\text { Corpo de } \\
\text { prova }\end{array}$ & $\begin{array}{c}\mathbf{A}_{\mathbf{l}} \\
(\mathbf{N} . \mathbf{m m})\end{array}$ & $\begin{array}{c}\mathbf{M g} \\
\mathbf{( N )}\end{array}$ & $\begin{array}{c}\delta_{\mathbf{o}} \\
(\mathbf{m m})\end{array}$ & $\begin{array}{c}\mathbf{b}(\mathbf{D}-\mathbf{a}) \\
\left(\mathbf{m m}^{2}\right)\end{array}$ & $\begin{array}{c}\mathbf{G}_{\mathbf{f}} \\
(\mathbf{N} / \mathbf{m})\end{array}$ & Média & $\begin{array}{c}\text { Desvio } \\
\text { Padrão }\end{array}$ \\
\hline GF-D1-1 & 131,10 & 29,62 & 0,071 & 1875 & 71,04 & & \\
GF-D1-2 & 112,90 & 30,07 & 0,066 & 1875 & 61,27 & 66,16 & 6,91 \\
GF-D1-3 & --- & --- & --- & --- & --- & & \\
\hline GF-D2-1 & 255,00 & 118,46 & 0,131 & 3750 & 72,13 & & \\
GF-D2-2 & --- & --- & --- & --- & --- & 69,29 & 4,01 \\
GF-D2-3 & 234,00 & 119,68 & 0,127 & 3750 & 66,45 & & \\
\hline
\end{tabular}

Para calcular a energia de fratura real foi usada a equação B.8, com a qual se montou um sistema de duas equações cujas incógnitas foram o $G_{F}$ e $a_{l}$. Por exemplo, a primeira equação foi elaborada com dados do corpo de prova GF-D1-1 $\mathrm{G}_{\mathrm{f}(0,5)}=71,04 \mathrm{~N} / \mathrm{m}$ e a segunda equação com os dados do corpo de prova GF-D2-1 $\mathrm{G}_{\mathrm{f}(0,5)}=72,13 \mathrm{~N} / \mathrm{m}$.

$$
G_{f}(\alpha)= \begin{cases}G_{F}\left(1-\frac{a_{l} / D}{2 .(1-\alpha)}\right) & 1-\alpha<a_{l} / D \\ G_{F} \frac{1-\alpha}{2 \cdot a_{l} / D} & 1-\alpha x>a_{l} / D\end{cases}
$$

Resolvendo o sistema de equações se obteve o valor de $G_{F}=73,22 \mathrm{~N} / \mathrm{m}$ e $a_{l}=2,233 \mathrm{~mm}$. Da mesma forma foram calculados os outros dois corpos de prova, onde se obteve $G_{\mathrm{F}}=71,63 \mathrm{~N} / \mathrm{m}$ e $a_{l}=10,847 \mathrm{~mm}$. A energia de fratura final é calculada como média das duas energias obtidas anteriormente resultando um valor de $\mathbf{G}_{\mathrm{F}}=\mathbf{7 2 , 4 3} \mathrm{N} / \mathrm{m}$. Assim, os valores calculados de $\mathrm{G}_{\mathrm{F}}$ podem-se considerar como o valor da energia de fratura real independente do tamanho.

As figuras B.14 e B.15 ilustram gráficos da curva experimental de carga versus deslocamento vertical e a carga versus abertura de fissura (CMOD) para cada corpo de prova. 

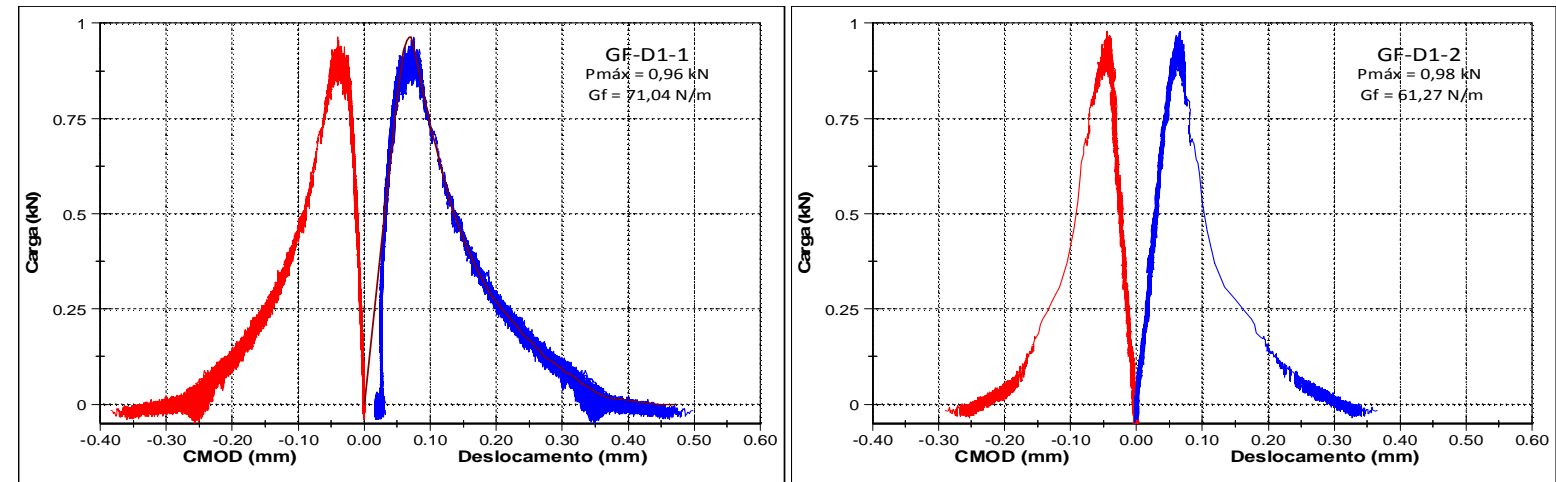

Figura B.14 - Curvas de carga-deslocamento e carga-abertura de fissura (CMOD) dos corpos de prova de $5 \times 7,5 \times 33,75 \mathrm{~cm}$.
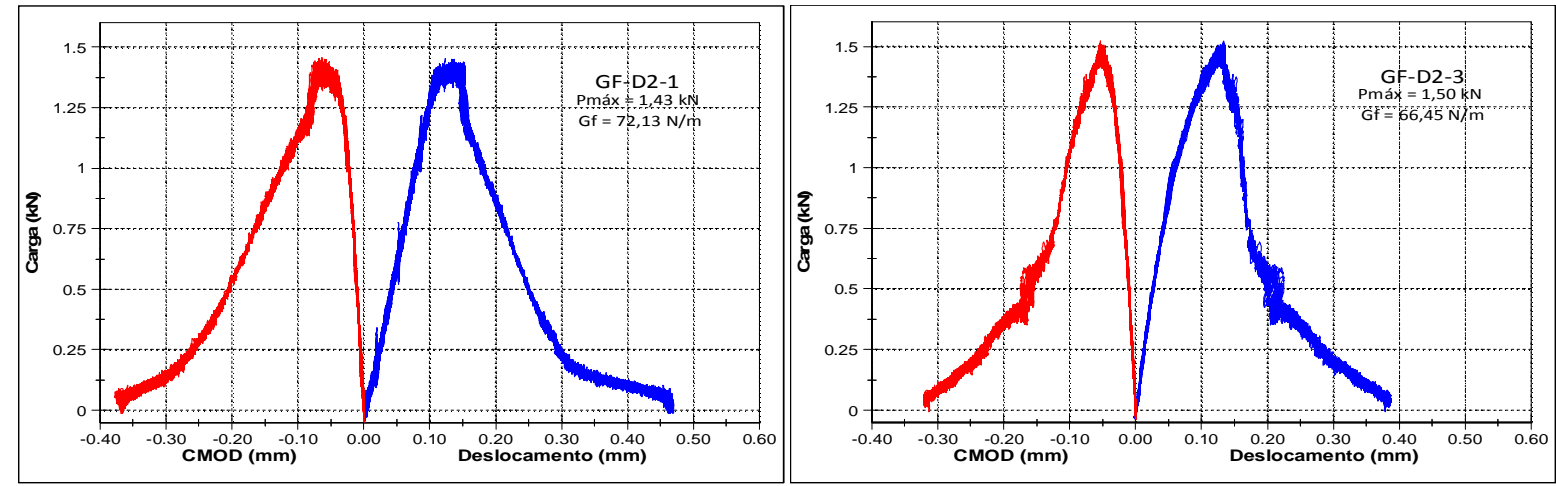

Figura B.15 - Curvas de carga-deslocamento e carga-abertura de fissura (CMOD) dos corpos de prova de $5 \times 15 \times 67,5 \mathrm{~cm}$.

\section{B.4 Propriedades mecânicas do aço}

$\mathrm{Na}$ armação dos modelos foram utilizadas duas categorias de aços, CA-50 e arame recozido. As propriedades mecânicas do aço CA-50 foram adotadas do fabricante Gerdau e são apresentadas na tabela B.8.

Tabela B.10 - Propriedades mecânicas do aço CA-50.

\begin{tabular}{ccc}
\hline $\begin{array}{c}\text { Módulo de } \\
\text { Elasticidade } \\
\text { (GPa) }\end{array}$ & $\begin{array}{c}\text { Tensão máx. } \\
\text { de } \\
\text { Resistência fu } \\
\text { (MPa) }\end{array}$ & $\begin{array}{c}\text { Tensão de } \\
\text { Escoamento fy } \\
\text { (MPa) }\end{array}$ \\
\hline 210,00 & 550,00 & 500,00 \\
\hline
\end{tabular}

O arame recozido usado nos modelos físicos foi ensaiado à tração com deformação controlada segundo a norma ASTM E8M:2000 e a norma NBR 6207:1982. O interesse de caracterizá-lo foi para conhecer as propriedades 
mecânicas do arame com as nervuras impressas na superfície mediante processo mecânico. Na figura B.7 ilustra o ensaio de tração.

As características desses arames encontram-se na tabela B.8

Tabela B.11 - Propriedades mecânicas do arame recozido com nervura.

\begin{tabular}{cccc}
\hline $\begin{array}{c}\text { Corpo de } \\
\text { Prova }\end{array}$ & $\begin{array}{c}\text { Módulo de } \\
\text { Elasticidade } \\
\text { (GPa) }\end{array}$ & $\begin{array}{c}\text { Tensão máx. de } \\
\text { Resistência fu } \\
\text { (MPa) }\end{array}$ & $\begin{array}{c}\text { Tensão de } \\
\text { Escoamento fy } \\
\text { (MPa) }\end{array}$ \\
\hline CP1 & 119,05 & 416,17 & 353,12 \\
CP2 & 113,64 & 394,93 & 345,30 \\
CP3 & 111,61 & 392,24 & 340,76 \\
\hline Media & 114,77 & $\mathbf{4 0 1 , 1 1}$ & 346,39 \\
D. Padrão & 3,85 & 13,11 & 6,25 \\
\hline
\end{tabular}

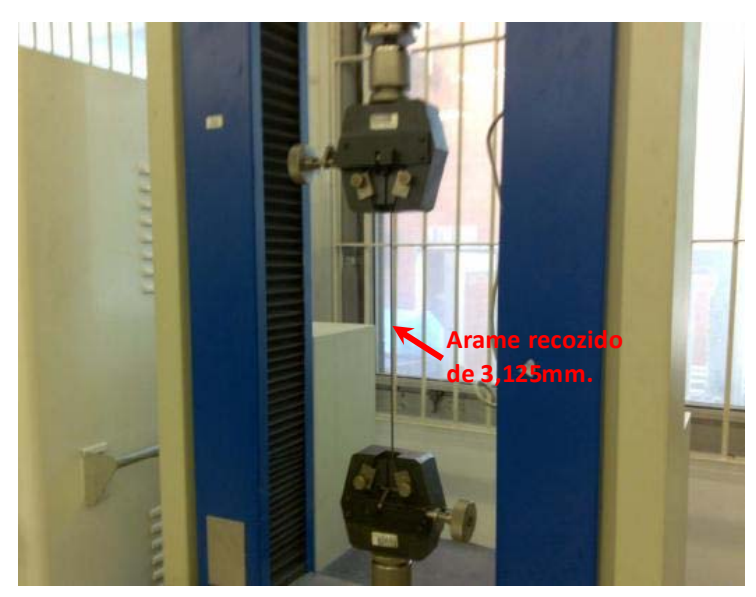

Figura B.16 - Ensaio de tração na prensa universal EMIC.

Os diagramas de tensão - deformação do aço com diâmetro de 3,215mm estão ilustrados na figura B.8, na qual se percebe que ao começo do ensaio existe um leve acomodamento, pelo fato do corpo de prova não estar prendido adequadamente à prensa. 


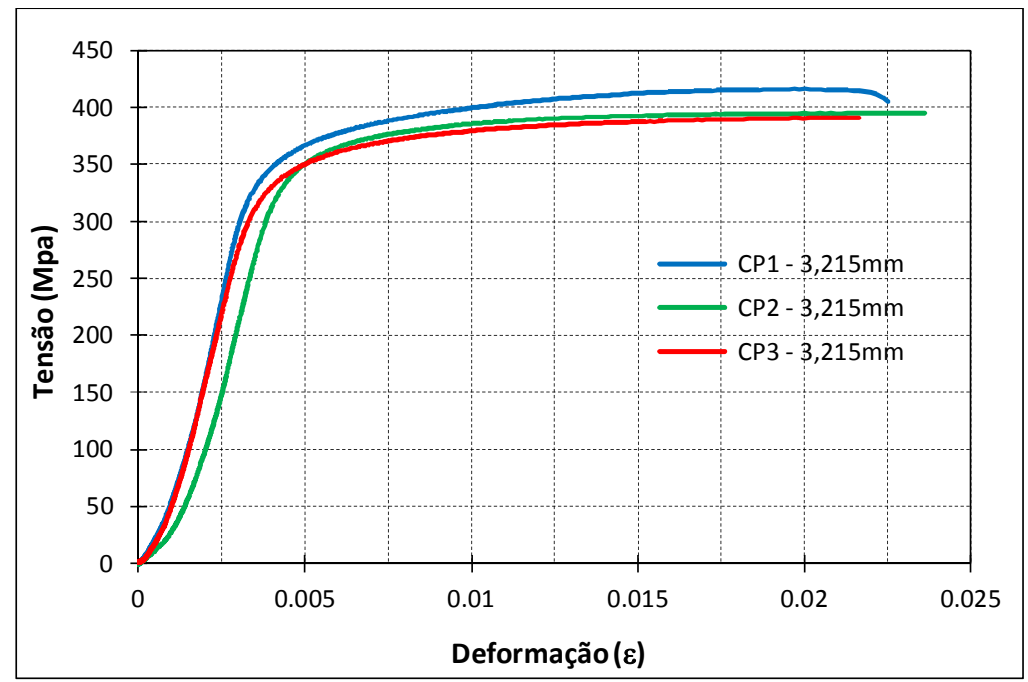

Figura B.17 - Gráfico de tensão - deformação das barras de aço com diâmetro de 3,215mm. 
Anexo

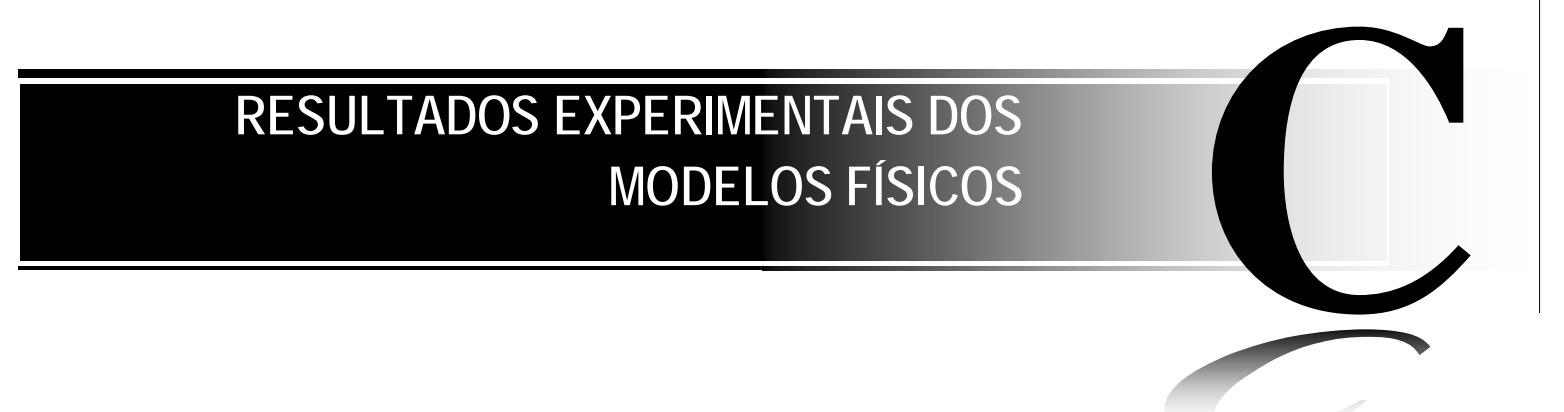

\section{C.1 Introdução}

Este anexo apresenta em forma detalhada alguns resultados experimentais obtidos durante a execução dos ensaios nos modelos reduzidos.

\section{C.2 Dados experimentais do modelo reduzido da ponte de rio Suaçui.}

Nas figuras C.1 a C.4 são mostradas as deformações medidas durante a execução do ensaio do modelo reduzido da ponte do rio Suaçui para cada elemento estrutural do estudo do caso III.

\section{C.3 Dados experimentais das vigas levemente armadas}

Nas figuras C.5 a C.12 são mostradas as curvas de carga-deslocamento das vigas levemente armadas ensaiadas até a ruptura. 


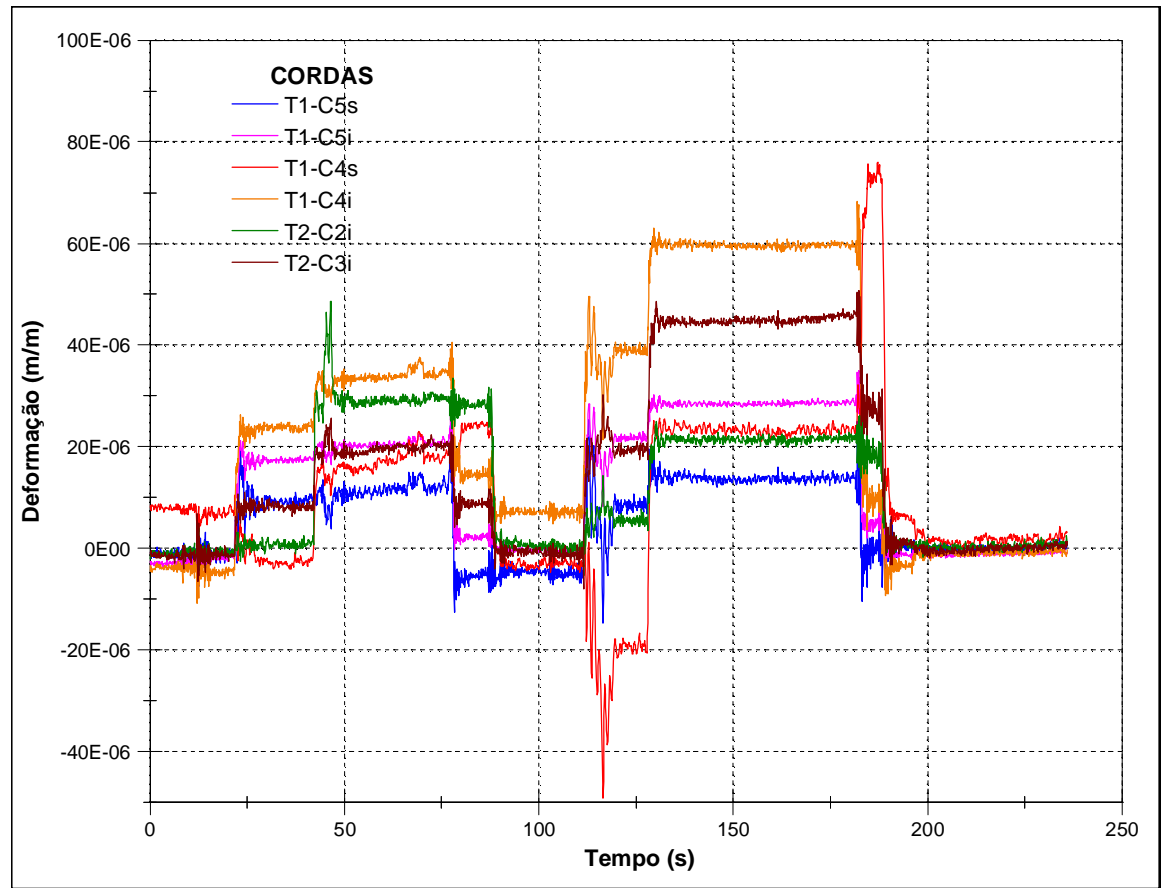

Figura C.1 - Deformações medidas nas cordas do modelo reduzido.

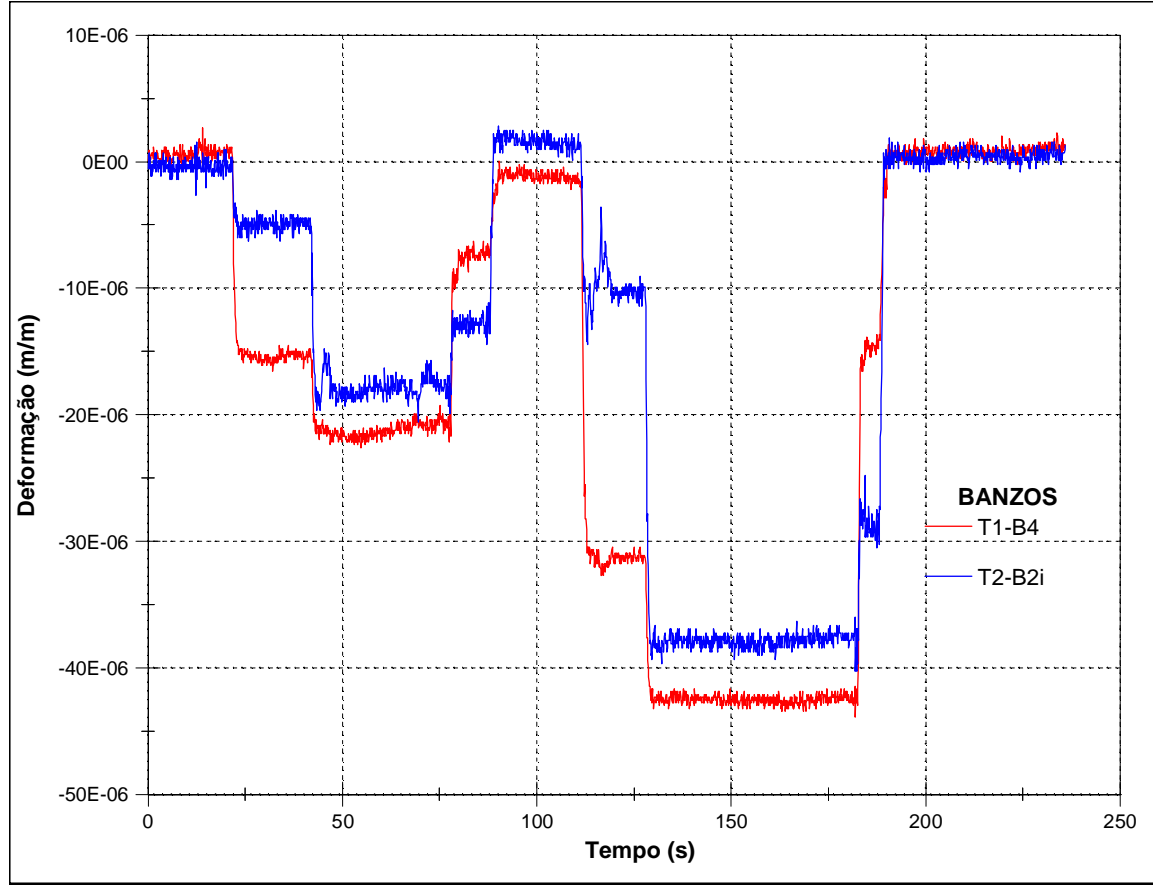

Figura C.2 - Deformações medidas nos banzos do modelo reduzido. 


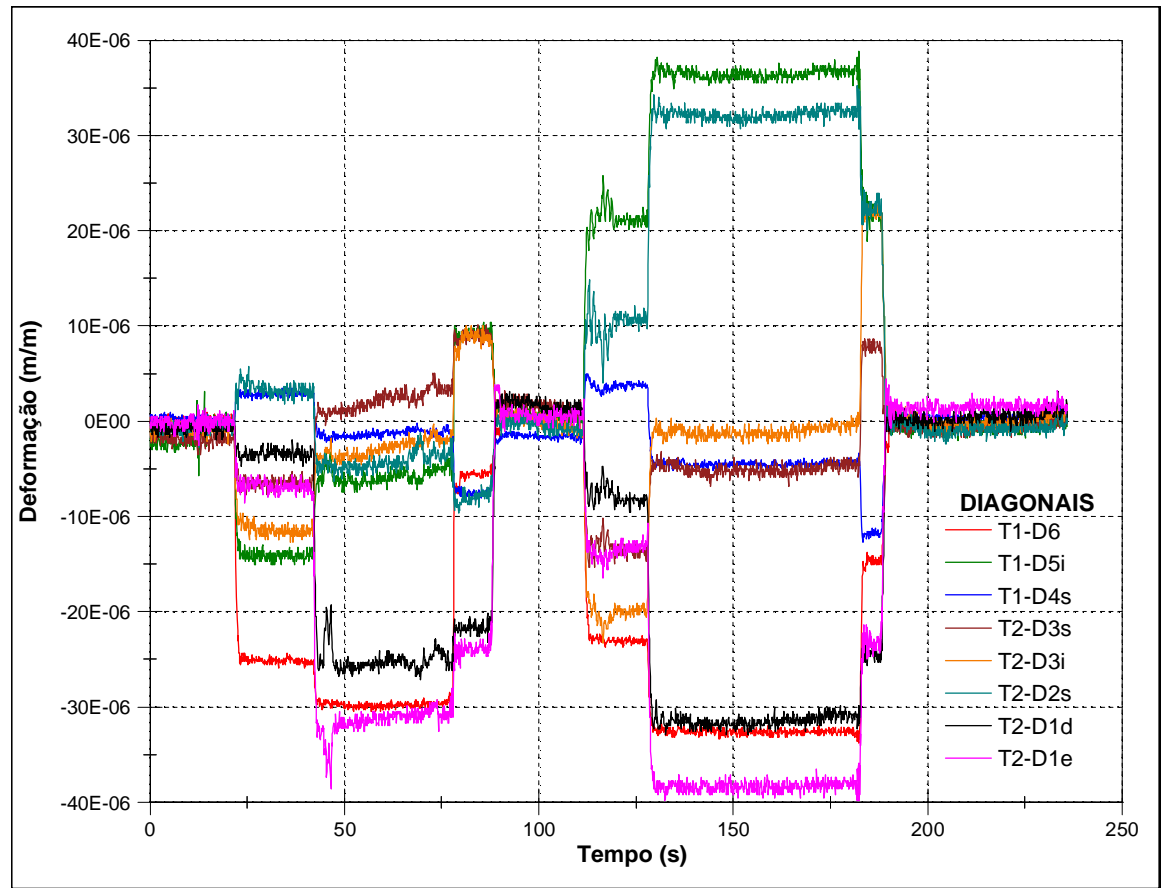

Figura C.3 - Deformações medidas nas diagonais do modelo reduzido.

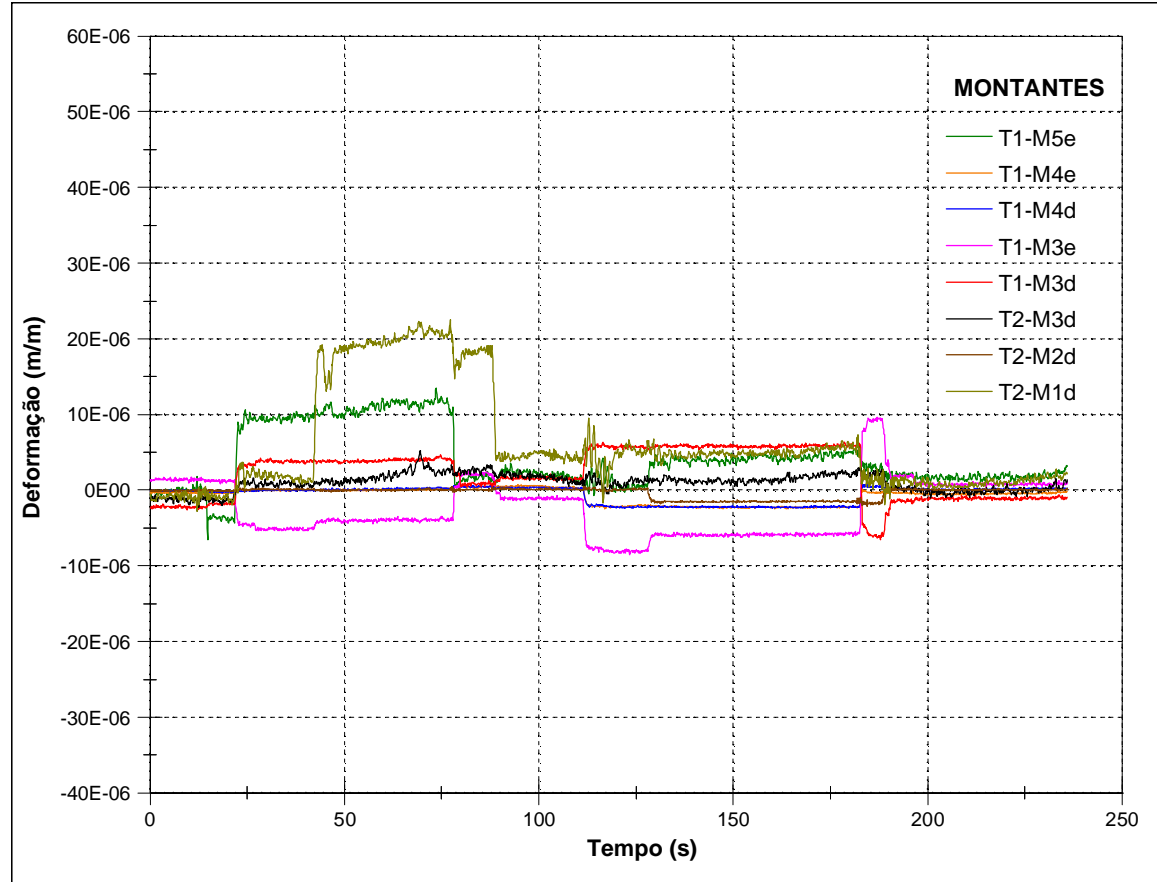

Figura C.4 - Deformações medidas nas montantes do modelo reduzido. 


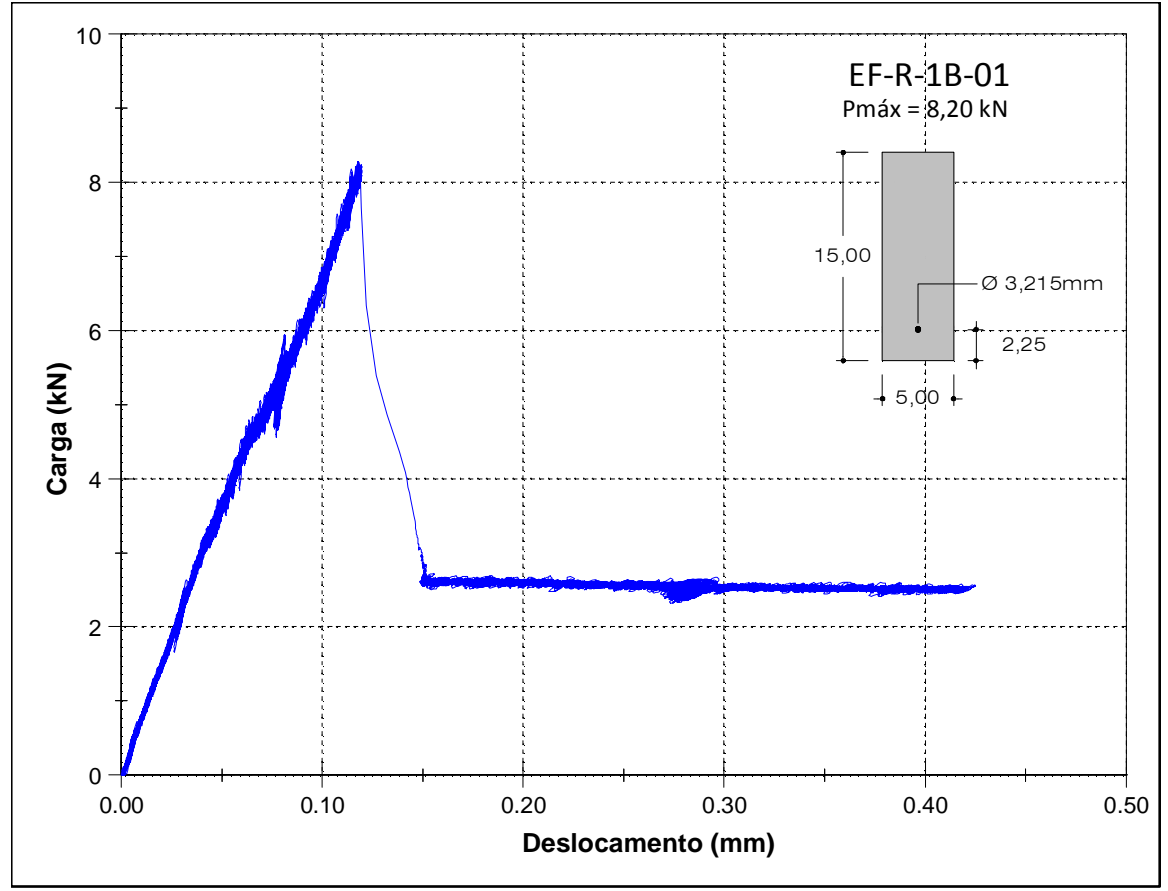

Figura C.5 - Curva carga-deslocamento da viga EF-R-1B-01.

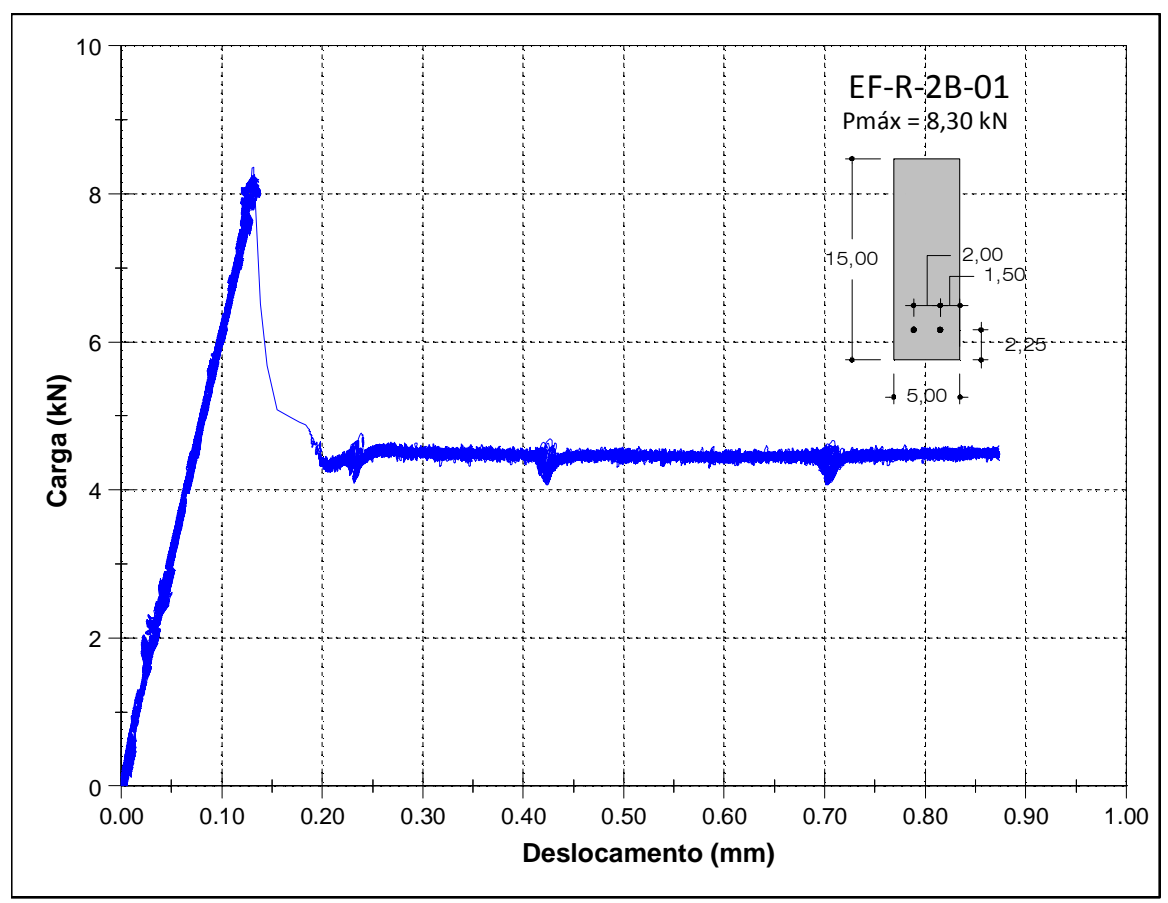

Figura C.6 - Curva carga-deslocamento da viga EF-R-2B-01. 


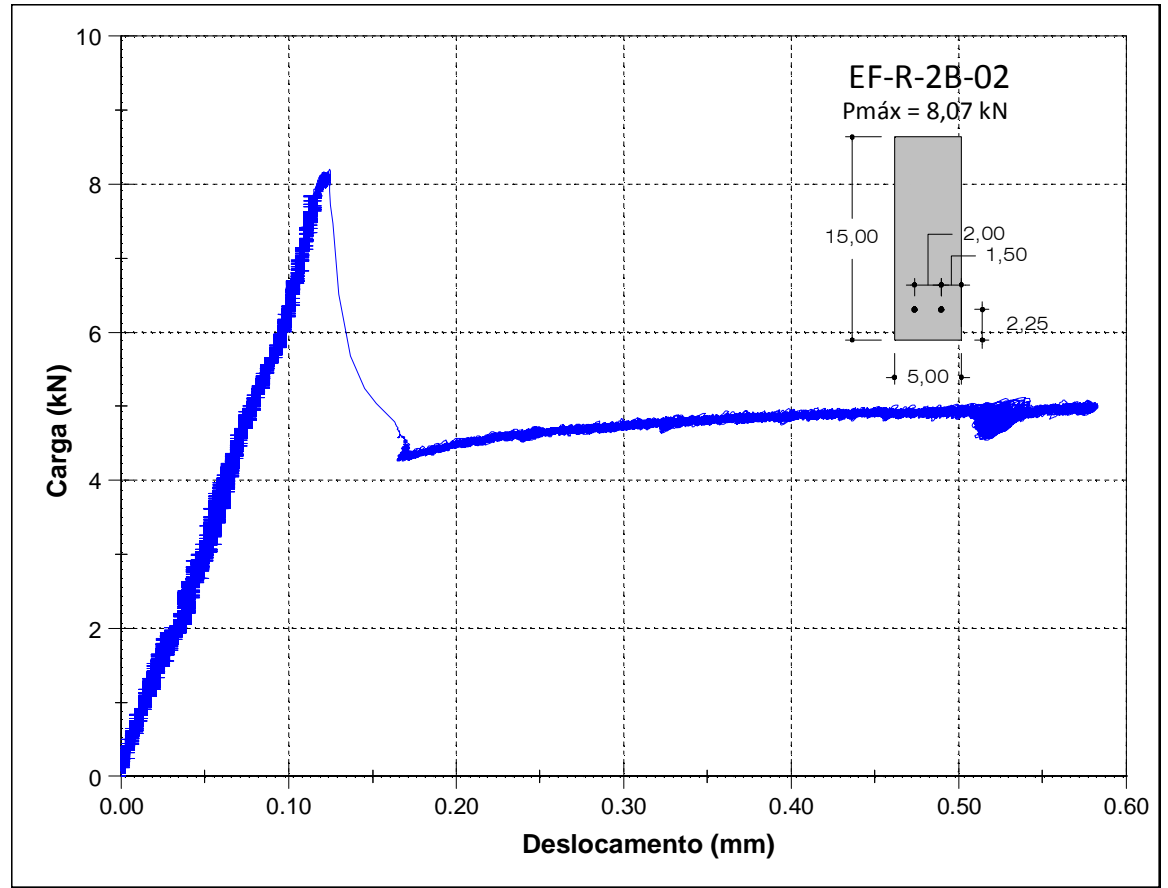

Figura C.7 - Curva carga-deslocamento da viga EF-R-2B-02

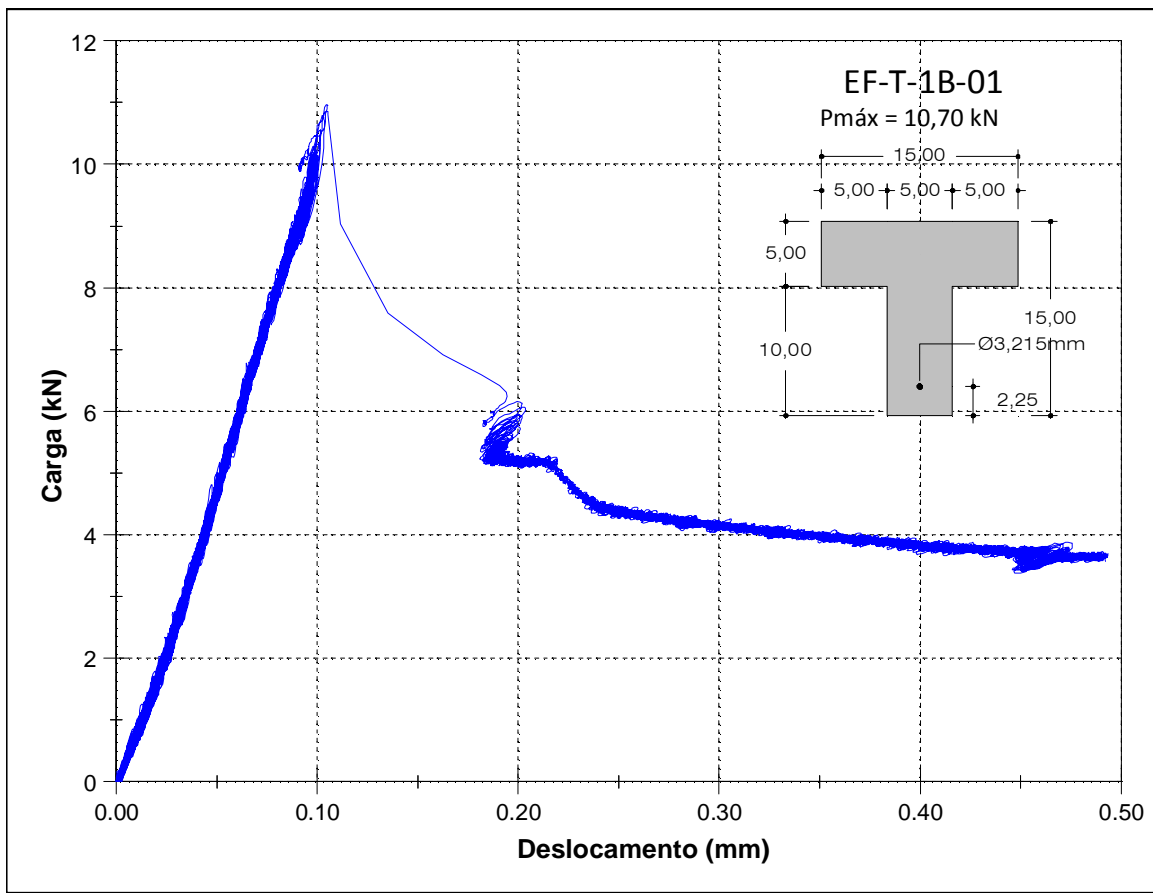

Figura C.8 - Curva carga-deslocamento da viga EF-T-1B-01 


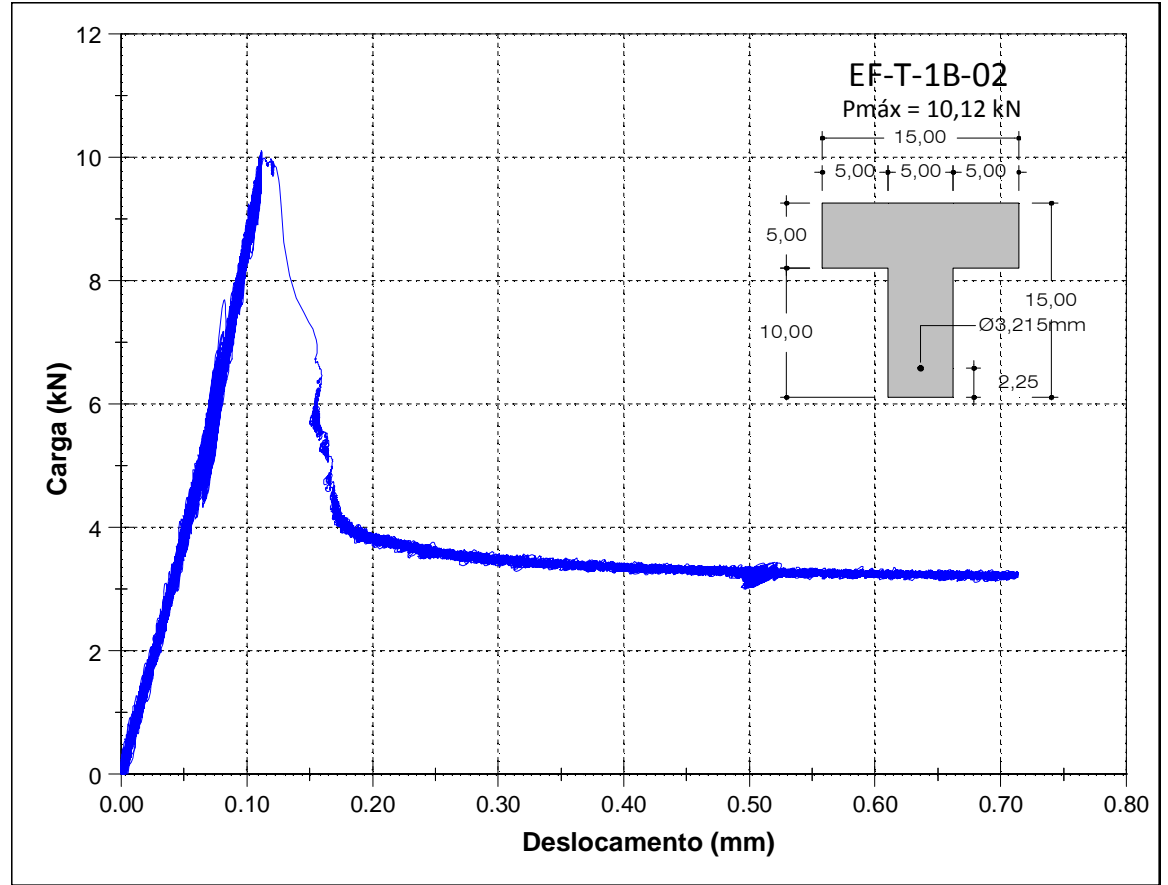

Figura C.9 - Curva carga-deslocamento da viga EF-T-1B-02

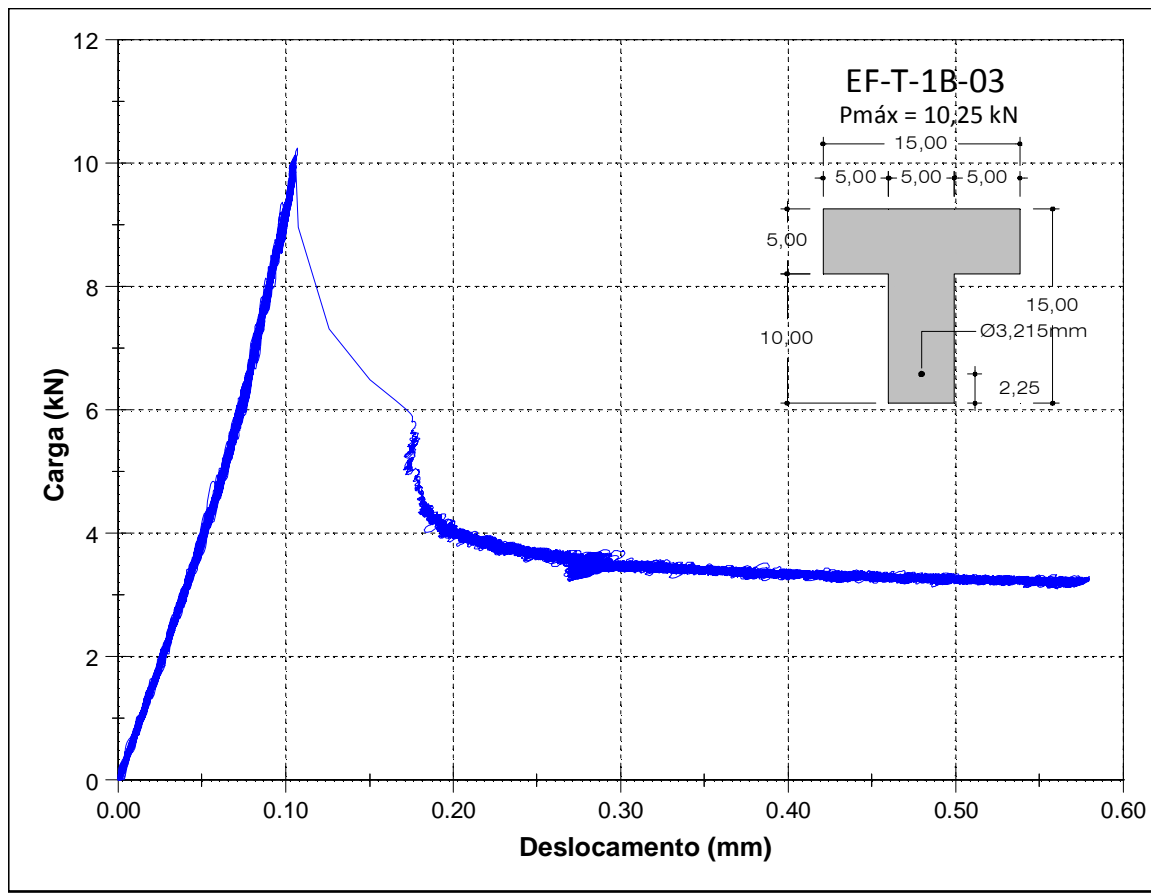

Figura C.10 - Curva carga-deslocamento da viga EF-T-1B-03. 


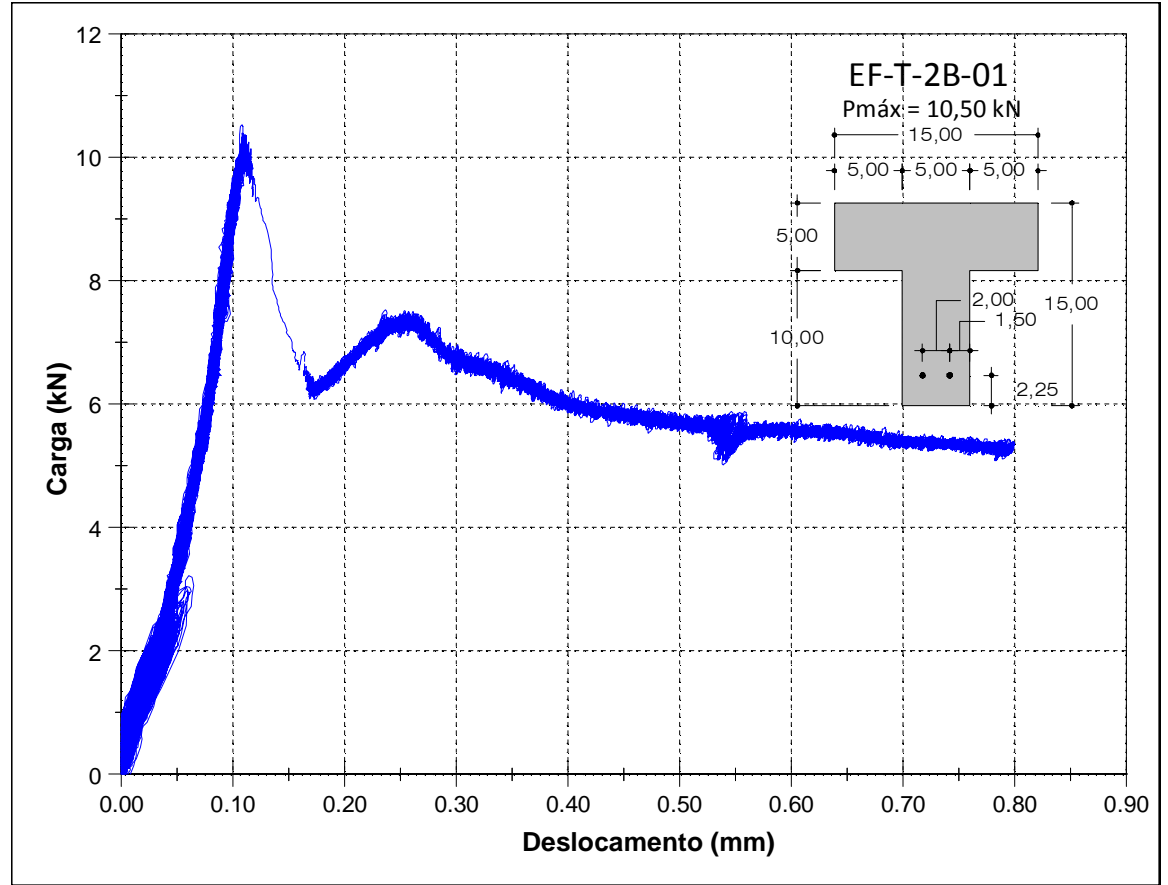

Figura C.11 - Curva carga-deslocamento da viga EF-T-2B-01.

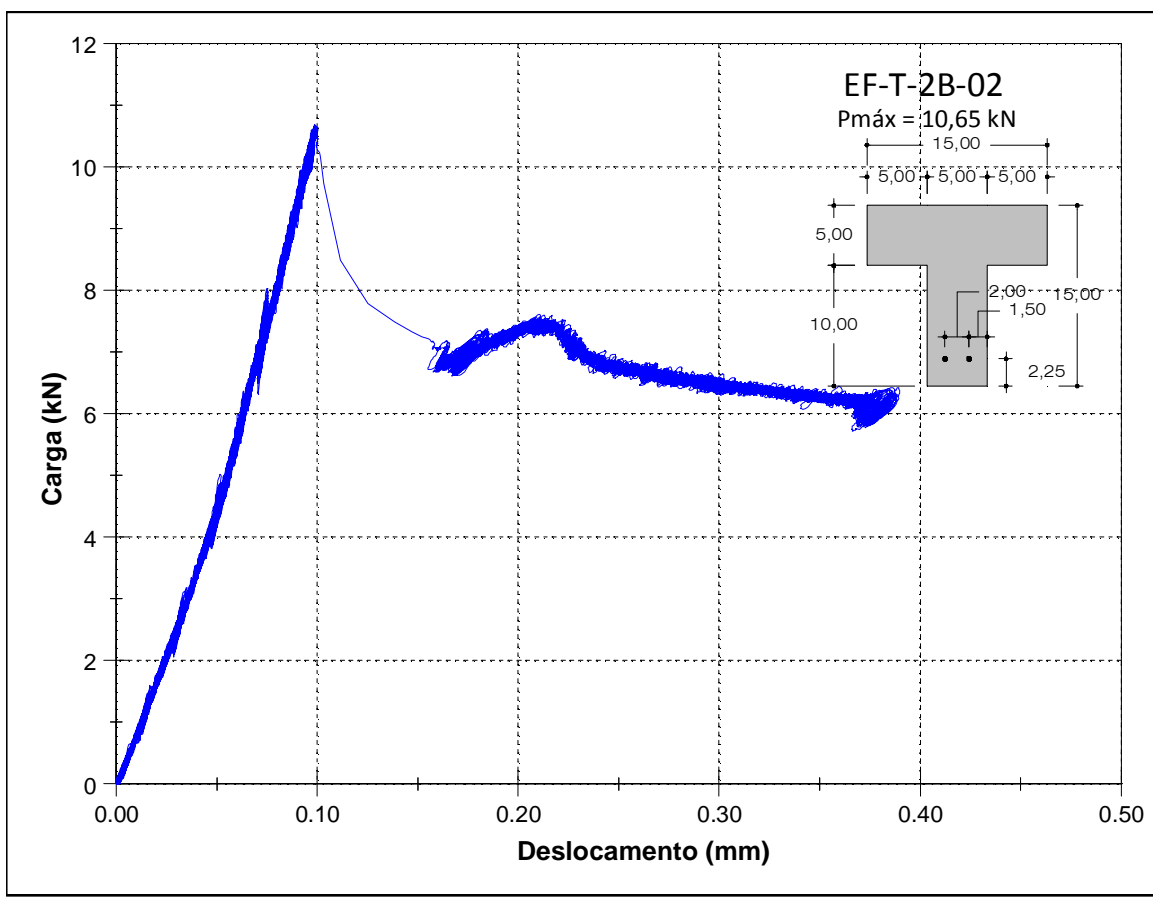

Figura C.12 - Curva carga-deslocamento da viga EF-T-2B-02. 
238

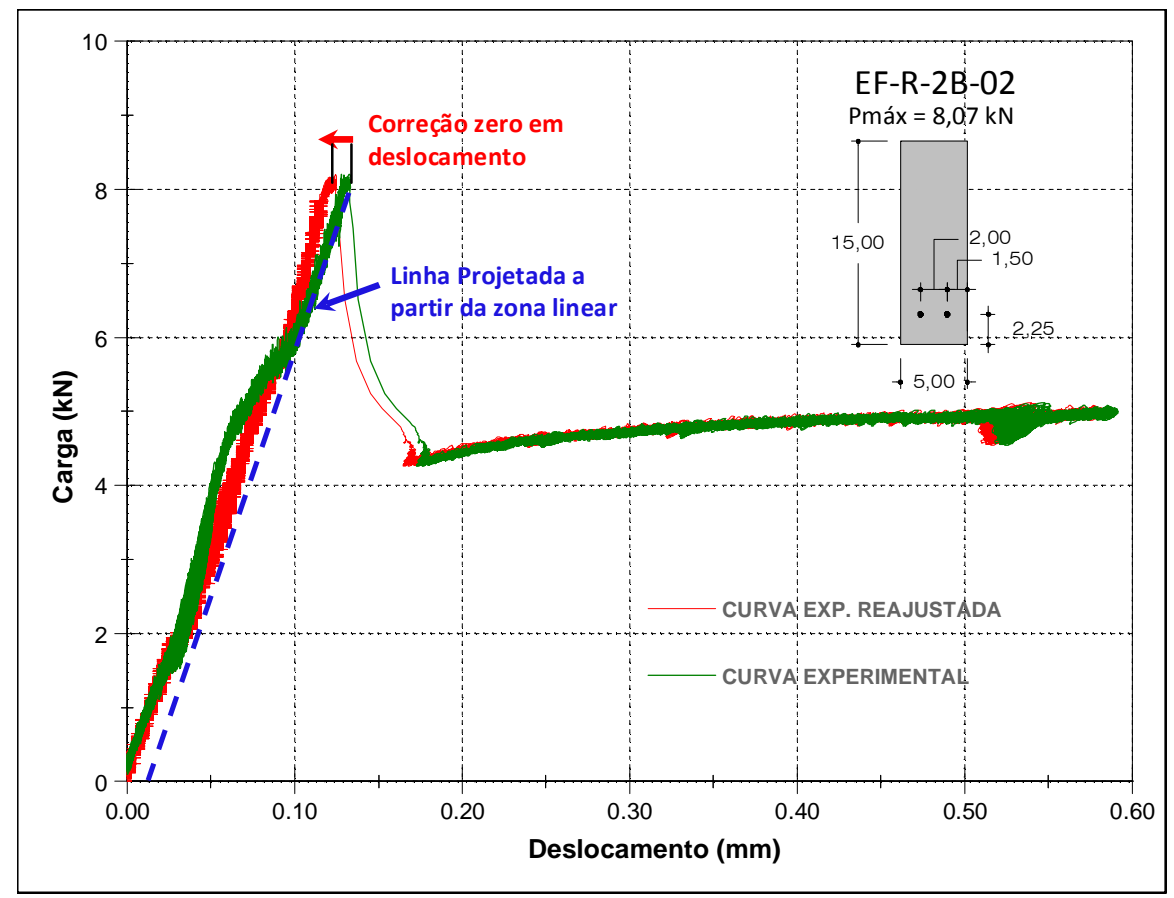

Figura C.13 - Exemplo de reajuste da curva carga-deslocamento da viga EF-R-2B-02. 


\section{Anexo}

\section{DIMENSIONAMENIODA PONIE DE MCROCONCRETO}

Neste anexo apresenta-se o dimensionamento do modelo reduzido da ponte de microconcreto, segundo a Norma NBR 6118:2003.

Forças solicitantes

\begin{tabular}{|c|c|c|}
\hline$M d=$ & 405,0 KN.cm & (Momento máximo) \\
\hline $\mathrm{Vd}=$ & $11,25 \mathrm{KN}$ & (Cortante máximo) \\
\hline
\end{tabular}

Geometria de uma seção geral (trapezoidal, tipo T e retangular)

$\begin{aligned} \mathrm{bf} & = & 15,00 \mathrm{~cm} \\ \mathrm{hf} & = & 2,50 \mathrm{~cm} \\ \mathrm{bw} & = & 5,00 \mathrm{~cm} \\ \mathrm{~h} & = & 8,50 \mathrm{~cm} \\ \mathrm{tw} & = & 2,00 \mathrm{~cm} \\ \mathrm{hw} & = & 6,00 \mathrm{~cm} \\ \mathrm{r} & = & 1,50 \mathrm{~cm} \\ \mathrm{~d} & = & 7,00 \mathrm{~cm} \\ \mathrm{~d}^{\prime} & = & 1,50 \mathrm{~cm}\end{aligned}$

(Largura da seção na parte superior)

(Altura da seção na parte superior.)

(Largura da alma da viga)

(Altura total da seção)

(Distância da parte inclinada)

(Altura da seção variável)

(Cobrimento)

(Altura efetiva da seção)

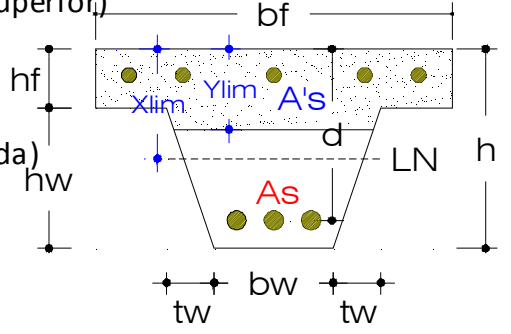

(Distância ao CG da armadura em compressão) 


\section{Propriedades Mecânicas do material}

\section{Concreto armado}

\begin{tabular}{|c|c|c|}
\hline $\mathrm{fck}=$ & 35,30 Мpa & (Resistência à compressão do concreto) \\
\hline$\gamma c=$ & 1,40 & (Coeficiente da resistência do concreto) \\
\hline $\mathrm{fcd}=$ & $2,52 \mathrm{KN} / \mathrm{cm} 2$ & (Resistência de cálculo do concreto) \\
\hline$\varepsilon c=$ & 0,0035 & (Deformação máxima do concreto) \\
\hline
\end{tabular}

dmáx,agr $=\quad 4,80 \mathrm{~mm}$

Aço de reforço longitudinal

fyk $=500,00 \mathrm{Mpa}$

$\gamma s=\quad 1,15$

(Tamanho de agregado máximo).

fyd $=\quad 43,48 \mathrm{KN} / \mathrm{cm} 2$ (Resistência de cálculo do aço)

$\begin{array}{rlr}\varepsilon s= & 0,0021 & (\text { CA-50 }=0,207 \% \text { e CA-60 }=0,248) \\ \text { Ecs }= & 2,10 E+11 \mathrm{Mpa} & \text { (Módulo de elasticidade do aço) }\end{array}$

$\rho \min =0,0015 \quad$ (Quantia mínima)

\section{Aço de reforço transversal}

\begin{tabular}{|c|c|c|}
\hline$\phi=$ & $3,22 \mathrm{~mm}$ & (Diâmetro do ferro do es tribo) \\
\hline$\alpha=$ & $90,00^{\circ}$ & (Ângulo de inclinação do estribo) \\
\hline fyk = & 346,39 Мра & (Resist. ao escoamento do aço) \\
\hline$\gamma s=$ & 1,15 & (Coeficiente da resistência aço) \\
\hline fyd $=$ & $30,12 \mathrm{KN} / \mathrm{cm} 2$ & (Resistência de cálculo do aço) \\
\hline
\end{tabular}

\section{Cálculo da área de aço longitudinal}

(a) Equilíbrio de forças normais e momentos fletores (Para armadura simples)

$$
\begin{aligned}
& \begin{array}{l}
R_{c d 1}+R_{c d 2}+R_{c d 31}+R_{c d 32}=R_{s d} \\
R_{c d 1}\left(d-\frac{h_{f}}{2}\right)+R_{c d 2}\left(d-\frac{y}{2}\right)+R_{c d 31}\left(d-h_{f}-\frac{y-h_{f}}{2}\right)+R_{c d 32}\left(d-h_{f}-\frac{y-h_{f}}{3}\right)=M_{d} \begin{array}{l}
R_{c d 1}=0,85 f_{c d} h_{f}\left(b_{f}-b_{w}\right) \\
R_{c d 2}=0,85 f_{c d} y \cdot b_{w} \\
R_{c d 31}=0,85 f_{c d}\left(y-h_{f}\right) \cdot(2 x) \\
R_{c d 32}=0,85 f_{c d}\left(y-h_{f}\right) \cdot\left(t_{w}-x\right) \\
R_{s d}=A_{s} f_{y d}
\end{array} \\
M_{d}=0,85 f_{c d}\left[h_{f}\left(b_{f}-b_{w}\right)\left(d-\frac{h_{f}}{2}\right)+y \cdot b_{w}\left(d-\frac{y}{2}\right)+\frac{t_{w}}{h_{w}}\left(y-h_{f}\right)\left((h-y)\left(2 d-h_{f}-y\right)+\frac{\left(h_{w}-h+y\right)}{3}\left(3 d-2 h_{f}-y\right)\right)\right] \\
a_{1}=\frac{2 t_{w}}{3 h_{w}} \\
a_{2}=\frac{t_{w}}{h_{w}}\left(-\frac{h_{f}}{3}-d-\frac{2 h}{3}\right)-\frac{b_{w}}{2}-\frac{t_{w}}{3} \\
a_{3}=\frac{t_{w}}{h_{w}}\left(-\frac{h_{f}{ }^{2}}{3}+h \cdot d+h_{f} \cdot d+\frac{h_{f} \cdot h}{3}\right)+t_{w}\left(d-\frac{h_{f}}{3}\right)+b_{w} d \\
a_{4}=\frac{t_{w} \cdot h_{f} \cdot h}{h_{w}}\left(\frac{h_{f}}{3}-d\right)+t_{w} \cdot h_{f}\left(\frac{2 h f}{3}-d\right)+h_{f} \cdot\left(b_{f}-b_{w}\right) \cdot\left(d-\frac{h_{f}}{2}\right)-\frac{M_{d}}{0,85 f_{c d}} \\
M_{w d}=0,85 f_{c d}\left[h_{f}\left(b_{f}-b_{w}\right)\left(d-\frac{h_{f}}{2}\right)+y_{\lim } \cdot b_{w}\left(d-\frac{y_{\lim }}{2}\right)+\frac{t_{w}}{h_{w}}\left(y_{\lim }-h_{f}\right)\left(\left(h-y_{\lim }\right)\left(2 d-h_{f}-y_{\lim }\right)+\frac{\left(h_{w}-h+y_{\lim }\right)}{3}\left(3 d-2 h_{f}-y_{\lim }\right)\right)\right]
\end{array}
\end{aligned}
$$

(b) Equilíbrio de forças normais e momentos fletores (Para armadura dupla)

$$
\begin{array}{ll}
R_{c d 1}=0,85 f_{c d} h_{f}\left(b_{f}-b_{w}\right) & R_{c d 32}=0,85 f_{c d}\left(y_{\lim }-h_{f}\right) \cdot\left(t_{w}-x\right) \\
R_{c d 2}=0,85 f_{c d} y_{\lim } \cdot b_{w} & R_{s d}=A_{s} f_{y d} \\
R_{c d 31}=0,85 f_{c d}\left(y_{\lim }-h_{f}\right) \cdot(2 x) & R_{s d}^{\prime}=A_{s}^{\prime} \sigma_{s d}^{\prime}
\end{array}
$$




$$
\begin{aligned}
& R_{c d 1}+R_{c d 2}+R_{c d 31}+R_{c d 32}+R_{s d}^{\prime}=R_{s d} \\
& R_{c d 1}\left(d-\frac{h_{f}}{2}\right)+R_{c d 2}\left(d-\frac{y_{\text {lim }}}{2}\right)+R_{c d 31}\left(d-h_{f}-\frac{y_{\text {lim }}-h_{f}}{2}\right)+R_{c d 32}\left(d-h_{f}-\frac{y_{\text {lim }}-h_{f}}{3}\right)+R_{s d}^{\prime}\left(d-d^{\prime}\right)=M_{d}
\end{aligned}
$$

(c) Determinação de parâmetros

$$
\begin{array}{rrlrl}
\mathrm{X}_{\lim }= & 4,40 \mathrm{~cm} & \left(\text { Linha neutra: } \mathrm{X}_{\lim }=\varepsilon_{\mathrm{c}} /\left(\varepsilon_{\mathrm{s}}+\varepsilon_{\mathrm{c}}\right) \cdot \mathrm{d}\right) & \mathrm{a} 1=0,22222 \\
\mathrm{Y}_{\lim }= & 3,52 \mathrm{~cm} & \left(\mathrm{Y}_{\lim }=0,80 \mathrm{X}_{\lim }\right) & \mathrm{a} 2= & -7,7 \mathrm{~cm} \\
\mathrm{Y}= & 1,8988 \mathrm{~cm} & \text { (Contribuição do concreto: } \mathrm{Y}=0,80 X^{\prime} & \text { a3 }= & 74,7 \mathrm{~cm} 2 \\
& & & \text { a4 }=-115,6 \mathrm{~cm} 3
\end{array}
$$

(d) Área de aço

$$
\begin{aligned}
& A_{s}=\frac{R_{c d 1}+R_{c d 2}+R_{c d 31}+R_{c d 32}}{f_{y d}}=0,85 \frac{f_{c d}}{f_{y d}}\left[h_{f}\left(b_{f}-b_{w}\right)+y \cdot b_{w}+\frac{t_{w}}{h_{w}}\left(y-h_{f}\right)\left(h-y+h_{w}\right)\right] \\
& A_{s}=\frac{R_{c d 1}+R_{c d 2}+R_{c d 31}+R_{c d 32}+R_{s d}^{\prime}}{f_{y d}} \\
& A_{s}=0,85 \frac{f_{c d}}{f_{y d}}\left[h_{f}\left(b_{f}-b_{w}\right)+y_{\lim } b_{w}+\frac{t_{w}}{h_{w}}\left(y_{\lim }-h_{f}\right)\left(h-y_{\lim }+h_{w}\right)\right]+\frac{M_{d}-M_{w d}}{f_{y d}\left(d-d^{\prime}\right)} \quad A_{s}^{\prime}=\frac{M_{d}-M_{w d}}{\sigma_{s d}^{\prime}\left(d-d^{\prime}\right)} \\
& \mathrm{M}_{w d}=405 \mathrm{KN} . \mathrm{cm} \quad \text { (Momento máximo para tração) } \\
& A_{s 1}=\quad 1,58 \mathrm{~cm} 2 \\
& A_{s 2}=\quad 0,00 \mathrm{~cm} 2 \quad\left(\text { As } 2=(M d-M w d) / f y d\left(d-d^{\prime}\right)\right) \\
& \text { As }=\quad 1,58 \mathrm{~cm} 2 \quad \text { (Aço a tração) } \quad \phi 1=8 \mathrm{~mm} \quad 0,50 \mathrm{~cm} 2
\end{aligned}
$$

\begin{tabular}{|c|c|c|}
\hline$\tau_{\mathrm{wd}}=$ & $0,321 \mathrm{KN} / \mathrm{cm} 2$ & (Tensão de cisal hamento de cortante de cálculo) $\tau_{w d}=\frac{r_{d}}{b_{w} d}$ \\
\hline $\mathrm{f}_{\mathrm{ctd}}=$ & 1,61 Мpa & (Resistência de tração do concreto) $\quad f_{c t d}=\frac{0,7.0,3}{1,4} f_{c k}{ }^{2 / 3} \quad$ (fck em n \\
\hline Vco $=$ & $3,39 \mathrm{KN}$ & (Força cortante resistida pelo concreto) $V_{c}=V_{c o}=0,6 f_{c t d} b_{w} d$ \\
\hline$\tau_{c}=$ & $0,097 \mathrm{KN} / \mathrm{cm} 2$ & (Tensão de cisal hamento resistida pelo concreto) \\
\hline$\tau_{\mathrm{sw}}=$ & $0,225 \mathrm{KN} / \mathrm{cm} 2$ & (Tensão de cisal hamento absorvida pelo estribo) $\tau_{s w}=\tau_{w d}-\tau_{c}$ \\
\hline & & É necesario o uso de estribos \\
\hline$\rho_{\text {sw }}=$ & 0,0083 & $\begin{array}{l}\text { (Taxa geométrica de armadura trans.) } \rho_{s w}=\overline{f_{y d}} \cdot \overline{\operatorname{sen} \alpha \cdot(\operatorname{sen} \alpha+\cos \alpha)} \\
\text { (Resistência a tracão direta) } f=0,3 .\left(f_{t}\right)^{2 / 3}\end{array}$ \\
\hline $\begin{array}{r}\mathrm{f}_{\mathrm{ctm}} \\
\rho_{\min }\end{array}$ & $\begin{array}{l}3,228 \text { IVIpa } \\
0,0214\end{array}$ & $\begin{array}{l}\text { (Resistência a tração direta) } f_{c t m}=0,3 .\left(f_{c k}\right)^{2 / 3} \\
\text { (Taxa geométrica de armadura trans. mínima } p_{\min }=\frac{0,20 \cdot f_{c t m}}{f}\end{array}$ \\
\hline$A_{s w}=$ & $0,16 \mathrm{~cm} 2$ & (Área da seção transversal dos es tribos) \\
\hline
\end{tabular}

\section{Cálculo da área de aço transversal (estribos)}

(a) Verificação da biela comprimida do concreto
$\alpha_{\mathrm{v} 2}=$
0,86
$\alpha_{v 2}=1-\frac{f_{c k}}{250}$
(fck em Mpa)
$\mathrm{V}_{\mathrm{Rd} 2}=\quad 28,65 \mathrm{KN}$
(Força cortante resistente de calculo, relativo à ruína das diagon
$V_{d}=11,25 \mathrm{KN}$ comprimidas do concreto) $\quad V_{R d 2}=0,27 \alpha_{v 2} f_{c d} b_{w} d$
$\Longrightarrow$ VRd2 $>$ Vd... ok!!!

(b) Verificações e cálculo de espaçamento dos estribos 


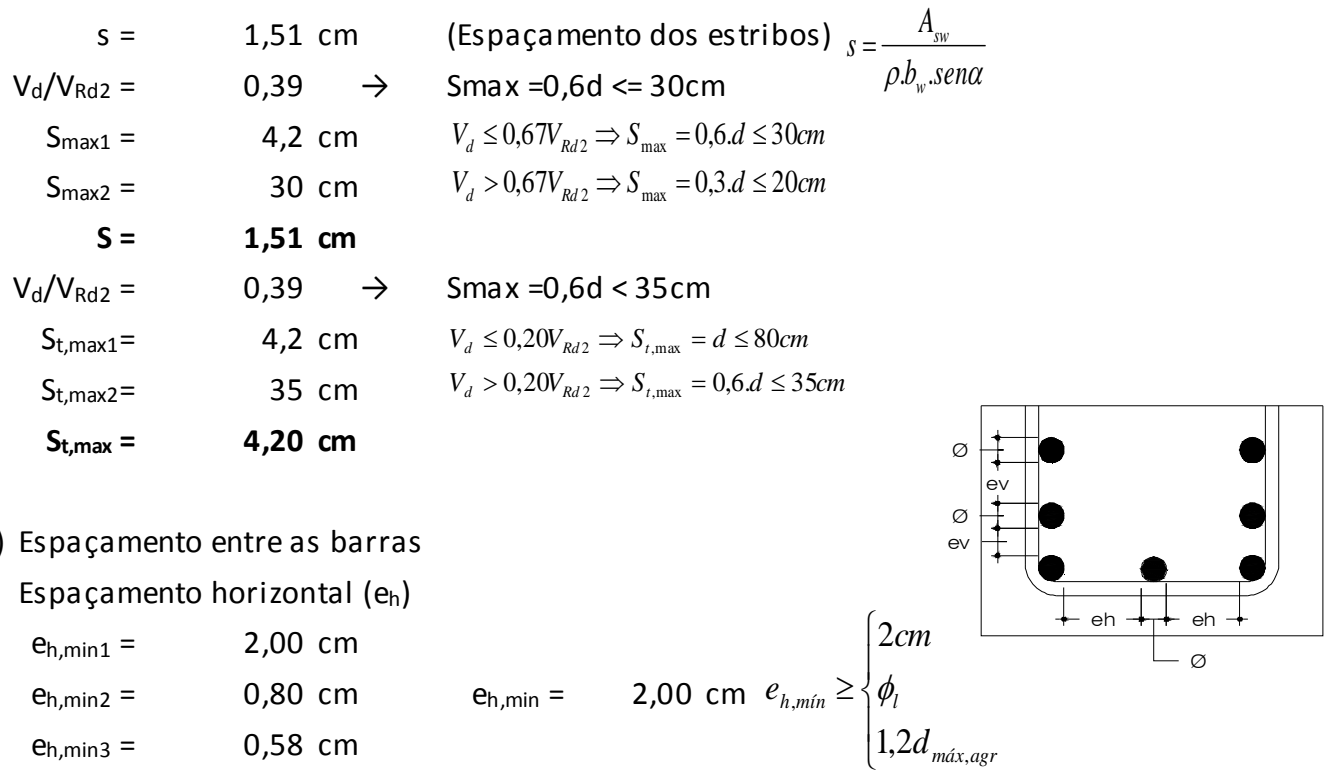

Espaçamento vertical (ev)

$\begin{array}{ll}\mathrm{e}_{\mathrm{v}, \min 1}= & 2,00 \mathrm{~cm} \\ \mathrm{e}_{\mathrm{v}, \min 2}= & 0,80 \mathrm{~cm} \\ \mathrm{e}_{\mathrm{v}, \min 3}= & 0,24 \mathrm{~cm}\end{array} \quad \mathrm{e}_{\mathrm{v}, \min }=\quad 2,00 \mathrm{~cm} \quad e_{v, \text { min }} \geq\left\{\begin{array}{l}2 \mathrm{~cm} \\ \phi_{l} \\ 0,5 d_{\text {máx } x \text { agr }}\end{array}\right.$

